\title{
Investigation of the Cause of Low Blister Threshold Temperatures in the RERTR-12 and AFIP-4 Experiments
}

M. K. Meyer, G. A. Moore, J.F. Jue, D.D. Keiser Jr., I.Y. Glagolenko, D.M. Wachs, P.E. Murray, A.B. Robinson, F.J. Rice, H. Ozaltun, S. J. Miller, M.A. Okuniewski, B.H. Rabin, H.W. Glunz, N.J. Lybeck

June 2012

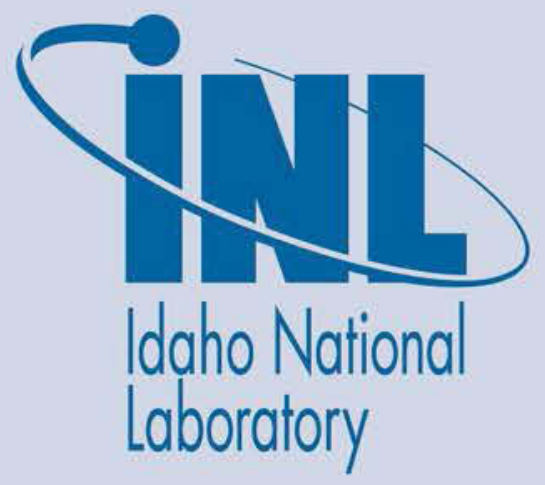

The INL is a U.S. Department of Energy National Laboratory operated by Battelle Energy Alliance 


\section{DISCLAIMER}

This information was prepared as an account of work sponsored by an agency of the U.S. Government. Neither the U.S. Government nor any agency thereof, nor any of their employees, makes any warranty, expressed or implied, or assumes any legal liability or responsibility for the accuracy, completeness, or usefulness, of any information, apparatus, product, or process disclosed, or represents that its use would not infringe privately owned rights. References herein to any specific commercial product,

process, or service by trade name, trade mark, manufacturer, or otherwise, does not necessarily constitute or imply its endorsement, recommendation, or favoring by the U.S. Government or any agency thereof. The views and opinions of authors expressed herein do not necessarily state or reflect those of the U.S. Government or any agency thereof. 


\section{Investigation of the Cause of Low Blister Threshold Temperatures in the RERTR-12 and AFIP-4 Experiments}

M. K. Meyer, G. A. Moore, J.F. Jue, D.D. Keiser Jr., I.Y. Glagolenko, D.M. Wachs, P.E. Murray, A.B. Robinson, F.J. Rice, H. Ozaltun, S.J. Miller, M.A. Okuniewski, B.H. Rabin, H.W. Glunz, N.J. Lybeck

June 2012

Idaho National Laboratory

Reduced Enrichment for Research and Test Reactors

Idaho Falls, Idaho 83415

http://www.inl.gov

Prepared for the

U.S. Department of Energy

Office of Nuclear Energy

Under DOE Idaho Operations Office

Contract DE-AC07-05ID14517 

Reduced Enrichment for Research and Test Reactors

\title{
Investigation of the Cause of Low Blister Threshold Temperatures in the RERTR-12 and AFIP-4 Experiments
}

\author{
INL/EXT-12-26500
}

June 2012

Approved by:
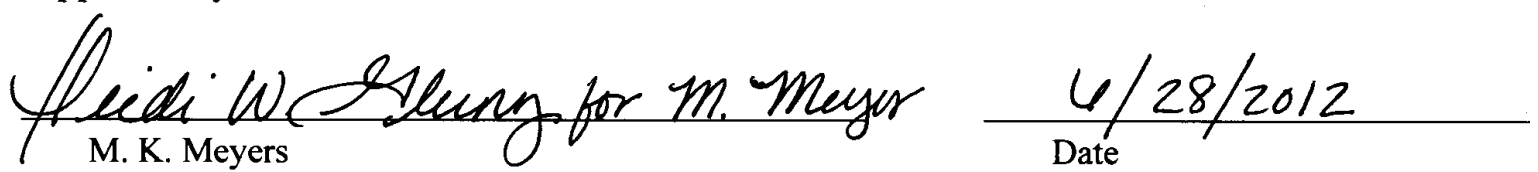

National Technical Lead for RERTR Fuel Development
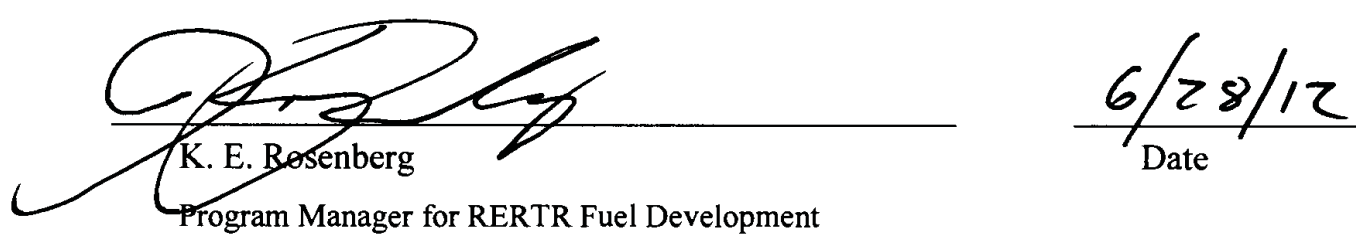



\section{SUMMARY}

Blister-threshold testing of fuel plates is a standard method through which the safety margin for operation of plate-type in research and test reactors is assessed. The blister-threshold temperature is indicative of the ability of fuel to operate at high temperatures for short periods of time (transient conditions) without failure. This method of testing was applied to the newly developed U-Mo monolithic fuel system. Blister annealing studies on the U-Mo monolithic fuel plates began in 2007, with the Reduced Enrichment for Research and Test Reactors (RERTR)-6 experiment, and they have continued as the U-Mo fuel system has evolved through the research and development process.

Blister anneal threshold temperatures from early irradiation experiments (RERTR-6 through RERTR-10) ranged from 400 to $500^{\circ} \mathrm{C}$. These temperatures were projected to be acceptable for NRC-licensed research reactors and the high-power Advanced Test Reactor (ATR) and the High Flux Isotope Reactor (HFIR) based on current safety analysis reports (SARs). Initial blister testing results from the RERTR-12 experiment capsules X1 and X2 showed a decrease in the blister-threshold temperatures. Blister threshold temperatures from this experiment ranged from 300 to $400^{\circ} \mathrm{C}$. Selected plates from the AFIP-4 experiment, which was fabricated using a process similar to that used to fabricate the RERTR-12 experiment, also underwent blister testing to determine whether results would be similar. The measured blister-threshold temperatures from the AFIP-4 plates fell within the same blister-threshold temperature range measured in the RERTR-12 plates.

Investigation of the cause of this decrease in blister threshold temperature is being conducted under the guidance of Idaho National Laboratory PLN-4155, "Analysis of Low Blister Threshold Temperatures in the RERTR-12 and AFIP-4 Experiments," and is driven by hypotheses. The main focus of the investigation is in the following areas:

1. Fabrication variables

2. Pre-irradiation characterization

3. Irradiation conditions

4. Post-irradiation examination

5. Additional blister testing

6. Mechanical modeling

This report documents the preliminary results of this investigation. Several hypotheses can be dismissed as a result of this investigation. Two primary categories of causes remain.

The most prominent theory, supported by the data, is that low blister-threshold temperature is the result of mechanical energy imparted on the samples during the fabrication process (hot and cold rolling) without adequate post processing (annealing). The mechanisms are not clearly understood and require further investigation, but can be divided into two categories:

- Residual Stress

- Undesirable interaction boundary and/or U-Mo microstructure change 
A secondary theory that cannot be dismissed with the information that is currently available is that a change in the test conditions has resulted in a statistically significant downward shift of measured blister temperature.

This report outlines the results of the forensic investigations conducted to date. The data and conclusions presented in this report are preliminary. An additional report will be generated when the entirety of the work in PLN-4155 is completed. Definitive cause and effect relationships will be established by future experimental programs. 


\section{Acknowledgements}

The authors would like to thank C. E. White for graphic arts, B. C. Hadden for technical editing and L. Dawson and M. Hurd from Quality-One International, Inc., for their assistance with the FMEA. 


\section{CONTENTS}

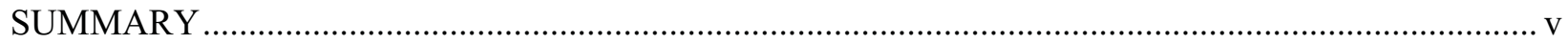

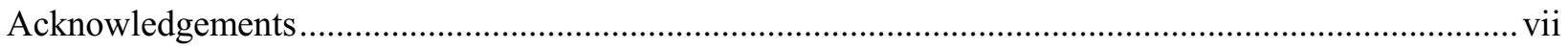

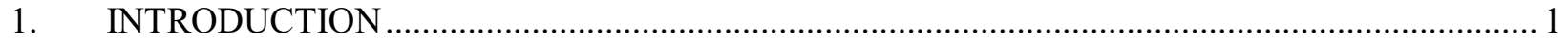

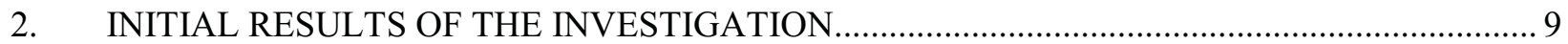

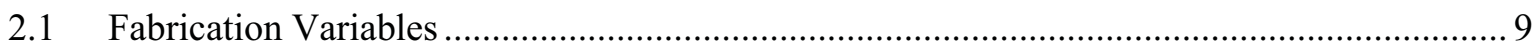

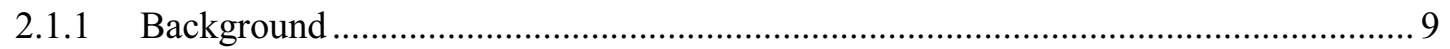

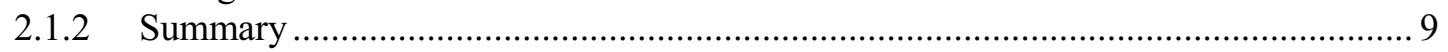

2.1.3 Summary of Fabrication Effects on Blister Temperature …................................. 25

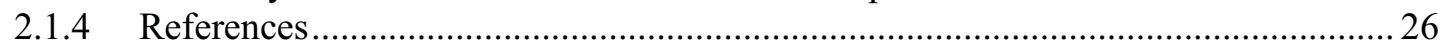

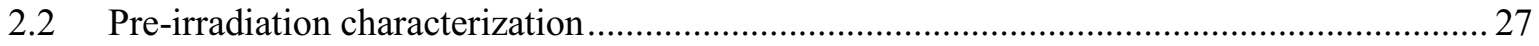

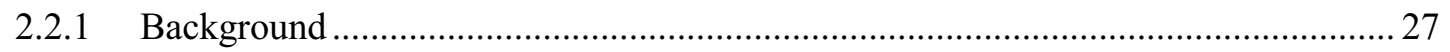

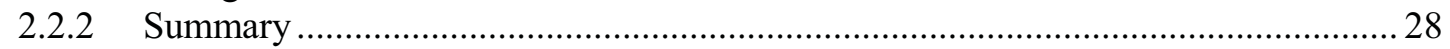

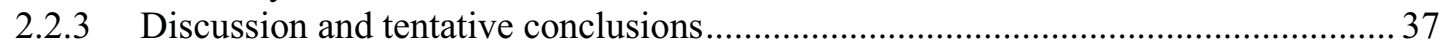

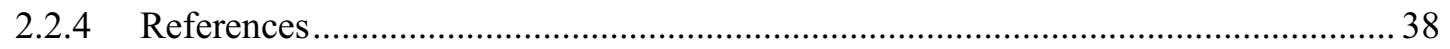

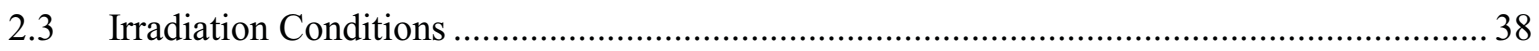

2.3.1 Operating Powers in RERTR Miniplate Experiments …..................................... 38

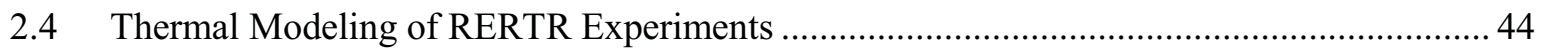

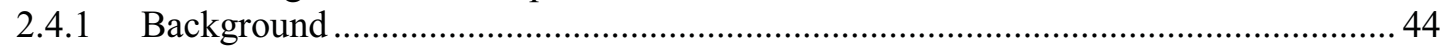

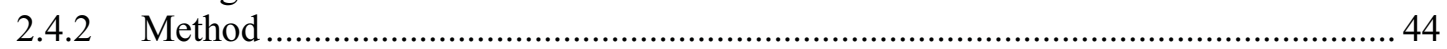

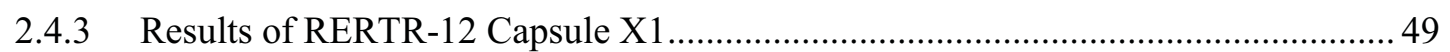

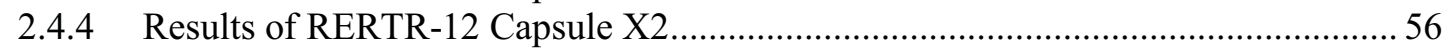

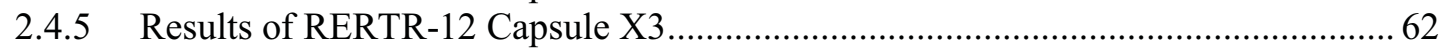

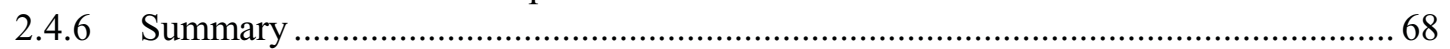

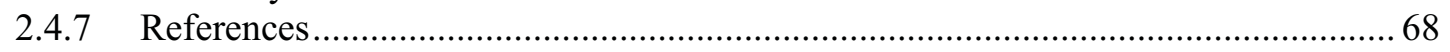

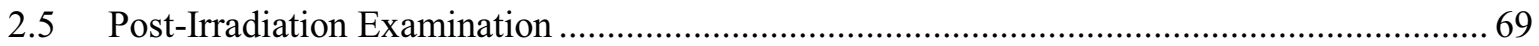

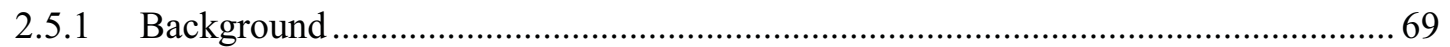

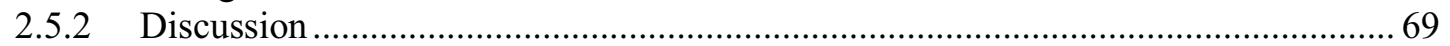

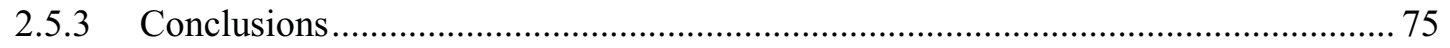

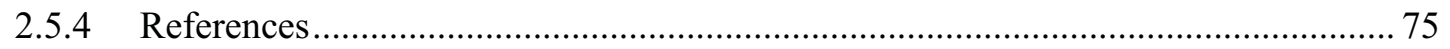

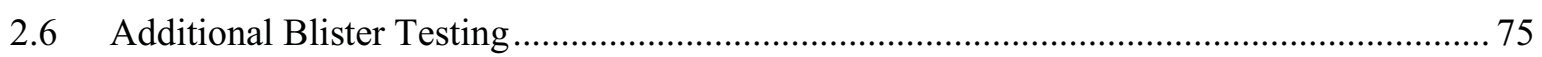

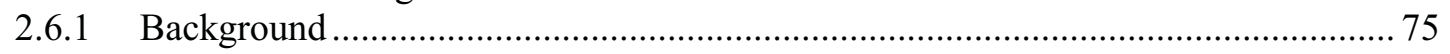

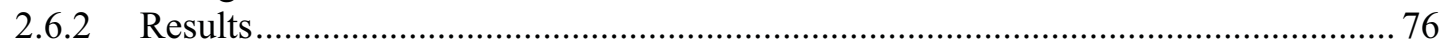

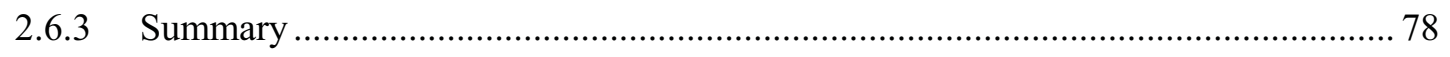

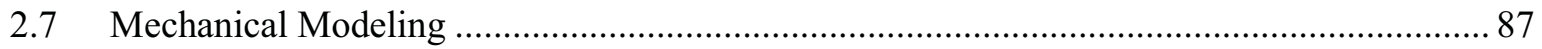

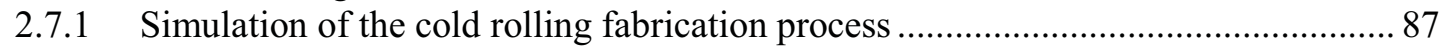

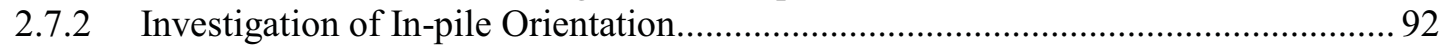

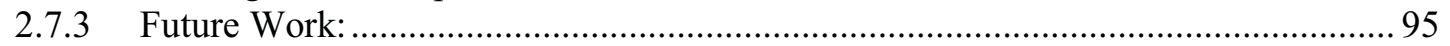

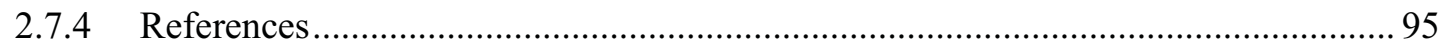

2.7.5 Experimental Measurements of Residual Stresses................................................... 96

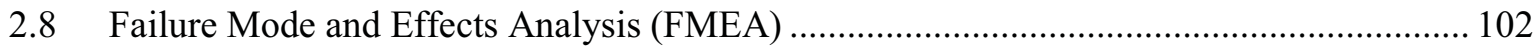




\section{FIGURES}

Figure 1. Curve fits of data from the two monolithic fuel blister testing campaigns. The data is fit using the average fuel plate fission density. Three circled data points (one from RERTR-10 and two from RERTR-12) were not included in the model fit................................. 3

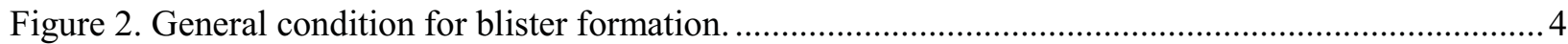

Figure 3. Type 1 blisters on the front side of plate L1P460 (RERTR-12). Average fission density $2.35 \times 10^{21}$ fiss $/ \mathrm{cm}^{3}$. Peak fission density $3.98 \times 10^{21} \mathrm{fiss} / \mathrm{cm}^{3}$. 4

Figure 4. Montage of optical metallography images of the transverse cut through a Type 1 blister (\#4) on plate L1P460 (RERTR-12). Average fission density $2.35 \times 10^{21} \mathrm{fiss} / \mathrm{cm}^{3}$. Peak fission density $3.98 \times 10^{21} \mathrm{fiss} / \mathrm{cm}^{3}$. 5

Figure 5. Type 2 blisters on the front side of plate L1P774 (RERTR-12). Average fission density $5.59 \times 10^{21}$ fiss $/ \mathrm{cm}^{3}$. Peak fission density $7.49 \times 10^{21} \mathrm{fiss} / \mathrm{cm}^{3}$. .5

Figure 6. Montage of optical metallography images of the transverse cut through Type 2 blister on plate L1P758 (RERTR-12). Average fission density $5.00 \times 10^{21}$ fiss $/ \mathrm{cm}^{3}$. Peak fission density $9.20 \times 10^{21}$ fiss $/ \mathrm{cc}$.

Figure 7. Optical metallography image $(500 \times)$ of the right end of the transverse cut through Type 2 blister on plate L1P758 (RERTR-12) shown in Figure 6.

Figure 8. "Pillow-like" type 2 blister on the back side of plate L1P754 (RERTR-12), which blistered in the core. Average fission density $8.13 \times 10^{21} \mathrm{fiss} / \mathrm{cm}^{3}$. Peak fission density $11.9 \times 10^{21}$ fiss $/ \mathrm{cm}^{3}$.

Figure 9. Optical metallography image $(500 \times)$ of the axial cut through Type 2 blister on fuel plate L1P754 (RERTR-12)...

Figure 10. Type 1 blisters on the back side of plate L2P15Z (RERTR-10A). Average fission density $1.34 \times 10^{21}$ fiss $/ \mathrm{cm}^{3}$. Peak fission density $1.83 \times 10^{21}$ fiss $/ \mathrm{cm}^{3}$.

Figure 11. Montage of the optical-metallography images of the transverse cut through a Type 1 blister on plate L1P15Z (RERTR-10A). Average fission density $1.34 \times 10^{21} \mathrm{fiss} / \mathrm{cm}^{3}$. Peak fission density $1.83 \times 10^{21}$ fiss $/ \mathrm{cm}^{3}$........

Figure 12. Type 2 blisters on the back side of plate L1P10T (RERTR-9B). Average fission density $7.22 \times 10^{21}$ fiss $/ \mathrm{cm}^{3}$. Peak fission density $9.63 \times 10^{21}$ fiss $/ \mathrm{cm}^{3}$. 8

Figure 13. Resistance annealing of cold-rolled foil at $925^{\circ} \mathrm{C}$ for $\sim 10$ seconds inside of an argonpurged fused-quartz tube.

Figure 14. A diagram of the monolithic-fuel-plate assembly.

Figure 15. An image of U-10 Mo foil from an irradiated plate L1F100 (RERTR-6) shows preferential fuel-cladding chemical interaction (FCCI) on the end (edge) of the foil.

Figure 16. The images of the blister tested plates L2F020 (RERTR-6, front side), N1F060 (RERTR-6, front side) and L1F110 (RERTR-7, front side). Left edge of the front side of the plates (with ID) was facing center of the ATR core.

Figure 17. An image of the RERTR-9A blister-tested miniplate L1F27C. Right edge of the front side of the plate (with ID) was facing ATR core. Blistering occurred over entire fuel zone, but only on the front side of the plate. 
Figure 18. Photographs of the RERTR-9B blister-tested miniplates, from left to right: L1F330 (front side), L1F35T (front side), L1P10T (front and back sides). Right edge of the front side of the plate (with ID) was facing ATR core.

Figure 19. Photographs of the blister tested RERTR-10 plates, from left to right: L1P30Z (back and front sides), L2P15Z (back side), L2F47Z (front side), and L2F46Z (back side). Right edge of the front side of the plate (with ID) was facing ATR core.

Figure 20. Photographs of the blister tested AFIP-4 plates, from left to right: L1H34Z (back side), L1H36Z (back side), L1B33Z (front side), and L1B51Z (back and front side)....................... 21

Figure 21. Example of the RERTR-12 wavy fuel foil. .22

Figure 22. Debond images of the two RERTR-12 candidate miniplates that did not pass postblister anneal UT evaluation. UT debond images of monolithic fuel plates exhibit a dark perimeter line around the fuel foils. This edge effect is associated with scattering of the ultrasonic beam by the edge of the foil.

Figure 23. Graphic representation of similarities associated with fuel plates in X1 and X2 capsules from RERTR-12 experiment.

Figure 24. The corner areas (junction between cladding, $\mathrm{Zr}$ and U-10Mo) from (a) RERTR-10A and (b) RERTR-12 show no extensive interaction.

Figure 25. An SEM micrograph shows microcracks in an RERTR-12 foil (Foil \#331, JJ580).

Figure 26. An SEM micrograph shows a gap between $\mathrm{Zr}$ and U-10Mo in an archive foil from AFIP-7 (foil \#386, JJ703) which was subjected to cold co-rolling, as was RERTR-12. 30

Figure 27. An SEM micrograph shows elongated feature in an RERTR-12 archive fuel plate (plate \#72-2, JJ998, archive of fuel plate L5P2B6)

Figure 28. SEM micrographs show equiaxed U-Mo grain structure in (a) RERTR-10A (from plate \# 42-6, JJ497) and (b) from the near-surface region of RERTR-12 (from plate 72-2, JJ998, archive of fuel plate L5P2B6).

Figure 29. Fuel foil chemical banding in (a) RERTR-10A (from foil \# 226-JJ678) and (b) RERTR-12 (foil \# 351, JJ611)...

Figure 30. Second phase in (a) RERTR-10A (from plate \#42-6, JJ497) and (b) RERTR-12 (from plate \#65-5, JJ599) plates.

Figure 31. Second phase precipitates along bond line in (a) RERTR-10A (from plate \#42-6, JJ497) and (b) RERTR-12 (from plate \#65-5, JJ599) plates.

Figure 32. An SEM micrograph shows a typical interface between U-10Mo and $\mathrm{Zr}$ in an RERTR12 foil subjected to $650^{\circ} \mathrm{C} / 1 \mathrm{hr}$ annealing treatment (foil \#331, JJ580).

Figure 33. Orientation of the RERTR miniplates towards reactor core center: a) edge-on, and b) face-on.

Figure 34. Local-to-average power/burnup peaking factors for a representative RERTR plate oriented edge-on towards reactor core center.

Figure 35. Local-to-average power/burnup peaking factors for a representative RERTR plate oriented face-on towards reactor core center.

Figure 36. Local-to-average power/burnup peaking factors for a representative AFIP-4 plate irradiated in the Center Flux Trap of ATR core. 
Figure 37. Blister-threshold temperature as a function of plate average heat flux and average burnup.

Figure 38. Blister threshold temperature as a function of plate peak local heat flux and peak local burnup. 44

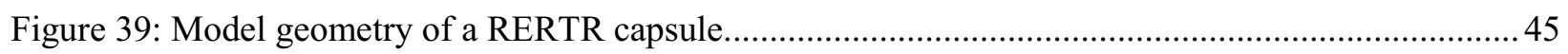

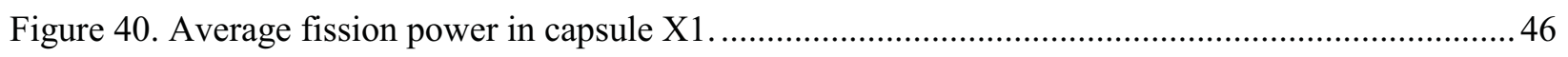

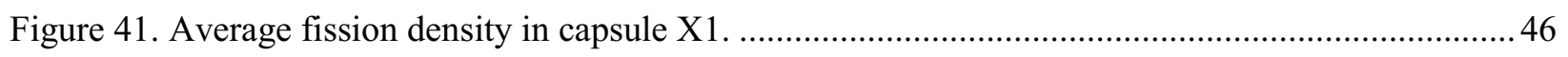

Figure 42. Peak to average fission power in the axial direction in capsule X1 . ......................................4 47

Figure 43. Peak to average fission power in the transverse direction in capsule X1 .............................. 47

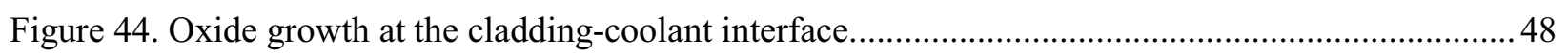

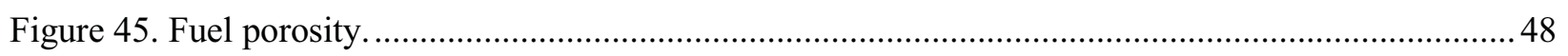

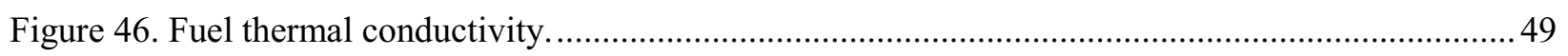

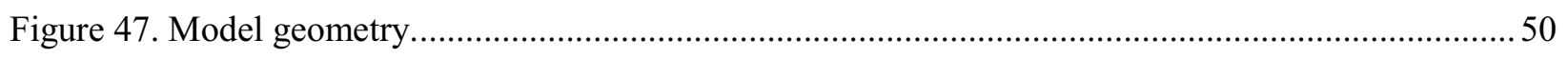

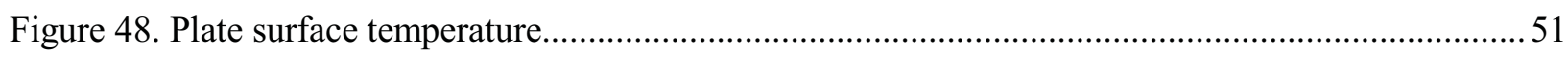

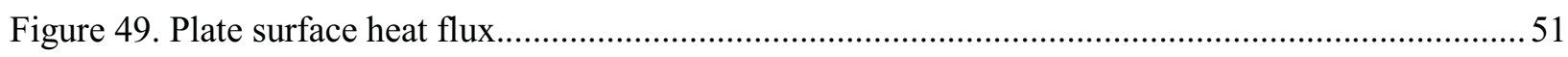

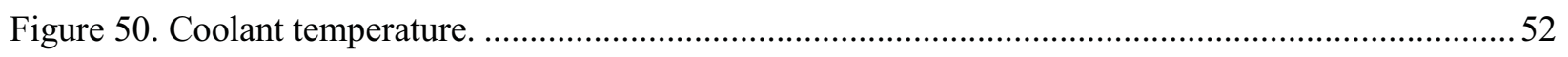

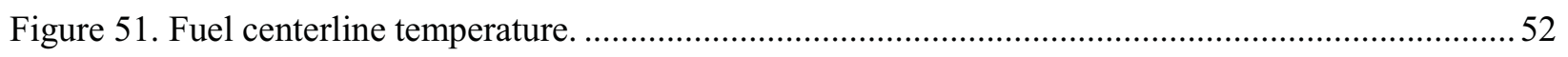

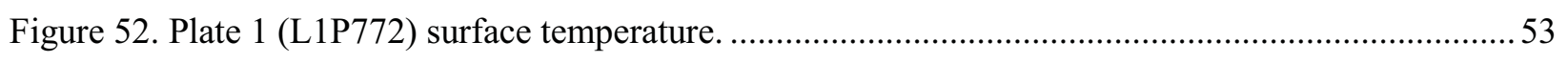

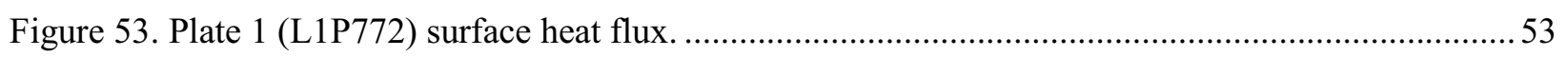

Figure 54. Plate 1 (L1P772) fuel centerline temperature ................................................................... 54

Figure 55. Plate 1 (L1P772) fuel/cladding interface temperature ........................................................... 54

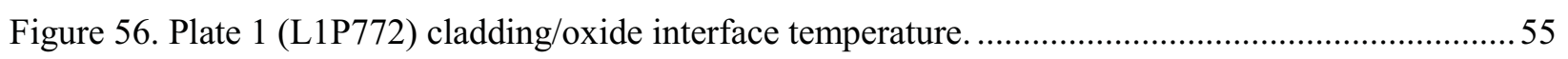

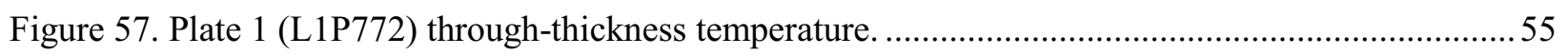

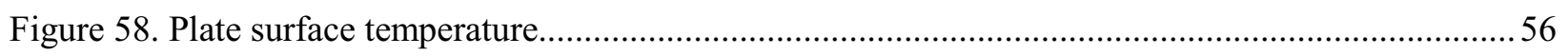

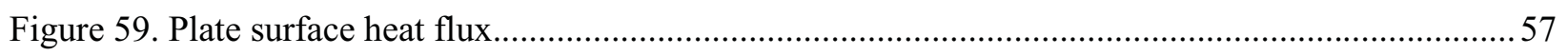

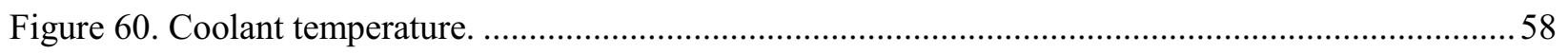

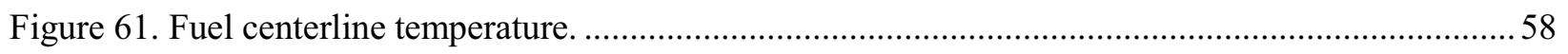

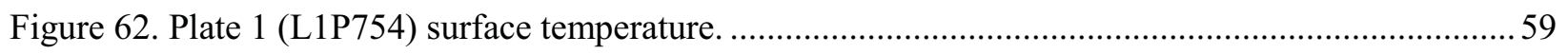

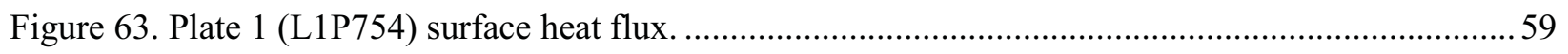

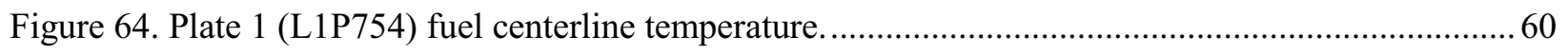

Figure 65. Plate 1 (L1P754) fuel/cladding interface temperature .......................................................... 60

Figure 66. Plate 1 (L1P754) cladding/oxide interface temperature ........................................................ 61

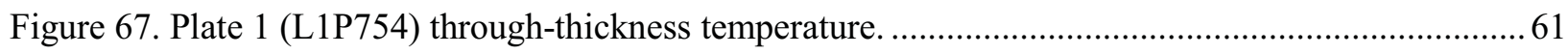

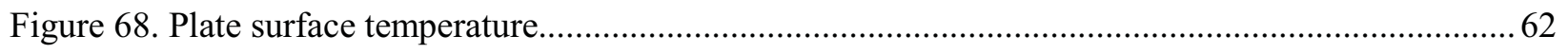

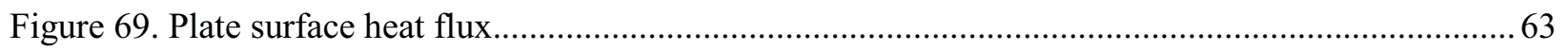


Figure 70. Coolant temperature.

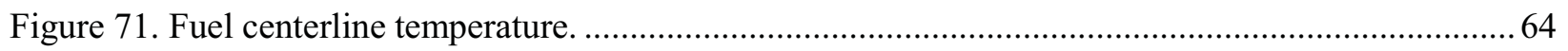

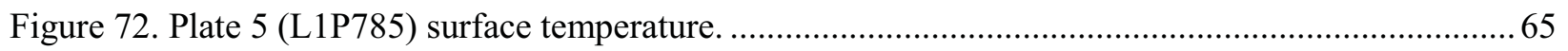

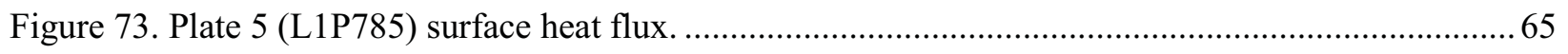

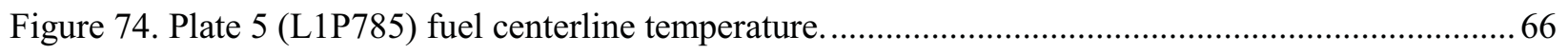

Figure 75. Plate 5 (L1P785) fuel/cladding interface temperature.......................................................... 66

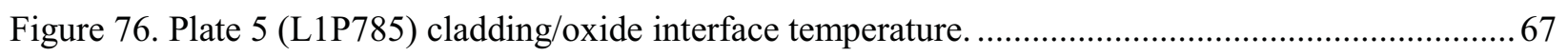

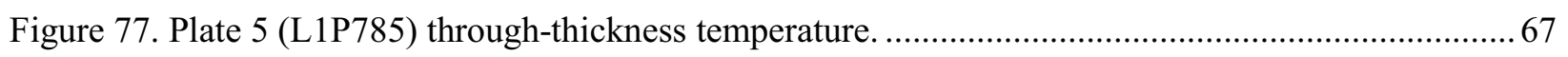

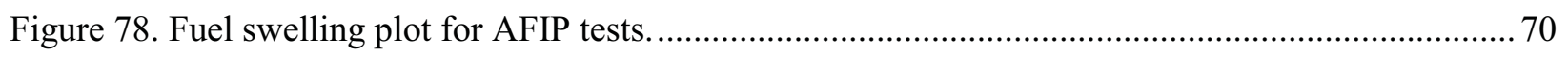

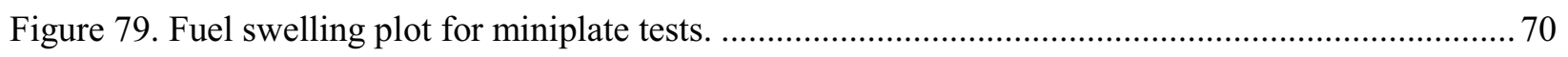

Figure 80. Comparison of axial gamma scans to axial calculated gradients (plate L1P755).................... 72

Figure 81. Comparisons of transverse gamma scans to transverse calculated gradients (plate

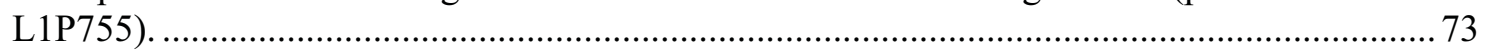

Figure 82. Cross section of RERTR-12 plate L1P755 $\left(5.3 \times 10^{21}\right.$ fissions $\left./ \mathrm{cm}^{3}\right)$. ................................... 73

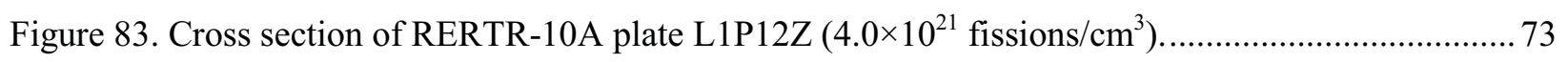

Figure 84. Image of foil edge from RERTR-12 plate L1P593 (left) $4.8 \times 10^{21}$ fissions $/ \mathrm{cm}^{3}$ and RERTR-10A plate L2P16Z (right) $2.45 \times 10^{21}$ fissions $/ \mathrm{cm}^{3}$............................................... 74

Figure 85. Image of foil edge from RERTR-12 plate L1P773 (left) $5.2 \times 10^{21}$ fissions $/ \mathrm{cm}^{3}$ and RERTR-10B plate L1F44N (right) $6.3 \times 10^{21}$ fissions $/ \mathrm{cm}^{3}$................................................ 74

Figure 86. Zirconium interface of RERTR-12 plate L1P755 (left) $5.5 \times 10^{21}$ fissions $/ \mathrm{cm}^{3}$ and

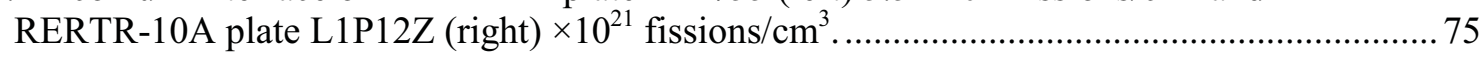

Figure 87. Blisters observed on the back side of plate $\mathrm{L} 1 \mathrm{H} 35 \mathrm{Z}$ during post-irradiation thermal

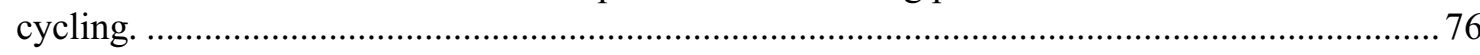

Figure 88. Post-irradiation UT image of plate L1H35Z. The top left hand corner of the UT image corresponds to the bottom left hand corner of the blistered plate image.................................. 77

Figure 89. Blisters observed on plate L1H38Z during post-irradiation thermal cycling (top image: front of the plate, bottom image: back of the plate)................................................................. 77

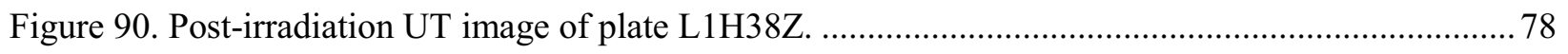

Figure 91. Blister temperature as a function of plate peak fission density. Three circled points (one from RERTR-10 and two from RERTR-12) were not included in the model fit. ..............79

Figure 92. Blister temperature versus local fission density including RERTR-10A plate L2F46Z. .......... 82

Figure 93. Blister temperature versus local fission density excluding RERTR-10A plate L2F46Z........... 82

Figure 94. Area of individual blisters versus fission density for all blisters types ................................... 83

Figure 95. Area of individual blisters versus fission density for Type 1 blisters..................................... 84

Figure 96. Area of individual blisters vs fission density for Type 2 blisters for plates with $\mathrm{Zr}$

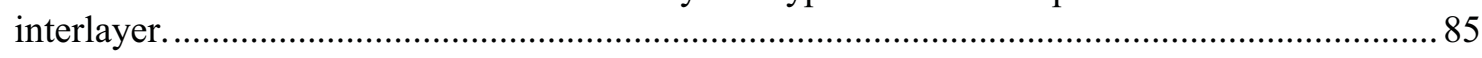

Figure 97. Individual blister area vs fission density for Type 2 blisters for all plates............................ 86 


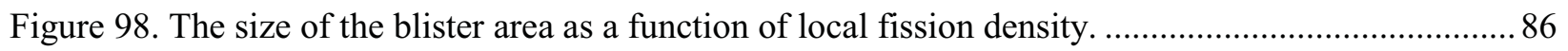

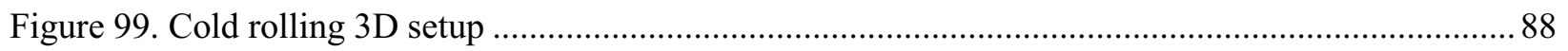

Figure 100. (a) A map of the equivalent stress [MPa] in the cold rolled foil and (b) an image of

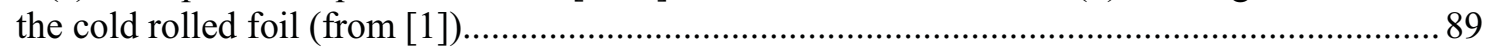

Figure 101. A map of the equivalent plastic strain along the thickness of the cold-rolled foil..................89

Figure 102. A map of the normal stress [MPa] along the rolling direction in the cold-rolled foil. ............90

Figure 103. A map of the normal stress along the width direction of the cold-rolled foil.......................90

Figure 104. Stress profiles along thickness of the cold rolled foil (a) normal stress, and (b) shear

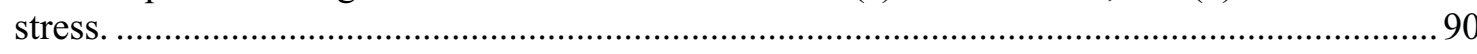

Figure 105. Stress profiles along thickness of the cold-rolled foil: (a) equivalent stress, and (b)

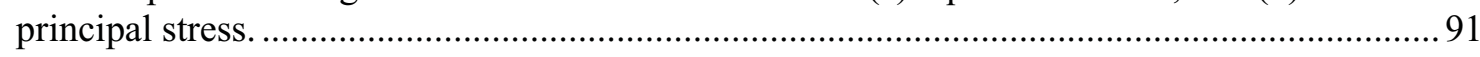

Figure 106. Burnup profiles for "edge-on" versus "face-on" simulations ............................................. 93

Figure 107. Equivalent stress contours for the plate in (a) edge-on (b) face-on configurations................94

Figure 108. Schematic of the sample, roughly to scale. The white area represents the region over which the residual stress was mapped. The origin for future plots is indicated at the lower left corner of the foil. Regions A, B, C, and D delineate the different mapping densities described in the text.

Figure 109. Spatially resolved maps of the normal components of the residual stress in the U$10 \mathrm{Mo}$ fuel foils in the clad fuel assembly.

Figure 110. Schematic of the four measurement locations on the miniplate. The shape of the rectangle associated with the points schematically reflects the geometry of the selected measurement area to determine the lattice strain. 99

Figure 111. Lattice parameter of the Al-6061 cladding at 4 locations in both the longitudinal and normal directions. The points at room temperature all agree within $300 \mu \varepsilon$. 100

Figure 112. Lattice parameter of the U-10wt.\%Mo fuel foil as a function of temperature. The normal direction is given by bank 1 and the longitudinal direction is given by bank 2 .

Figure 113. Lattice strain points 1 (a) and 4 (b) as a function of temperature. The normal direction is given by bank 1 and the longitudinal direction is given by bank 2 . 102

Figure 114. Root Cause Methodology Flow Diagram.

\section{TABLES}

Table 1. Blister threshold temperature data for monolithic fuel plates from the RERTR-6, 7, 9A, 9B, 10A, and 10B experiments. 1

Table 2. Blister threshold data from the RERTR-12 and AFIP-4 experiments. ......................................... 2

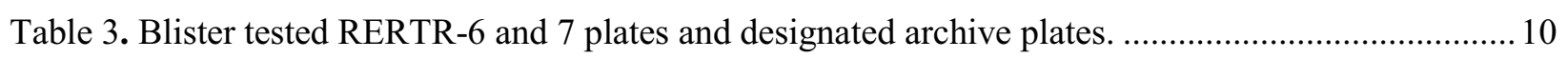

Table 4. Information on the blisters found on the plates from RERTR-6 and 7 experiments. ................... 13

Table 5. Information on the blister found on plate L1F27C from RERTR-9A experiment*..................... 15

Table 6. Information on the blisters found on the plates from RERTR-9B experiment........................... 18

Table 7. Information on blisters observed on the RERTR-10 plates. ....................................................20 


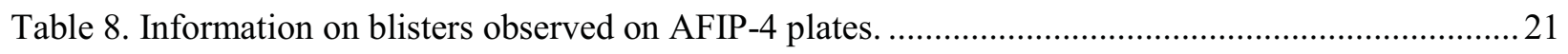

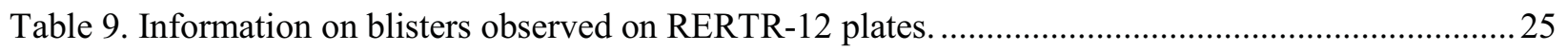

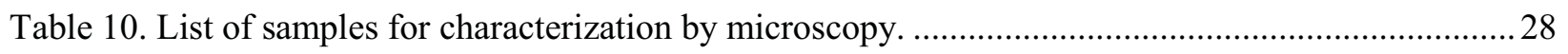

Table 11. Comparison of the key microstructural features between RERTR-12 (with cold rolling)

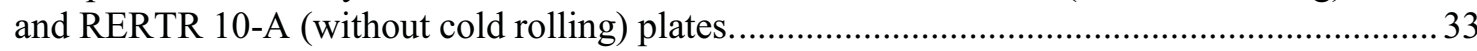

Table 12. Operating irradiation conditions for blister-tested RERTR plates.......................................... 42

Table 13. Oxide measurement summary of RERTR-12 insertion 1 in micrometers ............................... 71

Table 14. AFIP-4 plates selected for thermal cycling testing........................................................... 75

Table 15. Results of the thermal cycling test performed using AFIP-4 plates....................................... 76

Table 16. Estimated fission density at the location of the blisters and size of the blisters ...................... 80

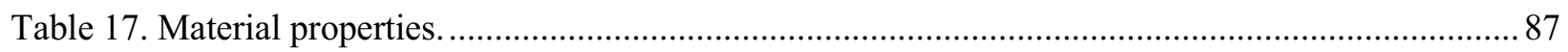




\section{ACRONYMS}

APS

ATR

BOL

CFD

CTE

DU

EDS

EOL

FB

FEA

FCCI

HEU

HFIR

HIP

INL

LANL

LANSCE

LEU

MFC

RERTR

SAR

SEM

SMARTS

VIM

WDS
Advanced Photon Source

Advanced Test Reactor

beginning of life

computational fluid dynamics

coefficient of thermal expansion

depleted uranium

energy dispersive X-ray spectroscopy

end of life

friction bonding

finite element analysis

fuel-cladding chemical interaction

highly enriched uranium

High Flux Isotope Reactor

hot isostatic pressing

Idaho National Laboratory

Los Alamos National Laboratory

Los Alamos Neutron Science Center

low-enriched uranium

Materials and Fuels Complex

Reduced Enrichment for Research and Test Reactors

safety analysis report

scanning electron microscopy

Spectrometer for Materials Research at Temperature and Stress

vacuum induction melting

wavelength dispersive X-ray spectroscopy 


\section{Investigation of the Cause of Low Blister Threshold Temperatures in the RERTR-12 and AFIP-4 Experiments \\ 1. INTRODUCTION}

The blister-threshold temperature of fuel plates is a standard test method through which the safety margin for operation of dispersion fuel in research and test reactors is assessed [1,2,3]. The blister-threshold temperature is indicative of the ability of fuel to operate at high temperatures for short periods of time (known, in nuclear reactor operations, as transient conditions) without failure. A common blister-test method is to heat, soak, remove, visually examine and, if there is no blister, return the sample to the furnace for testing at higher temperature. The process is repeated until the sample has blistered [4,5]. This method is used for testing most dispersion-fuel systems. It is presumed that once blistered, the fuel has reached the point of thermally induced breakaway swelling, when pores filled with gaseous fission products and helium become interconnected. In many cases blistering is preceded by cracking of the fuel particles and/or matrix.

This method of testing was applied to the newly developed U-Mo monolithic fuel system. Blister annealing studies on the U-Mo monolithic fuel plates began in 2007, with the Reduced Enrichment for Research and Test Reactors (RERTR)-6 experiment, and they have continued as the U-Mo fuel system has evolved through the research and development process.

Blister anneal threshold temperatures from early irradiation experiments (RERTR-6 through RERTR-10) ranged from 400 to $500^{\circ} \mathrm{C}$ (see Table 1). These temperatures were projected to be acceptable for NRC-licensed research reactors and the high-power Advanced Test Reactor (ATR) and the High Flux Isotope Reactor (HFIR) based on current safetyanalysis reports (SARs).

Table 1. Blister threshold temperature data for monolithic fuel plates from the RERTR-6, 7, 9A, 9B, 10A, and 10B experiments.

\begin{tabular}{|c|c|c|c|c|c|c|c|c|c|}
\hline Experiment & Plate ID & $\begin{array}{c}\text { Test } \\
\text { Train } \\
\text { Position }\end{array}$ & $\begin{array}{c}\text { Fuel Foil } \\
\text { Thickness } \\
\text { (inches) }\end{array}$ & $\begin{array}{c}\text { Diffusion } \\
\text { Barrier }\end{array}$ & $\begin{array}{c}\text { Plate } \\
\text { Bonding } \\
\text { Method }\end{array}$ & $\begin{array}{c}\text { Average } \\
\text { Fission } \\
\text { Density, } \\
\times 1^{21} \\
(\text { fissions/ } \\
\mathbf{c m}^{3} \text { ) }\end{array}$ & $\begin{array}{c}\text { Peak } \\
\text { Fission } \\
\text { Density }^{2} \text {, } \\
\times \mathbf{1 0}^{21} \\
(\text { fissions/ } \\
\mathbf{c m}^{3} \text { ) }\end{array}$ & $\begin{array}{c}\text { Measured } \\
\text { Blister } \\
\text { Temperature } \\
\left({ }^{\circ} \mathrm{C}\right)\end{array}$ & $\begin{array}{l}\text { Blister } \\
\text { Types }^{9}\end{array}$ \\
\hline RERTR-6 & L2F020 & A-4 & 0.020 & None & $\mathrm{FB}^{4}$ & 2.45 & 4.53 & 450 & 2 \\
\hline RERTR-6 & $\mathrm{N} 1 \mathrm{~F} 060^{1}$ & $\mathrm{C}-6$ & 0.010 & None & FB & 3.63 & 6.90 & 450 & 2 \\
\hline RERTR-7 & $\mathrm{L} 1 \mathrm{~F} 110^{8}$ & $\mathrm{C}-3$ & 0.010 & None & FB & 5.06 & 12.1 & 400 & 2 \\
\hline RERTR-9A & L1F27C 3 & A-5 & 0.010 & None & FB & 3.64 & 9.64 & 425 & 2 \\
\hline RERTR-9B & L1F330 & B-2 & 0.010 & None & $\mathrm{FB}$ & 5.99 & 14.6 & 400 & 2 \\
\hline RERTR-9B & L1F35T & D-1 & 0.010 & $\mathrm{Al}-\mathrm{Si}^{5}$ & FB & 6.67 & 14.3 & 425 & 2 \\
\hline RERTR-9B & L1P10T & D-5 & 0.010 & $\mathrm{Zr}$ & $\mathrm{HIP}^{6}$ & 5.71 & 12.1 & 400 & 2 \\
\hline RERTR-10A & $\mathrm{L}_{1 \mathrm{P}} 30 Z^{8}$ & A-1 & 0.010 & $\mathrm{Zr}$ & HIP & 2.88 & 6.41 & 400 & 2 \\
\hline RERTR-10A & L2P15Z & A-3 & 0.020 & $\mathrm{Zr}$ & HIP & 1.34 & 3.82 & 475 & 1 \\
\hline RERTR-10B & L2F47Z & D-7 & 0.010 & $\mathrm{Zr}$ & $\mathrm{FB}$ & 1.75 & 3.72 & 500 & 1 \\
\hline RERTR-10B & $\mathrm{L}_{2} \mathrm{~F} 46 \mathrm{Z}^{7}$ & B-6 & 0.020 & $\mathrm{Zr}$ & $\mathrm{FB}$ & 2.25 & 4.52 & $350^{7}$ & 1 \\
\hline
\end{tabular}

1- U-7Mo alloy was used

2- Estimated using beginning of life (BOL) plate power peaking factors

3- Information for plate $\mathrm{L} 1 \mathrm{~F} 27 \mathrm{C}$ is preliminary and requires additional verification

4- $\quad$ Friction Bonding

5- Al-Si thermal spray

6- Hot Isostatic Press

7- $\quad$ Blister tested in 2012

8- Blistered at starting temperature of the blister anneal test

9- Confirmation is required via optical metallography of plate cross-sections through blisters 
Results from the RERTR-12 blister anneal plates, selected from capsules X1 and X2, showed a decrease in the blisterthreshold temperatures. These temperatures range from 300 to $400^{\circ} \mathrm{C}$ (see Table 2). Two of the RERTR-12 plates irradiated to very high fission density, well in excess of 100\% Low Enriched Uranium (LEU) burnup, blistered in the core. Later, selected plates from the AFIP-4 experiment - which used a fabrication process similar to that of RERTR12 - underwent blister anneal testing to determine whether results would be similar to plates from the RERTR-12 experiment's X1 and X2 capsules. The measured blister-threshold temperatures from the AFIP-4 plates fell within the same blister-threshold temperature range measured in the RERTR-12 plates. In addition, the only remaining plate from the earlier RERTR experiments, i.e. plate L2F46Z from RERTR-10B, exhibited a low blister threshold temperature when tested in 2012.

Table 2. Blister threshold data from the RERTR-12 and AFIP-4 experiments.

\begin{tabular}{|c|c|c|c|c|c|c|c|c|c|}
\hline Experiment & Plate ID & $\begin{array}{c}\text { Test } \\
\text { Train } \\
\text { Position }\end{array}$ & $\begin{array}{c}\text { Fuel Foil } \\
\text { Thickness } \\
\text { (inches) }\end{array}$ & $\begin{array}{c}\text { Diffusion } \\
\text { Barrier }\end{array}$ & $\begin{array}{c}\text { Plate } \\
\text { Bonding } \\
\text { Method }\end{array}$ & $\begin{array}{c}\text { Average } \\
\text { Fission } \\
\text { Density, } \\
\mathbf{x} \mathbf{1 0}^{21} \\
(\text { fissions/ } \\
\mathbf{c m}^{3} \text { ) }\end{array}$ & $\begin{array}{c}\text { Peak } \\
\text { Fission } \\
\text { Density }^{1} \text {, } \\
\text { x 10 }{ }^{21} \\
\text { (fissions/ } \\
\text { cm }^{3} \text { ) }\end{array}$ & $\begin{array}{c}\text { Measured } \\
\text { Blister } \\
\text { Temperature } \\
\left({ }^{\circ} \mathrm{C}\right)\end{array}$ & $\begin{array}{l}\text { Blister } \\
\text { Types }^{3}\end{array}$ \\
\hline RERTR-12 (X1) & L1P460 & $\mathrm{C}-4$ & 0.010 & $\mathrm{Zr}$ & HIP & 2.35 & 3.98 & 400 & 1,2 \\
\hline RERTR-12 (X1) & L1P592 & $\mathrm{C}-7$ & 0.010 & $\mathrm{Zr}$ & HIP & 2.69 & 5.09 & 350 & 2 \\
\hline RERTR-12 (X2) & L1P463 & $\mathrm{D}-8$ & 0.010 & $\mathrm{Zr}$ & HIP & 2.86 & 4.86 & 350 & 1 \\
\hline RERTR-12 (X2) & L1P595 & D-7 & 0.010 & $\mathrm{Zr}$ & HIP & 3.41 & 6.38 & 325 & 2 \\
\hline RERTR-12 (X2) & L1P758 ${ }^{2}$ & D-6 & 0.010 & $\mathrm{Zr}$ & HIP & 5.00 & 9.20 & 300 & 2 \\
\hline RERTR-12 (X1) & L1P774 & $\mathrm{C}-5$ & 0.010 & $\mathrm{Zr}$ & HIP & 5.59 & 7.49 & 325 & 2 \\
\hline RERTR-12 (X1) & L1P772 & $\mathrm{C}-1$ & 0.010 & $\mathrm{Zr}$ & HIP & 5.77 & 7.83 & 325 & 2 \\
\hline RERTR-12 (X2) & L1P756 & D-5 & 0.010 & $\mathrm{Zr}$ & HIP & 7.05 & 9.10 & 300 & \\
\hline RERTR-12 (X2) & L1P754 & D-1 & 0.010 & $\mathrm{Zr}$ & HIP & 8.13 & 11.9 & $\begin{array}{c}\text { blistered in } \\
\text { the core at } \\
205.3^{\circ} \mathrm{C} \text { (est. } \\
\text { peak T) }\end{array}$ & 2 \\
\hline RERTR-12 (X3) & $\mathrm{L} 1 \mathrm{P} 785^{4}$ & B-5 & 0.010 & $\mathrm{Zr}$ & HIP & 9.15 & 13.08 & $\begin{array}{l}\text { blistered in } \\
\text { the core at } \\
210.1^{\circ} \mathrm{C} \\
\text { (est. peak T) }\end{array}$ & TBD \\
\hline AFIP-4 & L1H34Z & B-1 & 0.013 & $\mathrm{Zr}$ & HIP & 2.51 & 2.99 & 350 & 2 \\
\hline AFIP-4 & L1H36Z & B-6 & 0.013 & $\mathrm{Zr}$ & HIP & 4.45 & 5.03 & 300 & 2 \\
\hline AFIP-4 & L1B33Z & A-2 & 0.013 & $\mathrm{Zr}$ & FB & 4.06 & 4.59 & 300 & 2 \\
\hline AFIP-4 & L1B51Z & A-4 & 0.013 & $\mathrm{Zr}$ & FB & 4.56 & 5.20 & 300 & 2 \\
\hline
\end{tabular}

1- Estimated using beginning of life (BOL) plate power peaking factors

2- Blistered at starting temperature of the blister anneal test

3- Information is preliminary, additional metallography work is required to confirm types of the blisters

4- Post Irradiation Examination of plate L1P785 has not been performed 


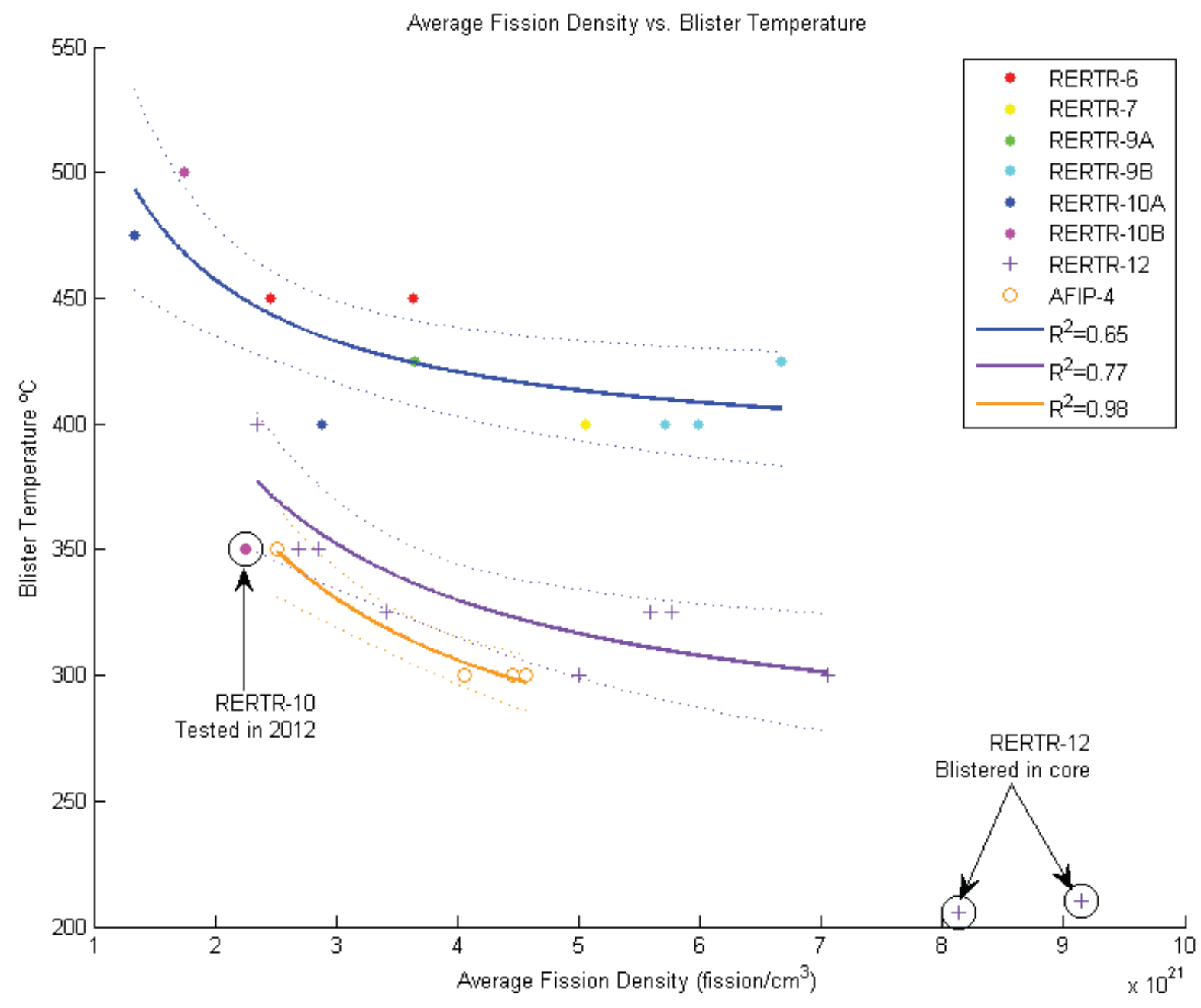

Figure 1. Curve fits of data from the two monolithic fuel blister testing campaigns. The data is fit using the average fuel plate fission density. Three circled data points (one from RERTR-10 and two from RERTR-12) were not included in the model fit.

As seen in Figure 1, the decrease in blister temperature with fission density in each of the two groups of plates (prior to RERTR-12 vs. RERTR-12 plus AFIP-4) appears to follow a trend similar to other fuel systems, decreasing with increasing fission density. Because of the iterative method historically established for collecting blister-threshold temperature data and the relatively small data sets, blister-threshold temperature data are inherently noisy. The data from the two blister test campaigns, nevertheless, appear to be statistically distinct (Figure 1) at the 95\% confidence level.

The mechanism of blister formation in monolithic fuels is not well understood. However, it is believed that blistering in materials generally occurs when the applied stress $(\sigma)$ exceeds material strength $\left(\sigma^{*}\right)$, as demonstrated in Figure 2. 


\section{Blister Formation}

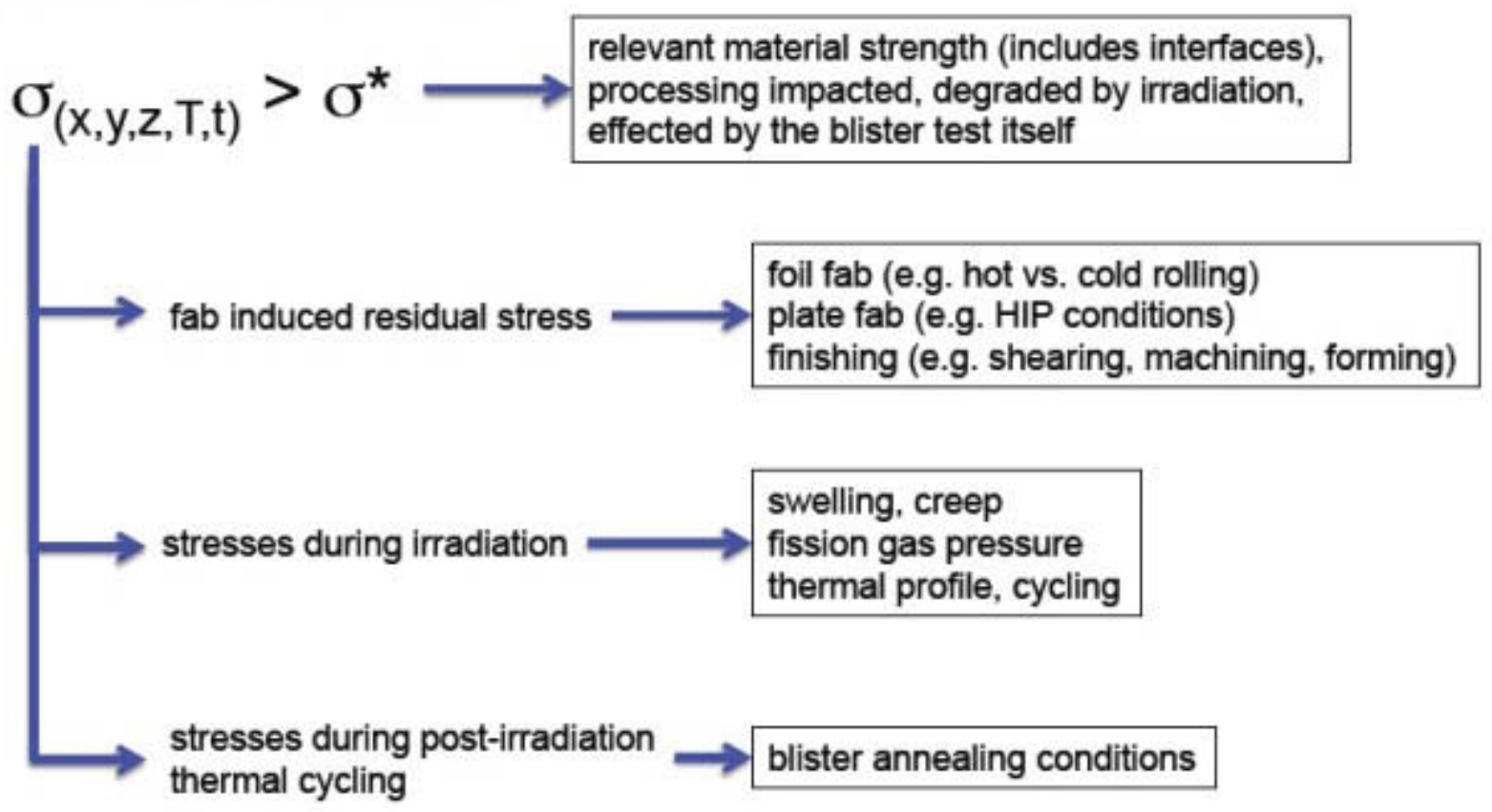

Figure 2. General condition for blister formation.

All blisters examined are preferentially located either at, or connected to, the corners or the edges of the U-Mo fuel foil. There appear to be two types of blisters. On the RERTR-12 plates, Type 1 blisters are designated as small blisters, less than about $0.17 \mathrm{~cm}^{2}$ in size, with some involvement of the clad-to-clad bond adjacent to the fuel-to-clad bond (see Figure 3). The upper limit of fission density for the formation of Type 1 blister is approximately $4 \times 10^{21}$ fiss $/ \mathrm{cm}^{3}$. It is apparent that at this low fission density, the fuel foil remains relatively strong because it has not yet become embrittled from the build-up of fission gases and other fission products. In addition, the plates with Type 1 blisters manage to endure several thermal cycles in the course of the annealing tests. It has been hypothesized that during the cool-down phase of the test, due to significant differences between thermophysical properties of U-Mo fuel and aluminum cladding, the foil can initiate a debond at the clad-to-clad interface adjacent to the fuel foil. This characteristic was observed during examination of irradiated fuel via optical metallography. As is shown in Figure 4, the fuel in these cases remains mostly intact, but the clad-to-clad bond is opened, with the separation moving towards the outer edges of the plate.

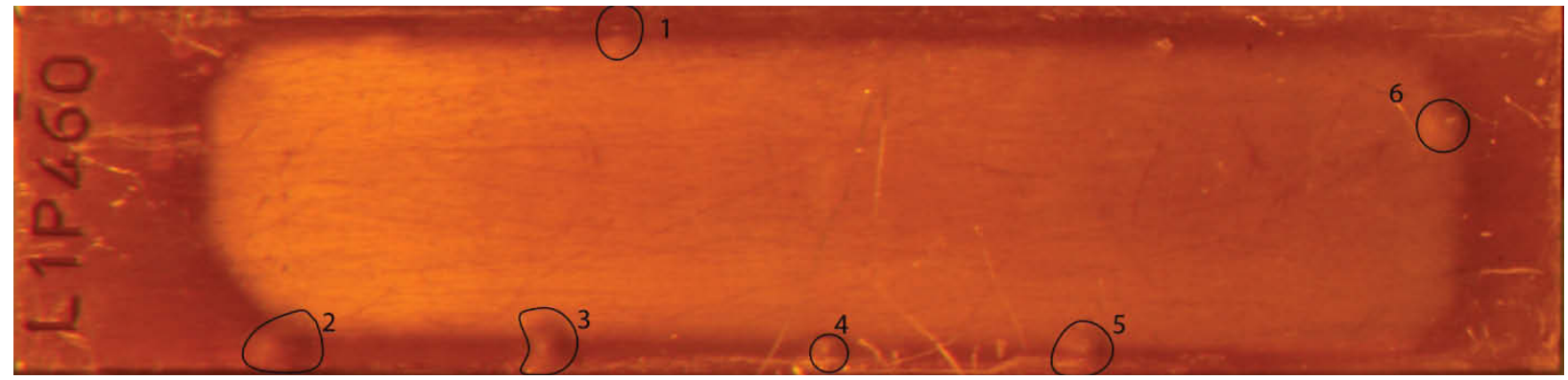

Figure 3. Type 1 blisters on the front side of plate L1P460 (RERTR-12). Average fission density $2.35 \times 10^{21} \mathrm{fiss} / \mathrm{cm}^{3}$. Peak fission density $3.98 \times 10^{21}$ fiss $/ \mathrm{cm}^{3}$. 


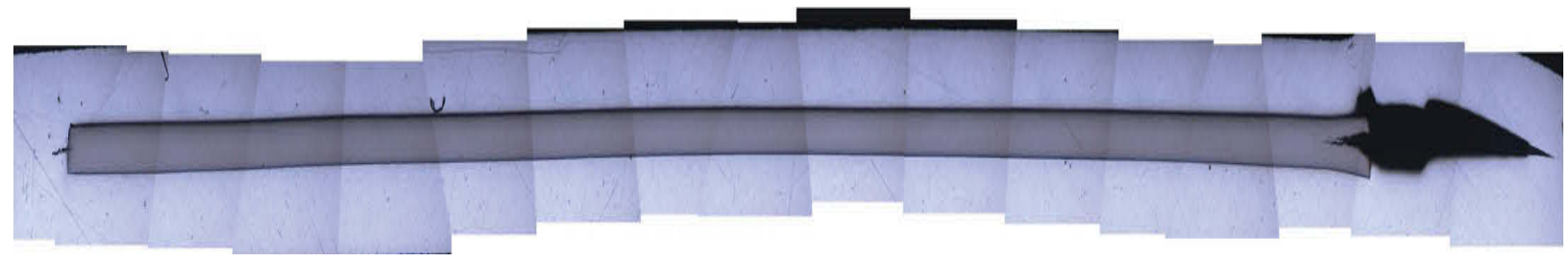

Figure 4. Montage of optical metallography images of the transverse cut through a Type 1 blister (\#4) on plate L1P460 (RERTR-12). Average fission density $2.35 \times 10^{21}$ fiss $/ \mathrm{cm}^{3}$. Peak fission density $3.98 \times 10^{21} \mathrm{fiss} / \mathrm{cm}^{3}$.

Type 1 blisters have not been observed on the plates with burnups exceeding $4.0 \times 10^{21} \mathrm{fiss} / \mathrm{cm}^{3}$; instead, Type 2 blisters (see Figure 5) are present over the fuel zone and cover a larger area. These blisters appear to grow larger with burnup, indicating that propagation may be fission gas driven. In fuel plates with fission densities exceeding $\sim 5.5 \times 10^{21}$ fiss $/ \mathrm{cm}^{3}$ (above 100\% low enriched uranium (LEU) burnup), the Type 2 blisters become more "pillow-like" in appearance (see Figure 8). At these high fission densities, the fuel foil is saturated with fission gases and other fission products and has become embrittled. A typical metallographic cross-section view of the Type 2 blister is shown in Figure 6, Figure 7 and Figure 9. As seen from these images, it appears that the tearing (cracking) in the Type 2 blisters usually occurs in the U-Mo foil, close to the U-Mo/Zr diffusion layer.

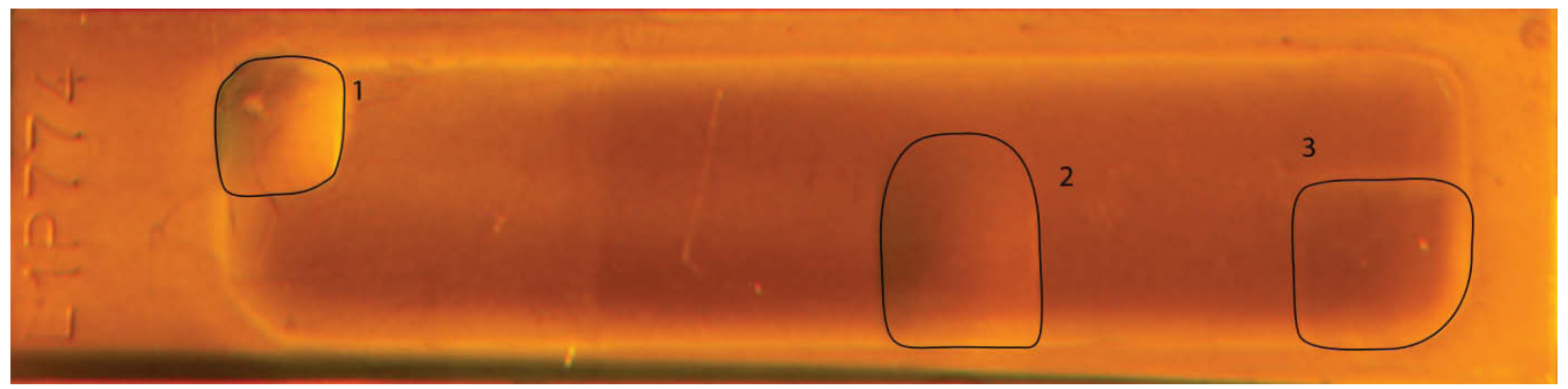

Figure 5. Type 2 blisters on the front side of plate L1P774 (RERTR-12). Average fission density $5.59 \times 10^{21}$ fiss $/ \mathrm{cm}^{3}$. Peak fission density $7.49 \times 10^{21}$ fiss $/ \mathrm{cm}^{3}$.

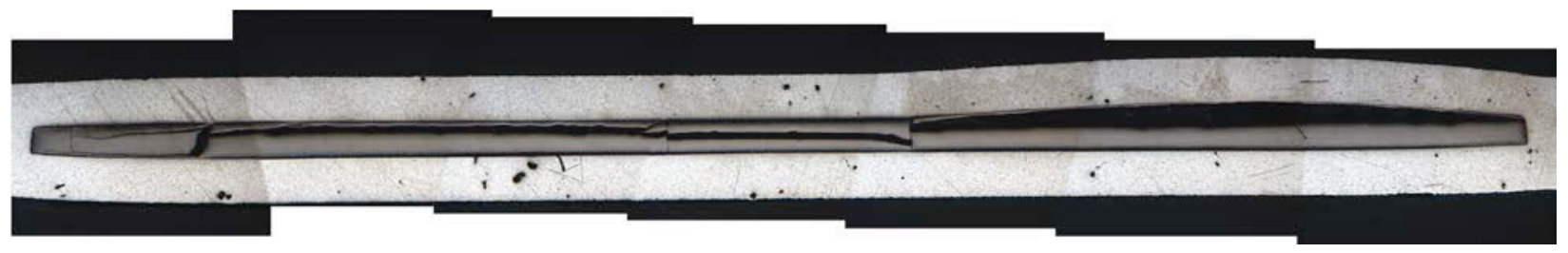

Figure 6. Montage of optical metallography images of the transverse cut through Type 2 blister on plate L1P758 (RERTR-12). Average fission density $5.00 \times 10^{21} \mathrm{fiss} / \mathrm{cm}^{3}$. Peak fission density $9.20 \times 10^{21} \mathrm{fiss} / \mathrm{cc}$. 


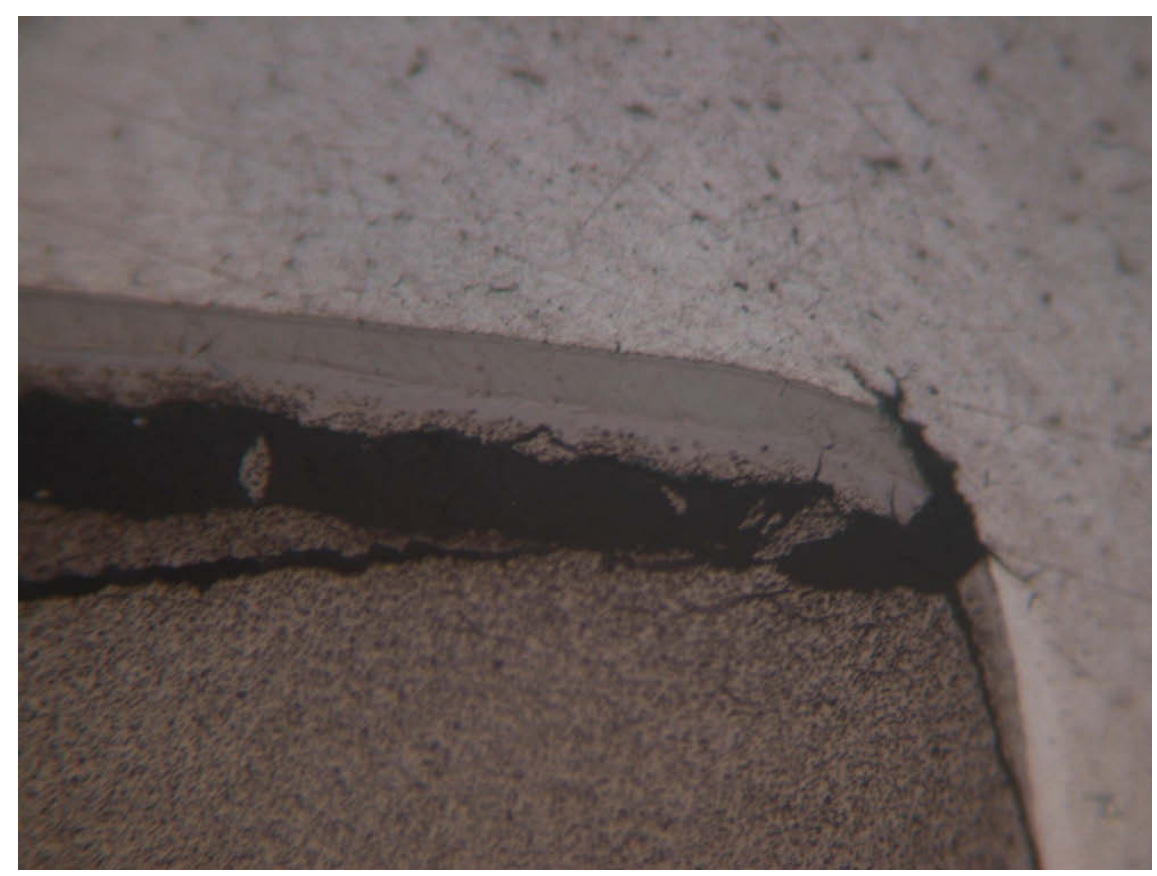

Figure 7. Optical metallography image $(500 \times)$ of the right end of the transverse cut through Type 2 blister on plate L1P758 (RERTR-12) shown in Figure 6.

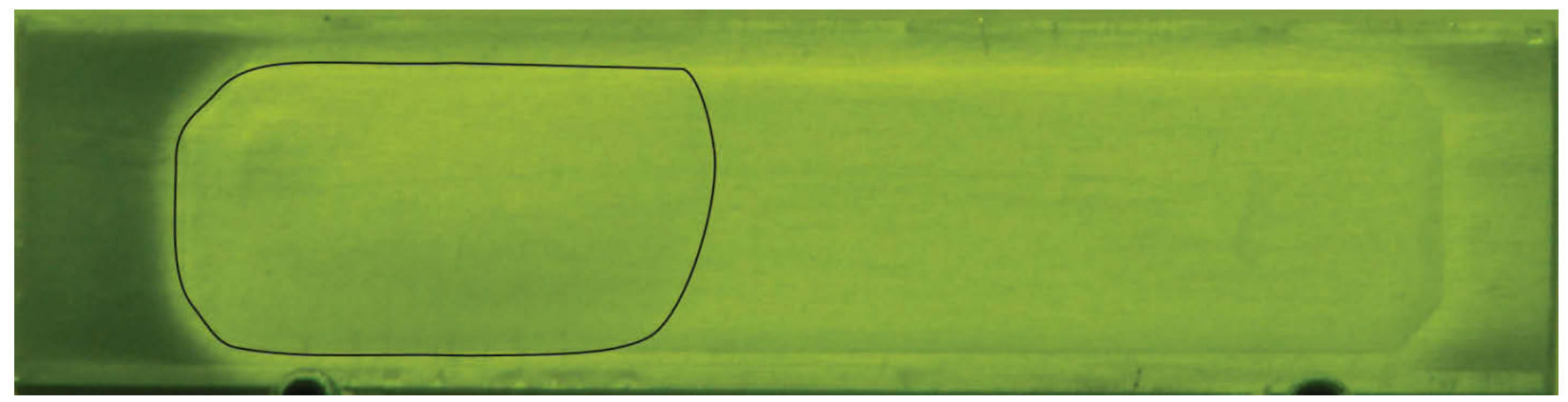

Figure 8. "Pillow-like" type 2 blister on the back side of plate L1P754 (RERTR-12), which blistered in the core. Average fission density $8.13 \times 10^{21}$ fiss $/ \mathrm{cm}^{3}$. Peak fission density $11.9 \times 10^{21}$ fiss $/ \mathrm{cm}^{3}$. 


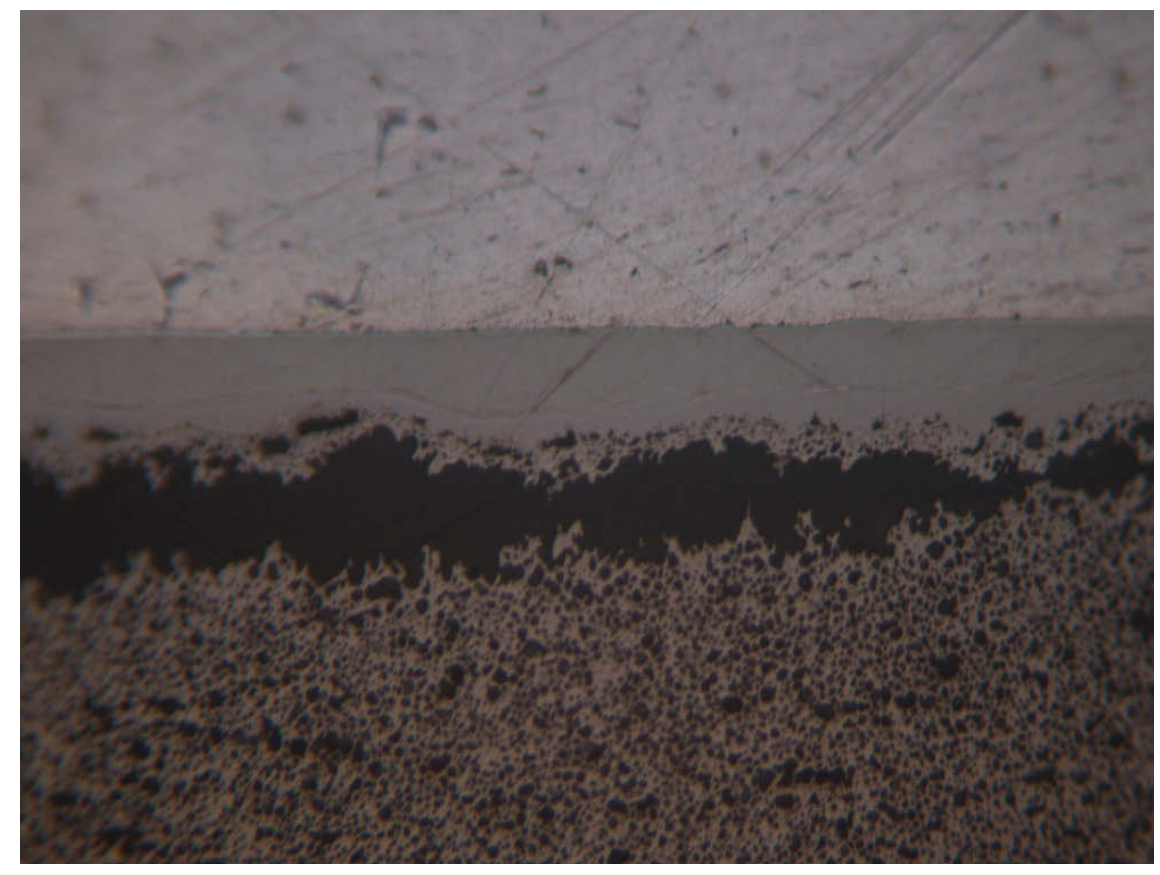

Figure 9. Optical metallography image (500×) of the axial cut through Type 2 blister on fuel plate L1P754 (RERTR12).

The same two types of blisters were observed on the plates from RERTR experiments conducted prior to RERTR-12. Figure 10 and Figure 11 demonstrate Type 1 blisters on a plate from the RERTR-10A experiment, and Figure 12 shows Type 2 blisters on a plate from the RERTR-9 experiment. Note that the Type 1 blister in Figure 11 did not result in fuel cracking.

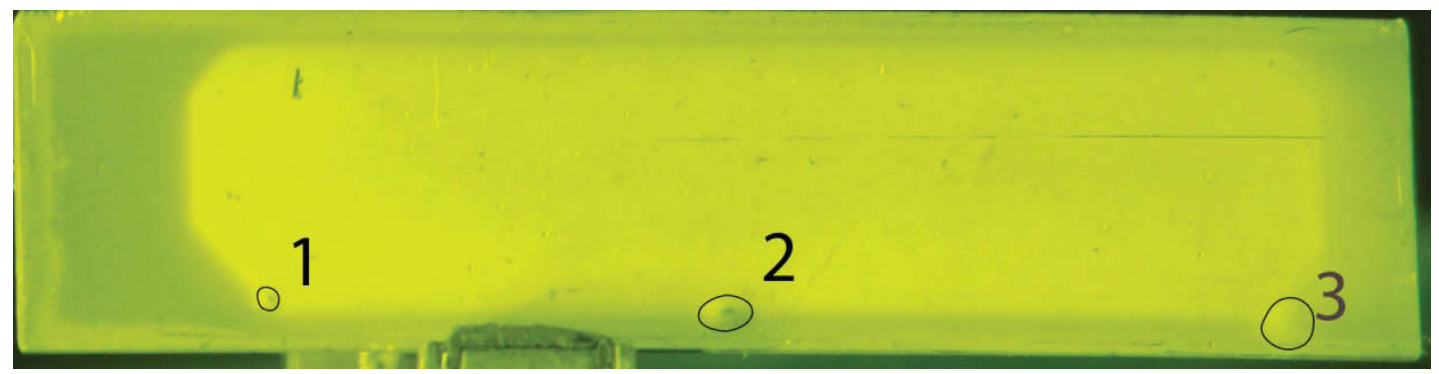

Figure 10. Type 1 blisters on the back side of plate L2P15Z (RERTR-10A). Average fission density $1.34 \times 10^{21}$ fiss $/ \mathrm{cm}^{3}$. Peak fission density $1.83 \times 10^{21} \mathrm{fiss} / \mathrm{cm}^{3}$.

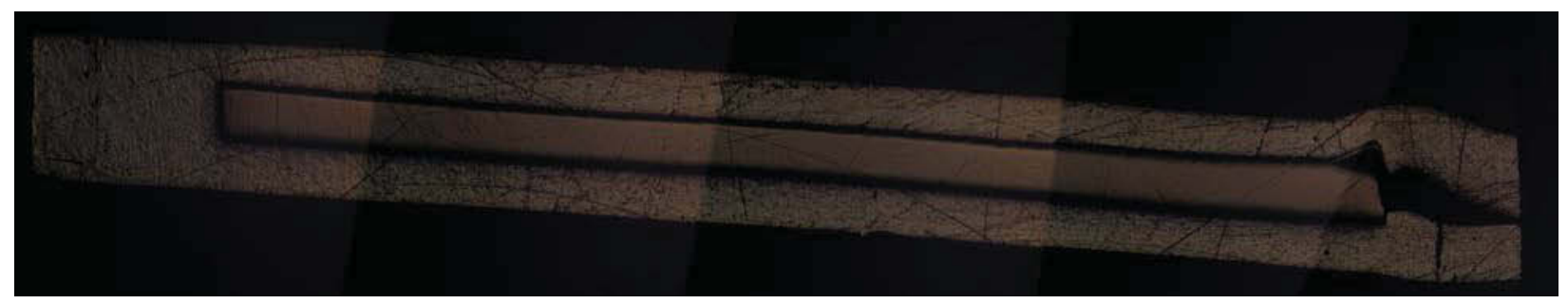

Figure 11. Montage of the optical-metallography images of the transverse cut through a Type 1 blister on plate L1P15Z (RERTR-10A). Average fission density $1.34 \times 10^{21}$ fiss $/ \mathrm{cm}^{3}$. Peak fission density $1.83 \times 10^{21} \mathrm{fiss} / \mathrm{cm}^{3}$. 


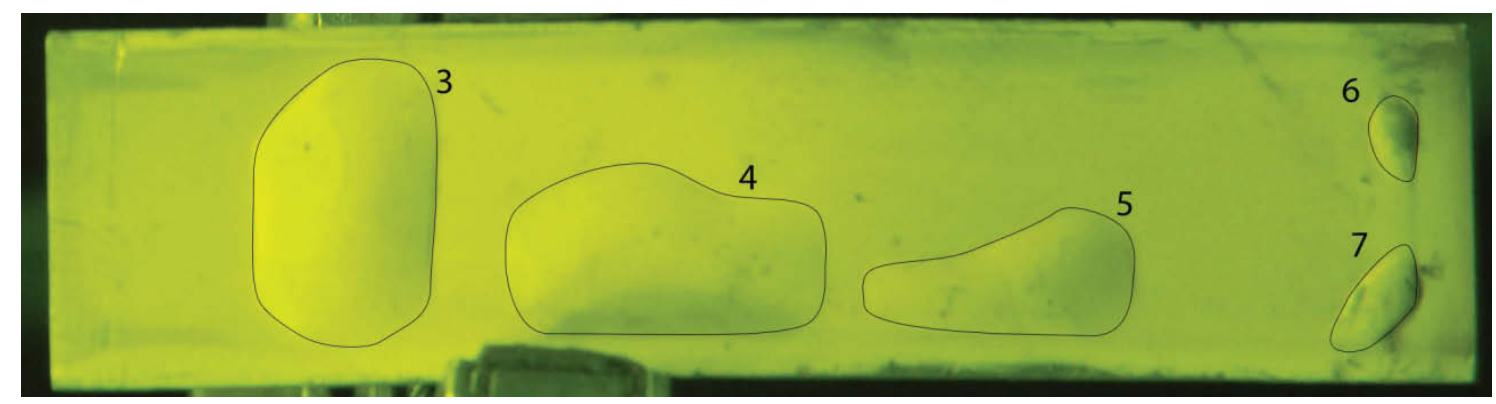

Figure 12. Type 2 blisters on the back side of plate L1P10T (RERTR-9B). Average fission density $7.22 \times 10^{21}$ fiss $/ \mathrm{cm}^{3}$. Peak fission density $9.63 \times 10^{21}$ fiss $/ \mathrm{cm}^{3}$.

The photographs of all blister tested plates and micrographs of selected blister cross-sections are presented in Appendix A. It has yet to be determined whether these lower blister-threshold temperatures would be acceptable for the NRC-licensed research reactors and high-power reactors like the ATR and HFIR. Nevertheless, these low temperature values imply that some significant changes may have occurred between the RERTR tests performed prior to and those beginning with RERTR-12, changes which warrant further investigation. An investigation has been launched to identify differences between the tests and to determine the cause of the lower blister-threshold temperature observed in irradiated fuel specimens from the RERTR-12 and AFIP-4 experiments.

Investigation is conducted under the guidance of PLN-4155, "Analysis of Low Blister Threshold Temperatures in the RERTR-12 and AFIP-4 Experiments" [6], and is driven by hypotheses about the causes of failure listed in the Appendix B of that plan. The main focus of the investigation is placed in the following areas:

1. Fabrication variables

2. Pre-irradiation characterization

3. Irradiation conditions

4. Post-irradiation examination

5. Additional blister testing

6. Mechanical modeling

This report documents preliminary results of the investigation. These results point to two theories that are supported by the data in this report. The most prominent theory supported by data is that low blister-threshold temperature is the result of mechanical energy imparted on the samples from process working (hot and cold rolling) without adequate post processing (annealing). The cause mechanisms are still under investigation, but can be classified into two categories:

- Residual Stress

- Undesirable interaction boundary and/or U-Mo microstructure change.

A secondary theory that cannot be ruled out with information currently available is that a change in the test conditions has resulted in a statistically significant downward shift of measured blister temperature.

Since this is a forensic investigation, correlation is established through a process of data mining. Definitive cause and effect relationships will be established by future experimental programs. 


\section{INITIAL RESULTS OF THE INVESTIGATION 2.1 Fabrication Variables}

\subsubsection{Background}

It has been postulated [6] that differences in as-built fuel plate microstructure, resulting from the differences in fuel fabrication process, might be responsible for the lower blister threshold temperature observed in RERTR-12 and AFIP-4 experiments as compared to the RERTR-6, 7, 9A, 9B, 10A and 10B tests. Therefore, the objective of this task is to establish key differences in fabrication process between the groups of plates with high and low blister temperatures and relate these differences to the unique features observed in microstructures of these plates.

To accomplish this task (see Section 2.1 of the PLN-4155), fabrication process data mining has been performed for the blister-threshold-tested fuel plates and process-history data have been compiled. Spreadsheets associated with fuel alloy chemistry, fuel foil, and plate-processing conditions have been established. Monolithic Fuel Plate ProcessingVariables Summary Sheets are attached (see Appendix B) as a useful tool to identify processing differences between all blister-threshold-tested fuel plates. Fuel-fabrication flowcharts have also been produced for each experiment, starting from RERTR-6, to document the evolution of the fuel-fabrication process and highlight major differences in fuelprocessing steps between the tests (see Appendix C). In addition, the graphs of the blister temperature as a function of several fabrication variables were constructed and are presented in Appendix G.

\subsubsection{Summary}

There are significant differences in the processing/fabrication parameters of monolithic fuel foils and fuel plates for testing in RERTR-6, 7, 9A, 9B, 10A, 10B, 12 and AFIP-2, 3, 4 irradiation experiments. These differences can be attributed to the fact that the fuel-fabrication process evolved with each experiment to meet fuel-performance and reactor-safety requirements (see Appendix C, with flowcharts of the fabrication process for each experiment).

Multiple changes were implemented to obtain:

- U-Mo foils that did not crack after roll-processing

- A barrier layer to limit reaction of the fuel foil and the cladding during irradiation

- Scale up of the fabrication process

- Foil thickness uniformity (target of $\sim 0.001$ in.)

- Alternative fabrication processes that could be more easily implemented

A brief review of the evolution of fabrication process history is presented below

\subsubsection{RERTR-6, 7}

Two plates from the RERTR-6 (L2F020, N1F060 ${ }^{1}$ ) and one plate from RERTR-7 (L1F110) experiments were blister tested after irradiation and exhibited blister threshold temperatures in the range of $400-450^{\circ} \mathrm{C}$. These frictionbonded plates contained bare foils (with no diffusion barrier layers). The foils for RERTR-6 and 7 were produced via cold rolling with subsequent resistance-anneal treatment at $925^{\circ} \mathrm{C}$. Plate L1F020 contained thick foil. A list of the archive plates associated with these plates is shown in Table 3. Archive fuel plates, which are used for fuel characterization before irradiation, are manufactured in a manner identical to the plates that are subjected to irradiation. When archive plates having enriched uranium alloy where not available, depleted uranium alloy material was prepared.

${ }^{1}$ Plate Identification Code

\begin{tabular}{|l|l|l|l|l|}
\hline $\mathbf{1}^{\text {st }}:$ Character & $\mathbf{2}^{\text {nd }}:$ Number & $\mathbf{3}^{\text {rd }}:$ Character & $\mathbf{4}^{\text {th }} \mathbf{- 5 ^ { \text { th } } \text { Numbers }}$ & $\mathbf{6}^{\text {th }}:$ Character \\
\hline L: U10Mo & $1: 0.010 "$ thick fuel & B or F: Friction Bond & Serial Number & Z: Zirconium interlayer \\
\hline N: U7Mo & $2: 0.020 "$ thick fuel & H or P: HIP & & C: Bonding Study, i.e. anviloy FB tool \\
\hline & & & & T*: Thermal Spray interlayer \\
\hline & & & & $0:$ No interlayer \\
\hline
\end{tabular}

*Note: In RERTR-9B plates having Zr co-rolled foils were designated with T vs Z: i.e. L1P10T 
Table 3. Blister tested RERTR-6 and 7 plates and designated archive plates.

\begin{tabular}{|l|l|l|l|l|l|l|}
\hline & \multicolumn{2}{|l|}{ AL Tracking Number } & \multicolumn{2}{c|}{ Chemistry } & \multicolumn{2}{c|}{ Isotopics } \\
\hline $\begin{array}{l}\text { Irradiated } \\
\text { Plate ID }\end{array}$ & Sample & Number & $\mathrm{U}$ & $\mathrm{Mo}$ & $\mathrm{U}^{235}$ & $\mathrm{U}^{238}$ \\
\hline L2F020 & U10Mo-18A & 86661 & 85.86 & 10.00 & 19.94 & 79.60 \\
\hline N1F060 & U7Mo-11 & 86459 & 92.39 & 6.53 & 19.73 & 79.80 \\
\hline L1F110 & 10Mo-21A & 87505 & 88.2 & 10.1 & 58.22 & 40.88 \\
\hline $\begin{array}{l}\text { Archive } \\
\text { Plate ID }\end{array}$ & & & & & & \\
\hline L2F010 & U10Mo-16 & - & - & - & - & - \\
\hline N1F080 & U7Mo-13A & 86461 & 92.99 & 6.52 & 19.72 & 79.81 \\
\hline L1F080 & U10Mo-07A & 86360 & 89.74 & 9.16 & 19.72 & 79.81 \\
\hline L1F100 & U10Mo-11 & 86363 & 90.14 & 9.12 & 19.72 & 79.82 \\
\hline
\end{tabular}

The alloys for RERTR-6 were prepared by arc melting using LEU feedstock and Mo foil. The uranium metal used was from the inventory at INL's Materials and Fuels Complex (MFC). Thirty to forty-gram buttons of U-10Mo were drop cast into graphite book molds to form coupons $\sim 0.9$ in. wide $\times 1.25$ in. long $\times 0.09$ in. thick, suitable for making two 0.010 -in.-thick mini-foils or one 0.020 -in.-thick foil.

The U-Mo alloys for RERTR-7 were prepared by arc-melt blending of 58\% high enriched uranium (HEU) and Mo foil. The 58\% HEU was obtained by arc melt blending 93\% HEU with depleted uranium (DU) in the needed proportions.

Chemical analysis results for the LEU-Mo foils indicate U-Mo composition was $+/-1 \mathrm{wt} . \%$ with respect to target Mo content and $+/-0.25 \mathrm{wt} . \%$ with respect to target U-235 content. Limited data exist on the levels of impurities in the LEU feedstock and prepared alloys associated with RERTR-6, -7. Three of five chemical analyses reported the presence of carbon impurity in the range of 82-340 ppm. The alloy associated with blister-tested plate N1F060 (U7Mo-11) also contained 2100 ppm copper, which is likely contamination from the arc-melting hearth.

Foils (of both U-10Mo and U-7Mo) were prepared via cold rolling, using $90 \%$ reduction ( $\sim 80 \%$ for 0.020 -in.-thick foils). The rolling took place in a radiological hood using a hand-cranked jeweler's mill. The foils were rolled to a thickness of $0.010 \pm 0.001 \mathrm{in}$. (Some of the U-10Mo composition foils were rolled to double thickness of $0.020 \mathrm{in}$.). Per-pass reduction was limited to 0.002 inch.

It was observed early on that when left in the as-rolled condition, the rolled foils would undergo severe cracking. The cracking was found to progress to the point of rendering a foil unusable within a few hours. Subsequently, a stress relief resistance-anneal treatment was performed, where the foil was held at $925^{\circ} \mathrm{C}$ for a few seconds, as monitored using an optical pyrometer (see Figure 13).

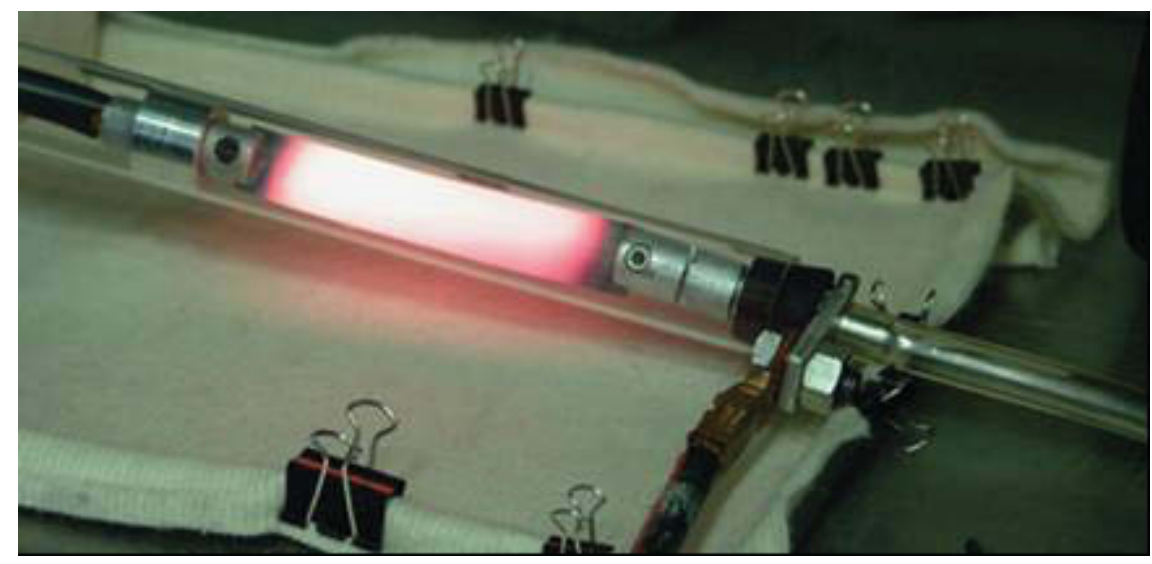

Figure 13. Resistance annealing of cold-rolled foil at $925^{\circ} \mathrm{C}$ for $\sim 10$ seconds inside of an argon-purged fused-quartz tube. 
Foils were sized using a hydraulic-press-driven blanking die located in the main RERTR glovebox. This die produced a foil measuring 3.25 in. $\times 0.75$ in., with corner radii of 0.125 in. It is noted in fabrication-summary documentation that the blanking die created significant burrs along foil edges and that burrs were removed via mechanical methods (i.e. sanding or filing). Oxide buildup on the fuel foil was removed by abrading the surface with 400 grit sandpaper. The foil was given a final wipe down with ethanol.

To fit the foil, a recess was machined in the bottom plate of the Al-6061-T6 cladding (see Figure 14). The area of this recess was slightly larger than the foil (by $0.005-0.010$ in.) on the perimeter to allow the fuel foil to be easily fit (and remain) in the assembly, despite some foil warping. A ScotchBrite abrasive pad was applied to prepared unmachined mating surfaces of the Al-6061 cladding prior to friction bonding (the outside surfaces of the plates were only cleaned to remove gross scale buildup).

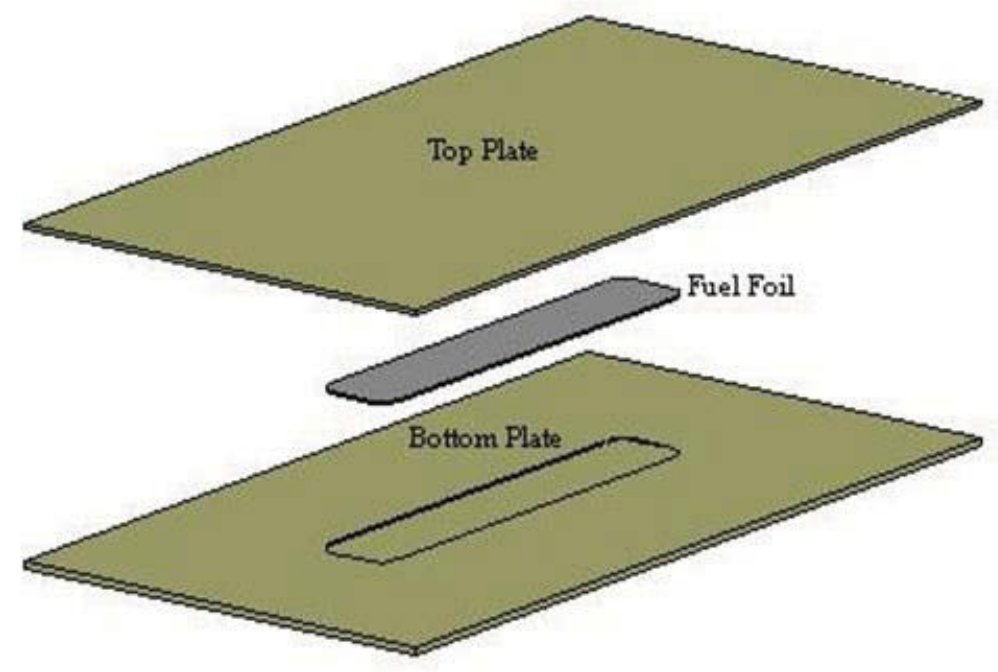

Figure 14. A diagram of the monolithic-fuel-plate assembly.

An image of the end (edge) of the irradiated fuel foil is shown in Figure 15. The image appears to indicate more pronounced fuel-cladding chemical interaction (FCCI) in the end region of the foil, as compared to the face region. This difference may be tied to cold work induced by blanking or, alternatively, attributed to the edge-on orientation of the fuel plate during irradiation.

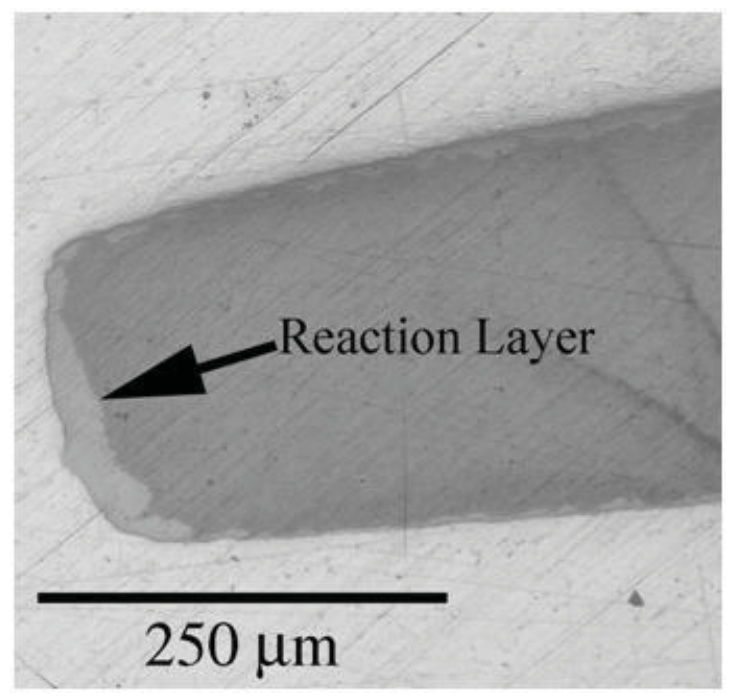

Figure 15. An image of U-10 Mo foil from an irradiated plate L1F100 (RERTR-6) shows preferential fuel-cladding chemical interaction (FCCI) on the end (edge) of the foil.

Thermal treatment history for RERTR-6 and RERTR-7 friction bonded plates is discussed below. 
During the friction-bonding (FB) process, a foil was exposed to $\sim 400-450^{\circ} \mathrm{C}$ for a few seconds as the tool pass was made. Eight FB passes per side were performed, for a total of sixteen passes. After FB of the cladding, a plate-flattening step was performed using a heated-platen hydraulic press. The conditions of this step were $385^{\circ} \mathrm{C}$ at $\sim 200$ psi for $3-4$ minutes. After flattening, a homogenization anneal treatment was applied to RERTR-6 plates only to enhance corrosion resistance of Al cladding by improving the uniformity of $\mathrm{Al}$ grain structure. This treatment was performed at $500^{\circ} \mathrm{C}$ for 30 minutes using a heated-platen press under light (typically $500 \mathrm{lb}$ force) loading to ensure good contact between the platens and the plate surface.

The minimum cladding thickness on each side of the fuel plate is called minclad. When referring to the different sides of the cladding relative to the fuel foil, the convention of "front" side and "back" side is used; with the front side corresponding to the side of the fuel plate with identification engraving. Minclad parameters help to identify location of the fuel foil within the cladding and establish that adequate cladding is present on both sides of the foil. Minclad measurements using an ultrasonic scanner were implemented beginning with RERTR-7 and, thus, were not used during inspection of the RERTR-6 fuel plates.

The primary differences in the fabrication process between the RERTR- 6 and 7 and the RERTR-12 and AFIP-4 experiments include:

- Bare foils without Zr interlayer (RERTR-6, 7) versus foils with Zr interlayer (RERTR-12, AFIP-4)

- Between 78 and 90\% cold rolling (RERTR-6, 7)

- Resistance anneal of fuel foils at $925^{\circ} \mathrm{C}$ for a few seconds (RERTR-6, 7)

- Plates clad with Al-6061 using FB process (RERTR-6, 7) versus hot isostatic press (HIP) process (RERTR-12). Some of the AFIP-4 plates were also friction bonded.

The one common feature in the fabrication process between the RERTR-6 and 7 and the RERTR-12 and AFIP-4 experiments was foil blanking.

Alloys for RERTR-6 and 7 were prepared via arc melting and arc melt casting in an argon atmosphere glove box. RERTR-12 alloys were created in the same manner with the exception of alloy 344 ( $40 \%$ enriched U-10Mo). This particular alloy was produced via vacuum induction alloying and casting at Y-12. AFIP-4 alloys, LEU-10Mo, were prepared via vacuum induction alloying and casting at Y-12.

The photographs of the blister-tested plates from the RERTR-6 and 7 experiments are shown in Figure 16. Additional information on the types of the blisters found on these plates is included in Table 4. As shown in this table, all blisters associated with the plates from RERTR- 6 and 7 experiments were classified as Type 2 blisters. An interesting fact is that the blister from plate L1F110 (RERTR-7) was located on the front of the cladding, which had lower minimum cladding thickness (0.014 in.) than the back (0.018 in.). 

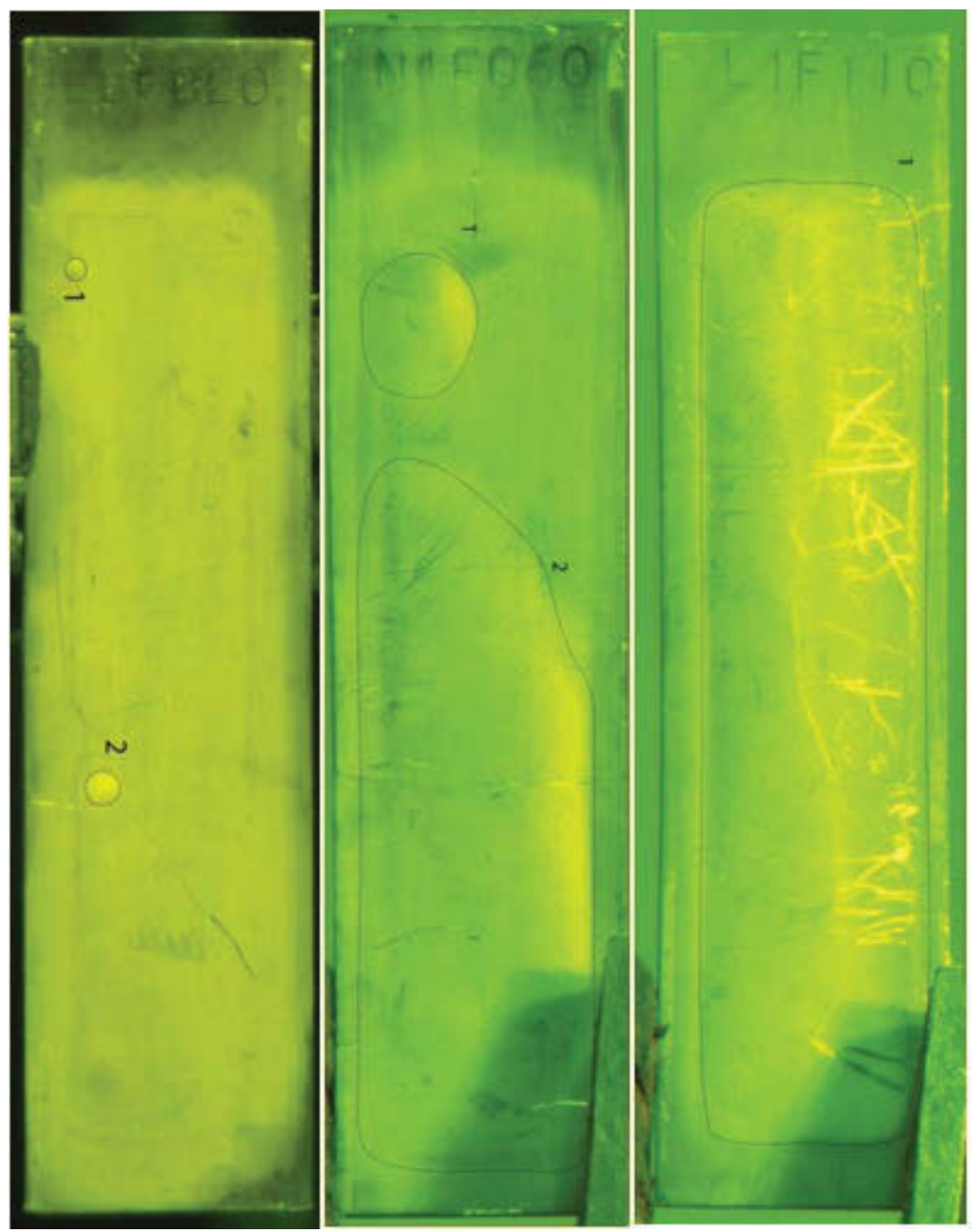

Figure 16. The images of the blister tested plates L2F020 (RERTR-6, front side), N1F060 (RERTR-6, front side) and L1F110 (RERTR-7, front side). Left edge of the front side of the plates (with ID) was facing center of the ATR core.

Table 4. Information on the blisters found on the plates from RERTR-6 and 7 experiments.

\begin{tabular}{|l|l|l|l|l|l|l|l|}
\hline Plate & $\begin{array}{c}\text { Blister } \\
\text { ID }\end{array}$ & $\begin{array}{c}\text { Blister Type } \\
(\mathbf{1} \text { or 2) }\end{array}$ & $\begin{array}{c}\text { Local Fission } \\
\text { Density, } \\
\times \mathbf{1 0}^{\mathbf{2 1}} \mathbf{f i s s} / \mathbf{c m}^{\mathbf{3}}\end{array}$ & $\begin{array}{c}\text { Blister } \\
\text { Temperature, } \\
\mathbf{}^{\mathbf{C}}\end{array}$ & $\begin{array}{c}\text { Blister } \\
\text { location }\end{array}$ & $\begin{array}{c}\text { Minclad } \\
\text { Front, } \\
\text { inches }\end{array}$ & $\begin{array}{c}\text { Minclad } \\
\text { Back, } \\
\text { inches }\end{array}$ \\
\hline \multirow{2}{*}{ L2F020 } & 1 & 2 & 3.07 & 450 & front & - & - \\
\cline { 2 - 8 } & 2 & 2 & 2.84 & 450 & front & - & - \\
\hline N1F060 & 1 & 2 & 5.52 & 450 & front & - & - \\
\hline N1F060 & 2 & 2 & 6.90 & 450 & front & - & - \\
\hline L1F110 & 1 & 2 & 1.21 & 400 & front & 0.014 & 0.018 \\
\hline
\end{tabular}

\subsubsection{RERTR-9A}

Only one plate (L1F27C) from RERTR-9A experiment was blister tested after irradiation and had a blister-threshold temperature of $425^{\circ} \mathrm{C}^{1}$. This friction-bonded plate contained a bare foil (no diffusion barrier layer). The foils for the plates in RERTR-9A experiment were processed by hot rolling followed by cold rolling and were subjected to resistance-annealing treatment at $925^{\circ} \mathrm{C}$ after cold rolling.

\footnotetext{
${ }^{1}$ Information for plate L1F27C requires further verification
} 
The alloys for RERTR-9A were prepared via arc melting 58\% HEU and Mo foil. The 58\% HEU was obtained via arc melt blending of $93 \%$ enriched HEU and DU. The uranium metal used was from the inventory at INL's MFC. 30$40 \mathrm{~g} \mathrm{U}-10 \mathrm{Mo}$ buttons were drop cast into graphite book molds to form coupons $\sim 0.9 \mathrm{in}$. wide $\times 1.25 \mathrm{in}$. long $\times 0.105 \mathrm{in}$. thick. Chemical analysis results for alloy 133, which was used in fuel plate L1F27C, are summarized in Appendix E.

Bare U-10Mo foils (HEU) were prepared via hot rolling of cast alloy coupons of $0.107-0.0135$ in. thick; at a total of $87 \%$ reduction. Hot rolling was performed using $650^{\circ} \mathrm{C}$-preheated carbon-steel rolling-pack assemblies, followed by a 30-minute post-hot-rolling anneal treatment at $650^{\circ} \mathrm{C}$. The foil (alloy 133) was then cold rolled from 0.0135 in. to 0.010 in., resulting in a $25 \%$ reduction.

Prior to shearing, the alloy 133 foil was resistance annealed at $925^{\circ} \mathrm{C}$ for several seconds. Three mini-foils (A, B, and $\mathrm{C}$ ) were cut from the larger foil using a bench shear. The edges of the mini-foils were deburred using 100 grit sand paper. Plate L1F27C was fabricated using foil 133-C by FB process with an anviloy tool. Because the plate had acceptable as-clad flatness, the $385^{\circ} \mathrm{C}$ post-FB flattening step was not performed on this plate.

In summary, the primary differences in the fabrication process between the RERTR-9A and the RERTR-12 and AFIP-4 experiments include:

- $\quad$ Bare foils, no Zr interlayer (RERTR-9A) versus foils with Zr interlayer (RERTR-12, AFIP-4)

- Resistance annealing of fuel foils at $925^{\circ} \mathrm{C}$ for a few seconds (RERTR-9A)

- Plates clad with Al-6061 using FB process (RERTR-9A) versus HIP process (RERTR-12). Some of AFIP-4 plates were also friction bonded

- Maximum of $10 \%$ per pass reduction during hot rolling versus $12 \%$ in AFIP-4 and $20-40 \%$ in RERTR-12.

Similarities in the fabrication process between RERTR-9A and RERTR-12, AFIP-4 experiments include:

- Foil shearing

- Coupons were hot rolled in carbon-steel rolling assemblies

- Foils were annealed after hot rolling at $650{ }^{\circ} \mathrm{C}$ for 30 minutes.

- Alloys for RERTR-9A were prepared via arc melting and arc melt casting in an argon atmosphere glove box. RERTR-12 alloys prepared via arc melting and arc melt casting in an argon atmosphere glove box; with the exception of alloy $344,40 \%$ enriched $\mathrm{U}-10 \mathrm{Mo}$, which was prepared via vacuum induction alloying and casting at Y-12. AFIP-4 alloys, LEU-10Mo, were prepared via vacuum induction alloying and casting at Y-12. 


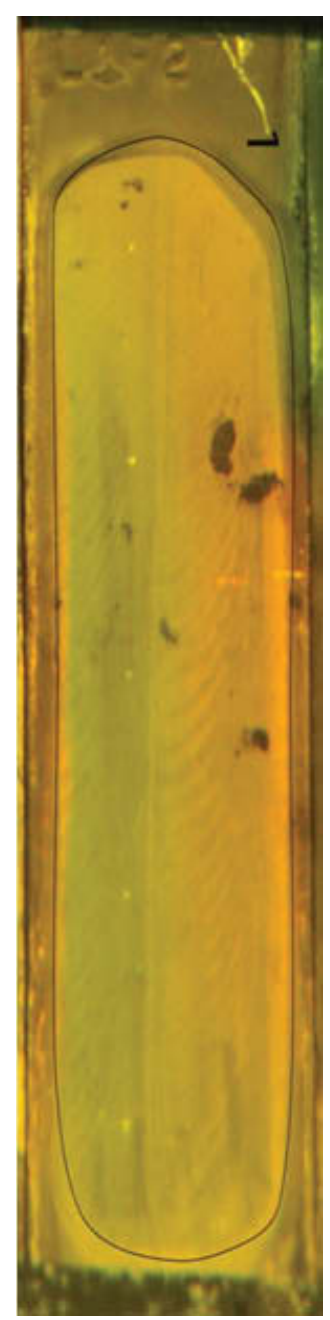

Figure 17. An image of the RERTR-9A blister-tested miniplate L1F27C. Right edge of the front side of the plate (with ID) was facing ATR core. Blistering occurred over entire fuel zone, but only on the front side of the plate.

A photograph of the RERTR-9A blister-tested miniplate L1F27C is shown in Figure 17. A pillow formed that encompassed the entire fuel zone. Additional information on the type of the blister found on this plate is included in Table 5.

Table 5. Information on the blister found on plate L1F27C from RERTR-9A experiment*.

\begin{tabular}{|c|l|l|l|l|l|l|l|}
\hline Plate & Blister ID & $\begin{array}{c}\text { Blister Type } \\
(\mathbf{1} \text { or 2) }\end{array}$ & $\begin{array}{c}\text { Local Fission } \\
\text { Density, } \\
\times \mathbf{1 0}^{\mathbf{2 1}}, \\
\mathbf{f i s s} / \mathbf{c m}^{\mathbf{3}}\end{array}$ & $\begin{array}{c}\text { Blister } \\
\text { Temperature, } \\
{ }^{\circ} \mathbf{C}\end{array}$ & $\begin{array}{c}\text { Blister } \\
\text { location }\end{array}$ & $\begin{array}{c}\text { Minclad } \\
\text { Front, } \\
\text { inches }\end{array}$ & $\begin{array}{c}\text { Minclad } \\
\text { Back, } \\
\text { inches }\end{array}$ \\
\hline L1F27C & 1 & 2 & 9.64 & 425 & front & 0.012 & 0.009 \\
\hline
\end{tabular}

${ }^{*}$ information on plate $\mathrm{L} 1 \mathrm{~F} 27 \mathrm{C}$ requires further verification

\subsubsection{RERTR-9B}

Plates L1F330, L1F35T and L1P10T from the RERTR-9B experiment had blister temperatures in the range of 400$425^{\circ} \mathrm{C}$. Plates L1F330 and L1F35T were friction bonded; plate L1P10T was bonded via HIP. Plate L1F330 contained a bare fuel foil without an interlayer. To prevent FCCI, plate L1F35T had an Al-Si thermal spray applied on the foilmating surfaces of the Al cladding, and plate L1P10T had a Zr co-rolled interlayer. All three foils were hot rolled in a rolling assembly, annealed at $650^{\circ} \mathrm{C}$ for $15-60$ minutes prior to decanning, and sheared to size using a bench shear. No cold rolling was performed. 
Alloys for RERTR-9B were prepared via arc melting 58\% HEU and Mo foil. The 58\% HEU was prepared via arc melt blending of $93 \%$ enriched U with DU. The uranium metal used was from the inventory at the INL's MFC. Thirty to forty gram U-10Mo buttons were drop cast into graphite book molds to form coupons $\sim 0.9 \mathrm{in}$. wide $\times 1.25 \mathrm{in}$. long $\times$ 0.105 in. thick. Results of chemical analyses of alloys 144, 147, and 148 are summarized in Appendix E of this report.

RERTR-9B miniplate L1P10T utilized fuel foil with Zr barrier layer, prepared via hot co-rolling. Zr barrier foils were not subjected to resistance annealing at $925^{\circ} \mathrm{C}$ to prevent oxidation of the $\mathrm{Zr}$ interlayer and minimize formation of the U-Zr interaction layer. None of the foils used in the RERTR-9B experiment, bare or Zr co-rolled, was resistance annealed; instead, RERTR-9B foils were annealed after hot rolling at $650^{\circ} \mathrm{C}$ for $15-60$ minutes prior to removal from their rolling assembly jacket.

Bare and $\mathrm{Zr}$ co-rolled HEU-10Mo foils were prepared via hot rolling of cast alloy coupons from $0.105-0.010$ in. thick, resulting in a $90 \%$ reduction. Hot rolling was performed using $650^{\circ} \mathrm{C}$-preheated carbon-steel rolling assemblies. The hot rolling schedule was not aggressive: with 47-50 hot passes completed at a maximum of $10 \%$ reduction per pass. Between 15 and 60 minutes of post-hot-rolling anneal treatment were performed. No cold rolling was utilized. Minifoils were sized using a bench shear, and the edges were deburred using 100 grit sand paper.

In summary, the primary differences in the fabrication process between the RERTR-9B and the RERTR-12 and AFIP-4 experiments include:

- HIP plate L1P10T contained Zr co-rolled foil, with the nominal thickness of $\mathrm{Zr}$ on each side of the foil equal to 0.0005 in. RERTR-12 and AFIP-4 foils both have 0.001-in.-thick Zr interlayer (nominal)

- $\quad$ FB plate L1F35T contained bare foil with Si thermal spray applied on the foil-mating surfaces of the Al cladding

- All RERTR-9B plates were hot rolled; no cold rolling was performed

- A maximum of 10\%-per-pass reduction was used during hot rolling of RERTR-9B plates, as compared to $12 \%$ reduction in AFIP-4 and 20-40\% in RERTR-12.

Similarities in fabrication processes between RERTR-9B and RERTR-12, AFIP-4 experiments include:

- Foil shearing

- Coupons hot rolled in carbon-steel rolling assemblies

- Foils annealed after hot rolling at $650^{\circ} \mathrm{C}$ for $15-60$ minutes.

- Alloys for RERTR-9B were prepared via arc melting and arc melt casting in an argon atmosphere glove box. RERTR-12 alloys prepared via arc melting and arc melt casting in an argon atmosphere glove box; with the exception of alloy $344,40 \%$ enriched U-10Mo, which was prepared via vacuum induction alloying and casting at Y-12. AFIP-4 alloys, LEU-10Mo, were prepared via vacuum induction alloying and casting at Y-12. 


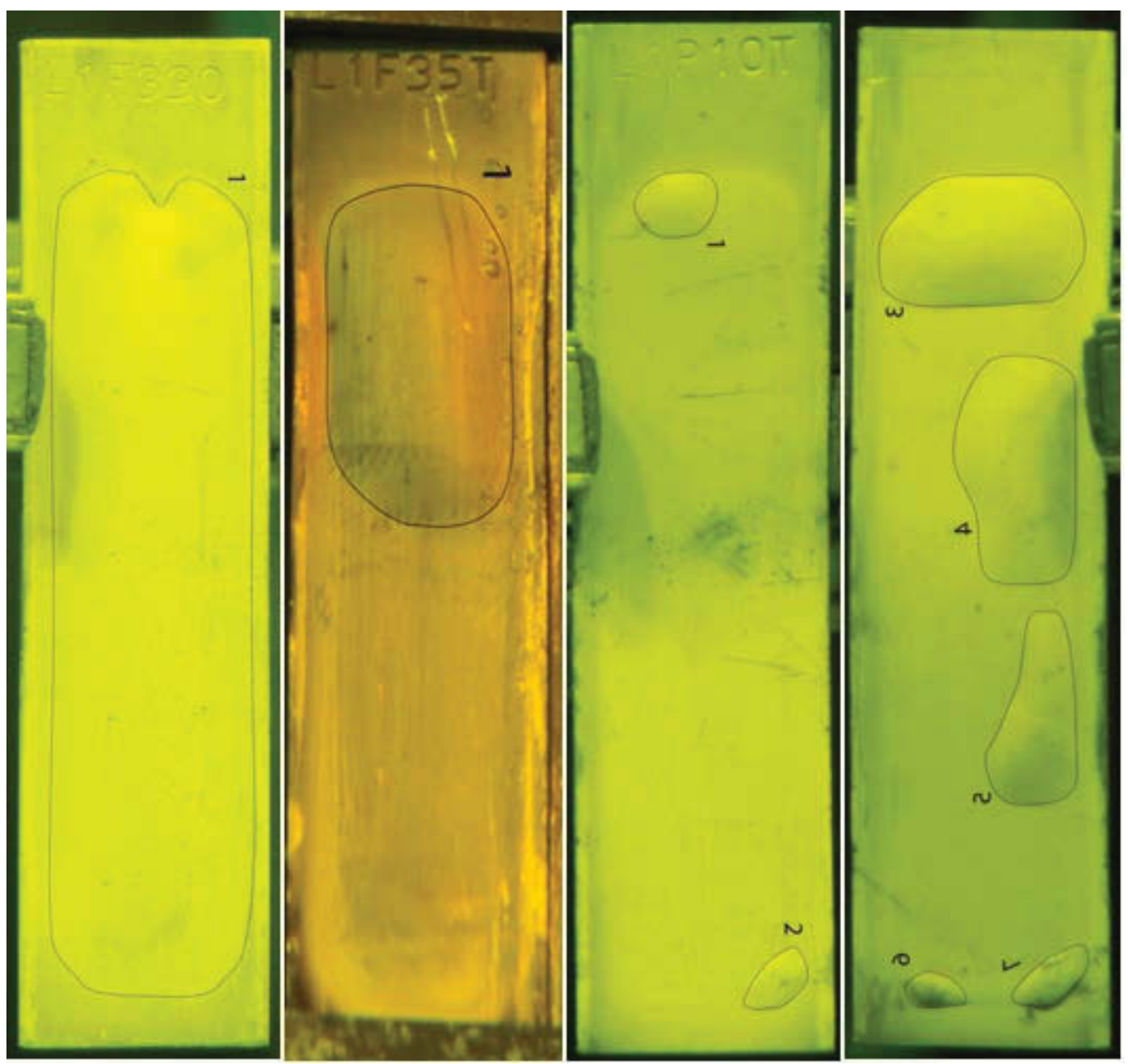

Figure 18. Photographs of the RERTR-9B blister-tested miniplates, from left to right: L1F330 (front side), L1F35T (front side), L1P10T (front and back sides). Right edge of the front side of the plate (with ID) was facing ATR core.

Photographs of the blister-tested RERTR-9B miniplates are shown in Figure 18. Additional information on the blisters observed on the plates from the RERTR-9B experiment is presented in Table 6. As seen from Figure 18, the blister on plate L1F330, which did not contain any interlayer, covers nearly the entire fuel zone. Plate L1F35T, with an Al-Si thermal spray, has one large pillow-like blister.

Plate L1P10T, with 0.0005-in.-thick Zr interlayer on both sides of the fuel foil (148-2), exhibits multiple smaller blisters on both sides of the plate. This is half of the nominal $\mathrm{Zr}$ thickness used in all subsequent plates. The fact that blisters 1 and 3, as well as blisters 2 and 7, are located back to back on both sides of the same plate might indicate bulk fuel separation.

During the hot-rolling process of foil 148 , four passes were applied between reheats. These conditions might be similar to cold rolling, taking into account extraction of heat from rollers when rolling pack is $\sim 0.050 \mathrm{in}$. thick. After hot rolling, the foils were annealed for $15 \mathrm{~min}$ at $650^{\circ} \mathrm{C}$. 
Table 6. Information on the blisters found on the plates from RERTR-9B experiment.

\begin{tabular}{|c|l|l|l|l|l|l|l|}
\hline Plate & Blister ID & $\begin{array}{c}\text { Blister Type } \\
\text { (1 or 2) }\end{array}$ & $\begin{array}{c}\text { Local } \\
\text { Fission } \\
\text { Density, } \\
\times \mathbf{1 0}^{\mathbf{2 1}}, \\
\mathbf{f i s s} / \mathbf{c m}^{\mathbf{3}}\end{array}$ & $\begin{array}{c}\text { Blister } \\
\text { Temperature, } \\
{ }^{\circ} \mathbf{C}\end{array}$ & $\begin{array}{c}\text { Blister } \\
\text { location }\end{array}$ & $\begin{array}{c}\text { Minclad } \\
\text { Front, } \\
\text { inches }\end{array}$ & $\begin{array}{c}\text { Minclad } \\
\text { Back, } \\
\text { inches }\end{array}$ \\
\hline L1F330 & 1 & 2 & 1.46 & 400 & front & 0.009 & 0.016 \\
\hline L1F35T & 1 & 2 & 1.43 & 425 & front & 0.011 & 0.014 \\
\hline \multirow{5}{*}{ L1P10T* } & 1 & 2 & 1.21 & 400 & front & 0.019 & 0.018 \\
\cline { 2 - 8 } & 2 & 2 & 4.95 & 400 & front & 0.019 & 0.018 \\
\cline { 2 - 8 } & 3 & 2 & 1.21 & 400 & back & 0.019 & 0.018 \\
\cline { 2 - 8 } & 5 & 2 & 6.34 & 400 & back & 0.019 & 0.018 \\
\cline { 2 - 8 } & 6 & 2 & 4.87 & 400 & back & 0.019 & 0.018 \\
\cline { 2 - 9 } & 7 & 2 & 10.7 & 400 & back & 0.019 & 0.018 \\
\hline
\end{tabular}

*Plate with a $\mathrm{Zr}$ interlayer

\subsubsection{RERTR-10A, 10B}

Plates L1P30Z, L2P15Z and L2F47Z were blister tested after irradiation and had blister-threshold temperatures in the range of $400-500^{\circ} \mathrm{C}$. Plate $\mathrm{L} 2 \mathrm{~F} 46 Z$ was blister tested in 2012 as part of low blister-threshold temperature investigation, and exhibited a blister temperature of $350^{\circ} \mathrm{C}$. All foils were prepared using hot rolling only, were rolled to thickness in the rolling assembly. No post-hot-rolling annealing treatment was used. Each of the four plates was fabricated with a Zr interlayer. Thick foils (0.020 in.) were used in plates L2P15Z and L2F46Z. Plates L1P30Z and L2P15Z were bonded by HIP while plates L2F46Z and L2F47Z were friction bonded.

Alloys for RERTR-10A were prepared via arc melting HEU and Mo foil. Thirty-three percent or 67\% (nominal) enrichment was used from the inventory at INL's MFC. Thirty to forty gram U-10Mo buttons were drop cast into graphite book molds to form coupons $\sim 0.9 \mathrm{in}$. wide $\times 1.25 \mathrm{in}$. long $\times 0.105 \mathrm{in}$. thick. Chemical analysis of uranium feedstock material is summarized in Appendix E. Chemical analysis of HEU alloys/foils prepared for RERTR-10A was not performed, given that enrichment blending was not performed. It is worth mentioning that the alloy used in plate L2F46Z was made using casting sprues from other alloys.

Bare and $\mathrm{Zr}$ co rolled HEU-10Mo foils were prepared via hot rolling of cast alloy coupons from 0.107 in. to 0.010 in. thick; resulting in $90 \%$ reduction. Thicker foils ( 0.020 in.) used in plates L2P15Z and L2F46Z were prepared using $81 \%$ reduction. Hot rolling was performed using $650^{\circ} \mathrm{C}$-preheated carbon-steel rolling assemblies. The hot-rolling schedules associated with RERTR-10A were not aggressive. Between 34 and 49 hot passes were performed, with a maximum 10\% per-pass reduction. An aggressive hot-rolling schedule was used for RERTR-10B Zr co-rolled foils. Specifically, a total of eight hot passes were accomplished, resulting in a maximum reduction of $35-40 \%$ per pass. No post-hot-rolling anneal treatment was performed, and no cold rolling was utilized.

Mini-foils were sized using a bench shear, and the edges were deburred using 100 grit sand paper. Fuel plates associated with RERTR-10A were clad using the HIP process at $560^{\circ} \mathrm{C}$ for 90 minutes and $15 \mathrm{ksi}$. RERTR-10B plates were clad via the FB process.

In summary, the primary differences in the fabrication process between RERTR-10A, -10B and RERTR-12, AFIP-4 experiments include:

- RERTR-10 plates were exclusively hot rolled; no cold rolling was utilized

- RERTR-10 plates were not annealed after hot-rolling, which may result in different levels of stress still remaining in the fuel (depending on the temperature of the final stages of hot rolling)

Similarities in fabrication process between the RERTR-10A and 10B and the RERTR-12 and AFIP-4 experiments include: 
- Foil shearing

- Coupons were hot rolled in carbon-steel rolling assemblies

Maximum of 35-40\% per-pass reduction during hot rolling in RERTR-10B experiment.

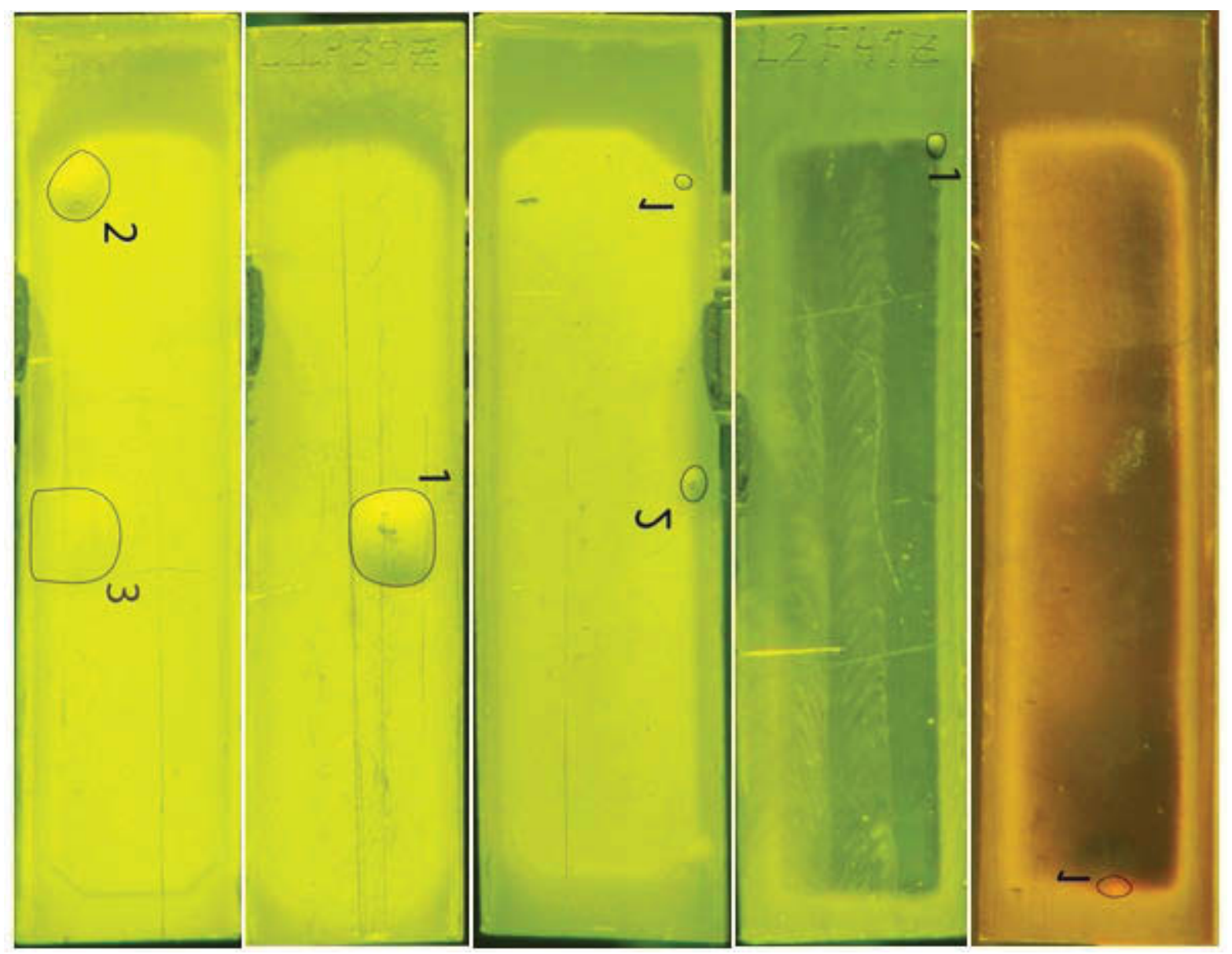

Figure 19. Photographs of the blister tested RERTR-10 plates, from left to right: L1P30Z (back and front sides), L2P15Z (back side), L2F47Z (front side), and L2F46Z (back side). Right edge of the front side of the plate (with ID) was facing ATR core.

The photographs of the blister-tested RERTR-10 plates are shown in Figure 19. Additional information on the blisters found on the RERTR-10 plates is presented in Table 7. As seen in Figure 19, small, Type-1 blisters were found on plates L2P15Z, L2F47Z and L2F46Z. These plates achieved relatively low average burnup (below $4 \times 10^{21}$ fissions $/ \mathrm{cm}^{3}$ ). Only one RERTR-10 plate (L2F46Z) was tested 2012; the rest were tested in 2010. Plate L2F46Z exhibited a lower than expected blister-threshold temperature of $350^{\circ} \mathrm{C}$. The alloy used in this particular plate was made of casting sprues and, thus, potentially contained higher levels of impurities. 
Table 7. Information on blisters observed on the RERTR-10 plates.

\begin{tabular}{|l|l|l|l|l|l|l|l|}
\hline \multicolumn{1}{|c|}{ Plate } & Blister ID & \multicolumn{1}{|c|}{$\begin{array}{c}\text { Blister Type } \\
\text { (1 or 2) }\end{array}$} & $\begin{array}{c}\text { Local } \\
\text { Fission } \\
\text { Density, } \\
\times \mathbf{1 0}^{\mathbf{2 1}}, \\
\mathbf{f i s s} / \mathbf{c m}^{3}\end{array}$ & $\begin{array}{c}\text { Blister } \\
\text { Temperature, } \\
{ }^{\mathbf{C}} \mathbf{C}\end{array}$ & $\begin{array}{c}\text { Blister } \\
\text { location }\end{array}$ & $\begin{array}{c}\text { Minclad } \\
\text { Front, } \\
\text { inches }\end{array}$ & $\begin{array}{c}\text { Minclad } \\
\text { Back, } \\
\text { inches }\end{array}$ \\
\hline \multirow{2}{*}{ L1P30Z } & 1 & 2 & 4.96 & 400 & front & 0.023 & 0.017 \\
\cline { 2 - 8 } & 2 & 2 & 5.76 & 400 & back & 0.023 & 0.017 \\
\hline \multirow{2}{*}{ L2P15Z } & 1 & 1 & 2.69 & 475 & back & 0.014 & 0.011 \\
\cline { 2 - 8 } & 2 & 1 & 2.55 & 475 & back & 0.014 & 0.011 \\
\hline L2F47Z & 1 & 1 & 3.72 & 500 & front & 0.007 & 0.012 \\
\hline L2F46Z & 1 & 1 & 2.92 & 350 & back & 0.014 & 0.013 \\
\hline
\end{tabular}

\subsubsection{AFIP-4:}

AFIP-4 fuel foils are $\sim 3.85$ times larger than RERTR mini-foils; i.e., they are $1.5 \mathrm{in}$. wide $\times 6.25 \mathrm{in}$. long, compared to the 0.75 -in.-wide $\times 3.25$-in.-long mini-foils. AFIP-4 foils were prepared in the same manner as RERTR-12 foils, i.e., using hot rolling followed by cold rolling. However AFIP-4 foils received a maximum of $12 \%$ per-pass reduction during hot rolling, substantially less than the 20-40\% reduction employed in RERTR-12. Overall dimensions of the AFIP-4 fuel plate are $2.2 \mathrm{in}$. wide $\times 6.25 \mathrm{in}$. long $\times 0.050 \mathrm{in}$. thick, compared to $1 \mathrm{in}$. wide $\times 4 \mathrm{in}$. long $\times 0.055 \mathrm{in}$. thick miniplates.

LEU-10Mo AFIP-4 fuel foils are 0.013 in. thick, with $0.001 \mathrm{in.} Z \mathrm{r}$ co-rolled on both sides. The fuel alloy for these foils was prepared in the form of cast and machined LEU-10Mo coupons, $\sim 3$ in. wide $\times 4$ in. long $\times 0.090$ in. thick. Alloying and casting operations were conducted at the Y-12 National Security Complex, Oak Ridge, TN, using vacuum induction melting (VIM). The carbon content of the LEU-10Mo was reported as $472 \mathrm{ppm}$, on the high end of the range (see Appendix E).

A total of twelve AFIP-4 plates were irradiated in two assemblies, each having six fuel plates. Six of the plates were clad with Al-6061 using friction bonding (FB), and the other six, via the HIP process. The friction bonding tool material utilized was Anviloy, a tungsten containing high thermal conductivity alloy.

As shown in Table 2, four of the AFIP-4 fuel plates have been blister tested to date; two of these were FBed and the other two were HIPed. The photographs of the blister-tested AFIP-4 plates are shown in Figure 20. A blister-threshold temperature of $300^{\circ} \mathrm{C}$ was measured for three of the four plates tested, and one plate (L1H34Z) had a blister temperature of $350^{\circ} \mathrm{C}$. These blister-temperature results are $\sim 25-50^{\circ} \mathrm{C}$ lower than RERTR-12 results. 


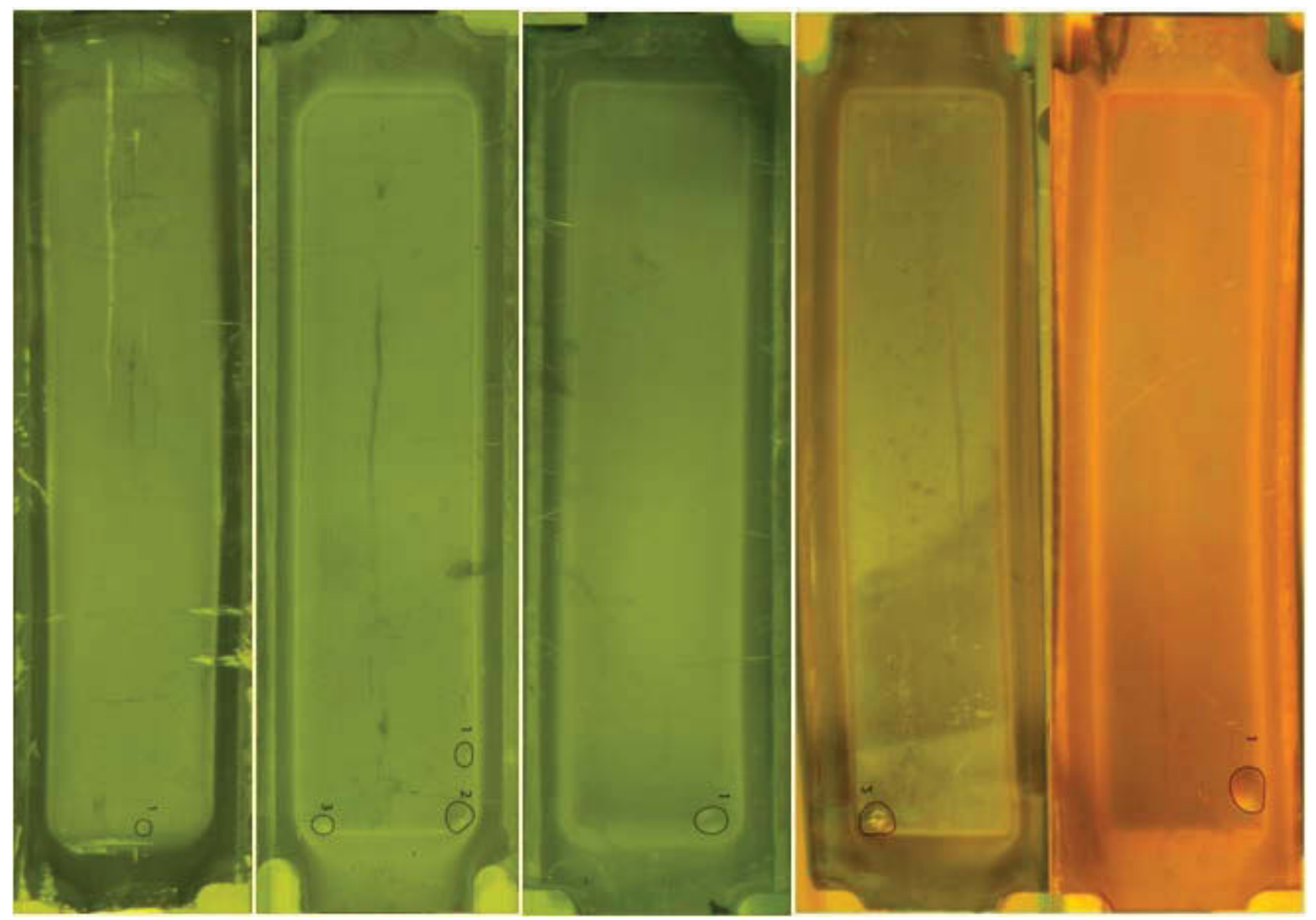

Figure 20. Photographs of the blister tested AFIP-4 plates, from left to right: L1H34Z (back side), L1H36Z (back side), L1B33Z (front side), and L1B51Z (back and front side).

Table 8. Information on blisters observed on AFIP-4 plates.

\begin{tabular}{|c|l|l|l|l|l|l|l|}
\hline Plate & Blister ID & \multicolumn{1}{|c|}{$\begin{array}{c}\text { Blister Type } \\
(\mathbf{1} \text { or 2) }\end{array}$} & $\begin{array}{c}\text { Local } \\
\text { Fission } \\
\text { Density, } \\
\times \mathbf{1 0}^{\mathbf{2 1}}, \\
\mathbf{f i s s} / \mathbf{c m}^{\mathbf{3}}\end{array}$ & $\begin{array}{c}\text { Blister } \\
\text { Temperature, } \\
{ }^{\circ} \mathbf{C}\end{array}$ & $\begin{array}{c}\text { Blister } \\
\text { location }\end{array}$ & $\begin{array}{c}\text { Minclad } \\
\text { Front, } \\
\text { inches }\end{array}$ & $\begin{array}{c}\text { Minclad } \\
\text { Back, } \\
\text { inches }\end{array}$ \\
\hline L1B33Z & 1 & 2 & 4.85 & 300 & front & 0.011 & 0.007 \\
\hline \multirow{2}{*}{ L1B51Z } & 1 & 2 & 4.92 & 300 & front & 0.012 & 0.009 \\
\cline { 2 - 9 } & 2 & 2 & 5.06 & 300 & back & 0.012 & 0.009 \\
\hline L1H34Z & 1 & 2 & 3.57 & 350 & back & 0.014 & 0.014 \\
\hline \multirow{3}{*}{ L1H36Z } & 1 & 2 & 4.84 & 300 & back & 0.016 & 0.013 \\
\cline { 2 - 8 } & 2 & 2 & 5.03 & 300 & back & 0.016 & 0.013 \\
\cline { 2 - 8 } & 3 & 2 & 5.07 & 300 & back & 0.016 & 0.013 \\
\hline
\end{tabular}

\subsubsection{RERTR-12:}

A total of fifty six fuel miniplates were prepared for the RERTR-12 experiment. These plates were irradiated in seven different capsules (X1, X2, X3, Y1, Y2, Y3 and Z). To date eight irradiated fuel miniplates from the RERTR-12 $\mathrm{X} 1$ and $\mathrm{X} 2$ capsules have been blister tested. The blister-threshold temperatures for these plates were in the range of $300-400^{\circ} \mathrm{C}$. Compared to the plates from RERTR-6, 7, 9 and 10 experiments, the blister-threshold temperature of the RERTR-12 plates were $\sim 100^{\circ} \mathrm{C}$ lower. It is believed that one plate (L1P754) from X2 capsule and one plate (L1P785) 
from X3 capsule blistered during irradiation in the reactor core. All fuel foils in RERTR-12 experiment were prepared using hot rolling, followed by cold rolling.

All fuel foils had 0.001-in.-nominal Zr barrier layer co-rolled on both sides of the foil. All plates were clad via HIP.

Twenty-six out of 27 fuel alloy coupons were prepared using arc melting at INL (30-40 g buttons). Alloys with U235 enrichments of 70, 50, 40, 30, 20 and $10 \mathrm{wt} . \%$ were prepared by arc-melt blending of $93 \mathrm{wt} . \%$ or $69 \mathrm{wt} . \%$ enriched HEU with DU. The uranium metal used was from the inventory at INL's MFC. All alloys utilized in RERTR-12 were nominally U-10Mo. Composition and impurity data for RERTR-12 alloys used in the X and Z capsules are presented in Appendix E of this report.

It should be mentioned that one alloy, 344, was prepared at Y-12 via VIM for the AFIP-6 experiment. A portion of the hot $\mathrm{Zr}$ co-rolled $40 \%$ enriched HEU-10Mo foil was utilized for making two fuel plates with 0.020 -in.-thick fuel meat. These plates were irradiated in capsule $Z$. None of the plates from capsule $Z$ have been blister tested as of the writing of this report.

Fuel foils were fabricated via hot rolling of canned coupons, in a similar fashion to fabrication of RERTR-9B, 10A and 10B experiments. After hot rolling, fuel foils were annealed at $650^{\circ} \mathrm{C}$ for 45 minutes in the rolling assembly. Following decanning, 8-45\% reduction via cold rolling was utilized to produce uniformly thick foil. Appendix F of this report contains information about the hot- and cold-rolling schedule used for fabrication of this test.

As shown in Figure 21, initial foils produced for the RERTR-12 experiment were stiff and wavy. It is believed that such waviness is a direct result of the aggressive cold-rolling schedule (i.e., 0.003 -in. reduction in four passes). Theoretically, the imparted waviness of the foils could have been eliminated with some additional cold rolling; however, in this particular case, additional cold rolling was not possible because the target foil thickness had already been achieved.

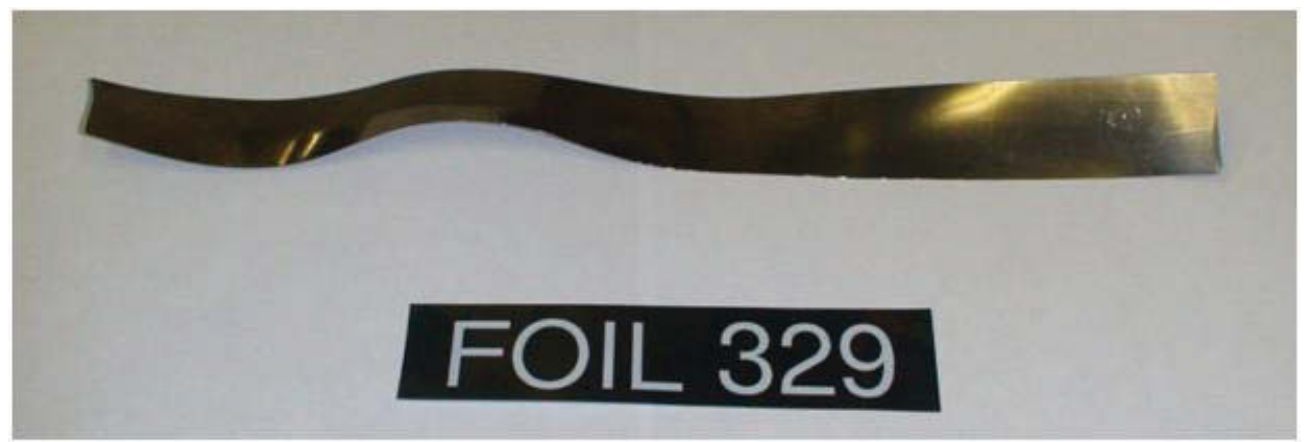

Figure 21. Example of the RERTR-12 wavy fuel foil.

Shearing or blanking of wavy mini-foils was complicated. In an attempt to resolve this problem, several wavy foils (327-2, 328-1, 329-2, 330-1, 330-3 and 331-3) were subjected to a flattening-anneal treatment, at $650^{\circ} \mathrm{C}$ for one hour in a vacuum furnace. Foil blanking was used primarily on flat 0.012 -in.-thick foils; other foils were sheared.

RERTR-12 fuel plates were clad with Al-6061 using HIP (nominal conditions: $560^{\circ} \mathrm{C}, 90$ minutes, $15 \mathrm{ksi}$ ). Eight HIP runs were performed in support of fabrication of the plates for capsules X1, X2, X3 and Z (first insertion). During HIP run 60, the HIP-can stem seal leaked, and the run was not successful; as a result, all six plates were designated as scrap. The bend-test samples taken from three plates associated with HIP run 65 fractured during testing (but did not delaminate). Such behavior was attributed to a thermal excursion that occurred during HIP run 65 . It is believed that temperature reached $600-625^{\circ} \mathrm{C}$ for several minutes before it was manually returned to $560^{\circ} \mathrm{C}$.

After final plate processing - e.g. surface machining and sizing - RERTR-12 fuel plates were subjected to a preirradiation blister anneal treatment. The main purpose of this test was to demonstrate an adequate fuel-clad bonding as is traditionally performed on dispersion-types fuels. The post-fabrication blister anneal treatment of the plates was conducted in a furnace at $485+/-15^{\circ} \mathrm{C}$ for a period of $30+/-10$ minutes. The plates were placed in a mechanical fixture to minimize bowing due to differential thermal expansion factors. Ultrasonic characterization was performed on each plate before and after the anneal treatment. As seen in Figure 22, two candidate fuel plates from capsule Y showed indications of debond after the pre-irradiation blister-anneal test and were therefore rejected from inclusion in the irradiation experiment. Plate L5P3C5 had a blister $\sim 1.5 \mathrm{~mm}$ in size at the fuel-foil-to-cladding edge. Plate L5P3C4 
exhibited an Al-Al debond indication, $<3 \mathrm{~mm}$, near the edge of the fuel plate. Both plates contained 0.025 in.-thick fuel foils. In the case of plate $\mathrm{L} 5 \mathrm{P} 3 \mathrm{C} 5$, the debond indication is likely associated with incomplete edge fill during HIP processing.
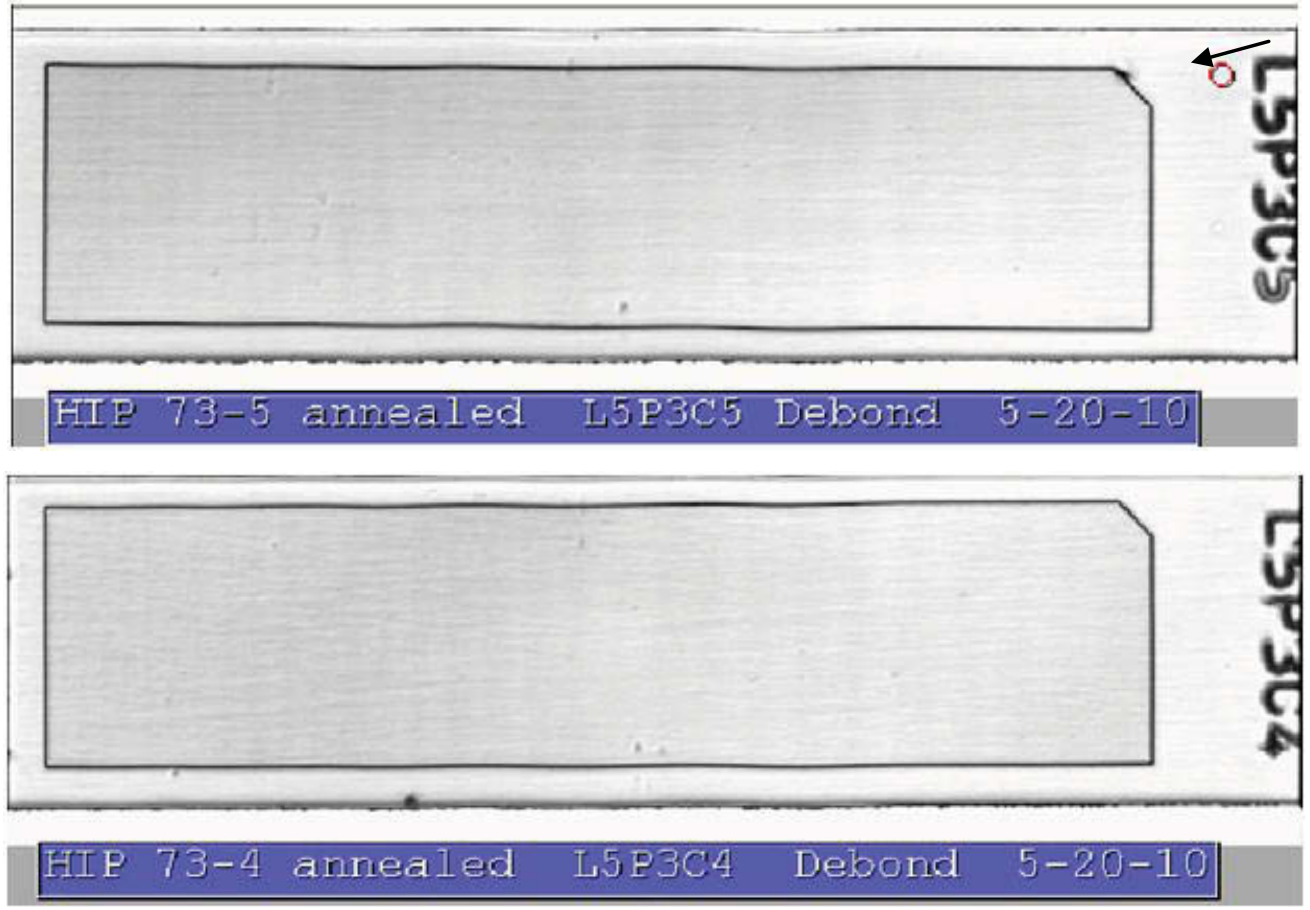

Figure 22. Debond images of the two RERTR-12 candidate miniplates that did not pass post-blister anneal UT evaluation. UT debond images of monolithic fuel plates exhibit a dark perimeter line around the fuel foils. This edge effect is associated with scattering of the ultrasonic beam by the edge of the foil.

In summary, the primary differences in the fabrication process between RERTR-12 and previous experiments (RERTR-6, 7, 9 and 10) include:

- Aggressive hot rolling associated with alloys 327-338 (RERTR-12), with up to 40\% reduction per pass

- Aggressive cold rolling associated with alloys 327-337 (RERTR-12), with 20-25\% reduction in four passes

- Cold rolling: $8-45 \%$ reduction

- Post-cold-rolling anneal of several RERTR-12 foils (327-2, 328-1, 329-2, 330-1, 330-3 and 331-3) at $650^{\circ} \mathrm{C}$ for one hour in a vacuum furnace

- Wavy fuel foils produced from alloys 327-339 (RERTR-12) as a result of not allowing for $\sim 0.006$ in. additional cold-rolling reduction to facilitate foil straightening

Other processing changes implemented during RERTR-12 fabrication campaign include:

- Diamond polishing compound for foil cleaning prior to clad bonding (previously, foil surfaces were cleaned using nitric and nitric/HF acids)

- A 0.005-in.-thick grafoil non-stick separator used in the HIP can (0.008-in.-thick grafoil was used prior to AFIP-4, and the change was made to reduce surface texture on HIP plates after processing)

- Neolube used as release agent in hot-rolling can assemblies (yttria was utilized prior to AFIP-4)

Common attributes of the RERTR-12 plates in the X1 and X2 capsules are graphically shown in Figure 23. Groups of plates highlighted by red or blue outlines share the same HIP run. The group of plates within the blue outline contains the foils that were hot and cold rolled less aggressively than the foils in the group of plates within the red outline. There appears to be no distinct correlation between fabrication variables, such as aggressively rolled foils, less aggressively rolled foils, post-cold-rolling annealed foils, and/or HIP run number, and the low-blister-threshold temperature. A table showing a comparison of rolling conditions is included as Appendix F. 
Information on blisters found on RERTR-12 plates is summarized in Table 9. The photographs of all blister-tested RERTR-12 plates are shown in Appendix A.

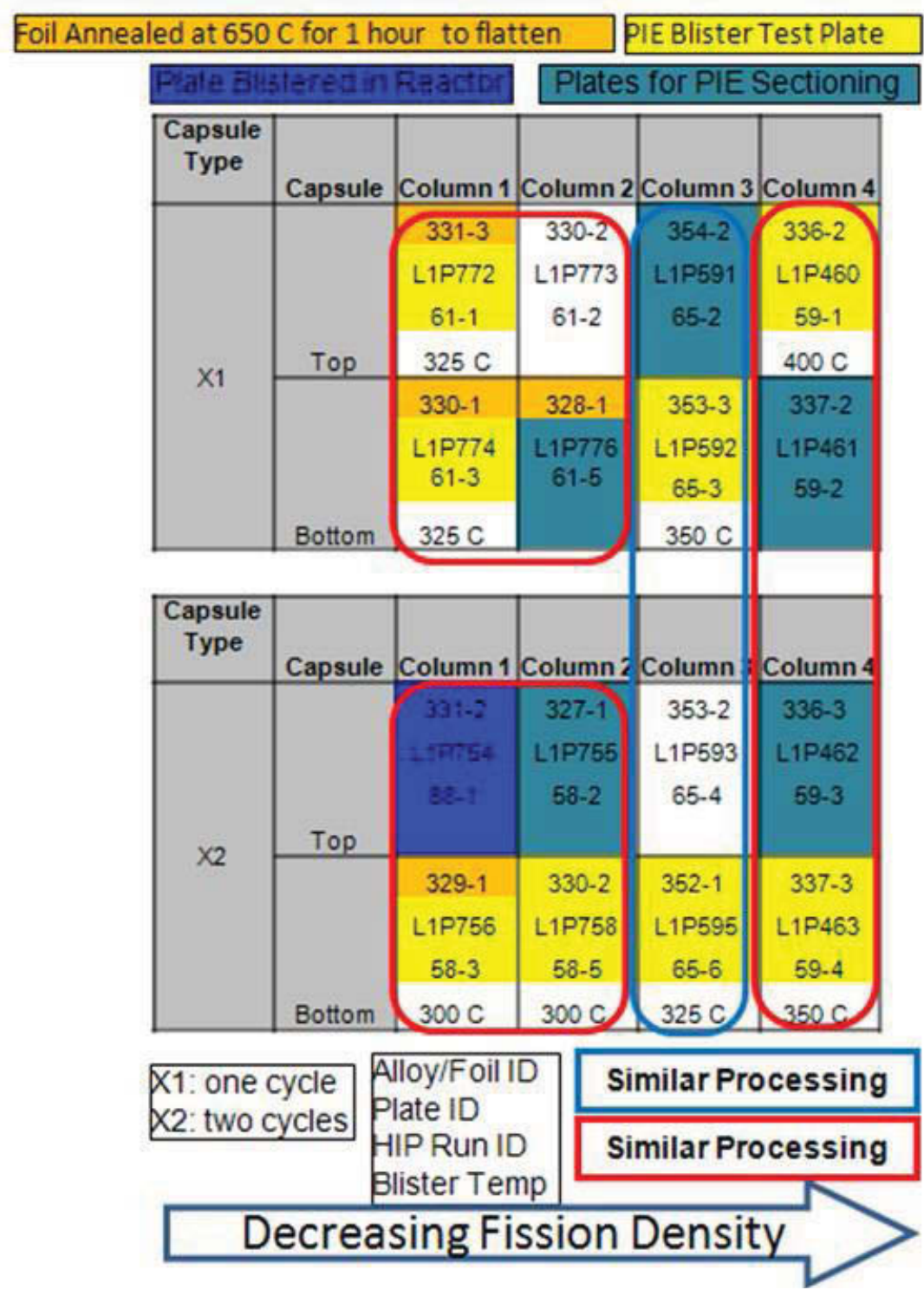

Figure 23. Graphic representation of similarities associated with fuel plates in X1 and X2 capsules from RERTR-12 experiment. 
Table 9. Information on blisters observed on RERTR-12 plates.

\begin{tabular}{|c|c|c|c|c|c|c|c|}
\hline Plate & Blister ID & $\begin{array}{l}\text { Blister Type } \\
\text { (1 or 2) }\end{array}$ & $\begin{array}{c}\text { Local } \\
\text { Fission } \\
\text { Density, } \\
\times \mathbf{1 0}^{\mathbf{2 1}} \\
\text { fiss } / \mathbf{c m}^{3} \\
\end{array}$ & $\begin{array}{c}\text { Blister } \\
\text { Temperature, } \\
{ }^{\circ} \mathrm{C}\end{array}$ & $\begin{array}{l}\text { Blister } \\
\text { location }\end{array}$ & $\begin{array}{l}\text { Minclad } \\
\text { front, } \\
\text { inches }\end{array}$ & $\begin{array}{c}\text { Minclad } \\
\text { back, } \\
\text { inches }\end{array}$ \\
\hline \multirow{9}{*}{ L1P460 } & 1 & 1 & 2.95 & 400 & front & 0.017 & 0.018 \\
\hline & 2 & 1 & 3.18 & 400 & front & 0.017 & 0.018 \\
\hline & 3 & 1 & 2.90 & 400 & front & 0.017 & 0.018 \\
\hline & 4 & 1 & 2.80 & 400 & front & 0.017 & 0.018 \\
\hline & 5 & 1 & 2.71 & 400 & front & 0.017 & 0.018 \\
\hline & 6 & 1 & 3.06 & 400 & front & 0.017 & 0.018 \\
\hline & 7 & 1 & 3.18 & 400 & back & 0.017 & 0.018 \\
\hline & 8 & 2 & 3.98 & 400 & back & 0.017 & 0.018 \\
\hline & 9 & 2 & 3.27 & 400 & back & 0.017 & 0.018 \\
\hline L1P463 & 1 & 1 & 3.42 & 350 & front & 0.019 & 0.017 \\
\hline \multirow[t]{2}{*}{ L1P592 } & 1 & 2 & 4.27 & 350 & front & 0.020 & 0.015 \\
\hline & 2 & 2 & 3.30 & 350 & back & 0.020 & 0.015 \\
\hline \multirow[t]{2}{*}{ L1P595 } & 1 & 2 & 6.38 & 325 & front & 0.019 & 0.015 \\
\hline & 2 & 2 & 5.76 & 325 & front & 0.019 & 0.015 \\
\hline \multirow[t]{2}{*}{ L1P756 } & 1 & 2 & 9.91 & 300 & front & 0.021 & 0.017 \\
\hline & 2 & 2 & 9.91 & 300 & back & 0.021 & 0.017 \\
\hline \multirow[t]{2}{*}{ L1P758 } & 1 & 2 & 9.19 & 300 & front & 0.017 & 0.017 \\
\hline & 2 & 2 & 9.19 & 300 & back & 0.017 & 0.017 \\
\hline \multirow[t]{2}{*}{ L1P772 } & 1 & 2 & 7.83 & 325 & front & 0.020 & 0.018 \\
\hline & 2 & 2 & 7.83 & 325 & back & 0.020 & 0.018 \\
\hline \multirow{6}{*}{ L1P774 } & 1 & 2 & 7.49 & 325 & front & 0.020 & 0.015 \\
\hline & 2 & 2 & 6.31 & 325 & front & 0.020 & 0.015 \\
\hline & 3 & 2 & 7.09 & 325 & front & 0.020 & 0.015 \\
\hline & 4 & 2 & 7.49 & 325 & back & 0.020 & 0.015 \\
\hline & 5 & 2 & 6.31 & 325 & back & 0.020 & 0.015 \\
\hline & 6 & 2 & 7.09 & 325 & back & 0.020 & 0.015 \\
\hline L1P754 & 1 & 2 & 1.17 & in reactor & back & 0.022 & 0.012 \\
\hline
\end{tabular}

\subsubsection{Summary of Fabrication Effects on Blister Temperature}

Analysis of the fabrication variables results in two preliminary findings:

1. Minimizing cold work during foil fabrication and/or high temperature annealing treatment (for the purpose of eliminating imparted residual stresses) seems to be linked to higher blister-threshold temperature

2. The variation in carbon impurity levels in arc melt prepared alloys associated with RERTR-6, 7, 9, 10, and 12 does not appear to be linked to differences in the blister threshold temperature data.

Supporting examples include:

- Carbon-content range for arc melt prepared RERTR-6, 7, and 9 alloys: 134-460 ppm

- Carbon-content range for arc melt prepared RERTR-12 alloys: 146-355 ppm 
- Uranium feedstock materials used for RERTR-6, 7, 9, 10, and 12: overall purity range: 99.7-99.9\% uranium.

\subsubsection{References}

1. Beeston, J.M., Hobbins, R.R., Gibson, G.W. and Francis, W.C., 1980. Development and irradiation performance of Uranium Aluminide fuels in test reactors. J. Nucl. Tech., 49, 136-149.

2. Snelgrove, J.L., "RERTR Progress in Qualifying Reduced-Enrichment Fuels," 1982.

3. Whitacre, R.R., “The UAlx Fuel Dispersion System”, EGG-PRP-8783, November 1989.

4. Hoffman, G.L., Snelgrove, J.L., "Irradiation Performance of Low-Enriched Uranium Fuel Elements," 1984.

5. Miller, L.G., Beeston, “Extended Life Aluminide Fuel Final Report, “ EGG-2441, June 1986.

6 . "Analysis of Low Blister Threshold Temperatures in the RERTR-12 and AFIP-4 Experiments, INL PLN-4155. 


\subsection{Pre-irradiation characterization}

\subsubsection{Background}

The objective of the pre-irradiation characterization of fuel plates is to identify key microstructural features. The data presented here emphasize differences between the groups of plates with high blisterthreshold temperature (RERTR-6, 7, 9 and 10A) and those with lower blister-threshold temperature (RERTR-12 and AFIP-4) and attempts to determine how these differences are related to both the fabrication process and fuel blister-test results. General characterization has been completed or is underway for archived materials from these irradiation experiments. Additional characterization was conducted on archival specimens from each experiment. The primary focus of the microstructural characterization was placed on the following areas:

$\underline{\text { U-Mo fuel foil region }}$

- Highly phase separated areas

- Grain structure

- Aligned carbides/oxides

- Boundaries between banding $\underline{\text { Interfaces }}$

- $\mathrm{U}-\mathrm{Mo} / \mathrm{Zr}$ interface

- U-Mo/cladding (A1-6061) interface

- Cladding/cladding bond line

- $\mathrm{Zr}$ /cladding (6061-Al) interface

- $\mathrm{U}-\mathrm{Mo} / \mathrm{Zr} / \mathrm{Cladding}$ triple junction

Seven samples were identified in the characterization plan for microscopy. These samples are listed in Table 10. Five of seven samples have been characterized to date. The remaining two samples are from the RERTR-9B and the AFIP-4 experiments. All but one sample (JJ580) are specimens from the official archives of fuel plates that were irradiated. The foil number, EML ID number, and corresponding irradiated fuel plate are provided in Table 10. For RERTR-12, no archived fuel plates subjected to the $650^{\circ} \mathrm{C} / 1$ hour flattening treatment were available. Thus, a fuel foil subjected to the same treatment was selected and characterized. Samples already characterized are shown in bold in Table 10. Some micrographs from archived fuel plates from the RERTR-12 second insertion are also included for comparison purposes.

The interface between $\mathrm{U}-\mathrm{Mo} / \mathrm{Zr}$ is critical for irradiation performance. Based on the previous TEM results, this layer contains at least three different phases: A molybdenum rich phase $\left(\mathrm{ZrMo}_{2}\right), \alpha-\mathrm{U}$, and $\mathrm{UZr}_{2}[1,2]$. Several other phases were also reported. The impact of these phases on the blistering behavior is not well understood. The interface between the chemical banding is also not well understood. More detailed scanning electron microscopy (SEM) characterization is planned for fuel plates \#42-6, JJ497 (from RERTR-10A) and \#65-5, JJ599 (from RERTR-12) in order to obtain more quantitative microstructural information. FIB/TEM will also be performed to fully understand the structure of the interfaces. 
Table 10. List of samples for characterization by microscopy.

\begin{tabular}{|c|c|c|c|c|}
\hline Experiment & $\begin{array}{c}\text { Fabrication } \\
\text { Process } \\
\end{array}$ & $\begin{array}{c}\text { Foil \# (EML\#)/ } \\
\text { archive for fuel } \\
\text { plate \# (blister } \\
\text { temperature) } \\
\end{array}$ & $\begin{array}{c}\text { Plate \# (EML\#)/ } \\
\text { archive for fuel } \\
\text { plate \# (blister } \\
\text { temperature) } \\
\text { Alloy \# } \\
\end{array}$ & Foil thickness, mil \\
\hline $\begin{array}{c}\text { RERTR-9B } \\
90 \% \text { hot } \\
0 \% \text { cold }\end{array}$ & \multirow{3}{*}{$\begin{array}{l}\text { Hot rolled at } \\
\qquad 650^{\circ} \mathrm{C}\end{array}$} & $\begin{array}{c}148(\mathrm{JJ} 401) / \\
\mathrm{L} 1 \mathrm{P} 10 \mathrm{~T}\left(400^{\circ} \mathrm{C}\right)\end{array}$ & foil only & 11 \\
\hline $\begin{array}{c}\text { RERTR-10A } \\
80 \% \text { hot } \\
0 \% \text { cold } \\
\end{array}$ & & $\begin{array}{c}226(\mathrm{JJ} 678) / \\
\mathrm{L} 2 \mathrm{P} 15 \mathrm{Z}\left(475^{\circ} \mathrm{C}\right)\end{array}$ & foil only & 21 \\
\hline $\begin{array}{c}\text { RERTR-10A } \\
90 \% \text { hot } \\
0 \% \text { cold }\end{array}$ & & $\mathrm{N} / \mathrm{A}$ & $\begin{array}{c}\text { 42-6 (JJ497)/ } \\
\text { L1P30Z }\left(400^{\circ} \mathrm{C}\right) \\
\text { Alloy } 223\end{array}$ & 11 \\
\hline $\begin{array}{l}\text { RERTR-12 } \\
79 \% \text { hot } \\
45 \% \text { cold }\end{array}$ & \multirow{3}{*}{$\begin{array}{l}\text { Hot rolled at } \\
650^{\circ} \mathrm{C} \text { and cold } \\
\text { rolled }\end{array}$} & $\begin{array}{c}354(\mathrm{CB} 612) / \\
\text { L1P591 }\end{array}$ & foil only & 12 \\
\hline $\begin{array}{c}\text { RERTR-12 } \\
80 \% \text { hot } \\
43 \% \text { cold } \\
\end{array}$ & & $\mathrm{N} / \mathrm{A}$ & $\begin{array}{c}\text { 65-5 (JJ599)/ } \\
\text { L1P592 }\left(350^{\circ} \mathrm{C}\right) \\
\text { Alloy } 353 \\
\end{array}$ & 12 \\
\hline $\begin{array}{c}\text { AFIP-4 } \\
78 \% \text { hot } \\
22 \% \text { cold } \\
\end{array}$ & & $\begin{array}{c}196(\mathrm{JJ} 500) / \\
\text { L1H37Z }\end{array}$ & foil only & 15 \\
\hline $\begin{array}{l}\text { RERTR-12 } \\
85 \% \text { hot } \\
20 \% \text { cold }\end{array}$ & $\begin{array}{l}\text { Hot rolled at } \\
650^{\circ} \mathrm{C} \text { and cold } \\
\text { rolled, then } \\
\text { annealed at } \\
650^{\circ} \mathrm{C} / 1 \mathrm{hr} \\
\end{array}$ & $\begin{array}{c}331(\mathrm{JJ} 580) / \\
\text { Similar to foil } \\
\text { used in L1P774 } \\
\left(325^{\circ} \mathrm{C}\right)\end{array}$ & foil only & 12 \\
\hline
\end{tabular}

All plates have $\mathrm{Zr}$ diffusion barrier.

Plates examined to date are highlighted in bold font.

\subsubsection{Summary}

Because only RERTR-10A and RERTR-12 archives have been fully characterized to date, comparisons are provided based on the results from these two experiments. From a microstructural point of view, fuel foils from both experiments exhibit grain diameters typically less than 20 microns with various amounts of chemical banding, second-phase precipitates, and areas of phase separation. The chemical banding originates from the inhomogeneity of molybdenum in the fuel meat. Second-phase precipitates mainly arise from carbon and oxygen impurities. The main second-phase precipitates are uranium carbides and oxides that contain little or no Mo. Phase separation is the result of slow cooling through the two-phase region ( $\alpha$ and $\gamma$ phase) during the hot-rolling and HIP-bonding processes. All the interfaces also exhibit interaction products in various quantities due to reaction between the different components (cladding, fuel meat and $\mathrm{Zr}$ diffusion barrier). As shown in Figure 24, the corner region (a 
triple junction between U-10Mo, Zr and Al-6061) exhibits minimal interaction product, unlike the roughly two-hundred microns observed in similar locations on the AFIP-6 archive plate.

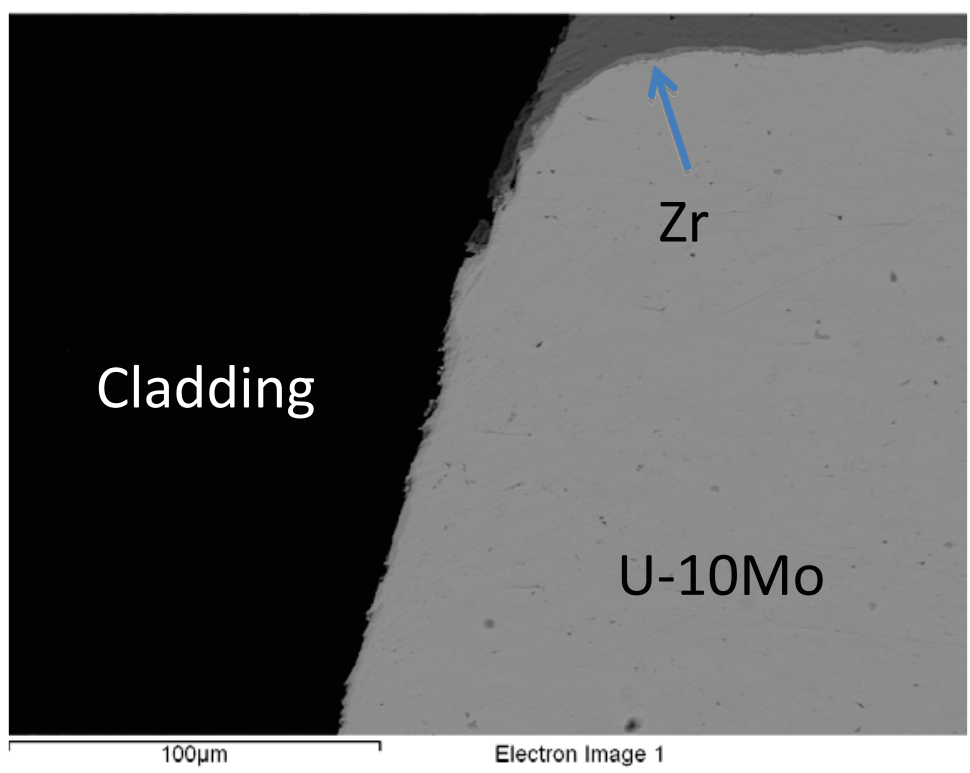

(a)

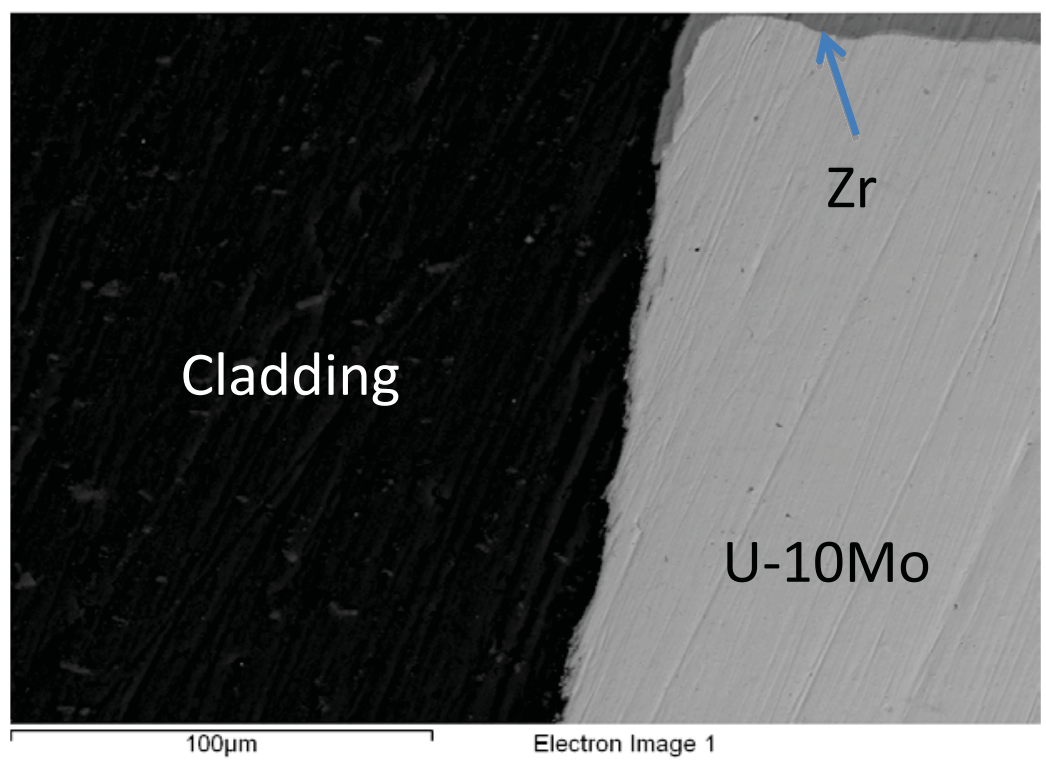

(b)

Figure 24. The corner areas (junction between cladding, $\mathrm{Zr}$ and U-10Mo) from (a) RERTR-10A and (b) RERTR-12 show no extensive interaction.

The following microstructural features and defects have been observed in the plates from the RERTR-12 and RERTR-10A experiments:

Interfacial defects exist near the U-Mo/Zr bond in plates from both experiments. Pull outs appear to be more pronounced in the plates produced by cold rolling (i.e., RERTR-12). Microcracks can also be 
seen in two of the RERTR-12 archived samples; Figure 25 shows an example. The area without a visible $\mathrm{U}-\mathrm{Mo} / \mathrm{Zr}$ interaction layer is the possible location of a "kissing bond," an area where a gap has opened under mechanical stress due to low bond strength. Figure 26 could be an example of such a gap in an archived fuel foil from the AFIP-7 experiment or there could have been sample pullout during polishing. Areas with possible kissing bonds are present in the plates from both the RERTR-10 and RERTR-12 experiments; however, the cold-rolled samples are more likely to exhibit this feature. To be more specific, a preliminary quantitative measurement of the percentage of area without a visible interaction layer from two RERTR-12 archive fuel plates (plates \#70-6, JJ999 and \#71-2, JJ1000, not part of this characterization plan) yields $12 \%$ and $40 \%$ of the bond line length, respectively. It is difficult to find an area without a visible interaction layer in the hot-rolled plate \#42-6, JJ599 from RERTR-10A.

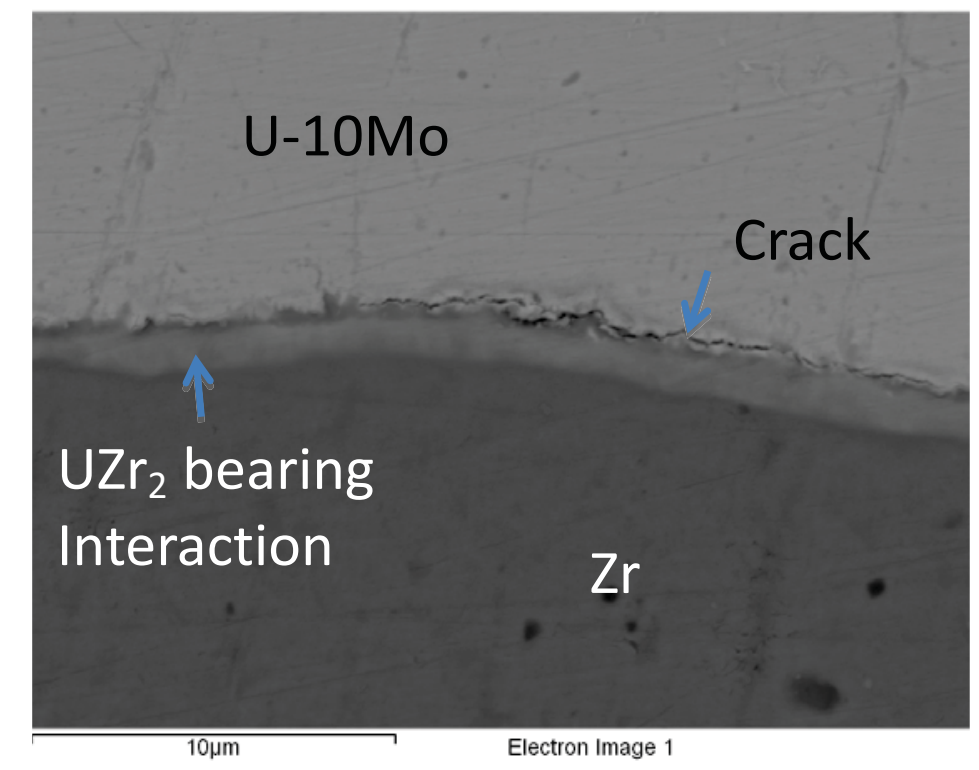

Figure 25. An SEM micrograph shows microcracks in an RERTR-12 foil (Foil \#331, JJ580).

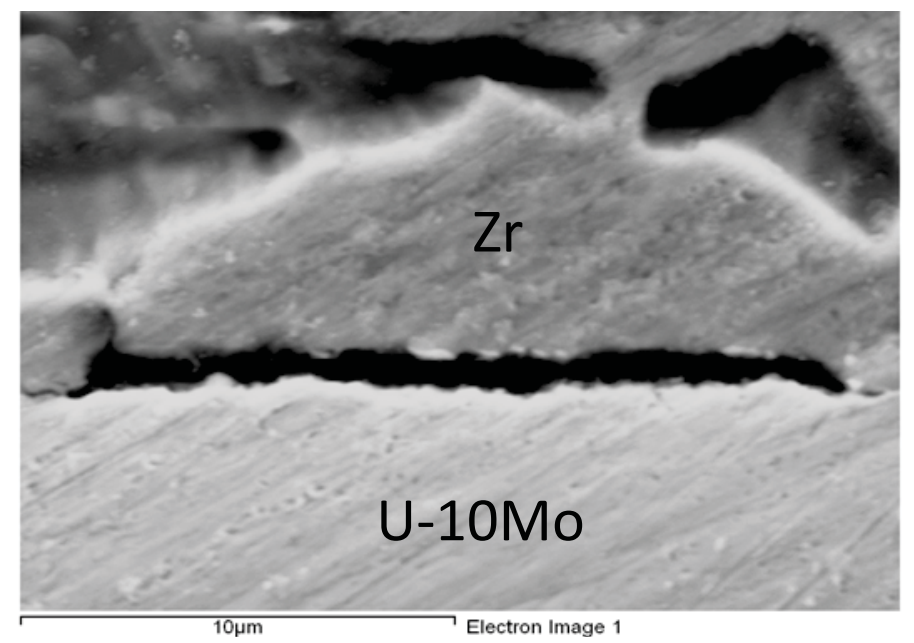

Figure 26. An SEM micrograph shows a gap between $\mathrm{Zr}$ and U-10Mo in an archive foil from AFIP-7 (foil \#386, JJ703) which was subjected to cold co-rolling, as was RERTR-12.

The grain structure of the plates from the RERTR-12 experiment is more complex than that seen in RERTR-10A plates. Archive samples from RERTR-10A exhibited an equiaxed grain structure throughout the fuel meat while samples from RERTR-12 seem to have an equiaxed grain structure only near the U- 
$10 \mathrm{Mo} / \mathrm{Zr}$ interface. Backscattered electron micrographs from the central region of the fuel meat in RERTR-12 archive samples show a possible elongated grain structure; Figure 27 provides an example. As shown in Figure 28, the grain size in the equiaxed grain area is smaller for RERTR-12 ( 7 microns from plate\# 72-2, JJ998) than RERTR-10A ( 12 microns from plate\# 42-6, JJ497). The grain size of the archived sample identified in the characterization plan for RERTR-12 (plate \#65-5, JJ599) will be determined. Since the grain-size information is currently from only one sample in each experiment, the uncertainty will be significant. However, these micrographs do provide an illustration of the microstructural difference.

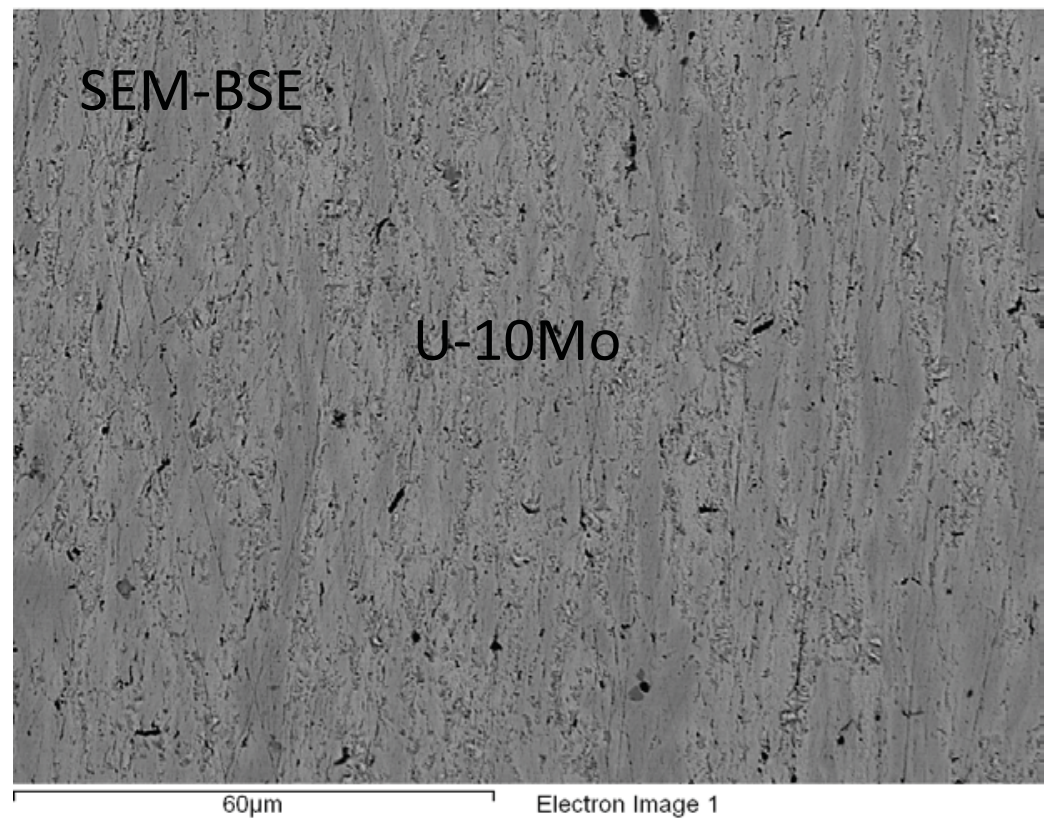

Figure 27. An SEM micrograph shows elongated feature in an RERTR-12 archive fuel plate (plate \#72-2, JJ998, archive of fuel plate L5P2B6)

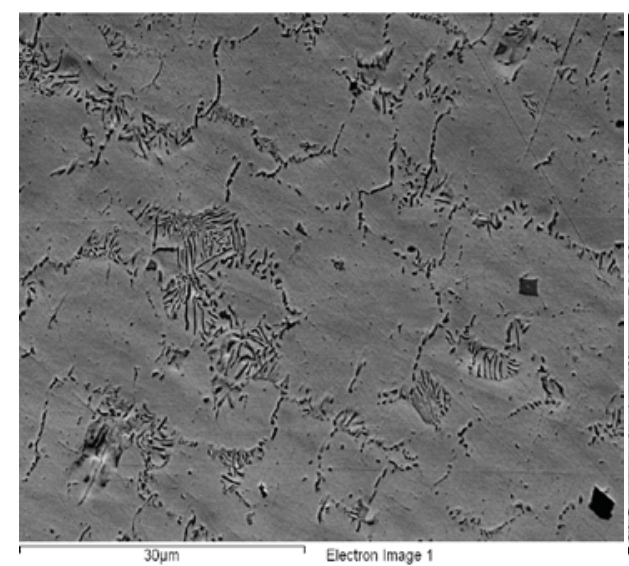

(a)

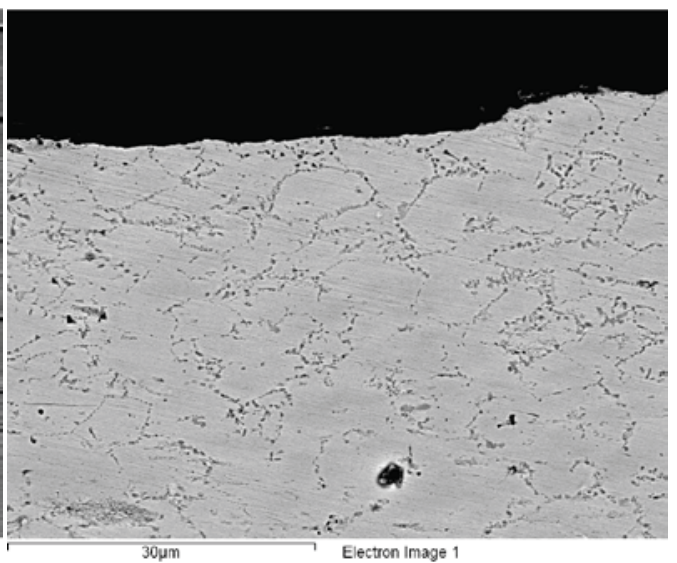

(b)

Figure 28. SEM micrographs show equiaxed U-Mo grain structure in (a) RERTR-10A (from plate \# 42-6, JJ497) and (b) from the near-surface region of RERTR-12 (from plate 72-2, JJ998, archive of fuel plate L5P2B6).

Both RERTR-12 and RERTR-10A exhibit chemical banding. As shown in Figure 29, cold-rolled plates from RERTR-12 appear to have more pronounced banding. Based on SEM/wavelength dispersive 
X-ray spectroscopy (WDS) mapping, the chemical banding is the result of the inhomogeneity of Mo concentration. Mo concentration in an RERTR-12 archive sample (foil \#337, JJ606, not listed in Table 10) was determined by SEM/energy dispersive X-ray spectroscopy (EDS) to vary from 8-11 wt.\%. The lighter colored bands have lower Mo concentration while the darker bands exhibit higher Mo concentration. The average Mo concentration across an area with pronounced bands comes very close to $10 \mathrm{wt} . \%$, which is the target Mo concentration of the fuel meat. The Mo concentration variation in the bands from RERTR-10A archive samples will be determined by SEM/EDS.

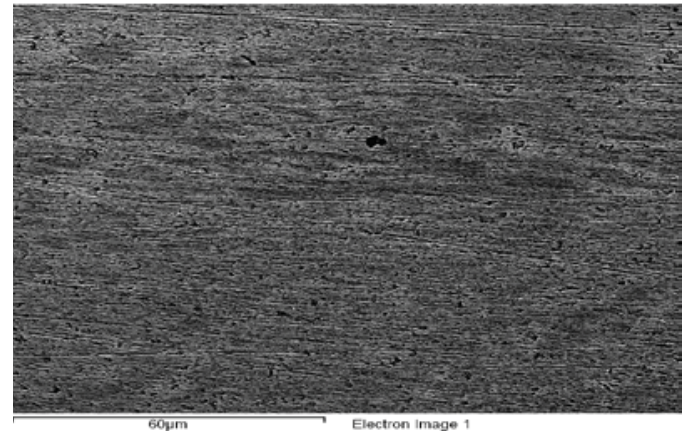

(a)

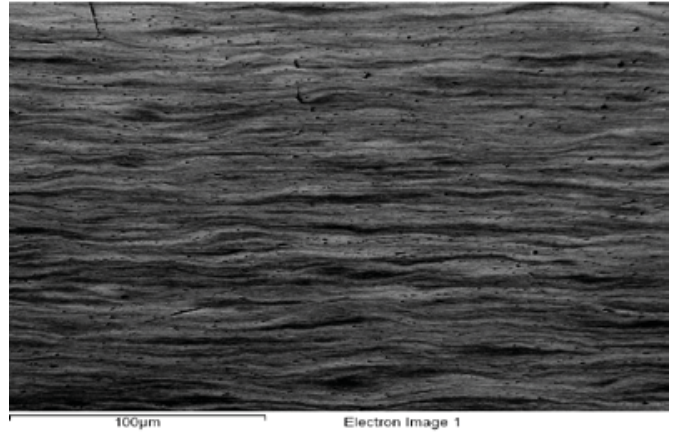

(b)

Figure 29. Fuel foil chemical banding in (a) RERTR-10A (from foil \# 226-JJ678) and (b) RERTR-12 (foil \# 351, JJ611).

Other differences in fuel-plate microstructure include:

1. More aligned second phase particles (mainly carbides, see Figure 30) were observed in RERTR-12 compared with RERTR-10A. It is possible that this can be explained by the differences in the levels of impurities (carbon and oxygen) in the feedstock materials. (Note that carbon content of RERTR10A was not determined). The impact of the rolling procedure on this feature is not known, but cannot be ruled out.

2. Fuel plates from both experiments exhibit no porosity along the aluminum-to-aluminum bond line. Precipitates, however, exist along the bond line. These precipitates are rich in Mg and O. SEM micrographs showing the bond line between two sides of cladding are presented in Figure 31. In general, plate \#42-6, JJ 497, from RERTR-10A exhibits slightly more precipitates along the bond line than plate \#65-5, JJ 599, from RERTR-12. This difference may be associated with the level of cleanliness of cladding materials. RERTR-10A had a thick oxide layer before cleaning; therefore slightly higher level of precipitates along the bond line can be expected.

A comparison of the microstructural characterization of RERTR-10A and RERTR-12 samples is presented in Table 11. The main microstructural differences identified between cold-rolled fuel plates (from RERTR-12) and fuel plates without cold rolling (RERTR-10A) are shown in bold font. The first five features are within the U-10Mo fuel meat while the next five features are related to interfaces. Information in Table 11 will be updated as more results become available. For reference, a typical microstucture of the $\mathrm{U}-10 \mathrm{Mo} / \mathrm{Zr}$ interface from an RERTR-12 foil subjected to annealing treatment at $650^{\circ} \mathrm{C}$ after cold rolling is shown in Figure 32. 
Table 11. Comparison of the key microstructural features between RERTR-12 (with cold rolling) and RERTR 10-A (without cold rolling) plates.

\begin{tabular}{|c|c|c|}
\hline $\begin{array}{c}\text { Key microstructural } \\
\text { features }\end{array}$ & $\begin{array}{c}\text { RERTR-12 } \\
\text { (hot rolling + cold rolling) }\end{array}$ & $\begin{array}{l}\text { RERTR-10A } \\
\text { (hot rolling) }\end{array}$ \\
\hline U-Mo grain structure & $\begin{array}{l}\text { 1. Non-homogeneous: regular } \\
\text { grains near } \mathrm{U}-\mathbf{1 0 M o} / \mathbf{Z r} \\
\text { interface, but elongated grains } \\
\text { and non-uniform grain } \\
\text { structure in the central area of } \\
\text { the fuel foil } \\
\text { 2. Significant variability in grain } \\
\text { structure from area to area }\end{array}$ & $\begin{array}{l}\text { 1. Relatively homogeneous with } \\
\text { phase separation along grain } \\
\text { boundaries }\end{array}$ \\
\hline Grain diameter & $\begin{array}{l}\text { 1. } 7 \mu \mathrm{m} \text { grains near } \mathrm{U}-10 \mathrm{Mo} / \mathrm{Zr} \\
\text { interface, not determined for } \\
\text { central area of the foil }\end{array}$ & $\begin{array}{l}\text { 1. } \sim 12 \mu \mathrm{m} \text { (not including phase } \\
\text { separation area) }\end{array}$ \\
\hline Chemical banding & $\begin{array}{l}\text { 1. Directional banding is present } \\
\text { (varies between } 8 \text { and } 11 \mathrm{wt} . \% \\
\text { Mo). } \\
\text { 2. Banding is extensive in some } \\
\text { samples }\end{array}$ & $\begin{array}{l}\text { 1. Banding appears to be less } \\
\text { extensive, details to be } \\
\text { determined (i.e. the Mo } \\
\text { composition in the bands and } \\
\text { the amount \& distribution of the } \\
\text { bands) }\end{array}$ \\
\hline Phase separation & $\begin{array}{l}\text { 1. Present (percentage to be } \\
\text { determined) }\end{array}$ & $\begin{array}{l}\text { 1. Present (percentage to be } \\
\text { determined) } \\
\text { Note: Phase separation does not } \\
\text { appear to be as extensive as } \\
\text { AFIP-3 and AFIP-6 }\end{array}$ \\
\hline Second phases & $\begin{array}{l}\text { 1. Present, some aligned second } \\
\text { phase carbides were observed. } \\
\text { (from fuel plate 65-5, JJ599) }\end{array}$ & $\begin{array}{l}\text { 1. Present, only isolated carbide } \\
\text { particles were observed (from } \\
\text { fuel plate 42-6, JJ497) }\end{array}$ \\
\hline
\end{tabular}




\begin{tabular}{|c|c|c|}
\hline $\mathrm{U}-10 \mathrm{Mo} / \mathrm{Zr}$ interface & $\begin{array}{l}\text { 1. One interaction layer }\left(\mathrm{UZr}_{2}\right. \\
\text { bearing) is visible; element } \\
\text { mapping shows a Mo-rich layer } \\
\text { followed by a Mo-depleted layer } \\
\text { toward U-Mo region. } \\
\text { 2. Percent of the area with a } \\
\text { visible interaction layer present } \\
\text { varies from sample to sample } \\
\text { (generally less than } 80 \% \text { of the } \\
\text { total area, except plates with the } \\
\text { foil subjected to } \mathbf{6 5 0} \mathbf{C}^{\circ} \mathrm{C} / \mathbf{1} \text { hour } \\
\text { flattening). } \\
\text { 3. Microcracks/or pullouts are } \\
\text { present in Mo enriched/depleted } \\
\text { layers (might be sample } \\
\text { preparation artifacts, however are } \\
\text { indicative of phase brittleness). } \\
\text { 4. Gaps were found in certain } \\
\text { regions of the U-10Mo/Zr } \\
\text { interface without a visible } \\
\text { interaction layer (might be sample } \\
\text { preparation artifacts, however are } \\
\text { indicative of weak interface) } \\
\text { Figure } 3 \text { is an example of such } \\
\text { defect. }\end{array}$ & $\begin{array}{l}\text { 1. One interaction layer }\left(\mathrm{UZr}_{2}\right. \\
\text { bearing) is visible; element } \\
\text { mapping shows a Mo-rich layer } \\
\text { followed by a Mo-depleted layer } \\
\text { toward U-Mo region. } \\
\text { 2. Very few areas without visible } \\
\text { interaction layer (UZZr } \mathbf{Z}_{2} \\
\text { bearing) exist } \\
\text { 3. Microcracks/or pullouts are } \\
\text { present in Mo enriched/depleted } \\
\text { layers (might be sample } \\
\text { preparation artifacts, however } \\
\text { are indicative of phase } \\
\text { brittleness). }\end{array}$ \\
\hline $\mathrm{Zr} / \mathrm{Al}$ interface & $\begin{array}{l}\text { 1. A uniform layer contains several } \\
\text { phases. } \\
\text { 2. Thickness to be determined } \\
\text { (typically less than } 2 \mu \mathrm{m} \text { ). }\end{array}$ & $\begin{array}{l}\text { 1. A uniform layer contains several } \\
\text { phases. } \\
\text { 2. Thickness to be determined } \\
\text { (typically less than } 2 \mu \mathrm{m} \text { ) }\end{array}$ \\
\hline $\mathrm{U}-10 \mathrm{Mo} / \mathrm{Al}$ interface & $\begin{array}{l}\text { 1. Silicon rich, thickness varies from } \\
\text { location to location (typically less } \\
\text { than } 2 \mu \mathrm{m} \text { ) }\end{array}$ & $\begin{array}{l}\text { 1. Silicon rich, thickness varies } \\
\text { from location to location } \\
\text { (typically less than } 2 \mu \mathrm{m} \text { ) }\end{array}$ \\
\hline $\mathrm{Al} / \mathrm{Al}$ interface & $\begin{array}{l}\text { 1. No visible voids; } \\
\text { 2. } \mathrm{Mg} / \mathrm{O} \text { rich precipitates exist along } \\
\text { bond line }\end{array}$ & $\begin{array}{l}\text { 1. No visible voids; } \\
\text { 2. Slightly more } \mathbf{M g} / \mathrm{O} \text { rich } \\
\text { precipitates exist along bond } \\
\text { line }\end{array}$ \\
\hline $\mathrm{U}-10 \mathrm{Mo} / \mathrm{Zr} / \mathrm{Al}$ junction & $\begin{array}{l}\text { 1. } \mathrm{Zr} \text { covered the corners. } \\
\text { 2. No significant interaction in this } \\
\text { region. }\end{array}$ & $\begin{array}{l}\text { 1. } \mathrm{Zr} \text { covered the corners. } \\
\text { 2. No significant interaction in this } \\
\text { region. }\end{array}$ \\
\hline
\end{tabular}

Bold font highlights major differences in microstructure between experiments 


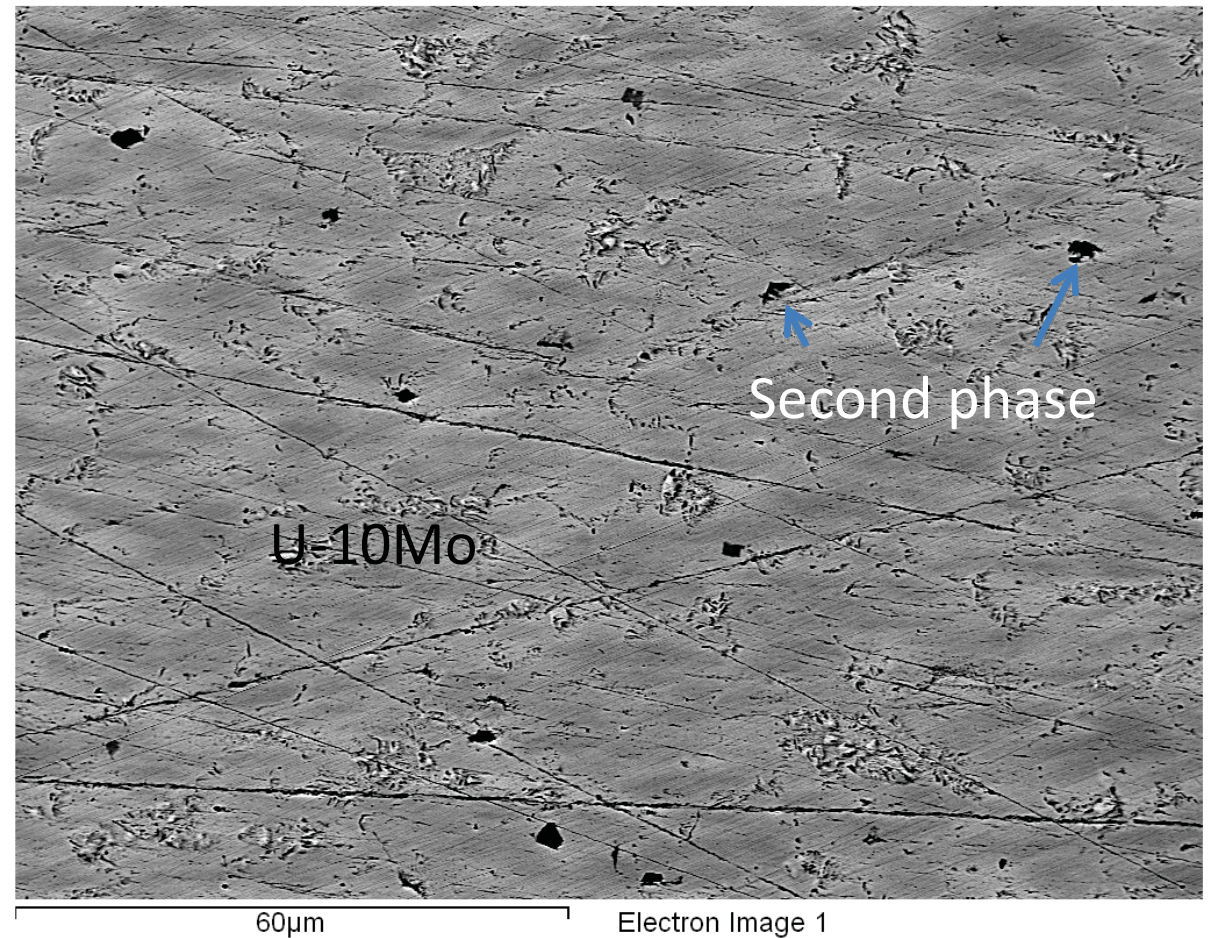

(a)

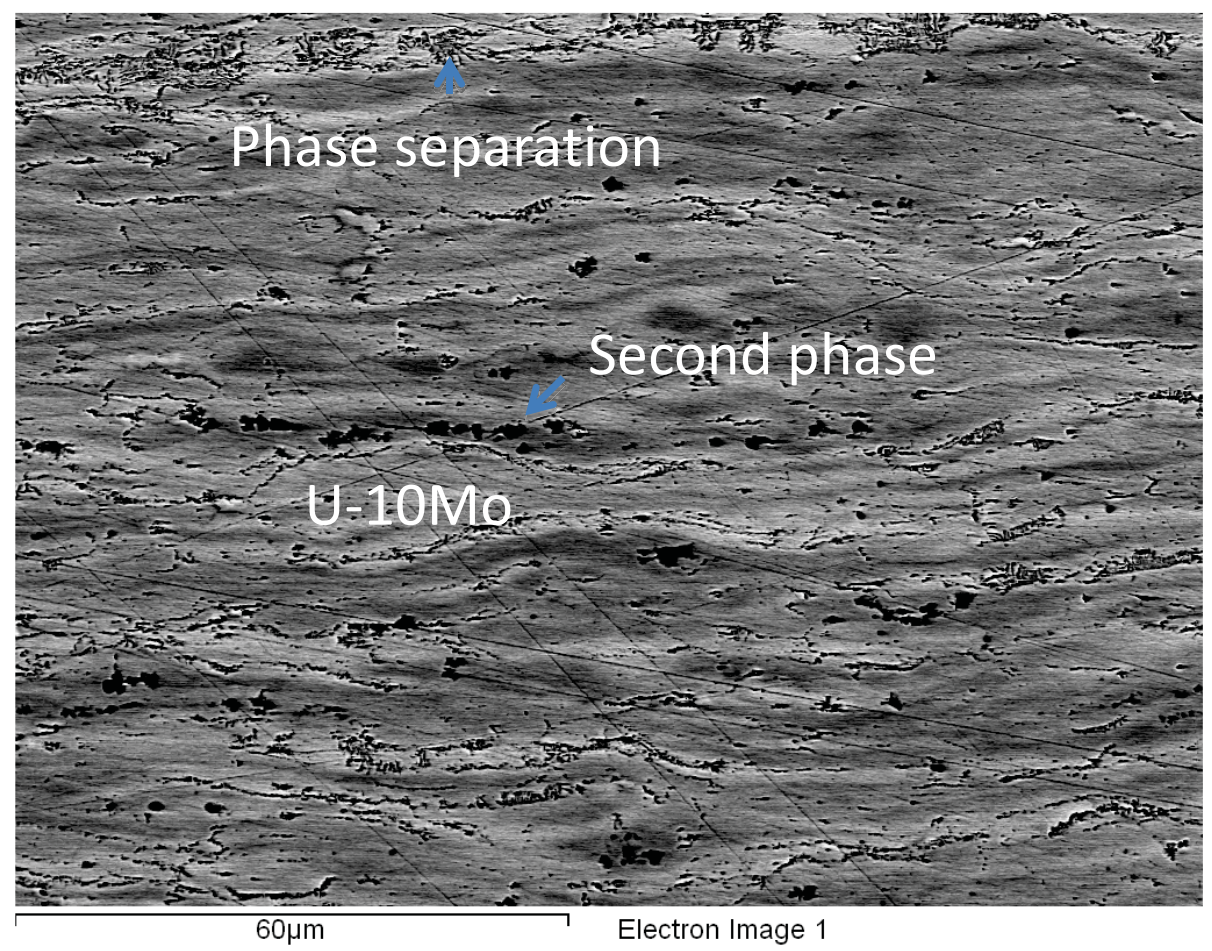

(b)

Figure 30. Second phase in (a) RERTR-10A (from plate \#42-6, JJ497) and (b) RERTR-12 (from plate \#65-5, JJ599) plates. 


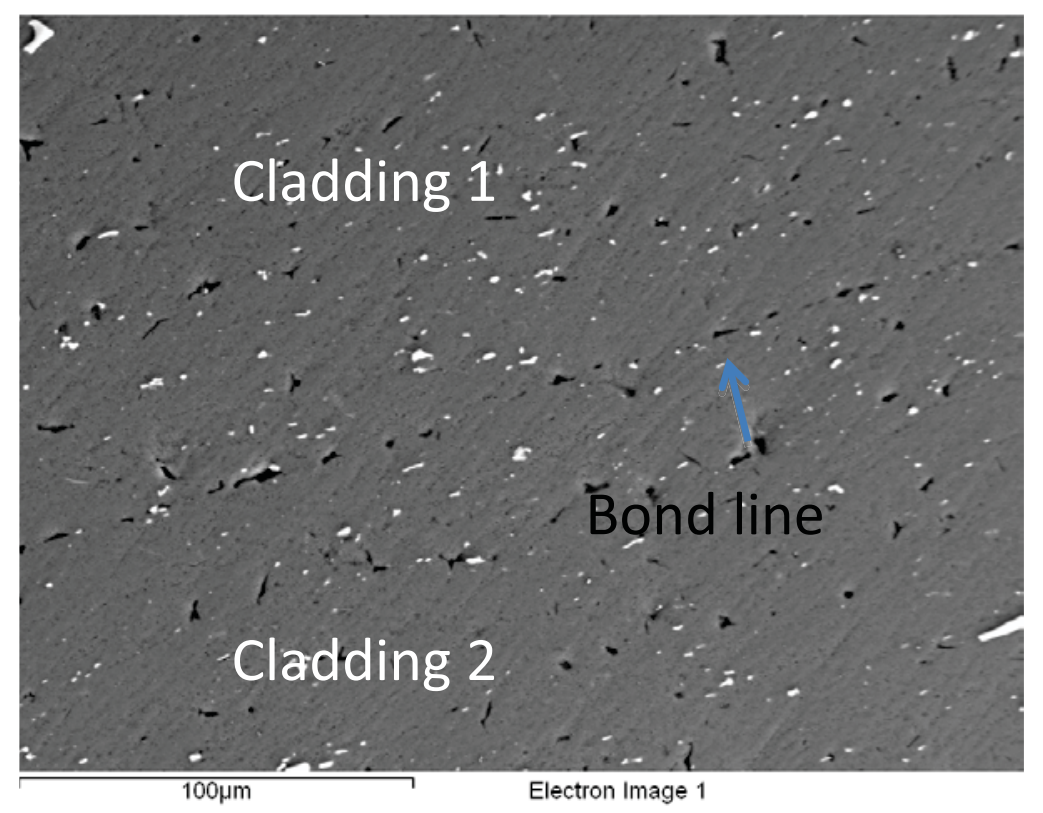

(a)

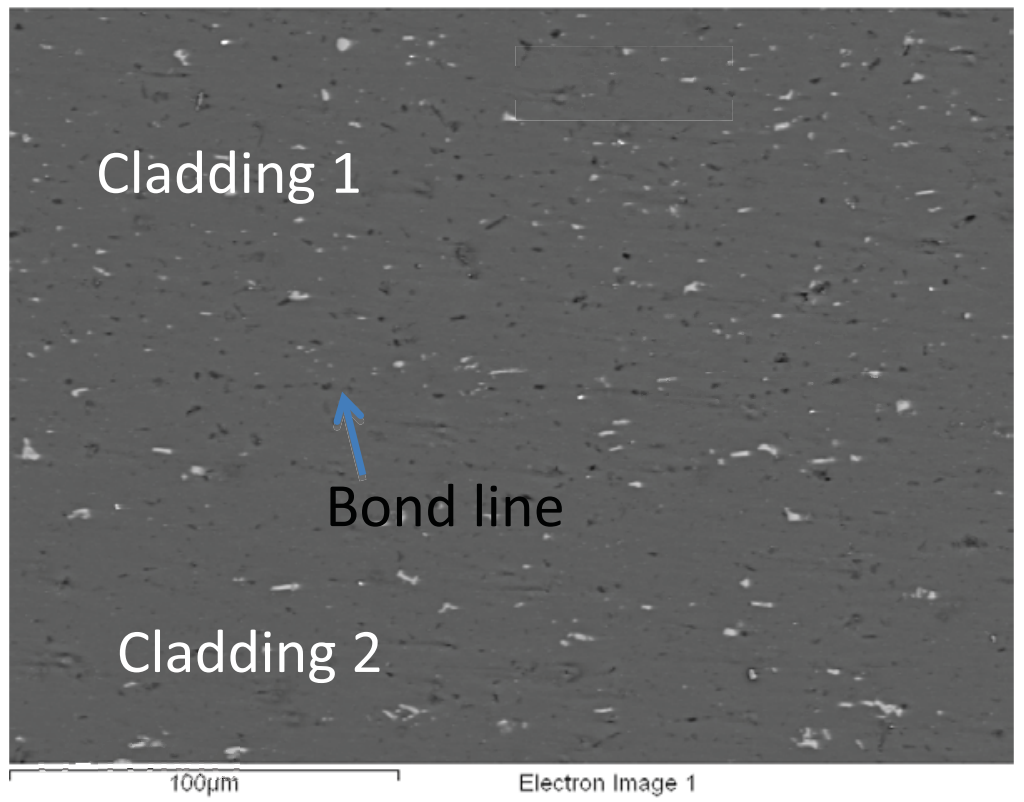

(b)

Figure 31. Second phase precipitates along bond line in (a) RERTR-10A (from plate \#42-6, JJ497) and (b) RERTR-12 (from plate \#65-5, JJ599) plates. 


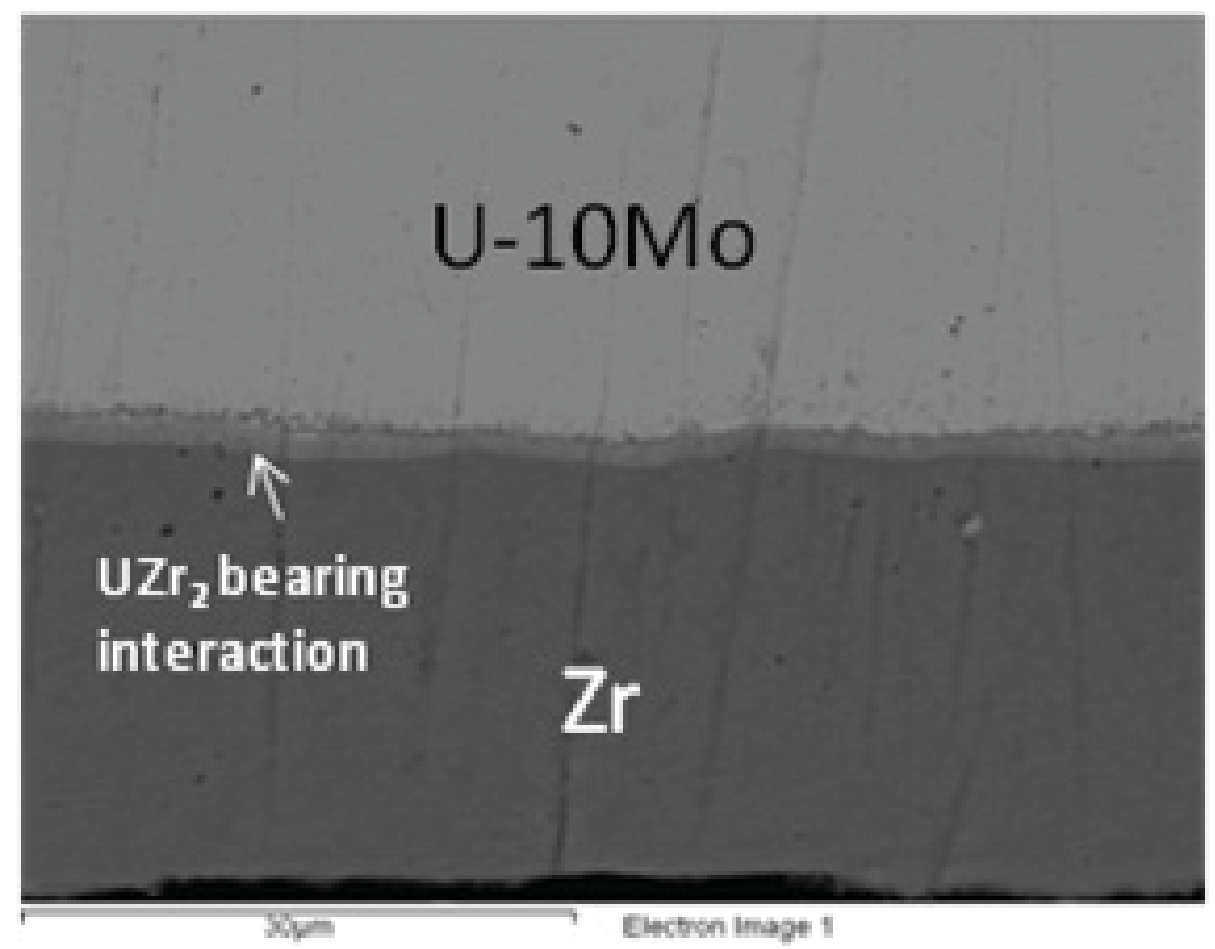

Figure 32. An SEM micrograph shows a typical interface between U-10Mo and Zr in an RERTR-12 foil subjected to $650^{\circ} \mathrm{C} / 1 \mathrm{hr}$ annealing treatment (foil \#331, JJ580).

\subsubsection{Discussion and tentative conclusions}

The differences between RERTR-12 and RERTR-10A microstructural features may have the following impact on the blistering temperature:

1. The difference in grain structure might be a direct result of cold-rolling. The impact of inhomogeneous grain structure on blister temperature is unknown at this time. The smaller grain size of the fuel is typically associated with larger grain boundary areas, where fission-gas bubbles tend to precipitate out and may more easily be released in blister anneal test.

2. The impact of chemical banding is not known at this time. However, if banding remains in the fuel after irradiation, the existence of Mo-depleted bands may have a negative impact on fission-gas retention. The more extensive banding structure in RERTR-12 samples might have a negative impact on blister temperature.

3. Aligned second phase carbides may be the sites for fission-product precipitation, which can potentially make crack propagation easier and thus negatively impact blister temperature. The higher frequency of aligned second phases in the fuel meat of RERTR-12 archived samples may have a negative impact on the blistering temperature.

4. The presence of weak Al-Al bonding may also enhance the possibility of Type 1 blister formation. Secondary phases along the bond line may reduce the cladding/cladding bond strength, which might manifest itself as a lower blister temperature. However the fact that RERTR-12 archive plate had less precipitates observed along the cladding/cladding bond line compared to RERTR-10A plate, suggests that this is unlikely a possible reason for the lower blister temperature in RERTR-12. 


\subsubsection{References}

1. E. Perez, B. Yao, D. D. Keiser Jr., and Y. H. Sohn, "Microstructural Analysis of as-Processed U10 wt.\%Mo Monolithic Fuel Plate in AA6061 matrix with Zr Diffusion Barrier," Journal of Nuclear Materials, 402, 8-14 (2010).

2. LANL technical report, LA-UR 09-06439 (2009).

\subsection{Irradiation Conditions}

The as-fabricated fuel microstructure evolves during irradiation. This process is affected by fuel irradiation conditions: power, temperature and burnup. It has been hypothesized previously (see PLN4155, "Analysis of Low Blister Threshold Temperatures in the RERTR-12 and AFIP-4 Experiments" [1]) that the difference in blister-threshold temperature between two groups of the RERTR experiments can be attributed to the difference in the irradiation conditions between experiments. The following section presents a more detailed discussion of fuel irradiation conditions (power, temperature and burnup) for the set of experiments prior to RERTR-12 and for the RERTR-12 and AFIP-4 experiments, i.e., those with high- and low-blister-threshold temperatures.

\subsubsection{Operating Powers in RERTR Miniplate Experiments}

As identified in PLN-4155 [1], one of the major differences between the two groups of experiments exhibiting high and low blister threshold temperature was their experiment configurations in the reactor core. The RERTR miniplate experiments are routinely irradiated in the large B positions of the ATR, which are located approximately half-way between the center of the core and its periphery. In all miniplate tests prior to RERTR-12, the fuel plates were oriented edge-on towards the core center (see Figure 33). This orientation results in largely non-uniform distribution of the plate power, producing steep burnup gradients across the plate width. As shown in Figure 34, which represents a typical power/burnup profile for the plate in the edge-on configuration, the hot edge of the plate (facing the core center) may achieve burnups roughly 2-3 times higher than the cold edge (away from the core center). On the whole, approximately half of the plate in the edge-on orientation is exposed to high irradiation conditions (power, burnup) and the other half of the plate is subjected to low power and burnup.

To obtain more uniform distribution of power/burnup within individual fuel plates, beginning with the RERTR-12, the experimental fuel plates were positioned face-on towards the core center (see Figure 33). A typical distribution of power/burnup for this configuration is shown in Figure 35. As can be seen from this figure, the regions with the highest power/burnup on the plate in the face-on configuration include the four corners, followed by the area along the perimeter of the plate. Such power peaking is explained by the combined effects of the fuel-to-moderator ratio and self-shielding phenomena. The middle region of the plate in the face-on configuration runs at relatively lower power and achieves lower burnup.

AFIP-4 plates, which are larger in size than RERTR mini-plates, were designed to study scale-up effects on fuel performance. These plates were irradiated in the Center Flux Trap (CFT) located at the exact center of the ATR core. Irradiation in this position resulted in the most uniform distribution of power/burnup within the plates, as shown in Figure 36. 

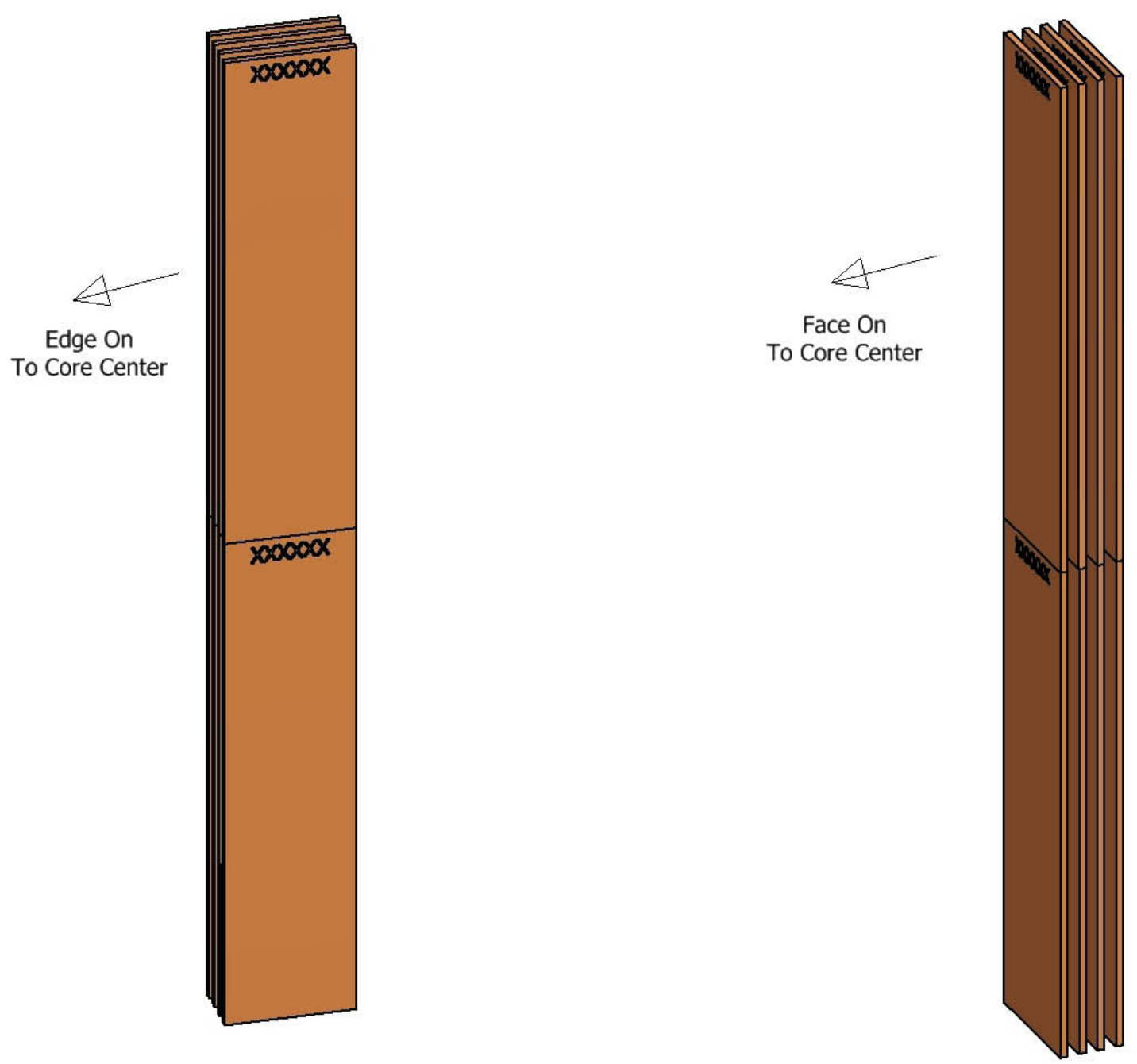

Figure 33. Orientation of the RERTR miniplates towards reactor core center: a) edge-on, and b) face-on. 


\begin{tabular}{|c|c|c|c|c|c|c|c|c|c|c|c|c|c|c|c|c|c|c|c|c|}
\hline & 1-hot & 2 & 3 & 4 & 5 & 6 & 7 & 8 & 9 & 10 & 11 & 12 & 13 & 14 & 15 & 16 & 17 & 18 & 19 & 20 - cold \\
\hline 1-top & 2.50 & 1.99 & 1.76 & 1.55 & 1.42 & 1.33 & 1.22 & 1.18 & 1.10 & 1.09 & 1.00 & 0.96 & 0.94 & 0.92 & 0.92 & 0.88 & 0.88 & 0.87 & 0.92 & 1.01 \\
\hline 2 & 95 & 55 & 37 & 21 & 10 & 1.04 & 0.95 & 0.92 & 0.86 & 0.85 & 0.78 & 0.75 & 0.73 & 0.71 & 0.71 & 0.68 & 0.68 & 0.67 & .71 & 0.79 \\
\hline 3 & 91 & 52 & 1.34 & 18 & 1.08 & 1.01 & 0.93 & 0.90 & 0.84 & 0.83 & 0.76 & 0.73 & 0.72 & 0.70 & 0.70 & 0.67 & 0.67 & 0.66 & 0.70 & 0.77 \\
\hline 4 & .85 & 1.47 & 1.30 & 1.14 & 1.04 & 0.98 & 0.90 & 0.87 & 0.81 & 0.80 & 0.74 & 0.71 & 0.69 & 0.68 & 0.68 & 0.65 & 0.65 & 0.64 & 0.68 & 0.75 \\
\hline 5 & 1.87 & 1.48 & 1.31 & 1.16 & 1.06 & 0.99 & 0.91 & 0.88 & 0.82 & 0.81 & 0.75 & 0.72 & 0.70 & 0.68 & 0.68 & 0.66 & 0.66 & 0.65 & 0.68 & 0.76 \\
\hline 6 & 1.89 & 1.50 & 1.32 & 1.17 & 1.07 & 1.00 & 0.92 & 0.89 & 0.83 & 0.82 & 0.75 & 0.73 & 0.71 & 0.69 & 0.69 & 0.66 & 0.66 & 0.65 & .69 & 0.76 \\
\hline 7 & 95 & 1.55 & 1.37 & 1.21 & 1.10 & 1.04 & 0.95 & 0.92 & 0.86 & 0.85 & 0.78 & 0.75 & 0.73 & 0.71 & 0.71 & 0.68 & 0.68 & 0.67 & 71 & 0.79 \\
\hline 8 & 89 & 1 & 1 & 1 & 1 & 1.00 & 0.92 & 0.89 & 0. & 0.82 & 0 & 0 & 1 & 0.69 & 0.69 & 0.66 & 56 & 55 & 59 & 076 \\
\hline 9 & .91 & 1.52 & 1.34 & 1.18 & 1.08 & 1.01 & 0.93 & 0.90 & 0.84 & 0.83 & 0.76 & 0.73 & 0.72 & 0.70 & 0.70 & 0.67 & 0.67 & 0.66 & .70 & .77 \\
\hline 10 & 1.91 & 1.52 & 1.34 & 1.18 & 1.08 & 1.01 & 0.93 & 0.90 & 0.84 & 0.83 & 0.76 & 0.73 & 0.72 & 0.70 & 0.70 & 0.67 & 0.67 & 0.66 & 0.70 & 0.77 \\
\hline 11 & 1.87 & 1.48 & 1.31 & 1.16 & 1.06 & 0.99 & 0.91 & 0.88 & 0.82 & 0.81 & 0.75 & 0.72 & 0.70 & 0.68 & 0.68 & 0.66 & 0.66 & 0.65 & 0.68 & 0.76 \\
\hline 12 & 97 & 1.56 & 1.38 & 1.22 & 1.11 & 1.05 & 0.96 & 0.93 & 0.86 & 0.85 & 0.79 & 0.76 & 0.74 & 0.72 & 0.72 & 0.69 & 0.69 & 0.68 & 0.72 & 0.80 \\
\hline 13 & 1.99 & 1.58 & 1.40 & 1.23 & 1.13 & 1.06 & 0.97 & 0.94 & 0.87 & 0.86 & 0.80 & 0.77 & 0.75 & 0.73 & 0.73 & 0.70 & 0.70 & 0.69 & 0.73 & 0.81 \\
\hline 14 & 1.97 & 1.56 & 1.38 & 1.22 & 1.11 & 1.05 & 0.96 & 0.93 & 0.86 & 0.85 & 0.79 & 0.76 & 0.74 & 0.72 & 0.72 & 0.69 & 0.69 & 0.68 & 0.72 & 0.80 \\
\hline 15 & 1.99 & 1.58 & 1.40 & 1.23 & 1.13 & 1.06 & 0.97 & 0.94 & 0.87 & 0.86 & 0.80 & 0.77 & 0.75 & 0.73 & 0.73 & 0.70 & 0.70 & 0.69 & 0.73 & 0.81 \\
\hline 16 & 2.07 & 1.65 & 1.45 & 1.28 & 1.17 & 1.10 & 1.01 & 0.98 & 0.91 & 0.90 & 0.83 & 0.80 & 0.78 & 0.76 & 0.76 & 0.73 & 0.73 & 0.72 & 0.76 & 0.84 \\
\hline 17 & 2.19 & 1.74 & 1.54 & 1.36 & 1.24 & 1.17 & 1.07 & 1.04 & 0.96 & 0.95 & 0.88 & 0.85 & 0.82 & 0.80 & 0.80 & 0.77 & 0.77 & 0.76 & 0.80 & 0.89 \\
\hline 18 & 2.15 & 1.71 & 1.51 & 1.33 & 1.22 & 1.14 & 1.05 & 1.02 & 0.95 & 0.93 & 0.86 & 0.83 & 0.81 & 0.79 & 0.79 & 0.76 & 0.76 & 0.75 & 0.79 & 0.87 \\
\hline 19 & 2.36 & 1.87 & 1.66 & 1.46 & 1.33 & 1.25 & 1.15 & 1.12 & 1.04 & 1.02 & 0.94 & 0.91 & 0.89 & 0.86 & 0.86 & 0.83 & 0.83 & 0.82 & 0.86 & 0.95 \\
\hline 0-bottom & 2.85 & 2.27 & 2.00 & 1.77 & 1.61 & 1.52 & 1.39 & 1.35 & 1.25 & 1.24 & 1.14 & 1.10 & 1.07 & 1.04 & 1.04 & 1.00 & 1.00 & 0.99 & 1.04 & 1.15 \\
\hline
\end{tabular}

Figure 34. Local-to-average power/burnup peaking factors for a representative RERTR plate oriented edge-on towards reactor core center.

\begin{tabular}{|c|c|c|c|c|c|c|c|c|c|c|c|c|c|c|c|c|c|c|c|c|}
\hline & 1 & 2 & 3 & 4 & 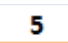 & 6 & 7 & 8 & 9 & 10 & 1 & 12 & 13 & 14 & 15 & 16 & 17 & 18 & 19 & 0 \\
\hline 1-top & 1.84 & 1.60 & .46 & 37 & 1.28 & 1.22 & .19 & 1.20 & 1.15 & 1.12 & 1.20 & 1.17 & 1.17 & 1.19 & 1.22 & 1.28 & 1.36 & 1.37 & 1.54 & 1.83 \\
\hline 2 & 48 & 28 & 17 & 10 & .03 & .98 & 96 & 0.96 & 0.93 & 0.90 & .96 & 0.94 & 0.94 & 0.96 & 0.98 & 1.03 & 1.09 & 1.10 & 1.24 & 1.47 \\
\hline 3 & 41 & 22 & 11 & 05 & .98 & .93 & .91 & 0.92 & 0.88 & 0.86 & 91 & 0.90 & 0.89 & 0.91 & 0.93 & .98 & .04 & 1.05 & 1.17 & 1.40 \\
\hline 4 & 38 & 1.20 & .09 & .03 & 0.96 & 0.91 & 0.90 & 0.90 & 0.87 & 0.84 & 0.90 & 0.88 & 0.88 & 0.90 & 0.92 & 0.96 & 1.02 & 1.03 & 1.16 & 1.38 \\
\hline 5 & 32 & 14 & 04 & 98 & .92 & 87 & 85 & .86 & 0.82 & 0.80 & 85 & 0.84 & 0.83 & 0.85 & 0.87 & 92 & 97 & .98 & 1.10 & 1.31 \\
\hline 6 & 1.30 & 12 & .03 & 0.97 & 0.90 & 0.86 & 0.84 & 0.84 & 0.81 & 0.79 & 0.84 & 0.83 & 0.82 & 0.84 & 0.86 & 0.90 & 0.96 & 0.97 & 1.08 & 1.29 \\
\hline 7 & 34 & 16 & 06 & 00 & 93 & 88 & 87 & 0.87 & 0.84 & 0.82 & 87 & 0.85 & 0.85 & 87 & 89 & 93 & 99 & .00 & 1.12 & 1.33 \\
\hline 8 & 1.29 & 1.11 & 1.02 & 0.96 & 0.90 & 0.85 & 0.83 & 0.84 & 0.81 & 0.78 & 0.84 & 0.82 & 0.81 & 0.83 & 0.85 & 0.90 & 0.95 & 0.96 & 1.07 & 1.28 \\
\hline 9 & 40 & 22 & 11 & .05 & 0.98 & 0.93 & 0.91 & 0.91 & 0.88 & 0.86 & 0.91 & 0.89 & 0.89 & 0.91 & 0.93 & 0.98 &. .04 & 1.05 & 1.17 & 1.40 \\
\hline 10 & 1.30 & .13 & 1.03 & 0.97 & 0.91 & 0.86 & 0.84 & 0.85 & 0.82 & 0.79 & 0.85 & 0.83 & 0.82 & 0.84 & 0.86 & 0.91 & 0.96 & 0.97 & 1.09 & 1.30 \\
\hline 11 & 33 & 16 & .06 & 99 & 0.93 & .88 & 0.87 & 0.87 & 0.84 & 0.81 & 0.87 & 0.85 & 0.85 & 0.87 & 0.89 & 0.93 & .98 & 1.00 & 1.12 & 1.33 \\
\hline 12 & 1.23 & .06 & 0.97 & 0.91 & 0.86 & 0.81 & 0.80 & 0.80 & 0.77 & 0.75 & 0.80 & 0.78 & 0.78 & 0.80 & 0.82 & 0.86 & 0.91 & 0.92 & 1.03 & 1.22 \\
\hline 13 & 29 & 11 & 02 & .96 & 0.90 & .85 & 0.83 & 0.84 & 0.81 & 0.78 & 0.84 & 0.82 & 0.81 & 0.83 & 0.85 & 0.90 & .95 & 0.96 & 1.07 & 1.28 \\
\hline 14 & 1.26 & 1.09 & 1.00 & 0.94 & 0.88 & 0.83 & 0.82 & 0.82 & 0.79 & 0.77 & 0.82 & 0.80 & 0.80 & 0.82 & 0.84 & 0.88 & .93 & 0.94 & 1.05 & 1.26 \\
\hline 15 & 1.26 & 10 & .00 & 0.94 & 0.88 & 0.84 & 0.82 & 0.82 & 0.79 & 0.77 & 0.82 & 0.81 & 0.80 & 0.82 & 0.84 & 0.88 & 0.93 & 0.94 & 1.06 & 1.26 \\
\hline 16 & 1.30 & 13 & 03 & 0.97 & 0.91 & 0.86 & 0.85 & 0.85 & 0.82 & 0.79 & 0.85 & 0.83 & 0.82 & 0.84 & 0.87 & 0.91 & .96 & 0.97 & 1.09 & 1.30 \\
\hline 17 & & 14 & .04 & 0.98 & 0.91 & 0.87 & 0.85 & 0.85 & 0.82 & 0.80 & 0.85 & 0.83 & 0.83 & 0.85 & 0.87 & 0.91 & 0.97 & 0.98 & 1.09 & 1.31 \\
\hline 18 & 1.34 & 16 & 06 & 1.00 & 0.93 & 0.89 & 0.87 & 0.87 & 0.84 & 0.82 & 0.87 & 0.85 & 0.85 & 0.87 & 0.89 & 0.93 & 99 & 1.00 & 1.12 & 1.34 \\
\hline 19 & & & 2 & 1.05 & 0.99 & 0.93 & 0.92 & 0.92 & 0.89 & 0.86 & 0.92 & 0.90 & 0.90 & 0.92 & 0.94 & 0.99 & 1.04 & 1.06 & 1.18 & 1.41 \\
\hline 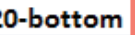 & 11 & 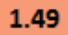 & 56 & 28 & .19 & 1.13 & 1.11 & 1.12 & 1.07 & 1.05 & 1.11 & 1.09 & 1.08 & 1.11 & 1.14 & 1.20 & 1.26 & 1.28 & 1.43 & 1.71 \\
\hline
\end{tabular}

Figure 35. Local-to-average power/burnup peaking factors for a representative RERTR plate oriented face-on towards reactor core center. 


\begin{tabular}{|c|c|c|c|c|c|c|c|c|c|c|c|c|c|c|c|c|c|c|c|c|}
\hline & 1 & 2 & 3 & 4 & 5 & 6 & 7 & 8 & 9 & 10 & 11 & 12 & 13 & 14 & 15 & 16 & 17 & 18 & 19 & 20 \\
\hline 1-top & 1.12 & 1.10 & 1.09 & 1.07 & 1.05 & 1.05 & 1.08 & 1.08 & L.06 & .07 & .09 & .06 & 1.05 & 1.08 & 1.06 & .10 & 1.08 & .10 & .10 & 1.10 \\
\hline 2 & 06 & L.01 & .98 & .00 & .98 & .99 & 97 & .98 & 95 & 97 & 98 & .00 & .97 & 99 & .00 & .01 & .04 & .02 & .02 & 1.04 \\
\hline 3 & 01 & 0.98 & .94 & .96 & .95 & .93 & .91 & 0.96 & .92 & .95 & .92 & .97 & 95 & 0.97 & .97 & .98 & .96 & .97 & .00 & 1.07 \\
\hline 4 & 03 & 0.97 & 0.98 & .93 & .97 & 0.93 & 0.94 & 0.91 & .91 & .92 & .95 & .94 & 94 & .93 & .98 & .97 & .96 & .99 & .01 & 1.04 \\
\hline 5 & 04 & .04 & .01 & 1.01 & 0.99 & 1.00 & 0.99 & 1.01 & 0.99 & 0.96 & 96 & 95 & 95 & 99 & 01 & .98 & .01 & .03 & .04 & .08 \\
\hline 6 & & 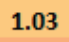 & 1 & 9 & .01 & 0.98 & 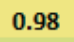 & - & & & & & & & 00 & .02 & & 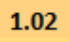 & & .10 \\
\hline 7 & 00 & 1.00 & .03 & 1.00 & 0.98 & 1.00 & 0.91 & 0.98 & .96 & .97 & .98 & 0.99 & & & 0.99 & 1.00 & 20 & L.01 & L.05 & 1.07 \\
\hline 8 & 03 & 1.02 & 1.02 & 0.98 & 0.98 & 0.98 & 0.98 & 0.96 & 1.00 & 0.95 & 0.96 & 0.97 & 0.96 & 0.95 & 1.00 & 0.98 & 1.01 & 1.03 & 1.05 & 1.08 \\
\hline 9 & 1.08 & 1.04 & 1.03 & 102 & 0.99 & 0.98 & 1.01 & 0.98 & 1.00 & 0.96 & 0.96 & 0.97 & 0.99 & 1.01 & 1.00 & 1.04 & 101 & 03 & 103 & 1.08 \\
\hline 10 & & & & & & & & & & & & & & & & 98 & 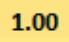 & & & .10 \\
\hline 11 & & & & & & & & & & & & & & & & .00 & & & & .07 \\
\hline 12 & 8 & 102 & 1.02 & 98 & .98 & 0.97 & 0 & 0 & 97 & 9 & 8 & 6 & 7 & 9 & 8 & 1.02 & 0 & 0 & 3 & .09 \\
\hline 13 & 1.03 & 1.02 & 0.98 & 1.01 & 0.99 & 0.99 & 0.94 & 1.00 & 0.99 & 0.98 & 0.98 & 0.98 & 0.97 & 0.99 & 1.01 & 1.01 & 1.00 & 1.04 & 1.04 & 1.08 \\
\hline 14 & 1.06 & 1.02 & 0.97 & 0.99 & 1.02 & 0.97 & 1.00 & 0.97 & 0.99 & 0.96 & 0.97 & 1.00 & 0.99 & 00 & 0.98 & 1.01 & 1 & 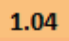 & 1.06 & 1.08 \\
\hline 15 & & & & & 1.00 & 0.98 & 1.00 & 0.96 & 97 & 97 & 97 & 0.96 & 0.96 & 0.98 & 0.99 & 1.01 & 1.00 & 1.05 & .07 & 1.08 \\
\hline 16 & & & 1.01 & & 0.97 & 0.99 & 1.00 & 0 & .93 & - & 6 & 98 & 8 & 8 & 7 & .99 & 8 & 0 & 2 & 1.09 \\
\hline 17 & & & & & & 0.95 & & & 0.75 & 0.00 & .93 & & & & & 0.99 & & & & 1.05 \\
\hline 18 & 1.02 & 1.04 & 0.97 & 0.99 & 0.97 & 0.96 & 0.96 & 0.95 & 0.94 & 0.96 & 0.92 & 0.91 & 0.93 & 0.94 & 0.95 & 0.98 & 0.98 & 1.00 & 1.01 & 1.08 \\
\hline 19 & 1.04 & 1.02 & 0.98 & 1.00 & 0.99 & 0.99 & 0.98 & 0.96 & 0.95 & 0.97 & 0.93 & 0.95 & 0.97 & 0.98 & 0.97 & 0.99 & 1.00 & 0.99 & 1.03 & 1.04 \\
\hline 0-bottom & 10 & .06 & .08 & .07 & L.04 & 1.05 & 1.04 & 1.05 & 1.06 & 1.08 & 1.04 & 1.06 & 1.06 & 1.06 & 1.06 & 1.07 & 1.10 & 1.11 & 1.08 & 1.14 \\
\hline
\end{tabular}

Figure 36. Local-to-average power/burnup peaking factors for a representative AFIP-4 plate irradiated in the Center Flux Trap of ATR core.

To determine if there were significant differences in the plate operational power profiles between the two groups of experiments that might have contributed to the differences in blister threshold temperatures, the values of the average and peak local heat fluxes for each of the blister-tested plates were compiled in Table 12. The three highest values in each column are highlighted in yellow. As seen in Table 12, RERTR-12 plates L1P772, L1P774 and L1P785 operated at the highest average plate power among all blister tested plates. Plates L1P772 and L1P785 also experienced high peak local heat flux. However plate L2F46Z from RERTR-10 experiment, which was blister tested in 2012, had the highest peak local heat flux among all plates due to a combination of relatively high average power and high power peaking factors. Plates L1P785 and L1P754 from RERTR-12 achieved the highest average burnup, which exceeds $100 \%$ LEU fuel burnup. Both plates blistered in the reactor core. However, the highest peak local burnup was estimated for plates L1F330, L1F35T and L1P10T from RERTR-9, due to a combination of relatively high average power and high power peaking factors. 
Table 12. Operating irradiation conditions for blister-tested RERTR plates.

\begin{tabular}{|c|c|c|c|c|c|c|c|}
\hline Experiment & Plate ID & $\begin{array}{c}\text { Plate } \\
\text { Orientation } \\
\text { Towards } \\
\text { Core Center }\end{array}$ & $\begin{array}{c}\text { Plate } \\
\text { Average } \\
\text { Heat Flux } \\
\text { (through } \\
\text { life), } \\
\mathrm{W} / \mathrm{cm}^{2}\end{array}$ & $\begin{array}{c}\text { Peak } \\
\text { Local } \\
\text { Heat Flux, } \\
\text { W/cm }\end{array}$ & $\begin{array}{c}\text { Average } \\
\text { Burnup, } \\
\times 10^{21} \\
\text { fiss } / \mathrm{cm}^{3}\end{array}$ & $\begin{array}{c}\text { Peak } \\
\text { Local } \\
\text { Burnup, } \\
\times 10^{21} \\
\text { fiss } / \mathrm{cm}^{3} \\
\end{array}$ & $\begin{array}{c}\text { Blister } \mathrm{T} \text {, } \\
{ }^{\circ} \mathrm{C}\end{array}$ \\
\hline \multirow[t]{2}{*}{ RERTR-6 } & L2F020 & Edge-on & 152.7 & $260.1^{2,3}$ & 2.45 & $3.65^{2,3}$ & 450 \\
\hline & N1F060 & Edge-on & 112.9 & $205.6^{2,3}$ & 3.63 & $5.52^{2,3}$ & 450 \\
\hline RERTR-7 & L1F110 & Edge-on & 238.4 & $469.6^{2,3}$ & 5.07 & $9.23^{2,3}$ & 400 \\
\hline \multirow[t]{4}{*}{ RERTR-9 } & L1F27C & Edge-on & 159.5 & $468.7^{3}$ & 3.64 & $9.65^{3}$ & 425 \\
\hline & L1F330 & Edge-on & 229.0 & $646.1^{3}$ & 5.99 & $14.6^{3}$ & 400 \\
\hline & L1F35T & Edge-on & 251.9 & $625.1^{3}$ & 6.60 & $14.2^{3}$ & 425 \\
\hline & L1P10T & Edge-on & 216.8 & $529.2^{3}$ & 5.70 & $12.1^{3}$ & 400 \\
\hline \multirow[t]{4}{*}{ RERTR-10 } & L1P30Z & Edge-on & 187.6 & $511.6^{3}$ & 2.88 & $6.42^{3}$ & 400 \\
\hline & L2P15Z & Edge-on & 164.0 & $574.1^{3}$ & 1.34 & $3.82^{3}$ & 475 \\
\hline & L2F47Z & Edge-on & 290.2 & $662.0^{3}$ & 1.75 & $3.73^{3}$ & 500 \\
\hline & $\mathrm{L}_{2} \mathrm{~F} 46 \mathrm{Z}^{1}$ & Edge-on & 381.1 & $836.1^{3}$ & 2.25 & $4.52^{3}$ & 350 \\
\hline \multirow[t]{10}{*}{ RERTR-12 } & L1P772 & Face-on & 476.0 & 723.7 & 5.78 & $7.65^{4}$ & 325 \\
\hline & L1P460 & Face-on & 195.1 & 339.7 & 2.35 & $3.57^{4}$ & 400 \\
\hline & L1P774 & Face-on & 462.0 & 692.7 & 5.59 & $7.36^{4}$ & 325 \\
\hline & L1P592 & Face-on & 224.6 & 425.5 & 2.69 & $4.66^{4}$ & 350 \\
\hline & L1P756 & Face-on & 327.7 & 528.5 & 7.05 & $9.61^{4}$ & 300 \\
\hline & L1P758 & Face-on & 235.9 & 491.9 & 5.00 & $8.50^{4}$ & 300 \\
\hline & L1P595 & Face-on & 160.6 & 345.0 & 3.41 & $5.07^{4}$ & 325 \\
\hline & L1P463 & Face-on & 134.5 & 255.5 & 2.86 & $4.22^{4}$ & 350 \\
\hline & L1P785 & Face-on & 419.6 & 723.4 & 9.15 & $11.4^{4}$ & $\begin{array}{l}\text { blistered in } \\
\text { the core at } \\
210.1^{\circ} \mathrm{C} \\
\text { (est. peak T) }\end{array}$ \\
\hline & L1P754 & Face-on & 375.4 & 641.3 & 8.13 & $10.9^{4}$ & $\begin{array}{c}\text { blistered in } \\
\text { the core at } \\
205.3^{\circ} \mathrm{C} \text { (est. } \\
\text { peak T) }\end{array}$ \\
\hline \multirow[t]{4}{*}{ AFIP-4 } & L1H34Z & $\begin{array}{l}\text { At core } \\
\text { center }\end{array}$ & 137.01 & $182.07^{3}$ & 2.51 & $2.99^{3}$ & 350 \\
\hline & L1B33Z & $\begin{array}{l}\text { At core } \\
\text { center }\end{array}$ & 219.20 & $296.63^{3}$ & 4.06 & $4.59^{3}$ & 300 \\
\hline & L1H36Z & $\begin{array}{l}\text { At core } \\
\text { center }\end{array}$ & 237.16 & $335.38^{3}$ & 4.45 & $5.03^{3}$ & 300 \\
\hline & L1B51Z & $\begin{array}{l}\text { At core } \\
\text { center }\end{array}$ & 243.81 & $350.21^{3}$ & 4.56 & $5.20^{3}$ & 300 \\
\hline
\end{tabular}

1. Tested in 2012

2. Most likely underestimated due to the coarser mesh used to model plates in these experiments

3. Estimated using plate power peaking factors at the beginning of life (BOL)

4. Estimated using plate power peaking factors at the end of life (EOL) 
The values of the average and peak local heat flux for the plates listed in Table 12 were plotted against blister threshold temperature (see Figure 37 and Figure 38). The level of burnup achieved in each individual plate is shown using the color scale located to the right of each figure (lower plate burnups are colored in blue, intermediate in gray and high burnups in red). As can be seen in these graphs, RERTR-12 plates operated over a wide range of average and local heat fluxes; nevertheless, all of the plates demonstrated low blister threshold temperature. Several plates from the RERTR experiments conducted prior to RERTR-12 operated at the same average power as RERTR-12 plates and achieved similar or higher burnup, yet RERTR-12 plates still exhibited lower blister-threshold temperature than the other plates. Based on this information, it appears that no direct correlation exists between plate operating powers and blister threshold temperatures.

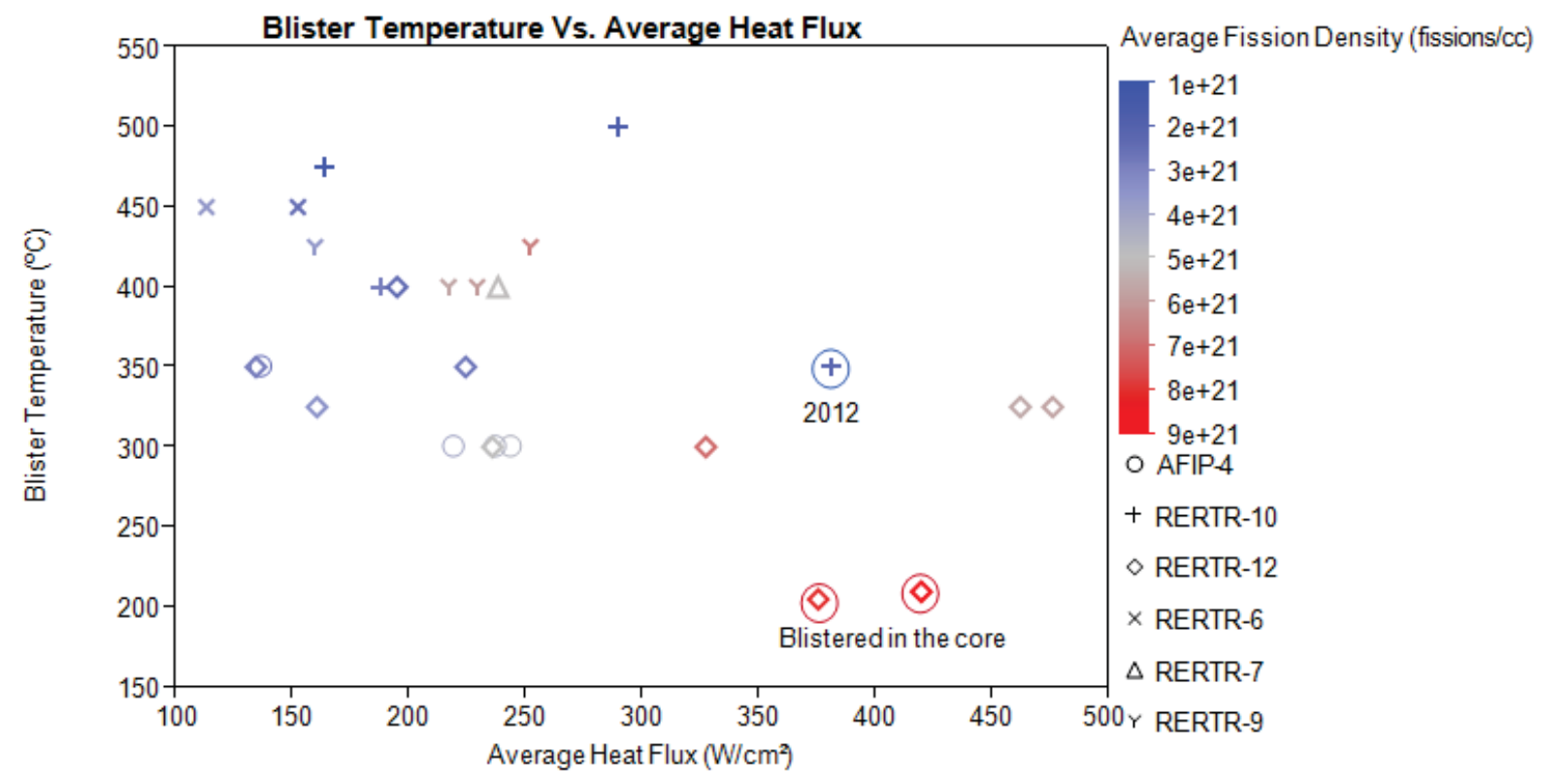

Figure 37. Blister-threshold temperature as a function of plate average heat flux and average burnup. 


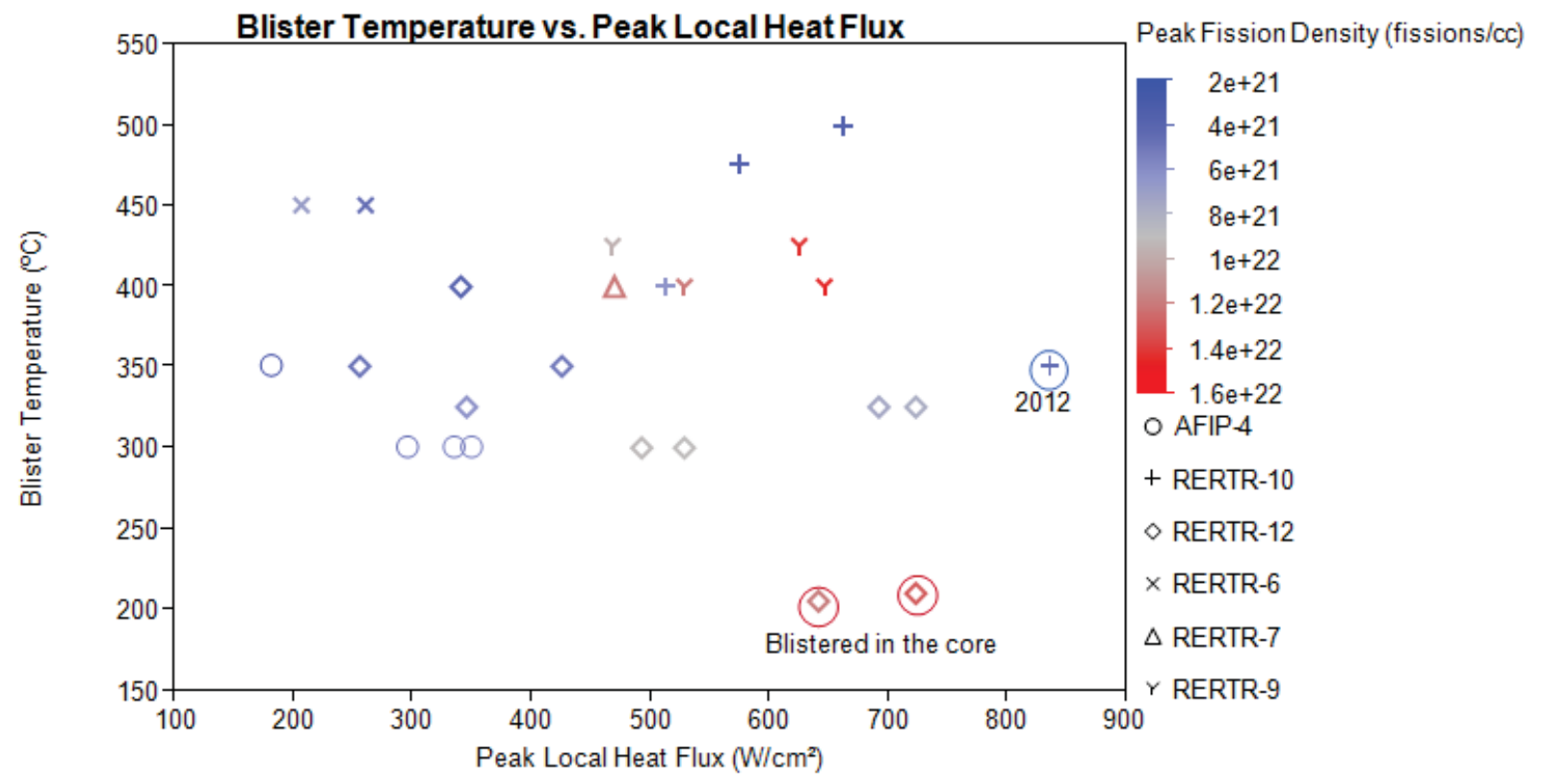

Figure 38. Blister threshold temperature as a function of plate peak local heat flux and peak local burnup.

\subsection{Thermal Modeling of RERTR Experiments}

\subsubsection{Background}

The detailed distribution of plate temperature and heat flux during irradiation of RERTR miniplate experiments was accomplished by using a computational fluid dynamics (CFD) model of the RERTR capsule with 8 miniplates. The model allows for calculating the temperature distribution within the fuel plate as a function of irradiation time. The model takes into account effects of oxide growth on the cladding and degradation of fuel thermal conductivity with burn-up.

The CFD analysis was done using FLUENT [2], and includes fission power obtained from the as-run reactor-physics analysis using MCNP-ORIGEN [7, 8]. The CFD analysis also takes into consideration the axial and transverse variations in fission power using a $20 \times 20$ uniform grid in the fuel zone and the effect of oxide growth and fuel swelling on fuel-plate temperature.

Computational results were obtained for RERTR-12 capsule X1, X2, and X3. The analysis will be extended to include RERTR-9, RERTR-10A, and AFIP-4 experiments. The method of analysis and the calculated plate temperature and heat flux for RERTR-12 capsules X1, X2, and X3 are presented below.

\subsubsection{Method}

The RERTR-12 capsule X1 was irradiated for one cycle (ATR cycle 146A) in position B-11 of the ATR core. Capsules X2 and X3 were irradiated for two cycles (ATR cycles 146A and 146B) in the same position. The FLUENT CFD model includes the capsule, eight fuel plates, and coolant channels inside the capsule, as shown in Figure 39. The coolant inlet temperature and pressure is $52^{\circ} \mathrm{C}$ and $2.5 \mathrm{MPa}$, and coolant flow is $0.0027 \mathrm{~m}^{3} / \mathrm{s}$ [3]. In the three interior flow channels between fuel plates, coolant velocity is $12.8 \mathrm{~m} / \mathrm{s}$, and in the two exterior flow channels between the fuel plates and capsule wall, coolant velocity is $10.3 \mathrm{~m} / \mathrm{s}$. 


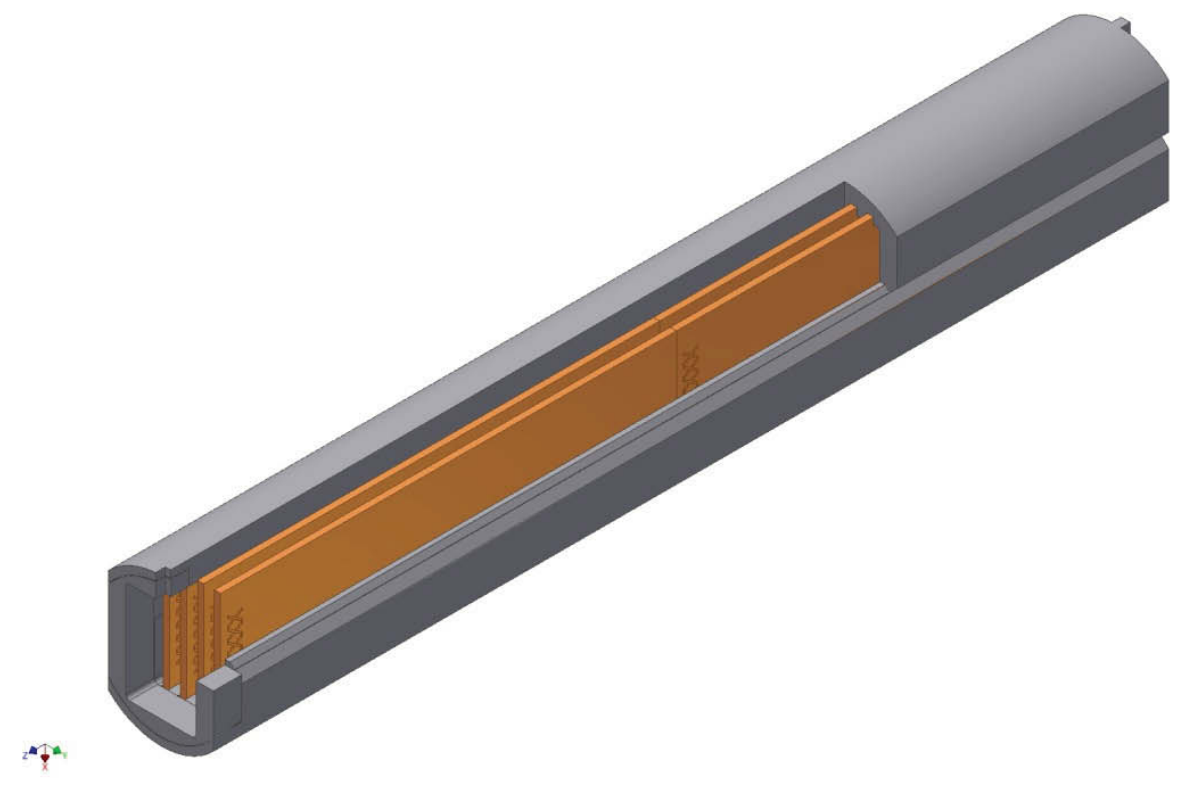

Figure 39: Model geometry of a RERTR capsule.

Flow inside the capsule is highly turbulent. Turbulence parameters include eddy viscosity, turbulent kinetic energy, and turbulent dissipation, which were estimated from boundary-layer theory [4]. The computational grid was refined near the plate surfaces in order to resolve flow and temperature in the boundary layer adjacent to the wall. The characteristic coordinate of the grid point adjacent to the wall, usually denoted as $\mathrm{y}^{+}$, is approximately equal to 5. Boundary layer theory [4] shows that $\mathrm{y}^{+}<5$ in the viscous sub-layer, $5<\mathrm{y}^{+}<70$ in the buffer layer, and $\mathrm{y}^{+}>70$ in the overlap layer. In the FLUENT model, turbulence is computed using the standard k- $\varepsilon$ model and the near-wall region is resolved using scalable wall functions.

The RERTR fuel plate materials include monolithic U-10Mo alloy fuel, aluminum cladding, and an oxide film that is produced by corrosion of aluminum in water. Thermo-physical properties of these materials were obtained from data compiled by INL and ANL $[5,6]$.

The important phenomena affecting fuel plate thermal conditions are fission power, fission density, coolant hydrodynamics, fuel-plate thermal properties, oxide growth at the coolant-cladding interface, and fuel swelling caused by accumulation of fission products. The oxide layer has a low thermal conductivity, and its thermal resistance increases the fuel and cladding temperatures. Fuel porosity resulting from fission gas decreases the effective thermal conductivity of the fuel and leads to an increase in fuel temperature.

As-run reactor-physics analysis using MCNP provides fission power and fission density in the plates [7]. Average plate power and fission density for each plate in capsule X1 are shown in Figure 40 and Figure 41 as a function of irradiation time expressed in effective full-power days. Plates are numbered C1 through C-8 to denote capsule $\mathrm{C}$ in the RERTR capsule stack-up in the core. The plates IDs corresponding to plates C-1 through C-8 are L1P772, L1P773, L1P591, L1P460, L1P774, L1P776, L1P592, and L1P461. These plates were placed in a face-on configuration, with plates 1 and 5 closest to core center and generating the highest power. Plates 2 through 4 and plates 6 through 8 are shielded by other plates and generate less power. 


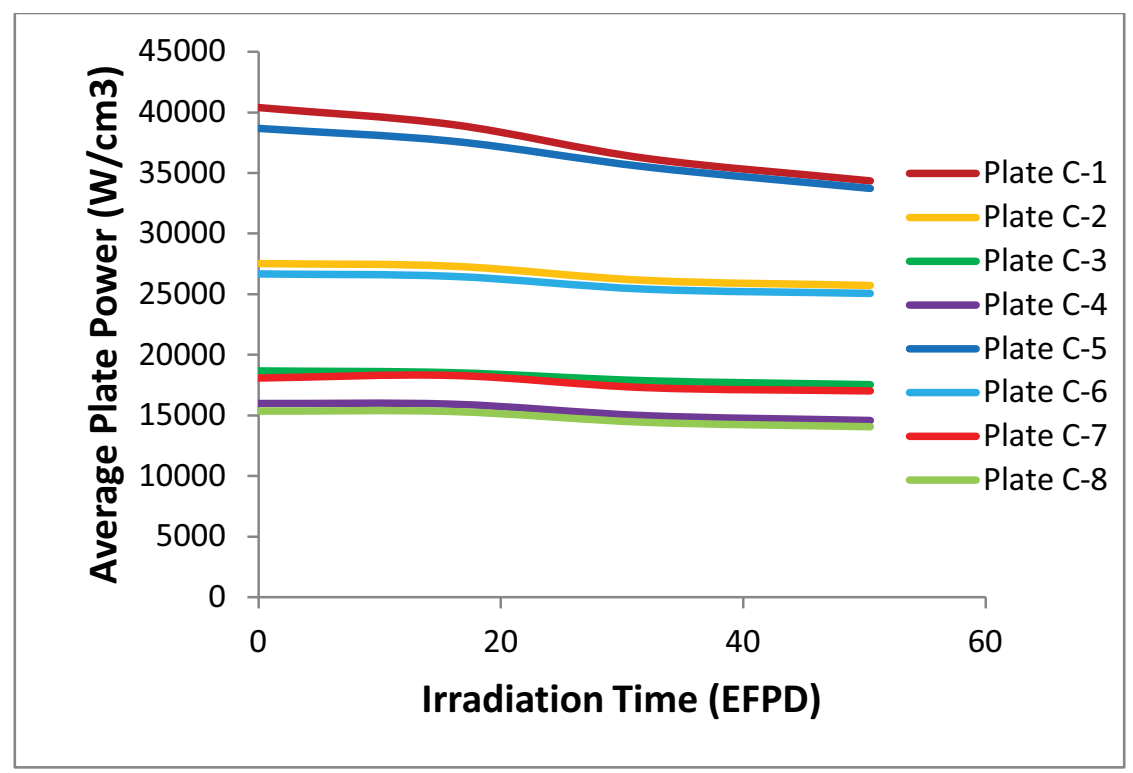

Figure 40. Average fission power in capsule X1.

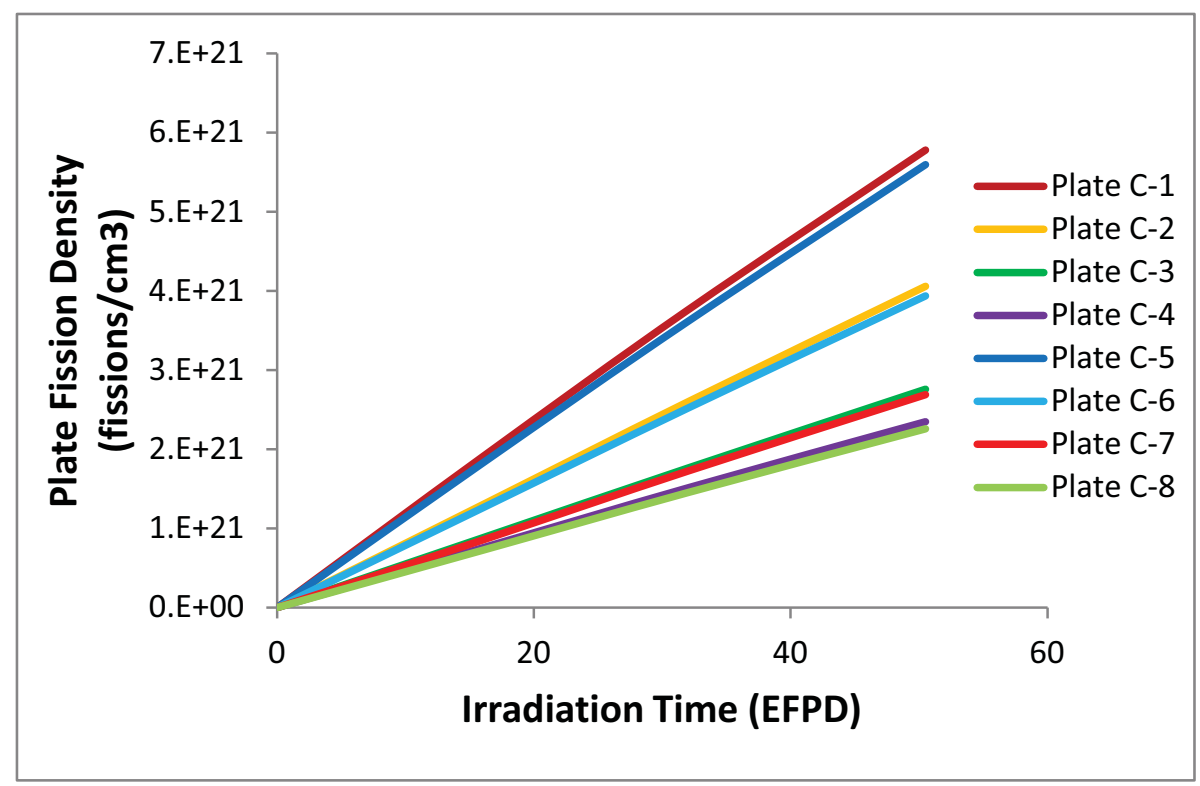

Figure 41. Average fission density in capsule X1.

As-run reactor-physics analysis using MCNP provides fission-power gradients in the fuel plates [8]. The distribution of fission power is expressed in terms of point-wise values of peak-to-average power in the axial and transverse directions. The peak-to-average power for each plate in capsule X1 is shown in Figure 42 and Figure 43. This distribution results in power peaks at the edges of the fuel foil. 


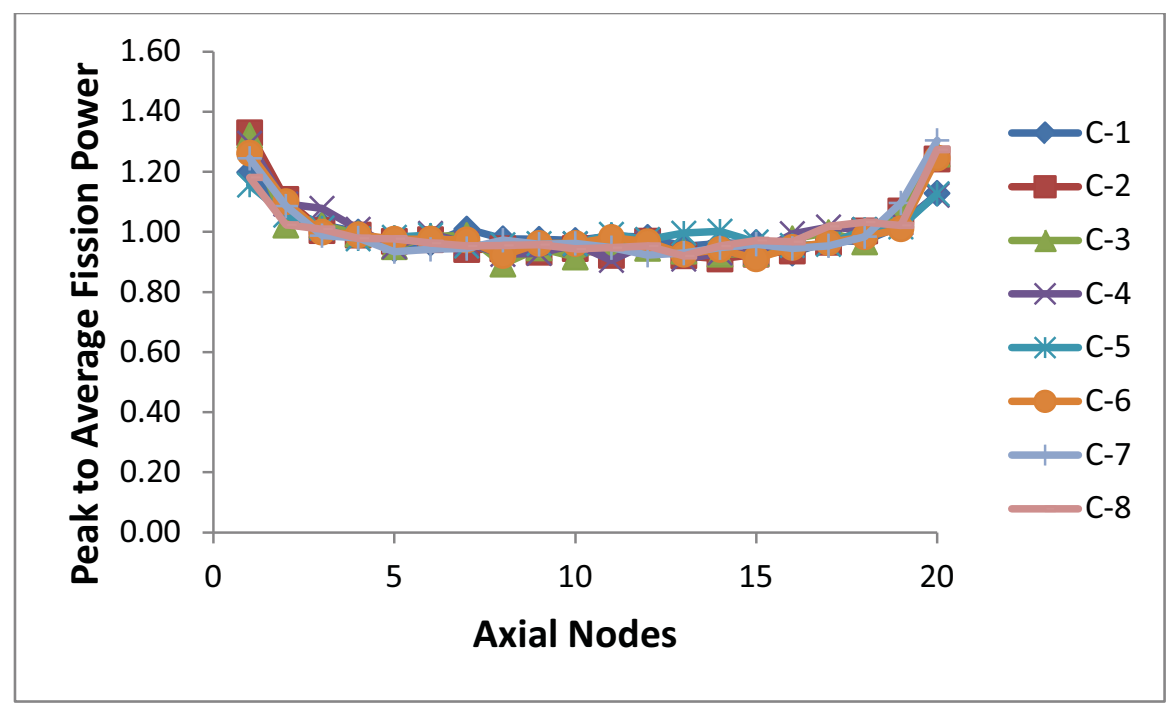

Figure 42. Peak to average fission power in the axial direction in capsule X1.

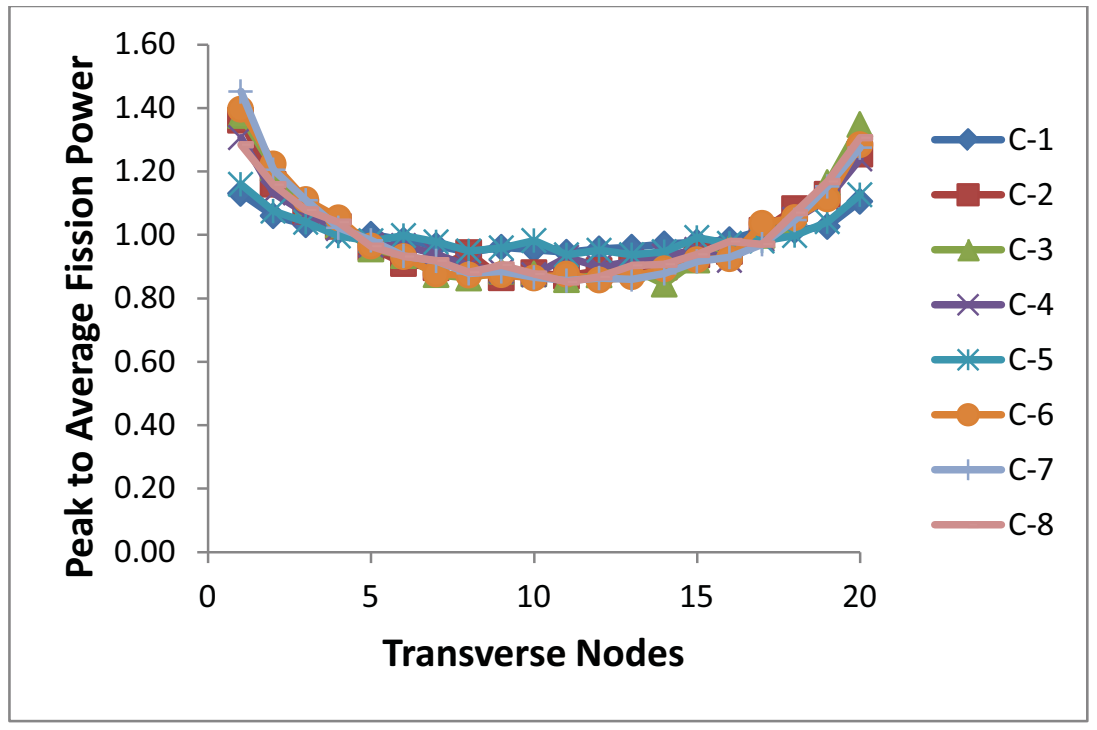

Figure 43. Peak to average fission power in the transverse direction in capsule X1.

Oxide growth at the cladding-coolant interface was modeled using the modified Griess correlation [9]. Oxide thickness depends on time and temperature. An initial oxide pre-film provides surface passivity. Assuming a pre-film thickness equal to 5 microns and a plate surface temperature equal to $127^{\circ} \mathrm{C}$, the oxide thickness was calculated as a function of irradiation time, and the result is shown in Figure 44. This result is used in the FLUENT model to account for the effect of oxide growth on fuelplate temperature. Thermal conditions leading to oxide spalling and blistering were evaluated using the modified Griess correlation and an analytical heat-transfer solution [10]. The condition for oxide spalling was assumed to be a $119^{\circ} \mathrm{C}$ temperature drop across the oxide layer. At values of plate heat flux seen in this study, an oxide thickness of approximately 50 microns is needed to reach the condition for oxide spalling. Note that the end-of-cycle oxide thickness shown in Figure 44 is well below this threshold. Also note that oxide growth obtained from the modified Griess correlation is greater than the measured growth that is described in Table 13 of this report. In future CFD simulations, these measurements will replace the theoretical calculation shown in Figure 44. 


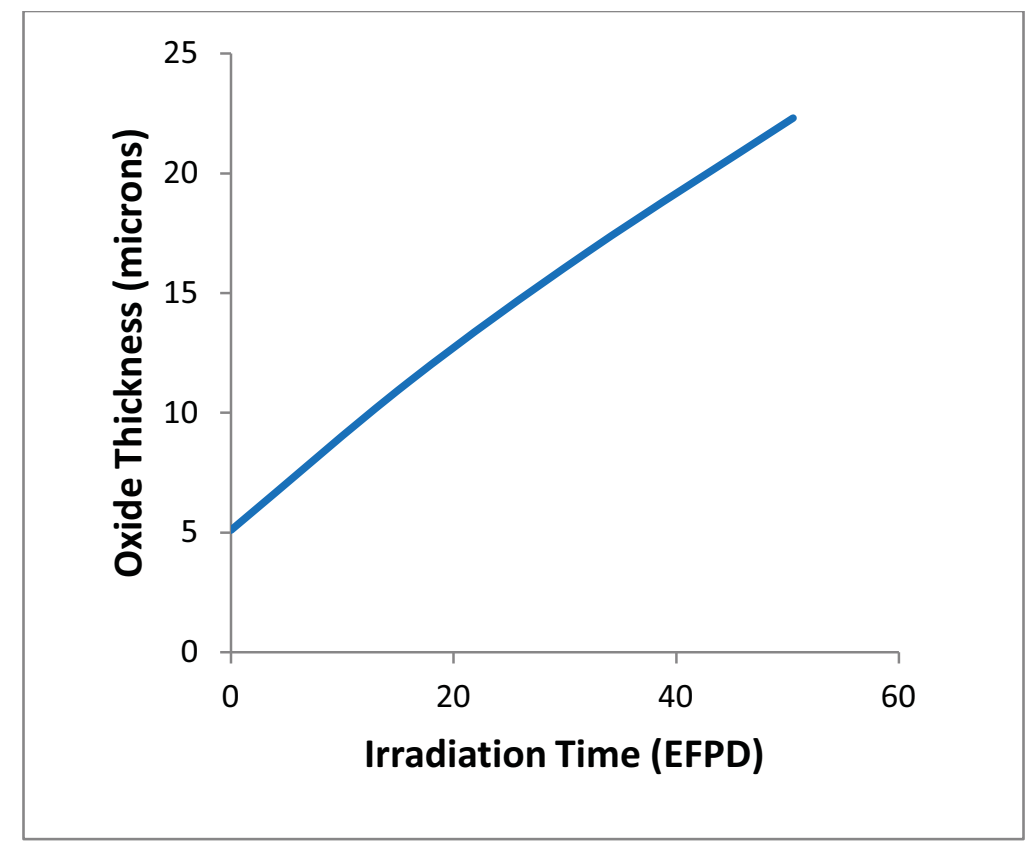

Figure 44. Oxide growth at the cladding-coolant interface.

Fuel swelling was modeled using an empirical correlation between fuel porosity and gaseous fissionproduct density [11]. In this case, porosity depends on irradiation time through the time evolution of fuel burnup, as shown in Figure 45. This result is used in the FLUENT model to account for the effect of fuel porosity on the thermal conductivity of the fuel foil, as described below.

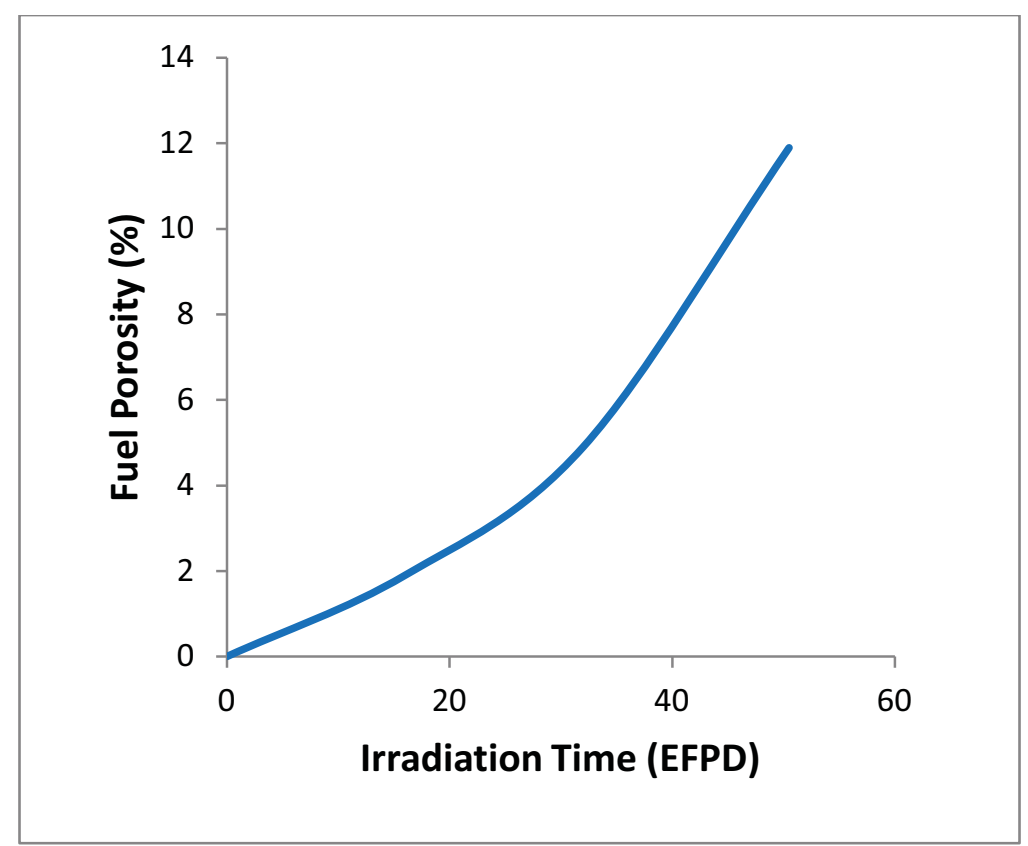

Figure 45. Fuel porosity.

The pores are assumed to be filled with a mixture of $90 \% \mathrm{Xe}$ and $10 \% \mathrm{Kr}$ [5], the thermal conductivity of which has been measured [12]. The thermal conductivity of fuel containing pores is obtained from a formula for properties of a two-phase mixture [13]. The upper-bound formula for the mean value of mixture thermal conductivity provides an accurate estimate of fuel thermal conductivity for 
values of porosity less than 0.3 [14]. Using this result, fuel thermal conductivity depends on temperature and irradiation time, as shown in Figure 46.

Note that this result only includes the effect of porosity on fuel thermal conductivity. Fuel swelling occurs due to the accumulation of solid fission products and gaseous fission products. Therefore total swelling is greater than that produced by porosity alone. The combined effect of fuel swelling and irradiation damage may lead to further reduction in fuel thermal conductivity. An effort to measure thermal conductivity of irradiated U-Mo fuel is underway. In future CFD simulations, these measurements will replace the theoretical calculation shown in Figure 46. Also note that capsules X2 and X3 were irradiated for two cycles and achieved greater burnup than capsule X1. Therefore the effect of oxide growth and fuel swelling on the fuel plate temperature distribution is more significant for capsules $\mathrm{X} 2$ and $\mathrm{X} 3$.

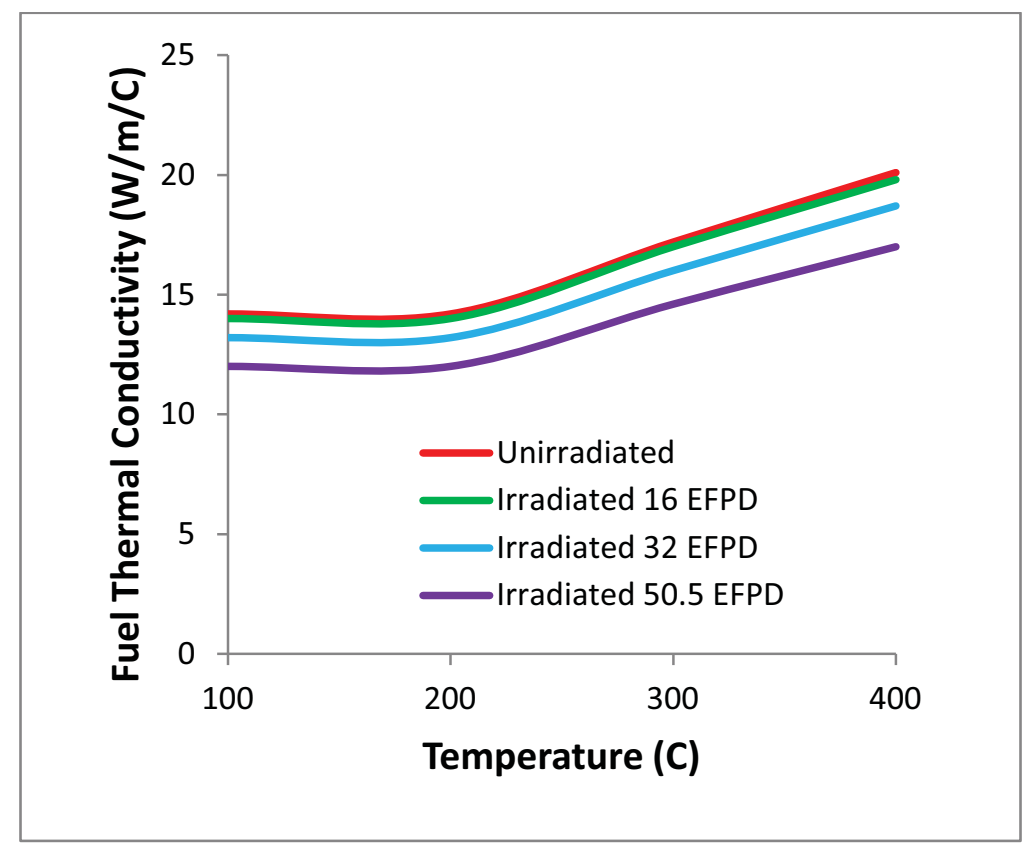

Figure 46. Fuel thermal conductivity.

\subsubsection{Results of RERTR-12 Capsule X1}

In this section, the results of CFD analysis of RERTR-12 capsule X1 are presented. The model geometry of a capsule containing eight plates is shown in Figure 47. In the figure, the fuel foil is presented as orange, and the cladding, yellow. The ATR primary coolant flows from the top of plates 1 through 4 to the bottom of plates 5 through 6 . Plates are numbered C-1 through C- 8 to denote capsule $\mathrm{C}$ in the RERTR capsule stack-up in the core. The plates IDs corresponding to plates C-1 through C-8 are L1P772, L1P773, L1P591, L1P460, L1P774, L1P776, L1P592, and L1P461. 


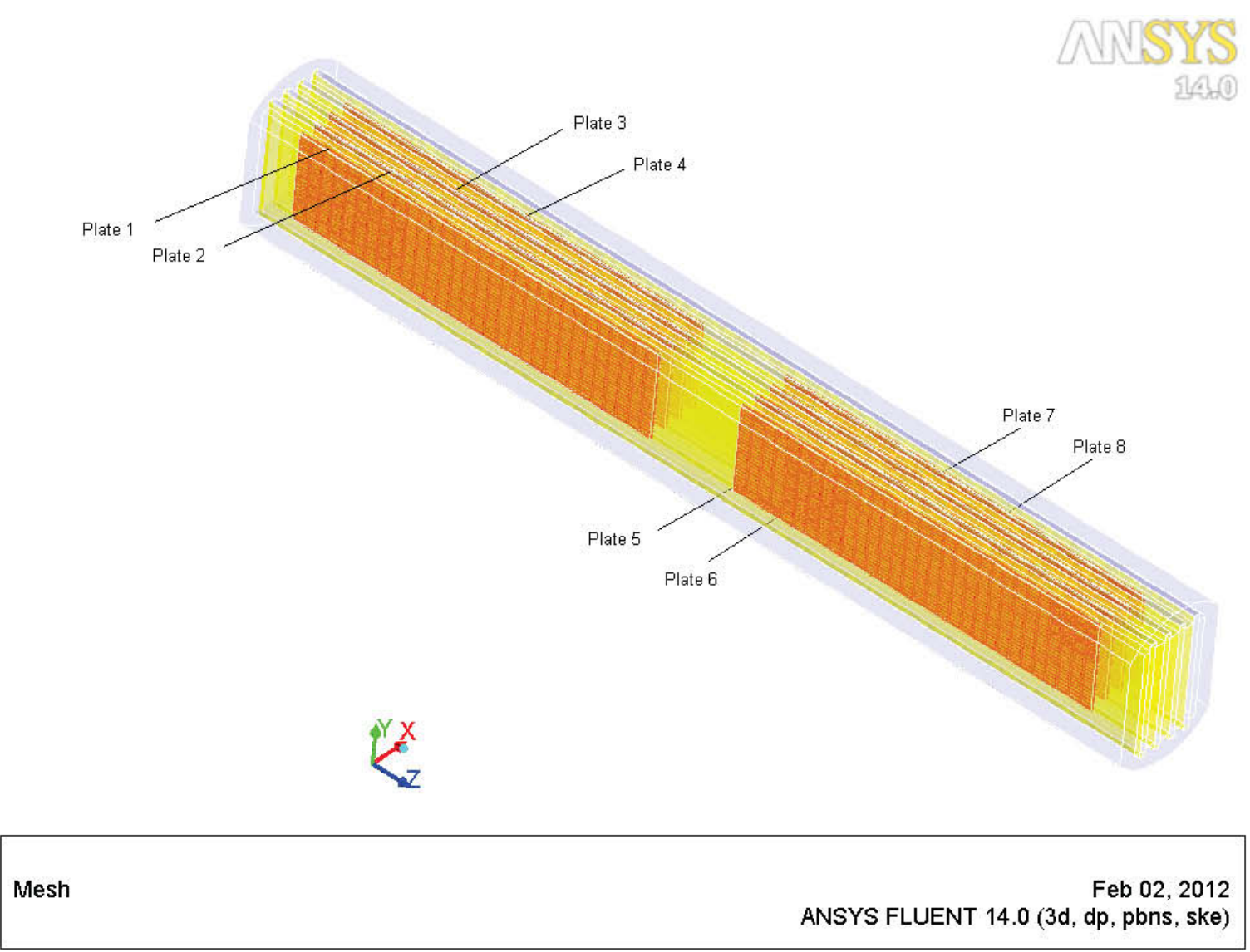

Figure 47. Model geometry.

CFD simulations of plate-surface temperature and heat flux at the beginning of irradiation are shown in Figure 48 and Figure 49. Plates 1 and 5 have the highest fission power since they face core center. Peaks in fission power occur at the edges of the fuel foil. The peak value of heat flux occurs at the leading edge of plate 1 since the top edge of the fuel foil is closest to core mid-plane. The peak value of temperature occurs at the trailing edge of plate 5 since coolant temperature is greatest at the bottom edge. The peak values of temperature and heat flux are $137^{\circ} \mathrm{C}$ and $574 \mathrm{~W} / \mathrm{cm}^{2}$. 


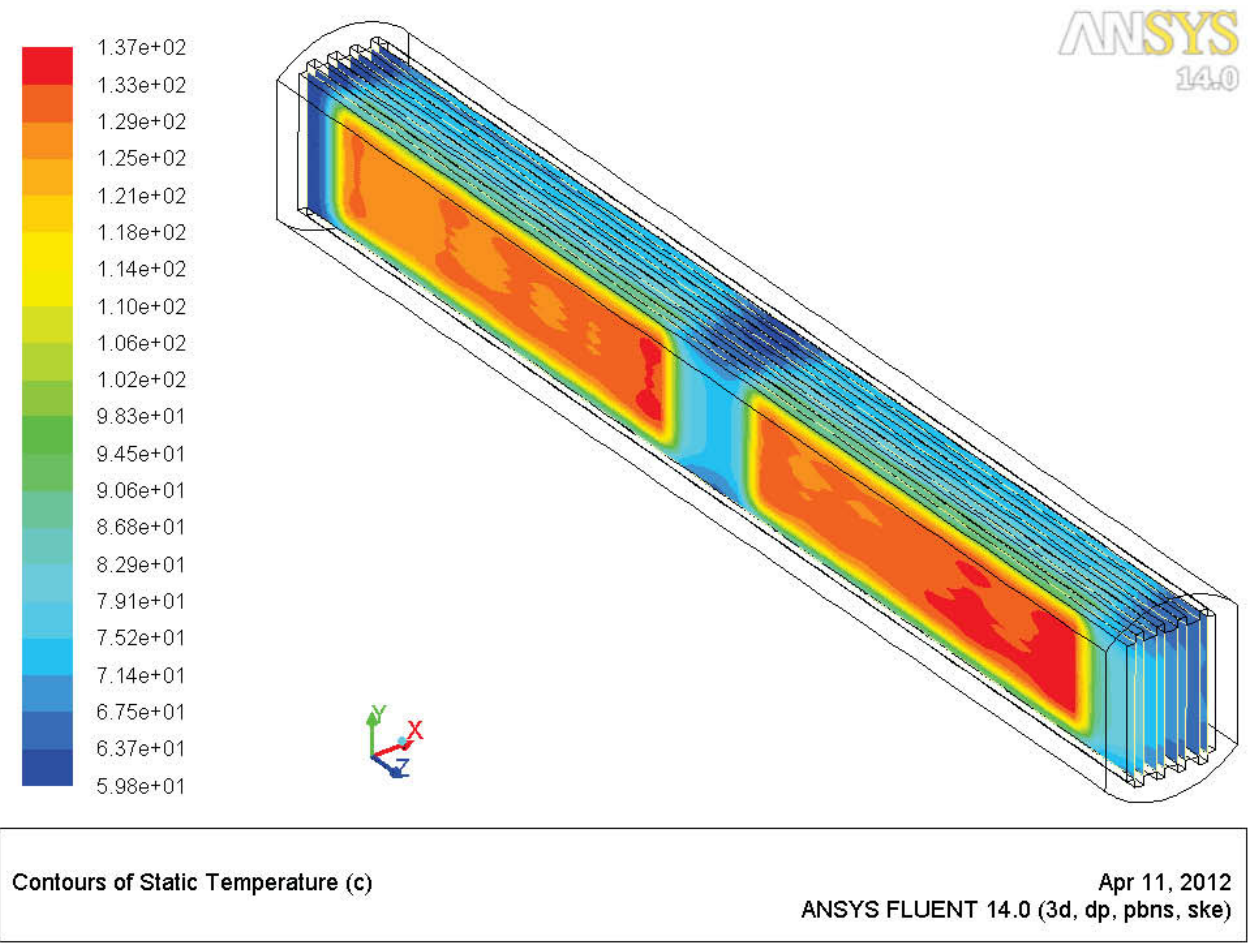

Figure 48. Plate surface temperature.

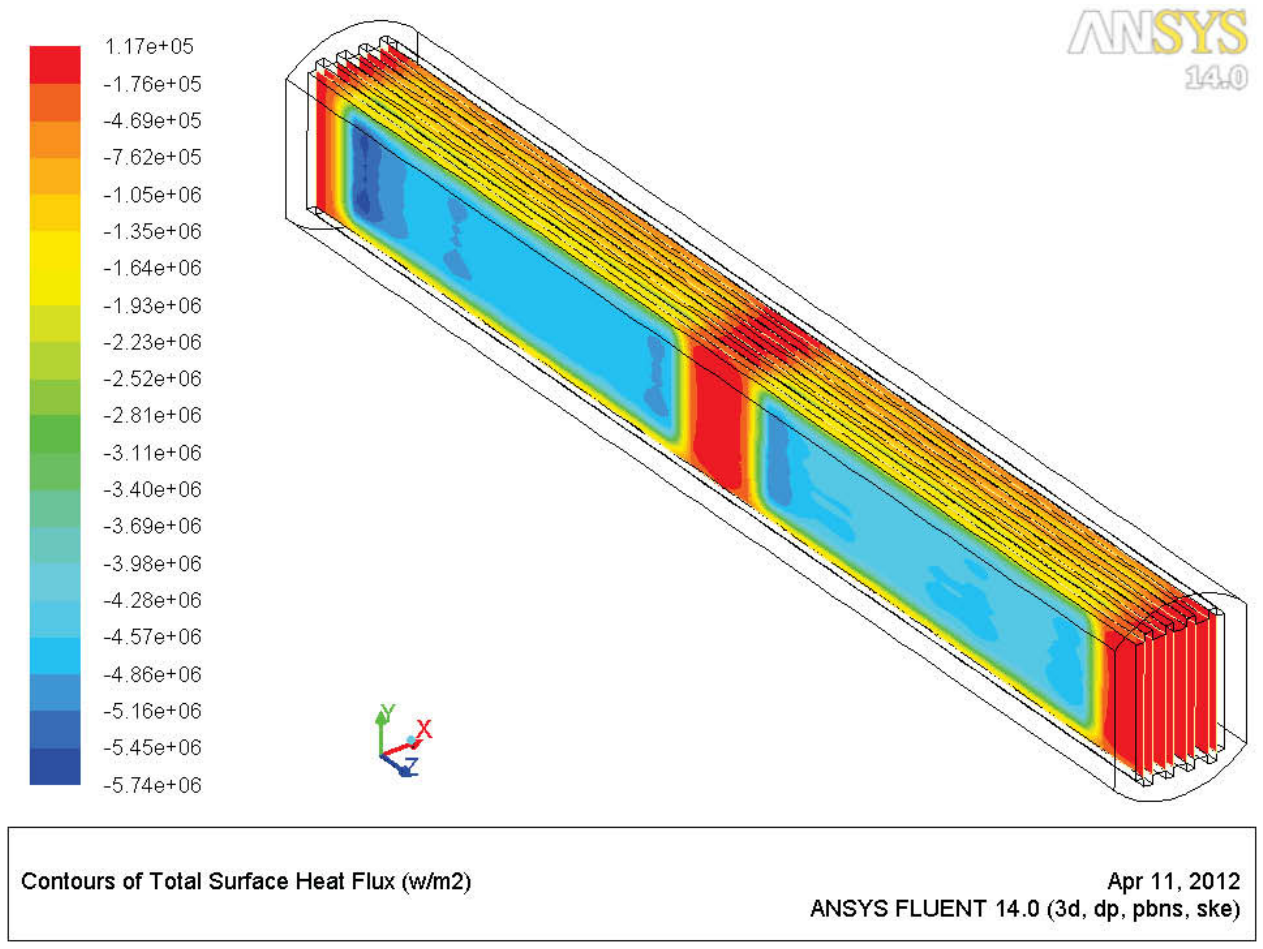

Figure 49. Plate surface heat flux.

CFD simulations of coolant temperature and fuel-centerline temperature at the beginning of irradiation are shown in Figure 50 and Figure 51. The peak value of fuel centerline temperature occurs at the leading and trailing edges of plates 1 and 5 where fission power is greatest. The peak value of coolant 
temperature occurs at the trailing edge of plate 5. The peak values of coolant temperature and fuel centerline temperature are $71^{\circ} \mathrm{C}$ and $188^{\circ} \mathrm{C}$.

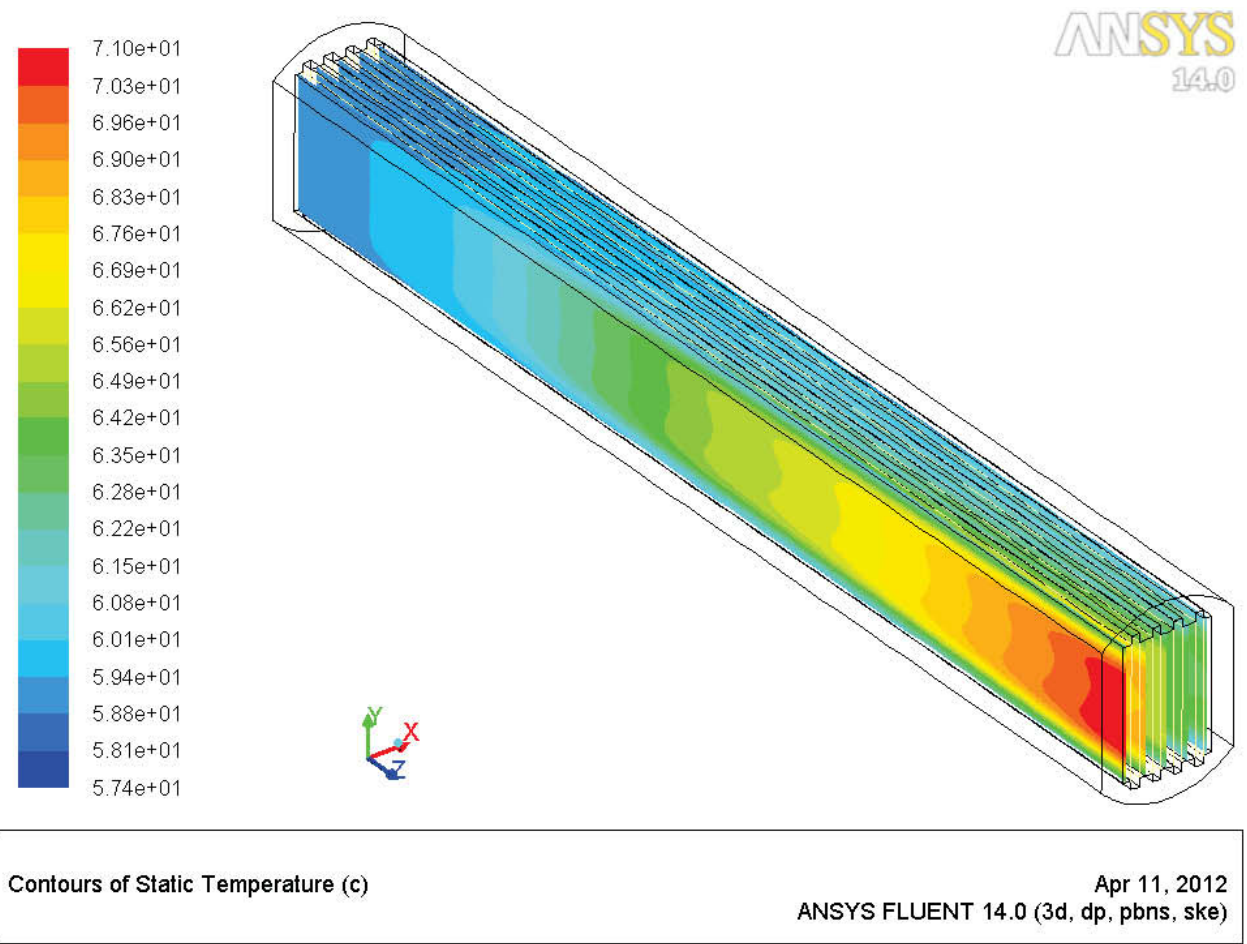

Figure 50. Coolant temperature.

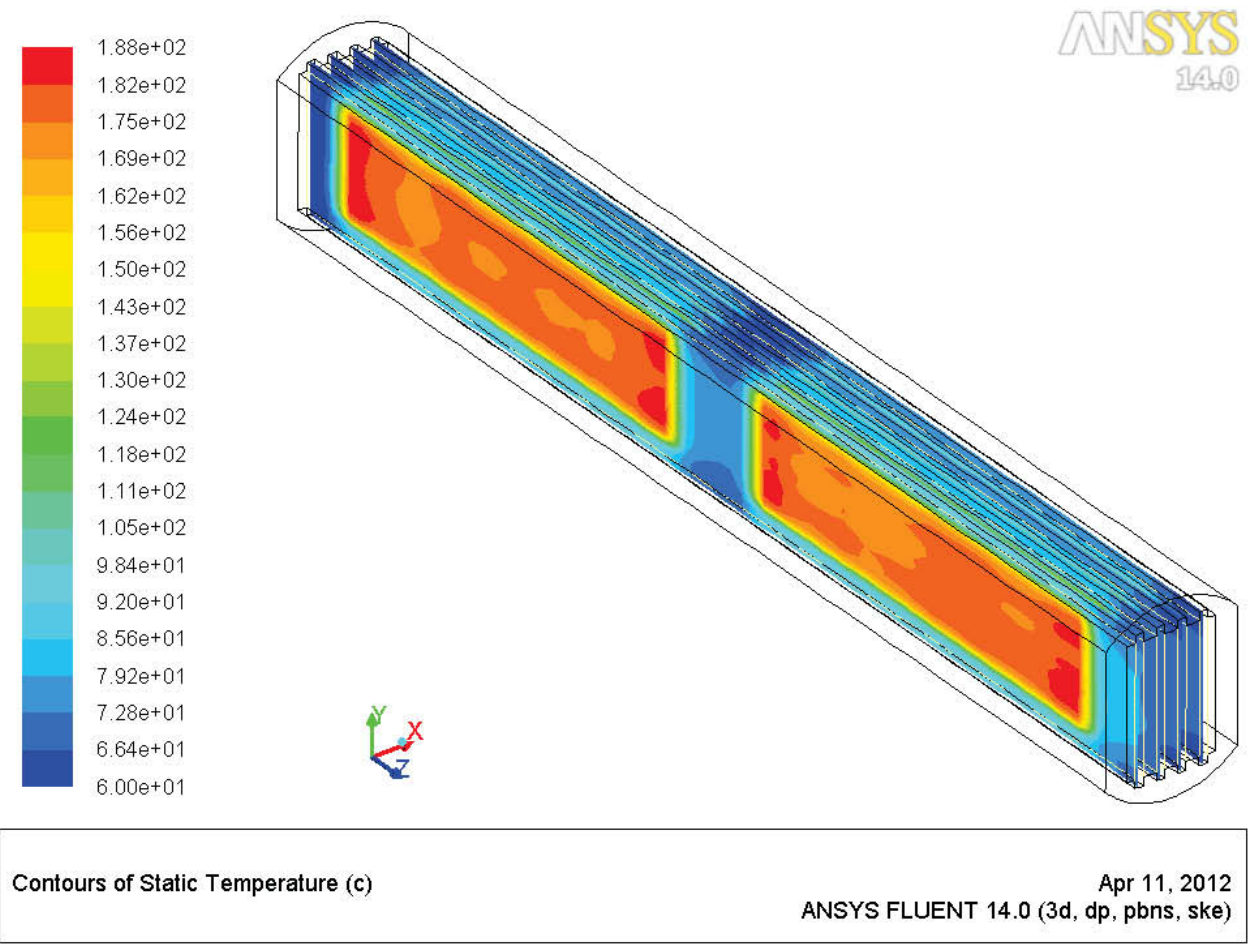

Figure 51. Fuel centerline temperature. 
The average and peak values of temperature and heat flux at the surfaces of plate 1, facing toward and away from core center, as a function of irradiation time are shown in Figure 52 and Figure 53. Both variables decrease during the cycle due to fuel burnup. Heat flux is greater and temperature is less at the oxide/coolant interface facing away from core center because coolant flow is higher in that channel.

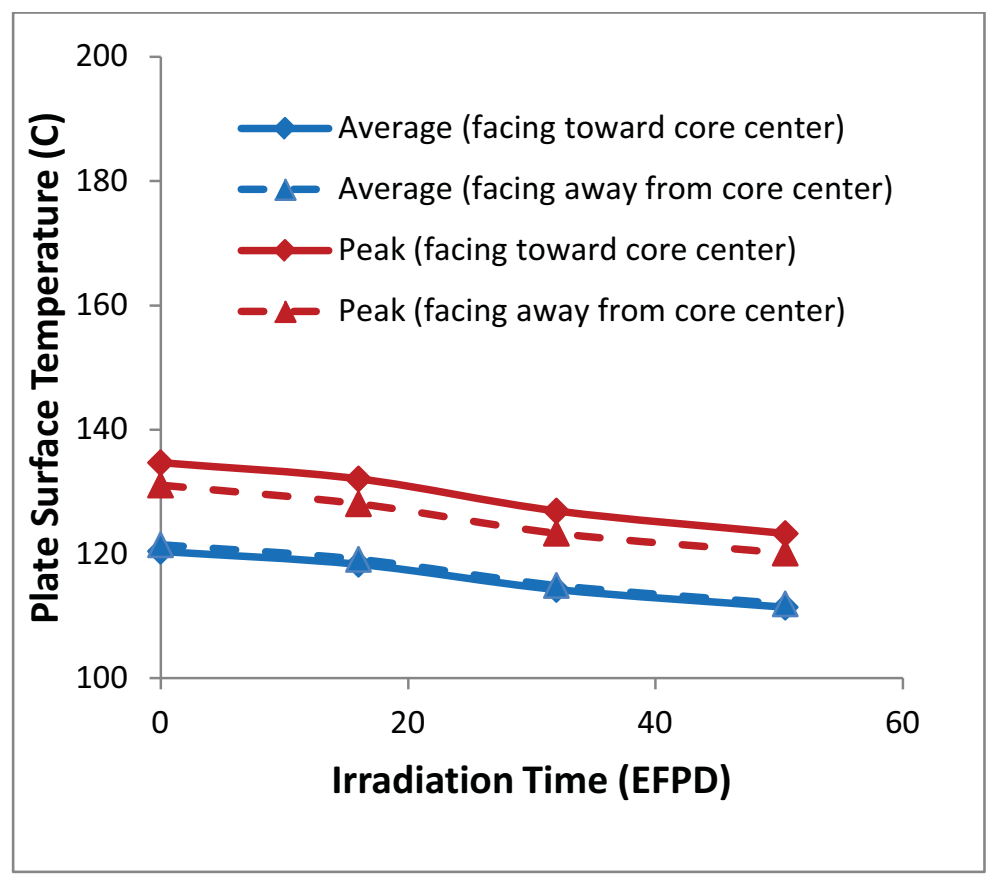

Figure 52. Plate 1 (L1P772) surface temperature.

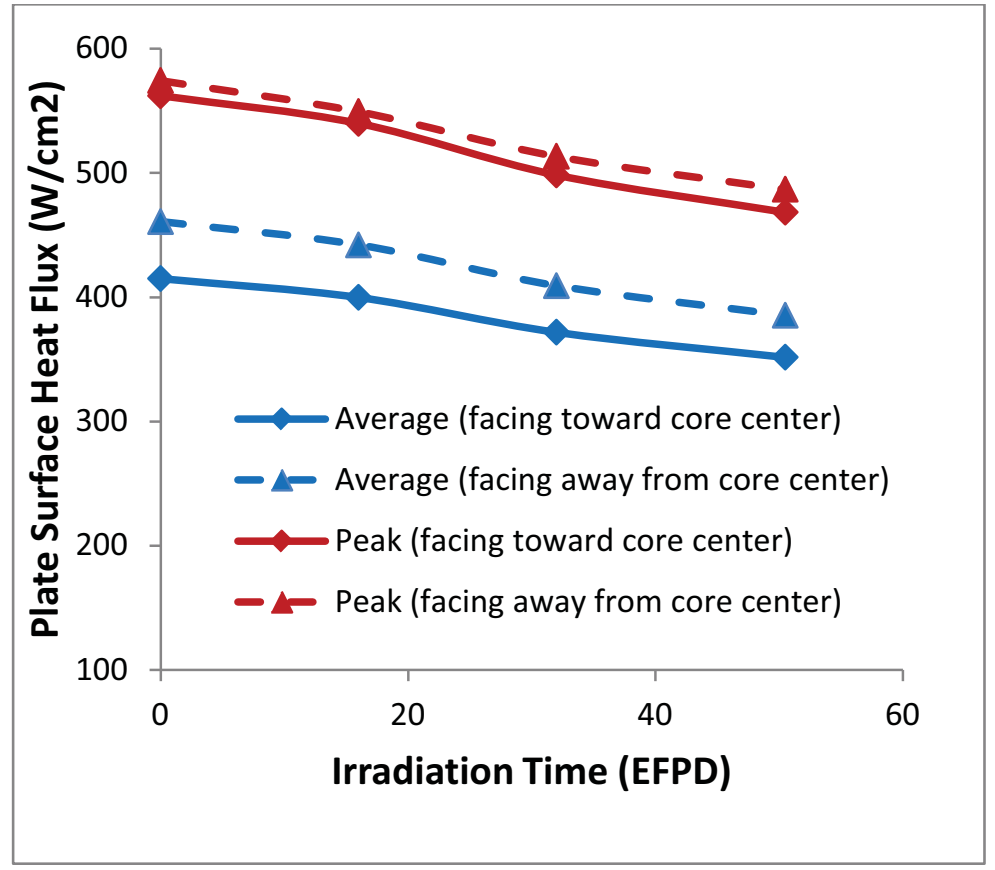

Figure 53. Plate 1 (L1P772) surface heat flux.

The average and peak values of fuel centerline temperature are shown in Figure 54. Fuel centerline temperature increases during the cycle because oxide growth and fuel swelling increase the thermal 
resistance of the plate. Similar behavior occurs for temperature at the fuel/cladding and cladding/oxide interfaces, as shown in Figure 55 and Figure 56.

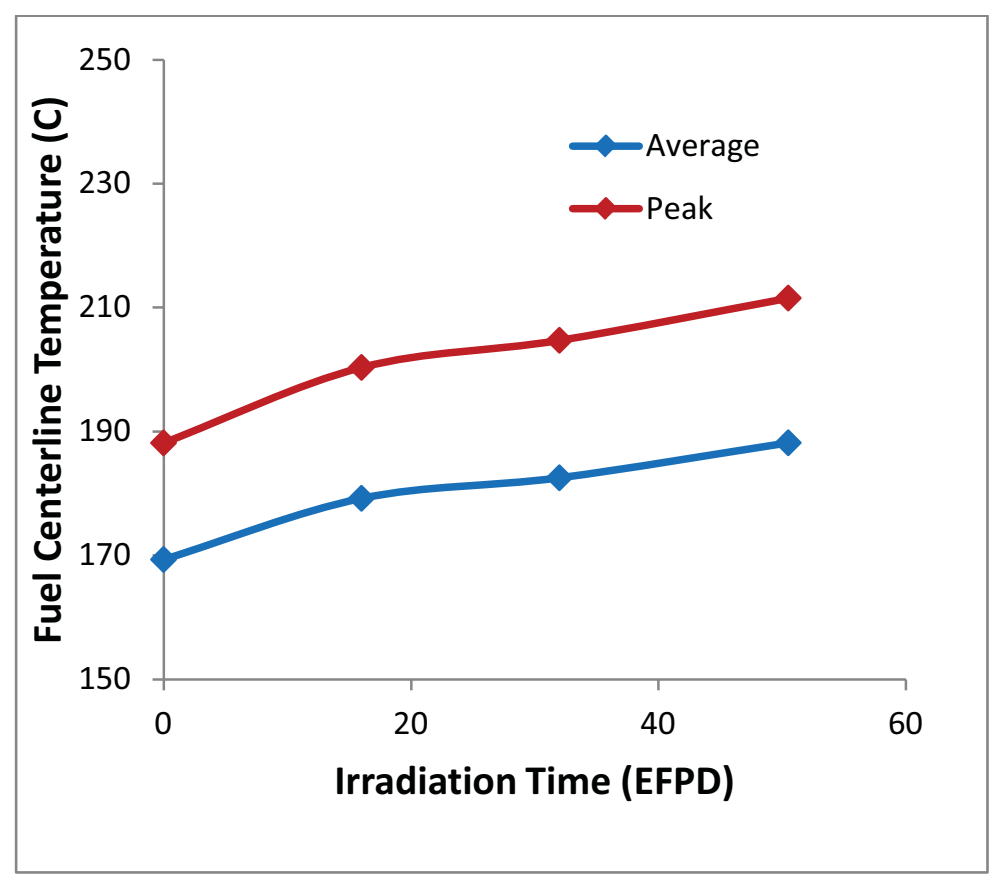

Figure 54. Plate 1 (L1P772) fuel centerline temperature.

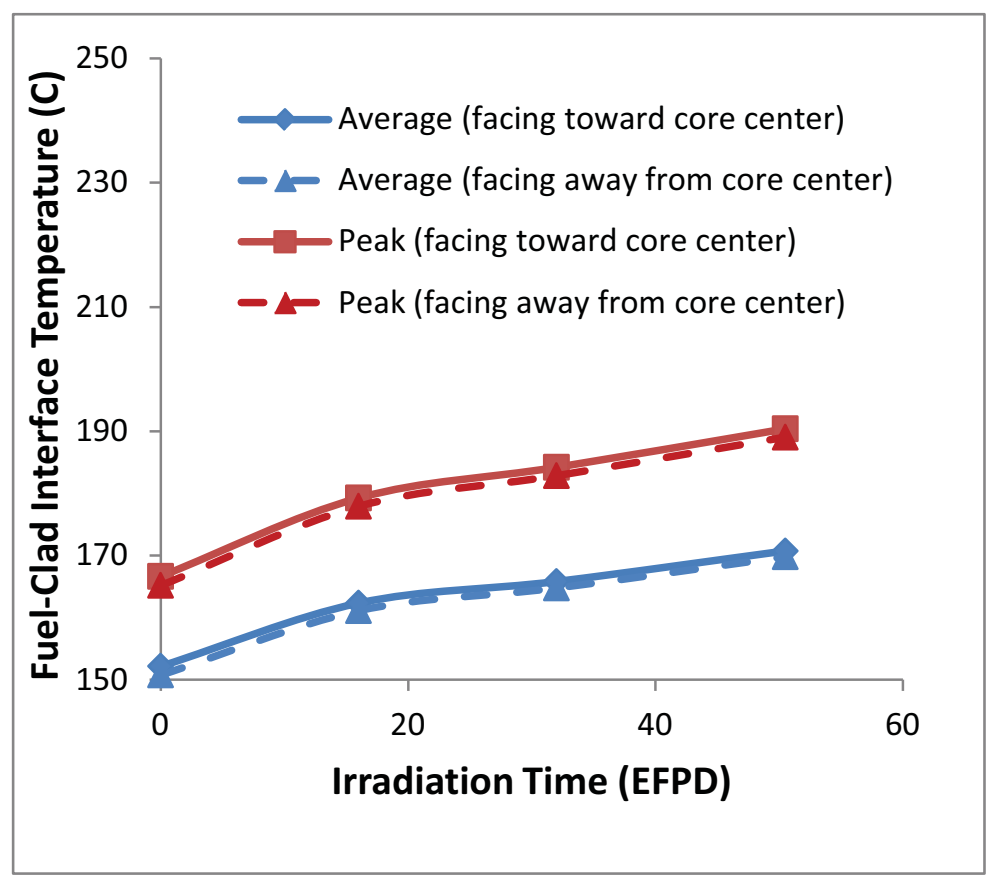

Figure 55. Plate 1 (L1P772) fuel/cladding interface temperature. 


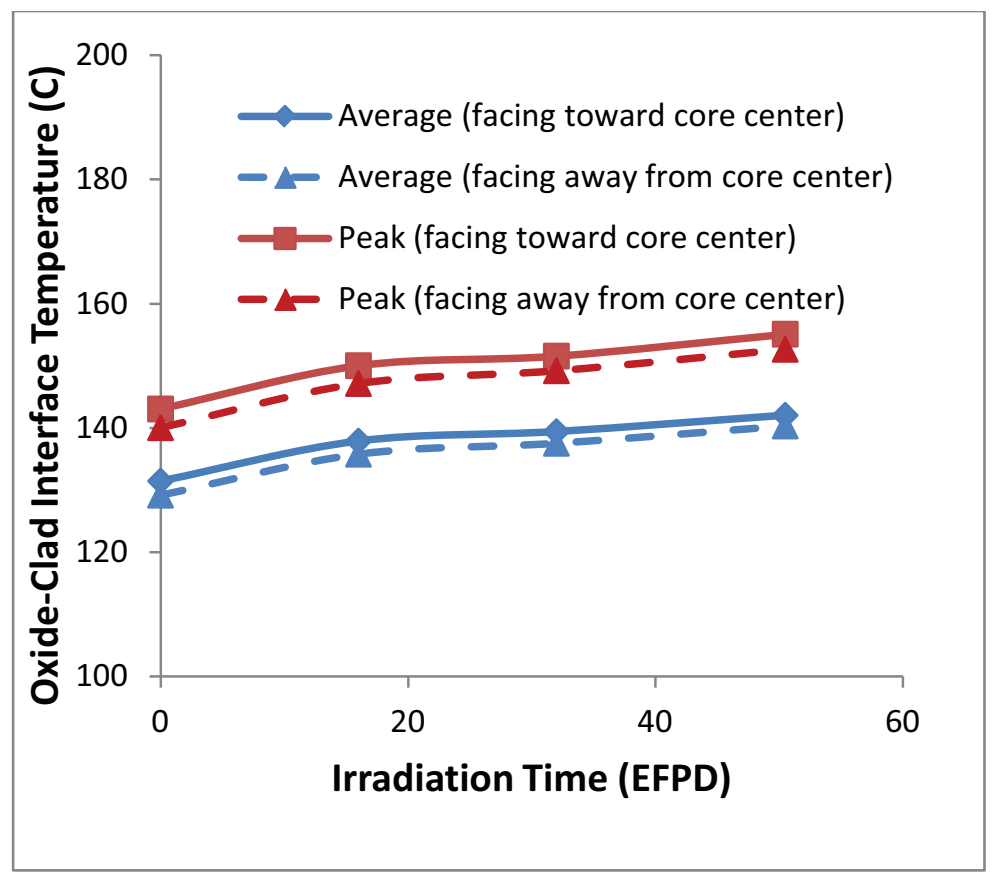

Figure 56. Plate 1 (L1P772) cladding/oxide interface temperature.

The largest temperature gradient within the fuel plates occurs in the oxide layer at the location of peak surface heat flux. The interior temperature distribution in plate 1 at the location of peak heat flux, as a function of irradiation time, is shown in Figure 57. An abrupt change in the temperature gradient occurs at the oxide/clad and clad/fuel interfaces due to the large difference in thermal conductivity of the layers. The maximum temperature gradient in the oxide, clad, and fuel layers is approximately $2500^{\circ} \mathrm{C} / \mathrm{mm}$, $30^{\circ} \mathrm{C} / \mathrm{mm}$, and $400^{\circ} \mathrm{C} / \mathrm{mm}$, respectively.

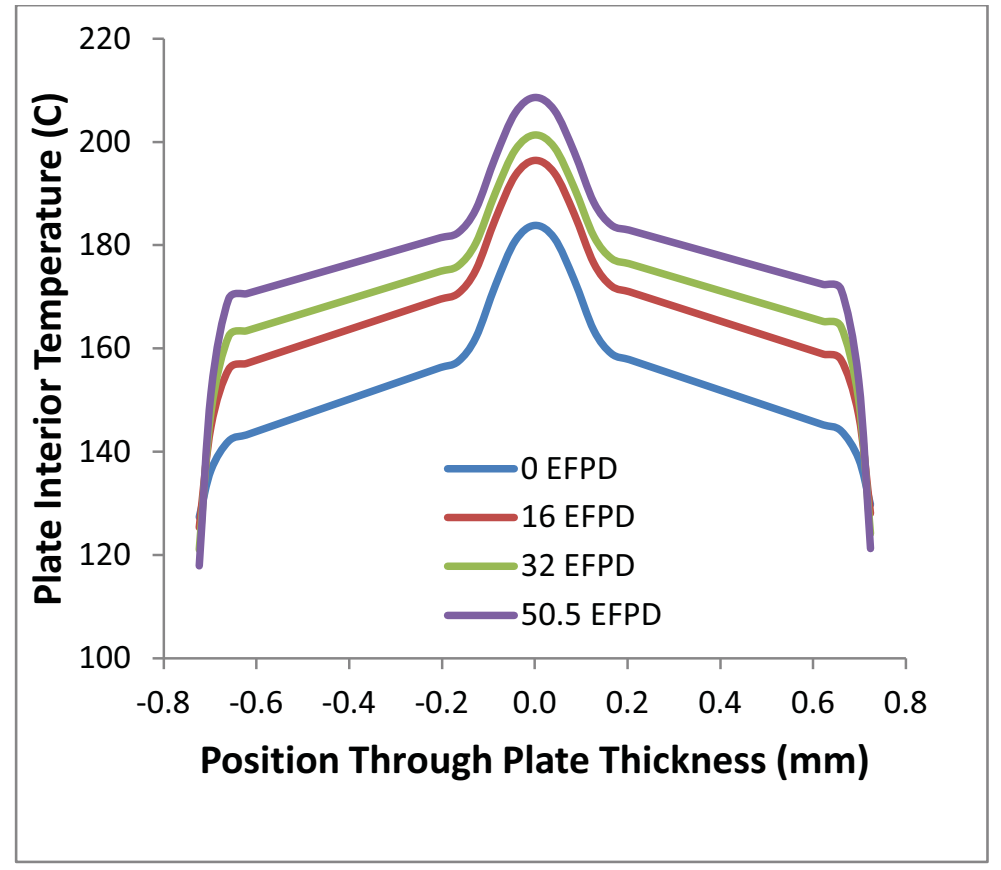

Figure 57. Plate 1 (L1P772) through-thickness temperature. 


\subsubsection{Results of RERTR-12 Capsule X2}

In this section, the results of CFD analysis of RERTR-12 capsule X2 are presented. The model geometry of a capsule containing eight plates is identical to that shown in Figure 47. Plates are numbered D-1 through D-8 to denote capsule D in the RERTR capsule stack-up in the core. The plates IDs corresponding to plates D-1 through D-8 are L1P754, L1P755, L1P593, L1P462, L1P756, L1P758, L1P595, and L1P463.

CFD simulations of plate-surface temperature and heat flux at the beginning of irradiation are shown in Figure 58 and Figure 59. Plates 1 and 5 have the highest fission power since they face core center. Peaks in fission power occur at the edges of the fuel foil. The peak value of heat flux occurs at the leading edge of plate 1 since the top edge of the fuel foil is closest to core mid-plane. The peak value of temperature occurs at the trailing edge of plate 1 since coolant temperature is greatest at the bottom edge. The peak values of temperature and heat flux are $130^{\circ} \mathrm{C}$ and $514 \mathrm{~W} / \mathrm{cm}^{2}$.

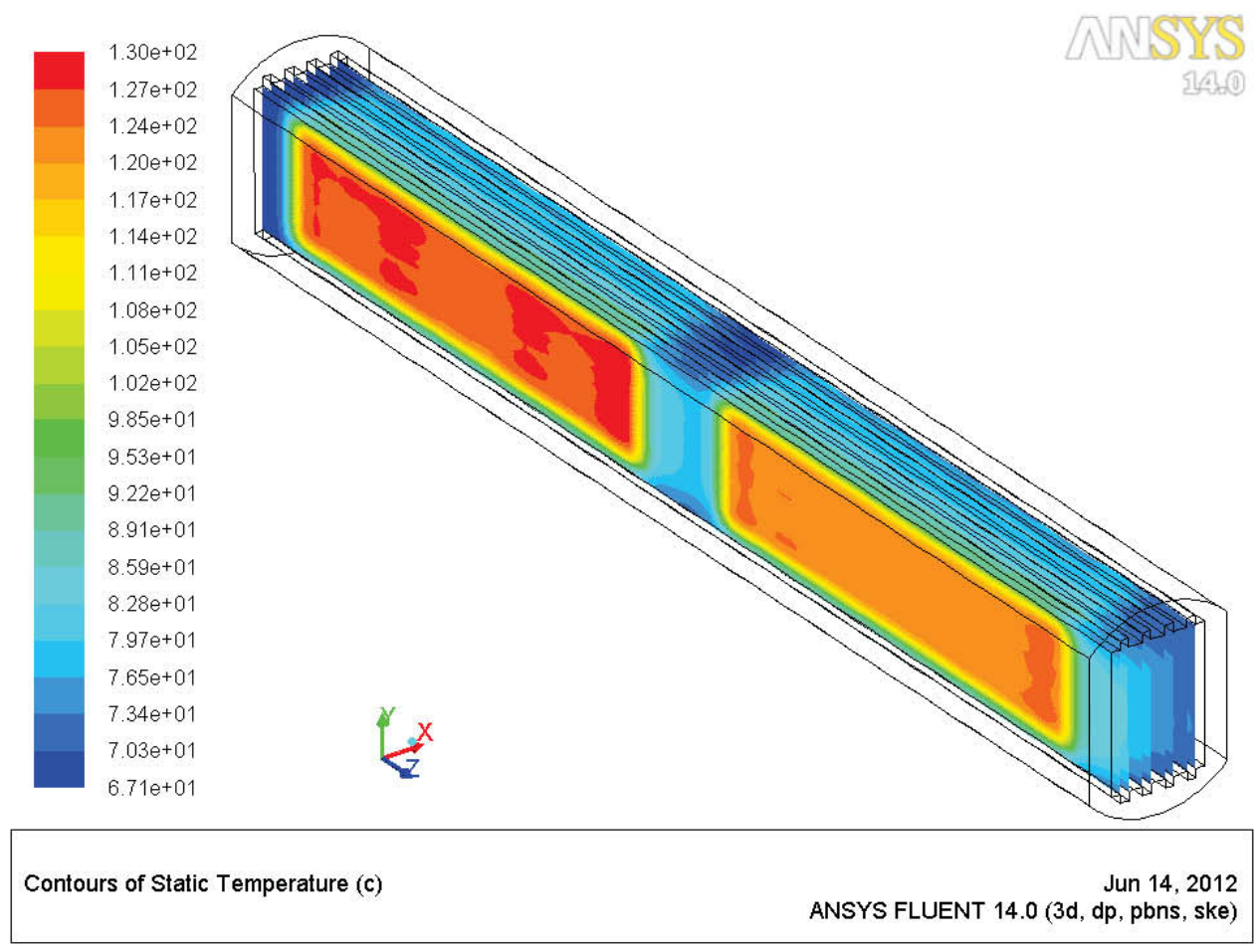

Figure 58. Plate surface temperature. 


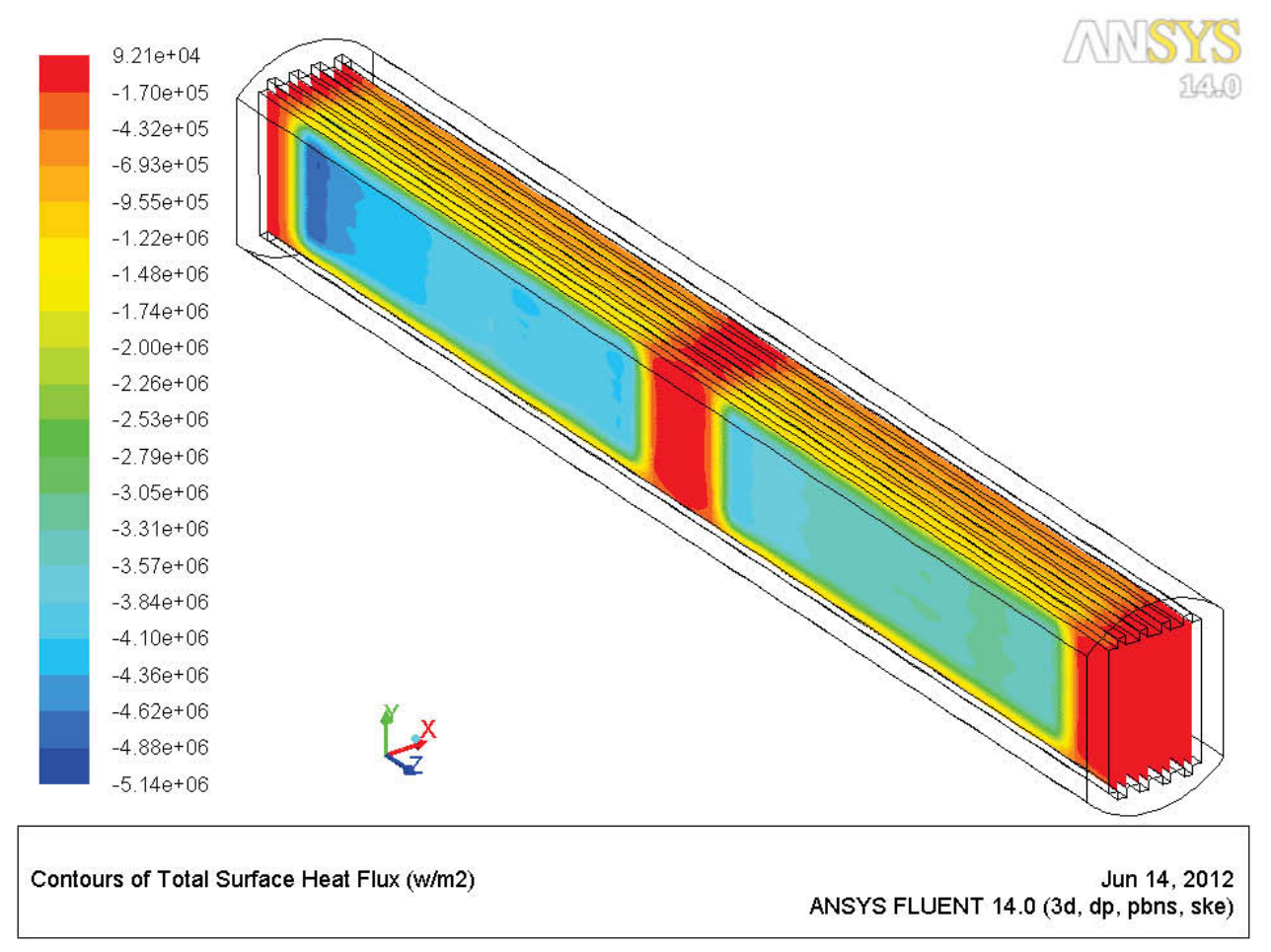

Figure 59. Plate surface heat flux.

CFD simulations of coolant temperature and fuel-centerline temperature at the beginning of irradiation are shown in Figure 60 and Figure 61. The peak value of fuel centerline temperature occurs at the leading edge of plate 1 where fission power is greatest. The peak value of coolant temperature occurs at the trailing edge of plate 5. The peak values of coolant temperature and fuel centerline temperature are $76^{\circ} \mathrm{C}$ and $178^{\circ} \mathrm{C}$. 


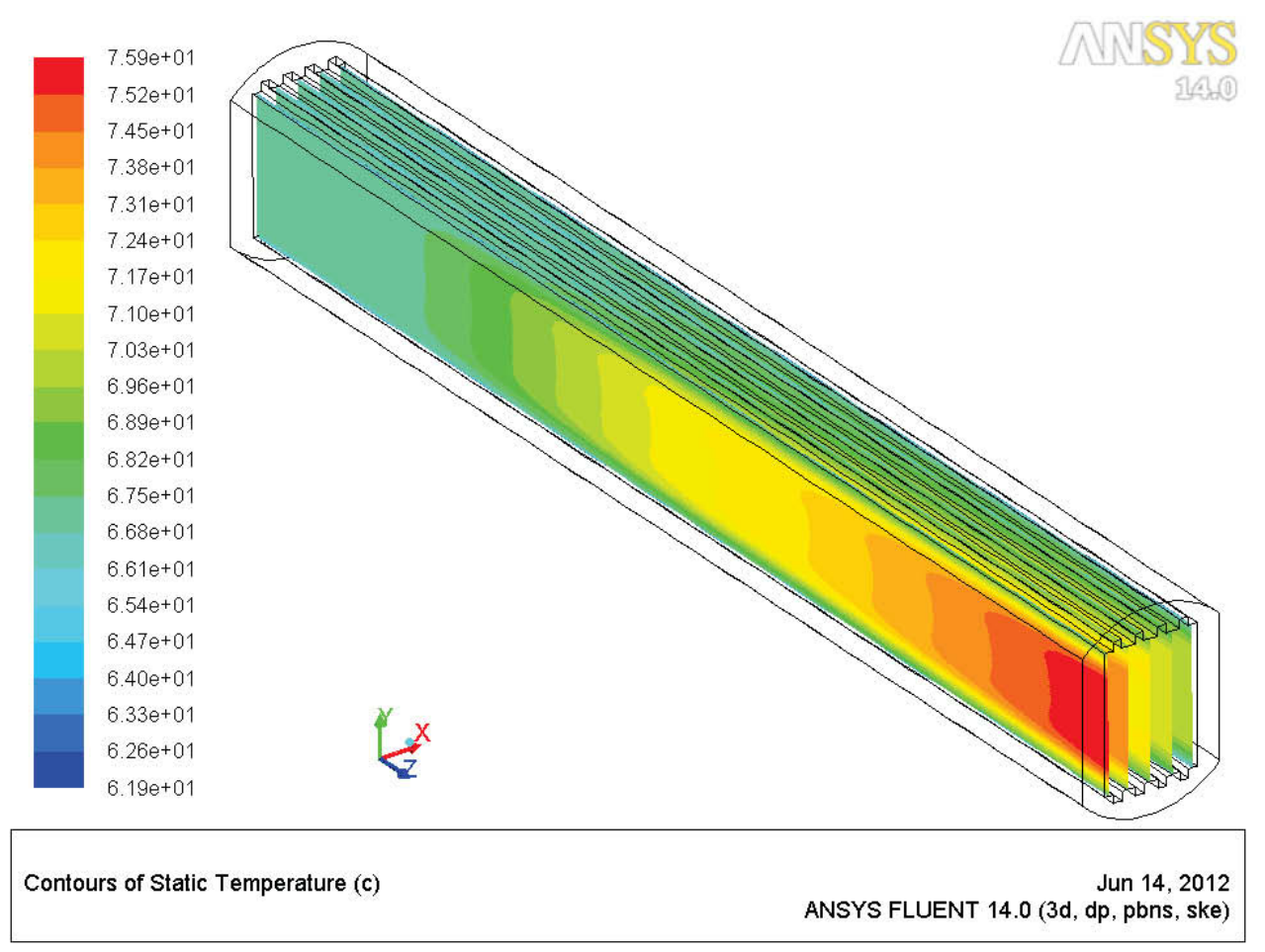

Figure 60. Coolant temperature.

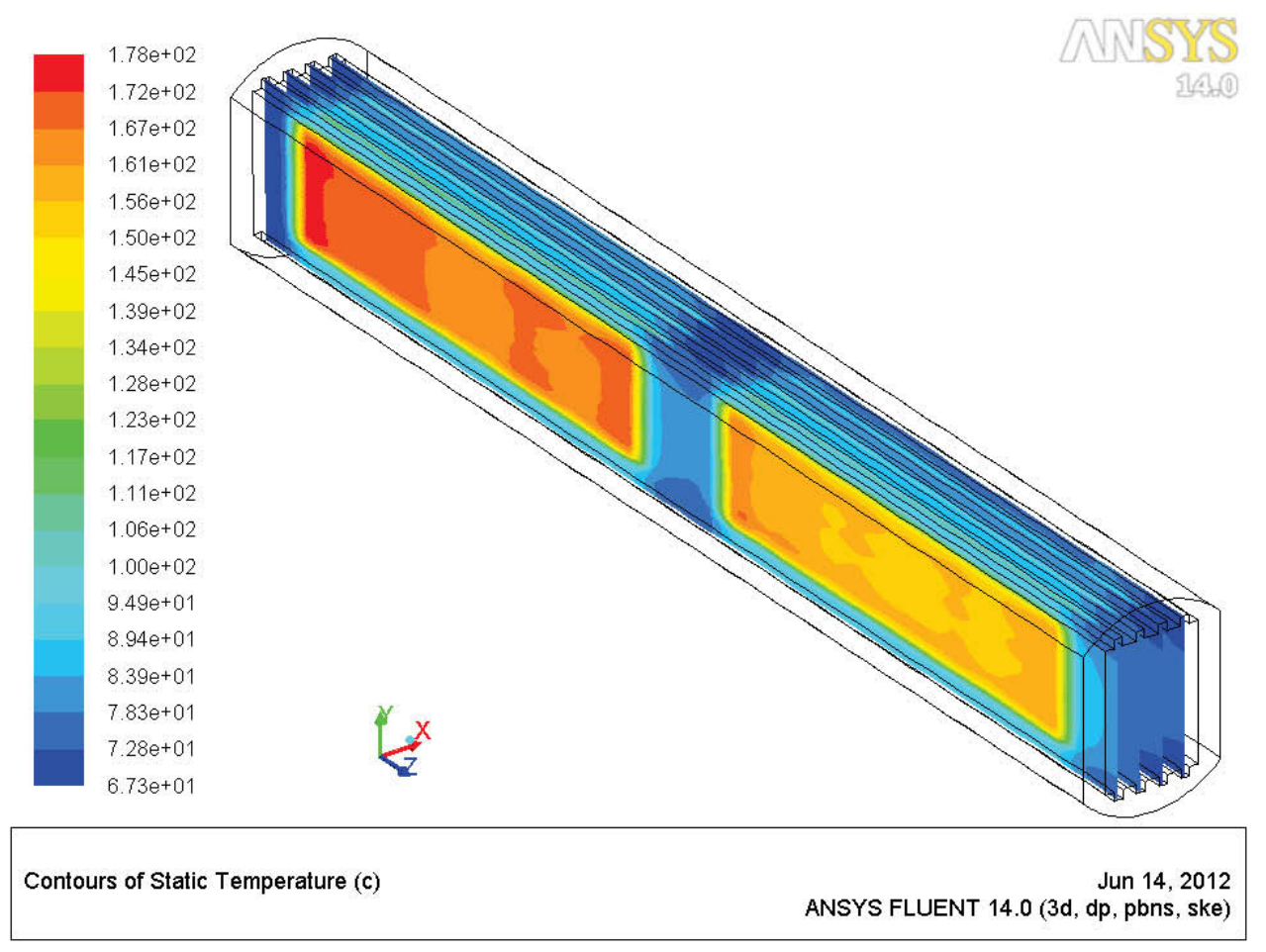

Figure 61. Fuel centerline temperature.

The average and peak values of temperature and heat flux at the surfaces of plate 1, facing toward and away from core center, as a function of irradiation time are shown in Figure 62 and Figure 63. Both 
variables decrease during the cycle due to fuel burnup. Heat flux is greater and temperature is less at the oxide/coolant interface facing away from core center because coolant flow is higher in that channel. An abrupt decrease in temperature and heat flux occurs at the beginning of the second cycle due to the difference between the beginning of cycle position and end of cycle position of the outer shims.

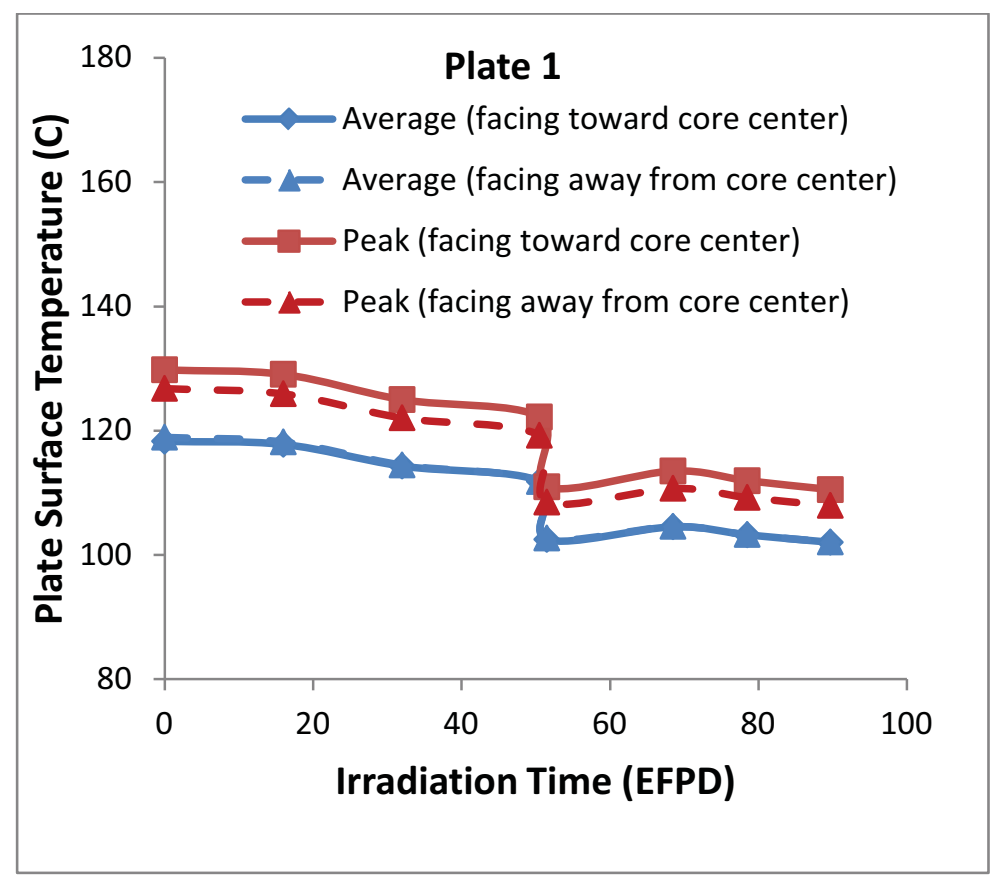

Figure 62. Plate 1 (L1P754) surface temperature.

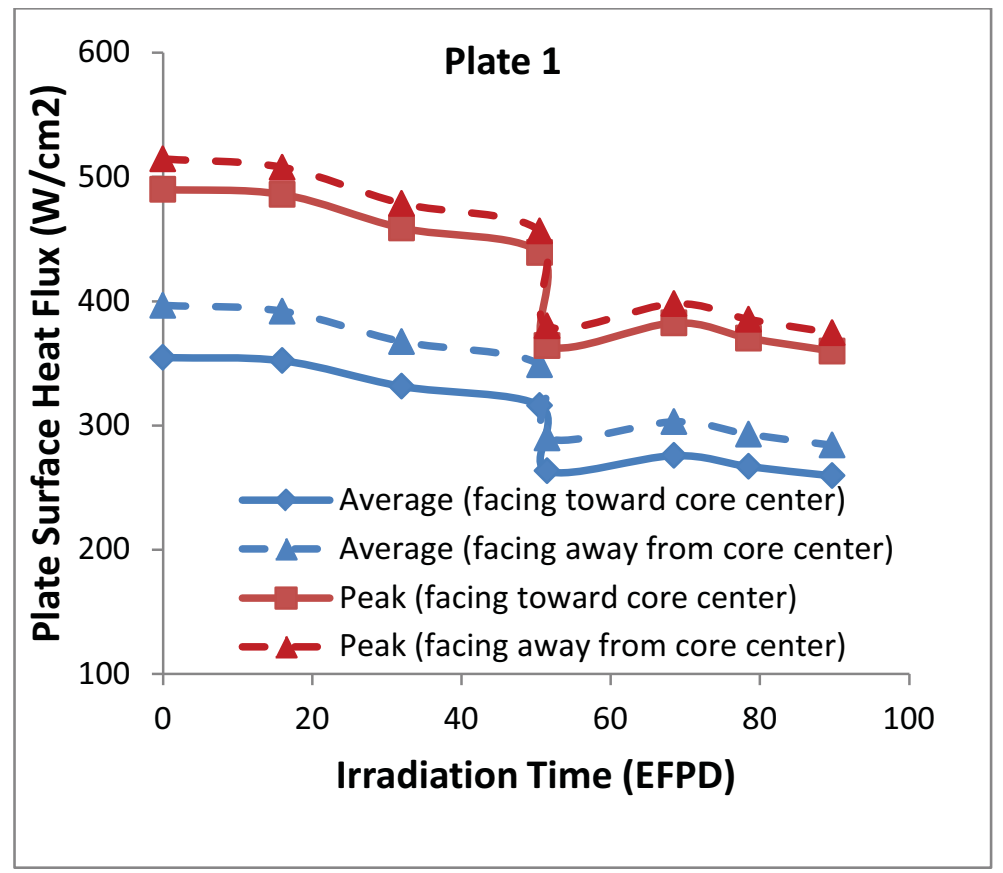

Figure 63. Plate 1 (L1P754) surface heat flux.

The average and peak values of fuel centerline temperature are shown in Figure 64. Fuel centerline temperature increases during each cycle because oxide growth and fuel swelling increase the thermal 
resistance of the plate. Similar behavior occurs for temperature at the fuel/cladding and cladding/oxide interfaces, as shown in Figure 65 and Figure 66. An abrupt decrease in temperature occurs at the beginning of the second cycle due the significant reduction in fission power at the start of that cycle.

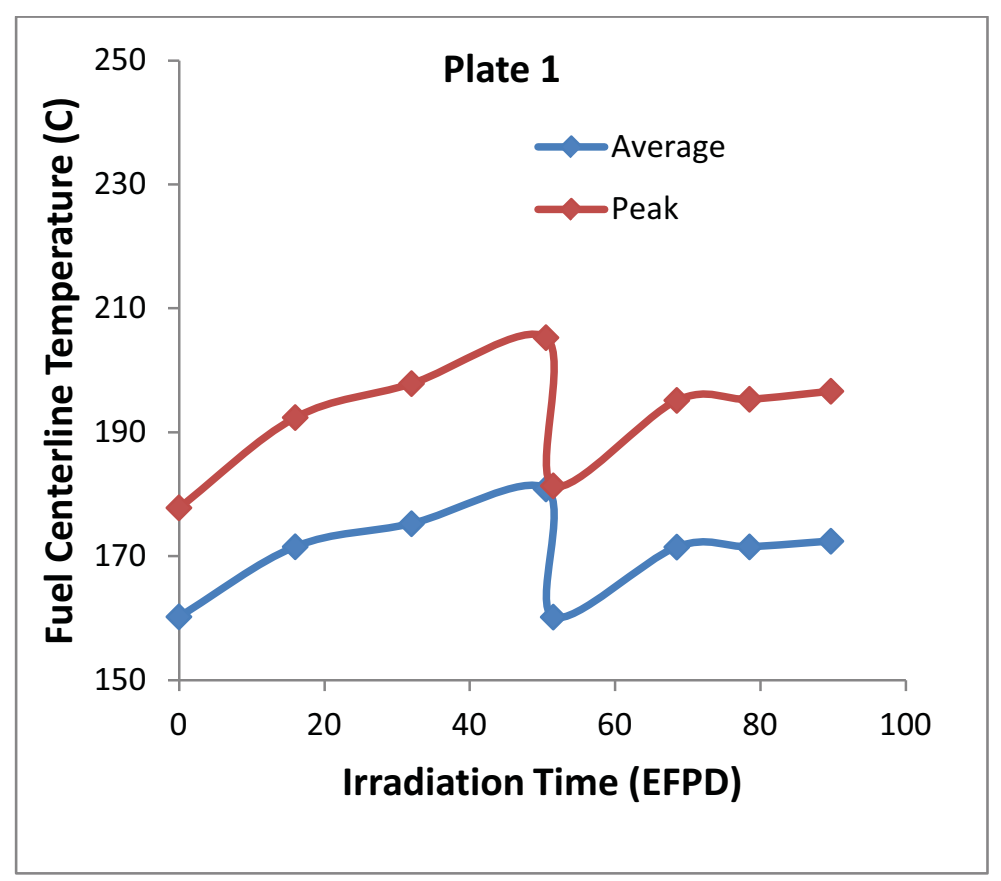

Figure 64. Plate 1 (L1P754) fuel centerline temperature.

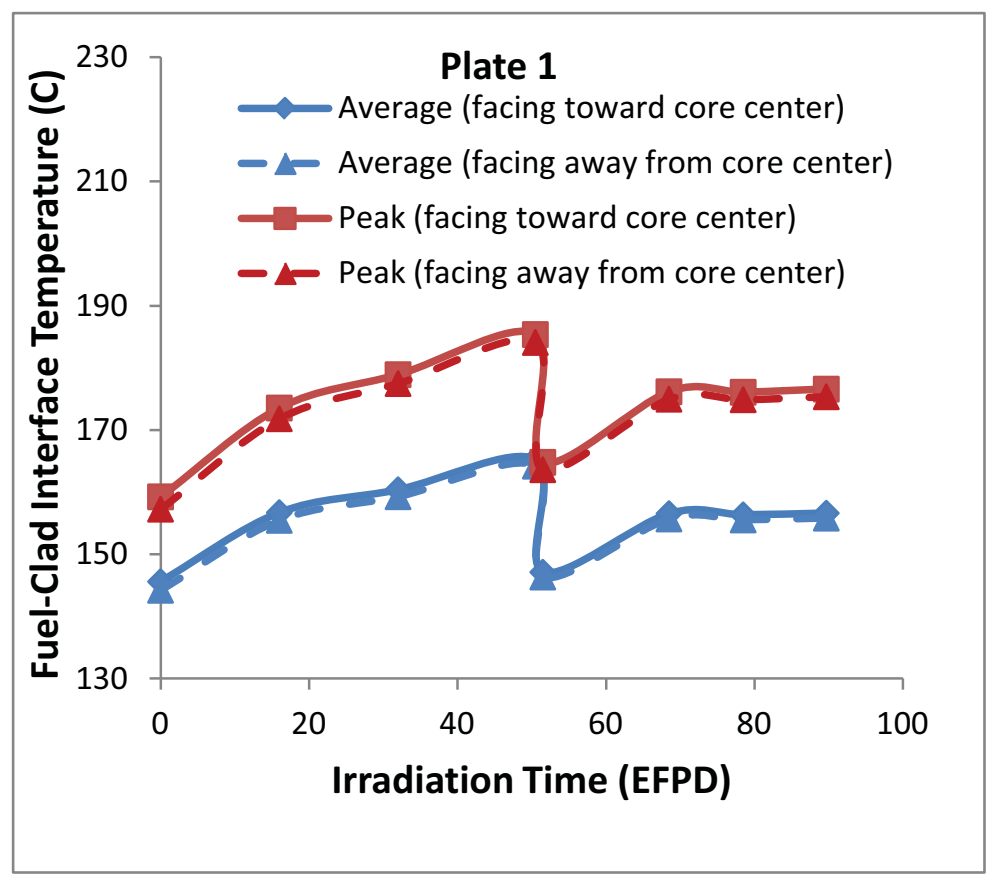

Figure 65. Plate 1 (L1P754) fuel/cladding interface temperature. 


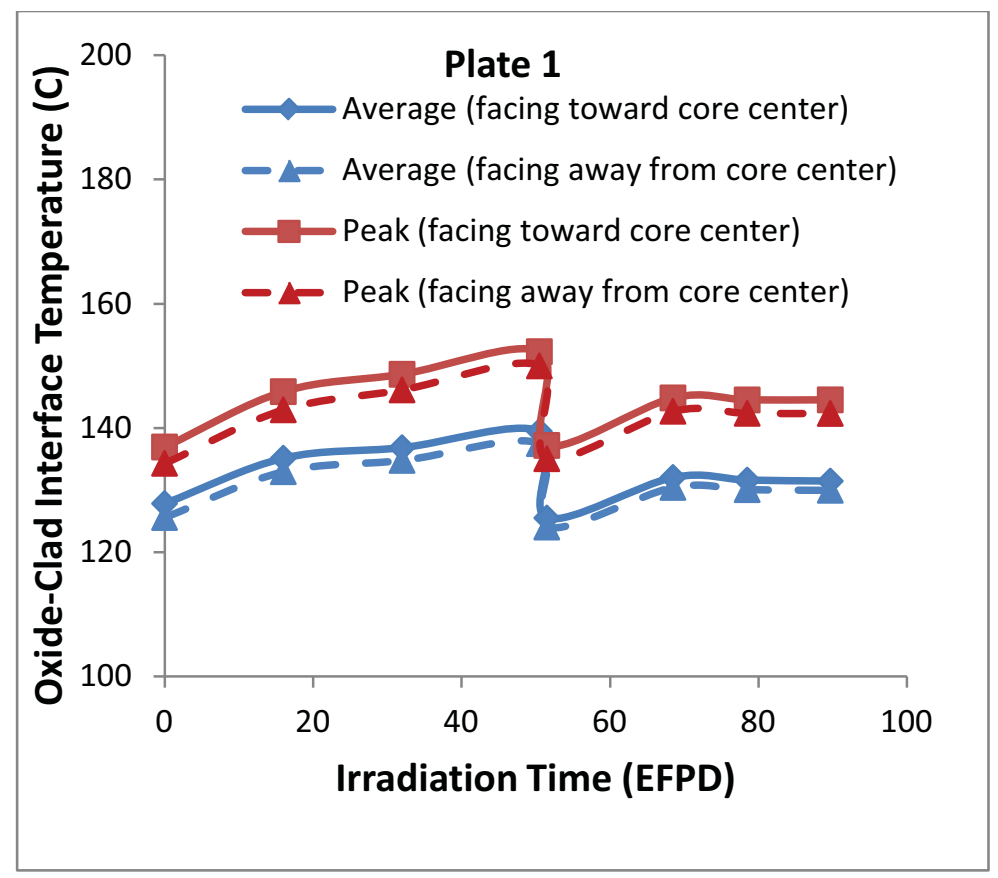

Figure 66. Plate 1 (L1P754) cladding/oxide interface temperature.

The largest temperature gradient within the fuel plates occurs in the oxide layer at the location of peak surface heat flux. The interior temperature distribution in plate 1 at the location of peak heat flux, as a function of irradiation time, is shown in Figure 67. An abrupt change in the temperature gradient occurs at the oxide/clad and clad/fuel interfaces due to the large difference in thermal conductivity of the layers. The maximum temperature gradient in the oxide, clad, and fuel layers is approximately $2300^{\circ} \mathrm{C} / \mathrm{mm}$, $30^{\circ} \mathrm{C} / \mathrm{mm}$, and $400^{\circ} \mathrm{C} / \mathrm{mm}$, respectively. The maximum plate temperature occurs at the end of the first irradiation cycle due to the significant reduction in fission power at the start of the second cycle.

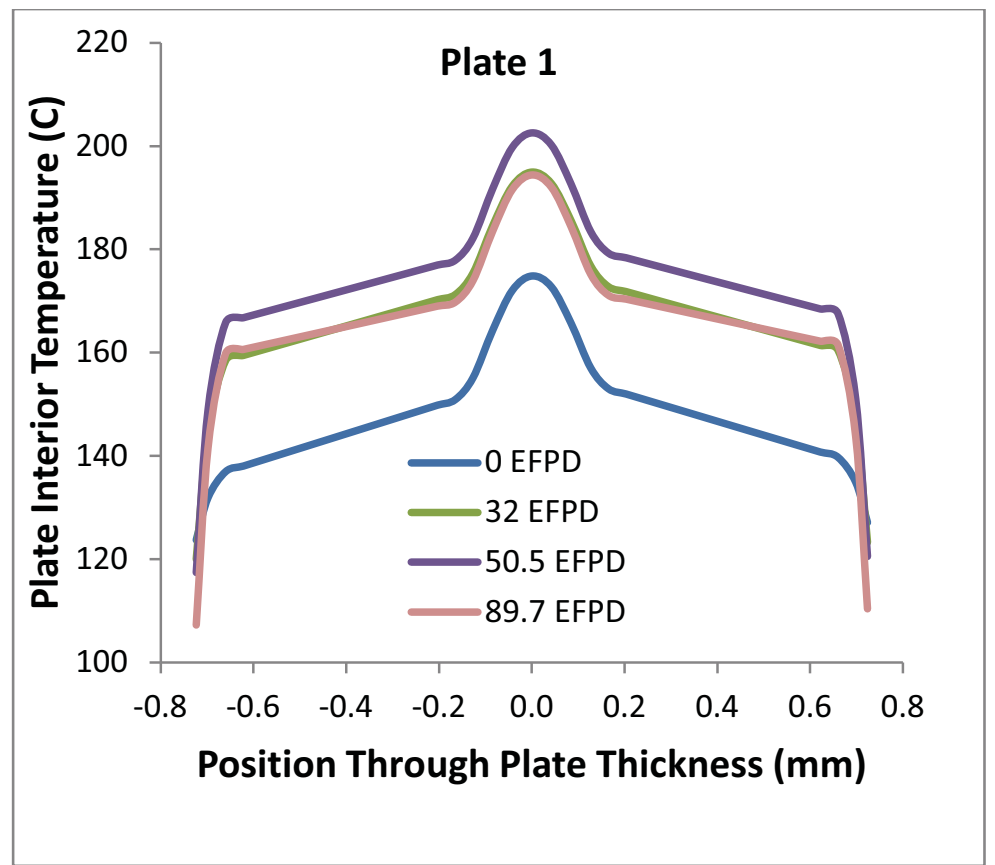

Figure 67. Plate 1 (L1P754) through-thickness temperature. 


\subsubsection{Results of RERTR-12 Capsule X3}

In this section, the results of CFD analysis of RERTR-12 capsule X3 are presented. The model geometry of a capsule containing eight plates is identical to that shown in Figure 47. Plates are numbered B-1 through B-8 to denote capsule B in the RERTR capsule stack-up in the core. The plates IDs corresponding to plates B-1 through B-8 are L1P759, L1P784, L1P596, L1P464, L1P785, L1P786, L1P590, and L1P465.

CFD simulations of plate-surface temperature and heat flux at the beginning of irradiation are shown in Figure 68 and Figure 69. Plates 1 and 5 have the highest fission power since they face core center. Peaks in fission power occur at the edges of the fuel foil. The peak value of heat flux occurs at the trailing edge of plate 5 since the bottom edge of the fuel foil is closest to core mid-plane. The peak value of temperature occurs at the trailing edge of plate 5 since coolant temperature is greatest at the bottom edge. The peak values of temperature and heat flux are $135^{\circ} \mathrm{C}$ and $544 \mathrm{~W} / \mathrm{cm}^{2}$.

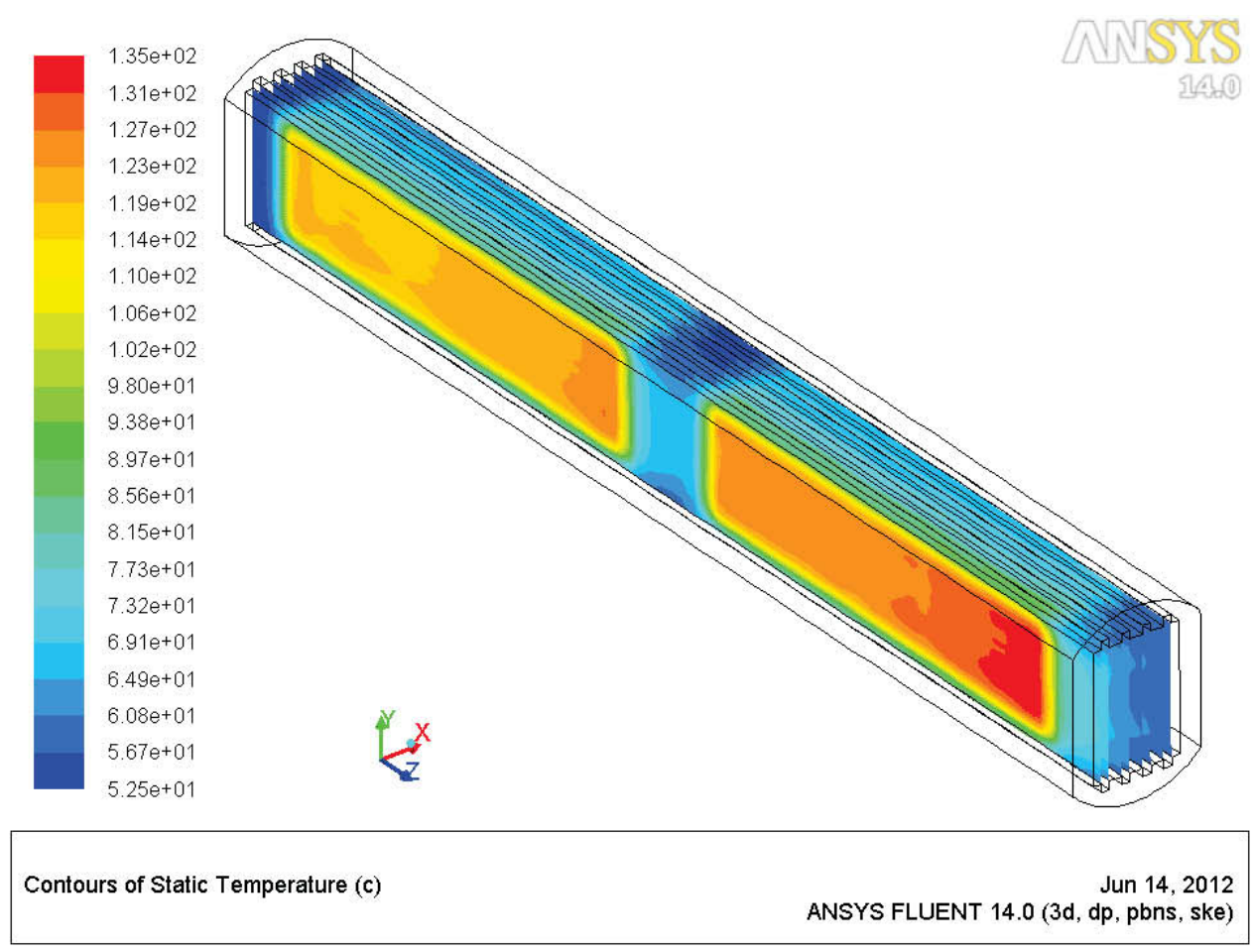

Figure 68. Plate surface temperature. 


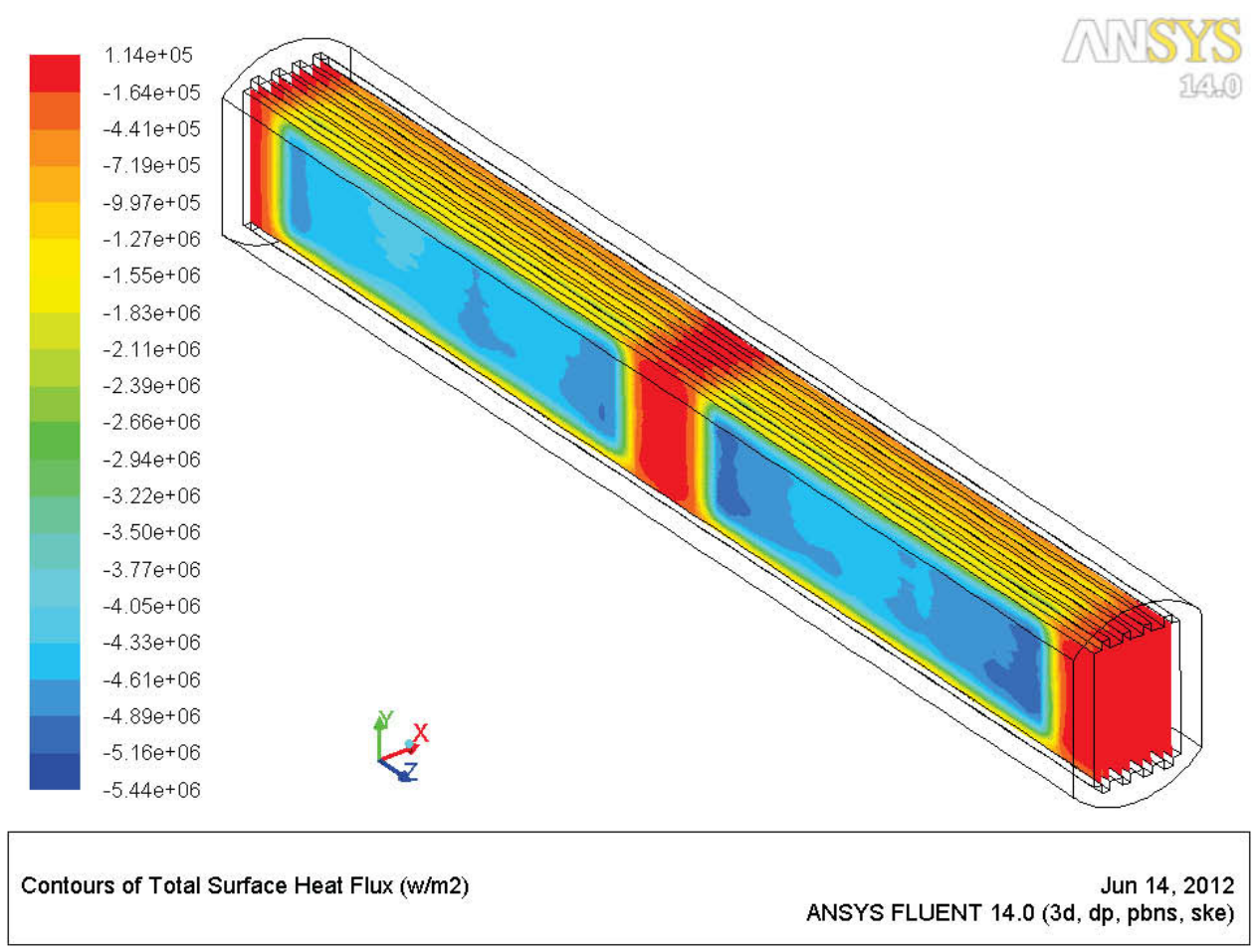

Figure 69. Plate surface heat flux.

CFD simulations of coolant temperature and fuel-centerline temperature at the beginning of irradiation are shown in Figure 70 and Figure 71. The peak value of fuel centerline temperature occurs at the leading and trailing edges of plate 5 where fission power is greatest. The peak value of coolant temperature occurs at the trailing edge of plate 5. The peak values of coolant temperature and fuel centerline temperature are $64^{\circ} \mathrm{C}$ and $187^{\circ} \mathrm{C}$. 


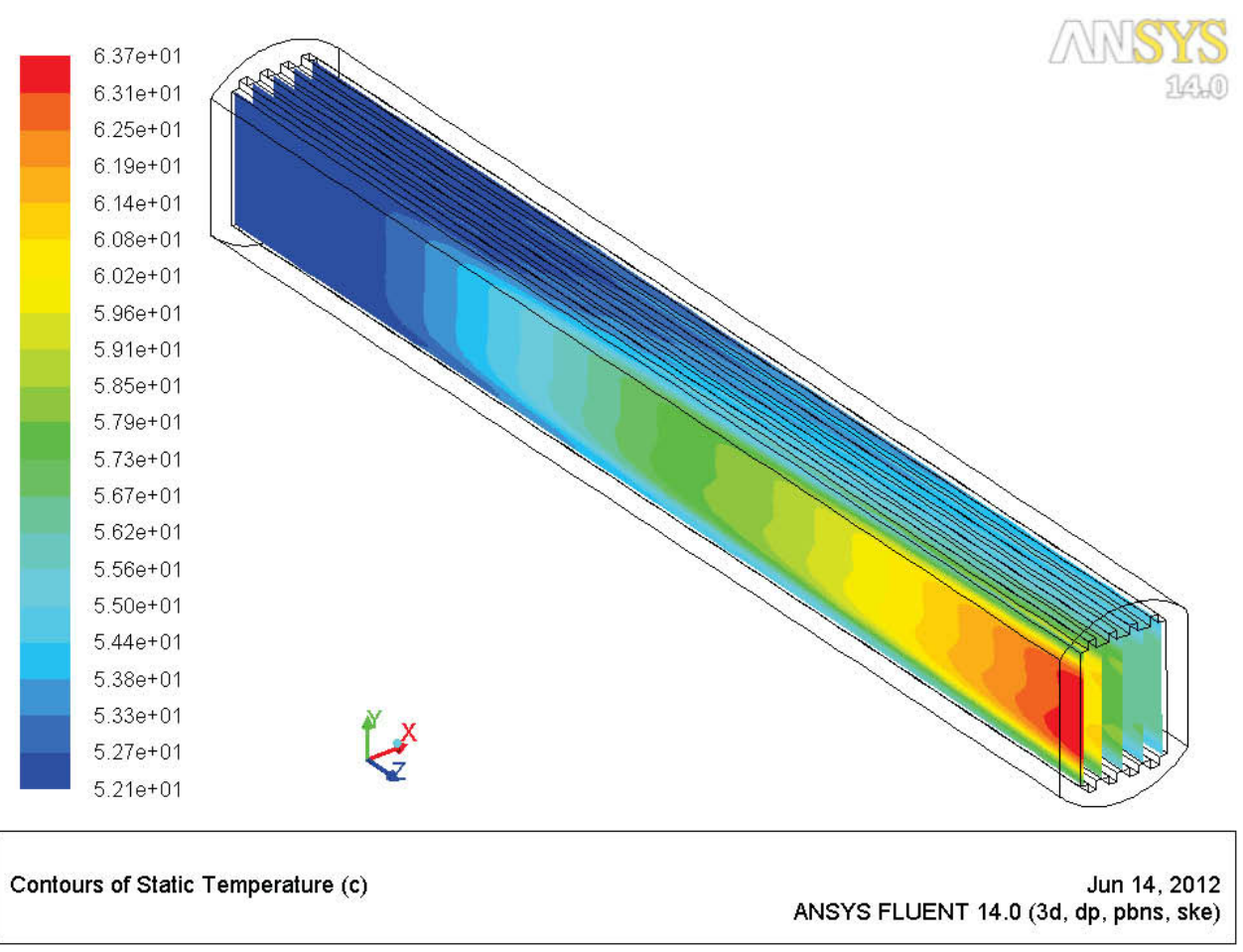

Figure 70. Coolant temperature.

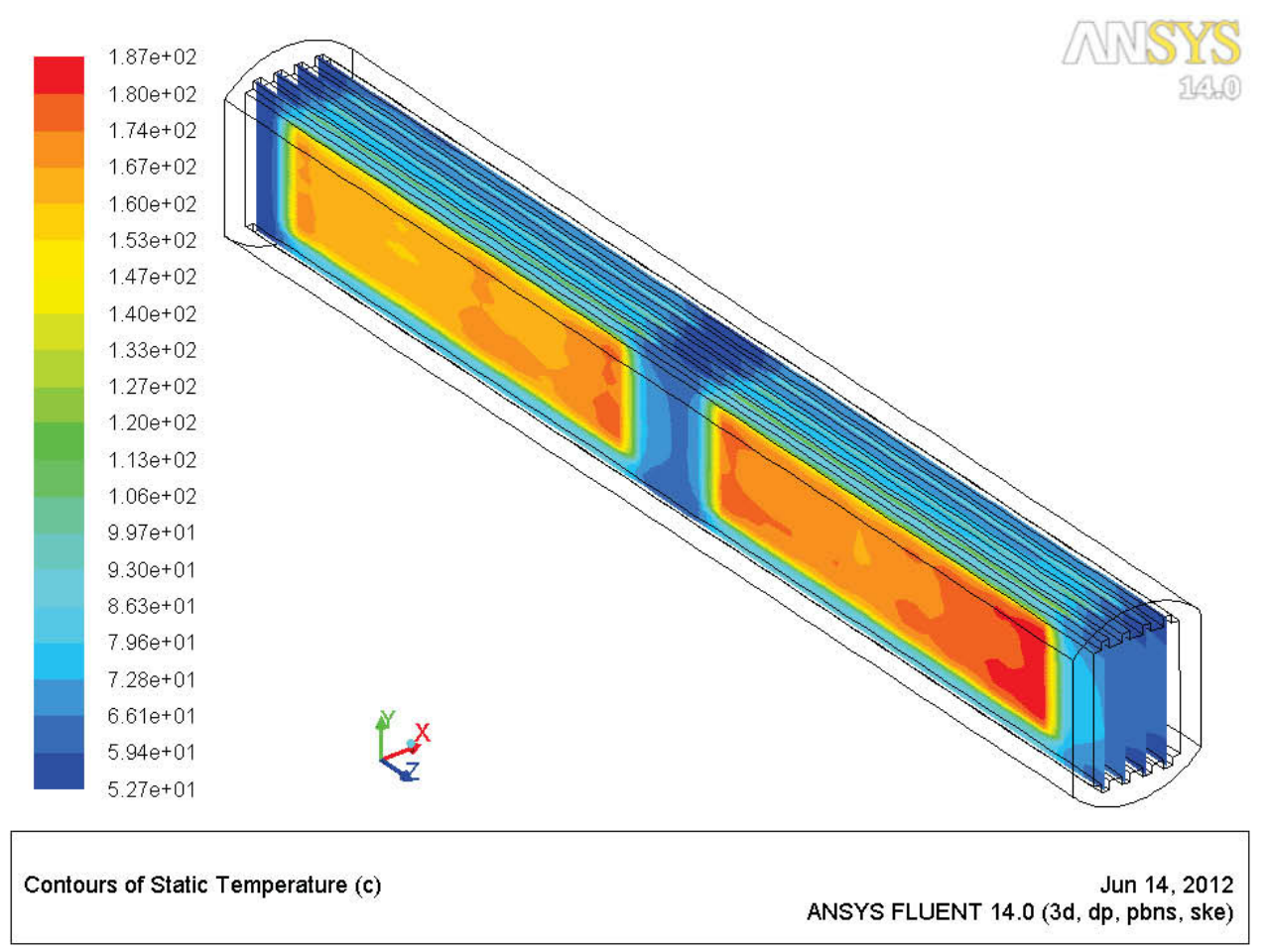

Figure 71. Fuel centerline temperature.

The average and peak values of temperature and heat flux at the surfaces of plate 5 , facing toward and away from core center, as a function of irradiation time are shown in Figure 72 and Figure 73 . Both 
variables decrease during the cycle due to fuel burnup. Heat flux is greater and temperature is less at the oxide/coolant interface facing away from core center because coolant flow is higher in that channel. An abrupt decrease in temperature and heat flux occurs at the beginning of the second cycle due to the difference between the beginning of cycle position and end of cycle position of the outer shims.

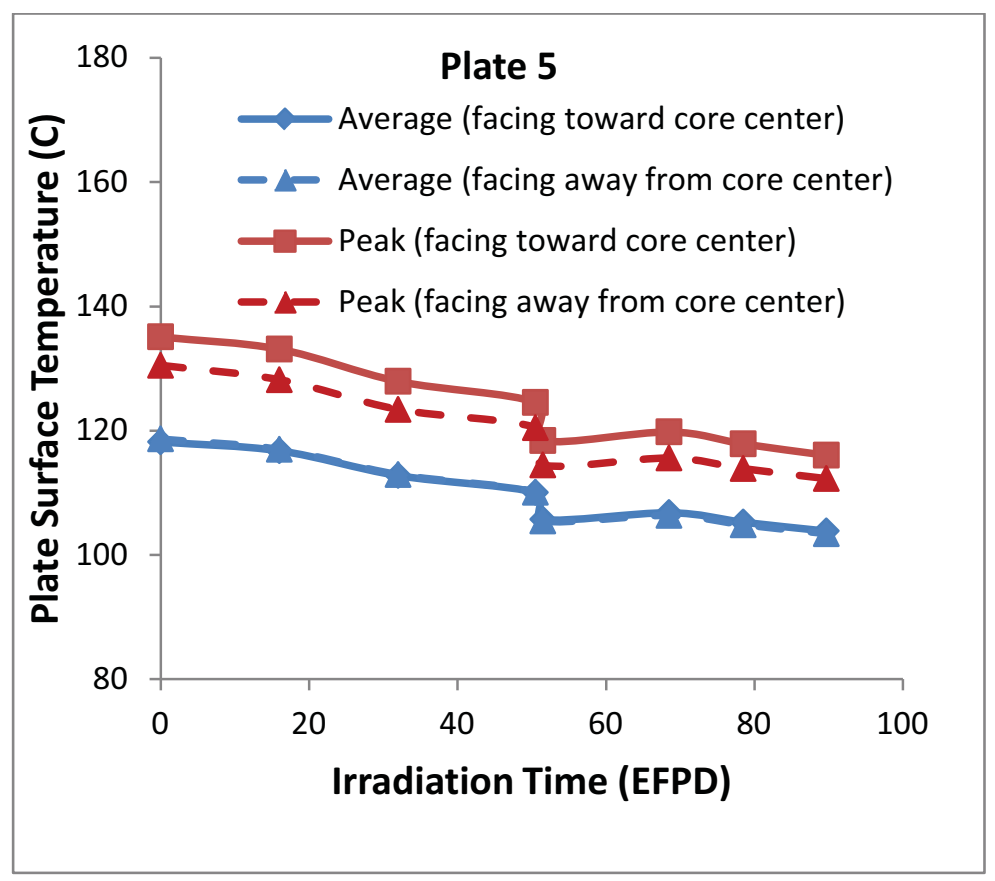

Figure 72. Plate 5 (L1P785) surface temperature.

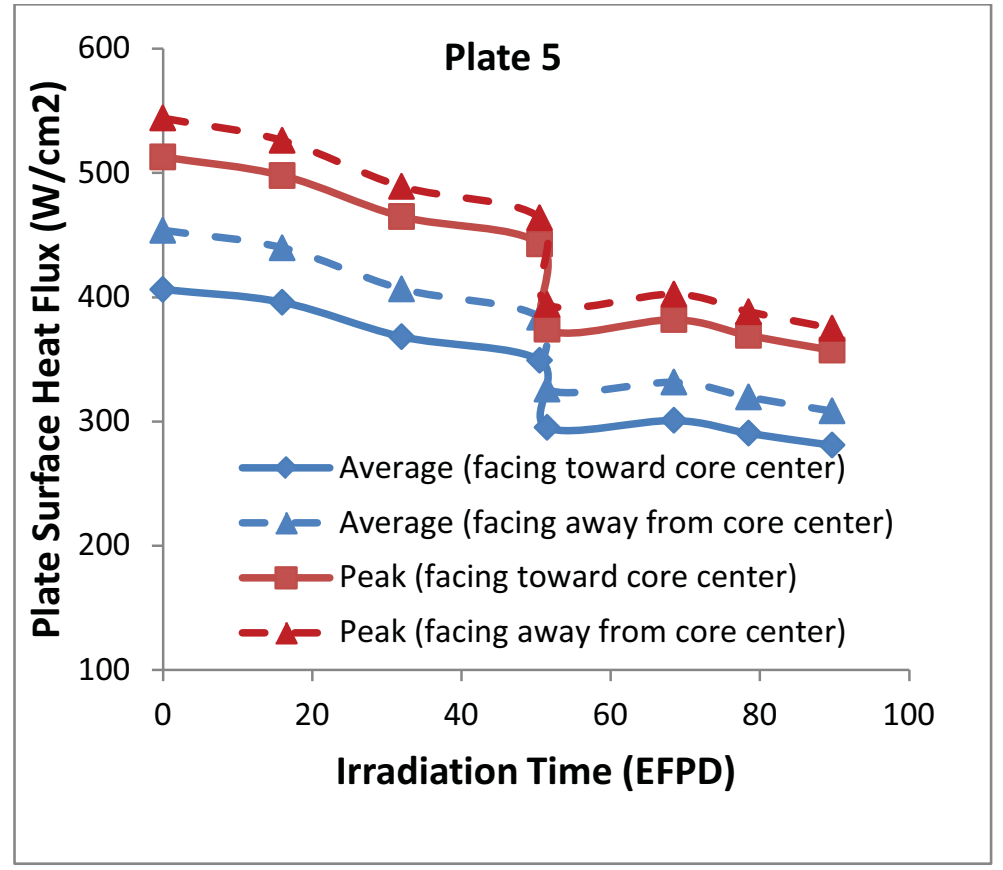

Figure 73. Plate 5 (L1P785) surface heat flux.

The average and peak values of fuel centerline temperature are shown in Figure 74. Fuel centerline temperature increases during each cycle because oxide growth and fuel swelling increase the thermal 
resistance of the plate. Similar behavior occurs for temperature at the fuel/cladding and cladding/oxide interfaces, as shown in Figure 75 and Figure 76. An abrupt decrease in temperature occurs at the beginning of the second cycle due to the significant reduction in fission power at the start of that cycle.

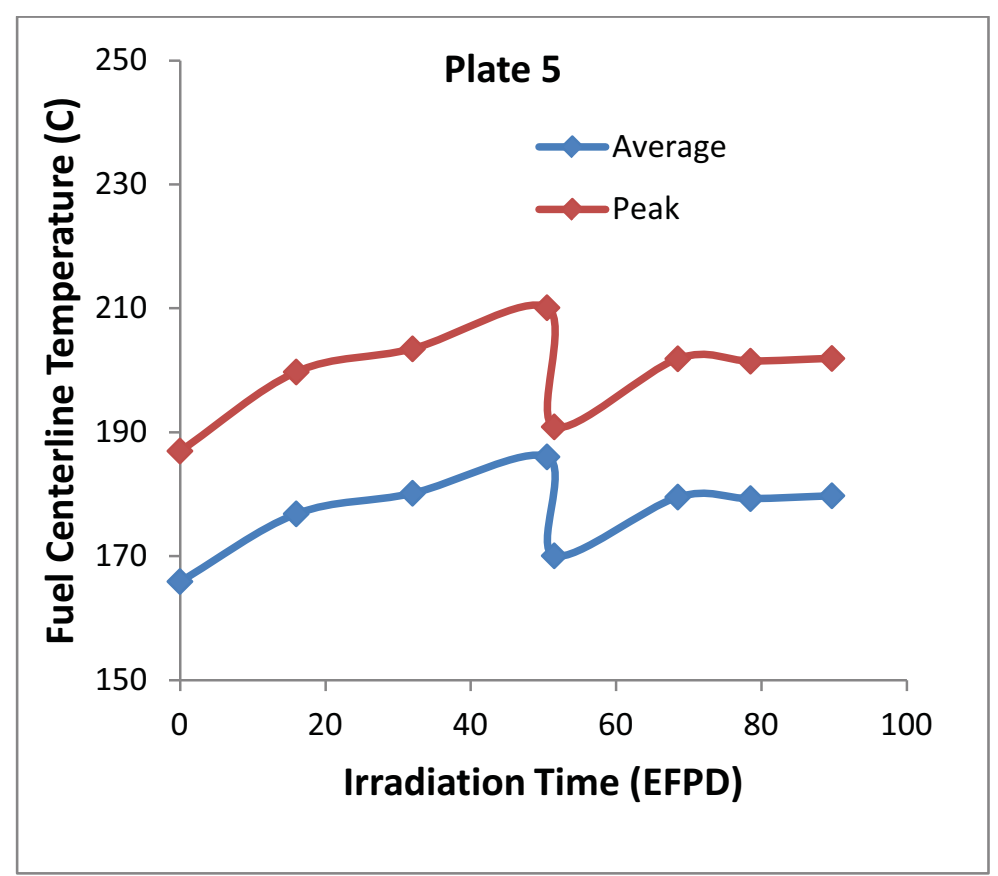

Figure 74. Plate 5 (L1P785) fuel centerline temperature.

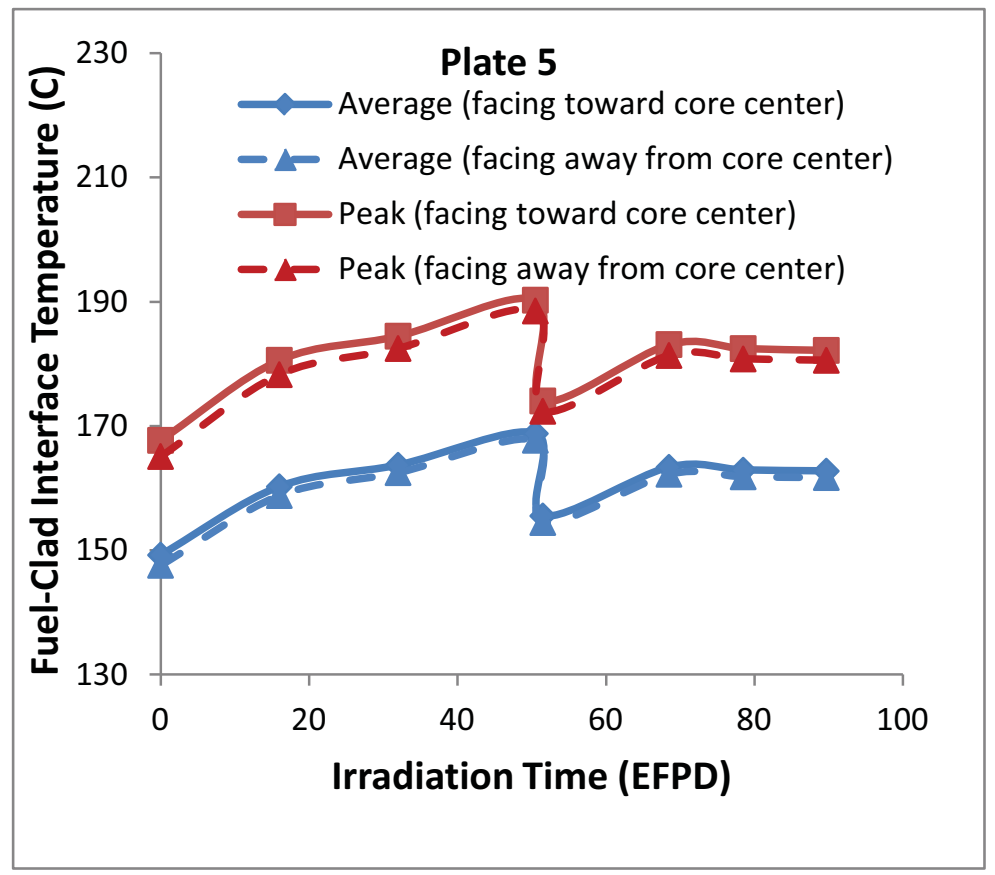

Figure 75. Plate 5 (L1P785) fuel/cladding interface temperature. 


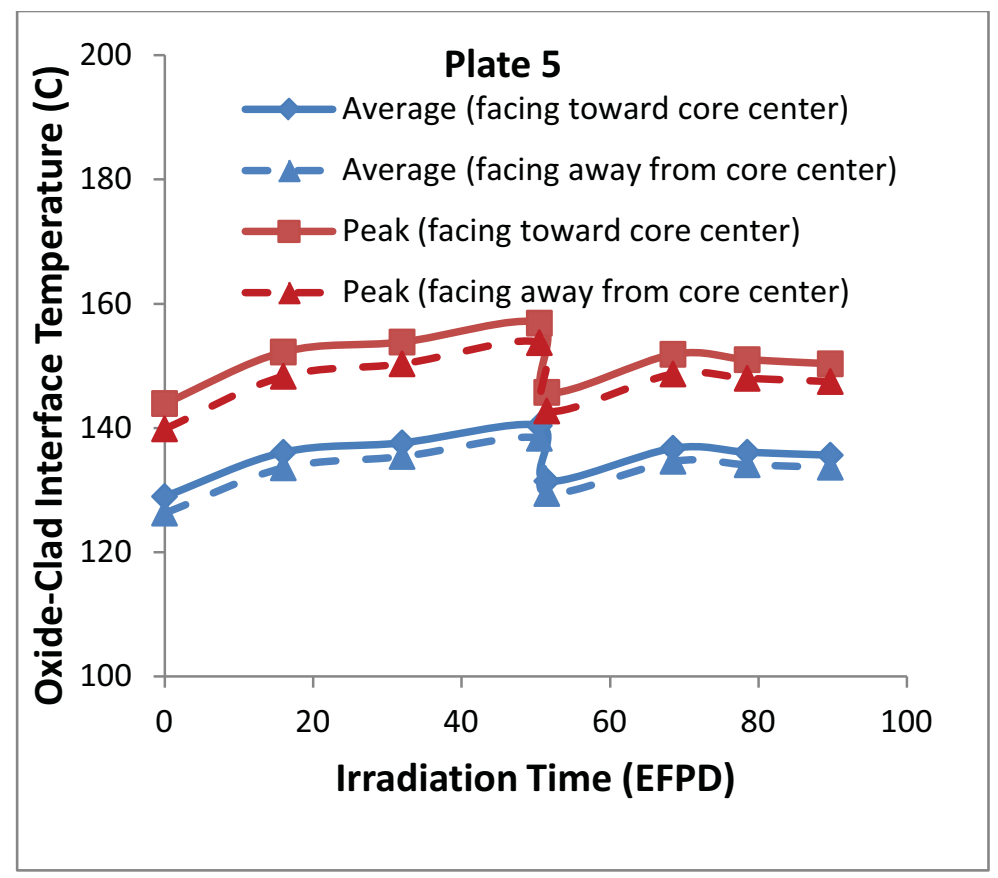

Figure 76. Plate 5 (L1P785) cladding/oxide interface temperature.

The largest temperature gradient within the fuel plates occurs in the oxide layer at the location of peak surface heat flux. The interior temperature distribution in plate 5 at the location of peak heat flux, as a function of irradiation time, is shown in Figure 77. An abrupt change in the temperature gradient occurs at the oxide/clad and clad/fuel interfaces due to the large difference in thermal conductivity of the layers. The maximum temperature gradient in the oxide, clad, and fuel layers is approximately $2400^{\circ} \mathrm{C} / \mathrm{mm}$, $30^{\circ} \mathrm{C} / \mathrm{mm}$, and $400^{\circ} \mathrm{C} / \mathrm{mm}$, respectively. The maximum plate temperature occurs at the end of the first irradiation cycle due to the significant reduction in fission power at the start of the second cycle.

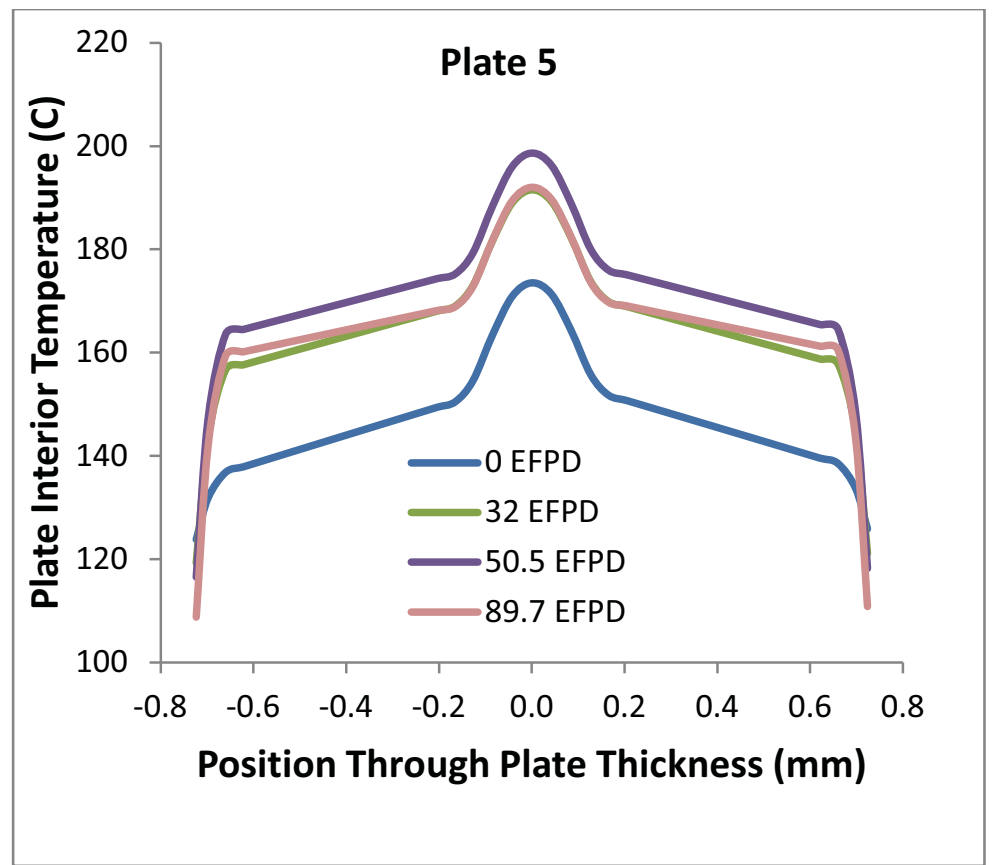

Figure 77. Plate 5 (L1P785) through-thickness temperature. 


\subsubsection{Summary}

Detailed distribution of temperature and heat flux in RERTR-12 capsules X1, X2, and X3 was obtained using CFD analysis. The results show the expected behavior: decreasing surface temperature and heat flux and increasing fuel and cladding temperature during the cycle. Predicted in-pile temperatures are well below the out-of-pile blister threshold temperature of $300^{\circ} \mathrm{C}$ to $400^{\circ} \mathrm{C}$.

Plates D-1 in RERTR-12 capsule X2 and B-5 in RERTR-12 capsule X3 experienced in-pile blister formation. These plates were irradiated to significantly higher burn-up (in excess of full LEU burnup) than those in capsule X1. Therefore, it is recommended that CFD modeling of these capsules be focused on predicting the irradiation conditions at the locations of blistering. This effort would involve identifying the blister locations on the computational grid in order to determine temperature and heat flux at these locations.

A validation study comparing the FLUENT CFD results to those obtained from empirical heattransfer models has been completed and will be provided in a separate report. The Petukhov correlation [15] was used to calculate the heat-transfer coefficient at the plate surface since it accounts for the effect of fluid-property variation in the boundary layer and is usually more accurate than other empirical correlations. The results of this validation study indicate good agreement between FLUENT and empirical heat-transfer models for coolant temperature, plate-surface temperature, and plate-interior temperature. Therefore, the computational results presented in this report provide accurate temperature predictions for use in studies of the blistering problem.

\subsubsection{References}

1. "Analysis of Low Blister Threshold Temperatures in RERTR-12 and AFIP-4 Experiments," PLN4155, April, 2012.

2. ANSYS FLUENT, Version 14.0., ANSYS Inc., October, 2011.

3. Wachs, D. M., "RERTR Large B Position Irradiation Vehicle Flow Test," EDF-8292, July, 2007.

4. Schlichting, H. and Gersten, K., Boundary-Layer Theory, $8^{\text {th }}$ edition, Springer-Verlag, 2000.

5. Rest, J., Kim, Y. S., Hofman, G. L., Meyer, M. K., and Hayes, S. L., "U-Mo Fuels Handbook," ANL09/31, November 2009.

6. Polkinghorne, S., T. and Lacy, J. M., "Thermophysical and Mechanical Properties of ATR Core Materials," PG-T-91-031, August, 1991.

7. Lillo, M. A., "RERTR-12-3 Projected Physics Analysis Results for Use in Thermal and Oxide Growth Evaluations," ECAR-1394, February, 2011.

8. Lillo, M. A., "MCNP-Calculated Fission Power Gradients for RERTR-12 Mini-Plates Irradiated in ATR,” ECAR-1832, March, 2012.

9. Griebenow, M. L. and Hanson, G. H., “ATR Core-1 Thermal-Hydraulics Test Results,” TR-727, September, 1976.

10. Medvedev, P. G., "Managing Corrosion During Irradiation of Aluminum Clad Fueled Test Plates in ATR," ECAR-1374, August, 2011.

11. Kim, Y. S. and Hofman, G. L., "Fission Product Induced Swelling of U-Mo Alloy Fuel," J. Nuclear Materials 419 (2011), 291-301.

12. Mason, E. A. and von Ubisch, H., "Thermal Conductivities of Rare Gas Mixtures," Physics of Fluids 3 (1960), 355-361.

13. Hashin, Z. and Shtrikman, S., "A Variational Approach to the Theory of the Effective Magnetic Permeability of Multiphase Materials,” J. Applied Physics 33 (1962), 3125-3131. 
14. Hayes, S. L., Hofman, G. L., Meyer, M. K., Rest, J., and Snelgrove, J. L., "Modeling of High-Density U-Mo Dispersion Fuel Plate Performance," International Meeting on Reduced Enrichment for Research and Test Reactors, November, 2002.

15. Petukhov. B. S., "Heat Transfer and Friction in Turbulent Pipe Flow With Variable Physical Properties," Advances in Heat Transfer, Vol. 6, Academic Press, 1970.

\subsection{Post-Irradiation Examination}

\subsubsection{Background}

In an effort to identify potential precursors that may lead to lower blister-threshold temperatures, post-irradiation data collected in the AFIP-4 and RERTR-12 capsules X1 and X2 were compared to previous experiment results. Comparisons of fuel swelling, gamma-scan results, oxide growth, and metallographic examinations are performed to identify any variations in performance between the experiments that could have contributed to the observed lower blistering temperature.

\subsubsection{Discussion}

Swelling data were calculated using the plate-thickness measurements taken during post-irradiation examinations of each of the experiments. The methods used and the calculated values can be found in [1] and [2].

Fuel swelling values for the monolithic AFIP tests are shown in Figure 78. The data do not show significant differences that would indicate AFIP-4 behaved differently than earlier tests. AFIP-4 data points all appear in line with observed swelling from AFIP-2 and AFIP-3.

Figure 79 plots fuel swelling for the monolithic miniplate tests that include plates from RERTR-7, 9, and 10 for comparison with RERTR-12 results. Data points from previous experiments $(7,9,10)$ are discrete measurement points taken using the plate and rodlet checker with calculated local fission densities while the RERTR-12 data are plate average swelling with plate average fission densities and may lead to an offset in the results. Figure 79 shows there is a discernible difference in behavior in the RERTR-12 data. The data appear to indicate an improved behavior in the RERTR-12 test with fuel swelling lower than was seen in previous tests for a given fission density. It is assumed that improved fuel-swelling behavior would not negatively impact blistering temperatures. 


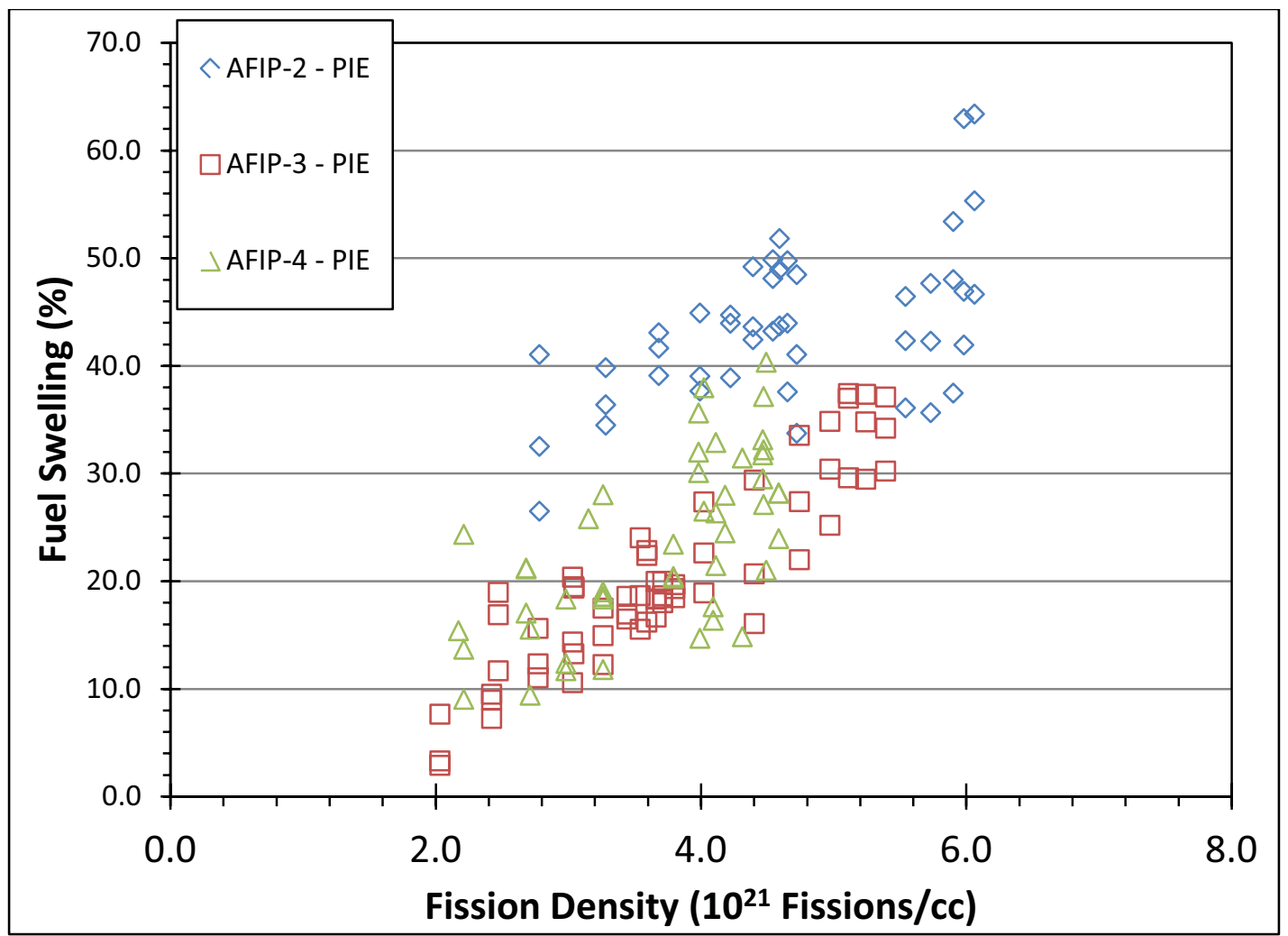

Figure 78. Fuel swelling plot for AFIP tests.

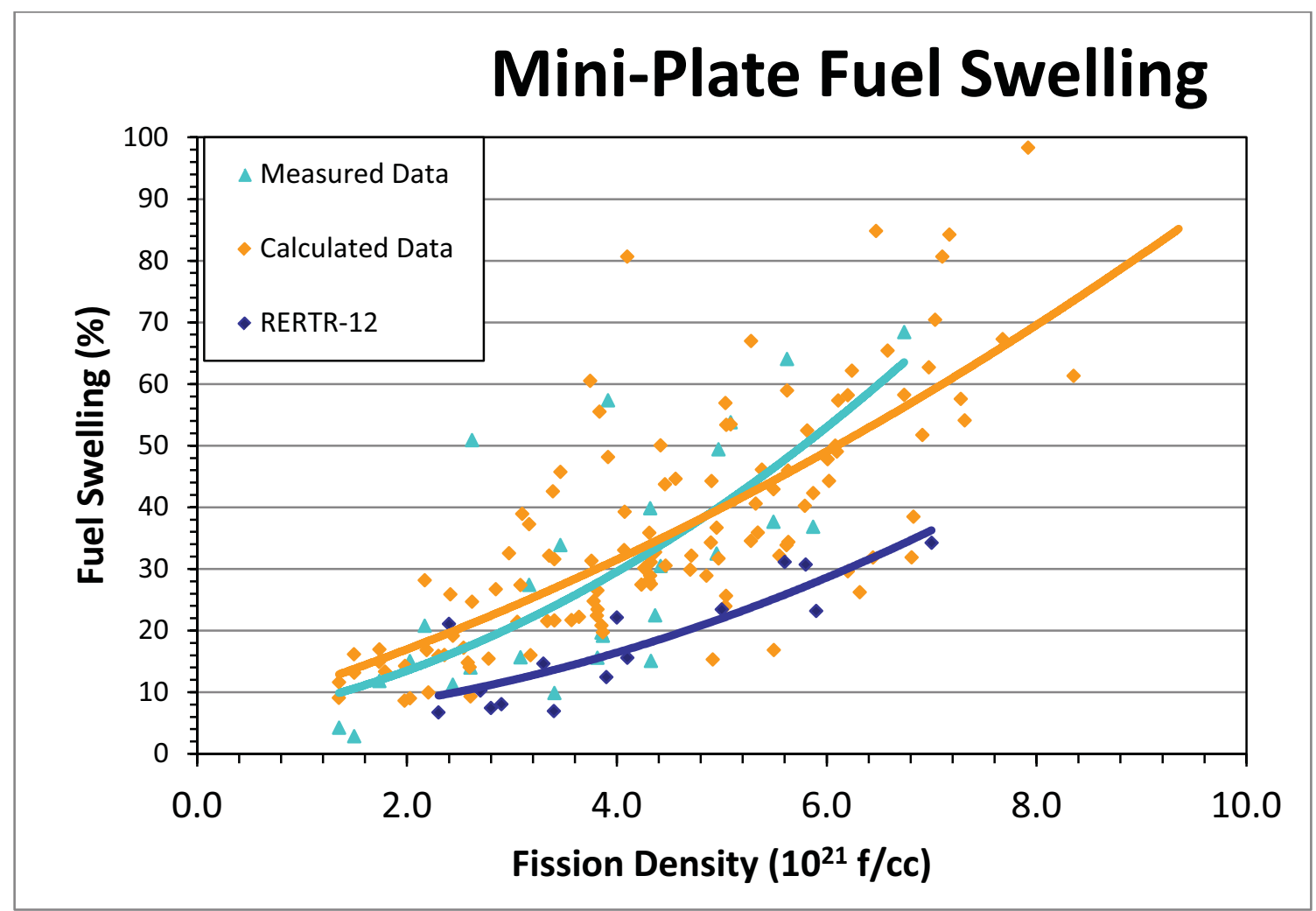

Figure 79. Fuel swelling plot for miniplate tests. 
A summary of the oxide thickness data from the RERTR-12 experiment is shown in Table 13. These values are in line with those seen in previous high-power miniplate tests. RERTR-9 plates showed per plate average oxide values of between 2 and $8 \mu \mathrm{m}$, RERTR-10 plates showed per plate average oxide values of between 2 and $12 \mu \mathrm{m}$. It is therefore assumed that oxide formation is not a cause of reduced blister temperature or an indication of reduced performance.

Table 13. Oxide measurement summary of RERTR-12 insertion 1 in micrometers

RERTR-12 X1

\begin{tabular}{|ll|}
\hline Plate L1P460 \\
Frontside & 5.8 \\
Backside & 5.7 \\
Max & 10.5 \\
\hline Plate L1P592 & \\
Frontside & 4.9 \\
Backside & 1.8 \\
Max & 6.9 \\
\hline Plate L1P591 \\
Frontside & 3.2 \\
Backside & 2.9 \\
Max & 4.8 \\
\hline Plate L1P461 & \\
Frontside & 5.7 \\
Backside & 5.0 \\
Max & 8.5 \\
\hline Plate L1P773 & \\
Frontside & 3.1 \\
Backside & 4.3 \\
Max & 7.8 \\
\hline Plate L1P772 \\
Frontside & 11.0 \\
Backside & 8.3 \\
Max & 13.2 \\
\hline Plate L1P774 & \\
Frontside & 10.9 \\
Backside & 7.6 \\
Max & 13.7 \\
\hline Plate L1P776 \\
Frontside & 3.8 \\
Backside & 4.2 \\
Max & 6.2 \\
\hline
\end{tabular}

RERTR-12 X2

\begin{tabular}{|ll|}
\hline Plate L1P756 \\
Frontside & 8.3 \\
Backside & 7.1 \\
Max & 9.7 \\
\hline Plate L1P755 & \\
Frontside & 6.8 \\
Backside & 7.4 \\
Max & 12.0 \\
\hline Plate L1P593 \\
Frontside & 4.5 \\
Backside & 4.1 \\
Max & 7.0 \\
\hline Plate L1P595 \\
Frontside & 4.4 \\
Backside & 6.4 \\
Max & 14.0 \\
\hline Plate L1P462 \\
Frontside & 6.4 \\
Backside & 6.1 \\
Max & 10.0 \\
\hline Plate L1P758 \\
Frontside & 3.8 \\
Backside & 7.0 \\
Max & 9.0 \\
\hline Plate L1P463 & \\
Frontside & 8.0 \\
Backside & 7.9 \\
Max & 10.5 \\
\hline Plate L1P754 \\
Frontside & 11.7 \\
Backside & 8.8 \\
Max & 15.6 \\
\hline
\end{tabular}


Gamma scans performed on the RERTR-12 plates cannot be compared directly to previous experiments because the irradiation orientation was changed from the traditional orientation of the plates within the reactor. However, comparisons of gamma scans to calculated physics data were completed to verify the calculated 2D fission-density plots. The two methods appear to be in close agreement. As expected, the physics data slightly over predict the peaking, especially in the horizontal direction, because they are based on the beginning-of-life power peaking factors. Plots of the physics against the gamma scans can be seen in Figure 80 and Figure 81.

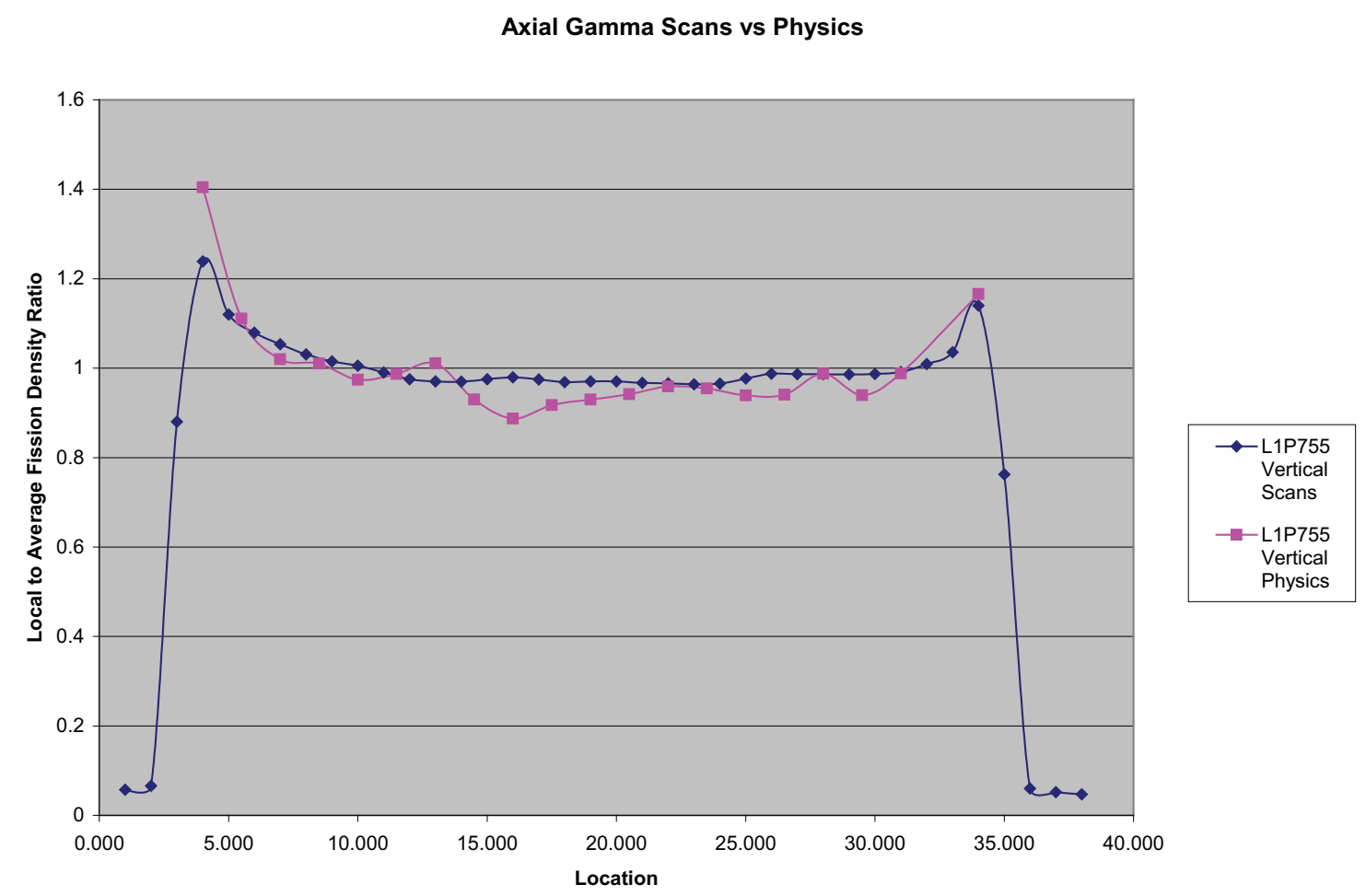

Figure 80. Comparison of axial gamma scans to axial calculated gradients (plate L1P755). 


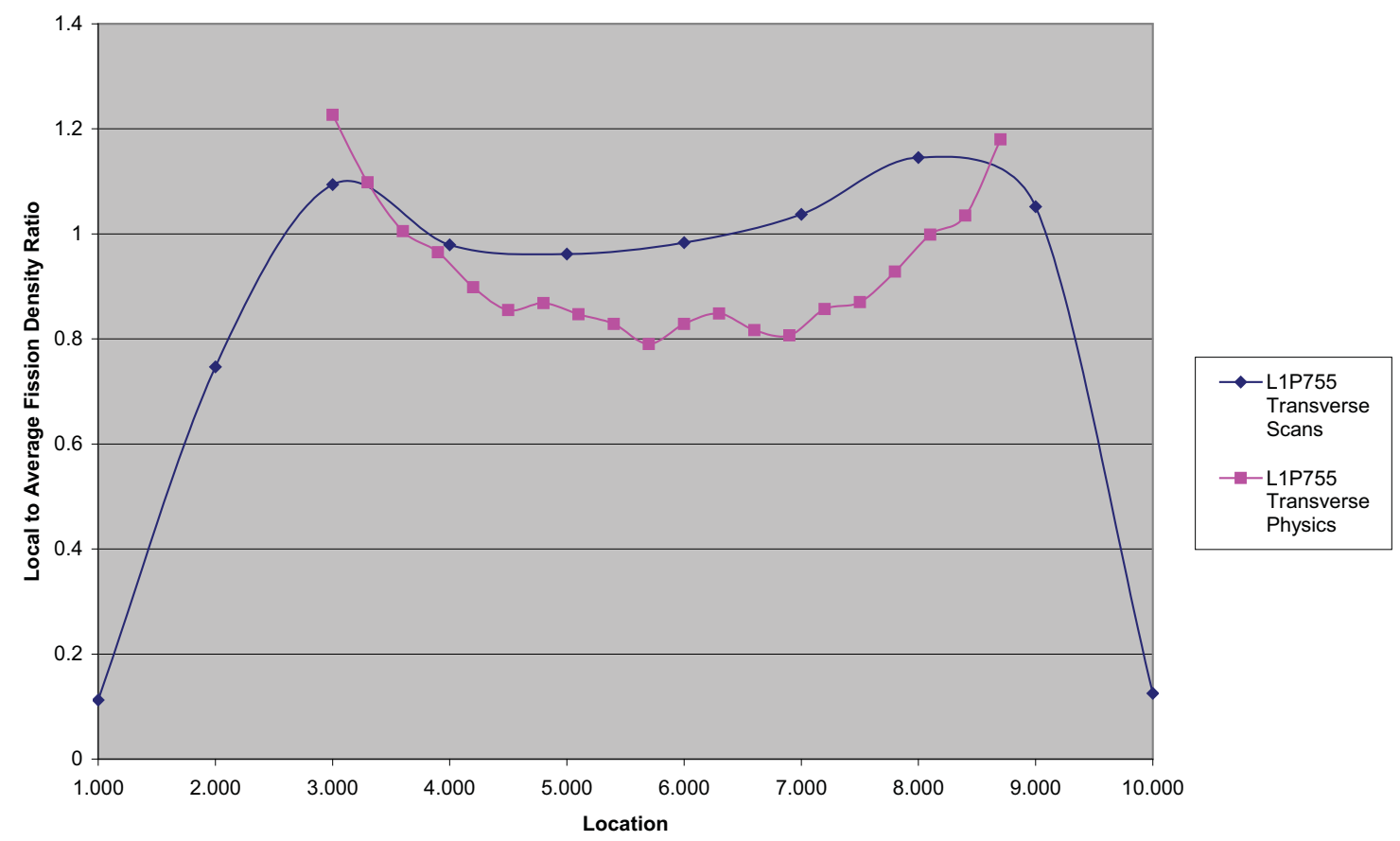

Figure 81. Comparisons of transverse gamma scans to transverse calculated gradients (plate L1P755).

Post-irradiation metallography was completed for all RERTR-12 plates (X1 and X2 capsules) that were not blister annealed. Analysis of cross sections focused on identifying any localized swelling, inspecting fuel-system interfaces, and identifying abnormalities in fission-gas porosity. Selected representative images are included here as examples and can be used for comparison to previous tests.

Figure 82 and Figure 83 show representative cross sections from zirconium co-rolled plates, one from RERTR-12 and one from RERTR-10A, respectively. Differences in peak swelling can be seen as the peak fission-density locations are different; however, overall behavior of the plates is very similar.

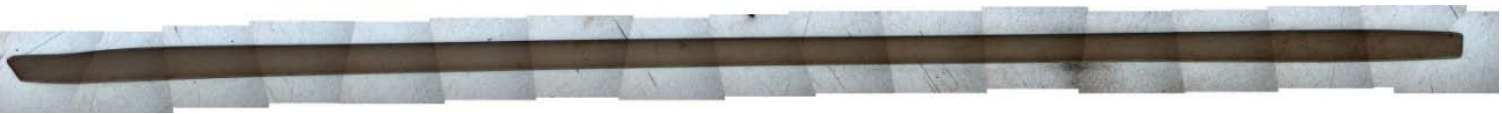

Figure 82. Cross section of RERTR-12 plate L1P755 $\left(5.3 \times 10^{21}\right.$ fissions $\left./ \mathrm{cm}^{3}\right)$.

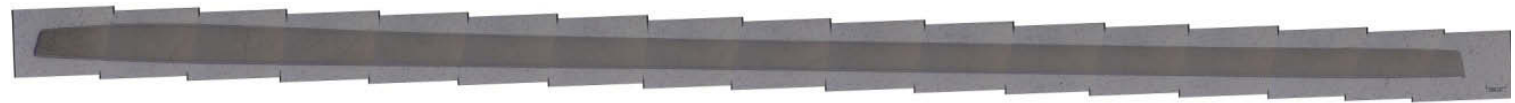

Figure 83. Cross section of RERTR-10A plate L1P12Z $\left(4.0 \times 10^{21}\right.$ fissions $\left./ \mathrm{cm}^{3}\right)$.

The uncovered ends of the foils (i.e., without $\mathrm{Zr}$ diffusion barrier) are areas of interest as many of the blisters that have formed on the RERTR-12 plates are on the periphery of the fuel zone. Inspection of the edges of the foils has indicated no significant defects and very little, if any, deviation from previous tests (see Figure 84 and Figure 85). Interaction layers are thin and do not indicate excessive porosity, essentially nothing is observed that would indicate lower blister temperatures. 


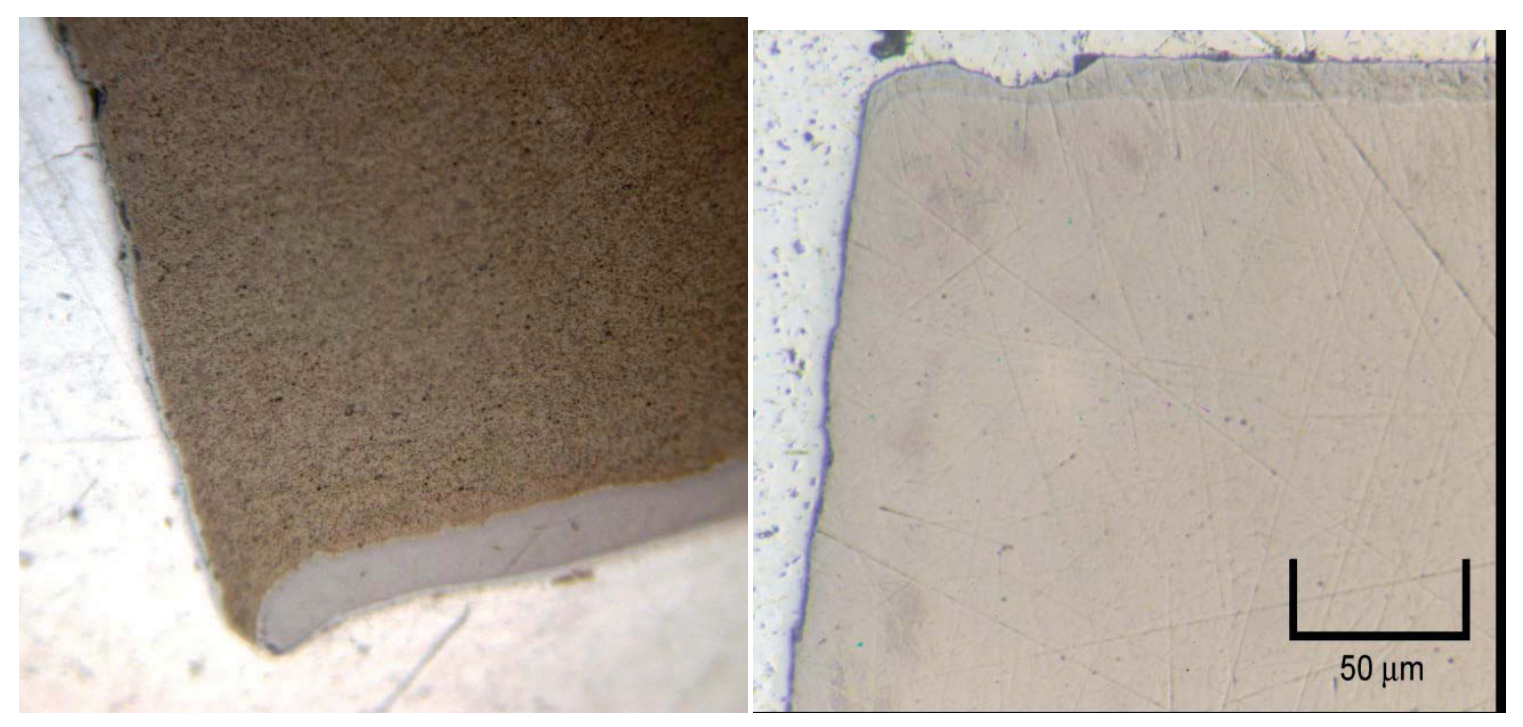

Figure 84. Image of foil edge from RERTR-12 plate L1P593 (left) $4.8 \times 10^{21}$ fissions $/ \mathrm{cm}^{3}$ and RERTR10 A plate L2P16Z (right) $2.45 \times 10^{21}$ fissions $/ \mathrm{cm}^{3}$.
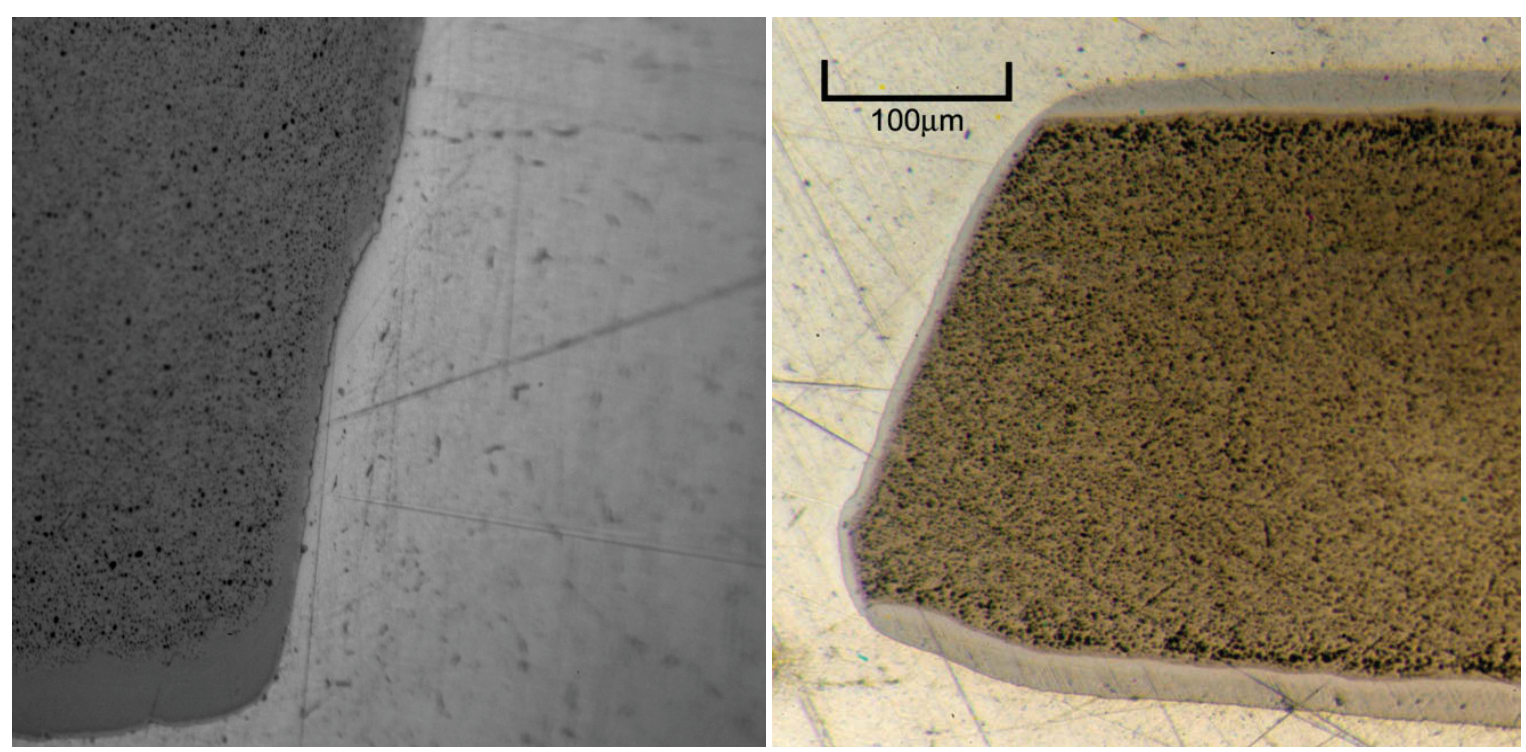

Figure 85. Image of foil edge from RERTR-12 plate L1P773 (left) $5.2 \times 10^{21}$ fissions $/ \mathrm{cm}^{3}$ and RERTR10B plate L1F44N (right) $6.3 \times 10^{21}$ fissions $/ \mathrm{cm}^{3}$.

Optical inspection of the zirconium interface applied to the fuel foil after irradiation also indicates very little deviation from previous experiments. Optical examination (see Figure 86), however, does not provide any information regarding chemical diffusion or micron-size diffusion layers that may exist but are not visible. 

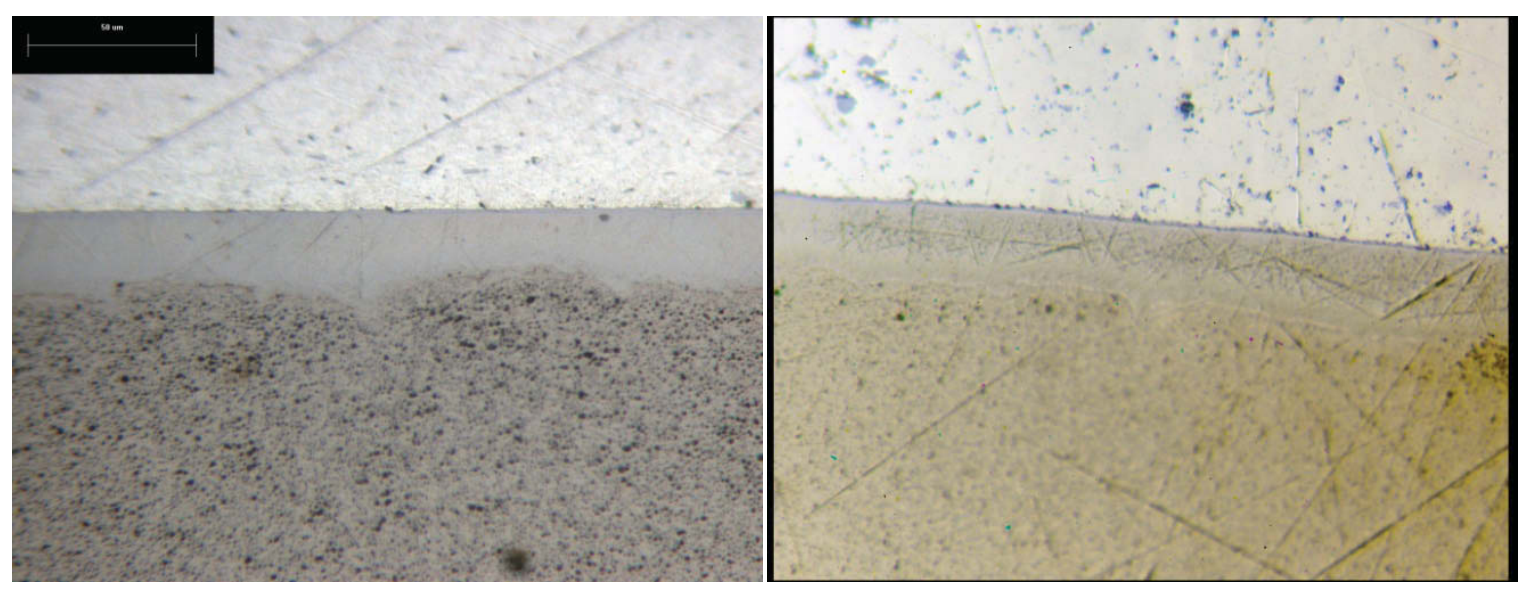

Figure 86. Zirconium interface of RERTR-12 plate L1P755 (left) $5.5 \times 10^{21}$ fissions $/ \mathrm{cm}^{3}$ and RERTR-10A plate L1P12Z (right) $\times 10^{21}$ fissions $/ \mathrm{cm}^{3}$.

\subsubsection{Conclusions}

To date, post-irradiation examination has not identified obvious anomalies or defects that that might lead to reduced blister threshold temperature. Further examinations with electron microscopy would assist in identifying any significant microstructural differences or interlayers which may be playing a role.

\subsubsection{References}

[1] ECAR -1367 “RERTR Miniplate Monolithic Fuel Swelling”.

[2] ECAR-1923 “AFIP Monolithic Fuel Swelling”.

\subsection{Additional Blister Testing}

\subsubsection{Background}

The procedure used for blister testing has been previously observed to affect test results in dispersion fuels. In the case of monolithic fuel, it was hypothesized that thermal cycling of the plates during blister annealing resulted in formation of blisters at lower temperature.

To test this hypothesis, two pairs of plates were selected from the AFIP-4 experiment. One plate underwent thermal cycling at a single temperature. If blistering did not occur after 10-15 thermal cycles, the temperature was increased, and thermal cycling continued. The second plate from each pair was subjected to an isothermal anneal for the equivalent time at temperature. Both plates in each pair have similar fission density (see Table 14).

Table 14. AFIP-4 plates selected for thermal cycling testing.

\begin{tabular}{|c|c|}
\hline lat & $\begin{array}{c}\text { Max Fission } \\
\text { Density }\end{array}$ \\
\hline
\end{tabular}

\begin{tabular}{lllll}
\hline L1B32Z & $4.74 \mathrm{E}+21$ & $4.09 \mathrm{E}+21$ & $3.71 \mathrm{E}+21$ & cycling \\
L1B52Z & $5.12 \mathrm{E}+21$ & $4.20 \mathrm{E}+21$ & $3.66 \mathrm{E}+21$ & continuous soak \\
\hline L1H35Z & $4.72 \mathrm{E}+21$ & $3.80 \mathrm{E}+21$ & $3.26 \mathrm{E}+21$ & cycling \\
L1H38Z & $4.88 \mathrm{E}+21$ & $3.90 \mathrm{E}+21$ & $3.43 \mathrm{E}+21$ & continuous soak
\end{tabular}


Plate L1H35Z, a HIP-bonded plate from the first set, was subjected to thermal cycling at three temperature settings 250,275 and $300^{\circ} \mathrm{C}$. Temperatures were selected based on the lowest starting temperature from the RERTR-12 and AFIP-4 blister anneal testing with the customary $25^{\circ} \mathrm{C}$ temperature increments if no blister was noted. Based on the number of cycles that the plates were subject to during blister-anneal testing up to $500^{\circ} \mathrm{C}$, the point at which typical blister anneal testing is usually concluded, the number of soaks decreased by one for each temperature increment. The sister plate L1H38Z, also a HIP-bonded plate, was continuously soaked at the same temperatures for an amount of time equal to the total time that the first plate was resident in the furnace. It should be noted that the blister location for the designation of the conclusion of the test was limited to those that formed over or touching the fuel zone. All blisters, including those outside of fuel zone, were noted, photographed and observed for changes.

\subsubsection{Results}

Results of the thermal cycling test are summarized in Table 15.

Table 15. Results of the thermal cycling test performed using AFIP-4 plates.

\begin{tabular}{|c|c|c|c|c|c|c|c|c|}
\hline $\begin{array}{c}\text { Plate } \\
\text { name }\end{array}$ & $\begin{array}{c}\text { Thermal } \\
\text { cycling }\end{array}$ & $\mathbf{T},{ }^{\circ} \mathbf{C}$ & $\begin{array}{c}\text { \#cycles } \times \\
\text { cycle time/ } \\
\text { blistered }\end{array}$ & $\mathbf{T},{ }^{\circ} \mathbf{C}$ & $\begin{array}{c}\text { \#cycles } \times \text { cycle } \\
\text { time/blistered }\end{array}$ & $\mathbf{T},{ }^{\circ} \mathbf{C}$ & $\begin{array}{c}\text { \#cycles } \times \\
\text { cycle time/ } \\
\text { blistered }\end{array}$ & $\begin{array}{c}\text { Total \# of } \\
\text { thermal } \\
\text { cycles }\end{array}$ \\
\hline L1H35Z & cycling & 250 & $\begin{array}{c}13 \times 20 \\
\mathrm{~min} / \mathrm{No}\end{array}$ & 275 & $12 \times 20 \mathrm{~min} / \mathrm{No}$ & 300 & $\begin{array}{c}10 \times 20 \\
\mathrm{~min} / \mathrm{Yes}\end{array}$ & 35 \\
\hline L1H38Z & soak & 250 & $\begin{array}{c}1 \times 260 \\
\mathrm{~min} / \mathrm{No}\end{array}$ & 275 & $1 \times 240 \mathrm{~min} / \mathrm{No}$ & 300 & $\begin{array}{c}1 \times 200 \\
\mathrm{~min} / \mathrm{Yes}\end{array}$ & 3 \\
\hline
\end{tabular}

Plate L1H35Z was subjected to a total of 35 thermal cycles (20 min each), as indicated in Table 15. Blister \#1 appeared at the end of the second cycle at $300^{\circ} \mathrm{C}$ in the clad to clad corner area on the back side of the plate (see Figure 87), outside of the fuel zone. Blister \#2 emerged over the clad to clad bond area, outside of fuel zone, in the eighth cycle at $300{ }^{\circ} \mathrm{C}$. Thermal cycling at this temperature continued until the tenth cycle at which point small blisters formed on the lower left corner of backside of the plate and test was concluded. The ultrasonic testing performed on the plate in the ATR canal following irradiation did not indicate a debond in the region of any of the blisters that formed on post-irradiation blister testing (see Figure 88).

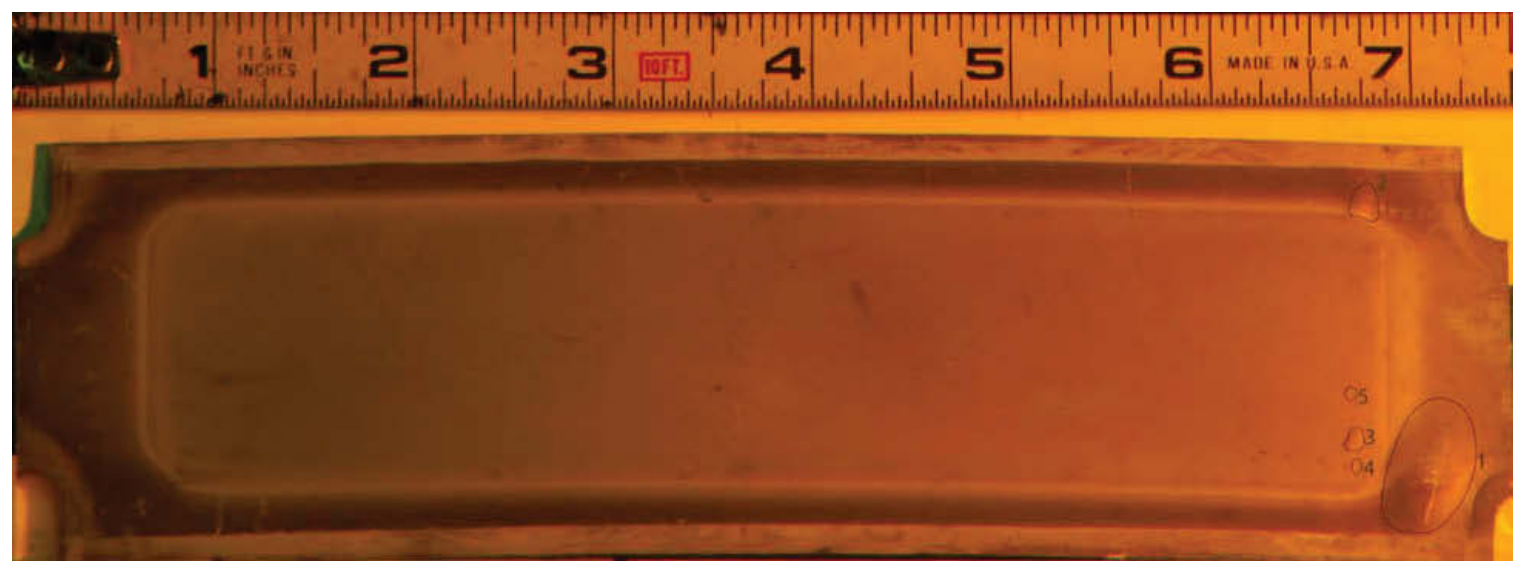

Figure 87. Blisters observed on the back side of plate L1H35Z during post-irradiation thermal cycling. 


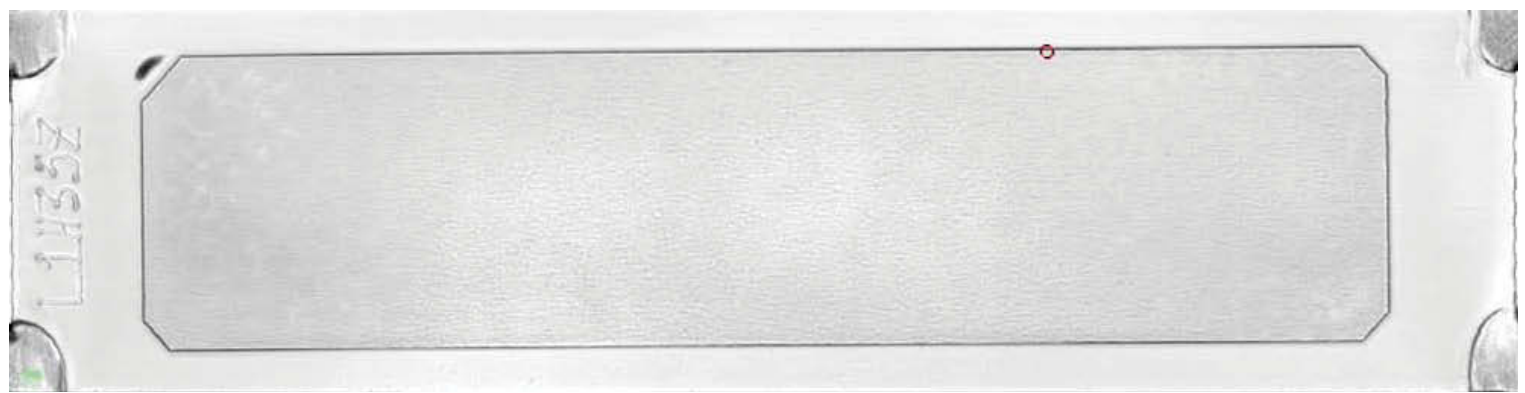

Figure 88. Post-irradiation UT image of plate L1H35Z. The top left hand corner of the UT image corresponds to the bottom left hand corner of the blistered plate image.

The second plate, L1H38Z (see Table 15) underwent integrated thermal soaks at 250,275 and $300^{\circ} \mathrm{C}$. Blister \# 21 (see Figure 89) on the back side of the plate started as a small area of discoloration (but not noticeably raised) after the soak at $250{ }^{\circ} \mathrm{C}$. It became more pronounced following the soak at $275^{\circ} \mathrm{C}$, but with little change after the $300^{\circ} \mathrm{C}$ anneal. In addition, numerous blisters had formed over the fuel zone following the 200 minute soak at $300^{\circ} \mathrm{C}$. A post-irradiation UT image of this plate taken in the ATR canal is shown in Figure 90. This image does show a debond indication in the region where one of the clad to clad blisters formed.

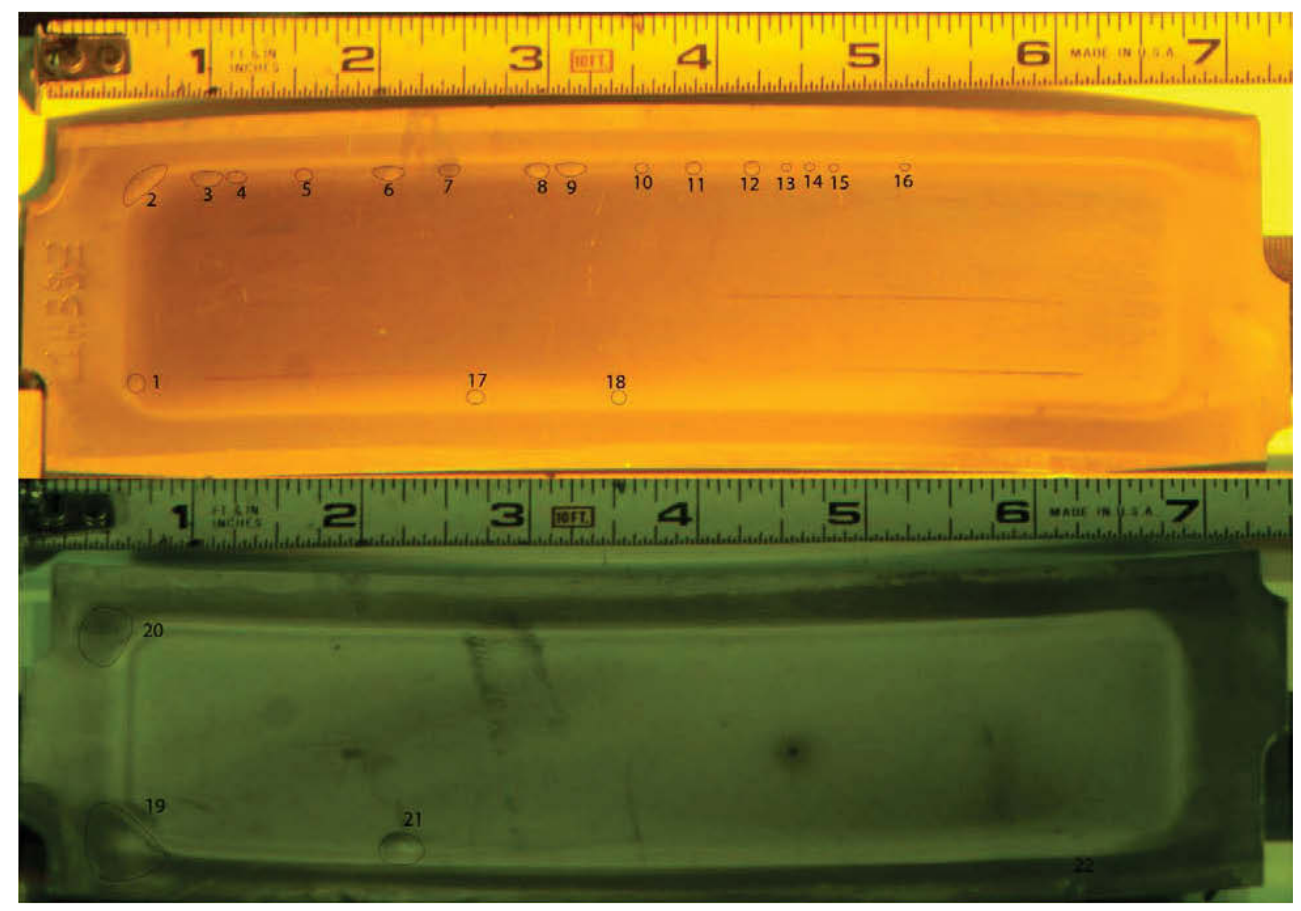

Figure 89. Blisters observed on plate L1H38Z during post-irradiation thermal cycling (top image: front of the plate, bottom image: back of the plate). 


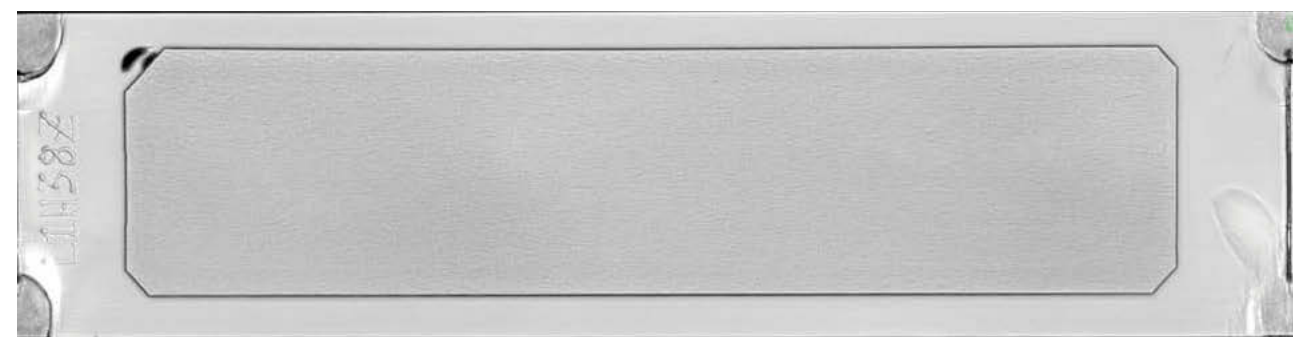

Figure 90. Post-irradiation UT image of plate L1H38Z.

\subsubsection{Summary}

Initial results from this test suggest that thermal cycling of the plate during the blister anneal test does not influence blister anneal temperature. The blister temperature of plates $\mathrm{L} 1 \mathrm{H} 38 \mathrm{Z}$ and L1H35Z was the same as AFIP-4 plates L1H34Z and L1H36Z at similar fission densities. Three additional tests will be conducted to confirm this result.

\subsubsection{Dependence of the blister anneal threshold temperature on local fission density}

It appears that blister formation on miniplates fabricated with a zirconium barrier layer may be a local phenomenon, and it is important to establish whether correlations exist between the blister temperature and fuel operating parameters on a local level. Earlier correlations of the dependence of blister anneal threshold temperature on fission density between the two groups of fuel plates (prior to RERTR-12 and starting from RERTR-12) were developed using the values of the plate average fission densities (see Figure 1). As mentioned in Section 2.3, non-uniform distribution of power leads to significant variations in fission density within each individual fuel foil. Blisters are usually observed in the areas with peak burnup. As seen from Figure 91, the blister temperature is reasonably well correlated with peak fission density for all RERTR experiments, with the "old" experiments data being statistically distinct from the "new" experiments data. 


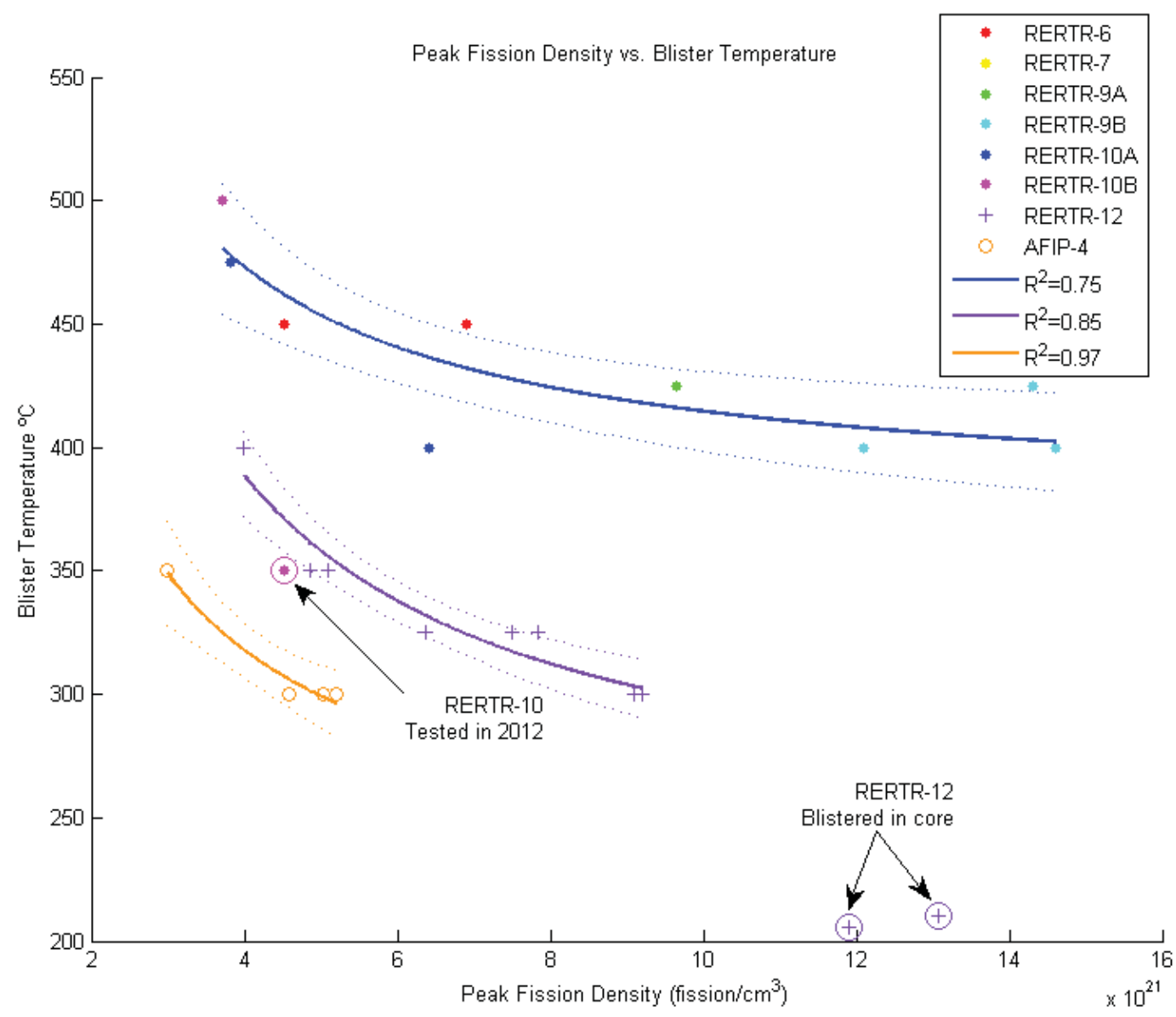

Figure 91. Blister temperature as a function of plate peak fission density. Three circled points (one from RERTR-10 and two from RERTR-12) were not included in the model fit.

Further refinement of the data by determining local fission density at the exact position of each blister within the plate establishes whether a correlation exists between blister-threshold temperatures and local fission density. Results of this analysis are presented in Table 16. 
Table 16. Estimated fission density at the location of the blisters and size of the blisters

\begin{tabular}{|c|c|c|c|c|c|c|}
\hline Experiment & Plate & $\begin{array}{l}\text { Blister } \\
\text { Type } \\
\text { (1 or 2) }\end{array}$ & $\begin{array}{l}\text { Local Fission } \\
\text { Density, } \\
\text { fiss } / \mathrm{cm}^{3}\end{array}$ & $\begin{array}{l}\text { Blister } \mathbf{T}, \\
{ }^{\circ} \mathbf{C}\end{array}$ & $\begin{array}{c}\text { Blister } \\
\text { area, } \mathbf{c m}^{2}\end{array}$ & Comments \\
\hline \multirow{27}{*}{ RERTR-12 } & \multirow{9}{*}{ L1P460 } & 1 & $2.95 \mathrm{E} 21$ & 400 & 0.08 & \\
\hline & & 1 & $3.18 \mathrm{E} 21$ & 400 & 0.16 & \\
\hline & & 1 & $2.90 \mathrm{E} 21$ & 400 & 0.13 & \\
\hline & & 1 & $2.80 \mathrm{E} 21$ & 400 & 0.04 & \\
\hline & & 1 & $2.71 \mathrm{E} 21$ & 400 & 0.11 & \\
\hline & & 1 & $3.06 \mathrm{E} 21$ & 400 & 0.09 & \\
\hline & & 1 & $3.18 \mathrm{E} 21$ & 400 & 0.11 & \\
\hline & & 2 & $3.98 \mathrm{E} 21$ & 400 & 0.22 & \\
\hline & & 2 & $3.27 \mathrm{E} 21$ & 400 & 0.16 & \\
\hline & \multirow[t]{6}{*}{ L1P774 } & 2 & $7.49 \mathrm{E} 21$ & 325 & 0.68 & \\
\hline & & 2 & $6.31 \mathrm{E} 21$ & 325 & 1.35 & \\
\hline & & 2 & $7.09 \mathrm{E} 21$ & 325 & 1.20 & \\
\hline & & 2 & 7.49E21 & 325 & 0.72 & \\
\hline & & 2 & $6.31 \mathrm{E} 21$ & 325 & 1.46 & \\
\hline & & 2 & $7.09 \mathrm{E} 21$ & 325 & 1.01 & \\
\hline & \multirow{2}{*}{ L1P756 } & 2 & $9.91 \mathrm{E} 21$ & 300 & 1.36 & \\
\hline & & 2 & $9.91 \mathrm{E} 21$ & 300 & 1.53 & \\
\hline & L1P463 & 1 & $3.42 \mathrm{E} 21$ & 350 & 0.06 & \\
\hline & \multirow[t]{2}{*}{ L1P592 } & 2 & $4.27 \mathrm{E} 21$ & 350 & 0.10 & \\
\hline & & 2 & $3.30 \mathrm{E} 21$ & 350 & 0.10 & \\
\hline & \multirow[t]{2}{*}{ L1P758 } & 2 & $9.19 \mathrm{E} 21$ & 300 & 0.60 & \\
\hline & & 2 & $9.19 \mathrm{E} 21$ & 300 & 0.35 & \\
\hline & \multirow[t]{2}{*}{ L1P595 } & 2 & $6.38 \mathrm{E} 21$ & 325 & 0.18 & \\
\hline & & 2 & $5.76 \mathrm{E} 21$ & 325 & 0.17 & \\
\hline & \multirow[t]{2}{*}{ L1P772 } & 2 & $7.83 \mathrm{E} 21$ & 325 & 2.86 & \\
\hline & & 2 & $7.83 \mathrm{E} 21$ & 325 & 3.21 & \\
\hline & L1P754 & 2 & $1.17 \mathrm{E} 22$ & $\begin{array}{l}\mathrm{TBD}, \\
\text { blistered in } \\
\text { reactor }\end{array}$ & 6.27 & \\
\hline \multirow{4}{*}{$\begin{array}{l}\text { RERTR-6 } \\
\text { All Type } 2\end{array}$} & \multirow[t]{2}{*}{ L2F020 } & 2 & $3.07 \mathrm{E} 21$ & 450 & 0.03 & \multirow{2}{*}{$\begin{array}{c}\text { No } \\
\text { interlayer }\end{array}$} \\
\hline & & 2 & $2.84 \mathrm{E} 21$ & 450 & 0.07 & \\
\hline & \multirow{2}{*}{ N1F060 } & 2 & $5.52 \mathrm{E} 21$ & 450 & 0.97 & \multirow{2}{*}{$\begin{array}{c}\text { No } \\
\text { interlayer }\end{array}$} \\
\hline & & 2 & $6.90 \mathrm{E} 21$ & 450 & 10.91 & \\
\hline RERTR-7 & L1F110 & 2 & $1.21 \mathrm{E} 22$ & 400 & 15.89 & $\begin{array}{c}\text { No } \\
\text { interlayer }\end{array}$ \\
\hline $\begin{array}{c}\text { RERTR-9A } \\
\text { Type } 2\end{array}$ & L1F27C & 2 & $9.64 \mathrm{E} 21$ & $\begin{array}{l}\text { TBD, } \\
\text { blistered in } \\
\text { reactor }\end{array}$ & 13.70 & $\begin{array}{c}\text { No } \\
\text { interlayer }\end{array}$ \\
\hline RERTR-9B & L1F35T & 2 & $1.43 \mathrm{E} 22$ & 425 & 4.42 & $\begin{array}{c}\text { Thermal } \\
\text { spray }\end{array}$ \\
\hline \multirow[t]{4}{*}{ All Type 2} & L1F330 & 2 & $1.46 \mathrm{E} 22$ & 400 & 16.23 & $\begin{array}{c}\text { No } \\
\text { interlayer }\end{array}$ \\
\hline & \multirow[t]{3}{*}{ L1P10T } & 2 & $1.21 \mathrm{E} 22$ & 400 & 0.42 & \\
\hline & & 2 & $4.95 \mathrm{E} 21$ & 400 & 0.24 & \\
\hline & & 2 & $1.21 \mathrm{E} 22$ & 400 & 2.21 & \\
\hline
\end{tabular}




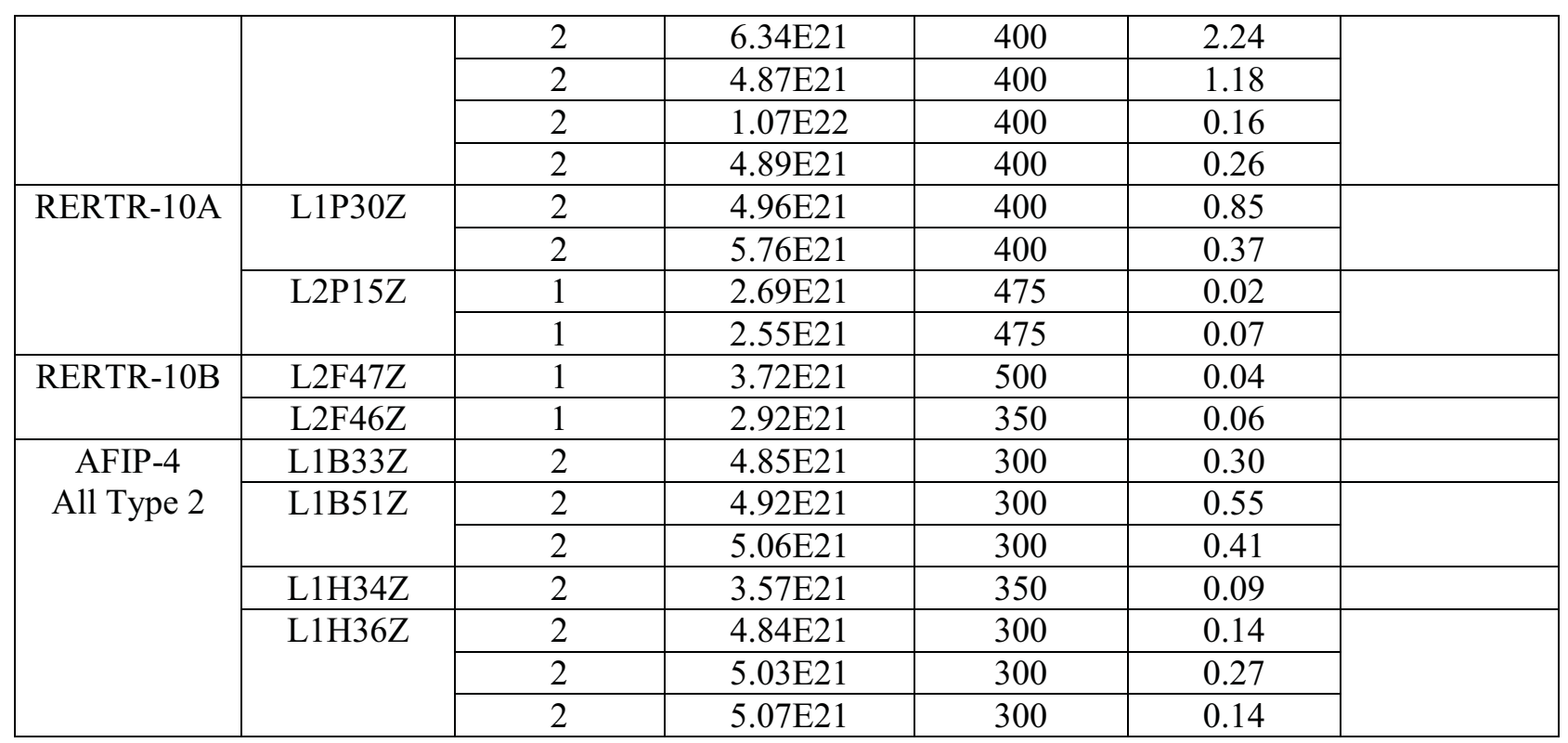

The data from Table 16 are plotted in Figure 92. This figure demonstrates that reasonable correlations exist between blister threshold temperatures and local fission densities in the RERTR-12 and AFIP-4 experiments; however, the data for the "old" experiments (prior to RERTR-12) show very poor correlation. This is attributed to "old" experiment data set including one data point (marked with a circle), i.e. plate L2F46Z from the RERTR-10A experiment, which appears to be an outlier. Plate L2F46Z (RERTR-10A) was blister annealed in 2012 and it is the only data point from the "old" data set that had low blister threshold temperature $\left(350^{\circ} \mathrm{C}\right)$. It is not clear why this particular plate exhibited lower blister temperature.

Four distinctive factors about L2F46Z plate are worth noting: 1$)$ the plate had thick $(0.020$-in.) fuel foil, 2) the plate operated at very high peak heat flux, 3) the alloy used in plate L2F46Z was made using casting sprues from other alloys and 4) the plate was stored for several years prior to blister testing in 2012. Statistical analysis of the data (see Appendix H) suggests that this particular point might be an outlier. In fact, excluding this data point from the data set (see Figure 93), results in a much better correlation between local fission density and blister anneal temperature for the pre-RERTR-12 data set. However a further explanation based on experimental facts is required to understand the factors that are causing the low blister threshold temperature. 


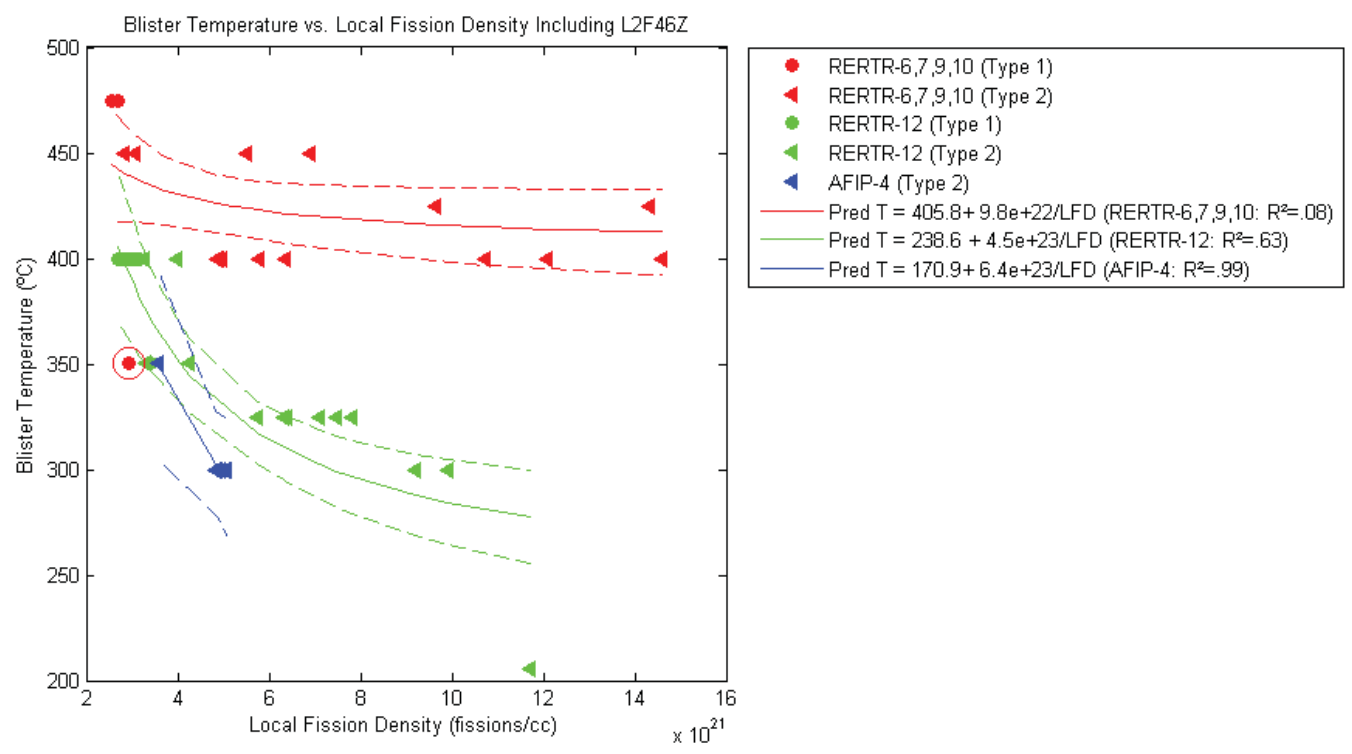

Figure 92. Blister temperature versus local fission density including RERTR-10A plate L2F46Z.

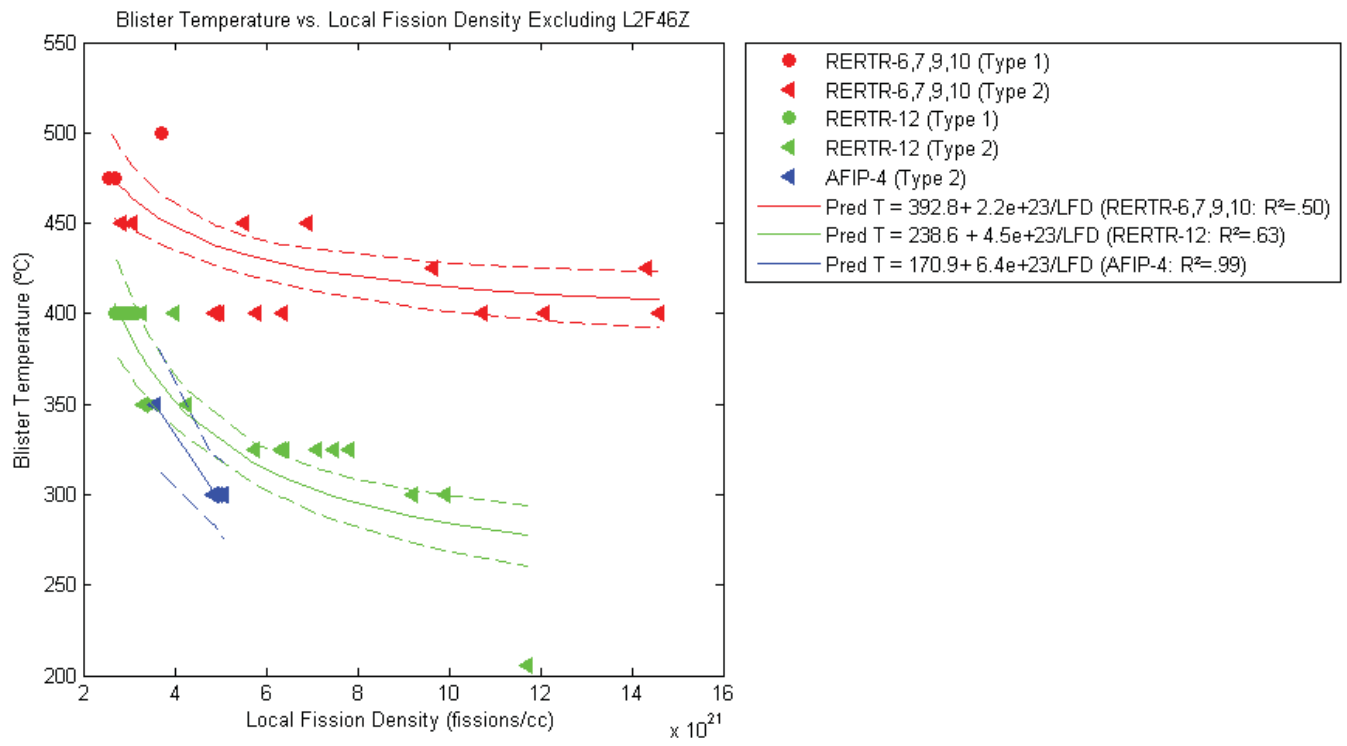

Figure 93. Blister temperature versus local fission density excluding RERTR-10A plate L2F46Z.

\subsubsection{Dependence of blister area on local fission density}

The following section summarizes the results from the determination of blister size as it correlates with the localized peak fission density in the discreet blister region. Blistered plates are listed in Table 16 with the corresponding areal blister size, localized peak fission density, blister type (1 or 2) and blister threshold temperature.

The area of all blisters for all blister annealed plates is plotted against fission density in Figure 94. The blisters within the oval are from plates without the zirconium interlayer and were larger Type 2 blisters with pillow-like characteristics. Two plates from the RERTR-6 experiment without the interlayer also exhibited smaller blisters. Most of the blisters to the left of the line at $4.0 \times 10^{21}$ fission density have Type 1 characteristics, with involvement of the clad to clad bond adjacent to the fuel in addition to the 
fuel-to-clad region. It is also interesting to note that all Type 1 blisters are from plates with a zirconium interlayer. Type 1 blisters are plotted separately in Figure 95. Further characterization work is required to understand the mechanism for formation of this type of blister.

The Type 2 blisters for plates with the Zr interlayer are plotted in Figure 96, and it is observed that they span all fission densities which include the region where the Type 1 blisters typically form. Type 2 blisters involve exclusively the clad-to-fuel interface. Examination of cross-sections from all sectioned blister anneal plates have repeatedly demonstrated that the blister does not occur between the $\mathrm{Zr}$ interlayer and the clad, but rather in the U-10Mo fuel meat in a region where fission-gas bubbles are observed to agglomerate. Figure 97 plots all the Type 2 blisters with the non-interlayer plates within the oval. Clearly, the interlayer makes a difference in the areal size of the blister. The mathematical fit of the Type 2 blister size data is presented in Figure 98.

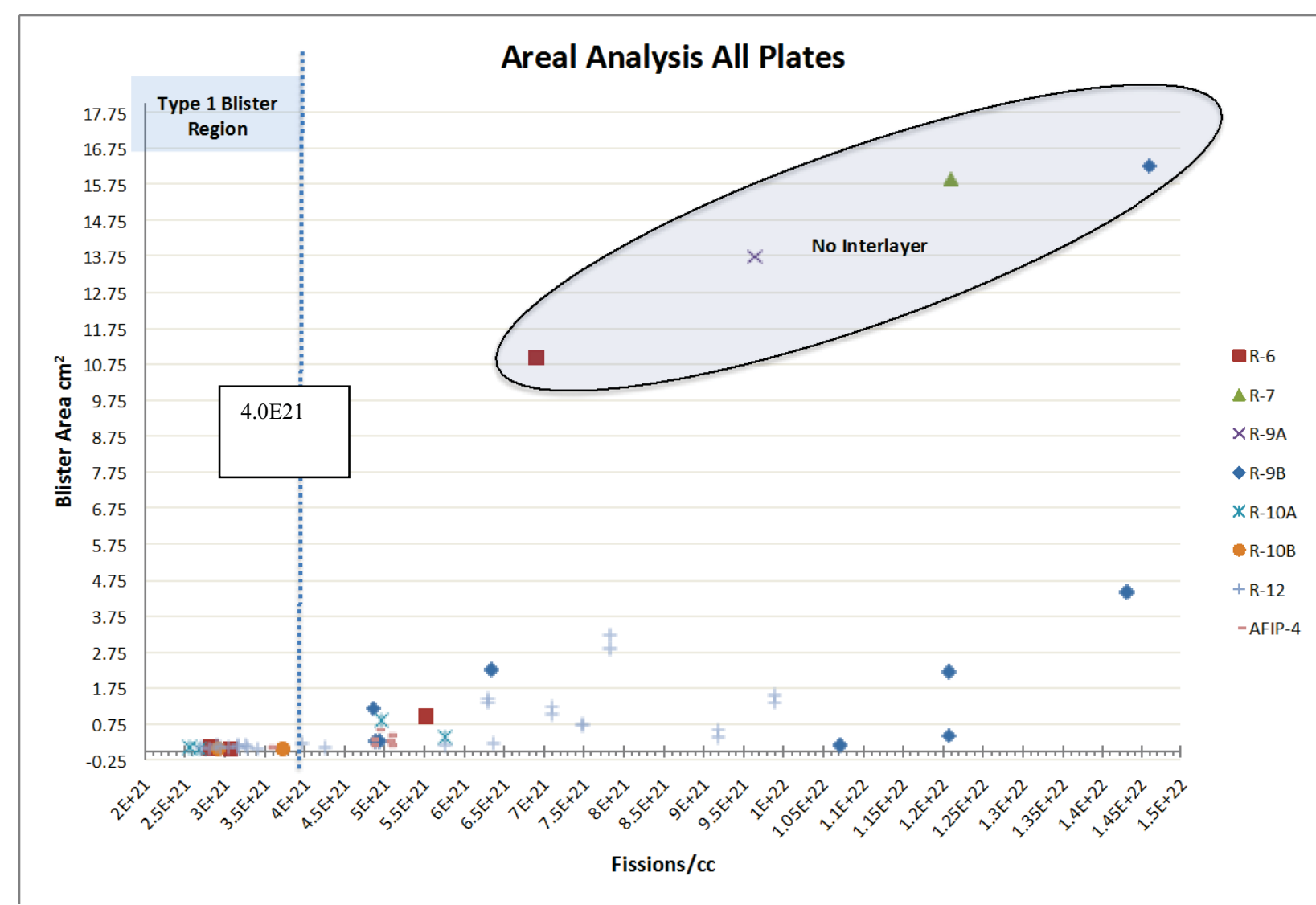

Figure 94. Area of individual blisters versus fission density for all blisters types 


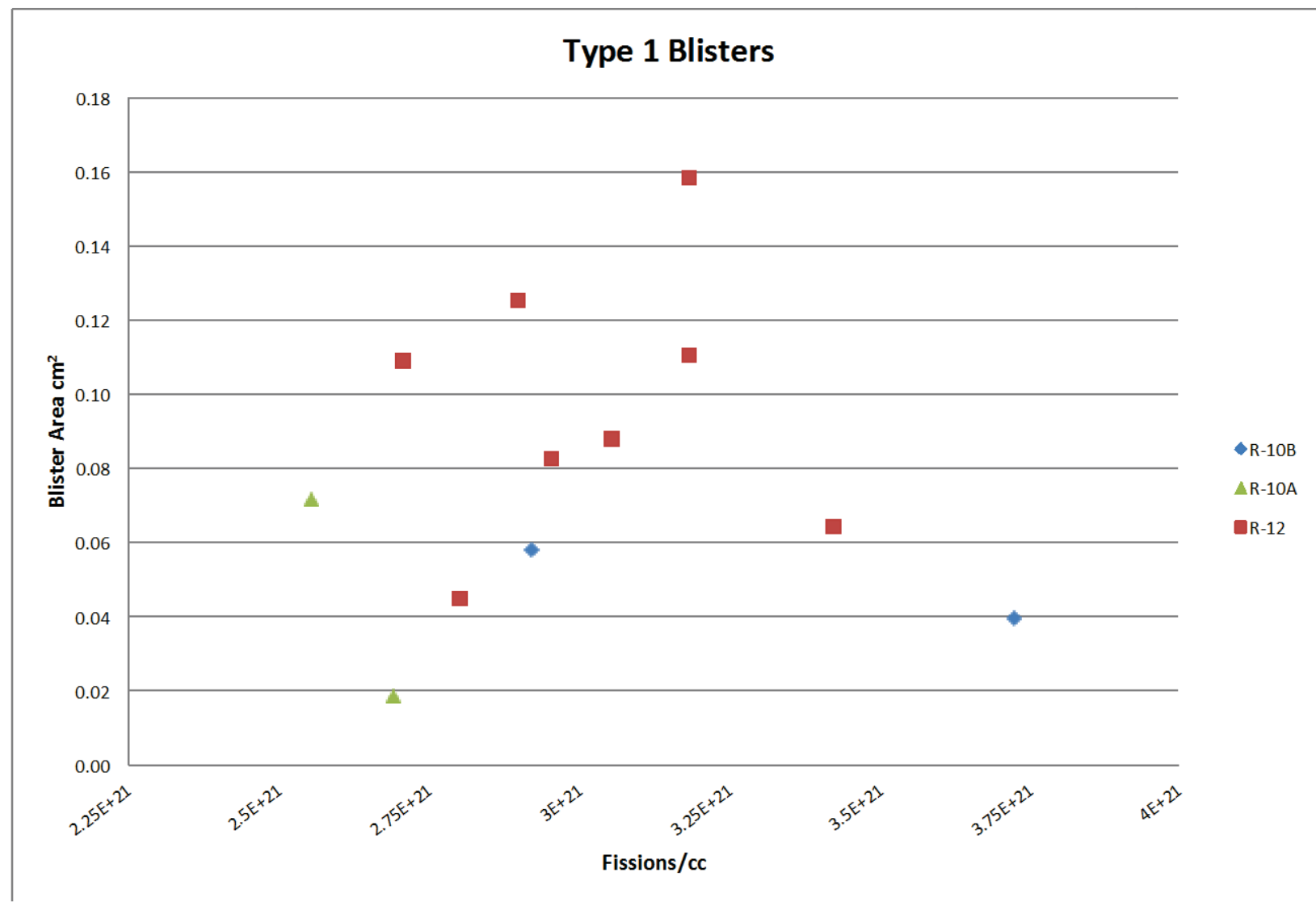

Figure 95. Area of individual blisters versus fission density for Type 1 blisters 


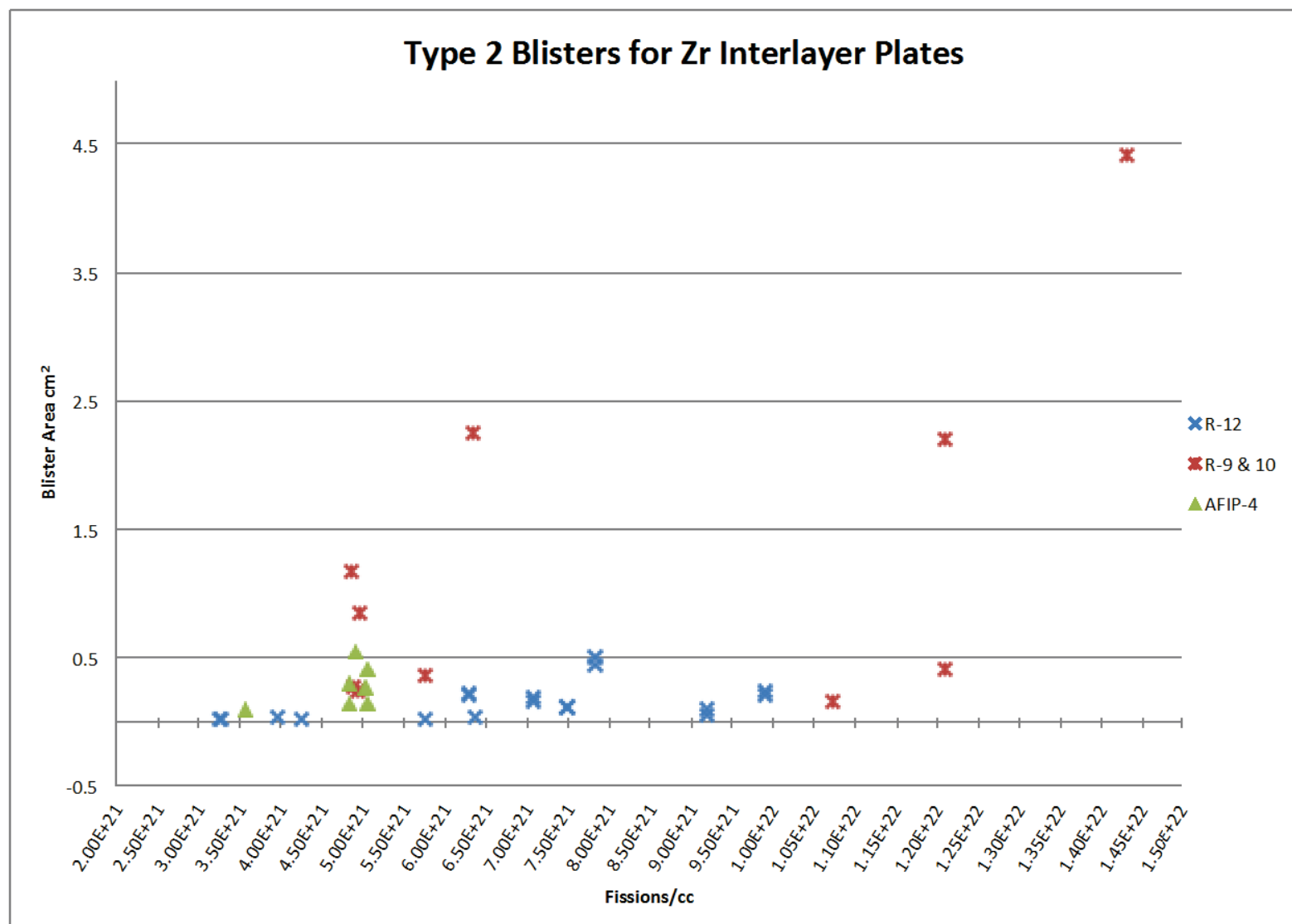

Figure 96. Area of individual blisters vs fission density for Type 2 blisters for plates with Zr interlayer. 


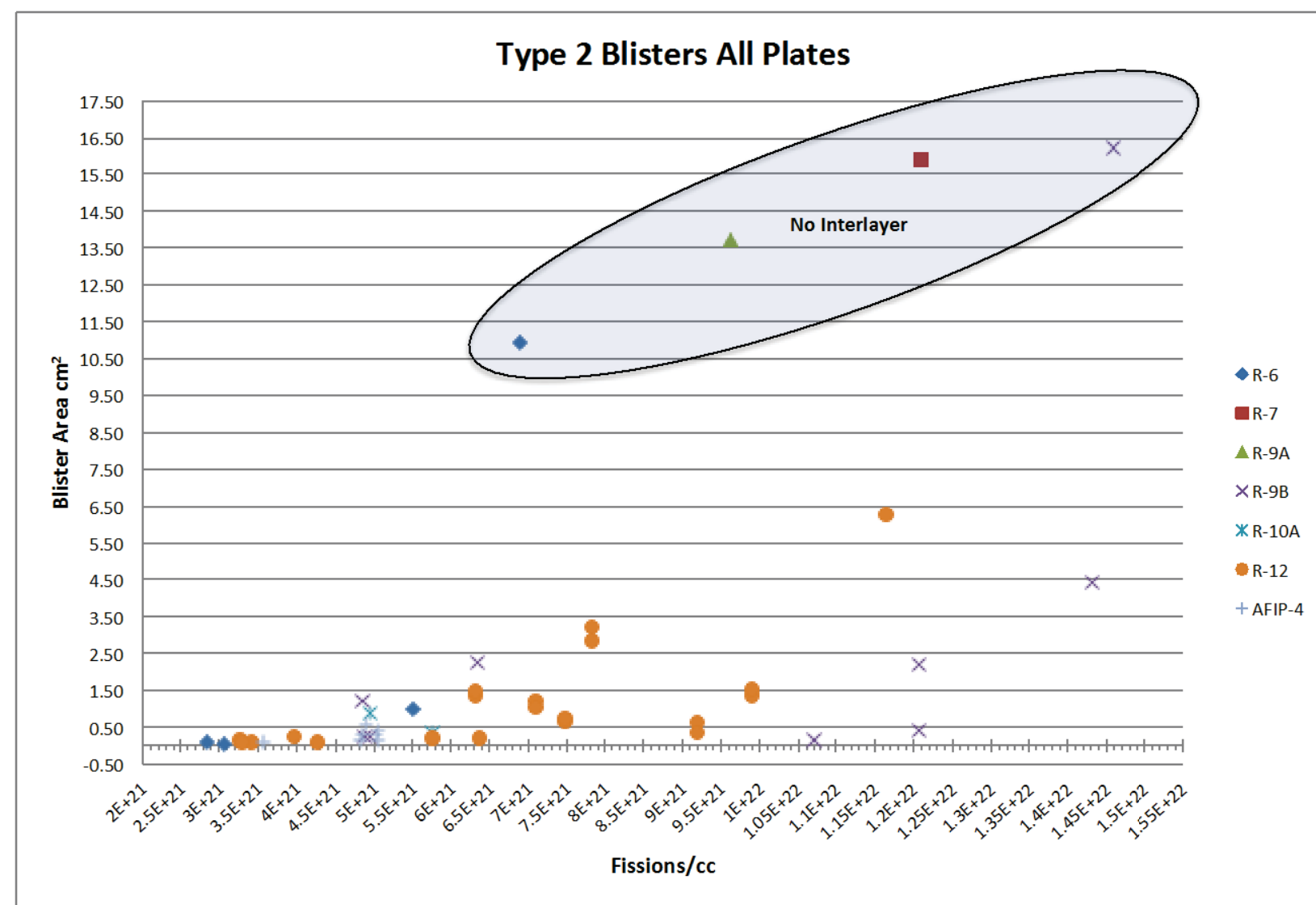

Figure 97. Individual blister area vs fission density for Type 2 blisters for all plates.

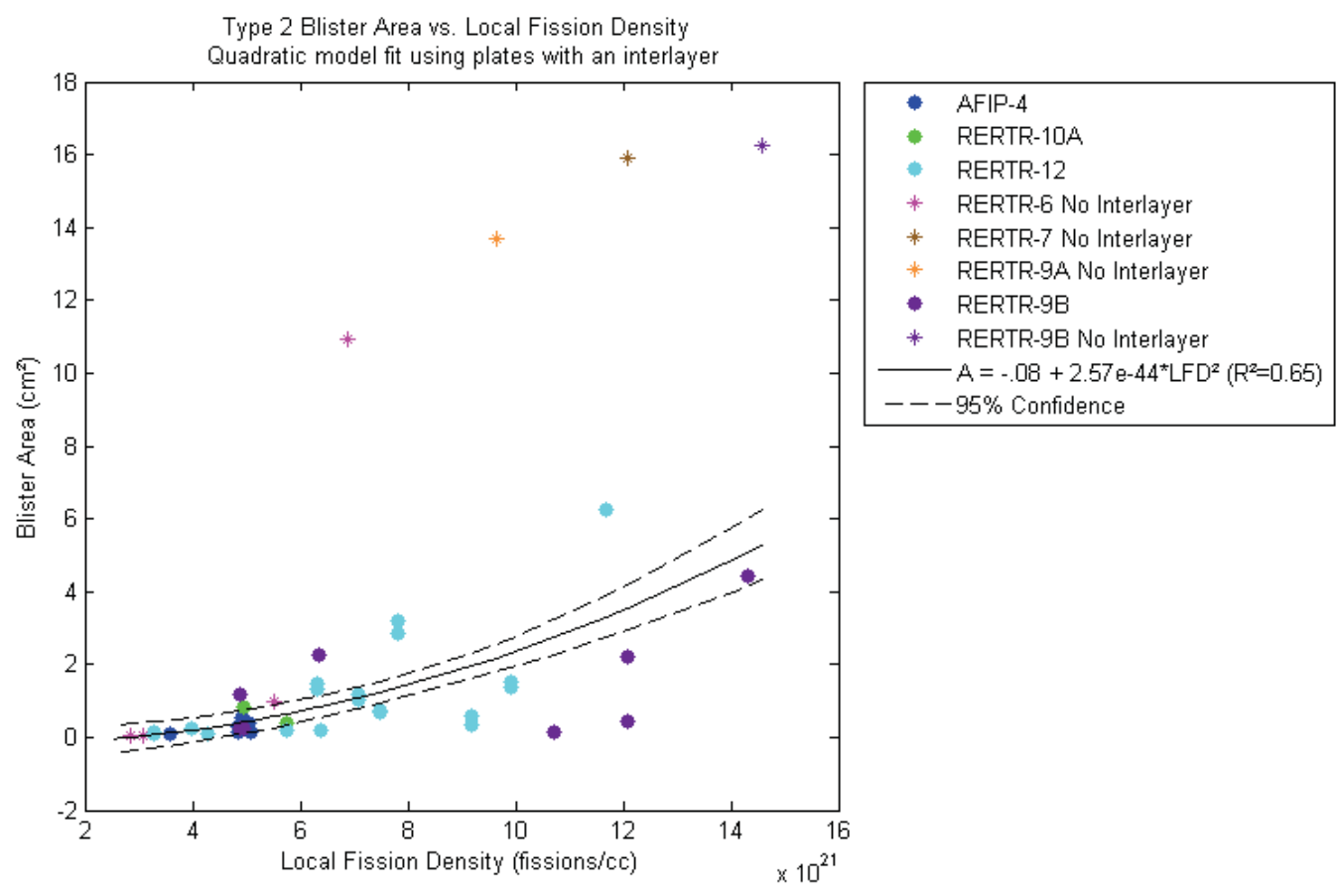

Figure 98. The size of the blister area as a function of local fission density. 


\subsection{Mechanical Modeling}

It has been hypothesized previously (see PLN-4155) that blister formation may be mechanically driven and that the evolution of stress prior to post-irradiation blister anneal testing might be responsible for the differences in blister threshold temperature seen between two groups of plates. Mechanical modeling was used to simulate the evolution of stress states in the plates produced by different fabrication methods and irradiated under different conditions and configurations and, ultimately, to link the differences in mechanical behavior of the plates to the differences in blister threshold temperatures.

\subsubsection{Simulation of the cold rolling fabrication process}

\subsubsection{Background}

Previous simulations have shown that residual stress states of the plates greatly affect their mechanical behavior during in-service conditions. It is important to define properly the initial stress state of the fuel foil to assess the stress-strain characteristics of the plates after the HIP process, during irradiation, and during post-irradiation blister annealing. The first series of simulations were performed for the plates assuming that as-rolled foils have negligible residual stress. It is known that this assumption (zero residual stress) was not correct for the cold-rolled foils; it is therefore important to first establish the initial state of the cold rolled foils.

To accomplish this task, a simulation of the cold rolling process was performed using ABAQUSExplicit, in which finite deformation elasto-plastic constitutive relations are used to estimate material deformation during the rolling process. Material parameters used in cold rolling simulations are given in Table 17.

Table 17. Material properties.

\begin{tabular}{|c|c|c|c|c|}
\hline Physical & \multicolumn{2}{|c|}{ Elastic } & \multicolumn{2}{c|}{ Plastic } \\
\hline Density[kg/m3] & $\begin{array}{c}\text { Modulus } \\
{[\mathbf{M P a}]}\end{array}$ & $\begin{array}{c}\text { Poisson's Ratio } \\
{[-]}\end{array}$ & $\begin{array}{c}\text { Stress } \\
{[\mathbf{M P a}]}\end{array}$ & Strain[mm/mm] \\
\hline 16750 & 90000 & 0.38 & $\begin{array}{c}883 \\
921.97\end{array}$ & $\begin{array}{c}0 \\
0.13886\end{array}$ \\
\hline
\end{tabular}

The following assumptions were made for this simulation

1. Due to a lack of compressive material properties, tensile properties were used

2. Material anisotropy was neglected since representative anisotropic data are not available

3. Since rolling speed is relatively slow, the material properties were assumed to be rate independent

4. The rolling specimen remains close to the ambient temperatures during the process; therefore, the temperature effects were ignored.

The full size $\mathrm{Zr}$ co-rolled $\mathrm{U}-10 \mathrm{Mo}$ fuel foil, which is approximately $85 \mathrm{~mm}$ wide $\times 750 \mathrm{~mm}$ long $\times$ $0.5 \mathrm{~mm}$ thick, was subjected to a simulated cold rolling process. Rollers were modeled with dimensions of $203.2 \mathrm{~mm}$ long and $41.275 \mathrm{~mm}$ in diameter. Approximate rolling speed is $27.4 \mathrm{~mm} / \mathrm{sec}$ as described in [1]. Angular velocity of $1.33 \mathrm{rad} / \mathrm{sec}$ was applied to the rollers so that the slip would be virtually zero, (i.e. $\left.W_{\text {roller }}=V_{\text {foil }} / r\right)$.

To reduce computational time, the model took advantage of the symmetry conditions about the $x-y$ and $x-z$ planes (thickness and width directions). The quarter-symmetric model was meshed with 3D linear brick elements (C3D8R), using reduced integration with relaxed stiffness hourglass control. Ten layers, equally spaced, were used to represent the thickness of the foil. Nodal divisions along the length and width directions are 250 and 80 , respectively. The 3D rigid element (R3D4) of ABAQUS was used to 
represent the roll surface. The rigid surface was comprised of 250 equally spaced elements around a quarter of the roll circumference. This setup can be seen in Figure 99.

Initial thickness of the simulated work piece was $0.5 \mathrm{~mm}$. The gap between the rolls was slightly shorter than the projected final thickness to accommodate the elastic recovery of the cold-rolled foil. Consequently, the gap between the rollers was set to be $0.250 \mathrm{~mm}$ to achieve foil thickness of approximately $0.254 \mathrm{~mm}$ after the rolling process (thickness reduction ratio of $50 \%$ ). To reduce computational expense, a representative section, with reduced width and length dimensions $(3 \mathrm{~mm}$ wide $\times$ $6 \mathrm{~mm}$ long $\times 0.5 \mathrm{~mm}$ thick), was used.

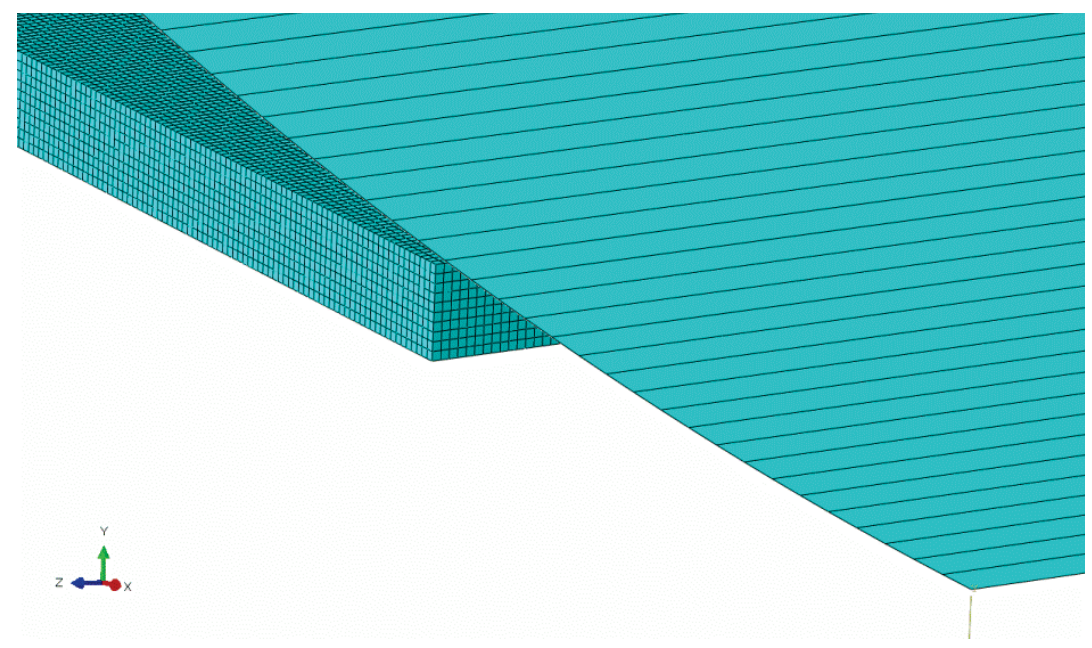

Figure 99. Cold rolling 3D setup

A surface-to-surface contact condition was defined between the roll and the roll strip. Relative tangential displacement was provided through a finite sliding condition. The contact-friction conditions were implemented using a penalty method. The friction coefficient was assumed to be 0.3 between the roller and the work piece.

\subsubsection{Results and Discussion}

Figure 100 presents a side-by-side comparison of the equivalent stress map of the cold-rolled foil predicted by modeling and an actual image of a cold-rolled foil with cracks at the edge. As seen in results from simulation (Figure 100a), the areas with the highest stress (marked by the arrows) are concentrated along the edge of the foil, running roughly its entire length. Such regions of high stress are expected to be more susceptible to the development of localized cracks, as is observed during the rolling process (Figure $100 b)$.

Figure 100a demonstrates that cold rolling results in significant variability of the magnitude of the equivalent stress over the entire foil area, with stress as high as $\sim 500 \mathrm{MPa}$ in the mid-section and as low as $30 \mathrm{MPa}$ in other regions. This is important because the fuel foils for the actual plates are cut from the cold rolled strip, which results in a redistribution of residual stresses that are present after rolling; therefore, the initial stress field of a trimmed foil would depend on the location of the actual cut.

For this simulation it was assumed that the foils were cut out from the volumetric center of the cold rolled foil, where the stress pattern is relatively uniform. 

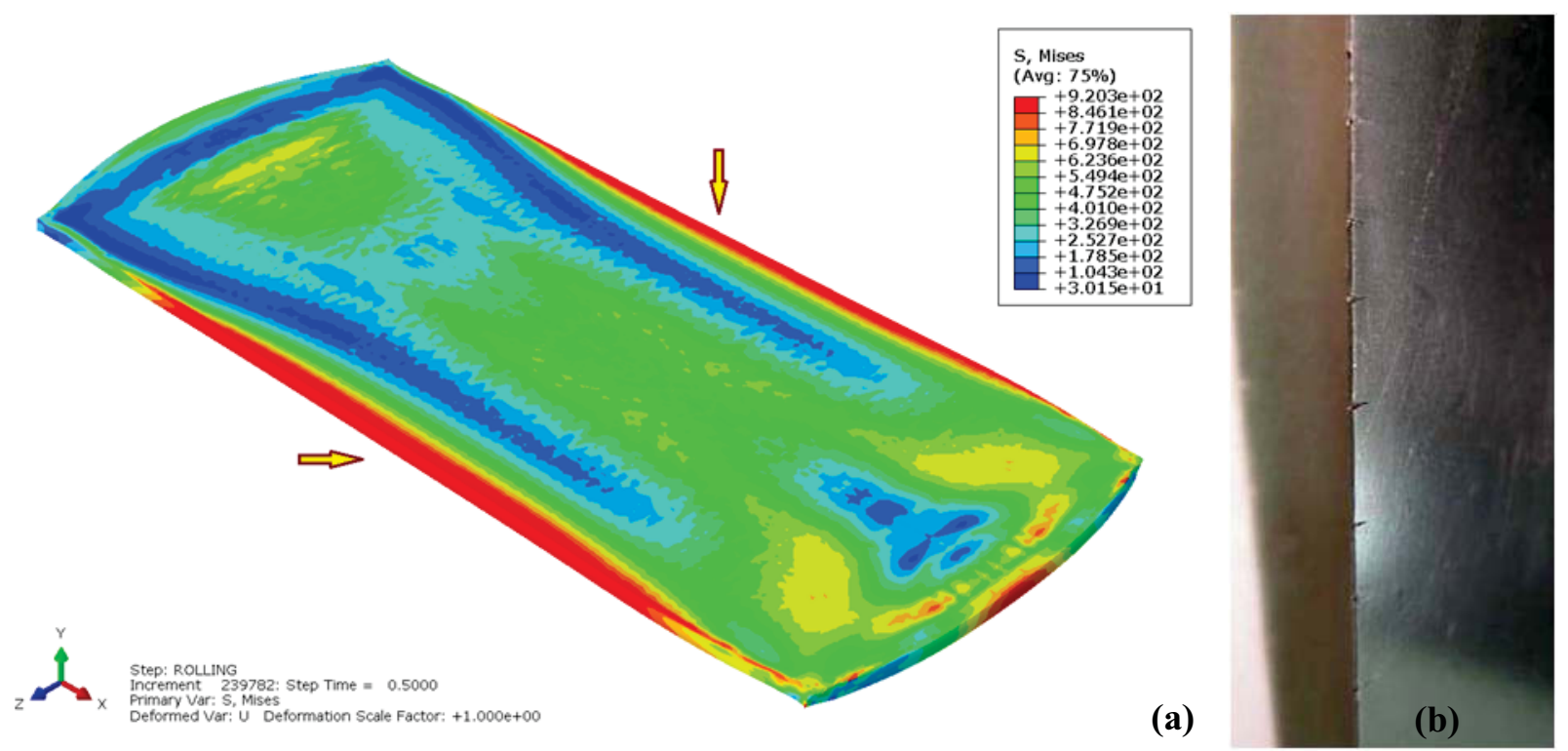

Figure 100. (a) A map of the equivalent stress [MPa] in the cold rolled foil and (b) an image of the cold rolled foil (from [1])

Simulations presented in this work consider a foil with 50\% cold reduction in a single pass. Because of this high reduction ratio, high plastic deformations and material anisotropy are anticipated. Figure 101 presents the calculated deformation pattern along the thickness of the cold-rolled foil. As seen from the contour plot, the areas of high plasticity are located close to the surface of the cold-rolled foil.

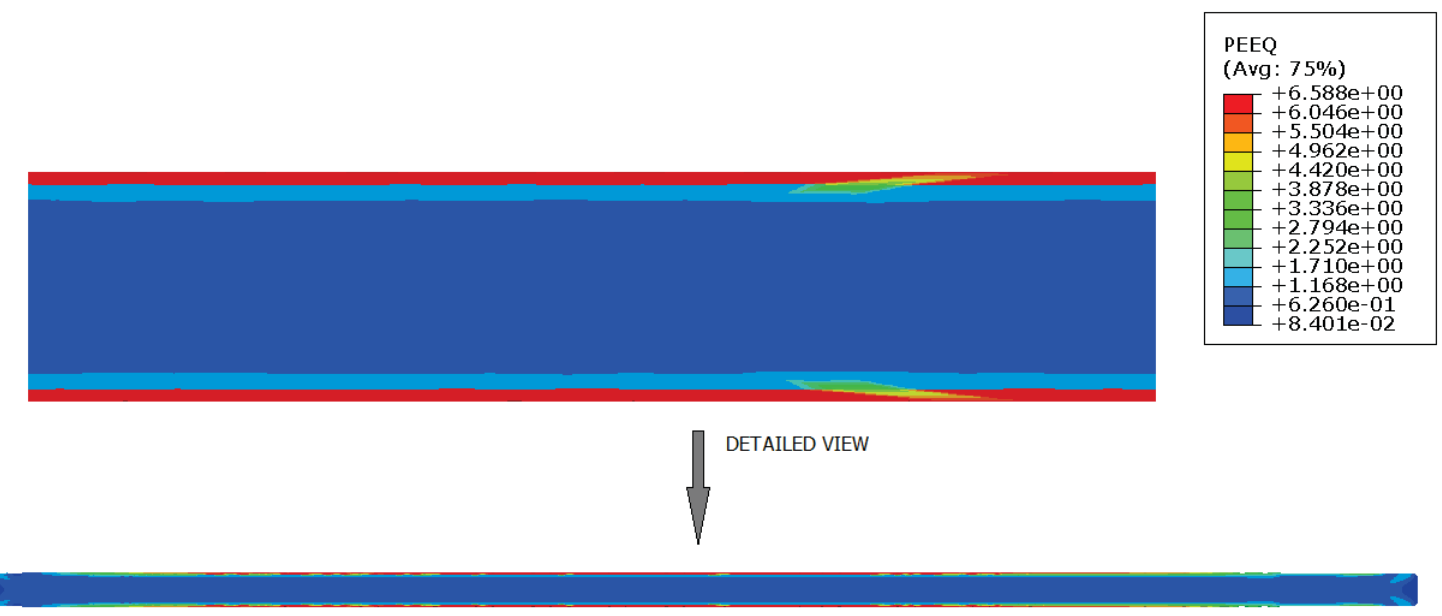

Figure 101. A map of the equivalent plastic strain along the thickness of the cold-rolled foil.

Simulation also predicts that the normal stresses (both tensile and compressive) in the core of the cold-rolled foil can reach significant magnitude. The greatest normal stress component was found to be in the rolling direction. Figure 102 shows normal stress variation along the rolling direction. The presence of high stress and, especially, plastic strains would significantly affect grain orientations which, in turn, can lead to an anisotropic material behavior. 

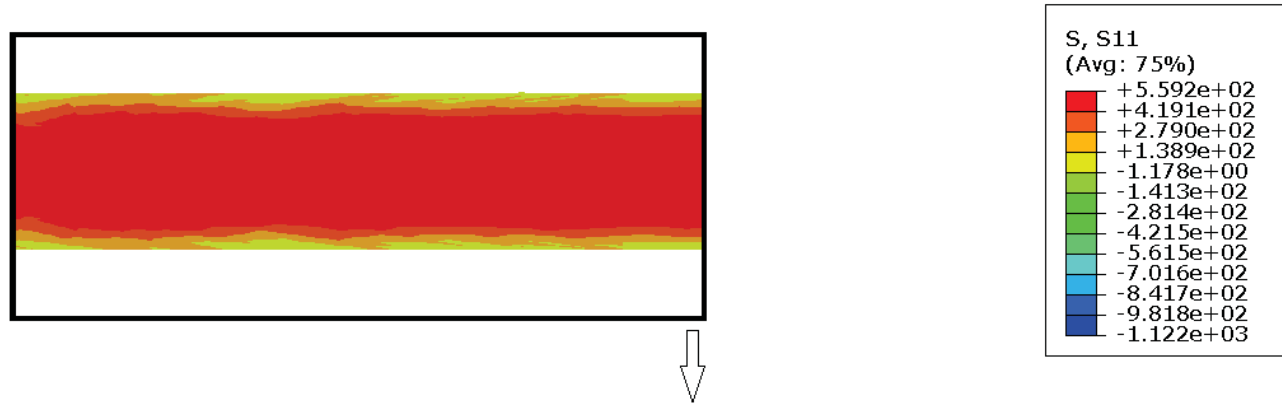

Figure 102. A map of the normal stress [MPa] along the rolling direction in the cold-rolled foil.

Similar behavior was observed for the normal stress component along the width direction $\left(\sigma_{\mathrm{zz}}\right)$ of the cold-rolled foil (see Figure 103). However, the stress component in this direction goes from $-400 \mathrm{MPa}$ (compressive) on the foil surface to $+200 \mathrm{MPa}$ (tensile) in the core of the foil, which demonstrates a clear transition from compressive to tensile state.
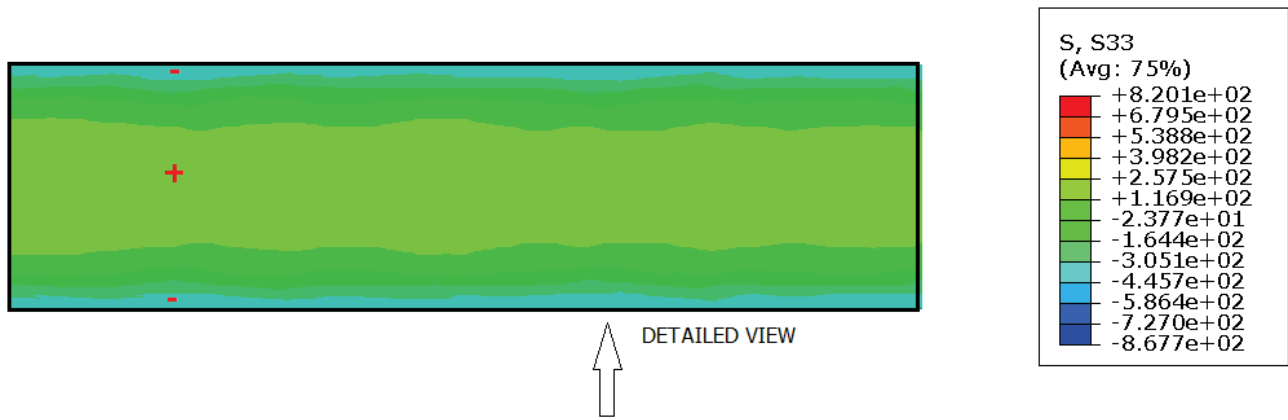

Figure 103. A map of the normal stress along the width direction of the cold-rolled foil.

Figure 104 compares calculated normal stress and shear stress patterns in cold rolled foil. As seen from the graphs, the shear stress is significantly lower in magnitude than normal stress. The latter is particularly high in the foil rolling direction.
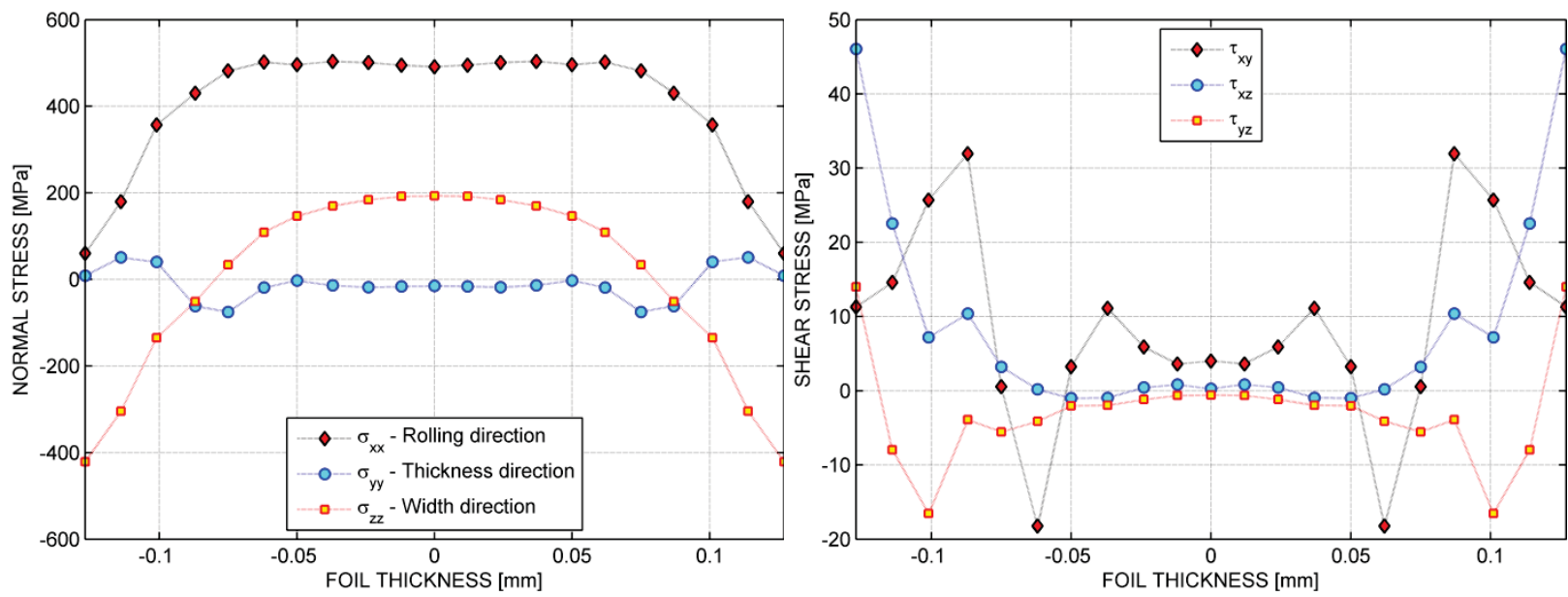

Figure 104. Stress profiles along thickness of the cold rolled foil (a) normal stress, and (b) shear stress. 
Finally, Figure 105 presents equivalent stress and principal stress profiles along the thickness of the cold-rolled foil. The magnitude of the overall stress (Figure 105a) fluctuates between 440 and $525 \mathrm{MPa}$. Governing principal stress trends (Figure 105b) suggest a transition from compressive state to a tensile state along the thickness of the cold-rolled foil. From these figures, it can be understood that the surface of the foil is under a compressive state of approximately $475 \mathrm{MPa}$, while the core of the foil experiences a tensile state of approximately $450 \mathrm{MPa}$.
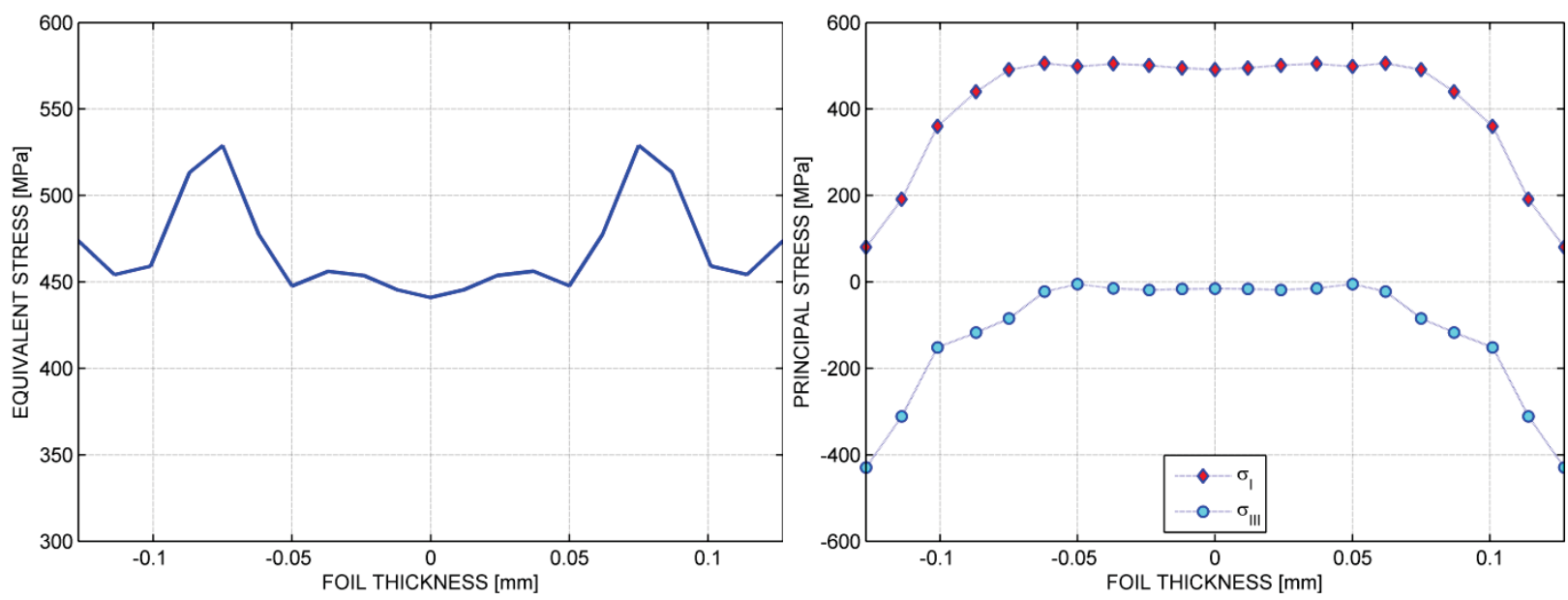

Figure 105. Stress profiles along thickness of the cold-rolled foil: (a) equivalent stress, and (b) principal stress.

\subsubsection{Conclusions}

Several ABAQUS simulations were performed to define the initial stress state of the cold-rolled foil. Simulations demonstrate that both stress and strain vary along the thickness of foil, reaching substantial magnitude in some regions.

Usually, having a compressive stress state on the foil surface is considered beneficial; however, the presence of very high plastic deformations on the surface of the foil may suggest that these local regions may behave differently than the foil center during irradiation and blister anneal tests. Because of this fact, the bond itself and the neighboring regions should be further evaluated by strain-based criteria, rather than stress-based criteria.

Unlike the foil surface, the plastic deformations of the fuel core are lower in magnitude, which means that the fuel core can tolerate further strains. However, the fuel core was found to be in a tensile stress state, which might indicate that this region is more susceptible to blister formations and crack development.

Another important conclusion is based on the fact that the cold-rolled strip showed significant stress variations (from $\sim 30 \mathrm{MPa}$ to $\sim 920 \mathrm{MPa}$, as shown in Figure 100). This implies that foils produced from the different regions of the same cold-rolled strip might exhibit different mechanical behavior under irradiation and during blister anneal. In fact, this could manifest itself as foils cut out from the same cold roll strip having different blister temperatures.

Finally, simulations suggest there is likely material anisotropy in the cold-rolled foil. Anisotropy is typical for cold rolled materials. Both microstructural effects (which were not considered in current simulations) and anisotropic effects may lead to differences in mechanical behavior during irradiation and subsequent blister anneal testing.

The simulations of the initial stress state show the presence of extensive stress and strain fields on the cold-rolled foils. The next step is to develop models and run simulations to determine stress evolution in 
those plates with cold-rolled foils during in-service conditions. These simulations will include plate bonding process via HIP, plate irradiation in two different configurations ("face-on" versus "edge-on") and post-irradiation blister anneal treatment. This work is in progress. Ultimately results obtained for the plates with cold rolled foils will be compared with results for the plates with hot rolled foils.

\subsubsection{Investigation of In-pile Orientation}

\subsubsection{Background}

A major change occurred in configuration of the plates in the reactor core with the RERTR-12 experiment. In all mini-plate experiments prior to RERTR-12, the plates were oriented "edge-on" towards core center. That configuration resulted in non-uniform distribution of power and burnup within the plates. To reduce this effect and obtain more uniform distribution, RERTR-12 plates were irradiated in a "face-on" configuration towards the core center. AFIP-4 was irradiated in the Center Flux Trap position. Correspondingly, a transverse profile similar to "face-on" configuration was observed in AFIP-4 plates. The axial profile was a negative parabolic with a maximum burnup of $\sim 4.5 \times 10^{21}$ fissions $/ \mathrm{cm}^{3}$ at the core centerline.

It has been hypothesized (see PLN-4155) that different in-core experiment configurations might be associated with different stress fields, which, in turn, can lead to differences in blister threshold temperatures. To evaluate this hypothesis and assess stress fields of the plates in "edge-on" versus "faceon" configurations, several finite element simulations were performed on plates with hot-rolled and annealed foil properties (i.e. RERTR-10 plates). Because the foils in these plates are annealed prior to the HIP process, it is assumed that there are very little or no residual stress before the HIP canning. Furthermore, it was assumed that there is no material anisotropy before HIP bonding. Although this assumption is not entirely accurate, it is expected that annealing will reduce the material anisotropy and relieve some of the stresses caused by the hot-rolling process. Consequently, hot-rolled and annealed foil should have smaller stress gradients, less anisotropy, and more-uniform microstructure than the foils fabricated with the cold-rolling technique.

Irradiation models of the plates fabricated with cold-rolled foils are currently under development. As mentioned previously, cold-rolling simulations showed evidence of residual stress of considerable magnitude and with significant stress gradients. Therefore, a quite different HIP stress profile is expected.

The following section presents results of the analysis of the structural response in the hot-rolled and annealed foils irradiated in "edge-on" and "face-on" configurations.

\subsubsection{Model}

Simulations were accomplished using a plate with the average fission density of $4.04 \times 10^{21}$ fissions $/ \mathrm{cm}^{3}$. The burnup profiles were selected to be representative of the plates in the "edge-on" and "face-on" configurations. Swelling was modeled as an isotropic volumetric strain rate using the swelling equation [2] and the local-to-average fission rates across the width of the plate (shown in Figure 106). Each plate was irradiated for 98 days at an average fission rate of $5.7 \times 10^{21}$ fissions $/ \mathrm{cm}^{3}-\mathrm{s}$. Material properties and the governing mathematical formulations have been previously documented $[3,4]$. 


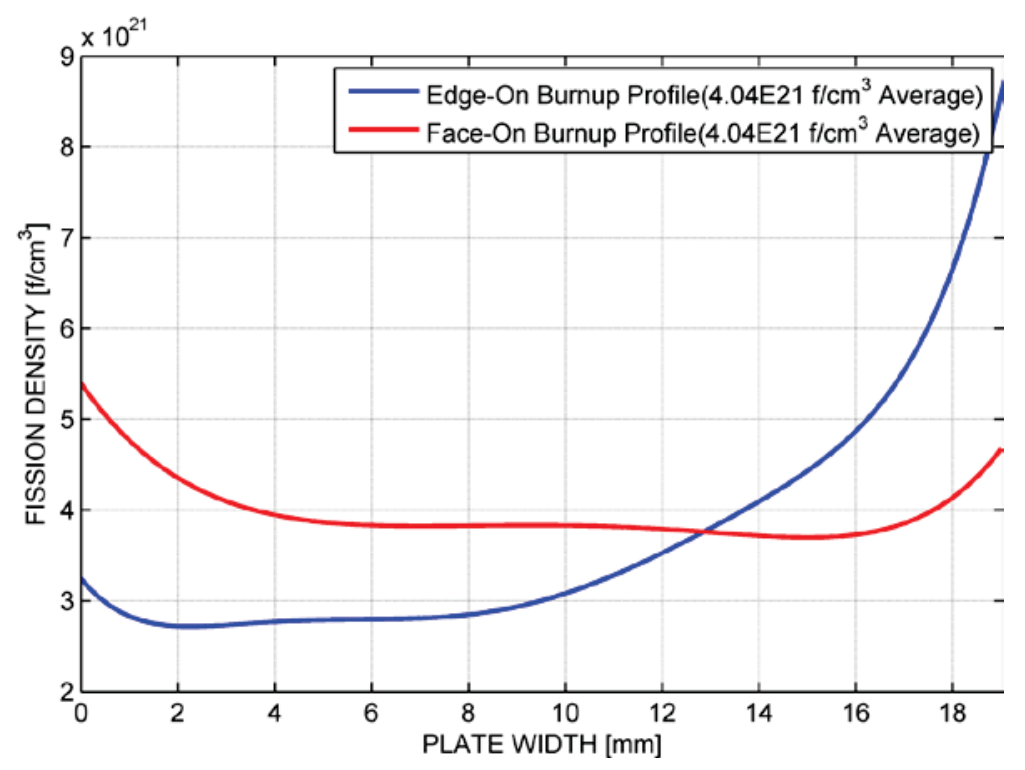

Figure 106. Burnup profiles for "edge-on" versus "face-on" simulations

\subsubsection{Results and Discussion}

The largest tensile stress (largest maximum principal stress), equal to $127 \mathrm{MPa}$, was predicted for the plates in the edge-on configuration. This compares to $77 \mathrm{MPa}$ for the plates in the face-on configuration. Compressive stresses for the edge-on plates range from -25 to $-835 \mathrm{MPa}$ and, for the face-on plates, from -12 to $-468 \mathrm{MPa}$. The yield stress for $\mathrm{U}-10 \mathrm{Mo}$ is $760 \mathrm{MPa}$ at $94^{\circ} \mathrm{C}$ and $655 \mathrm{MPa}$ at $205^{\circ} \mathrm{C}$ for unirradiated U-10Mo. The irradiated properties of U-10Mo have not yet been determined; therefore, material properties were modeled as constant through irradiation. Fracture strength measurements of irradiated U-10Mo will be necessary to calculate the mechanical conditions for blister formation, if the blister is initiated within the fuel. If the blisters initiate at the UMo-Zr interface, material properties of the interface will be required to calculate the mechanical conditions necessary for blister formation. The operating temperature of the fuel is between 142 and $167^{\circ} \mathrm{C}$, depending on location. All directional, principal, and equivalent (Von-Mises) stresses in the plates for both irradiation conditions are below the un-irradiated yield strength; thus, no plastic yielding is seen in the plate simulations. Despite the fact that none of the principle stresses exceeds the yield stress of the material, it is still possible for yielding to occur from the combination of stresses. For this reason, the equivalent stress was calculated and is shown in Figure 107. 

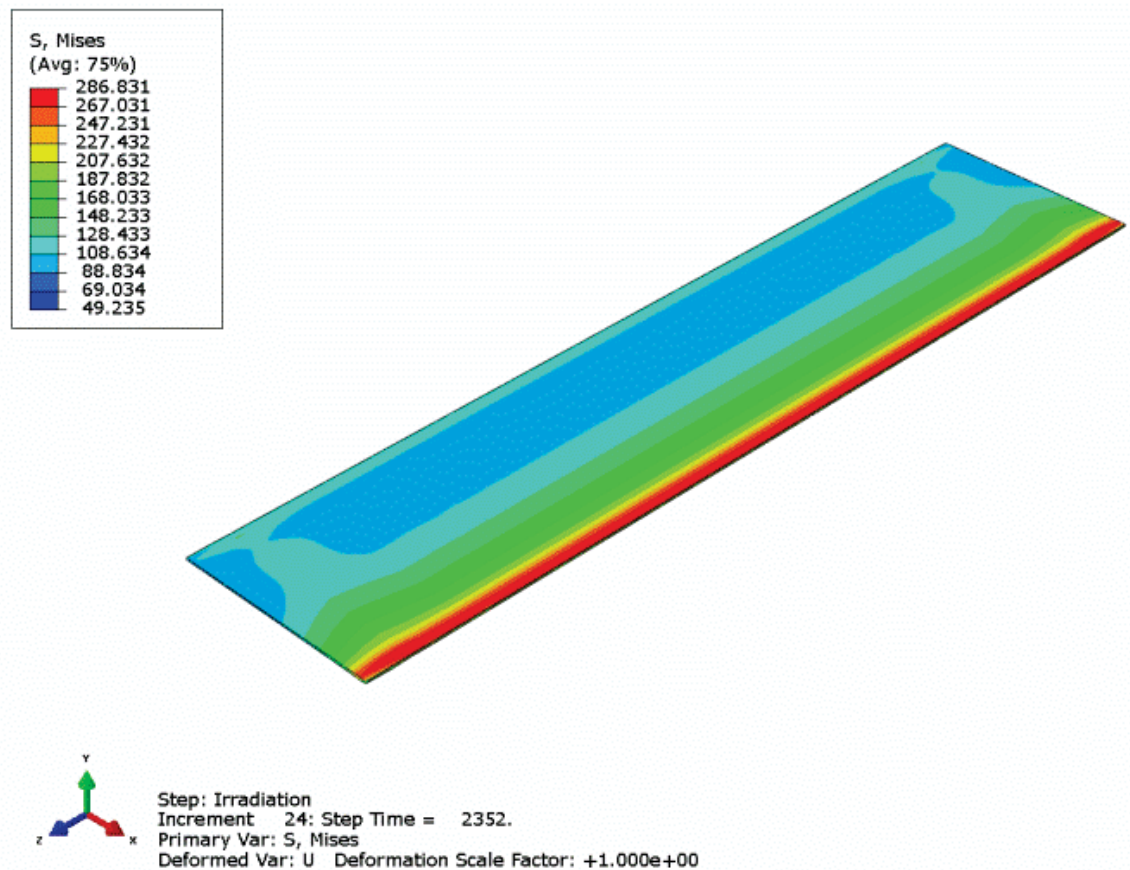

(a)

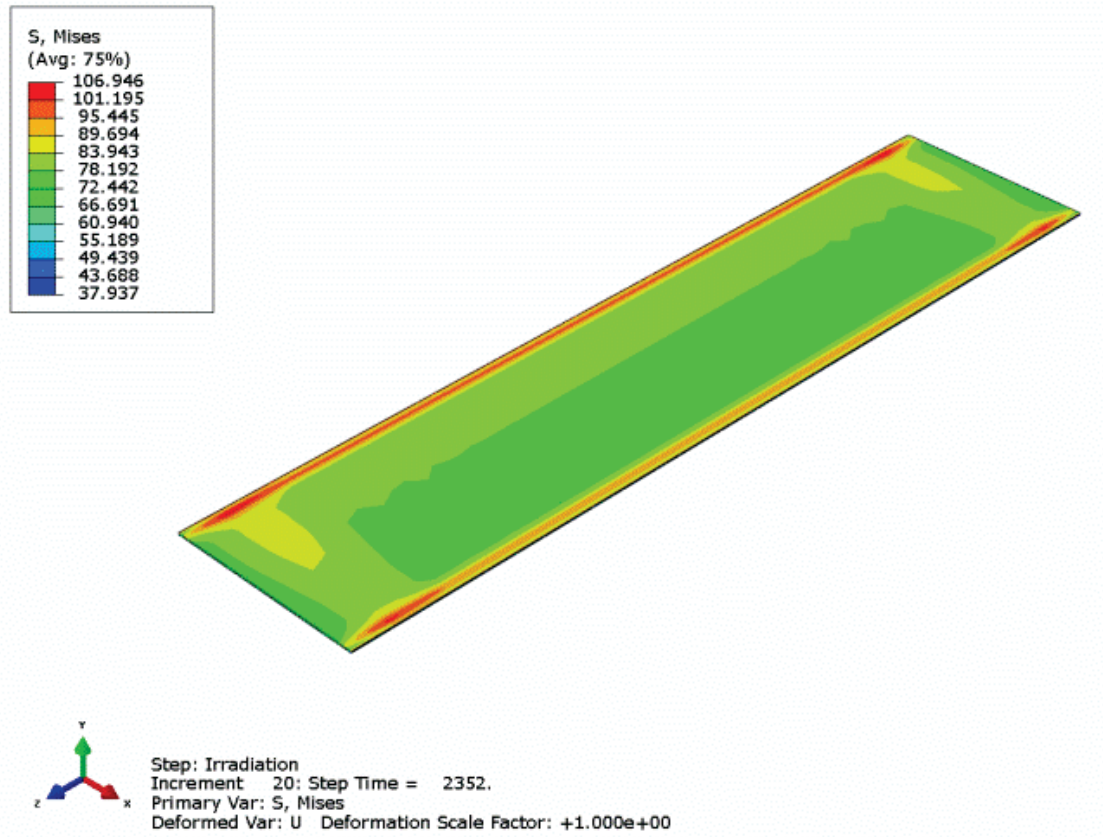

(b)

Figure 107. Equivalent stress contours for the plate in (a) edge-on (b) face-on configurations.

Stresses in the cladding are found to be similar for plates in both orientations. Yielding of the aluminum occurs around all of the sides of the fuel for both irradiation conditions. It is assumed that the cladding is sufficiently ductile at the end of irradiation that a strain-based failure will dominate. For plates in edge-on orientation, the plastic strain is $\sim 0.2$ at most locations on the high-burnup edge and reaches a maximum of 0.372 at the corners of the plate. For plates in the face-on orientation, plastic strain has a maximum of 0.104 . This shows that cladding cracking is more likely to occur in plates with edge-on orientation; however, simulations deviate from experimental measurements of the plate thickness at the 
plate sides. Thus, strain values of the cladding should be used with caution if the attempt is to apply strain-based failure criteria.

In the thickness direction $\left(\sigma_{22}\right)$, a tensile state is observed from the onset of irradiation at locations just inside the ends of the fuel. The stress magnitude along the thickness direction $\left(\sigma_{22}\right)$ grows from slightly compressive at the beginning of the irradiation to a localized maximum (near the top and bottom of the plates) of $74 \mathrm{MPa}$ and $123 \mathrm{MPa}$ for the plates in the face-on and edge-on orientations, respectively. It was found that the majority of the plate has very little stress in the thickness direction $\left(\sigma_{22}\right)$, and there is compressive stress at the plate perimeter (up to $-390 \mathrm{MPa}$ ). For locations where a tensile state is observed along the thickness direction, the stresses in the other two directions (along the length and width of the foils) are compressive. At the beginning of irradiation, the magnitude of these stresses is between - 249 and $-285 \mathrm{MPa}$ for $\sigma_{11}$ (along plate width); and -251 and -268 MPa for $\sigma_{33}$ (along plate length). Shear stresses have a magnitude less than $30 \mathrm{MPa}$ at all times; thus, shear stresses should have little or no contribution to the overall stress state of the foils (i.e., the stress state of the foil is not shear dominated).

\subsubsection{Conclusions}

Irradiation behaviors of the plates with hot-rolled and annealed foil were simulated in two different irradiation configurations (edge-on and face-on).

It was shown that the magnitude of stresses is greater in the fuel plates in the edge-on orientation, however, the same model cannot be used to make accurate assessment for the lower blister temperatures observed in the RERTR-12 "cold-rolled" plates. Although the blister anneal tests for these plates have not yet been modeled, extrapolation of the previous results [5] suggests that the magnitude of tensile stress during blister testing will be higher for the plates in the edge-on orientation. For plates irradiated in the face-on configuration, the swelling strain is distributed more or less uniformly across the entire plate. Consequently, no localized stress concentration was found on foils which were irradiated in the face-on orientation.

Conclusions from model simulations can only be made in reference to the assumed blister mechanism and the irradiation-dependent material properties of U10Mo. Plate orientation in reactor can alter several parameters affecting blister formation: (1) more fission gas will be created at the locations of higher burnup, (2) swelling due to solid fission products will be greater at locations of higher burnup, (3) yield strength will be affected at locations of higher burnup, (4) higher stresses are observed at locations of higher burnup. Simulations of plate configuration have lead to conclusion (4) above, however accurate prediction of blister formation requires a more comprehensive description of blistering mechanism and the knowledge of the irradiation dependent material properties at the blister location.

\subsubsection{Future Work:}

A mechanistic model for the development of fission gas bubbles, the stresses they produce, and the conditions required to form a blister is under development. It combines aspects of stress and temperature dependent gaseous swelling, creep around bubbles, and stresses between bubbles. The macroscopic results of this mechanism will be modeled. Additionally, an attempt will be made to model this mechanism on a meso-scale coupled with macroscopic models. The feasibility of this modeling technique is not yet clear, however, this has been performed, with varying degrees of success, for LWR fuel. The predictive ability of these models will be limited by the irradiation-dependent elastic-plastic properties of the fuel.

\subsubsection{References}

[1] G. A. Moore and M. C. Marshall (2010). Co-Rolled U10Mo/Zirconium- Barrier-Layer Monolithic Fuel Foil Fabrication Process. INL Internal Report, Paper Number INL/EXT 10-17774. 
[2] G.1. Hofman, Yeon Soo Kim, A.B. Robinson. "Fission Induced Swelling and Creep of Uranium Molybdenum Alloy Fuel”. RRFM 2009 - 13th Research Reactor Fuel Management Conference, (2009), ISBN 978-92-95064-07-2, pp. 74-78.

[3] Ozaltun, H., Shen, H., Medvedev, P., 2011. Assessment of residual stresses on U10Mo alloy based monolithic miniplates during Hot Isostatic Pressing. J. Nucl. Mater. 419 (1-3), 76-84.

[4] Ozaltun, H., Shen, H., Medvedev, P., 2011. Numerical simulation for mechanical behavior of U10Mo monolithic miniplates for research and test reactors. IMECE2011-62114. ASME 2011 International Mechanical Engineering Congress \& Exposition. Nov 11-17, 2011, Denver/CO.

[5] Ozaltun, H., Shen, H., Medvedev, P., 2012. Computational evaluation for the mechanical behavior of U10mo fuel miniplates subject to thermal cycling. J. Nucl. Eng. Des.

[6] Ozaltun, H., Miller S., 2012. Finite element simulations of monolithic plates for the conversion of high performance research reactors: NBSR, MITR, MURR and AFIP. IMECE2012-89011. ASME 2012. International Mechanical Engineering Congress \& Exposition. Nov 9-15, 2012, Houston/TX.

\subsubsection{Experimental Measurements of Residual Stresses}

Measurements of residual stresses in the as-fabricated plates were conducted via synchrotron x-ray diffraction and neutron diffraction at the Advanced Photon Source (APS) and Los Alamos Neutron Science Center (LANSCE), respectively. Additional measurements using annealed foils will provide a more straightforward benchmark for the FEA model. The current data sets were taken from plates fabricated using cold rolled foils. Tensile stress or temperature can be applied to these specimens during residual-stress measurement and may be used as an 'internal' benchmark of the measurement itself.

\subsubsection{Synchrotron x-ray Diffraction}

Residual stresses develop in monolithic fuels during the hot isostatic pressing (HIP'ing) fabrication process upon cooling due to the difference in the coefficients of thermal expansion (CTE) between U$10 \mathrm{wt} . \% \mathrm{Mo}$ and the aluminum cladding. The $\mathrm{CTE}$ of $\mathrm{U}-10 \mathrm{wt} . \% \mathrm{Mo}, \sim 11.8 \times 10^{-6} /{ }^{\circ} \mathrm{C}$ at room temperature, is roughly half that of aluminum, $23.1 \times 10^{-6} /{ }^{\circ} \mathrm{C}$ at room temperature $[1,2]$. Synchrotron $\mathrm{x}$-ray diffraction was utilized at the APS on beamline 1-ID [3] at Argonne National Laboratory to measure the residual stress in as-fabricated RERTR miniplates [4]. This work analyzed the full residual strain tensor of the fuel foil (U-10wt.\%Mo) clad in Al-6061 in the form of a miniplate. One quadrant of the fuel foil was measured with a spatial resolution of $0.1 \mathrm{~mm}$. Residual stresses were calculated from the measured strains using the tensoral form of Hooke's law. This research was carried out by a team of researchers from INL, LANL, and ANL.

The fuel plates were fabricated as follows: depleted uranium and molybdenum feedstock were arcmelted in an inert atmosphere and cast into a $2.5 \mathrm{~mm}$ thick coupon and hot rolled at $650^{\circ} \mathrm{C}$. A zirconium diffusion barrier ( $\sim 0.025 \mathrm{~mm}$ thick) was co-rolled onto the fuel foil during the hot-rolling process. The foil was annealed at $650^{\circ} \mathrm{C}$ for 45 minutes, followed by cold rolling to the final thickness of $0.28 \mathrm{~mm}$. The finished foils were hand polished with $15 \mu \mathrm{m}$ diamond paste and cleaned with ethanol before being bonded to the aluminum cladding (Al 6061 in the T6 condition). A recess that loosely fit the U-10Mo foil was machined into one side of the aluminum cladding; thus, the cladding is thinner on one side of the foil. Six sub-assemblies of U-10Mo foil and aluminum cladding were stacked vertically with graphite parting layers and tool-steel strongbacks separating each sample [5]. The samples were heated to the HIPing temperature of $560^{\circ} \mathrm{C}$ at $4.8^{\circ} \mathrm{C} / \mathrm{min}$, at which point $104 \mathrm{MPa}$ of pressure was applied during the 90 -minute soak time. Subsequently, the HIP assembly was cooled at $\sim 6.7^{\circ} \mathrm{C} / \mathrm{min}$ to room temperature. For additional fuel plate fabrication details, see Jue et al. [5]. 
A schematic of the sample is shown in Figure 108. The transverse (1) and longitudinal (2) directions of the sample are labeled in the figure and the sample normal direction (3) is out of the page. The dimensions of the U-10Mo foil were $90 \mathrm{~mm}$ long, $19 \mathrm{~mm}$ wide and $0.28 \mathrm{~mm}$ thick, and the final dimensions of the fuel assembly was $150 \mathrm{~mm} \times 50 \mathrm{~mm} \times 1.5 \mathrm{~mm}$.

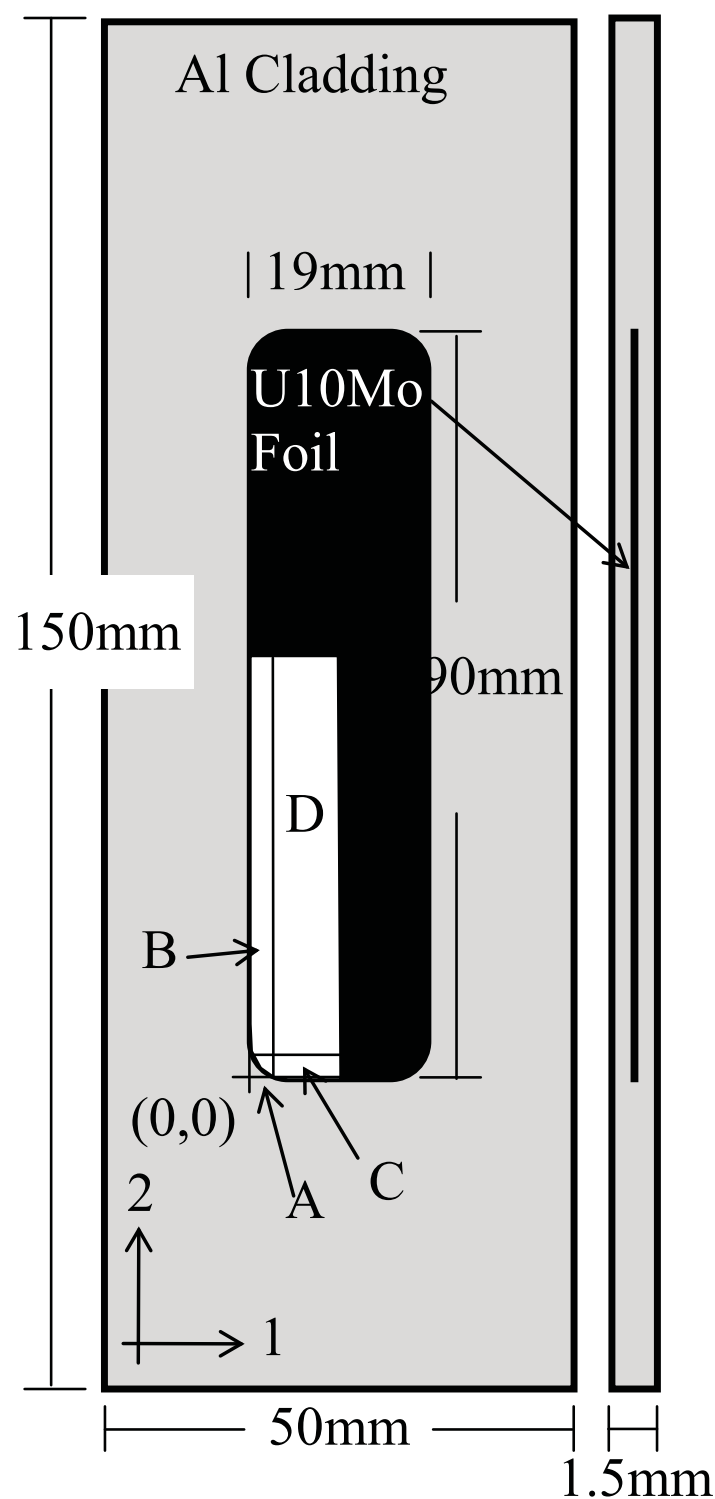

Figure 108. Schematic of the sample, roughly to scale. The white area represents the region over which the residual stress was mapped. The origin for future plots is indicated at the lower left corner of the foil. Regions A, B, C, and D delineate the different mapping densities described in the text.

Strain profiles with variable step sizes in the $\mathrm{x}$ and $\mathrm{y}$ directions were selected to optimize the density of points collected where steep strain gradients were expected. Within $4 \mathrm{~mm}$ of the origin (region A in Figure 108), including the corner of the U-10Mo foil, diffraction patterns were collected at intervals of $0.1 \mathrm{~mm}$ in both directions. Away from the corner, along either edge (regions B and C), the sampling period was $0.5 \mathrm{~mm}$ along the edge and $0.1 \mathrm{~mm}$ transverse to the edge. At distances greater than $4 \mathrm{~mm}$ from either edge (region D), the sampling period was $0.5 \mathrm{~mm}$ in each direction. In this way, one-quarter of the sample was profiled. This resulted in 2-D diffraction images which were collected at 5408 positions 
on the sample. Over most of the positions, diffraction patterns were collected at $\omega=0^{\circ}$ (sample normal was parallel to the beam), $45^{\circ}$ and $60^{\circ}$. Due to beam time constraints, patterns were only collected at $\omega=0^{\circ}$ and $45^{\circ}$ in the section away from the edges (part of region $\mathrm{D}$ ).

Figure 109 (a-c) shows contour plots of the transverse, longitudinal, and normal stresses, respectively, over the portion of the fuel foil profiled with high-energy x-ray diffraction. Note that the scale of the plots of the two in-plane stresses (a-b) are the same, and the plot of the normal stress (c) is on a different, smaller, scale. The in-plane stresses are strongly compressive, approaching $-275 \mathrm{MPa}$ in the longitudinal direction and $-120 \mathrm{MPa}$ in the transverse direction near the center of the fuel foil. The normal component of the stress is weakly compressive near the center of the foil and tensile near the corner. The disparityin the residual stress between the two in-plane directions far from the edges and the tensile normal stress - suggests that plastic deformation in the aluminum cladding during fabrication by hot isostatic pressing also contributes to the residual-stress field. A tensile in-plane residual stress near the yield strength of aluminum must be present in the cladding to balance the large in-plane compressive stresses in the U-10Mo fuel foil. Also, Figure 109 indicates that the stress in the transverse direction at the fuel-foil edge $($ at $\mathrm{x}=0)$ drops to 0 , indicating that there may not be bonding between the fuel and the cladding in this region, potentially allowing for gas-bubble build-up. Note that the model that was used to determine the stresses in this experimental study assumed that the fuel foil has isotropic mechanical properties. This assumption is currently under investigation.

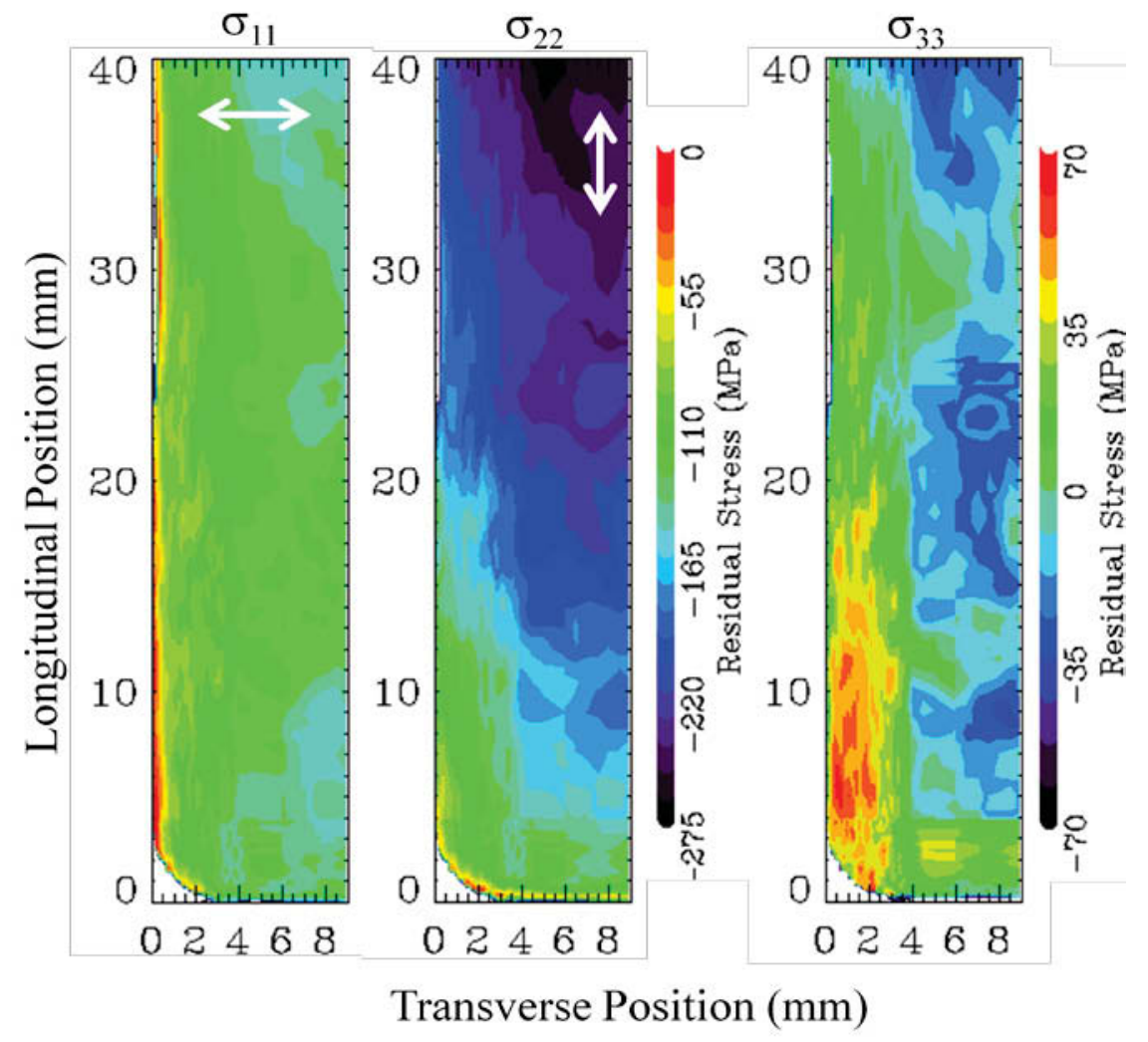

Figure 109. Spatially resolved maps of the normal components of the residual stress in the U-10Mo fuel foils in the clad fuel assembly.

\subsubsection{Neutron diffraction}

Neutron diffraction was conducted on an as-fabricated miniplate at the Spectrometer for Materials Research at Temperature and Stress (SMARTS) beamline at LANSCE at Los Alamos National 
Laboratory (LANL) by collaborators from LANL and INL. Neutron diffraction can also be utilized to measure elastic phase strains in materials. This is accomplished in a manner similar to that of x-ray diffraction in that the lattice parameter is utilized as an internal strain gauge. This experiment measured the strain evolution the fuel foil and cladding of a miniplate as it was heated to $350^{\circ} \mathrm{C}$. The plate was fabricated in the manner that was detailed by Jue et al. [5]. Four locations within the plate were chosen to monitor during the heating experiment. Two of the positions were located in the cladding, while the other two were located in the fuel foil region (although the cladding response was simultaneously measured). The positions are shown in Figure 110. Points 2 and 3 are located in the cladding-only region, whereas points 1 and 4 are located in the $\mathrm{Al}$ and $\mathrm{U}-10 \mathrm{wt} . \%$ Mo bonded region. Point 4 is located in the region that was determined to have the largest in-plane residual stress, which was compressive in nature, and minimal edge effects, as shown in Figure 110. Point 1 is located near the fuel-foil edge, where edge effects are a factor.

During the experiment, the miniplate was heated at a rate of $3^{\circ} \mathrm{C} / \mathrm{min}$ in increments of $5-20^{\circ} \mathrm{C}$. Once the desired measurement temperature was achieved, the plate was held at a constant temperature for 10 minutes for equilibration purposes. Following this, the diffraction patterns were acquired for $\sim 20$ minutes at each point. A copper heating fixture enveloped the entire miniplate throughout the experiment and also served as an "internal calibrant" through the measurement of the copper lattice parameter as a function of temperature.

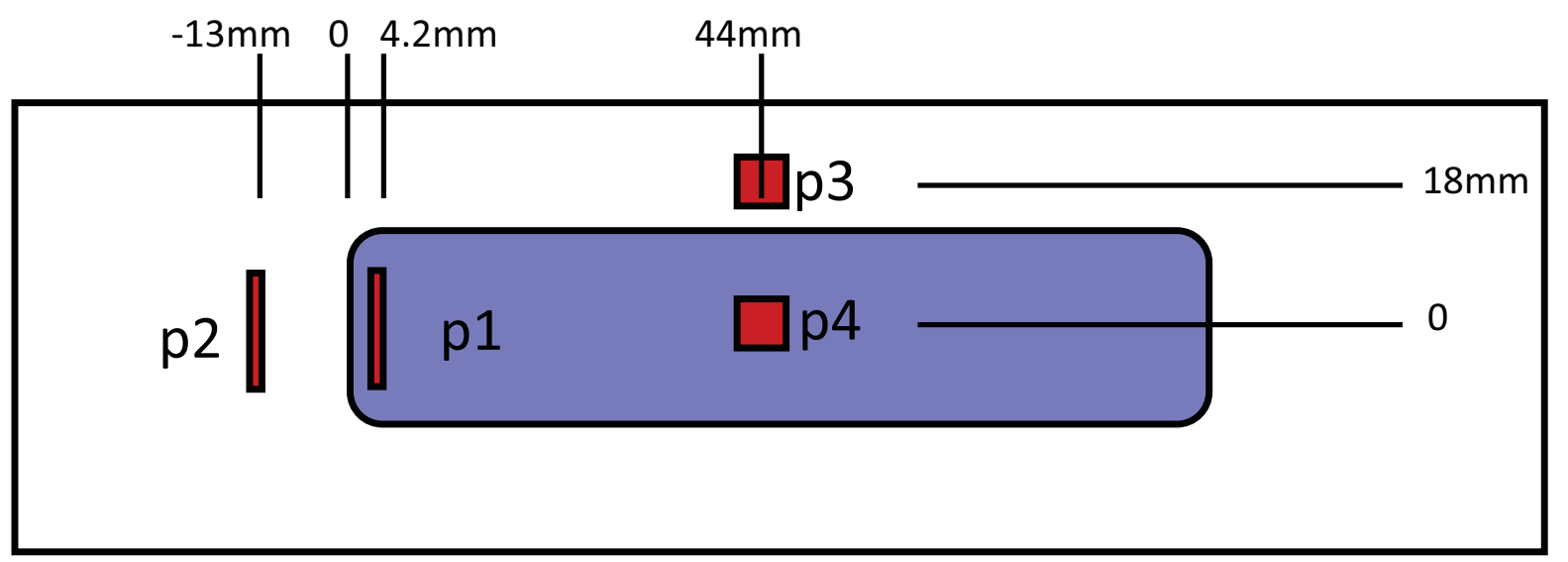

Figure 110. Schematic of the four measurement locations on the miniplate. The shape of the rectangle associated with the points schematically reflects the geometry of the selected measurement area to determine the lattice strain.

Figure 111 shows change in the Al-6061 cladding lattice parameter as a function of increasing temperature at all four points in the specimen-normal (bank 1) and longitudinal (bank 2) directions. It is interesting to note that the lattice parameters for points 2 (in cladding and away from the foil edge) and point 4 (fuel foil is bonded to the Al cladding) are very similar. This contradicts a previous conclusion with respect to the synchrotron $\mathrm{x}$-ray diffraction measurements since it was deduced that, due to the large in-plane compression $(\sim 250 \mathrm{MPa})$ near the center of the fuel foil, the Al cladding must have $\sim 50 \mathrm{MPa}$ tensile stress to balance the stresses. As a possible explanation for this, there may be large strain gradients near the foil interface, which may not be detectable since these values represent an average, throughthickness measurement. In a similar fashion, it was anticipated that the normal stress component of Al should be close to zero in this region. At point 2, which is located far away from the fuel foil, it is anticipated that the residual stresses should be near zero. Based on the elastic modulus (70 GPa) and Poisson's ratio ( 0.35 ) for $\mathrm{Al}$, the lattice parameter at point 4 in bank 2 (longitudinal) should be around $0.004 \AA$ larger than what was measured at point 4 in bank 1 (normal), as well as $0.003 \AA$ larger than what was measured at point 2 for both the longitudinal and normal components. The lack of the differences in 
the lattice parameter could be explained by a few factors: (1) there is a very low variation $(<20 \mathrm{MPa})$ in the stress, which is less than the uncertainty; (2) the stress on the cladding is equal (agreement of points 2 and 4) and hydrostatic (both the normal and longitudinal stresses agree); or (3) there is a rapid change of stress near the boundary of the fuel and cladding, suggesting that the $\mathrm{Zr}$ interdiffusion layer and the associated intermetallics $\left(\mathrm{UZr}_{2}\right)$ play a large role in balancing the compressive stresses on the U$10 \mathrm{wt} . \% \mathrm{Mo}$. The previous synchrotron x-ray diffraction data that was obtained at APS is currently undergoing further analysis for residual stress in the $\mathrm{Zr}$ diffusion layer and intermetallics.

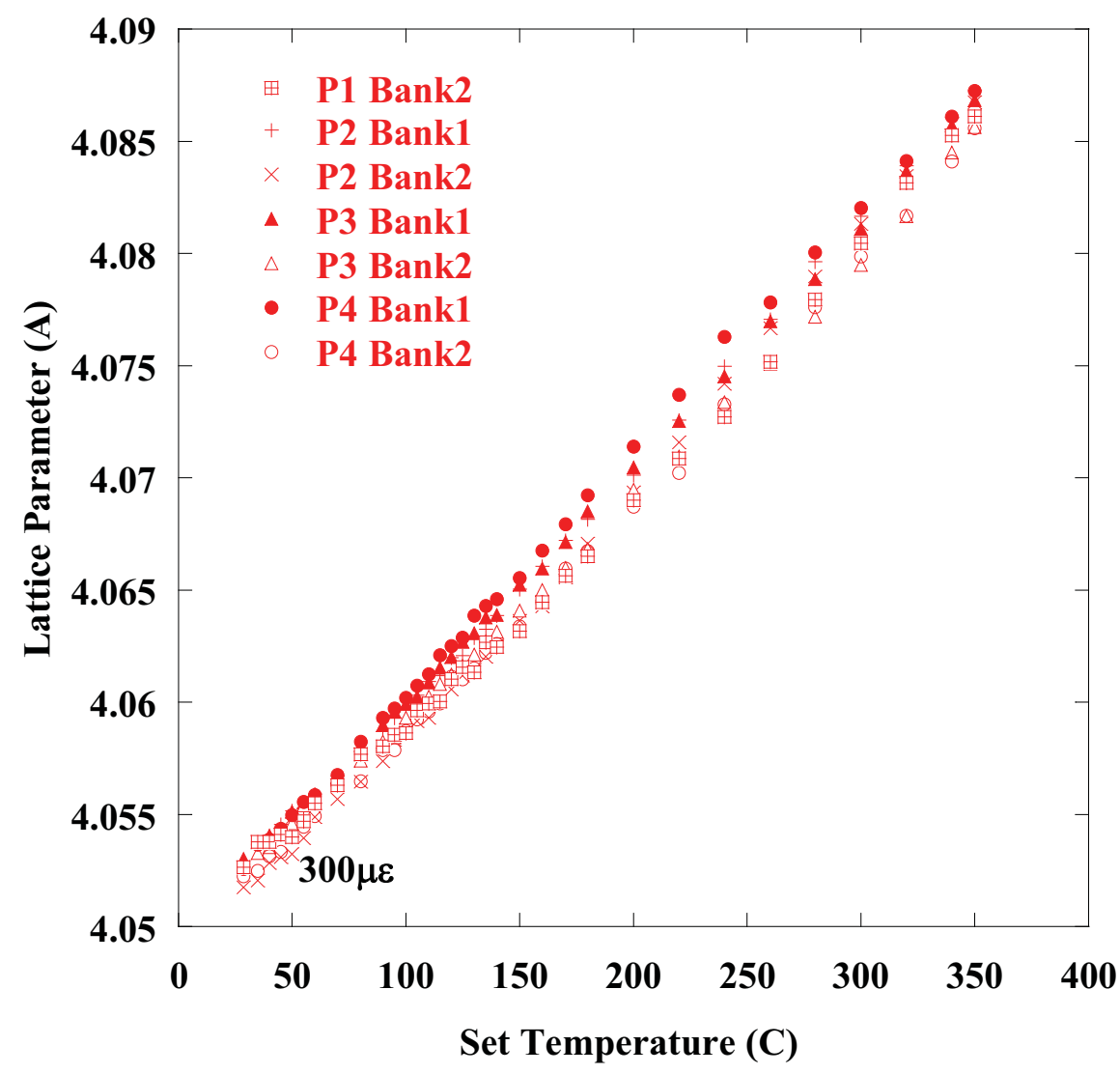

Figure 111. Lattice parameter of the Al-6061 cladding at 4 locations in both the longitudinal and normal directions. The points at room temperature all agree within $300 \mu \varepsilon$.

Figure 112 shows the change in the lattice parameter of the U-10wt.\%Mo fuel foil as the temperature is increased during the experiment at points 1 and 4 . Note that, at room temperature, there is a large difference in the lattice parameter, which is due to a large in-plane longitudinal compressive stress in the fuel foil (Figure 112), which decreases the lattice parameter in the longitudinal direction (bank 2). Moreover, the Poisson's ratio increases the lattice parameter in the normal direction (bank 1). As the temperature is increased to $\sim 220^{\circ} \mathrm{C}$, the lattice parameters in the longitudinal direction at points 1 and 4 increase at the same rate. After reaching $\sim 220^{\circ} \mathrm{C}$, the increase in the longitudinal lattice parameter slowed, which could represent the onset of the Al 6061 creep. However, the lattice parameter for the normal direction at point 4 remained relatively unchanged until $\sim 150^{\circ} \mathrm{C}$, at which it began to increase. Also, note that at around $150^{\circ} \mathrm{C}$, the lattice parameters switched order at point 4 . This is a significant measurement since these measurements were taken at the same point and time; therefore, the temperature must be equivalent. The deviatoric stress in the U-10wt.\%Mo foil is the source of this difference. Based on the lattice parameters, the stress has to be tensile in the longitudinal direction and/or compressive in the normal direction. At $350^{\circ} \mathrm{C}$ the flow strength of the $\mathrm{Al}$ is given by Ozaltun et al. [1] as $\sim 13 \mathrm{MPa}$. Since 
this value is so low, it again points to the possibility of the $\mathrm{Zr}$ diffusion layer and its intermetallics that may play a critical role in balancing the stresses, or that there is a large stress gradient at the interface.

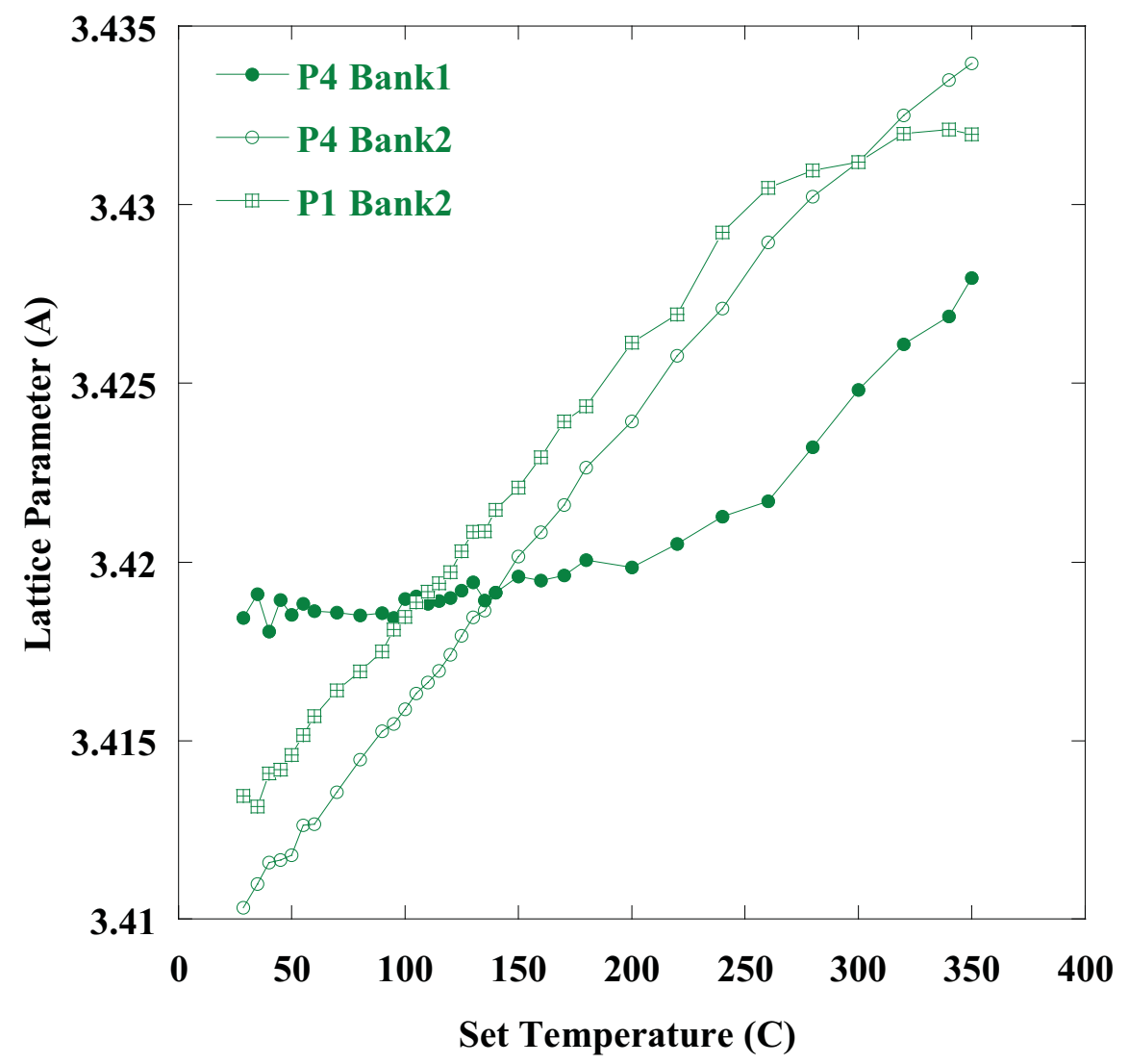

Figure 112. Lattice parameter of the U-10wt.\%Mo fuel foil as a function of temperature. The normal direction is given by bank 1 and the longitudinal direction is given by bank 2 .

Figure 113 shows the lattice strain at points 1 (a) and 4 (b) as a function of temperature. The lattice strains were determined via the measured lattice parameters. The solid lines shown in the graphs represent the calculated linear CTE for $\mathrm{Al}$ (blue) and $\mathrm{U}-10 \mathrm{wt} . \% \mathrm{Mo}$ (red) taken from Ozaltun et al. [1] at $100^{\circ} \mathrm{C}$. The $\mathrm{Al}$ in-plane strains agree well with the calculated $\mathrm{CTE}$ at $100^{\circ} \mathrm{C}$, but begin to deviate around $250^{\circ} \mathrm{C}$ because the CTE temperature dependence has not been incorporated yet. Also, the in-plane strains within the U-10wt.\%Mo closely follow the Al CTE, but then this diverges around $220-250^{\circ} \mathrm{C}$. At point 4 , the normal strain is uniform until around $150^{\circ} \mathrm{C}$. As the heating process continues, the compressive stresses in the $\mathrm{Al}$ relax and, therefore, the $\mathrm{U}-10 \mathrm{wt}$ \% Mo lattice contracts in the normal direction. In turn, this is balanced by the thermal expansion of the U-10wt.\%Mo in the normal direction. 

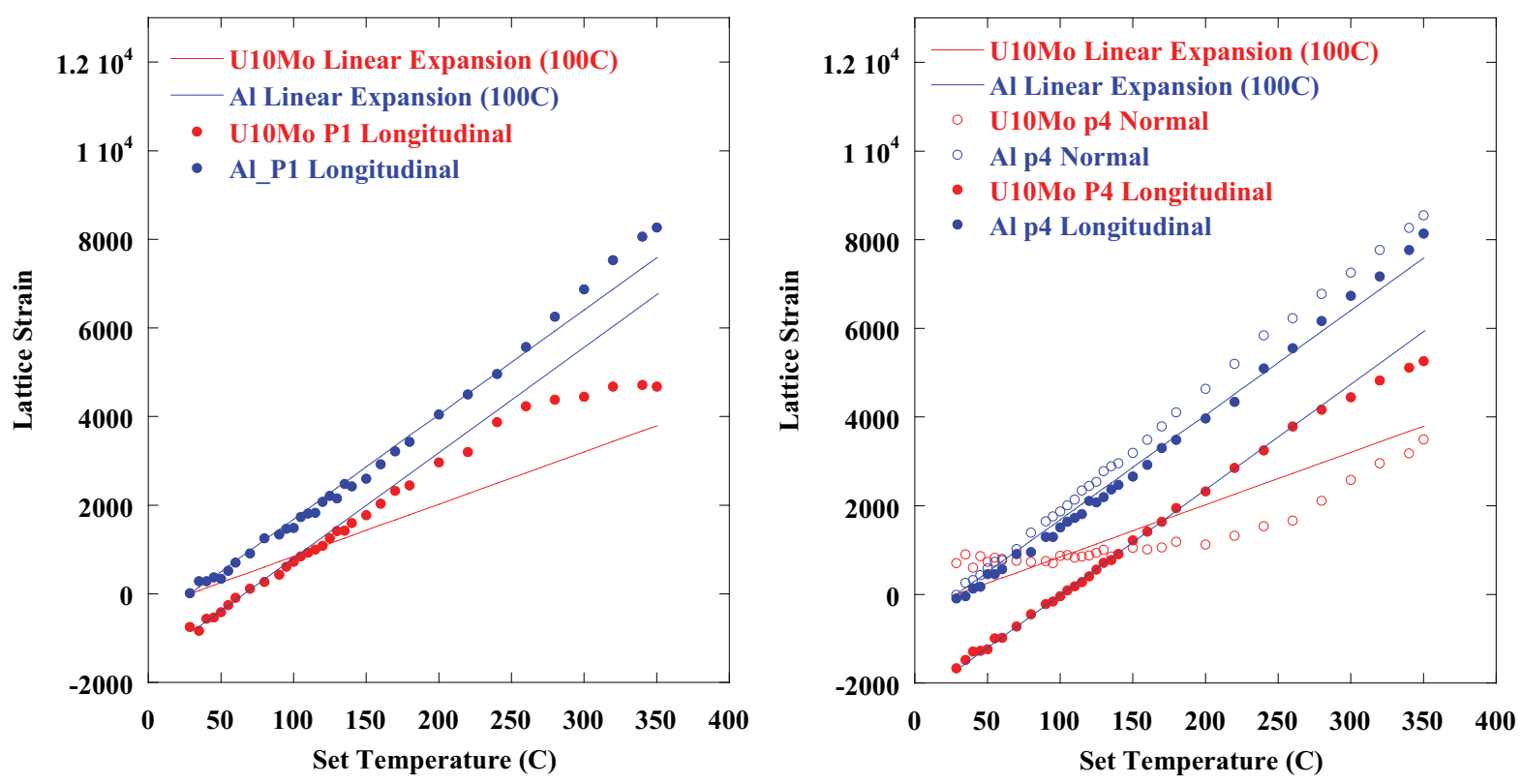

Figure 113. Lattice strain points 1 (a) and 4 (b) as a function of temperature. The normal direction is given by bank 1 and the longitudinal direction is given by bank 2 .

\subsubsection{References}

[1] Ozaltun, H., Medvedev, P. G., "Structural Behavior of Monolithic Fuel Plates during Hot Isostatic Pressing and Annealing," RRFM 2010: proceedings of the 14th International Topical Meeting on Research Reactor Fuel Management, held 21-25 Mar 2010 in Marrakech, Morocco,.p. 11.

[2] Fackelmann, J. M., Bauer, A. A., D.P., M. "Literature Survey on Dilute Uranium Alloys," BMIX-10264 1969.

[3] Haeffner, D. R., Almer, J. D., Lienert, U., The use of high energy X-rays from the Advanced Photon Source to Study Stresses in Materials," Mat Sci Eng A, 399.1-2 (2005) pp. 120-127.

[4] Noyan, I. C., Cohen, J. B. The Theory of Stress/Strain Analysis with Diffraction. Measurement of Residual and Applied Stress Using Neutron Diffraction, M.T. Hutchings and A.D. Krawitz, eds., Kluwer Academic Publishers, the Netherlands, 51-65. 1992.

[5] Jue, J. F., Park, B. H., Clark, C. R., Moore, G. A., Keiser, D. D., "Fabrication of Monolithic RERTR Fuels by Hot Isostatic Pressing,” Nuclear Technology, 172.2 (2009), pp. 204-210.

\subsection{Failure Mode and Effects Analysis (FMEA)}

Many plausible scenarios exist that may explain the low temperature blistering phenomenon. The number and diversity of hypotheses prompted the need to utilize an unbiased approach to rank the probability of these issues occurring and resulting in changes in blister threshold behavior. The INL contracted QualityOne to lead them through a Root Cause Analysis, including a Failure Modes and Effects Analysis. The Root Cause Analysis (RCA) method defined in the flow diagram (Figure 114) below utilizes several problem solving techniques iterating between inductive and deductive phases of problem decomposition. 


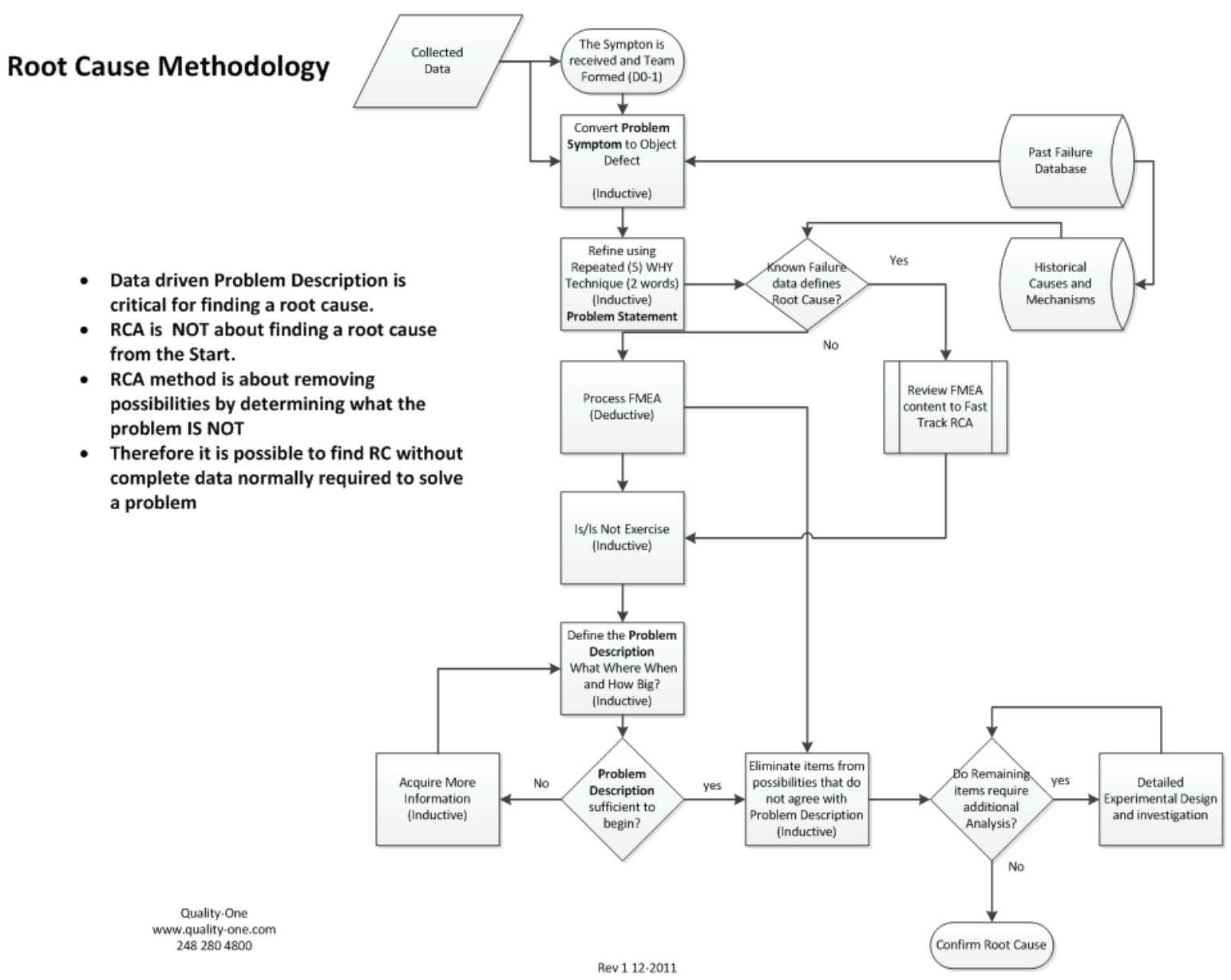

Figure 114. Root Cause Methodology Flow Diagram.

The breakdown of the problem has isolated three primary and several plausible theories. The primary theories are supported by the collected data and require an additional experiment to convert the probable causes to root causes.

Alternative hypotheses exist without supporting data that link them directly to the blistering effect. The plausibility of these alternatives was determined by the specific expertise of team members. The use of a Potential Process Failure Mode and Effects Analysis (PFMEA) defined single and multi-point cause combinations which could result in blistering and other undesirable effects.

The most prominent theory supported by data is:

"Stored mechanical energy" imparted on the samples from process working (hot and cold rolling) without adequate relief.

The cause mechanisms are still under investigation, but can be classified into two categories:

1. Residual Stress

2. Undesirable interaction boundary and/or U-Mo microstructure change

A secondary theory also supported by data, is: "test condition change resulting in a statistically significant downward shift of measured outcomes." 
All samples, with low blister temperature, exhibited predictable linkage to the stored mechanical energy theory. Other possible and plausible hypotheses were also discussed and will be documented in the final report resulting from this exercise. 
Appendix A

Photographs of the Blister Annealed Monolithic Fuel Plates and Micrographs of Blister Cross-sections 
Plate L2F020

\section{RERTR-6}

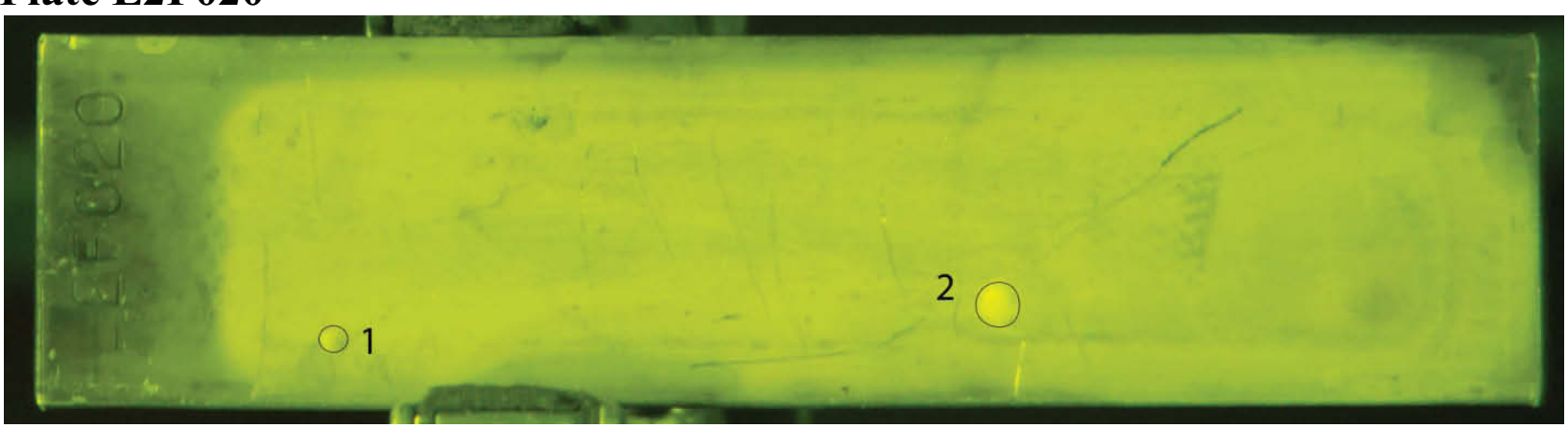

Figure 1. Type 2 blisters on the front side of plate L2F020 (RERTR-6). Average fission density $2.45 \times$ $10^{21}$ fissions $/ \mathrm{cm}^{3}$. Peak fission density $4.53 \times 10^{21}$ fissions $/ \mathrm{cm}^{3}$. No diffusion barrier was applied. Blisters \#1 and \#2 are located close to the left edge of the plate, which was facing core center.

\section{Plate N1F060}

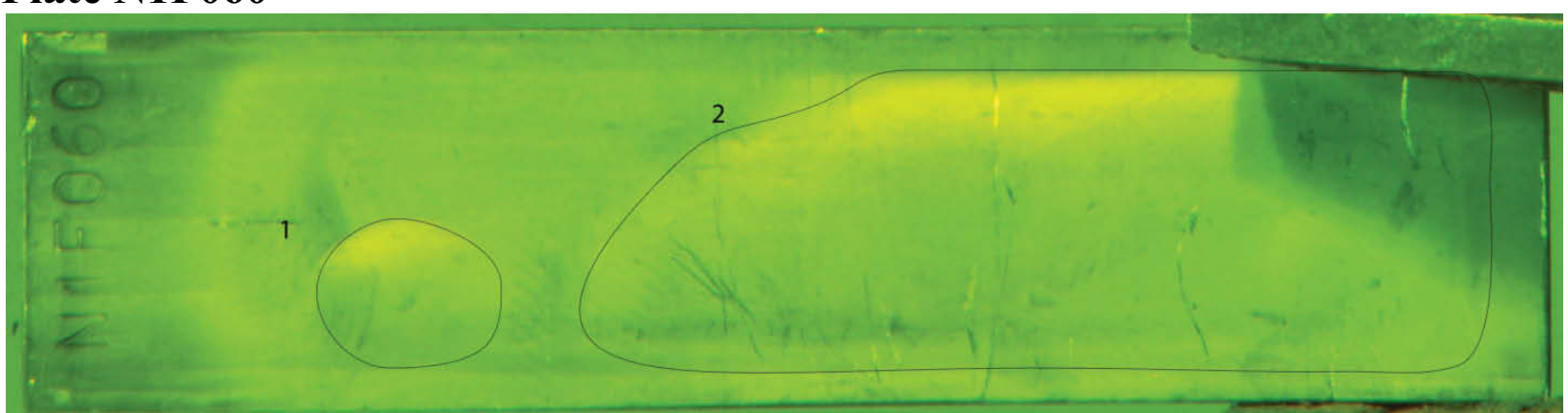

Figure 2. Type 2 blisters on the front side of plate N1F060 (RERTR-6). Average fission density $3.63 \times$ $10^{21}$ fissions $/ \mathrm{cm}^{3}$. Peak fission density $6.90 \times 10^{21}$ fissions $/ \mathrm{cm}^{3}$. No diffusion barrier was applied. Blister $\# 1$ is located close to the left edge of the plate, which was facing core center. Blister \# 2 stretches from the left side of the plate (facing the core center) to the right side of the plate (away from the core center). 


\section{RERTR-7}

\section{Plate L1F110}

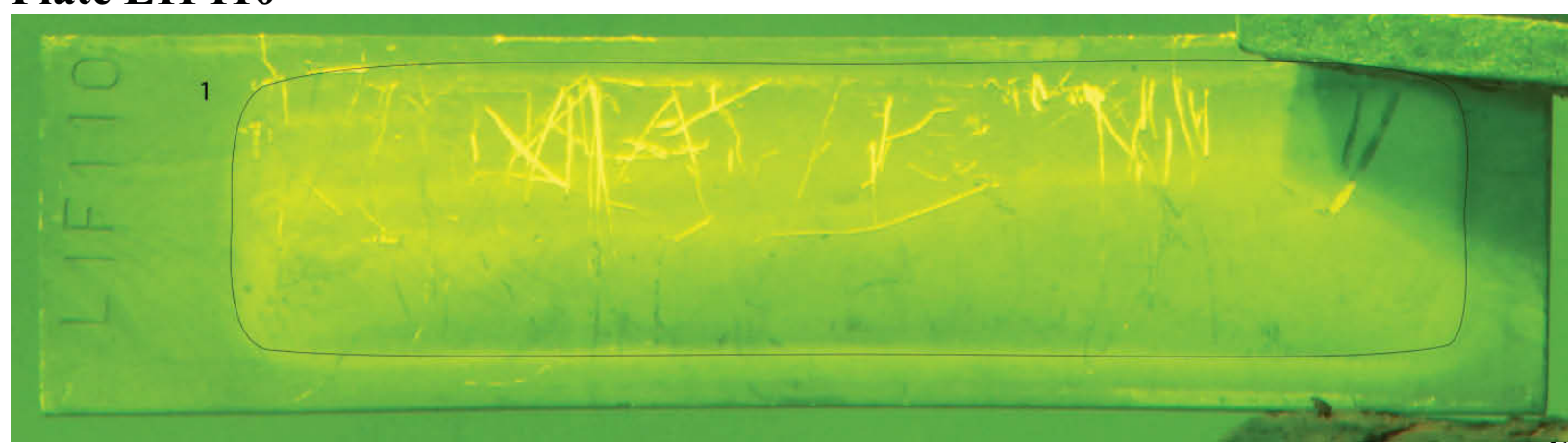

Figure 3. Type 2 blister on the front side of plate L1F110 (RERTR-6). Average fission density $5.06 \times 10^{21}$ fissions $/ \mathrm{cm}^{3}$. Peak fission density $12.1 \times 10^{21}$ fissions $/ \mathrm{cm}^{3}$. No diffusion barrier was applied. Blister \#1 covers the entire fuel foil area. Right edge of the plate was facing core center. 


\section{RERTR-9A}

\section{Plate L1F27C}

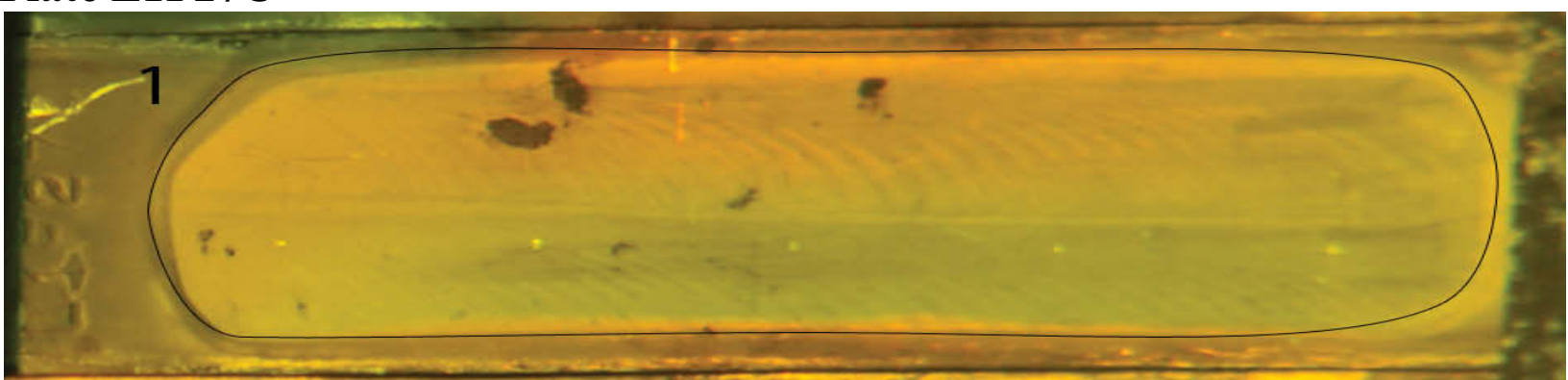

Figure 4. Type 2 blister on the front side of plate L1F27C (RERTR-9A). Average fission density $3.64 \times$ $10^{21}$ fissions $/ \mathrm{cm}^{3}$. Peak fission density $9.64 \times 10^{21}$ fissions $/ \mathrm{cm}^{3}$. No diffusion barrier was applied. Blister \#1 covers the entire fuel foil area. Right edge of the plate was facing core center. 


\section{Plate L1F330}

\section{RERTR-9B}

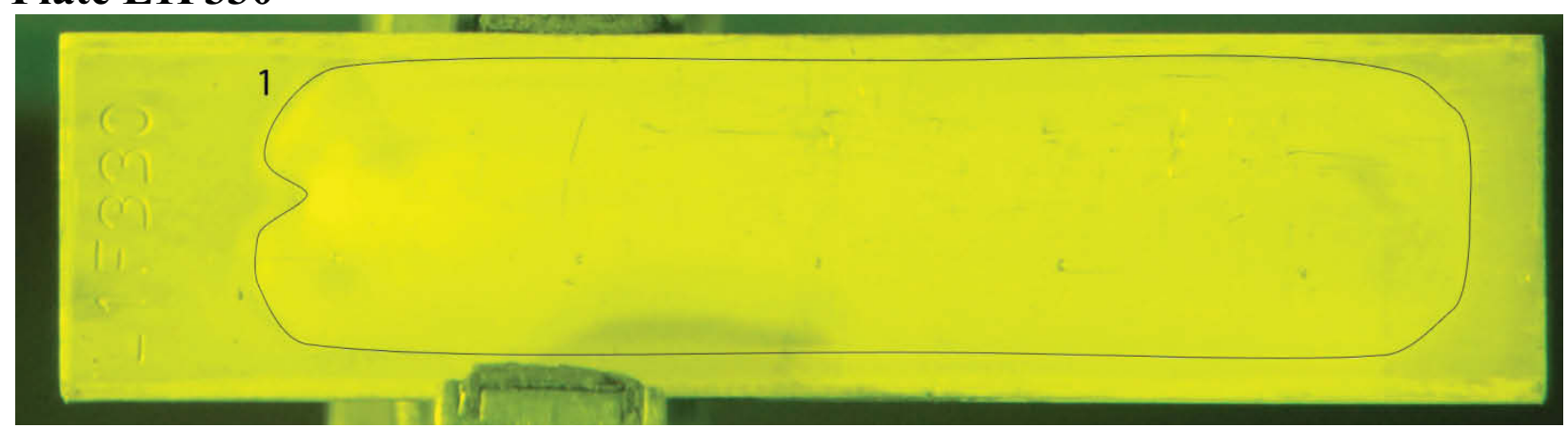

Figure 5. Type 2 blister on the front side of plate L1F330 (RERTR-9B). Average fission density $5.99 \times$ $10^{21}$ fissions $/ \mathrm{cm}^{3}$. Peak fission density $14.6 \times 10^{21}$ fissions $/ \mathrm{cm}^{3}$. No diffusion barrier was applied. Blister \#1 covers the entire fuel foil area. Right edge of the plate was facing core center.

\section{Plate L1F35TC}

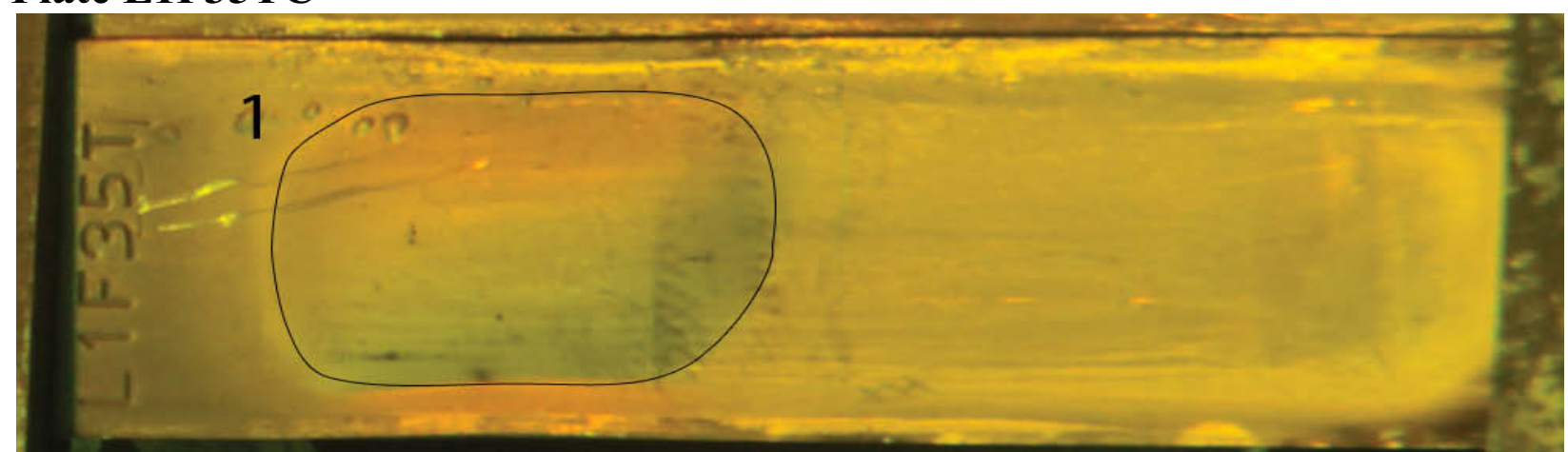

Figure 6. Type 2 blister on the front side of plate L1F35T (RERTR-9B). Average fission density $6.67 \times$ $10^{21}$ fissions $/ \mathrm{cm}^{3}$. Peak fission density $14.3 \times 10^{21}$ fissions $/ \mathrm{cm}^{3}$. Al-Si thermal spray was applied. Blister \#1 stretches from the right side to the left side of the fuel zone. Right edge of the plate was facing core center. 


\section{Plate L1P10T}

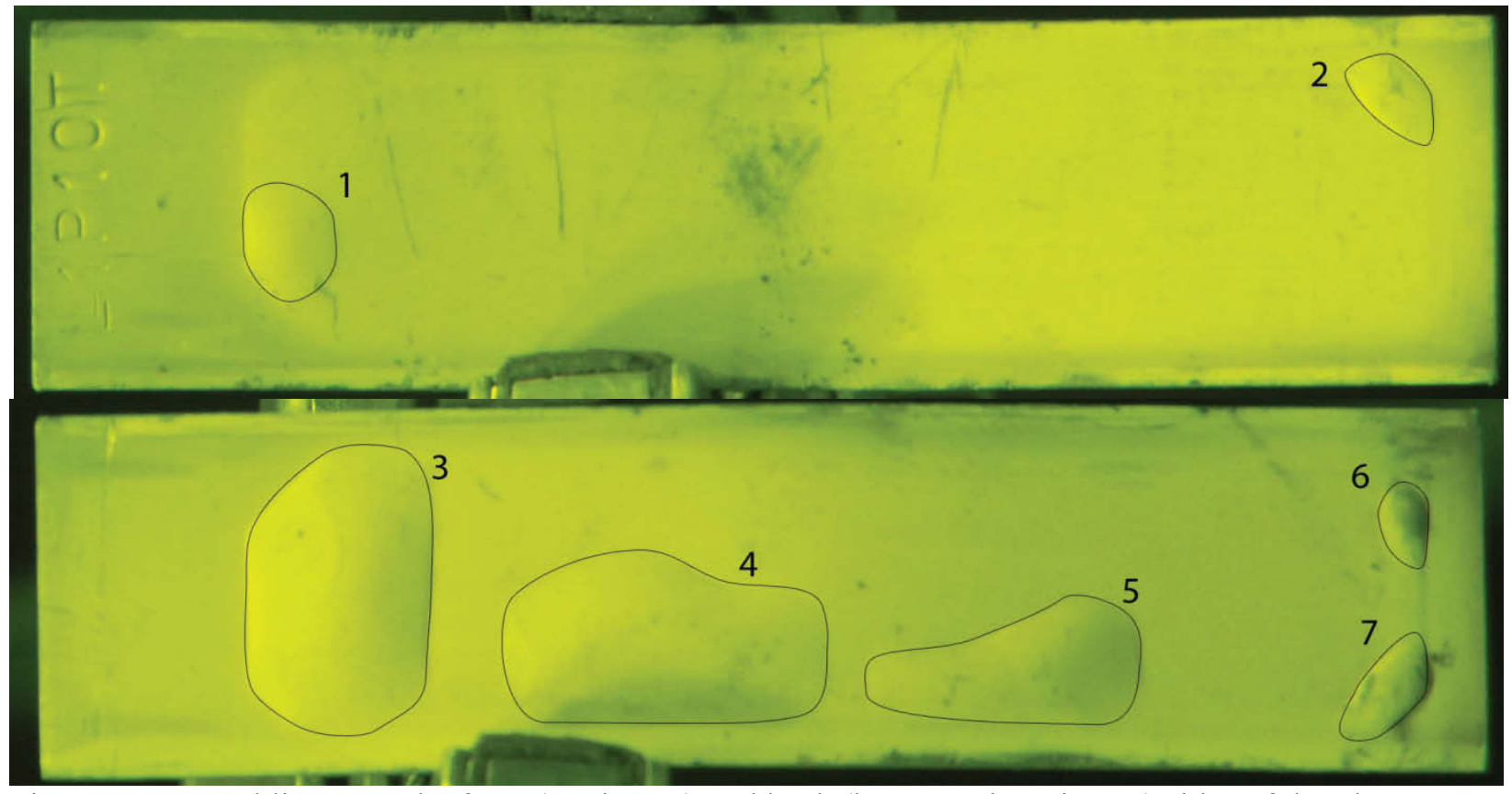

Figure 7. Type 2 blisters on the front (top image) and back (bottom mirror image) sides of the plate

L1P10T (RERTR-9B). Average fission density $5.71 \times 10^{21}$ fissions $/ \mathrm{cm}^{3}$. Peak fission density $12.1 \times 10^{21}$ fissions $/ \mathrm{cm}^{3}$. Zr diffusion barrier was applied. Blister \#2 is close to the right edge of the plate, which was facing core center.

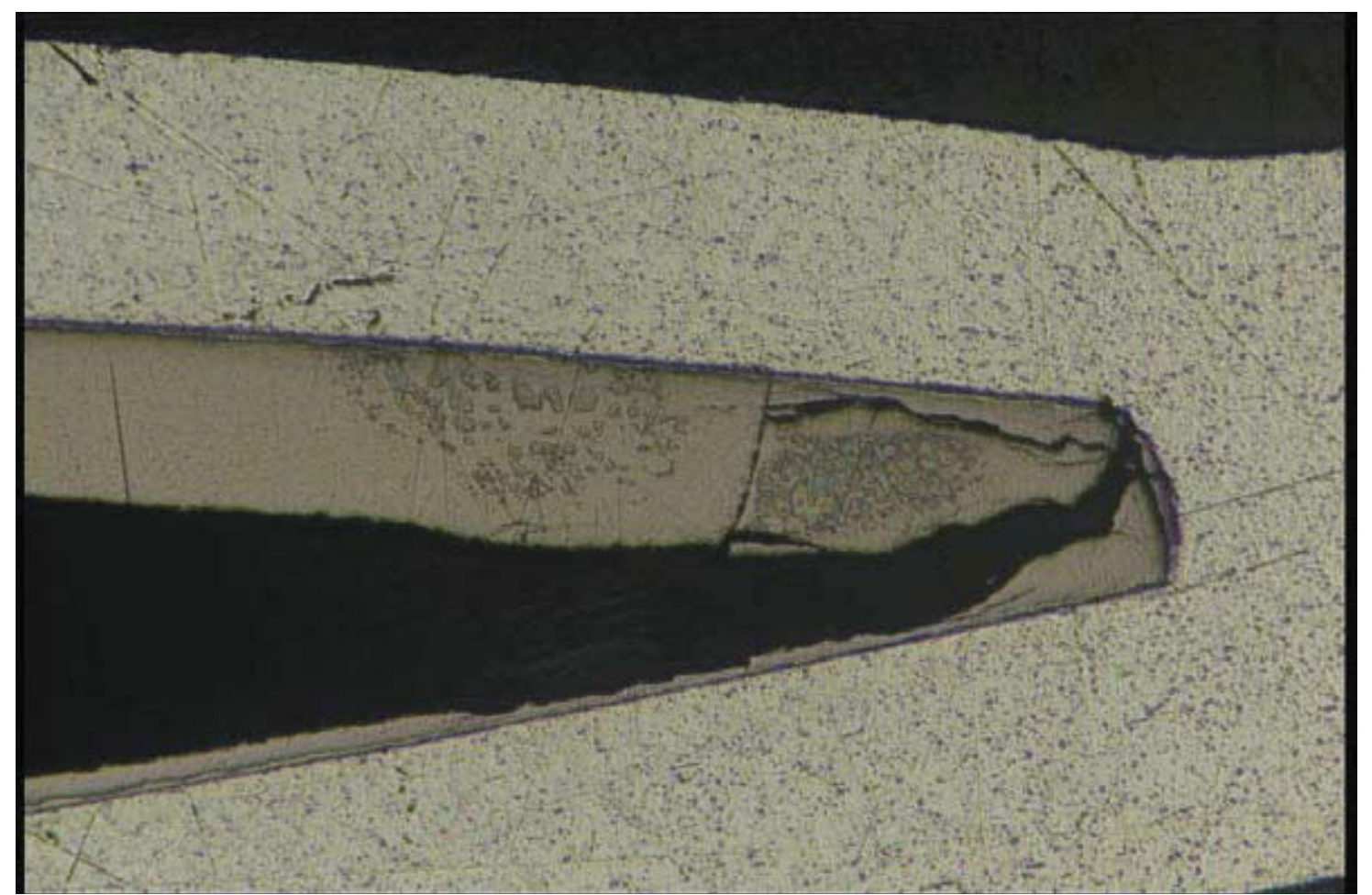

Figure 8. Optical metallography image of the cross-section through the blister in plate L1P10T (RERTR9B). 


\section{RERTR-10A}

\section{Plate L1P30Z}

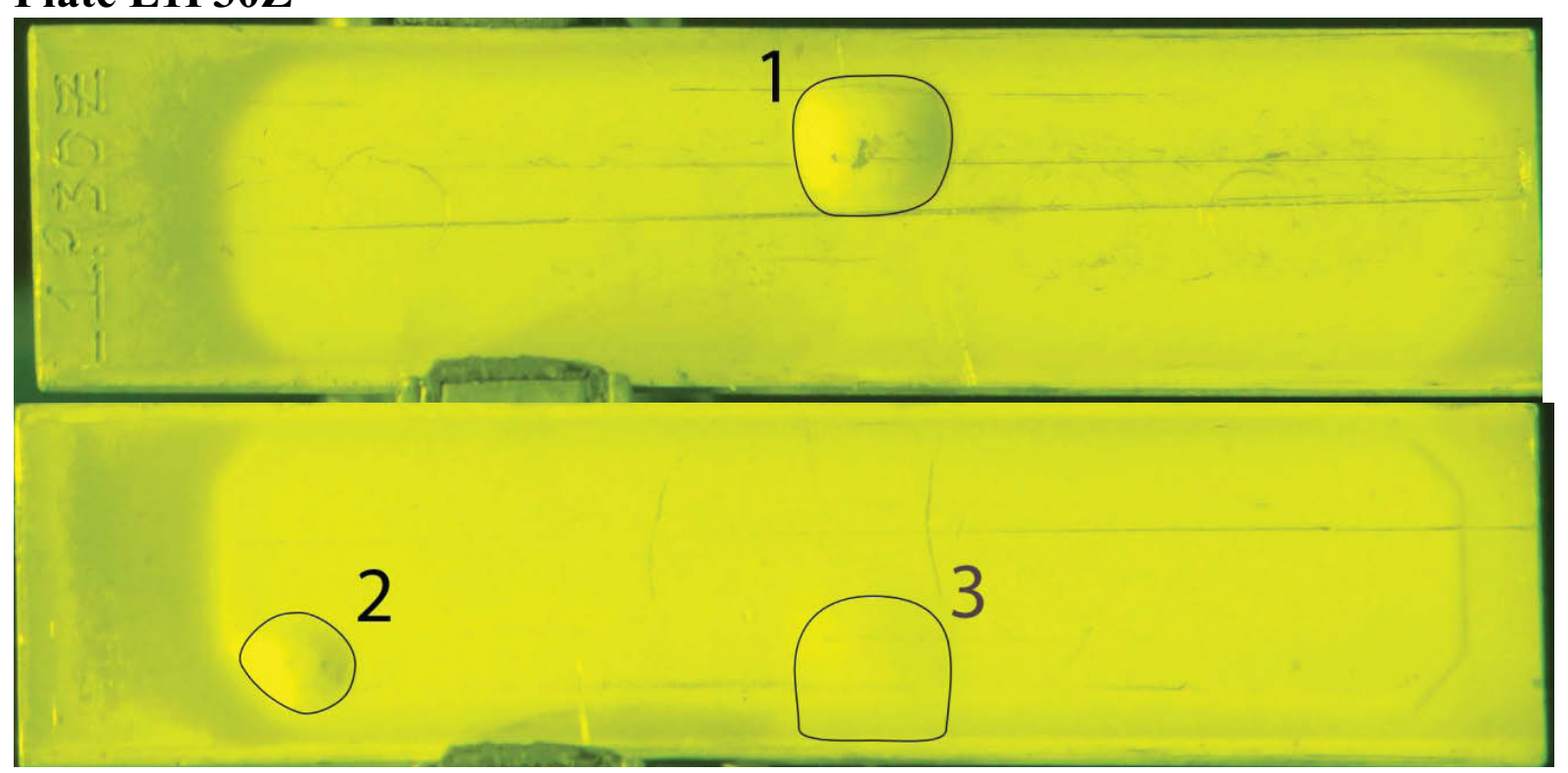

Figure 9. Type 2 blisters on the front (top image) and back (bottom mirror image) sides of plate L1P30Z (RERTR-10A). Average fission density $2.88 \times 10^{21}$ fissions $/ \mathrm{cm}^{3}$. Peak fission density $6.41 \times 10^{21}$

fissions $/ \mathrm{cm}^{3}$. Zr diffusion barrier was applied. Blister \#1 is close to the right edge of the plate, which was facing core center. 


\section{Plate L2P15Z}

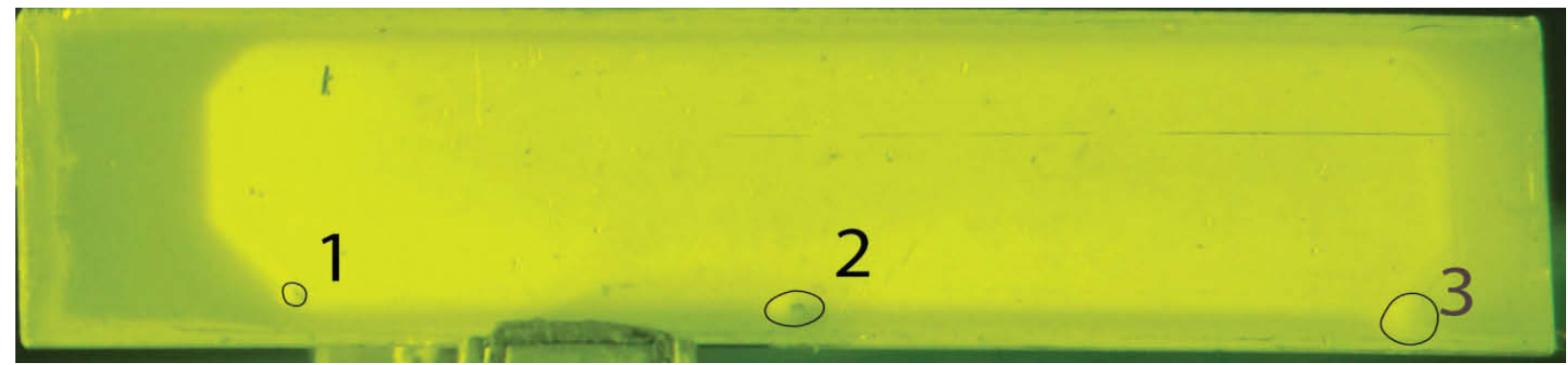

Figure 10. Type 1 blisters on the back side of plate L2P15Z (RERTR-10A). Average fission density 1.34 $\times 10^{21}$ fissions $/ \mathrm{cm}^{3}$. Peak fission density $3.82 \times 10^{21}$ fissions $/ \mathrm{cm}^{3} . \mathrm{Zr}$ diffusion barrier was applied. Blisters \#1, \#2 and \#3 are close to the edge of the plate that was facing core center.

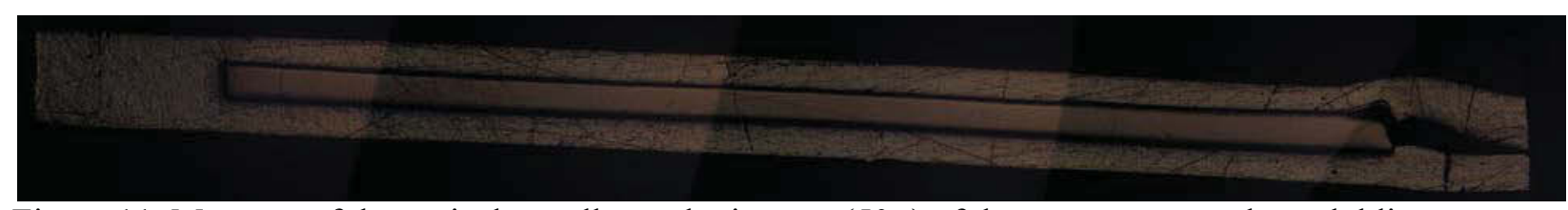

Figure 11. Montage of the optical metallography images $(50 \times)$ of the transverse cut through blister on plate L2P15Z.

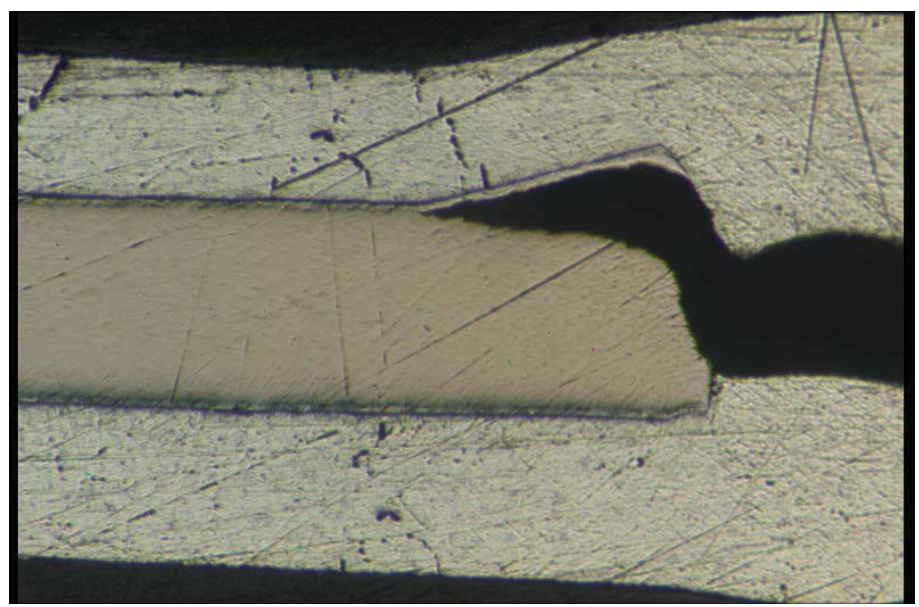

Figure 12. Optical image $(50 \times)$ of the blistered right end of the transverse cut in plate L2P15Z. 


\section{Plate L2F47Z}

\section{RERTR-10B}

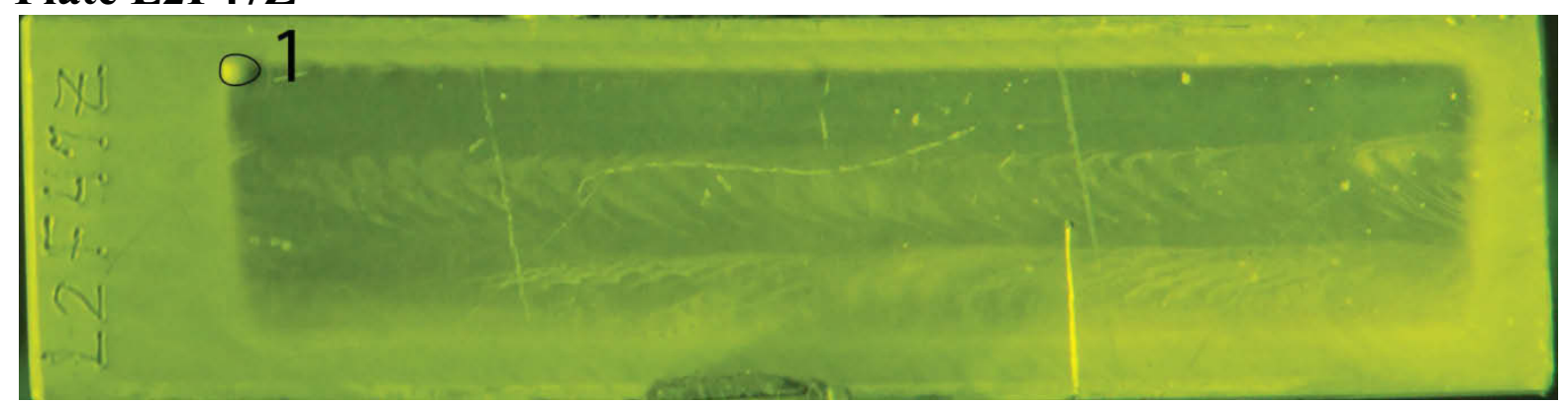

Figure 13. Type 1 blister on the front side of plate L2F47Z (RERTR-10B). Average fission density $1.75 \times$ $10^{21}$ fissions $/ \mathrm{cm}^{3}$. Peak fission density $3.72 \times 10^{21}$ fissions $/ \mathrm{cm} 3$. Zr diffusion barrier was applied. Blister $\# 1$ is close to the right edge of the plate, which was facing core center.

\section{Plate L2F46Z (blister tested in 2012)}

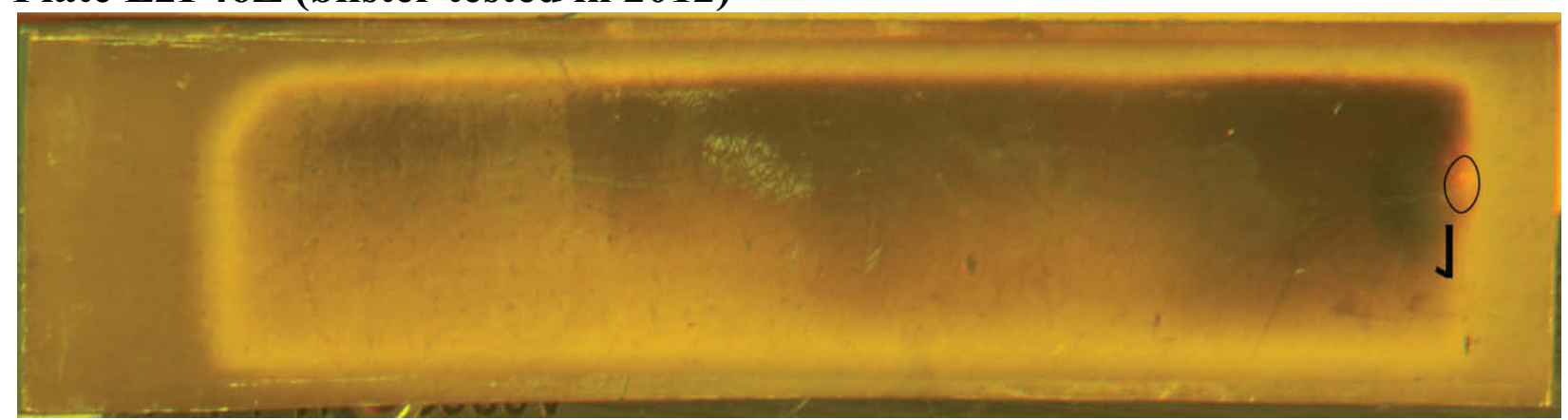

Figure 14. Type 1 blister on the back side of plate L2F46Z (RERTR-10B). Average fission density $2.25 \times$ $10^{21}$ fissions $/ \mathrm{cm}^{3}$. Peak fission density $4.52 \times 10^{21}$ fissions $/ \mathrm{cm}^{3}$. Zr diffusion barrier was applied. 


\section{Plate L1P460}

\section{RERTR-12}

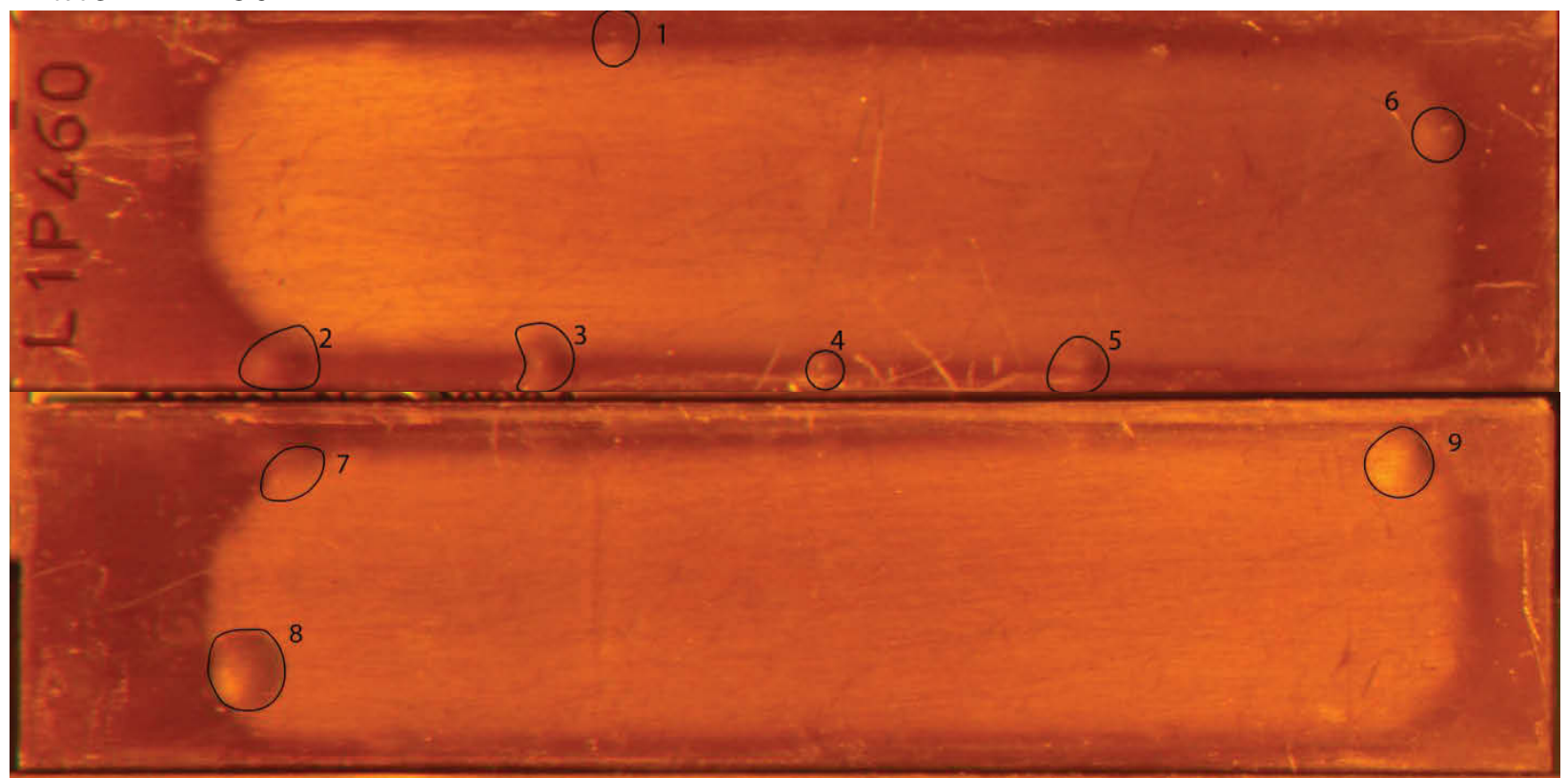

Figure 15. Type 1 blisters on the front (top image) and back (bottom image) sides of the plate L1P460 (RERTR-12). Average fission density $2.35 \times 10^{21}$ fissions $/ \mathrm{cm}^{3}$. Peak fission density $3.98 \times 10^{21}$ fissions $/ \mathrm{cm}^{3}$. $\mathrm{Zr}$ diffusion barrier was applied.

Figure 16. Montage of the optical metallography images $(50 \times)$ of the transverse cut through blister \#4 on plate L1P460.

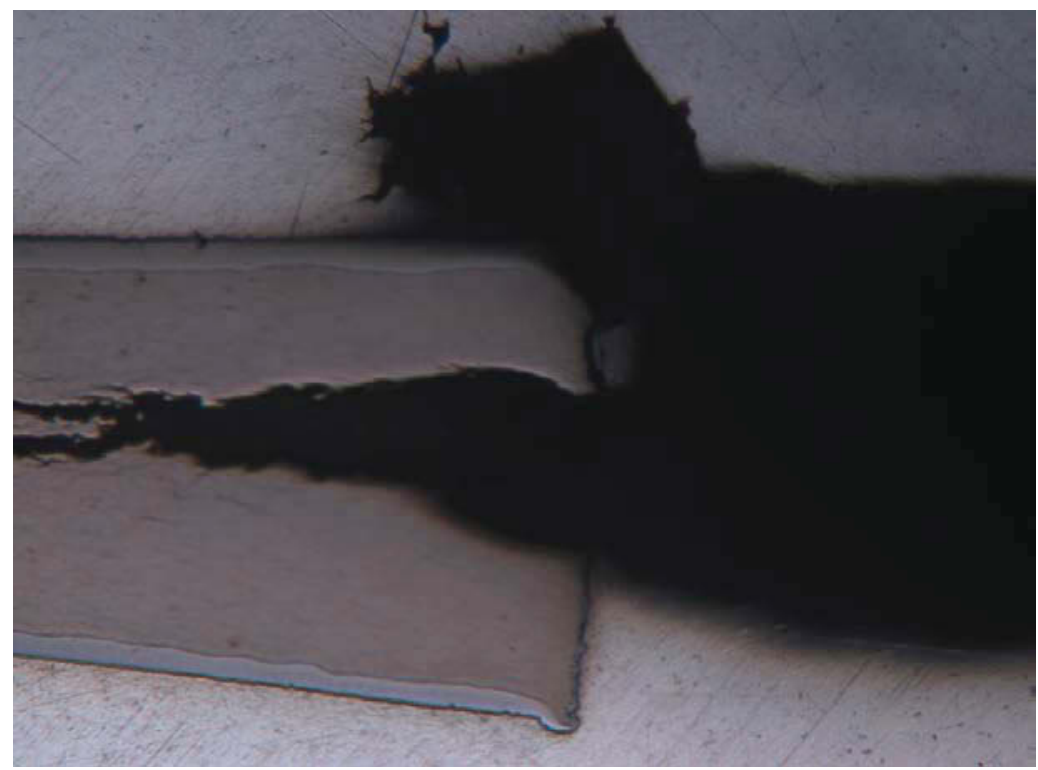

Figure 17. Optical image $(200 \times)$ of the blistered right end of the transverse cut in plate L1P460. 


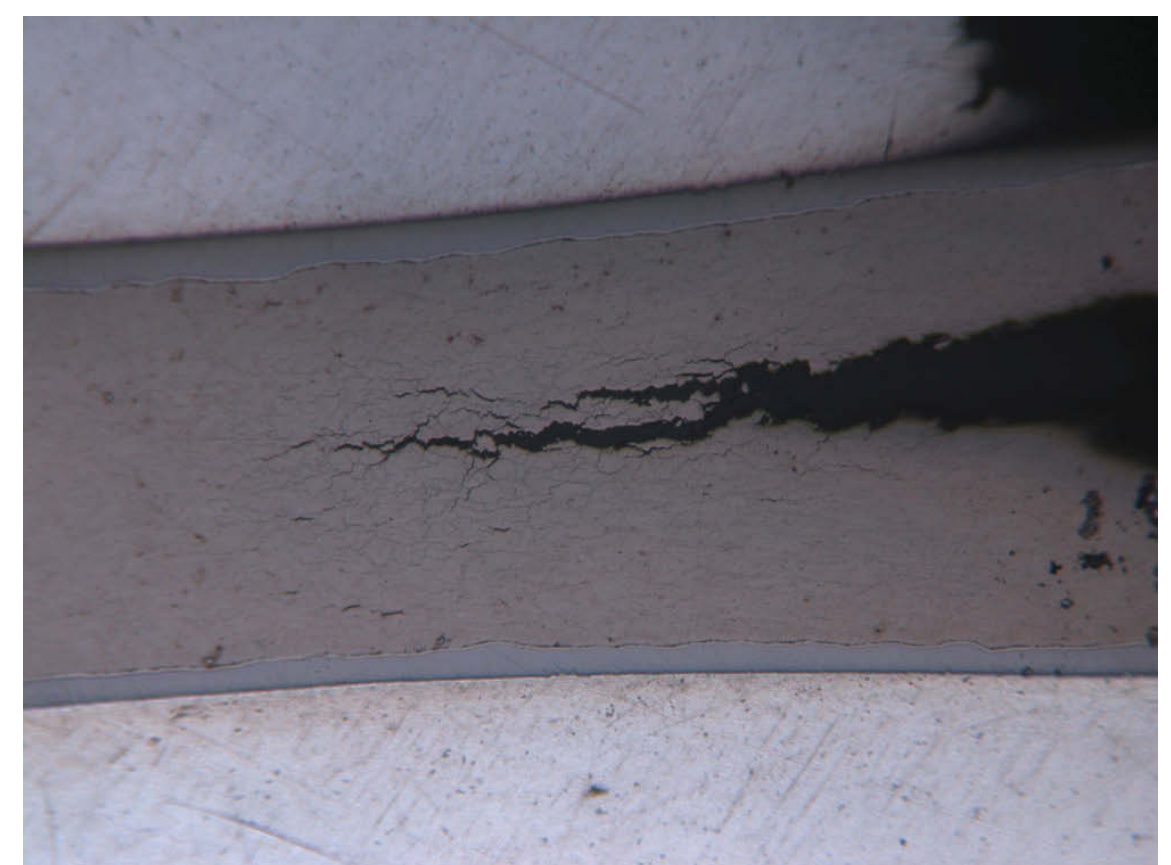

Figure 18. Optical image $(200 \times)$ of the fuel crack in the blistered right end of the transverse cut in plate L1P460.

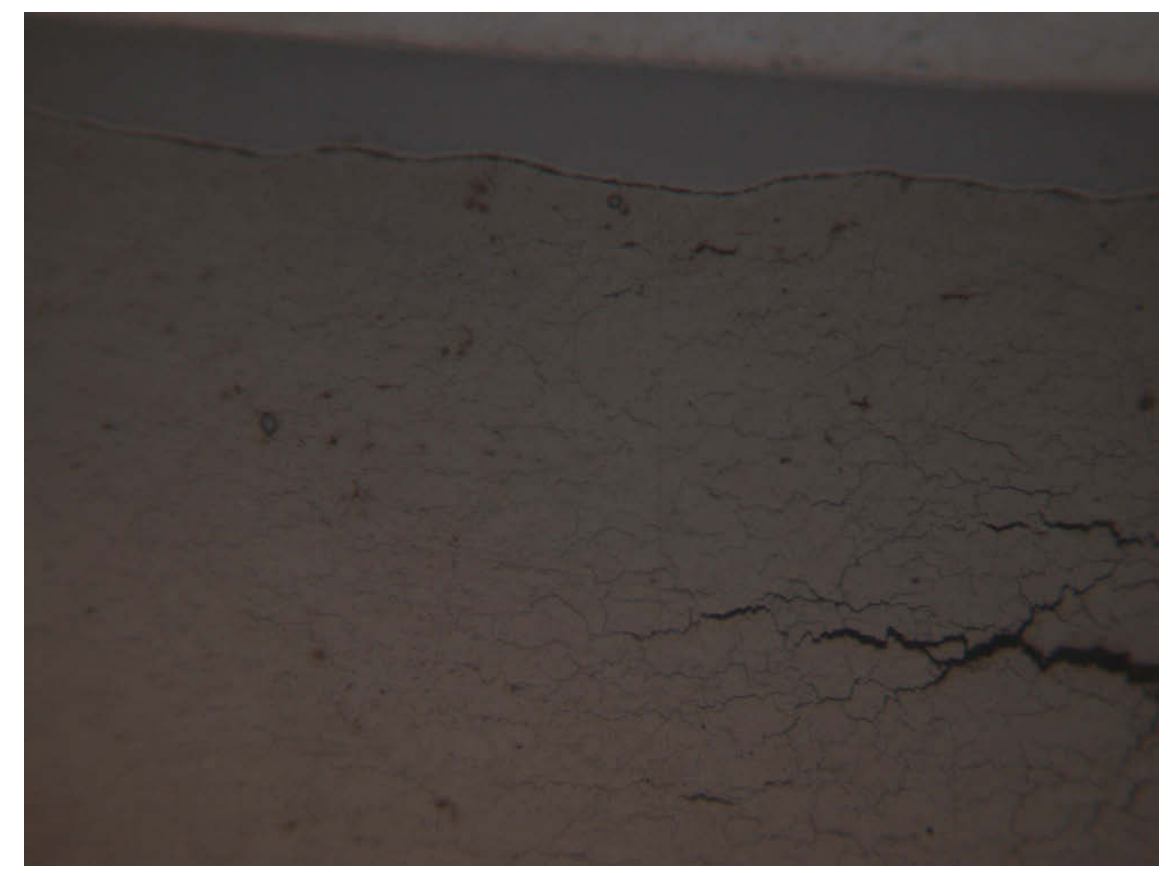

Figure 19. Optical image $(500 \times)$ of the fuel crack in the left end of the transverse cut in plate L1P460. 
Figure 20. Optical image $(500 \times)$ of the fuel crack in the left end of the transverse cut in plate L1P460.

\section{Plate L1P592}

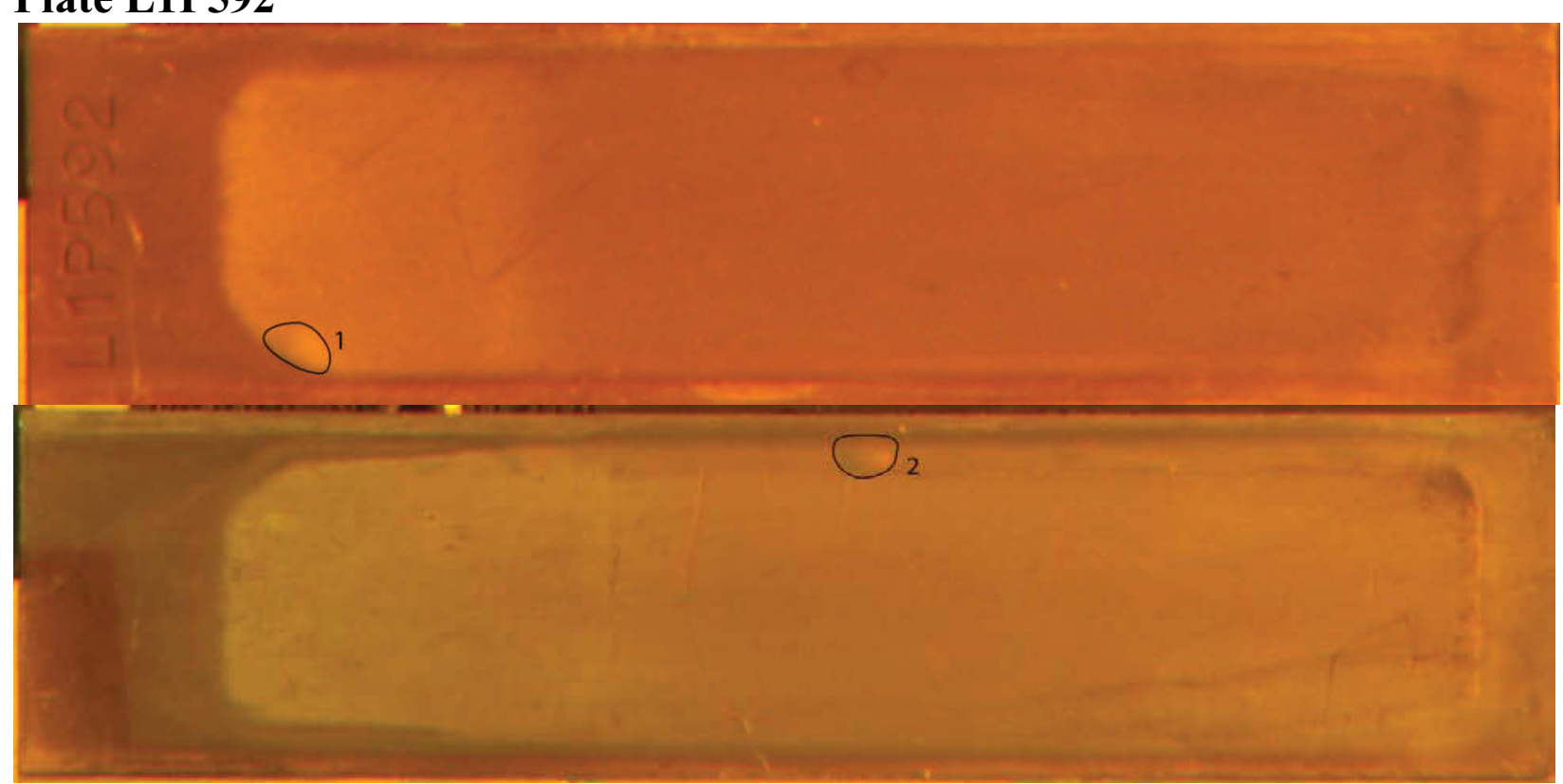

Figure 21. Type 2 blisters on the front (top image) and back (bottom image) sides of plate L1P592 (RERTR-12). Average fission density $2.69 \times 10^{21}$ fissions $/ \mathrm{cm}^{3}$. Peak fission density $5.09 \times 10^{21}$ fissions $/ \mathrm{cm}^{3}$. Zr diffusion barrier was applied. 


\section{Plate L1P463}

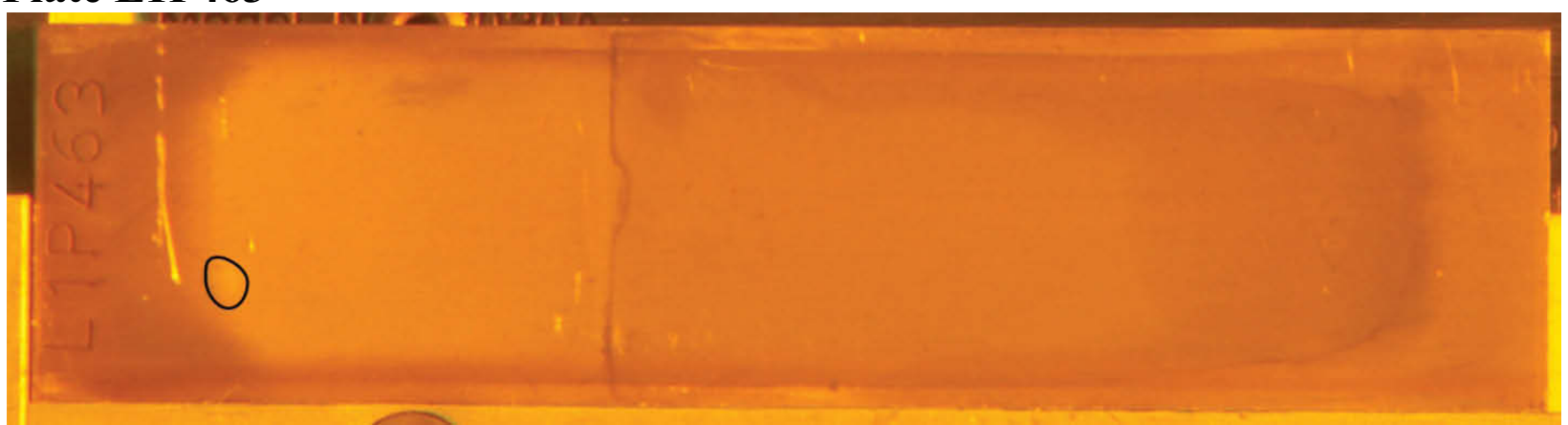

Figure 22. Type 1 blister on the front side of plate L1P463 (RERTR-12). Average fission density $2.86 \times$ $10^{21}$ fissions $/ \mathrm{cm}^{3}$. Peak fission density $4.86 \times 10^{21}$ fissions $/ \mathrm{cm}^{3}$. Zr diffusion barrier was applied.

\section{Plate L1P595}

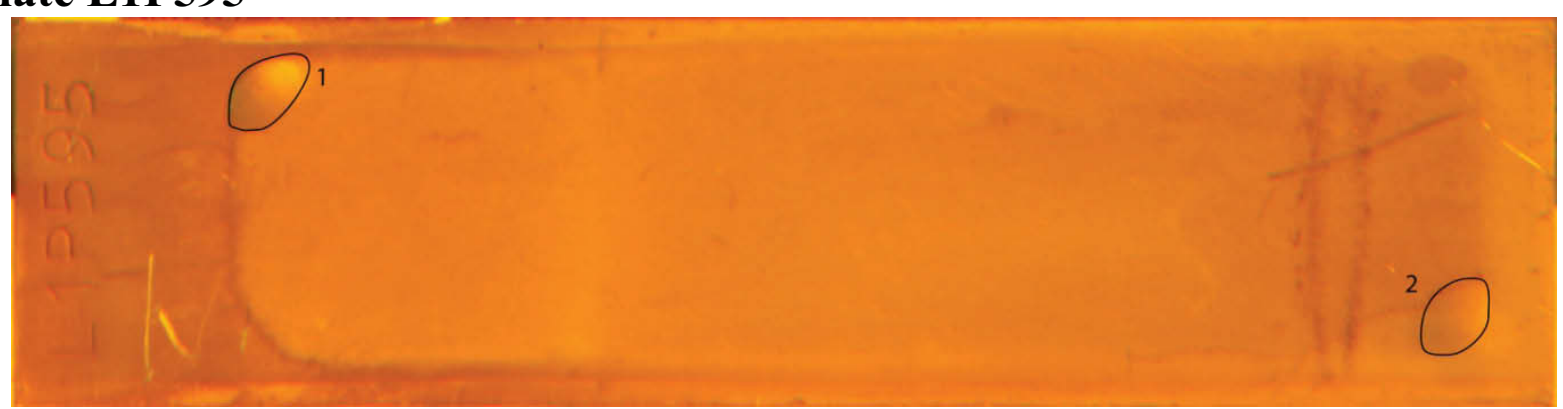

Figure 23. Type 2 blisters on the front side of plate L1P595 (RERTR-12). Average fission density $3.41 \times$ $10^{21}$ fissions $/ \mathrm{cm}^{3}$. Peak fission density $6.38 \times 10^{21}$ fissions $/ \mathrm{cm}^{3} . \mathrm{Zr}$ diffusion barrier was applied.

\section{Plate L1P758}

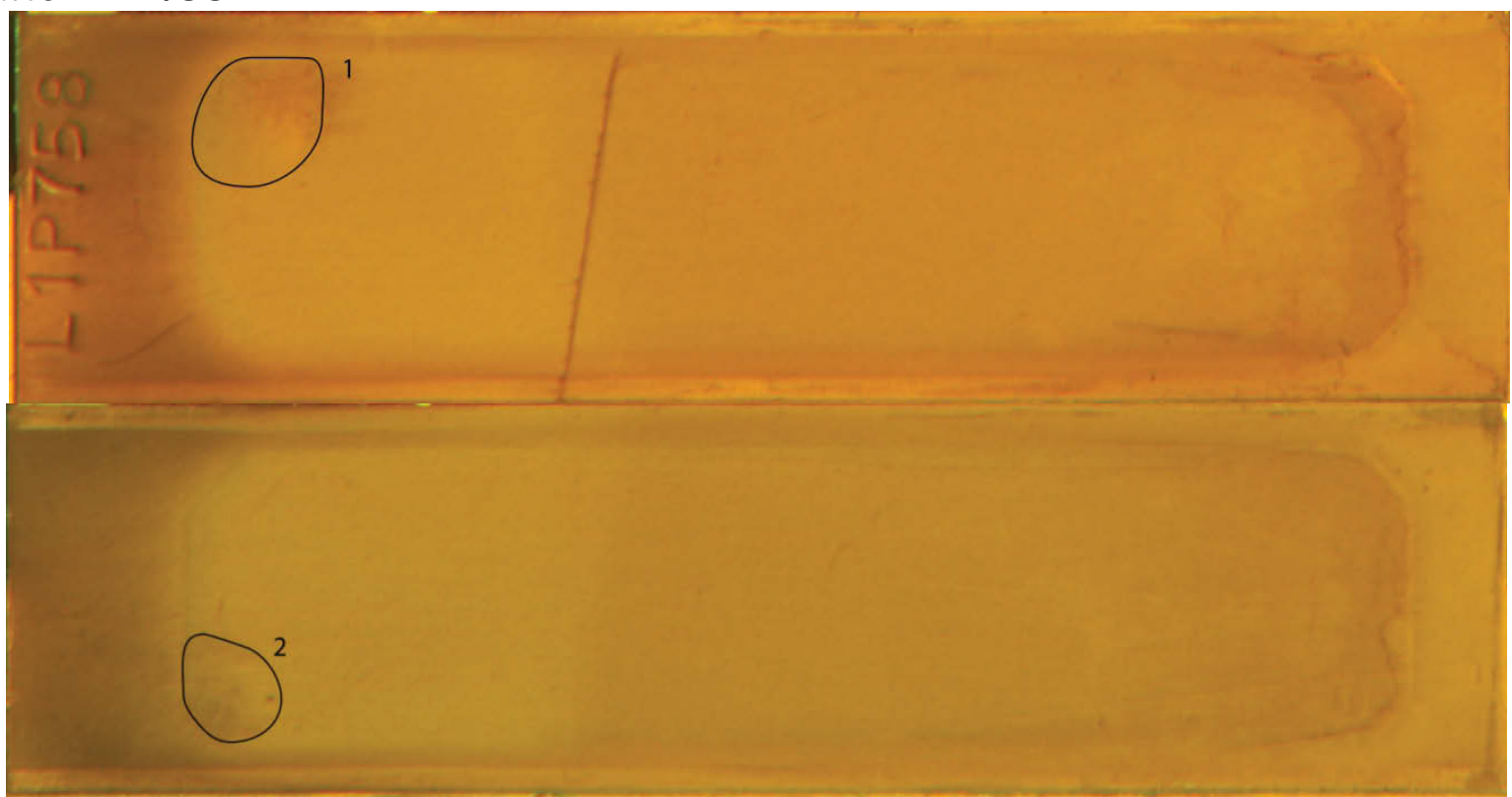

Figure 24. Type 2 blisters on the front (top image) and back (bottom image) sides of plate L1P758 (RERTR-12). Average fission density $5.00 \times 10^{21}$ fissions $/ \mathrm{cm}^{3}$. Peak fission density $9.20 \times 10^{21}$ fissions $/ \mathrm{cm}^{3}$. Zr diffusion barrier was applied. 


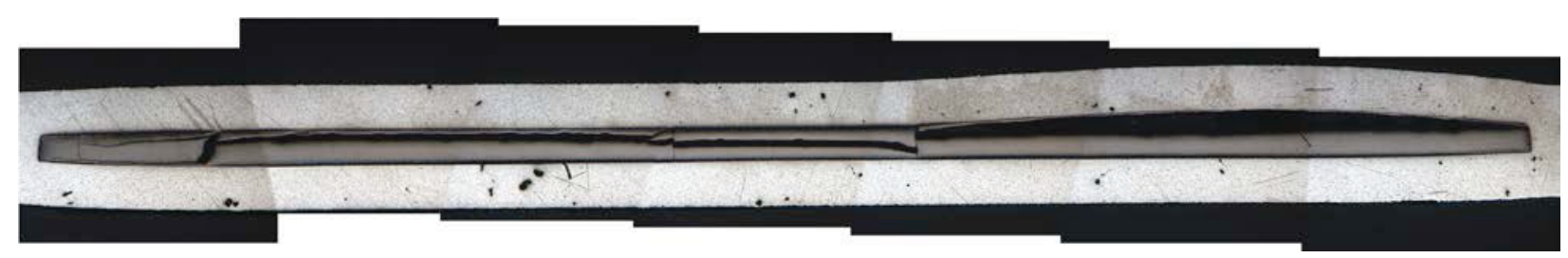

Figure 25. Montage of the optical metallography images $(50 \times)$ for plate L1P758. Transverse cut through the blister.

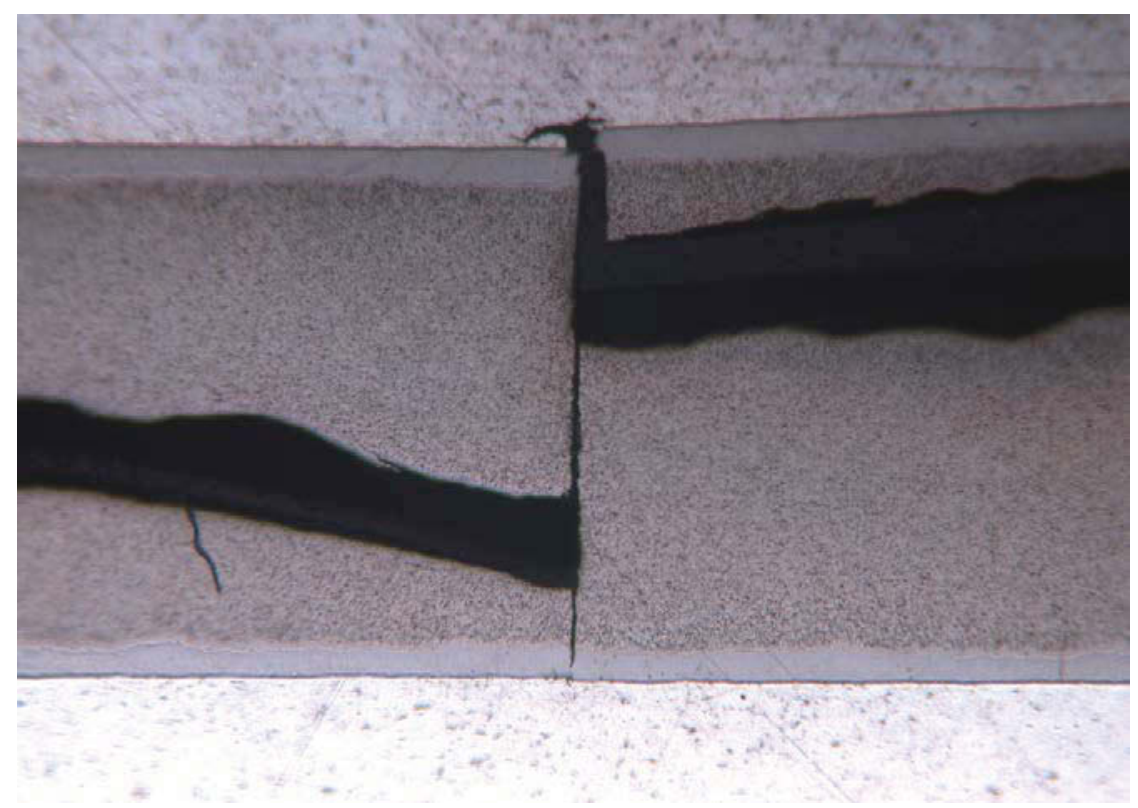

Figure 26. Optical metallography image $(200 \times)$ of the crack observed in the transverse cut of the plate L1P758.

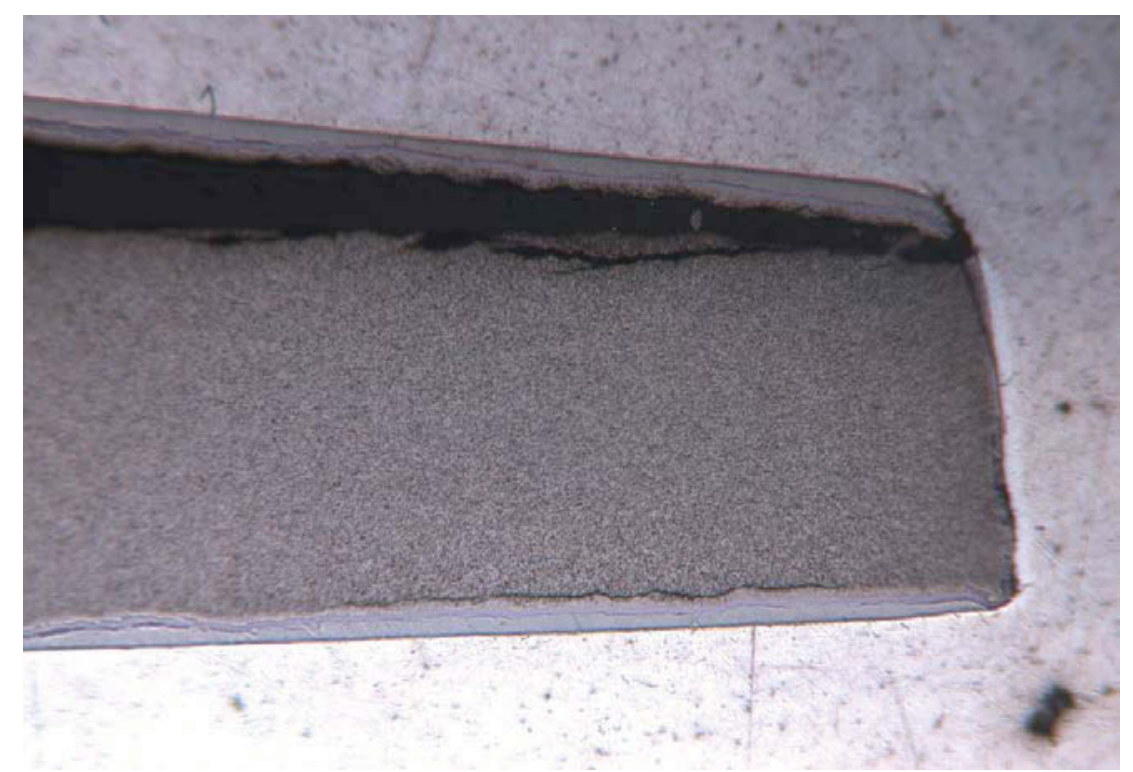

Figure 27. Optical metallography image $(200 \times)$ of the right end of the transverse cut in plate L1P758.

Appendix A 


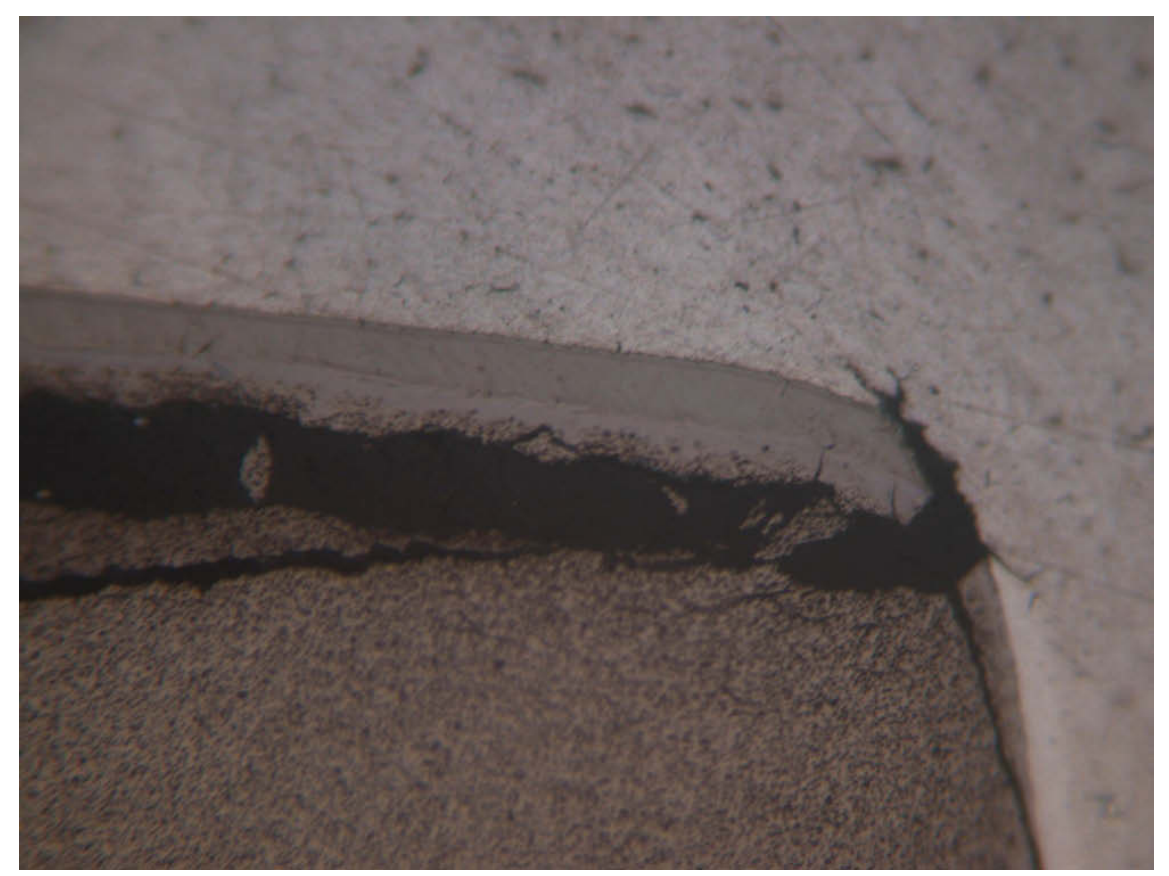

(a)

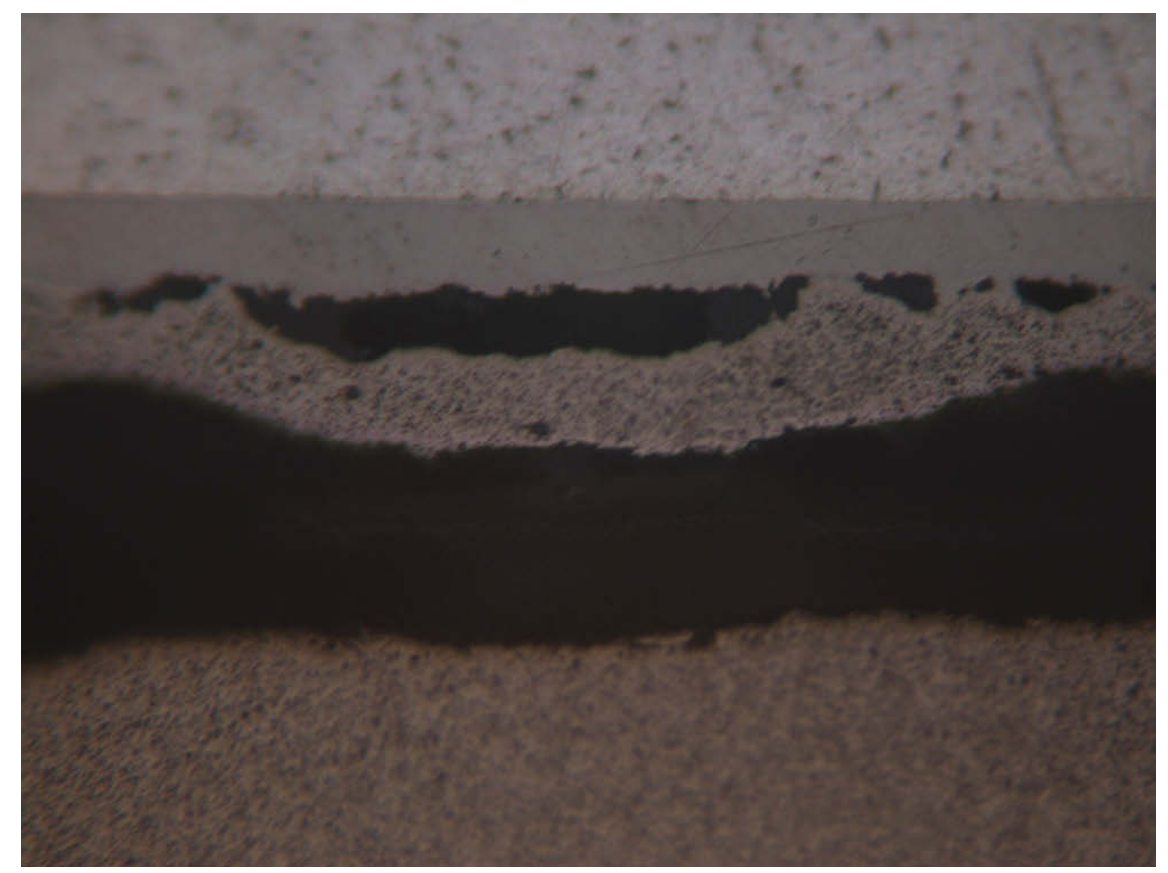

(b)

Figure 28. Optical metallography image $(500 \times)$ of the right end crack (a) and porosity above the crack (b) in the transverse cut of plate L1P758. 


\section{Plate L1P774}

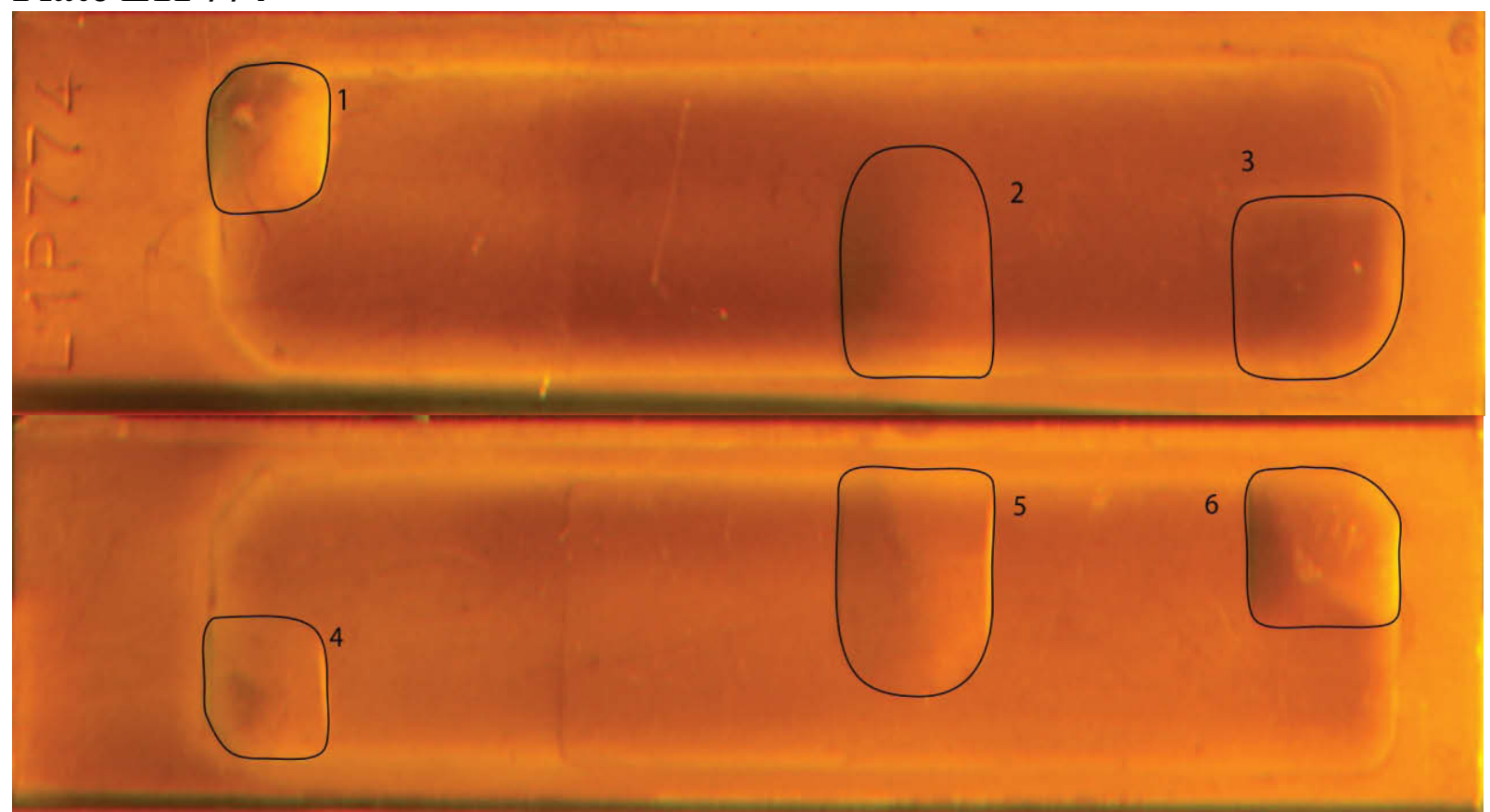

Figure 29. Type 2 blisters on the front (top image) and back (bottom image) sides of plate L1P774 (RERTR-12). Average fission density $5.59 \times 10^{21}$ fissions $/ \mathrm{cm}^{3}$. Peak fission density $7.49 \times 10^{21}$ fissions $/ \mathrm{cm}^{3}$. Zr diffusion barrier was applied.

\section{Plate L1P772}

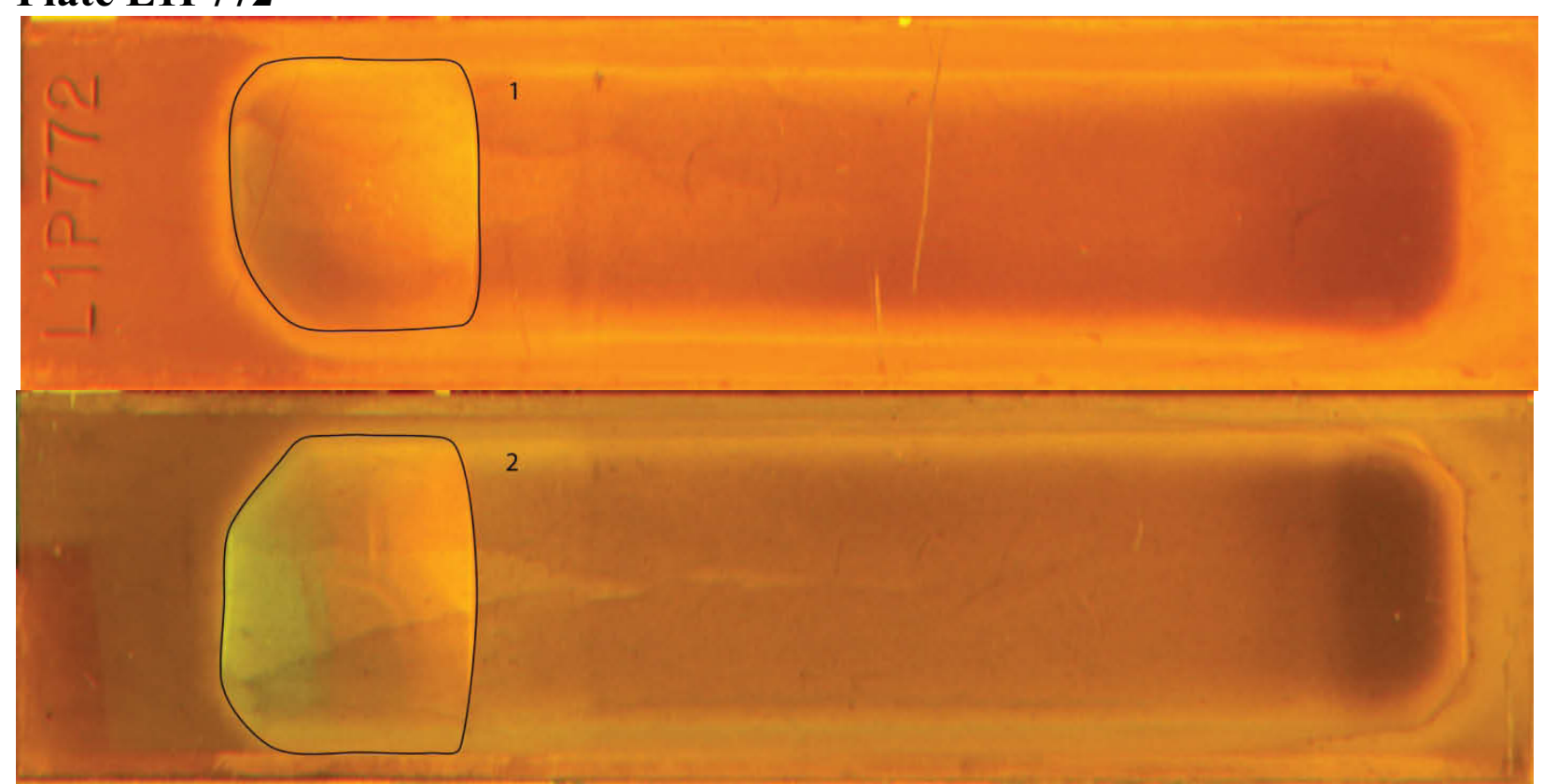

Figure 30. Type 2 blisters on the front (top image) and back (bottom image) sides of plate L1P772 (RERTR-12). Average fission density $5.77 \times 10^{21}$ fissions $/ \mathrm{cm}^{3}$. Peak fission density $7.83 \times 10^{21}$ fissions $/ \mathrm{cm}^{3}$. Zr diffusion barrier was applied. 


\section{Plate L1P756}

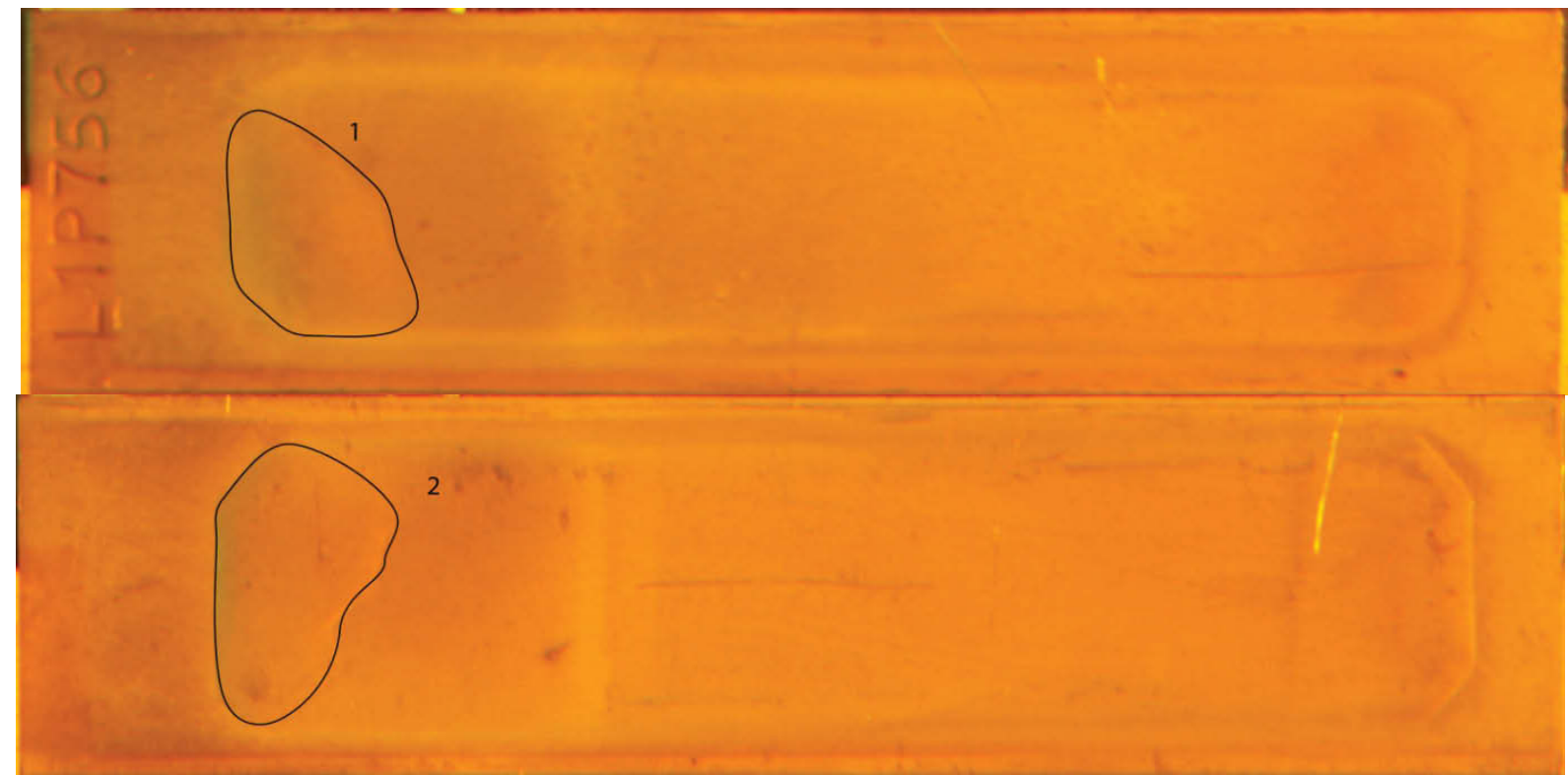

Figure 31. Type 2 blisters on the front (top image) and back (bottom image) sides of plate L1P756 (RERTR-12). Average fission density $7.05 \times 10^{21}$ fissions $/ \mathrm{cm}^{3}$. Peak fission density $9.10 \times 10^{21}$ fissions $/ \mathrm{cm}^{3}$. Zr diffusion barrier was applied.

\section{Plate L1P754 (blistered in the core)}

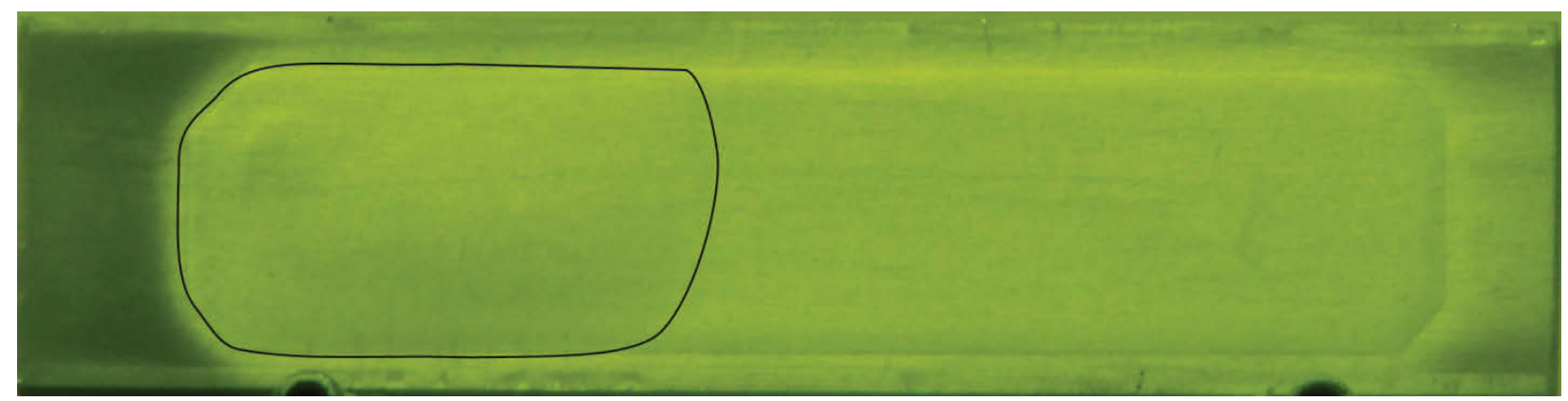

Figure 32. Type 2 blisters on the back side of plate L1P754 (RERTR-12), which blistered in the core. Average fission density $8.13 \times 10^{21}$ fissions $/ \mathrm{cm}^{3}$. Peak fission density $11.9 \times 10^{21}$ fissions $/ \mathrm{cm}^{3}$. Zr diffusion barrier was applied.

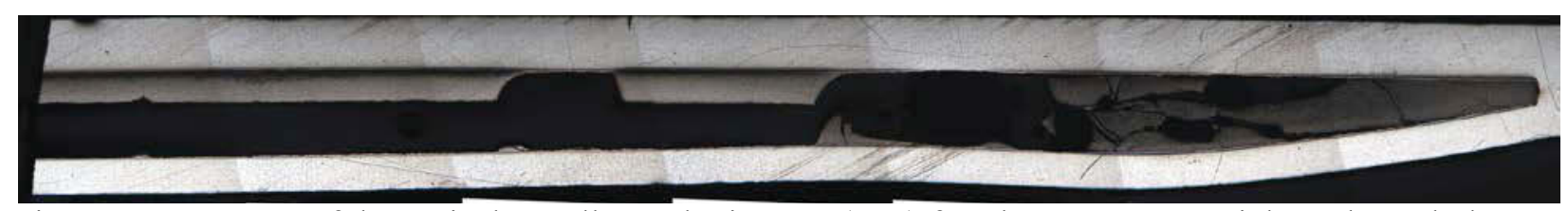

Figure 33. Montage of the optical metallography images (50×) for plate L1P754. Axial cut through the blister. 


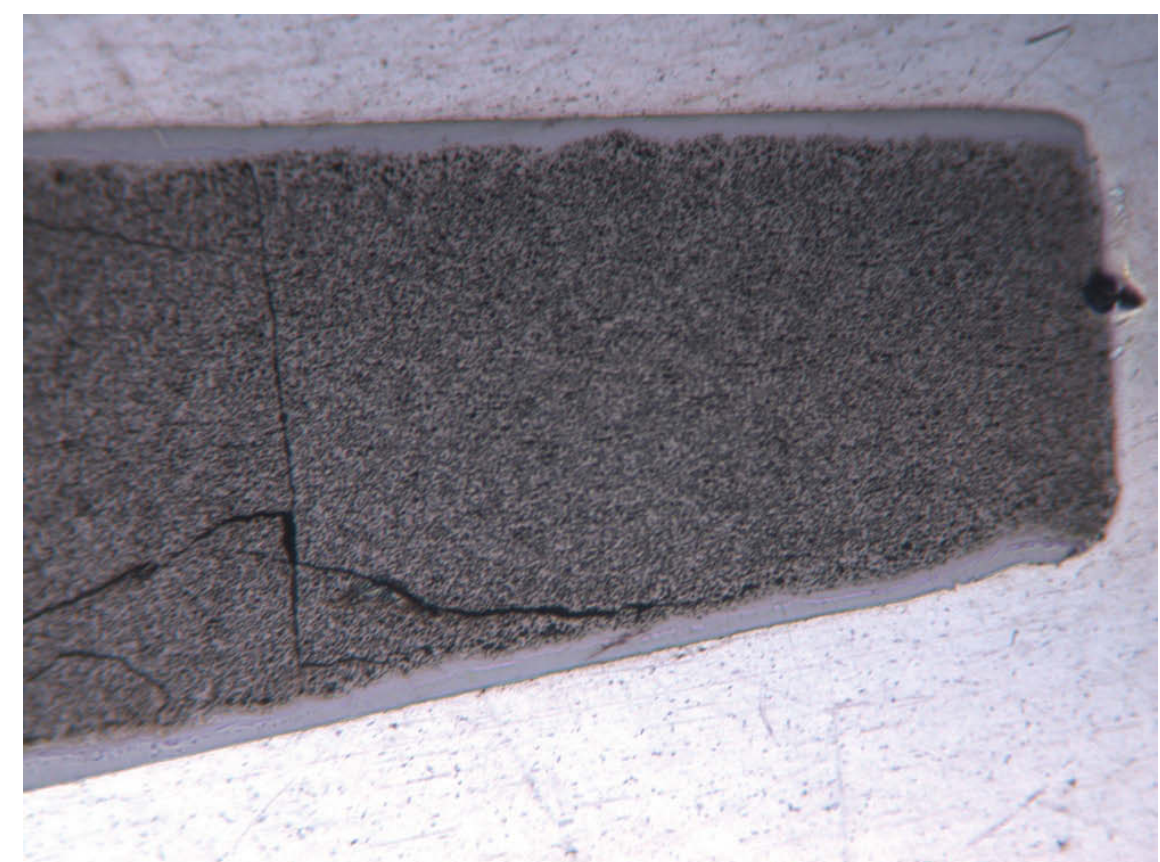

Figure 34. Optical metallography image $(200 \times)$ of the fuel end. Axial cut of plate L1P754.

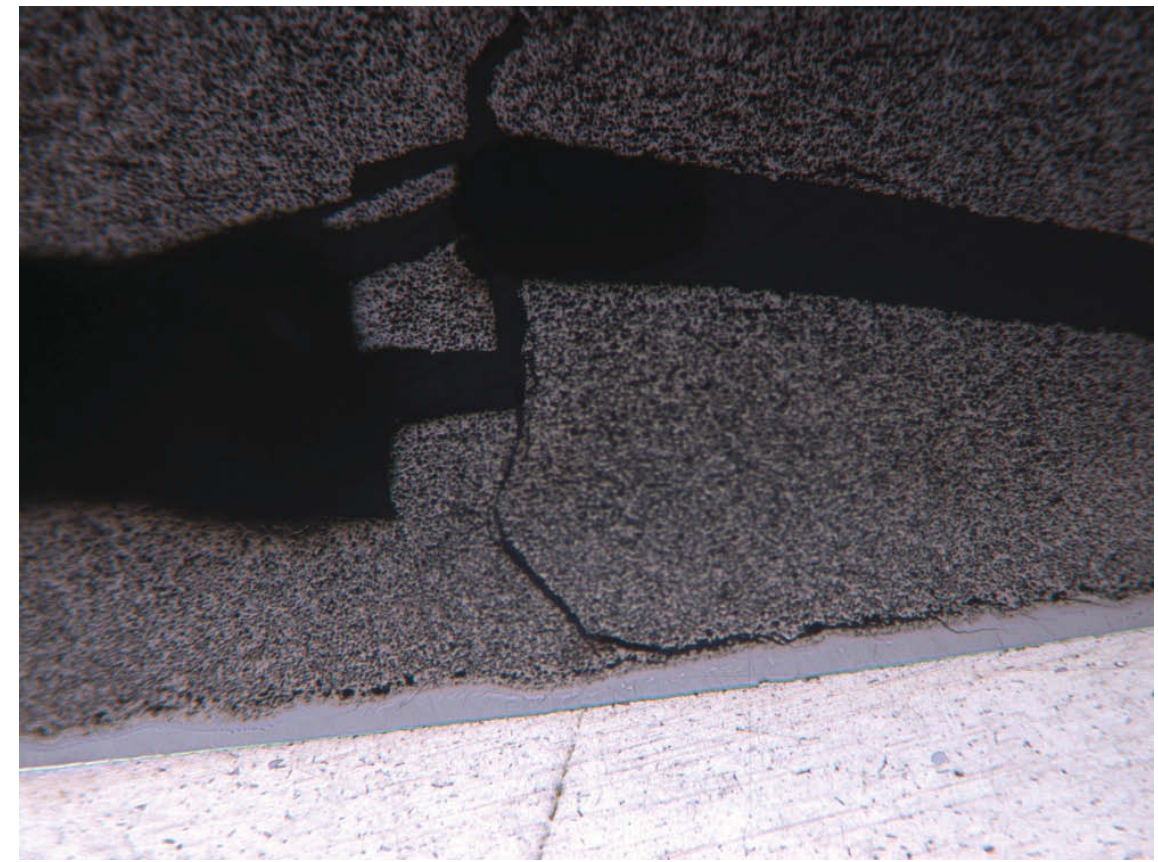

Figure 35. Optical metallography image $(200 \times)$ of the crack in the fuel, axial cut of plate L1P754. 

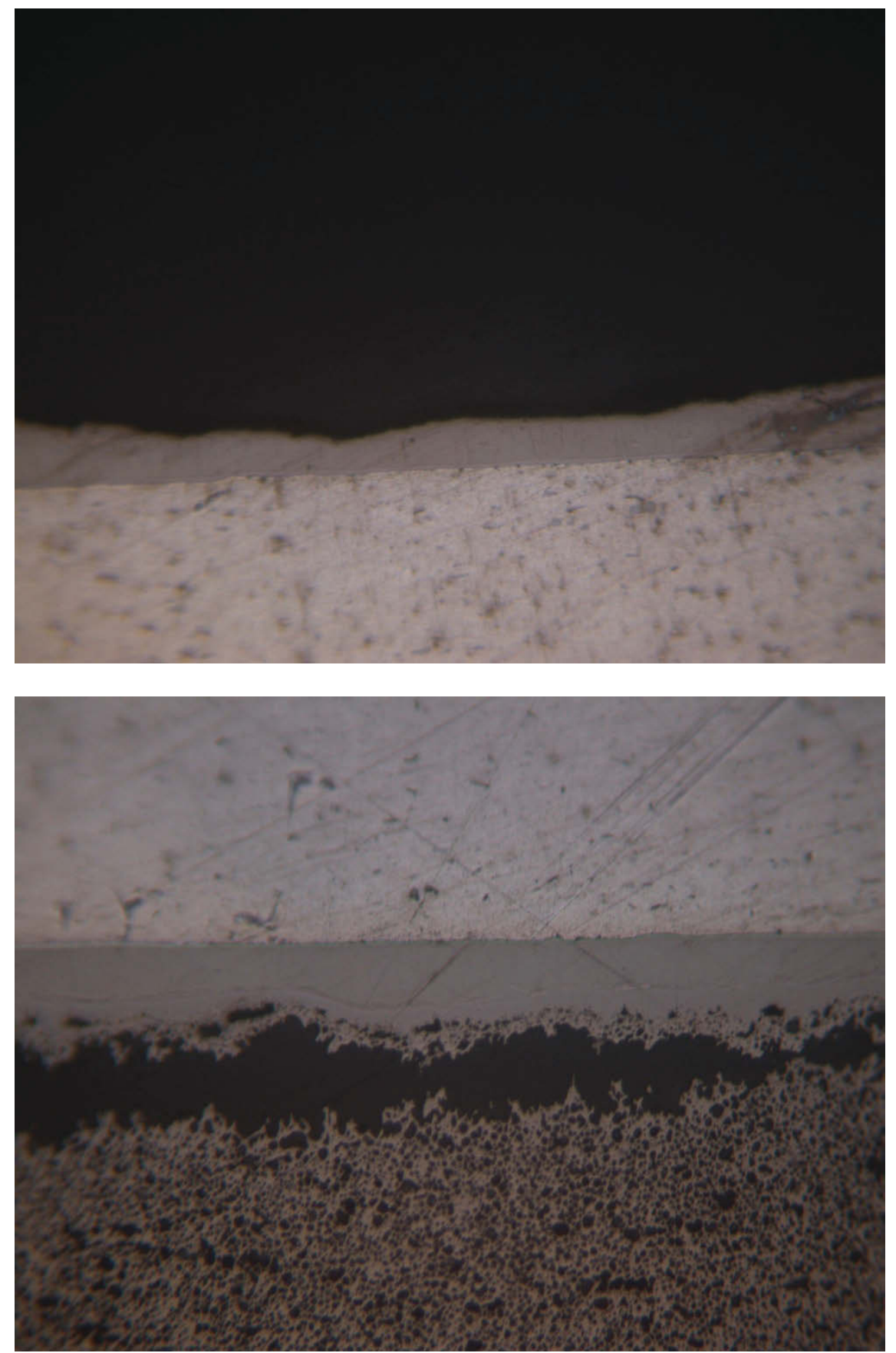

Figure 36. Optical metallography image $(500 \times)$ of debond in the axial cut of plate L1P754.

Appendix A 


\section{AFIP-4}

\section{Plate L1H34Z}

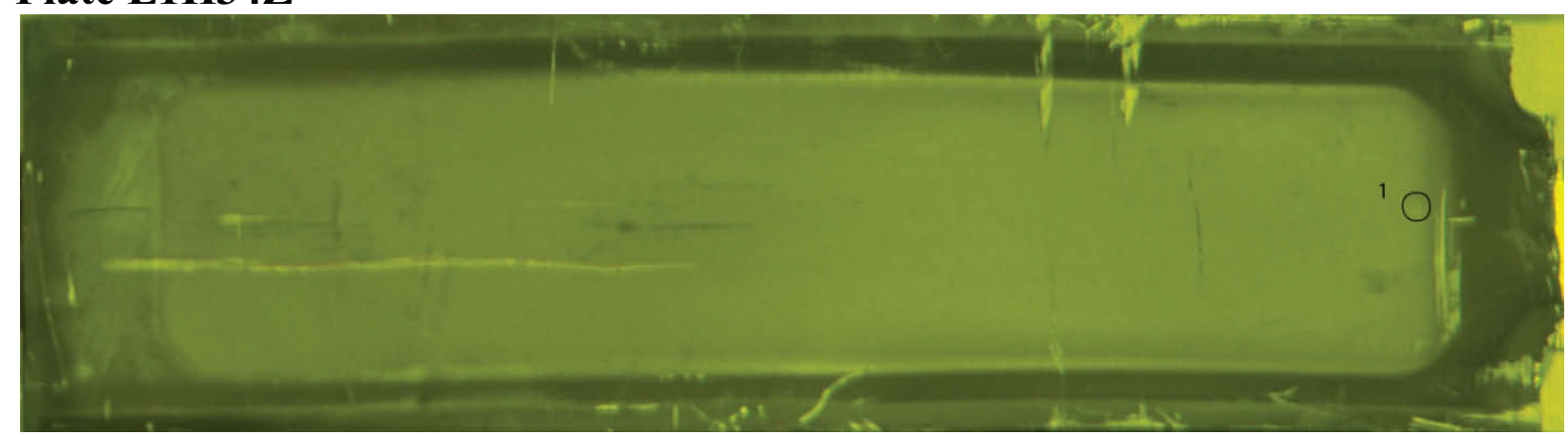

Figure 37. Type 2 blisters on the back side of plate L1H34Z (AFIP-4). Average fission density $2.51 \times$ $10^{21}$ fissions $/ \mathrm{cm}^{3}$. Peak fission density $2.99 \times 10^{21}$ fissions $/ \mathrm{cm}^{3} . \mathrm{Zr}$ diffusion barrier was applied.

\section{Plate L1H36Z}

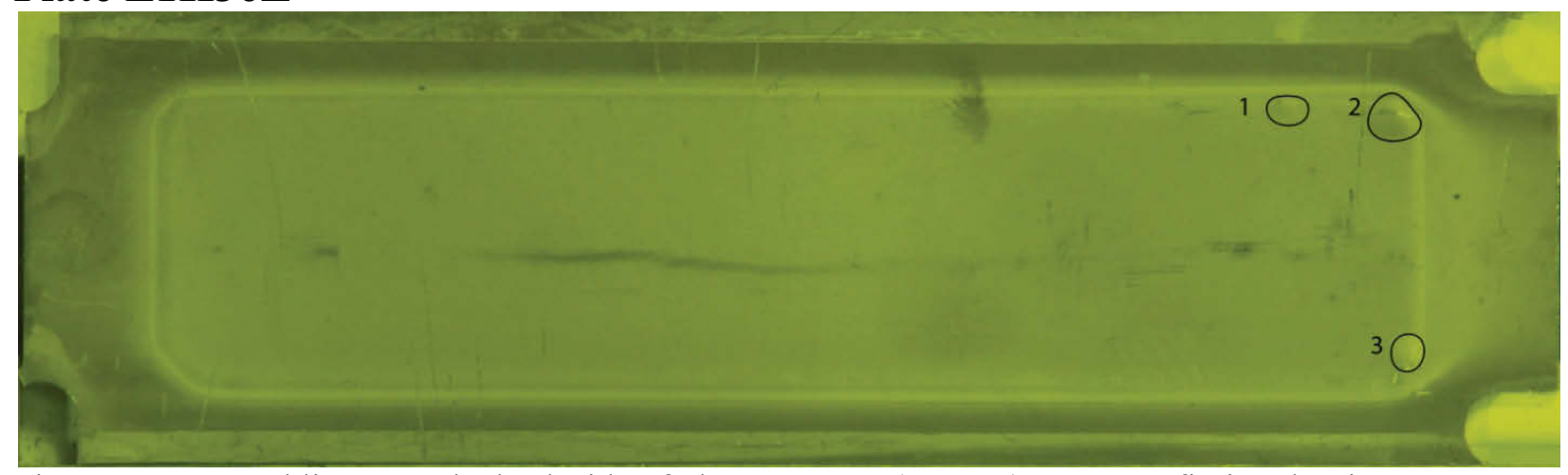

Figure 38. Type 2 blisters on the back side of plate L1H36Z (AFIP-4). Average fission density $4.45 \times$ $10^{21}$ fissions $/ \mathrm{cm}^{3}$. Peak fission density $5.03 \times 10^{21}$ fissions $/ \mathrm{cm}^{3}$. Zr diffusion barrier was applied.

\section{Plate L1B33Z}

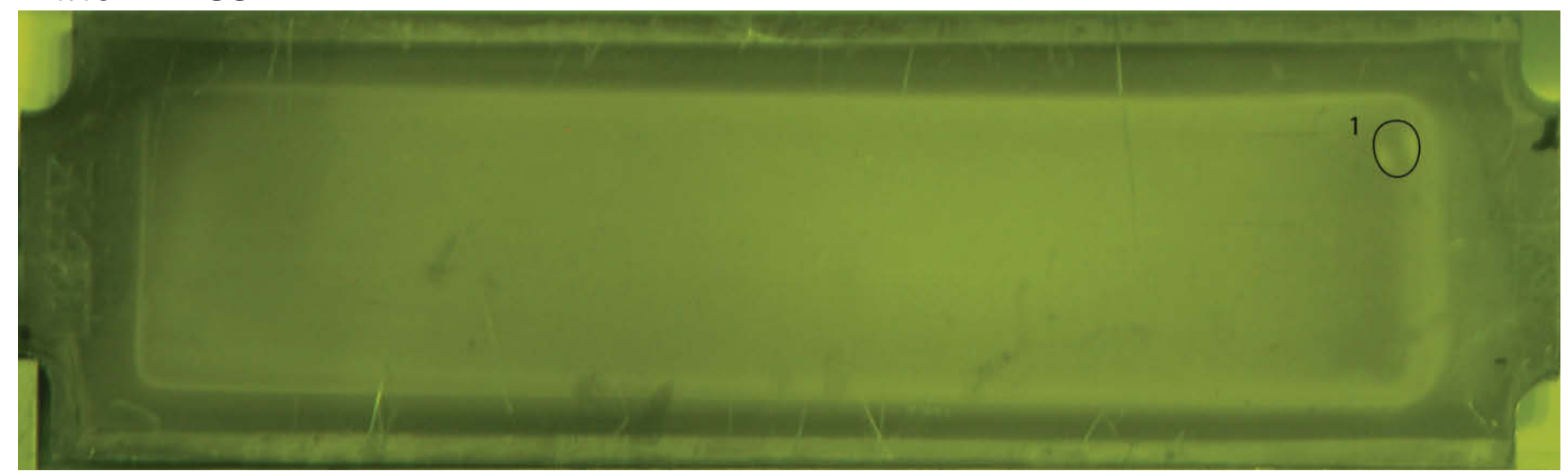

Figure 39. Type 2 blisters on the front side of plate L1B33Z (AFIP-4). Average fission density $4.06 \times$ $10^{21}$ fissions $/ \mathrm{cm}^{3}$. Peak fission density $4.59 \times 10^{21}$ fissions $/ \mathrm{cm}^{3} . \mathrm{Zr}$ diffusion barrier was applied. 


\section{Plate L1B51Z}

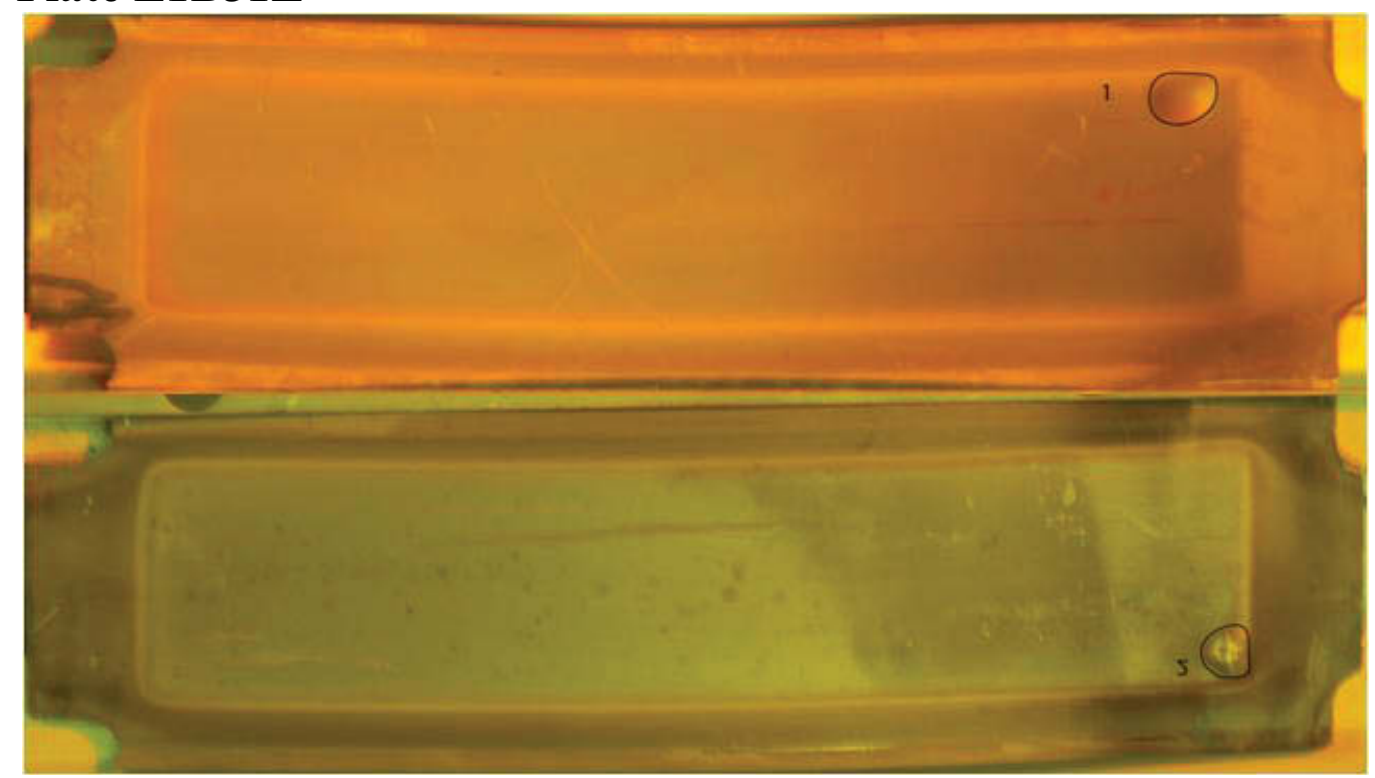

Figure 40. Type 2 blisters on the front (top image) and back (bottom image) sides of plate L1B51Z (AFIP-4). Average fission density $4.56 \times 10^{21}$ fissions $/ \mathrm{cm}^{3}$. Peak fission density $5.20 \times 10^{21}$ fissions $/ \mathrm{cm}^{3}$. $\mathrm{Zr}$ diffusion barrier was applied. 
Appendix A 
Appendix B

Monolithic Plate Processing-Variables Summary Sheets for Blister Tested Plates

Appendix B 
Monolithic Plate Processing-Variables Summary

\begin{tabular}{|c|c|c|c|c|}
\hline Experiement: & RERTR-6 & Capsule Position: & & \\
\hline Plate: & N1F060 & Foil ID: & U7M0-11 & \\
\hline Blister Temperature (' $\mathrm{C})$ & 450 & Fuel Meat Thickness(in.): & 0.010 & \\
\hline Average Fission Density (fission/cc $\times 10^{\wedge} 21$ ) & 3.83 & Enrichment $(\% \mathrm{U}-235 / \mathrm{U}$ tot): & $20 \%$ & \\
\hline Peak Fissions Denstiy (fission $/ \mathrm{cc} \times 10^{\wedge} 21$ ) & 4.89 & Cladding Method: & Friction Bonding & \\
\hline Composition & U7Mo & & & \\
\hline Enrichment (\% U-235/Utotal) & $20 \%$ & & & \\
\hline Alloy Materials & HEU & DU & Mo foil & Mo Powder \\
\hline Alloying/Casting & arc melter & Vacuum Induction Melter (VIM) & & \\
\hline Casting mold & graphite & & & \\
\hline Coupon & not surface machined & surface machined & & \\
\hline Coupon heat treatment/homogenization & None & & & \\
\hline Alloy Carbon Content (ppm) & 340 & & & \\
\hline
\end{tabular}

Step 2: Foil Fabrication

\begin{tabular}{|c|c|c|c|}
\hline Foil Type: & Roll bonded barrier laver & Bare & \\
\hline Barrier Layer & $\mathrm{Zr}$ & NA & \\
\hline Hot Rolling & Yes & No & \\
\hline Barrier Layer cleaning & \multirow{11}{*}{\multicolumn{2}{|c|}{ NA }} & \\
\hline Can Material & & & \\
\hline Release Agent & & & \\
\hline Coupon Cleaning & & & \\
\hline Furnace Temperature & & & \\
\hline Schedule (max pass reduction) & & & \\
\hline Total Hot Rolling Reduction (\%) & & & \\
\hline Number of Passes & & & \\
\hline Post Roll Anneal & & & \\
\hline Anneal time/total time (min) & & & \\
\hline \multicolumn{2}{|l|}{ Total time at temperature } & & \\
\hline Cold Rolling & Yes & No & \\
\hline Schedule: "reduction" & "medium" 1-2\%/pass & "light" gradual <1\% pass & "Aggre ssive" $>2 \%$ pass \\
\hline Cold Rolling Reduction (\%) & $88 \%$ & & \\
\hline Number of Passes & $\sim 50$ & & \\
\hline Foil Character & Flat and ductile & wavy and stiff & \\
\hline Foil Thickness & standard $\left(0.010-0.013^{\prime \prime}\right)$ & Thick $0.020^{\prime \prime}$ or $>$ & \\
\hline Post cold rolling anneal & No & Yes & \\
\hline heating method & None & Furance anneal $650 \mathrm{C} / 1 \mathrm{hr}$ & resistive heating: $925 \mathrm{C}, 10 \mathrm{sec}$ \\
\hline Foil Sizing & Blanking & Shearing & \\
\hline Foil Cleaning & diamond polish & nitirc/HF & None \\
\hline
\end{tabular}

Step 3: Cladding

\begin{tabular}{|c|c|c|c|}
\hline Cladding type & Al 6061 & & \\
\hline Thermal Spray Barrier Layer on Cladding & No & Yes & Type: \\
\hline Clad bonding method & HIP & Friction Bond & \\
\hline HIP temperature & $\mathrm{NA}$ & & \\
\hline HIP Hold Time & NA & & \\
\hline Pressure (Ksi) & $\mathrm{NA}$ & & \\
\hline
\end{tabular}

\begin{tabular}{|c|c|c|}
\hline Autoclave treatment & Yes & \\
\hline Water $\mathrm{pH}$ & adjusted & not adjusted \\
\hline Temperature & $185 \mathrm{C}$ & \\
\hline Time at Temperature & $18 \mathrm{hrs}$ & $4 \mathrm{hrs}$ \\
\hline Miniplate Blister anneal treatment & Yes & No \\
\hline
\end{tabular}


Monolithic Plate Processing-Variables Summary

\begin{tabular}{|c|c|c|c|c|}
\hline \multirow{2}{*}{$\begin{array}{r}\text { Experiement: } \\
\text { Plate: }\end{array}$} & RERTR-6 & Capsule Position: & & \\
\hline & L2F020 & Foil ID: & U10M0-18A & \\
\hline \multirow{3}{*}{$\begin{array}{r}\text { Blister Temperature ('C) } \\
\text { Average Fission Density (fission } / \mathrm{cc} \times 10^{\wedge} 21 \text { ) } \\
\text { Peak Fissions Denstiy (fission } / \mathrm{cc} \times 10^{\wedge} 21 \text { ) }\end{array}$} & 450 & Fuel Meat Thickness (in.): & 0.020 & \\
\hline & 2.52 & Enrichment (\% U-235/Utot): & $20 \%$ & \\
\hline & 3.24 & Cladding Method: & Friction Bonding & \\
\hline \multicolumn{5}{|l|}{ Step 1: alloying-> coup on fabrication } \\
\hline Composition & U10Mo & & & \\
\hline Enrichment (\% U-235/Utotal) & $20 \%$ & & & \\
\hline Alloy Materials & HEU & DU & Mo foil & Mo Powder \\
\hline Alloving/Casting & arc melter & Vacuum Induction Melter (VIM) & & \\
\hline Casting mold & graphite & & & \\
\hline Coupon & not surface machined & surface machined & & \\
\hline Coupon heat treatment/homogenization & None & & & \\
\hline Allov Carbon Content (ppm) & - & & & \\
\hline
\end{tabular}

Step 2: Foil Fabrication

\begin{tabular}{|r|c|c|}
\hline Foil Type: & Roll bonded barrier layer & Bare \\
\hline Barrier Layer & $\mathrm{Zr}$ & NA \\
\hline \multicolumn{3}{|c|}{} \\
\hline Hot Rolling & Yes & No \\
\hline
\end{tabular}

\begin{tabular}{|r|r|r|}
\hline Hot Rolling & Yes & No \\
\hline Barrier Layer cleaning & & \\
\hline Can Material & & \\
\hline Release Agent & & \\
\hline Coupon Cleaning & & NA \\
\hline Furnace Temperature & & \\
\hline Schedule (max pass reduction) & & \\
\hline Total Hot Rolling Reduction (\%) & & \\
\hline Number of Passes & & \\
\hline Post Roll Anneal & & \\
\hline Anneal time/total time (min) & & \\
\hline Total time at temperature & & \\
\hline
\end{tabular}

\begin{tabular}{|c|c|c|c|}
\hline Cold Rolling & Yes & No & \\
\hline Schedule: "reduction" & "medium" 1-2\%/pass & "light" gradual <1\% pass & "Aggre ssive" $>2 \%$ pass \\
\hline Cold Rolling Reduction (\%) & $78 \%$ & & \\
\hline Number of Passes & $\sim 40$ & & \\
\hline Foil Character & Flat and ductile & wavy and stiff & \\
\hline Foil Thickness & standard (0.010-0.013") & Thick $0.020^{\prime \prime}$ or $>$ & \\
\hline
\end{tabular}

\begin{tabular}{|c|c|c|c|}
\hline Post cold rolling anneal & No & Yes & \\
\hline heating method & None & Furance anneal $650 \mathrm{C} / 1 \mathrm{hr}$ & re sistive heating: $925 \mathrm{C}, 10 \mathrm{sec}$ \\
\hline Foil Sizing & Blanking & Shearing & \\
\hline Foil Cleaning & diam ond polish & nitirc/HF & None \\
\hline
\end{tabular}

Step 3: Cladding

Step 3: Cladding
\begin{tabular}{|r|c|c|}
\hline Cladding type & Al 6061 & Yes \\
\hline Thermal Sprav Barrier Laver on Cladding & No & Friction Bond \\
\hline Clad bonding method & HIP & \\
\hline HIP tem perature & NA & NA \\
\hline HIP Hold Time & NA & NA \\
\hline Pressure (Ksi) & N &
\end{tabular}

Step 4: Final Processing

\begin{tabular}{|c|c|c|}
\hline Autoclave treatment & Yes & \\
\hline Water $\mathrm{pH}$ & adjusted & not adjusted \\
\hline Temperature & $185 \mathrm{C}$ & \\
\hline Time at Temperature & $18 \mathrm{hrs}$ & $4 \mathrm{hrs}$ \\
\hline Miniplate Blister anneal treatment & Yes & No \\
\hline
\end{tabular}


Monolithic Plate Processing-Variables Summary

\begin{tabular}{r|r|r|c|} 
Experiement: & RERTR-7 & Capsule Position: & \\
\cline { 2 - 4 } & Plate: & Foil ID: & U10M0-21 \\
\cline { 2 - 4 } Blister Temperature ('C) & 400 & Fuel Meat Thickness (in.): & 0.010 \\
\cline { 2 - 4 } Average Fission Density (fission $\left./ \mathrm{cc} \times 10^{n} 21\right)$ & 5.14 & Enrichment (\% U-235/Utot): & $58 \%$ \\
Peak Fissions Denstiy (fission/cc $\times 10^{n} 21$ ) & 7.1 & Cladding Method: & Friction Bonding \\
\cline { 2 - 4 } & &
\end{tabular}

\begin{tabular}{|c|c|c|c|c|}
\hline Composition & U10Mo & & & \\
\hline Enrichment (\% U-235/Utotal) & $58 \%$ & & & \\
\hline Alloy Materials & HEU & DU & Mo foil & Mo Powder \\
\hline Alloying/Casting & arc melter & Vacuum Induction Melter (VIM) & & \\
\hline Casting mold & graphite & & & \\
\hline Coupon & not surface machined & surface machined & & \\
\hline Coupon heat treatment/homogenization & None & & & \\
\hline Alloy Carbon Content (ppm) & 134 & & & \\
\hline
\end{tabular}

Step 2: Foil Fabrication

\begin{tabular}{|c|c|c|c|}
\hline Foil Type: & Roll bonded barrier layer & Bare & \\
\hline Barrier Layer & $\mathrm{Zr}$ & NA & \\
\hline Hot Rolling & Yes & No & \\
\hline Barrier Layer cleaning & \multirow{11}{*}{\multicolumn{2}{|c|}{ NA }} & \\
\hline Can Material & & & \\
\hline Release Agent & & & \\
\hline Coupon Cleaning & & & \\
\hline Furnace Temperature & & & \\
\hline Schedule (max passreduction) & & & \\
\hline Total Hot Rolling Reduction (\%) & & & \\
\hline Number of Passes & & & \\
\hline Post Roll Anneal & & & \\
\hline Anneal time/total time (min) & & & \\
\hline \multicolumn{2}{|l|}{ Total time at temperature } & & \\
\hline Cold Rolling & Yes & No & \\
\hline Schedule: "reduction" & "medium" 1-2\%/pass & "light" gradual <1\% pass & "Aggre ssive" $>2 \%$ pass \\
\hline Cold Rolling Reduction (\%) & $88 \%$ & & \\
\hline Number of Passes & $\sim 50$ & & \\
\hline Foil Character & Flat and ductile & wavy and stiff & \\
\hline Foil Thickness & standard $\left(0.010-0.013^{\prime \prime}\right)$ & Thick $0.020^{\prime \prime}$ or $>$ & \\
\hline Post cold rolling anneal & No & Yes & \\
\hline heating method & None & Furance anneal $650 \mathrm{c} / 1 \mathrm{hr}$ & re sistive heating: $925 \mathrm{C}, 10 \mathrm{sec}$ \\
\hline Foil Sizing & Blanking & Shearing & \\
\hline Foil Cleaning & diam ond polish & nitirc/HF & None \\
\hline
\end{tabular}

Step 3: Cladding

Step 3: Cladding
\begin{tabular}{|r|c|c|}
\hline Cladding type & Al 6061 & Yes \\
\hline Thermal Sprav Barrier Laver on Cladding & No & Friction Bond \\
\hline Clad bonding method & HIP \\
\hline HIP temperature & NA \\
\hline HIP Hold Time & NA \\
\hline Pressure (Ksi) & NA \\
\hline
\end{tabular}

Step 4: Final Processing

\begin{tabular}{|r|c|c|}
\hline Autoclave treatment & Yes & \\
\hline Water pH & adjusted & not adjusted \\
\hline Temperature & $185 \mathrm{C}$ & $4 \mathrm{hrs}$ \\
\hline Time at Temperature & $18 \mathrm{hrs}$ & No \\
\hline \multicolumn{2}{|c|}{} & Yes \\
\hline
\end{tabular}


Monolithic Plate Processing-Variables Summary

\begin{tabular}{|c|c|c|c|c|}
\hline Experiement: & RERTR-9A & Capsule Position: & & \\
\hline Plate: & L1F27C & Foil ID: & 133 & \\
\hline Blister Temperature (' $\mathrm{C}$ ) & 400 & Fuel Meat Thickness (in.): & 0.010 & \\
\hline Average Fission Density (fission/cc $\times 10^{n} 21$ ) & 3.74 & Enrichment (\% U-235/Utot): & $58 \%$ & \\
\hline Peak Fissions Denstiy (fission $/ \mathrm{cc} \times 10^{n} 21$ ) & 5.46 & Cladding Method: & Friction Bonding & \\
\hline \multicolumn{2}{|l|}{ Step 1: alloying-> coup on fabrication } & & & \\
\hline Composition & U10Mo & & & \\
\hline Enrichment (\% U-235/Utotal) & $58 \%$ & & & \\
\hline Alloy Materials & HEU & DU & Mo foil & Mo Powder \\
\hline Alloving/Casting & arc melter & Vacuum Induction Melter (VIM) & & \\
\hline Casting mold & graphite & & & \\
\hline Coupon & not surface machined & surface machined & & \\
\hline Coupon heat treatment/homogenization & None & & & \\
\hline Alloy Carbon Content (ppm) & 450 & & & \\
\hline
\end{tabular}

Step 2: Foil Fabrication

\begin{tabular}{|c|c|c|c|}
\hline Foil Type: & Roll bonded barrier laver & Bare & \\
\hline Barrier Layer & $\mathrm{Zr}$ & NA & \\
\hline Hot Rolling & Yes & No & \\
\hline Barrier Layer cleaning & polish/degrease & degrease & \\
\hline Can Material & carbon steel & & \\
\hline Release Agent & carbon "neolube" & Yttria & None \\
\hline Coupon Cleaning & chemical "nitric" & brush & NA \\
\hline Furnace Temperature & $650 \mathrm{C}$ & & \\
\hline Schedule (max passreduction) & "medium" $20 \%$ pass & "light" gradual <20\% pass & "Aggressive" $>20 \%$ pass \\
\hline Total Hot Rolling Reduction (\%) & $87 \%$ & & \\
\hline Number of Passes & 43 & & \\
\hline Post Roll Anneal & Yes & No & \\
\hline Anneal time/total time (min) & $30 / 85$ & & \\
\hline Total time at temperature & Med: 120 min & Short: $<100 \mathrm{~min}$ & Long $>150 \mathrm{~min}$. \\
\hline
\end{tabular}

\begin{tabular}{|c|c|c|c|}
\hline Cold Rolling & Yes & No & \\
\hline Schedule: "reduction" & "medium" 1-2\%/pass & "light" gradual <1\% pass & "Aggre ssive" >2\% pass \\
\hline Cold Rolling Reduction (\%) & $25 \%$ & & \\
\hline Number of Passes & 7 & & \\
\hline Foil Character & Flat and ductile & wavy and stiff & \\
\hline Foil Thickness & standard $\left(0.010-0.013^{\prime \prime}\right)$ & Thick $0.020^{\prime \prime}$ or $>$ & \\
\hline
\end{tabular}

\begin{tabular}{|c|c|c|c|}
\hline Post cold rolling anneal & No & Yes & \\
\hline heating method & None & Furance anneal $650 \mathrm{C} / 1 \mathrm{hr}$ & re sistive heating: $925 \mathrm{C}, 10 \mathrm{sec}$ \\
\hline Foil Sizing & Blanking & Shearing & \\
\hline Foil Cleaning & diam ond polish & nitirc/HF & None \\
\hline
\end{tabular}

Step 3: Cladding

Step 3: Cladding
\begin{tabular}{|r|c|c|c|}
\hline Cladding type & Al 6061 & Yes & Type: \\
\hline Thermal Spray Barrier Layer on Cladding & No & Friction Bond & \\
\hline Clad bonding method & HIP & \\
\hline HIP temperature & NA & NA \\
\hline HIP Hold Time & NA &
\end{tabular}

Step 4: Final Processing

\begin{tabular}{|c|c|c|}
\hline Autoclave treatment & Yes & \\
\hline Water $\mathrm{pH}$ & adjusted & not adjusted \\
\hline Temperature & $185 \mathrm{C}$ & \\
\hline Time at Temperature & $18 \mathrm{hrs}$ & $4 \mathrm{hrs}$ \\
\hline Blister anneal treatment & Yes & No \\
\hline
\end{tabular}


Monolithic Plate Processing-Variables Summary

\begin{tabular}{|c|c|c|c|c|}
\hline Experiement: & RERTR-9B & Capsule Position: & & \\
\hline Plate: & L1F330 & Foil ID: & 144 & \\
\hline Blister Temperature ('C) & 400 & Fuel Meat Thickness (in.): & 0.010 & \\
\hline Average Fission Density (fission $/ \mathrm{cc} \times 10^{\wedge} 21$ ), & 6.05 & Enrichment (\% U-235/Utot): & $58 \%$ & \\
\hline Peak Fissions Denstiy (fission $/ \mathrm{cc} \times 10^{n} 21$ ) & 8.41 & Cladding Method: & Friction Bonding & \\
\hline & & & & \\
\hline Composition & U10Mo & & & \\
\hline Enrichment (\% U-235/Utotal) & $58 \%$ & & & \\
\hline Alloy Materials & HEU & DU & Mo foil & Mo Powder \\
\hline Alloving/Casting & arc melter & Vacuum Induction Melter (VIM) & & \\
\hline Casting mold & graphite & & & \\
\hline Coupon & not surface machined & surface machined & & \\
\hline Coupon heat treatment/homogenization & None & & & \\
\hline Alloy Carbon Content (ppm) & 360 & & & \\
\hline
\end{tabular}

Step 2: Foil Fabrication

\begin{tabular}{|c|c|c|c|}
\hline Foil Type: & Roll bonded barrier laver & Bare & \\
\hline Barrier Layer & $\mathrm{Zr}$ & NA & \\
\hline Hot Rolling & Yes & No & \\
\hline Barrier Layer cleaning & polish/degrease & degrease & \\
\hline Can Material & carbon steel & & \\
\hline Release Agent & carbon "neolube" & Yttria & None \\
\hline Coupon Cleaning & chemical "nitric" & brush & NA \\
\hline Furnace Temperature & $650 \mathrm{C}$ & & \\
\hline Schedule (max pass reduction) & "medium" 20\% pass & "light" gradual <20\% pass & "Aggressive" $>20 \%$ pass \\
\hline Total Hot Rolling Reduction (\%) & $90 \%$ & & \\
\hline Number of Passes & 50 & & \\
\hline Post Roll Anneal & Yes & No & \\
\hline Anneal time/total time (min) & $30 / 136$ & & \\
\hline Total time at temperature & Med: $120 \mathrm{~min}$ & Short: $<100 \mathrm{~min}$ & Long >150 min. \\
\hline
\end{tabular}

\begin{tabular}{|c|c|c|c|}
\hline Cold Rolling & Yes & No & \\
\hline Schedule: "reduction" & "m edium" 1-2\%/pass & "light" gradual <1\% pass & "Aggre ssive" $>2 \%$ pass \\
\hline Cold Rolling Reduction (\%) & - & & \\
\hline Number of Passes & - & & \\
\hline Foil Character & Flat and ductile & wavy and stiff & \\
\hline Foil Thickness & standard $\left(0.010-0.013^{\prime \prime}\right)$ & Thick $0.020^{\prime \prime}$ or > & \\
\hline
\end{tabular}

\begin{tabular}{|c|c|c|c|}
\hline Post cold rolling anneal & No & Yes & \\
\hline heating method & None & Furance anneal $650 \mathrm{C} / 1 \mathrm{hr}$ & re sistive heating: $925 \mathrm{C}, 10 \mathrm{sec}$ \\
\hline Foil Sizing & Blanking & Shearing & \\
\hline Foil Cleaning & diam ond polish & nitirc/HF & None \\
\hline
\end{tabular}

Step 3: Cladding

\begin{tabular}{|c|c|c|c|}
\hline Cladding type & Al 6061 & & \\
\hline Thermal Spray Barrier Layer on Cladding & No & Yes & Type: \\
\hline Clad bonding method & HIP & Friction Bond & \\
\hline HIP temperature & NA & & \\
\hline HIP Hold Time & NA & & \\
\hline Pre ssure (Ksi) & NA & & \\
\hline
\end{tabular}

Step 4: Final Processing

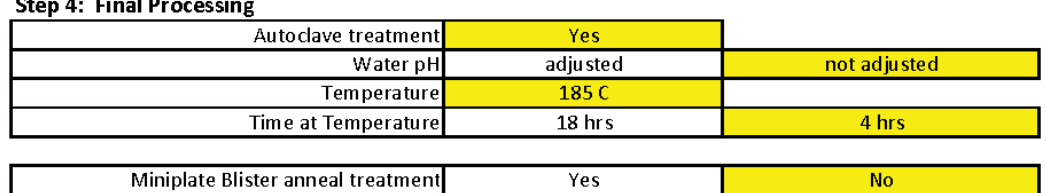


Monolithic Plate Processing-Variables Summary

\begin{tabular}{r|r|r|r|}
\cline { 2 - 4 } & RERTR-9B & Capsule Position: & \\
\cline { 2 - 4 } Plate: & L1F35T & Foil ID: & $147-2$ \\
\cline { 2 - 4 } Blister Temperature ('C) & 425 & Fuel Meat Thickness (in.): & 0.010 \\
\cline { 2 - 4 } Average Fission Density (fission/cc $\times 10^{\wedge} 21$ ) & 7.45 & Enrichment (\% U-235/Utot): & $58 \%$ \\
\cline { 2 - 4 } Peak Fissions Denstiy (fission/cc $\times 10^{\wedge} 21$ ) & 9.99 & Cladding Method: & Friction Bonding \\
\cline { 2 - 4 }
\end{tabular}

\begin{tabular}{|c|c|c|c|c|}
\hline Composition & U10Mo & & & \\
\hline Enrichment (\% U-235/Utotal) & $58 \%$ & & & \\
\hline Alloy Materials & HEU & DU & Mo foil & Mo Powder \\
\hline Alloving/Casting & arc melter & Vacuum Induction Melter (VIM) & & \\
\hline Casting mold & graphite & & & \\
\hline Coupon & not surface machined & surface machined & & \\
\hline Coupon heat treatment/homogenization & None & & & \\
\hline Alloy Carbon Content (ppm) & 460 & & & \\
\hline
\end{tabular}

\begin{tabular}{|c|c|c|c|}
\hline Foil Type: & Roll bonded barrier layer & Bare & \\
\hline Barrier Layer & $\mathrm{Zr}$ & Thermal Spray on cladding & \\
\hline Hot Rolling & Yes & No & \\
\hline Barrier Layer cleaning & polish/degrease & degrease & \\
\hline Can Material & carbon steel & & \\
\hline Release Agent & carbon "neolube" & Yttria & None \\
\hline Coupon Cleaning & chemical "nitric" & brush & $\mathrm{NA}$ \\
\hline Furnace Temperature & $650 \mathrm{C}$ & & \\
\hline Schedule (max pass reduction) & "medium" 20\% pass & "light" gradual <20\% pass & "Aggressive" $>20 \%$ pass \\
\hline Total Hot Rolling Reduction (\%) & $90 \%$ & & \\
\hline Number of Passes & 48 & & \\
\hline Post Roll Anneal & Yes & No & \\
\hline Anneal time/total time (min) & $60 / 173$ & & \\
\hline Total time at temperature & Med: $~ 120 \mathrm{~min}$ & Short: $<100 \mathrm{~min}$ & Long $>150 \mathrm{~min}$. \\
\hline
\end{tabular}

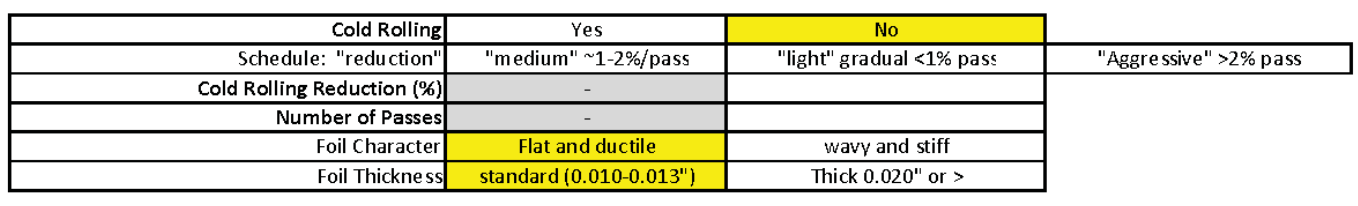

\begin{tabular}{|c|c|c|c|}
\hline Post cold rolling anneal & No & Yes & \\
\hline heating method & None & Furance anneal $650 \mathrm{C} / 1 \mathrm{hr}$ & re sistive heating: $925 \mathrm{C}, 10 \mathrm{sec}$ \\
\hline Foil Sizing & Blanking & Shearing & \\
\hline Foil Cleaning & diam ond polish & nitirc & None \\
\hline
\end{tabular}

\begin{tabular}{|c|c|}
\hline Cladding type & Al 6061 \\
\hline Thermal Spray Barrier Laver on Cladding & No \\
\hline Clad bonding method & HIP \\
\hline HIP temperature & NA \\
\hline HIP Hold Time & NA \\
\hline Pressure (Ksi) & NA \\
\hline
\end{tabular}

\begin{tabular}{l} 
Step 4: Final Processing \\
\begin{tabular}{|r|c|c|}
\hline Autoclave treatment & Yes & not adjusted \\
\hline Water $\mathrm{pH}$ & adjusted & \\
\hline Temperature & $185 \mathrm{C}$ & $4 \mathrm{hrs}$ \\
\hline Time at Temperature & $18 \mathrm{hrs}$ & No \\
\hline
\end{tabular} \\
\hline
\end{tabular}


Monolithic Plate Processing-Variables Summary

\begin{tabular}{|c|c|c|c|c|}
\hline Experiement: & RERTR-9B & Capsule Position: & & \\
\hline Plate: & L1P10T & Foil ID: & $148-2$ & \\
\hline Blister Temperature ('C) & 400 & Fuel Meat Thickness (in.): & 0.010 & \\
\hline Average Fission Density (fission/cc $\times 10^{\wedge} 21$ ) & 7.22 & Enrichment (\% U-235/Utot): & $58 \%$ & \\
\hline Peak Fissions Denstiy (fission/cc $\times 10^{n} 21$ ) & 9.63 & Cladding Method: & HIP & \\
\hline Step 1: alloying-> coup on fabrication & & & & \\
\hline Composition & U10Mo & & & \\
\hline Enrichment (\% U-235/Utotal) & $58 \%$ & & & \\
\hline Allo Materials & HEU & DU & Mo foil & Mo Powder \\
\hline Alloving/Casting & arc melter & Vacuum Induction Melter (VIM) & & \\
\hline Casting mold & graphite & & & \\
\hline Coupon & not surface machined & surface machined & & \\
\hline Coupon heat treatment/homogenization & None & & & \\
\hline Alloy Carbon Content (ppm) & 290 & & & \\
\hline
\end{tabular}

Step 2: Foil Fabrication

\begin{tabular}{|r|c|c|}
\hline Foil TYpe: & Roll bonded barrier layer & Bare \\
\hline Barrier Layer & $\mathrm{Zr}$ & NA \\
\hline
\end{tabular}

\begin{tabular}{|c|c|c|c|}
\hline Hot Rolling & Yes & No & \\
\hline Barrier Layer cleaning & polish/degrease & degrease & \\
\hline Can Material & carbon steel & & \\
\hline Release Agent & carbon "neolube" & Yttria & None \\
\hline Coupon Cleaning & chemical "nitric" & brush & $\mathrm{NA}$ \\
\hline Furnace Temperature & $650 \mathrm{C}$ & & \\
\hline Schedule (max pass reduction) & "m edium" 20\% pass & "light" gradual <20\% pass & "Aggressive" $>20 \%$ pass \\
\hline Total Hot Rolling Reduction (\%) & $90 \%$ & & \\
\hline Number of Passes & 47 & & \\
\hline Post Roll Anneal & Yes & No & \\
\hline Anneal time/total time (min) & $60 / 173$ & & \\
\hline Total time at temperature & Med: 120 min & Short: $<100 \mathrm{~min}$ & Long $>150 \mathrm{~min}$. \\
\hline
\end{tabular}

\begin{tabular}{|c|c|c|c|}
\hline Cold Rolling & Yes & No & \\
\hline Schedule: "reduction" & "medium" 1-2\%/pass & "light" gradual <1\% pass & "Aggre ssive" $>2 \%$ pass \\
\hline Cold Rolling Reduction (\%) & - & & \\
\hline Number of Passes & - & & \\
\hline Foil Character & Flat and ductile & wavy and stiff & \\
\hline Foil Thickness & standard $\left(0.010-0.013^{\prime \prime}\right)$ & Thick $0.020^{\prime \prime}$ or $>$ & \\
\hline
\end{tabular}

\begin{tabular}{|c|c|c|c|}
\hline Post cold rolling anneal & No & Yes & \\
\hline heating method & None & Furance anneal $650 \mathrm{c} / 1 \mathrm{hr}$ & re sistive heating: $925 \mathrm{C}, 10 \mathrm{sec}$ \\
\hline Foil Sizing & Blanking & Shearing & \\
\hline Foil Cleaning & diam ond polish & nitirc/HF & None \\
\hline
\end{tabular}

Step 3: Cladding

\begin{tabular}{|c|c|c|c|}
\hline Cladding type & Al 6061 & & \\
\hline Thermal Spray Barrier Layer on Cladding & No & Yes & Type: \\
\hline Clad bonding method & HIP & Friction Bond & \\
\hline HIP temperature & 560 & & \\
\hline HIP Hold Time & 90 & & \\
\hline Pressure (Ksi) & 15 & & \\
\hline
\end{tabular}

Step 4: Final Processing

\begin{tabular}{|c|c|c|}
\hline Autoclave treatment & Yes & \\
\hline Water $\mathrm{pH}$ & $\overline{\text { adjusted }}$ & not adjusted \\
\hline Temperature & $185 \mathrm{C}$ & \\
\hline Time at Temperature & $18 \mathrm{hrs}$ & $4 \mathrm{hrs}$ \\
\hline Blister anneal treatment & Yes & No \\
\hline
\end{tabular}


Monolithic Plate Processing-Variables Summary

\begin{tabular}{|c|c|c|c|}
\hline Experiement: & RERTR-10A & Capsule Position: & - \\
\hline Plate: & L1P30Z & Foil ID: & 223 \\
\hline Blister Temperature ('C) & 400 & Fuel Meat Thickness (in.): & 0.010 \\
\hline Average Fission Density (fission/cc $\times 10^{n} 21$ ) & 2.88 & Enrichment (\% U-235/Utot): & $67 \%$ \\
\hline Peak Fissions Denstiy (fission/cc $\times 10^{n} 21$ ) & 3.83 & Cladding Method: & HIP \\
\hline
\end{tabular}

Step 1: alloying-> coupon fabrication

\begin{tabular}{|c|c|c|c|c|}
\hline Composition & U10Mo & & & \\
\hline Enrichment (\% U-235/Utotal) & $67 \%$ & & & \\
\hline Alloy Materials & $\mathrm{HEU}$ & $\mathrm{DU}$ & Mo foil & Mo Powder \\
\hline Alloying/Casting & arc melter & Vacuum Induction Melter (VIM) & & \\
\hline Casting mold & graphite & & & \\
\hline Coupon & not surface machined & surface machined & & \\
\hline Coupon heat treatment/homogenization & None & & & \\
\hline Alloy Carbon Content (ppm) & - & & & \\
\hline
\end{tabular}

Step 2: Foil Fabrication

\begin{tabular}{|c|c|c|c|}
\hline Foil Type: & Roll bonded barrier layer & Bare & \\
\hline Barrier Layer & $\mathrm{Zr}$ & NA & \\
\hline Hot Rolling & Yes & No & \\
\hline Barrier Layer cleaning & polish/degrease & degrease & \\
\hline Can Material & carbon steel & & \\
\hline Release Agent & carbon "neolube" & Yttria & None \\
\hline Coupon Cleaning & chemical "nitric" & brush & NA \\
\hline Furnace Temperature & $650 \mathrm{C}$ & & \\
\hline Schedule & "medium" 20\% pass & "light" gradual <20\% pass & "Aggressive" $>20 \%$ pass \\
\hline Total Hot Rolling Reduction (\%) & $90 \%$ & & \\
\hline Number of Passes & 49 & & \\
\hline Post Roll Anneal & Yes & No & \\
\hline Anneal time/total time ( $\min )$ & $0 / 110$ & & \\
\hline Total time at temperature & Med: $\sim 120 \mathrm{~min}$ & Short: $<100 \mathrm{~min}$ & Long $>150 \mathrm{~min}$. \\
\hline Cold Rolling & Yes & No & \\
\hline Schedule: "reduction" & \multirow{3}{*}{\multicolumn{3}{|c|}{ NA }} \\
\hline Cold Rolling Reduction (\%) & & & \\
\hline Number of Passes & & & \\
\hline Foil Character & Flat and ductile & wavy and stiff & \\
\hline Foil Thickness & standard $\left(0.010-0.013^{\prime \prime}\right)$ & Thick $0.020^{\prime \prime}$ or $>$ & \\
\hline Post cold rolling anneal & No & Yes & \\
\hline heating method & None & Furance anneal $650 \mathrm{C} / 1 \mathrm{hr}$ & resistive heating \\
\hline Foil Sizing & Blanking & Shearing & \\
\hline Foil Cleaning & diamond polish & nitirc/HF & None \\
\hline
\end{tabular}

Step 3: Cladding

\begin{tabular}{|r|c|c|c|}
\hline Cladding type & Al 6061 & \multicolumn{2}{|c|}{ Type: } \\
\hline Thermal Spray Barrier Layer on Cladding & No & Yes & \\
\hline Clad bonding method & HIP & Friction Bond & \\
\hline
\end{tabular}

\begin{tabular}{|r|c|}
\hline HIP temperature & $560 \mathrm{C}$ \\
\hline HIP Hold Time & $90 \mathrm{~min}$ \\
\hline Pressure (Ksi) & 15 \\
\hline
\end{tabular}

Step 4: Final Processing

\begin{tabular}{|c|c|c|}
\hline Autoclave treatment & Yes & \\
\hline Water $\mathrm{pH}$ & adjusted & not adjusted \\
\hline Temperature & $185 \mathrm{C}$ & \\
\hline Time at Temperature & $18 \mathrm{hrs}$ & $4 \mathrm{hrs}$ \\
\hline Blister anneal treatment & Yes & No \\
\hline
\end{tabular}


Monolithic Plate Processing-Variables Summary

\begin{tabular}{|c|c|c|c|}
\hline Experiement: & RERTR-10A & Capsule Position: & - \\
\hline Plate: & L2P15Z & Foil ID: & 226 \\
\hline Blister Temperature ('C) & 475 & Fuel Meat Thickness (in.): & 0.020 \\
\hline Average Fission Density (fission/cc $\times 10^{n} 21$ ) & 1.35 & Enrichment (\% U-235/Utot): & $33 \%$ \\
\hline Peak Fissions Denstiy (fission/cc $\times 10^{n} 21$ ) & 1.92 & Cladd ing Method: & HIP \\
\hline
\end{tabular}

Step 1: alloying-> coupon fabrication

\begin{tabular}{|c|c|c|c|c|}
\hline Composition & U10Mo & & & \\
\hline Enrichment (\% U-235/Utotal) & $33 \%$ & & & \\
\hline Alloy Materials & HEU & DU & Mo foil & Mo Powder \\
\hline Alloying/Casting & arc melter & Vacuum Induction Melter (VIM) & & \\
\hline Casting mold & graphite & & & \\
\hline Coupon & not surface machined & surface machined & & \\
\hline Coupon heat treatment/homogenization & None & & & \\
\hline Alloy Carbon Content (ppm) & - & & & \\
\hline
\end{tabular}

\begin{tabular}{|c|c|c|c|}
\hline Foil Type: & Roll bonded barrier layer & Bare & \\
\hline Barrier Layer & $\mathrm{Zr}$ & NA & \\
\hline Hot Rolling & Yes & No & \\
\hline Barrier Layer cleaning & polish/degrease & degrease & \\
\hline Can Material & carbon steel & & \\
\hline Release Agent & carbon "neolube" & Yttria & None \\
\hline Coupon Cleaning & chemical "nitric" & brush & NA \\
\hline Furnace Temperature & $650 \mathrm{C}$ & & \\
\hline Schedule & "medium" $\sim 20 \%$ pass & "light" gradual <20\% pass & "Aggressive" $>20 \%$ pass \\
\hline Total Hot Rolling Reduction (\%) & $80 \%$ & & \\
\hline Number of Passes & 34 & & \\
\hline Post Roll Anneal & Yes & No & \\
\hline Anneal time/total time (min) & $0 / 115$ & & \\
\hline Total time at temperature & Med: $\sim 120 \mathrm{~min}$ & Short: $<100 \mathrm{~min}$ & Long $>150 \mathrm{~min}$. \\
\hline Cold Rolling & Yes & No & \\
\hline Schedule: "reduction" & \multirow{3}{*}{\multicolumn{3}{|c|}{ NA }} \\
\hline Cold Rolling Reduction (\%) & & & \\
\hline Number of Passes & & & \\
\hline Foil Character & Flat and ductile & wawy and stiff & \\
\hline Foil Thickness & standard (0.010-0.013") & Thick $0.020^{\prime \prime}$ or $>$ & \\
\hline Post cold rolling anneal & No & Yes & \\
\hline heating method & None & Furance anneal $650 \mathrm{C} / 1 \mathrm{hr}$ & resistive heating \\
\hline Foil Sizing & Blanking & Shearing & \\
\hline Foil Cleaning & diamond polish & nitirc/HF & None \\
\hline
\end{tabular}

\begin{tabular}{|c|c|c|c|}
\hline Cladding type & Al 6061 & & \\
\hline Thermal Spray Barrier Layer on Cladding & No & Yes & Type: \\
\hline Clad bonding method & HIP & Friction Bond & \\
\hline HIP temperature & $560 \mathrm{C}$ & & \\
\hline HIP Hold Time & $90 \mathrm{~min}$ & & \\
\hline Pressure (Ksi) & 15 & & \\
\hline
\end{tabular}

Step 4: Final Processing

\begin{tabular}{|c|c|c|}
\hline Autoclave treatment & Yes & \\
\hline Water $\mathrm{pH}$ & adjusted & not adjusted \\
\hline Temperature & $185 \mathrm{C}$ & \\
\hline Time at Temperature & $18 \mathrm{hrs}$ & $4 \mathrm{hrs}$ \\
\hline Blister anneal treatment & Yes & No \\
\hline
\end{tabular}


Monolithic Plate Processing-Variables Summary

\begin{tabular}{|c|c|c|c|}
\hline Experiement: & RERTR-10B & Capsule Position: & - \\
\hline Plate: & L2F47Z & Foil ID: & 227 \\
\hline Blister Temperature ('C) & 500 & Fuel Meat Thickness (in.): & 0.020 \\
\hline verage Fission Density (fission/cc $\times 10^{n} 21$ ) & 1.76 & Enrichment (\% U-235/Utot): & $33 \%$ \\
\hline Peak Fissions Denstiy (fission/cc $\times 10^{n} 21$ ) & 2.28 & Cladding Method: & Friction Bonding \\
\hline
\end{tabular}

Step 1: alloying-> coupon fabrication

\begin{tabular}{|c|c|c|c|c|}
\hline Composition & U10Mo & & & \\
\hline Enrichment (\% U-235/Utotal) & $33 \%$ & & & \\
\hline Alloy Materials & HEU & $\mathrm{DU}$ & Mo foil & Mo Powder \\
\hline Alloying/Casting & arc melter & Vacuum Induction Melter (VIM) & & \\
\hline Casting mold & graphite & & & \\
\hline Coupon & not surface machined & surface machined & & \\
\hline Coupon heat treatment/homogenization & None & & & \\
\hline Alloy Carbon Content (ppm) & - & & & \\
\hline
\end{tabular}

Step 2: Foil Fabrication

\begin{tabular}{|r|c|c|}
\hline Foil Type: & Roll bonded barrier layer & Bare \\
\hline Barrier Layer & $\mathrm{Zr}$ & NA \\
\hline
\end{tabular}

\begin{tabular}{|c|c|c|c|}
\hline Hot Rolling & Yes & No & \\
\hline Barrier Layer cleaning & polish/degrease & degrease & \\
\hline Can Material & carbon steel & & \\
\hline Release Agent & carbon "neolube" & Yttria & None \\
\hline Coupon Cleaning & chemical "nitric" & brush & NA \\
\hline Furnace Temperature & $650 \mathrm{C}$ & & \\
\hline Schedule & "medium" $20 \%$ pass & "light" gradual <20\% pass & "Aggressive" $>20 \%$ pass \\
\hline Total Hot Rolling Reduction (\%) & $81 \%$ & & \\
\hline Number of Passes & 8 & & \\
\hline Post Roll Anneal & Yes & No & \\
\hline Anneal time/total time (min) & $0 / 95$ & & \\
\hline Total time at temperature & Med: $\sim 120 \mathrm{~min}$ & Short: $<100 \mathrm{~min}$ & Long $>150 \mathrm{~min}$. \\
\hline Cold Rolling & Yes & No & \\
\hline Schedule: "reduction" & \multirow{3}{*}{\multicolumn{3}{|c|}{ NA }} \\
\hline Cold Rolling Reduction (\%) & & & \\
\hline Number of Passes & & & \\
\hline Foil Character & Flat and ductile & wawy and stiff & \\
\hline Foil Thickness & standard $(0.010-0.013 ")$ & Thick $0.020^{\prime \prime}$ or $>$ & \\
\hline
\end{tabular}

\begin{tabular}{|r|c|c|c|}
\hline Post cold rolling anneal & No & Yes & \\
\hline heating method & None & Furance anneal $650 \mathrm{C} / 1 \mathrm{hr}$ & resistive heating \\
\hline
\end{tabular}

\begin{tabular}{|r|c|c|c|}
\hline Foil Sizing & Blanking & Shearing & \\
\hline Foil Cleaning & diamond polish & nitirc/HF & None \\
\hline
\end{tabular}

Step 3: Cladding
\begin{tabular}{|r|c|c|c|}
\hline Cladding type & Al 6061 & Yes & Type: \\
\hline Thermal Spray Barrier Layer on Cladding & No & Friction Bond & \\
\hline Clad bonding method & HIP & \\
\hline
\end{tabular}

\begin{tabular}{|r|c|}
\hline HIP temperature & - \\
\hline HIP Hold Time & - \\
\hline Pressure (Ksi) & - \\
\hline
\end{tabular}

Step 4: Final Processing

\begin{tabular}{l} 
Step 4: Final Processing \\
\begin{tabular}{|r|c|c|}
\hline Autoclave treatment & Yes & not adjusted \\
\hline Water $\mathrm{pH}$ & adjusted & $4 \mathrm{hrs}$ \\
\hline Temperature & $185 \mathrm{C}$ & No \\
\hline Time at Temperature & $18 \mathrm{hrs}$ & \\
\hline
\end{tabular} \\
\hline
\end{tabular}


Monolithic Plate Processing-Variables Summary

\begin{tabular}{r|c|r|c|} 
Experiement: & RERTR-10B & Capsule Position: & - \\
\cline { 2 - 4 } & Plate: & Foil ID: & 249 \\
\cline { 2 - 4 } Blister Temperature ('C) & $\mathbf{3 0 0}$ & Fuel Meat Thickness (in.): & 0.020 \\
\cline { 2 - 4 } Average Fission Density (fission/cc x 10²1) & $\mathbf{2 . 2 8}$ & Enrichment (\% U-235/Utot): & $33 \%$ \\
Peak Fissions Denstiy (fission/cc x 10n21) & $\mathbf{2 . 8 1}$ & Cladding Method: & Friction Bonding \\
\cline { 2 - 4 } & &
\end{tabular}

\begin{tabular}{|c|c|c|c|c|}
\hline Composition & $\mathrm{U} 10 \mathrm{Mo}$ & & & \\
\hline Enrichment (\% U-235/Utotal) & $33 \%$ & & & \\
\hline Alloy Materials & HEU & $\mathrm{DU}$ & Mo foil & Mo Powder \\
\hline Alloying/Casting & arc melter & Vacuum Induction Melter (VIM) & & \\
\hline Casting mold & graphite & & & \\
\hline Coupon & not surface machined & surface machined & & \\
\hline Coupon heat treatment/homogenization & None & & & \\
\hline Alloy Carbon Content (ppm) & - & & & \\
\hline
\end{tabular}

Step 2: Foil Fabrication

\begin{tabular}{|c|c|c|c|}
\hline Foil Type: & Roll bonded barrier layer & Bare & \\
\hline Barrier Layer & $\mathrm{Zr}$ & NA & \\
\hline Hot Rolling & Yes & No & \\
\hline Barrier Layer cleaning & polish/degrease & degrease & \\
\hline Can Material & carbon steel & & \\
\hline Release Agent & carbon "neolube" & Yttria & None \\
\hline Coupon Cleaning & chemical "nitric" & brush & NA \\
\hline Furnace Temperature & $650 \mathrm{C}$ & & \\
\hline Schedule & "medium" $20 \%$ pass & "light" gradual <20\% pass & "Aggressive" $>20 \%$ pass \\
\hline Total Hot Rolling Reduction (\%) & $81 \%$ & & \\
\hline Number of Passes & 8 & & \\
\hline Post Roll Anneal & Yes & No & \\
\hline Anneal time/total time $(\min )$ & $0 / 105$ & & \\
\hline Total time at temperature & Med: $\sim 120 \mathrm{~min}$ & Short: $<100 \mathrm{~min}$ & Long $>150 \mathrm{~min}$. \\
\hline Cold Rolling & Yes & No & \\
\hline Schedule: "reduction" & \multirow{3}{*}{\multicolumn{3}{|c|}{ NA }} \\
\hline Cold Rolling Reduction (\%) & & & \\
\hline Number of Passes & & & \\
\hline Foil Character & Flat and ductile & wavy and stiff & \\
\hline Foil Thickness & standard $\left(0.010-0.013^{\prime \prime}\right)$ & Thick $0.020^{\prime \prime}$ or $>$ & \\
\hline Post cold rolling anneal & No & Yes & \\
\hline heating method & None & Furance anneal $650 \mathrm{C} / 1 \mathrm{hr}$ & resistive heating \\
\hline Foil Sizing & Blanking & Shearing & \\
\hline Foil Cleaning & diamond polish & nitirc/HF & None \\
\hline
\end{tabular}

\section{Step 3: Cladding}

\begin{tabular}{|r|c|c|c|}
\hline Cladding type & Al 6061 & \multicolumn{2}{|c|}{ Type: } \\
\hline Thermal Spray Barrier Layer on Cladding & No & Yes & Friction Bond \\
\hline Clad bonding method & HIP & .
\end{tabular}

\begin{tabular}{|r|c|}
\hline HIP temperature & - \\
\hline HIP Hold Time & - \\
\hline Pressure (Ksi) & - \\
\hline
\end{tabular}

Step 4: Final Processing

Step 4: Final Processing
\begin{tabular}{|r|c|c|}
\hline Autoclave treatment & Yes & not adjusted \\
\hline Water $\mathrm{pH}$ & adjusted & $4 \mathrm{hrs}$ \\
\hline Temperature & $185 \mathrm{C}$ & No \\
\hline Time at Temperature & $18 \mathrm{hrs}$ & Yes \\
\hline
\end{tabular}


Monolithic Plate Processing-Variables Summary

\begin{tabular}{|c|c|c|c|}
\hline Experiement: [ & RERTR-12 & Capsule Position: & $\mathrm{X} 1(12-\mathrm{C}): 1$ \\
\hline Plate: & LIP772 & Foil ID: & $331-3$ \\
\hline Blister Temperature ('C) & 325 & Fuel Meat Thickness (in.): & 0.010 \\
\hline Average Fission Density (fission/cc $\times 10^{\wedge} 21$ ) & 5.77 & Enrichment (\% U-235/Utot): & $70 \%$ \\
\hline Peak Fissions Denstiy (fission/cc $\times 10^{\wedge} 21$ ) & 7.83 & Cladding Method: & HIP \\
\hline
\end{tabular}

Step 1: alloying-> coupon fabrication

\begin{tabular}{|c|c|c|c|c|}
\hline Composition & U10Mo & & & \\
\hline Enrichment (\% U-235/Utotal) & $70 \%$ & & & \\
\hline Alloy Materials & HEU & DU & Mo foil & Mo Powder \\
\hline Alloying/Casting & arc melter & Vacuum Induction Melter (VIM) & & \\
\hline Casting mold & graphite & & & \\
\hline Coupon & not surface machined & surface machined & & \\
\hline Coupon heat treatment/homogenization & None & & & \\
\hline Alloy Carbon Content (ppm) & 320 & & & \\
\hline
\end{tabular}

Step 2: Foil Fabrication

\begin{tabular}{|c|c|c|c|}
\hline Foil Type: & Roll bonded barrier layer & Bare & \\
\hline Barrier Layer & $\mathrm{Zr}$ & NA & \\
\hline Hot Rolling & Yes & No & \\
\hline Barrier Layer cleaning & polish/degrease & degrease & \\
\hline Can Material & carbon steel & & \\
\hline Release Agent & carbon "neolube" & Yttria & None \\
\hline Coupon Cleaning & chemical "nitric" & brush & NA \\
\hline Furnace Temperature & $650 \mathrm{C}$ & & \\
\hline Schedule & "medium" 20\% pass & "light" gradual <20\% pass & "Aggressive" $>20 \%$ pass \\
\hline Total Hot Rolling Reduction (\%) & $86 \%$ & & \\
\hline Number of Passes & 8 & & \\
\hline Post Roll Anneal & Yes & No & \\
\hline Anneal time/total time $(\min )$ & $45 / 140$ & & \\
\hline Total time at temperature & Med: $\sim 120 \mathrm{~min}$ & Short: $<100 \mathrm{~min}$ & Long $>150 \mathrm{~min}$. \\
\hline Cold Rolling & Yes & No & \\
\hline Schedule: "reduction" & "medium" 1-2\%/pass & "light" gradual < $1 \%$ pass & "Aggressive" $>2 \%$ pass \\
\hline Cold Rolling Reduction (\%) & $20 \%$ & & \\
\hline & $4 \%$ & & \\
\hline Foil Character & Flat and ductile & wavy and stiff & \\
\hline Foil Thickness & standard $(0.010-0.013 ")$ & Thick 0.020 " or $>$ & \\
\hline
\end{tabular}

\begin{tabular}{|c|c|c|c|}
\hline Post cold rolling anneal & No & Yes & \\
\hline heating method & None & Furance anneal $650 \mathrm{C} / 1 \mathrm{hr}$ & resistive heating \\
\hline Foil Sizing & Blanking & Shearing & \\
\hline Foil Cleaning & diamond polish & nitirc/HF & None \\
\hline
\end{tabular}

Step 3: Cladding

\begin{tabular}{|c|c|c|c|}
\hline Cladding type & Al 6061 & & \\
\hline Thermal Spray Barrier Layer on Cladding & No & Yes & Type \\
\hline Clad bonding method & HIP & Friction Bond & TLPB \\
\hline
\end{tabular}

\begin{tabular}{|r|c|}
\hline HIP temperature & $560 \mathrm{C}$ \\
\hline HIP Hold Time & $90 \mathrm{~min}$ \\
\hline Pressure (Ksi) & 15 \\
\hline
\end{tabular}

Step 4: Final Processing

\begin{tabular}{|c|c|c|}
\hline Autoclave treatment & Yes & \\
\hline Water $\mathrm{pH}$ & adjusted & not adjusted \\
\hline Temperature & $185 \mathrm{C}$ & \\
\hline Time at Temperature & $18 \mathrm{hrs}$ & $4 \mathrm{hrs}$ \\
\hline Blister anneal treatment & Yes & No \\
\hline
\end{tabular}


Monolithic Plate Processing-Variables Summary

\begin{tabular}{|c|c|c|c|}
\hline Experiement: & RERTR-12 & Capsule Position: & $\mathrm{X} 1(12-\mathrm{C}): 5$ \\
\hline Plate: & L1P774 & Foil ID: & 330.1 \\
\hline Blister Temperature ('C) & 325 & Fuel Meat Thickness (in.): & 0.010 \\
\hline Average Fission Density (fission/cc $\times 10^{n} 21$ ) & 2.59 & Enrichment (\% U-235/Utot): & $70 \%$ \\
\hline Peak Fissions Denstiy (fission/cc $\times 10^{n} 21$ ) & 5.77 & Cladding Method: & HIP \\
\hline
\end{tabular}

Step 1: alloying-> coupon fabrication

\begin{tabular}{|c|c|c|c|c|}
\hline Composition & U10Mo & & & \\
\hline Enrichment (\% U-235/Utotal) & $70 \%$ & & & \\
\hline Alloy Materials & HEU & $\mathrm{DU}$ & Mo foil & Mo Powder \\
\hline Alloying/Casting & arc melter & Vacuum Induction Melter (VIM) & & \\
\hline Casting mold & graphite & & & \\
\hline Coupon & not surface machined & surface machined & & \\
\hline Coupon heat treatment/homogenization & None & & & \\
\hline Alloy Carbon Content (ppm) & 320 & & & \\
\hline
\end{tabular}

\begin{tabular}{|c|c|c|c|}
\hline Foil Type: & Roll bonded barrier layer & Bare & \\
\hline Barrier Layer & $\mathrm{Zr}$ & NA & \\
\hline Hot Rolling & Yes & No & \\
\hline Barrier Layer cleaning & polish/degrease & degrease & \\
\hline Can Material & carbon steel & & \\
\hline Release Agent & carbon "neolube" & Yttria & None \\
\hline Coupon Cleaning & chemical "nitric" & brush & NA \\
\hline Furnace Temperature & $650 \mathrm{C}$ & & \\
\hline Schedule & "medium" $20 \%$ pass & "light" gradual <20\% pass & "Aggressive" $>20 \%$ pass \\
\hline Total Hot Rolling Reduction (\%) & $85 \%$ & & \\
\hline Number of Passes & 8 & & \\
\hline Post Roll Anneal & Yes & No & \\
\hline Anneal time/total time $(\min )$ & $45 / 140$ & & \\
\hline Total time at temperature & Med: $\sim 120 \mathrm{~min}$ & Short: $<100 \mathrm{~min}$ & Long $>150 \mathrm{~min}$. \\
\hline Cold Rolling & Yes & No & \\
\hline Schedule: "reduction" & "medium" 1-2\%/pass & "light" gradual <1\% pass & "Aggressive" $>2 \%$ pass \\
\hline Cold Rolling Reduction (\%) & $20 \%$ & & \\
\hline Number of Passes & 4 & & \\
\hline Foil Character & Flat and ductile & waw and stiff & \\
\hline Foil Thickness & standard $\left(0.010-0.013^{\prime \prime}\right)$ & Thick 0.020 " or $>$ & \\
\hline Post cold rolling anneal & No & Yes & \\
\hline heating method & None & Furance anneal $650 \mathrm{C} / 1 \mathrm{hr}$ & resistive heating \\
\hline Foil Sizing & Blanking & Shearing & \\
\hline Foil Cleaning & diamond polish & nitirc/HF & None \\
\hline
\end{tabular}

\begin{tabular}{|c|c|c|c|}
\hline Cladding type & Al 6061 & & \\
\hline Thermal Spray Barrier Layer on Cladding & No & Yes & Type \\
\hline Clad bonding method & HIP & Friction Bond & TLPB \\
\hline HIP temperature & $560 \mathrm{C}$ & & \\
\hline HIP Hold Time & $90 \mathrm{~min}$ & & \\
\hline Pressure (Ksi) & 15 & & \\
\hline
\end{tabular}

Step 4: Final Processing

\begin{tabular}{|r|c|c|}
\hline Autoclave treatment & Yes & not adjusted \\
\hline Water $\mathrm{pH}$ & adjusted & 4 hrs \\
\hline Temperature & $185 \mathrm{C}$ & No \\
\hline Time at Temperature & $18 \mathrm{hrs}$ & \\
\hline
\end{tabular}


Monolithic Plate Processing-Variables Summary

\begin{tabular}{|c|c|c|c|}
\hline Experiement: & RERTR-12 & Capsule Position: & $\mathrm{X} 1(12-\mathrm{C}): 7$ \\
\hline Plate: & L1P592 & Foil ID: & $353-3$ \\
\hline Blister Temperature ('C) & 350 & Fuel Meat Thickness (in.): & 0.010 \\
\hline Average Fission Density (fission/cc $\times 10^{n} 21$ ) & 2.69 & Enrichment (\% U-235/Utot): & $50 \%$ \\
\hline Peak Fissions Denstiy (fission/cc $\times 10^{\wedge} 21$ ) & 5.09 & Cladding Method: & HIP \\
\hline
\end{tabular}

Step 1: alloying-> coupon fabrication

\begin{tabular}{|c|c|c|c|c|}
\hline Composition & U10Mo & & & \\
\hline Enrichment (\% U-235/Utotal) & $50 \%$ & & & \\
\hline Alloy Materials & HEU & $\mathrm{DU}$ & Mo foil & Mo Powder \\
\hline Alloying/Casting & arc melter & Vacuum Induction Melter (VIM) & & \\
\hline Casting mold & graphite & & & \\
\hline Coupon & not surface machined & surface machined & & \\
\hline Coupon heat treatment/homogenization & None & & & \\
\hline Alloy Carbon Content (ppm) & 313 & & & \\
\hline
\end{tabular}

Step 2: Foil Fabrication

\begin{tabular}{|r|c|c|}
\hline Foil Type: & Roll bonded barrier layer & Bare \\
\hline Barrier Layer & $\mathrm{Zr}$ & NA \\
\hline
\end{tabular}

\begin{tabular}{|c|c|c|c|}
\hline Hot Rolling & Yes & No & \\
\hline Barrier Layer cleaning & polish/degrease & degrease & \\
\hline Can Material & carbon steel & & \\
\hline Release Agent & carbon "neolube" & Yttria & None \\
\hline Coupon Cleaning & chemical "nitric" & brush & NA \\
\hline Furnace Temperature & $650 \mathrm{C}$ & & \\
\hline Schedule & "medium" $\sim 20 \%$ pass & "light" gradual <20\% pass & "Aggressive" $>20 \%$ pass \\
\hline Total Hot Rolling Reduction (\%) & $80 \%$ & & \\
\hline Number of Passes & 26 & & \\
\hline Post Roll Anneal & Yes & No & \\
\hline Anneal time/total time $(\min )$ & $45 / 140$ & & \\
\hline Total time at temperature & Med: $\sim 120 \mathrm{~min}$ & Short: $<100 \mathrm{~min}$ & Long $>150 \mathrm{~min}$. \\
\hline Cold Rolling & Yes & No & \\
\hline Schedule: "reduction" & "medium" 1-2\%/pass & "light" gradual < 1\% pass & "Aggressive" $>2 \%$ pass \\
\hline Cold Rolling Reduction (\%) & $43 \%$ & & \\
\hline Number of Passes & 33 & & \\
\hline Foil Character & Flat and ductile & wawy and stiff & \\
\hline Foil Thickness & standard $\left(0.010-0.013^{\prime \prime}\right)$ & Thick $0.020^{\prime \prime}$ or $>$ & \\
\hline
\end{tabular}

\begin{tabular}{|r|c|c|c|}
\hline Post cold rolling anneal & No & Yes & \\
\hline heating method & None & Furance anneal $650 \mathrm{C} / 1 \mathrm{hr}$ & resistive heating \\
\hline
\end{tabular}

\begin{tabular}{|r|c|c|c|}
\hline Foil Sizing & Blanking & Shearing & \\
\hline Foil Cleaning & diamond polish & nitirc/HF & None \\
\hline
\end{tabular}

\section{Step 3: Cladding}

\begin{tabular}{|c|c|c|c|}
\hline Cladding type & Al 6061 & & \\
\hline Thermal Spray Barrier Layer on Cladding & No & Yes & Type \\
\hline Clad bonding method & HIP & Friction Bond & TLPB \\
\hline
\end{tabular}

\begin{tabular}{|r|c|}
\hline HIP temperature & $560 \mathrm{C}$ \\
\hline HIP Hold Time & $90 \mathrm{~min}$ \\
\hline Pressure (Ksi) & 15 \\
\hline
\end{tabular}

Step 4: Final Processing

\begin{tabular}{|c|c|c|}
\hline Autoclave treatment & Yes & \\
\hline Water $\mathrm{pH}$ & adjusted & not adjusted \\
\hline Temperature & $185 \mathrm{C}$ & \\
\hline Time at Temperature & $18 \mathrm{hrs}$ & $4 \mathrm{hrs}$ \\
\hline Blister anneal treatment & Yes & No \\
\hline
\end{tabular}


Monolithic Plate Processing-Variables Summary

\begin{tabular}{|c|c|c|c|}
\hline Experiement: & RERTR-12 & Capsule Position: & $\mathrm{X} 1(12-\mathrm{C}): 4$ \\
\hline Plate: & L1P460 & Foil ID: & $336-2$ \\
\hline Blister Temperature ('C) & 400 & Fuel Meat Thickness (in.): & 0.010 \\
\hline Average Fission Density (fission/cc $\times 10^{\Omega} 21$ ) & 2.35 & Enrichment (\% U-235/Utot): & $40 \%$ \\
\hline Peak Fissions Denstiy (fission/cc $\times 10^{\wedge} 21$ ) & 3.98 & Cladding Method: & HIP \\
\hline
\end{tabular}

\begin{tabular}{|c|c|c|c|c|}
\hline Composition & U10Mo & & & \\
\hline Enrichment (\% U-235/Utotal) & $40 \%$ & & & \\
\hline Alloy Materials & $\mathrm{HEU}$ & DU & Mo foil & Mo Powder \\
\hline Alloying/Casting & arc melter & Vacuum Induction Melter (VIM) & & \\
\hline Casting mold & graphite & & & \\
\hline Coupon & not surface machined & surface machined & & \\
\hline Coupon heat treatment/homogenization & None & & & \\
\hline Alloy Carbon Content (ppm) & 322 & & & \\
\hline
\end{tabular}

\begin{tabular}{|c|c|c|c|}
\hline Foil Type: & Roll bonded barrier layer & Bare & \\
\hline Barrier Layer & $\mathrm{Zr}$ & $\mathrm{NA}$ & \\
\hline Hot Rolling & Yes & No & \\
\hline Barrier Layer cleaning & polish/degrease & degrease & \\
\hline Can Material & carbon steel & & \\
\hline Release Agent & carbon "neolube" & Yttria & None \\
\hline Coupon Cleaning & chemical "nitric" & brush & $\mathrm{NA}$ \\
\hline Furnace Temperature & $650 \mathrm{C}$ & & \\
\hline Schedule & "medium" 20\% pass & "light" gradual <20\% pass & "Aggressive" $>20 \%$ pass \\
\hline Total Hot Rolling Reduction (\%) & $86 \%$ & & \\
\hline Number of Passes & 15 & & \\
\hline Post Roll Anneal & Yes & No & \\
\hline Anneal time/total time (min) & $45 / 165$ & & \\
\hline Total time at temperature & Med: $\sim 120 \mathrm{~min}$ & Short: $<100 \mathrm{~min}$ & Long $>150 \mathrm{~min}$. \\
\hline Cold Rolling & Yes & No & \\
\hline Schedule: "reduction" & "medium" 1-2\%/pass & "light" gradual < $1 \%$ pass & "Aggressive" $>2 \%$ pass \\
\hline Cold Rolling Reduction (\%) & $20 \%$ & & \\
\hline Number of Passes & 4 & & \\
\hline Foil Character & Flat and ductile & wavy and stiff & \\
\hline Foil Thickness & standard $\left(0.010-0.013^{\prime \prime}\right)$ & Thick $0.020^{\prime \prime}$ or $>$ & \\
\hline Post cold rolling anneal & No & Yes & \\
\hline heating method & None & Furance anneal $650 \mathrm{C} / 1 \mathrm{hr}$ & resistive heating \\
\hline Foil Sizing & Blanking & Shearing & \\
\hline Foil Cleaning & diamond polish & nitirc/HF & None \\
\hline
\end{tabular}

Step 3: Cladding
\begin{tabular}{|r|c|c|c|}
\hline Cladding type & Al 6061 & Yes & Type: \\
\hline Thermal Spray Barrier Layer on Cladding & No & Friction Bond & \\
\hline Clad bonding method & HIP & \\
\hline HIP temperature & $560 \mathrm{C}$ & \\
\hline HIP Hold Time & $90 \mathrm{~min}$ & 15 & \\
\hline Pressure (Ksi) & r &
\end{tabular}

Step 4: Final Processing
\begin{tabular}{|r|c|c|}
\hline Autoclave treatment & Yes & not adjusted \\
\hline Water $\mathrm{pH}$ & adjusted & $4 \mathrm{hrs}$ \\
\hline Temperature & $185 \mathrm{C}$ & No \\
\hline Time at Temperature & $18 \mathrm{hrs}$ & Yes \\
\hline
\end{tabular}


Monolithic Plate Processing-Variables Summary

\begin{tabular}{|c|c|c|c|}
\hline Experiement: & RERTR-12 & Capsule Position: & $X 2(12-C): 5$ \\
\hline Plate: & LIP756 & Foil ID: & $329-1$ \\
\hline Blister Temperature ('C) & 300 & Fuel Meat Thickness (in.): & 0.010 \\
\hline Average Fission Density (fission/cc $\times 10^{\wedge} 21$ ) & 7.05 & Enrichment (\% U-235/Utot): & $70 \%$ \\
\hline Peak Fissions Denstiy (fission/cc $\times 10^{n} 21$ ) & 9.10 & Cladding Method: & HIP \\
\hline
\end{tabular}

Step 1: alloying-> coupon fabrication

\begin{tabular}{|c|c|c|c|c|}
\hline Composition & U10Mo & & & \\
\hline Enrichment (\% U-235/Utotal) & $70 \%$ & & & \\
\hline Alloy Materials & HEU & DU & Mo foil & Mo Powder \\
\hline Alloying/Casting & arc melter & Vacuum Induction Melter (VIM) & & \\
\hline Casting mold & graphite & & & \\
\hline Coupon & not surface machined & surface machined & & \\
\hline Coupon heat treatment/homogenization & None & & & \\
\hline Alloy Carbon Content (ppm) & 320 & & & \\
\hline
\end{tabular}

Step 2: Foil Fabrication

\begin{tabular}{|c|c|c|c|}
\hline Foil Type: & Roll bonded barrier layer & Bare & \\
\hline Barrier Layer & $\mathrm{Zr}$ & NA & \\
\hline Hot Rolling & Yes & No & \\
\hline Barrier Layer cleaning & polish/degrease & degrease & \\
\hline Can Material & carbon steel & & \\
\hline Release Agent & carbon "neolube" & Yttria & None \\
\hline Coupon Cleaning & chemical "nitric" & brush & NA \\
\hline Furnace Temperature & $650 \mathrm{C}$ & & \\
\hline Schedule & "medium" 20\% pass & "light" gradual <20\% pass & "Aggressive" $>20 \%$ pass \\
\hline Total Hot Rolling Reduction (\%) & $86 \%$ & & \\
\hline Number of Passes & 10 & & \\
\hline Post Roll Anneal & Yes & No & \\
\hline Anneal time/total time $(\mathrm{min})$ & $45 / 140$ & & \\
\hline Total time at temperature & Med: $\sim 120 \mathrm{~min}$ & Short: $<100 \mathrm{~min}$ & Long $>150 \mathrm{~min}$. \\
\hline Cold Rolling & Yes & No & \\
\hline Schedule: "reduction" & "medium" 1-2\%/pass & "light" gradual < $1 \%$ pass & "Aggressive" $>2 \%$ pass \\
\hline Cold Rolling Reduction (\%) & $20 \%$ & & \\
\hline Number of Passes & 4 & & \\
\hline Foil Character & Flat and ductile & wavy and stiff & \\
\hline Foil Thickness & standard $\left(0.010-0.013^{\prime \prime}\right)$ & Thick $0.020^{\prime \prime}$ or $>$ & \\
\hline
\end{tabular}

\begin{tabular}{|c|c|c|c|}
\hline Post cold rolling anneal & No & Yes & \\
\hline heating method & None & Furance anneal $650 \mathrm{C} / 1 \mathrm{hr}$ & resistive heating \\
\hline Foil Sizing & Blanking & Shearing & \\
\hline Foil Cleaning & diamond polish & nitirc/HF & None \\
\hline
\end{tabular}

Step 3: Cladding

\begin{tabular}{|r|c|c|c|}
\hline Cladding type & Al 6061 & \multicolumn{2}{|c|}{ Type: } \\
\hline Thermal Spray Barrier Layer on Cladding & No & Yes & Friction Bond \\
\hline Clad bonding method & HIP & .
\end{tabular}

\begin{tabular}{|r|c|}
\hline HIP temperature & $560 \mathrm{C}$ \\
\hline HIP Hold Time & $90 \mathrm{~min}$ \\
\hline Pressure (Ksi) & 15 \\
\hline
\end{tabular}

Step 4: Final Processing

\begin{tabular}{l} 
Step 4: Final Processing \\
\begin{tabular}{|r|c|c|}
\hline Autoclave treatment & Yes & not adjusted \\
\hline Water $\mathrm{pH}$ & adjusted & $4 \mathrm{hrs}$ \\
\hline Temperature & $185 \mathrm{C}$ & No \\
\hline Time at Temperature & $18 \mathrm{hrs}$ & \\
\hline
\end{tabular} \\
\hline
\end{tabular}


Monolithic Plate Processing-Variables Summary

\begin{tabular}{|c|c|c|c|}
\hline Experiement: [ & RERTR-12 & Capsule Position: & $\mathrm{X} 2(12-\mathrm{C}): 6$ \\
\hline Plate: & L1P758 & Foil ID: & $330-2$ \\
\hline Blister Temperature ('C) & 300 & Fuel Meat Thickness (in.): & 0.010 \\
\hline Average Fission Density (fission/cc $\times 10^{\wedge} 21$ ) & 5 & Enrichment (\% U-235/Utot): & $70 \%$ \\
\hline Peak Fissions Denstiy (fission/cc $\times 10^{n} 21$ ) & 9.19 & Cladding Method: & HIP \\
\hline
\end{tabular}

\begin{tabular}{|c|c|c|c|c|}
\hline Composition & U10Mo & & & \\
\hline Enrichment (\% U-235/Utotal) & $70 \%$ & & & \\
\hline Alloy Materials & HEU & DU & Mo foil & Mo Powder \\
\hline Alloying/Casting & arc melter & Vacuum Induction Melter (VIM) & & \\
\hline Casting mold & graphite & & & \\
\hline Coupon & not surface machined & surface machined & & \\
\hline Coupon heat treatment/homogenization & None & & & \\
\hline Alloy Carbon Content (ppm) & 320 & & & \\
\hline
\end{tabular}

\begin{tabular}{|c|c|c|c|}
\hline Foil Type: & Roll bonded barrier layer & Bare & \\
\hline Barrier Layer & $\mathrm{Zr}$ & NA & \\
\hline Hot Rolling & Yes & No & \\
\hline Barrier Layer cleaning & polish/degrease & degrease & \\
\hline Can Material & carbon steel & & \\
\hline Release Agent & carbon "neolube" & Yttria & None \\
\hline Coupon Cleaning & chemical "nitric" & brush & NA \\
\hline Furnace Temperature & $650 \mathrm{C}$ & & \\
\hline Schedule & "medium" $\sim 20 \%$ pass & "light" gradual <20\% pass & "Aggressive" $>20 \%$ pass \\
\hline Total Hot Rolling Reduction (\%) & $86 \%$ & & \\
\hline Number of Passes & 10 & & \\
\hline Post Roll Anneal & Yes & No & \\
\hline Anneal time/total time (min) & $45 / 140$ & & \\
\hline Total time at temperature & Med: $\sim 120 \mathrm{~min}$ & Short: $<100 \mathrm{~min}$ & Long $>150 \mathrm{~min}$. \\
\hline Cold Rolling & Yes & No & \\
\hline Schedule: "reduction" & "medium" $\sim 1-2 \% /$ pass & "light" gradual $<1 \%$ pass & "Aggressive" $>2 \%$ pass \\
\hline Cold Rolling Reduction (\%) & $20 \%$ & & \\
\hline Number of Passes & 4 & & \\
\hline Foil Character & Flat and ductile & wawy and stiff & \\
\hline Foil Thickness & standard (0.010-0.013") & Thick $0.020^{\prime \prime}$ or $>$ & \\
\hline Post cold rolling anneal & No & Yes & \\
\hline heating method & None & Furance anneal $650 \mathrm{C} / 1 \mathrm{hr}$ & resistive heating \\
\hline Foil Sizing & Blanking & Shearing & \\
\hline Foil Cleaning & diamond polish & nitirc/HF & None \\
\hline
\end{tabular}

\section{Step 3: Cladding}

\begin{tabular}{|r|c|c|c|}
\hline Cladding type & Al 6061 & \multicolumn{2}{|c|}{ Type: } \\
\hline Thermal Spray Barrier Layer on Cladding & No & Yes & \\
\hline Clad bonding method & HIP & Friction Bond & \\
\hline
\end{tabular}

\begin{tabular}{|r|c|}
\hline HIP temperature & $560 \mathrm{C}$ \\
\hline HIP Hold Time & $90 \mathrm{~min}$ \\
\hline Pressure (Ksi) & 15 \\
\hline
\end{tabular}

Step 4: Final Processing

\begin{tabular}{l} 
Step 4: Final Processing \\
\begin{tabular}{|r|c|c|}
\hline Autoclave treatment & Yes & not adjusted \\
\hline Water $\mathrm{pH}$ & adjusted & $4 \mathrm{hrs}$ \\
\hline Temperature & $185 \mathrm{C}$ & No \\
\hline Time at Temperature & $18 \mathrm{hrs}$ & \\
\hline
\end{tabular} \\
\hline
\end{tabular}


Monolithic Plate Processing-Variables Summary

\begin{tabular}{|c|c|c|c|}
\hline Experiement: & RERTR-12 & Capsule Position: & $\mathrm{X} 2(12-\mathrm{C}): 7$ \\
\hline Plate: & L1P595 & Foil ID: & $352-1$ \\
\hline Blister Temperature ('C) & 325 & Fuel Meat Thickness (in.): & 0.010 \\
\hline Average Fission Density (fission/cc $\times 10^{\wedge} 21$ ) & 3.41 & Enrichment (\% U-235/Utot): & $50 \%$ \\
\hline Peak Fissions Denstiy (fission/cc x 10 21 ) & 6.38 & Cladding Method: & HIP \\
\hline
\end{tabular}

Step 1: alloying-> coupon fabrication

\begin{tabular}{|c|c|c|c|c|}
\hline Composition & U10Mo & & & \\
\hline Enrichment (\% U-235/Utotal) & $50 \%$ & & & \\
\hline Alloy Materials & HEU & $\mathrm{DU}$ & Mo foil & Mo Powder \\
\hline Alloying/Casting & arc melter & Vacuum Induction Melter (VIM) & & \\
\hline Casting mold & graphite & & & \\
\hline Coupon & not surface machined & surface machined & & \\
\hline Coupon heat treatment/homogenization & None & & & \\
\hline Alloy Carbon Content (ppm) & 192 & & & \\
\hline
\end{tabular}

Step 2: Foil Fabrication

\begin{tabular}{|r|c|c|}
\hline Foil Type: & Roll bonded barrier layer & Bare \\
\hline Barrier Layer & $\mathrm{Zr}$ & NA \\
\hline
\end{tabular}

\begin{tabular}{|c|c|c|c|}
\hline Hot Rolling & Yes & No & \\
\hline Barrier Layer cleaning & polish/degrease & degrease & \\
\hline Can Material & carbon steel & & \\
\hline Release Agent & carbon "neolube" & Yttria & None \\
\hline Coupon Cleaning & chemical "nitric" & brush & NA \\
\hline Furnace Temperature & $650 \mathrm{C}$ & & \\
\hline Schedule & "medium" $\sim 20 \%$ pass & "light" gradual <20\% pass & "Aggressive" $>20 \%$ pass \\
\hline Total Hot Rolling Reduction (\%) & $79 \%$ & & \\
\hline Number of Passes & 19 & & \\
\hline Post Roll Anneal & Yes & No & \\
\hline Anneal time/total time $(\min )$ & $45 / 140$ & & \\
\hline Total time at temperature & Med: $\sim 120 \mathrm{~min}$ & Short: $<100 \mathrm{~min}$ & Long $>150 \mathrm{~min}$. \\
\hline Cold Rolling & Yes & No & \\
\hline Schedule: "reduction" & "medium" 1-2\%/pass & "light" gradual < $1 \%$ pass & "Aggressive" $>2 \%$ pass \\
\hline Cold Rolling Reduction (\%) & $45 \%$ & & \\
\hline Number of Passes & 45 & & \\
\hline Foil Character & Flat and ductile & wawy and stiff & \\
\hline Foil Thickness & standard $\left(0.010-0.013^{\prime \prime}\right)$ & Thick $0.020^{\prime \prime}$ or $>$ & \\
\hline
\end{tabular}

\begin{tabular}{|c|c|c|c|}
\hline Post cold rolling anneal & No & Yes & \\
\hline heating method & None & Furance anneal $650 \mathrm{C} / 1 \mathrm{hr}$ & resistive heating \\
\hline Foil Sizing & Blanking & Shearing & \\
\hline Foil Cleaning & diamond polish & nitirc/HF & None \\
\hline
\end{tabular}

\begin{tabular}{|c|c|c|c|}
\hline Cladding type & Al 6061 & & \\
\hline Thermal Spray Barrier Layer on Cladding & No & Yes & Type: \\
\hline Clad bonding method & HIP & Friction Bond & \\
\hline HIP temperature & $560 \mathrm{C}$ & & \\
\hline HIP Hold Time & $90 \mathrm{~min}$ & & \\
\hline Pressure (Ksi) & 15 & & \\
\hline
\end{tabular}

Step 4: Final Processing

\begin{tabular}{|c|c|c|}
\hline Autoclave treatment & Yes & \\
\hline Water $\mathrm{pH}$ & adjusted & not adjusted \\
\hline Temperature & $185 \mathrm{C}$ & \\
\hline Time at Temperature & $18 \mathrm{hrs}$ & $4 \mathrm{hrs}$ \\
\hline Blister anneal treatment & Yes & No \\
\hline
\end{tabular}


Monolithic Plate Processing-Variables Summary

\begin{tabular}{|c|c|c|c|}
\hline Experiement: & RERTR-12 & Capsule Position: & $\mathrm{X} 2(12-\mathrm{C}): 8$ \\
\hline Plate: & L1P463 & Foil ID: & $337-3$ \\
\hline Blister Temperature ('C) & 350 & Fuel Meat Thickness (in.): & 0.010 \\
\hline Average Fission Density (fission/cc $\times 10^{n} 21$ ) & 2.86 & Enrichment (\% U-235/Utot): & $40 \%$ \\
\hline Peak Fissions Denstiy (fission/cc $\times 10^{n} 21$ ) & 3.76 & Cladding Method: & HIP \\
\hline
\end{tabular}

Step 1: alloying-> coupon fabrication
\begin{tabular}{|r|c|c|c|}
\hline Composition & U10Mo & \multicolumn{2}{c}{ Mo foil } \\
\cline { 1 - 2 } Enrichment (\% U-235/Utotal) & $40 \%$ & DU & Mo Powder \\
\hline Alloy Materials & HEU & Vacuum Induction Melter (VIM) & \\
\hline Alloying/Casting & arc melter & surface machined \\
\hline Casting mold & graphite & \multicolumn{1}{|c}{} \\
\hline Coupon & not surface machined & None & \\
\hline Coupon heat treatment/homogenization & Alloy Carbon Content (ppm) & 355 &
\end{tabular}

Step 2: Foil Fabrication

Step 2: Foil Fabrication
\begin{tabular}{|r|c|c|}
\hline Foil Type: & Roll bonded barrier layer & Bare \\
\hline Barrier Layer & $\mathrm{Zr}$ & NA \\
\hline
\end{tabular}

\begin{tabular}{|c|c|c|c|}
\hline Hot Rolling & Yes & No & \\
\hline Barrier Layer cleaning & polish/degrease & degrease & \\
\hline Can Material & carbon steel & & \\
\hline Release Agent & carbon "neolube" & Yttria & None \\
\hline Coupon Cleaning & chemical "nitric" & brush & NA \\
\hline Furnace Temperature & $650 \mathrm{C}$ & & \\
\hline Schedule & "medium" $\sim 20 \%$ pass & "light" gradual <20\% pass & "Aggressive" $>20 \%$ pass \\
\hline Total Hot Rolling Reduction (\%) & $85 \%$ & & \\
\hline Number of Passes & 11 & & \\
\hline Post Roll Anneal & Yes & No & \\
\hline Anneal time/total time $(\min )$ & $45 / 150$ & & \\
\hline Total time at temperature & Med: $\sim 120 \mathrm{~min}$ & Short: $<100 \mathrm{~min}$ & Long $>150 \mathrm{~min}$. \\
\hline Cold Rolling & Yes & No & \\
\hline Schedule: "reduction" & "medium" 1-2\%/pass & "light" gradual < $1 \%$ pass & "Aggressive" $>2 \%$ pass \\
\hline Cold Rolling Reduction (\%) & $20 \%$ & & \\
\hline Number of Passes & 4 & & \\
\hline Foil Character & Flat and ductile & wawy and stiff & \\
\hline Foil Thickness & standard $\left(0.010-0.013^{\prime \prime}\right)$ & Thick 0.020 " or $>$ & \\
\hline
\end{tabular}

\begin{tabular}{|c|c|c|c|}
\hline Post cold rolling ann eal & No & Yes & \\
\hline heating method & None & Furance anneal $650 \mathrm{C} / 1 \mathrm{hr}$ & resistive heating \\
\hline Foil Sizing & Blanking & Shearing & \\
\hline Foil Cleaning & diamond polish & nitirc/HF & None \\
\hline
\end{tabular}

Step 3: Cladding

\begin{tabular}{|c|c|c|c|}
\hline Cladding type & Al 6061 & & \\
\hline Thermal Spray Barrier Layer on Cladding & No & Yes & Type: \\
\hline Clad bonding method & HIP & Friction Bond & \\
\hline HIP temperature & $560 \mathrm{C}$ & & \\
\hline HIP Hold Time & $90 \mathrm{~min}$ & & \\
\hline Pressure (Ksi) & 15 & & \\
\hline
\end{tabular}

Step 4: Final Processing

\begin{tabular}{|c|c|c|}
\hline Autoclave treatment & Yes & \\
\hline Water $\mathrm{pH}$ & adjusted & not adjusted \\
\hline Temperature & $185 \mathrm{C}$ & \\
\hline Time at Temperature & $18 \mathrm{hrs}$ & $4 \mathrm{hrs}$ \\
\hline Blister anneal treatment & Yes & No \\
\hline
\end{tabular}


Monolithic Plate Processing-Variables Summary

\begin{tabular}{|c|c|c|c|}
\hline Experiement: & AFIP-4 & Capsule Position: & B1 \\
\hline Plate: & L1H34Z & Foil ID: & $194-2-2$ \\
\hline Blister Temperature ('C) & 350 & Fuel Meat Thickness (in.): & 0.013 \\
\hline Average Fission Density (fission/cc $\times 10^{\wedge} 21$ ) & 2.51 & Enrichment (\% U-235/Utot): & $20 \%$ \\
\hline Peak Fissions Denstiy (fission/cc $\times 10^{n} 21$ ) & 3.60 & Cladding Method: & HIP \\
\hline
\end{tabular}

Step 1: alloying-> coupon fabrication

\begin{tabular}{|c|c|c|c|c|}
\hline Composition & U10Mo & & & \\
\hline Enrichment (\% U-235/Utotal) & $20 \%$ & & & \\
\hline Alloy Materials & HEU & DU & Mo foil & Mo Powder \\
\hline Alloying/Casting & arc melter & Vacuum Induction Melter (VIM) & & \\
\hline Casting mold & graphite & & & \\
\hline Coupon & not surface machined & surface machined & & \\
\hline Coupon heat treatment/homogenization & None & & & \\
\hline Alloy Carbon Content (ppm) & 472 & & & \\
\hline
\end{tabular}

Step 2: Foil Fabrication

\begin{tabular}{|c|c|c|c|}
\hline Foil Type: & Roll bonded barrier layer & Bare & \\
\hline Barrier Layer & $\mathrm{Zr}$ & NA & \\
\hline Hot Rolling & Yes & No & \\
\hline Barrier Layer cleaning & polish/degrease & degrease & \\
\hline Can Material & carbon steel & & \\
\hline Release Agent & carbon "neolube" & Yttria & None \\
\hline Coupon Cleaning & chemical "nitric" & brush & NA \\
\hline Furnace Temperature & $650 \mathrm{C}$ & & \\
\hline Schedule & "medium" 20\% pass & "light" gradual <20\% pass & "Aggressive" $>20 \%$ pass \\
\hline Total Hot Rolling Reduction (\%) & $79 \%$ & & \\
\hline Number of Passes & 26 & & \\
\hline Post Roll Anneal & Yes & No & \\
\hline Anneal time/total time $(\mathrm{min})$ & $45 / 175$ & & \\
\hline Total time at temperature & Med: $\sim 120 \mathrm{~min}$ & Short: $<100 \mathrm{~min}$ & Long $>150 \mathrm{~min}$. \\
\hline Cold Rolling & Yes & No & \\
\hline Schedule: "reduction" & "medium" 1-2\%/pass & "light" gradual < $1 \%$ pass & "Aggressive" $>2 \%$ pass \\
\hline Cold Rolling Reduction (\%) & $22 \%$ & & \\
\hline Number of Passes & 12 & & \\
\hline Foil Character & Flat and ductile & wavy and stiff & \\
\hline Foil Thickness & standard $\left(0.010-0.013^{\prime \prime}\right)$ & Thick $0.020^{\prime \prime}$ or $>$ & \\
\hline
\end{tabular}

\begin{tabular}{|c|c|c|c|}
\hline Post cold rolling anneal & No & Yes & \\
\hline heating method & None & Furance anneal $650 \mathrm{C} / 1 \mathrm{hr}$ & resistive heating \\
\hline Foil Sizing & Blanking & Shearing & \\
\hline Foil Cleaning & diamond polish & nitirc/HF & None \\
\hline
\end{tabular}

Step 3: Cladding

\begin{tabular}{|r|c|c|c|}
\hline Cladding type & Al 6061 & \multicolumn{2}{|c|}{ Type: } \\
\hline Thermal Spray Barrier Layer on Cladding & No & Yes & Friction Bond \\
\hline Clad bonding method & HIP & .
\end{tabular}

\begin{tabular}{|r|c|}
\hline HIP temperature & $560 \mathrm{C}$ \\
\hline HIP Hold Time & $90 \mathrm{~min}$ \\
\hline Pressure (Ksi) & 15 \\
\hline
\end{tabular}

Step 4: Final Processing

\begin{tabular}{l} 
Step 4: Final Processing \\
\begin{tabular}{|r|c|c|}
\hline Autoclave treatment & Yes & not adjusted \\
\hline Water $\mathrm{pH}$ & adjusted & $4 \mathrm{hrs}$ \\
\hline Temperature & $185 \mathrm{C}$ & No \\
\hline Time at Temperature & $18 \mathrm{hrs}$ & \\
\hline
\end{tabular} \\
\hline
\end{tabular}


Monolithic Plate Processing-Variables Summary

\begin{tabular}{|c|c|c|c|}
\hline Experiement: [ & AFIP-4 & Capsule Position: & B3 \\
\hline Plate: & L1H36Z & Foil ID: & 194-3-1 \\
\hline Blister Temperature ('C) & 300 & Fuel Meat Thickness (in.): & 0.013 \\
\hline Average Fission Density (fission/cc $\times 10^{\wedge} 21$ ) & 4.45 & Enrichment (\% U-235/Utot): & $20 \%$ \\
\hline Peak Fissions Denstiy (fission/cc $\times 10^{n} 21$ ) & 5.21 & Cladding Method: & HIP \\
\hline
\end{tabular}

Step 1: alloying-> coupon fabrication

\begin{tabular}{|c|c|c|c|c|}
\hline Composition & U10Mo & & & \\
\hline Enrichment (\% U-235/Utotal) & $20 \%$ & & & \\
\hline Alloy Materials & HEU & DU & Mo foil & Mo Powder \\
\hline Alloying/Casting & arc melter & Vacuum Induction Melter (VIM) & & \\
\hline Casting mold & graphite & & & \\
\hline Coupon & not surface machined & surface machined & & \\
\hline Coupon heat treatment/homogenization & None & & & \\
\hline Alloy Carbon Content (ppm) & 472 & & & \\
\hline
\end{tabular}

Step 2: Foil Fabrication

\begin{tabular}{|c|c|c|c|}
\hline Foil Type: & Roll bonded barrier layer & Bare & \\
\hline Barrier Layer & $\mathrm{Zr}$ & NA & \\
\hline Hot Rolling & Yes & No & \\
\hline Barrier Layer cleaning & polish/degrease & degrease & \\
\hline Can Material & carbon steel & & \\
\hline Release Agent & carbon "neolube" & Yttria & None \\
\hline Coupon Cleaning & chemical "nitric" & brush & NA \\
\hline Furnace Temperature & $650 \mathrm{C}$ & & \\
\hline Schedule & "medium" $\sim 20 \%$ pass & "light" gradual $<20 \%$ pass & "Aggressive" $>20 \%$ pass \\
\hline Total Hot Rolling Reduction (\%) & $79 \%$ & & \\
\hline Number of Passes & 26 & & \\
\hline Post Roll Anneal & Yes & No & \\
\hline Anneal time/total time (min) & $45 / 175$ & & \\
\hline Total time at temperature & Med: $\sim 120 \mathrm{~min}$ & Short: $<100 \mathrm{~min}$ & Long $>150 \mathrm{~min}$. \\
\hline Cold Rolling & Yes & No & \\
\hline Schedule: "reduction" & "medium" 1-2\%/pass & "light" gradual < $1 \%$ pass & "Aggressive" $>2 \%$ pass \\
\hline Cold Rolling Reduction (\%) & $22 \%$ & & \\
\hline Number of Passes & 12 & & \\
\hline Foil Character & Flat and ductile & wawy and stiff & \\
\hline Foil Thickness & standard $\left(0.010-0.013^{\prime \prime}\right)$ & Thick $0.020^{\prime \prime}$ or $>$ & \\
\hline Post cold rolling anneal & No & Yes & \\
\hline heating method & None & Furance anneal $650 \mathrm{C} / 1 \mathrm{hr}$ & resistive heating \\
\hline Foil Sizing & Blanking & Shearing & \\
\hline Foil Cleaning & diamond polish & nitirc/HF & None \\
\hline
\end{tabular}

Step 3: Cladding

Step 3: Cladding
\begin{tabular}{|r|c|c|c|}
\hline Cladding type & Al 6061 & Yes & Type: \\
\hline Thermal Spray Barrier Layer on Cladding & No & Friction Bond & \\
\hline Clad bonding method & HIP & \\
\hline
\end{tabular}

\begin{tabular}{|r|c|}
\hline HIP temperature & $560 \mathrm{C}$ \\
\hline HIP Hold Time & $90 \mathrm{~min}$ \\
\hline Pressure (Ksi) & 15 \\
\hline
\end{tabular}

Step 4: Final Processing

\begin{tabular}{l} 
Step 4: Final Processing \\
\begin{tabular}{|r|c|c|}
\hline Autoclave treatment & Yes & not adjusted \\
\hline Water pH & adjusted & 4 hrs \\
\hline Temperature & $180 \mathrm{C}$ & No \\
\hline Time at Temperature & $18 \mathrm{hrs}$ & Yes \\
\hline Blister anneal treatment & &
\end{tabular} \\
\hline
\end{tabular}


Monolithic Plate Processing-Variables Summary

\begin{tabular}{|c|c|c|c|}
\hline Experiement: & AFIP-4 & Capsule Position: & B3 \\
\hline Plate: & L1B33Z & Foil ID: & $196-4-2$ \\
\hline Blister Temperature ('C) & 300 & Fuel Meat Thickness (in.): & 0.013 \\
\hline Average Fission Density (fission/cc $\times 10^{n} 21$ ) & 4.06 & Enrichment (\% U-235/Utot): & $20 \%$ \\
\hline Peak Fissions Denstiy (fission/cc $\times 10^{n} 21$ ) & 5.03 & Cladding Method: & Friction Bonding \\
\hline
\end{tabular}

\begin{tabular}{|c|c|c|c|c|}
\hline Composition & U10Mo & & & \\
\hline Enrichment (\% U-235/Utotal) & $20 \%$ & & & \\
\hline Alloy Materials & HEU & $\mathrm{DU}$ & Mo foil & Mo Powder \\
\hline Alloying/Casting & arc melter & Vacuum Induction Melter (VIM) & & \\
\hline Casting mold & graphite & & & \\
\hline Coupon & not surface machined & surface machined & & \\
\hline Coupon heat treatment/homogenization & None & & & \\
\hline Alloy Carbon Content (ppm) & 472 & & & \\
\hline
\end{tabular}

Step 2: Foil Fabrication

Step 2: Foil Fabrication
\begin{tabular}{|r|c|c|}
\hline Foil Type: & Roll bonded barrier layer & Bare \\
\hline Barrier Layer & $\mathrm{Zr}$ & NA \\
\hline
\end{tabular}

\begin{tabular}{|c|c|c|c|}
\hline Hot Rolling & Yes & No & \\
\hline Barrier Layer cleaning & polish/degrease & degrease & \\
\hline Can Material & carbon steel & & \\
\hline Release Agent & carbon "neolube" & Yttria & None \\
\hline Coupon Cleaning & chemical "nitric" & brush & NA \\
\hline Furnace Temperature & $650 \mathrm{C}$ & & \\
\hline Schedule & "medium" $\sim 20 \%$ pass & "light" gradual $<20 \%$ pass & "Aggressive" $>20 \%$ pass \\
\hline Total Hot Rolling Reduction (\%) & $79 \%$ & & \\
\hline Number of Passes & 24 & & \\
\hline Post Roll Anneal & Yes & No & \\
\hline Anneal time/total time ( $\min )$ & $45 / 180$ & & \\
\hline Total time at temperature & Med: $\sim 120 \mathrm{~min}$ & Short: $<100 \mathrm{~min}$ & Long $>150 \mathrm{~min}$. \\
\hline Cold Rolling & Yes & No & \\
\hline Schedule: "reduction" & "medium" 1-2\%/pass & "light" gradual $<1 \%$ pass & "Aggressive" $>2 \%$ pass \\
\hline Cold Rolling Reduction (\%) & $22 \%$ & & \\
\hline Number of Passes & 14 & & \\
\hline Foil Character & Flat and ductile & waw and stiff & \\
\hline Foil Thickness & standard (0.010-0.013") & Thick $0.020^{\prime \prime}$ or $>$ & \\
\hline
\end{tabular}

\begin{tabular}{|c|c|c|c|}
\hline Post cold rolling ann eal & No & Yes & \\
\hline heating method & None & Furance anneal $650 \mathrm{C} / 1 \mathrm{hr}$ & resistive heating \\
\hline Foil Sizing & Blanking & Shearing & \\
\hline Foil Cleaning & diamond polish & nitirc/HF & None \\
\hline
\end{tabular}

Step 3: Cladding

Step 3: Cladding
\begin{tabular}{|r|c|c|c|}
\hline Cladding type & Al 6061 & Yes & Type: \\
\hline Thermal Spray Barrier Layer on Cladding & No & Friction Bond & \\
\hline Clad bonding method & HIP & \\
\hline HIP temperature & - & - \\
\hline HIP Hold Time & - & \\
\hline Pressure (Ksi) & - &
\end{tabular}

Step 4: Final Processing

\begin{tabular}{|c|c|c|}
\hline Autoclave treatment & Yes & \\
\hline Water $\mathrm{pH}$ & adjusted & not adjusted \\
\hline Temperature & $180 \mathrm{C}$ & \\
\hline Time at Temperature & $18 \mathrm{hrs}$ & $4 \mathrm{hrs}$ \\
\hline Blister anneal treatment & Yes & No \\
\hline
\end{tabular}


Monolithic Plate Processing-Variables Summary

\begin{tabular}{|c|c|c|c|}
\hline Experiement: & AFIP-4 & Capsule Position: & - \\
\hline Plate: & L1B51Z & Foil ID: & $196-3-1$ \\
\hline Blister Temperature ('C) & 300 & Fuel Meat Thickness (in.): & 0.013 \\
\hline Average Fission Density (fission/cc $\times 10^{n} 21$ ) & 4.56 & Enrichment (\% U-235/Utot): & $20 \%$ \\
\hline Peak Fissions Denstiy (fission/cc $\times 10^{\wedge} 21$ ) & 5.24 & Cladding Method: & Friction Bonding \\
\hline
\end{tabular}

\begin{tabular}{|c|c|c|c|c|}
\hline Composition & U10Mo & & & \\
\hline Enrichment (\% U-235/Utotal) & $20 \%$ & & & \\
\hline Alloy Materials & $\mathrm{HEU}$ & DU & Mo foil & Mo Powder \\
\hline Alloying/Casting & arc melter & Vacuum Induction Melter (VIM) & & \\
\hline Casting mold & graphite & & & \\
\hline Coupon & not surface machined & surface machined & & \\
\hline Coupon heat treatment/homogenization & None & & & \\
\hline Alloy Carbon Content (ppm) & 472 & & & \\
\hline
\end{tabular}

\begin{tabular}{|c|c|c|c|}
\hline Foil Type: & Roll bonded barrier layer & Bare & \\
\hline Barrier Layer & $\mathrm{Zr}$ & NA & \\
\hline Hot Rolling & Yes & No & \\
\hline Barrier Layer cleaning & polish/degrease & degrease & \\
\hline Can Material & carbon steel & & \\
\hline Release Agent & carbon "neolube" & Yttria & None \\
\hline Coupon Cleaning & chemical "nitric" & brush & NA \\
\hline Furnace Temperature & $650 \mathrm{C}$ & & \\
\hline Schedule & "medium" 20\% pass & "light" gradual <20\% pass & "Aggressive" $>20 \%$ pass \\
\hline Total Hot Rolling Reduction (\%) & $79 \%$ & & \\
\hline Number of Passes & 24 & & \\
\hline Post Roll Anneal & Yes & No & \\
\hline Anneal time/total time $(\min )$ & $45 / 180$ & & \\
\hline Total time at temperature & Med: $\sim 120 \mathrm{~min}$ & Short: $<100 \mathrm{~min}$ & Long $>150 \mathrm{~min}$. \\
\hline Cold Rolling & Yes & No & \\
\hline Schedule: "reduction" & "medium" 1-2\%/pass & "light" gradual < $1 \%$ pass & "Aggressive" $>2 \%$ pass \\
\hline Cold Rolling Reduction (\%) & $22 \%$ & & \\
\hline Number of Passes & 14 & & \\
\hline Foil Character & Flat and ductile & wavy and stiff & \\
\hline Foil Thickness & standard $\left(0.010-0.013^{\prime \prime}\right)$ & Thick $0.020^{\prime \prime}$ or $>$ & \\
\hline Post cold rolling anneal & No & Yes & \\
\hline heating method & None & Furance anneal $650 \mathrm{C} / 1 \mathrm{hr}$ & resistive heating \\
\hline Foil Sizing & Blanking & Shearing & \\
\hline Foil Cleaning & diamond polish & nitirc/HF & None \\
\hline
\end{tabular}

Step 3: Cladding

\begin{tabular}{|c|c|c|c|}
\hline Cladding type & Al 6061 & & \\
\hline Thermal Spray Barrier Layer on Cladding & No & Yes & Type: \\
\hline Clad bonding method & HIP & Friction Bond & \\
\hline
\end{tabular}

\begin{tabular}{|r|c|}
\hline HIP temperature & - \\
\hline HIP Hold Time & - \\
\hline Pressure (Ksi) & - \\
\hline
\end{tabular}

Step 4: Final Processing
\begin{tabular}{|r|c|c|}
\hline Autoclave treatment & Yes & not adjusted \\
\hline Water $\mathrm{pH}$ & adjusted & $4 \mathrm{hrs}$ \\
\hline Temperature & $180 \mathrm{C}$ & No \\
\hline Time at Temperature & $18 \mathrm{hrs}$ & Yes \\
\hline
\end{tabular}


Appendix C

Fabrication Process Flowcharts

Appendix C

152 


\section{RERTR-6, 7 U-Mo Foil Fabrication "Bare foils"}

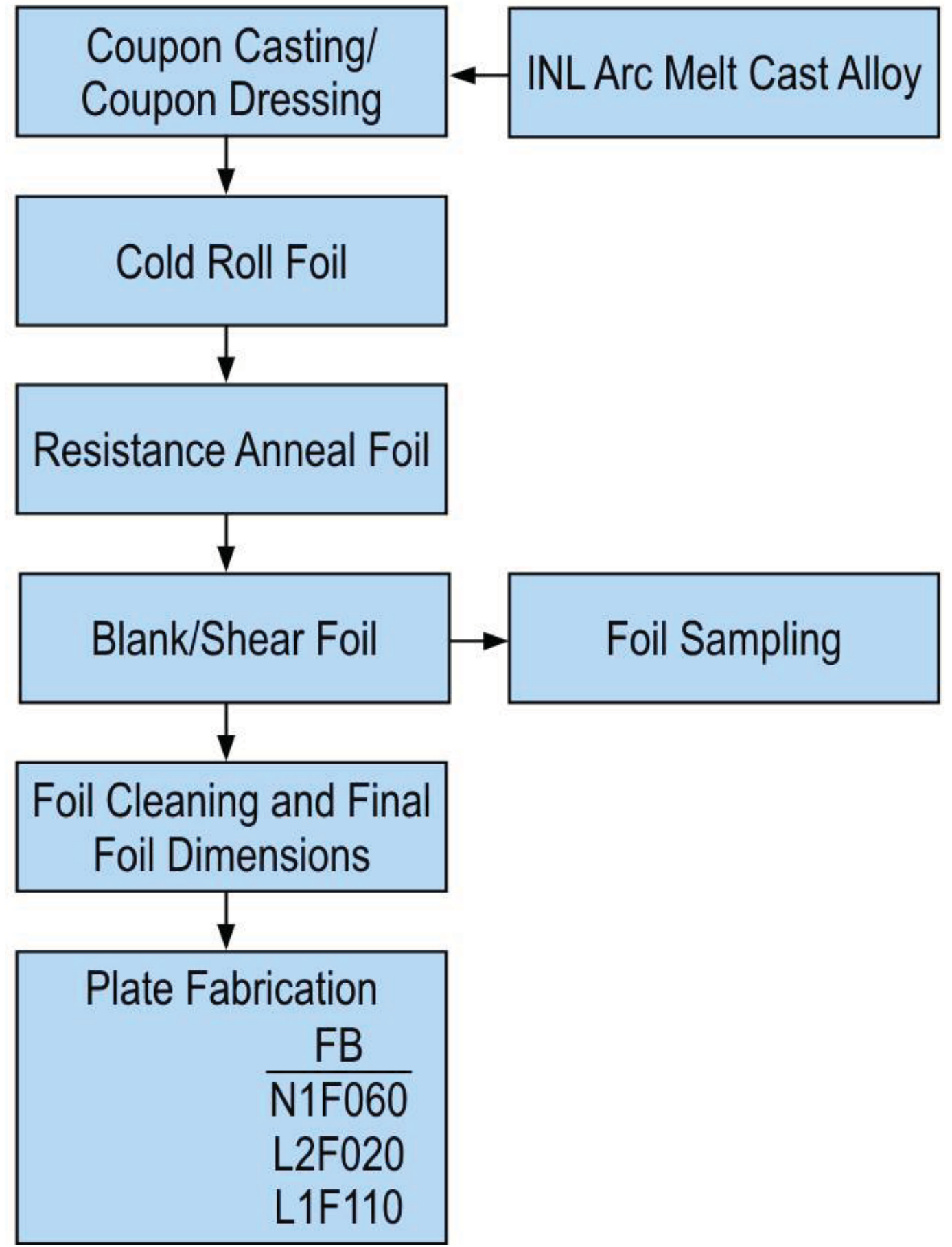




\section{RERTR-9A U-Mo Foil Fabrication \\ "Bare foils"}

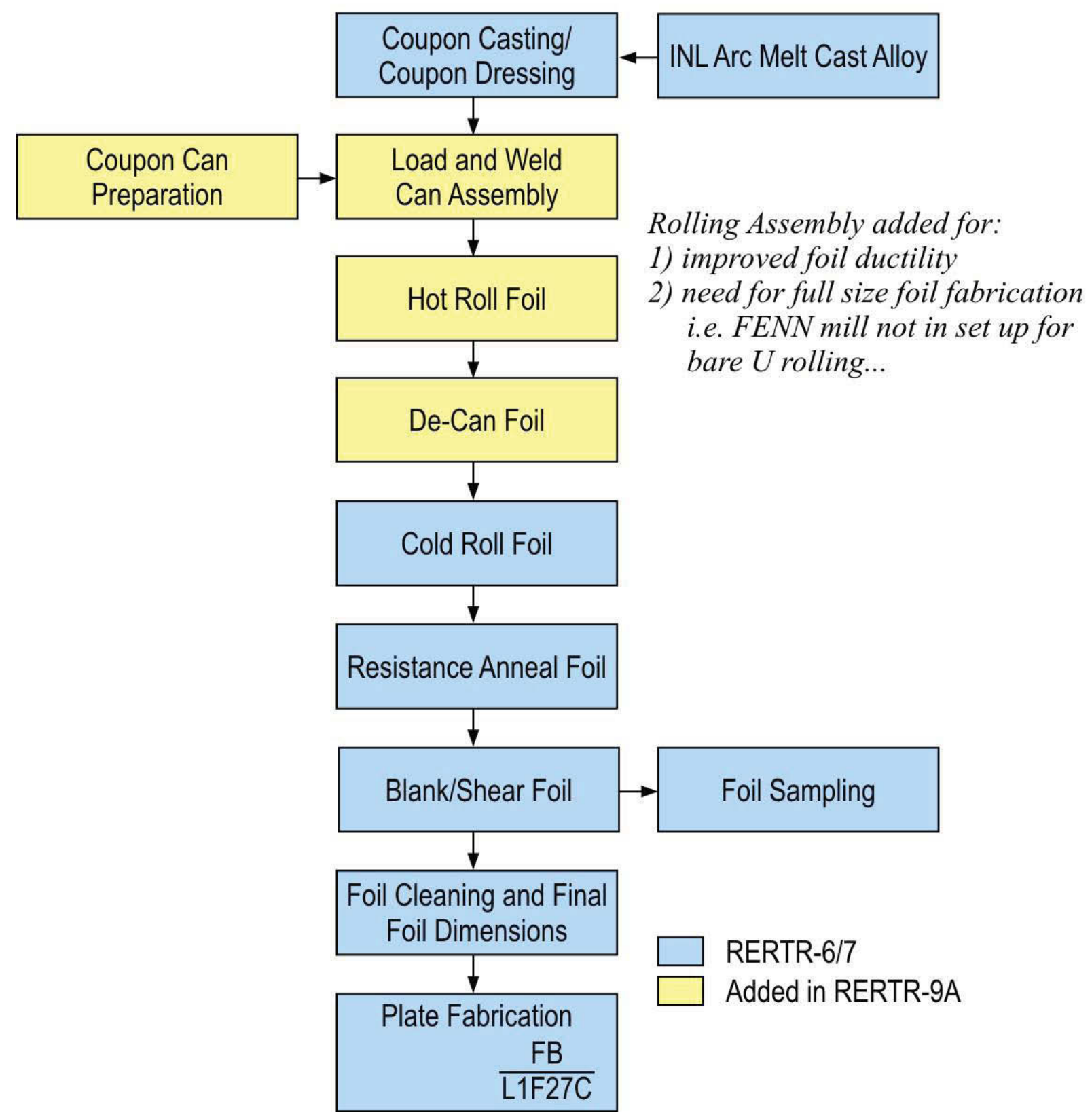




\section{RERTR-9B U-Mo Foil Fabrication "Bare and $\mathrm{Zr}$ co-rolled foils"}

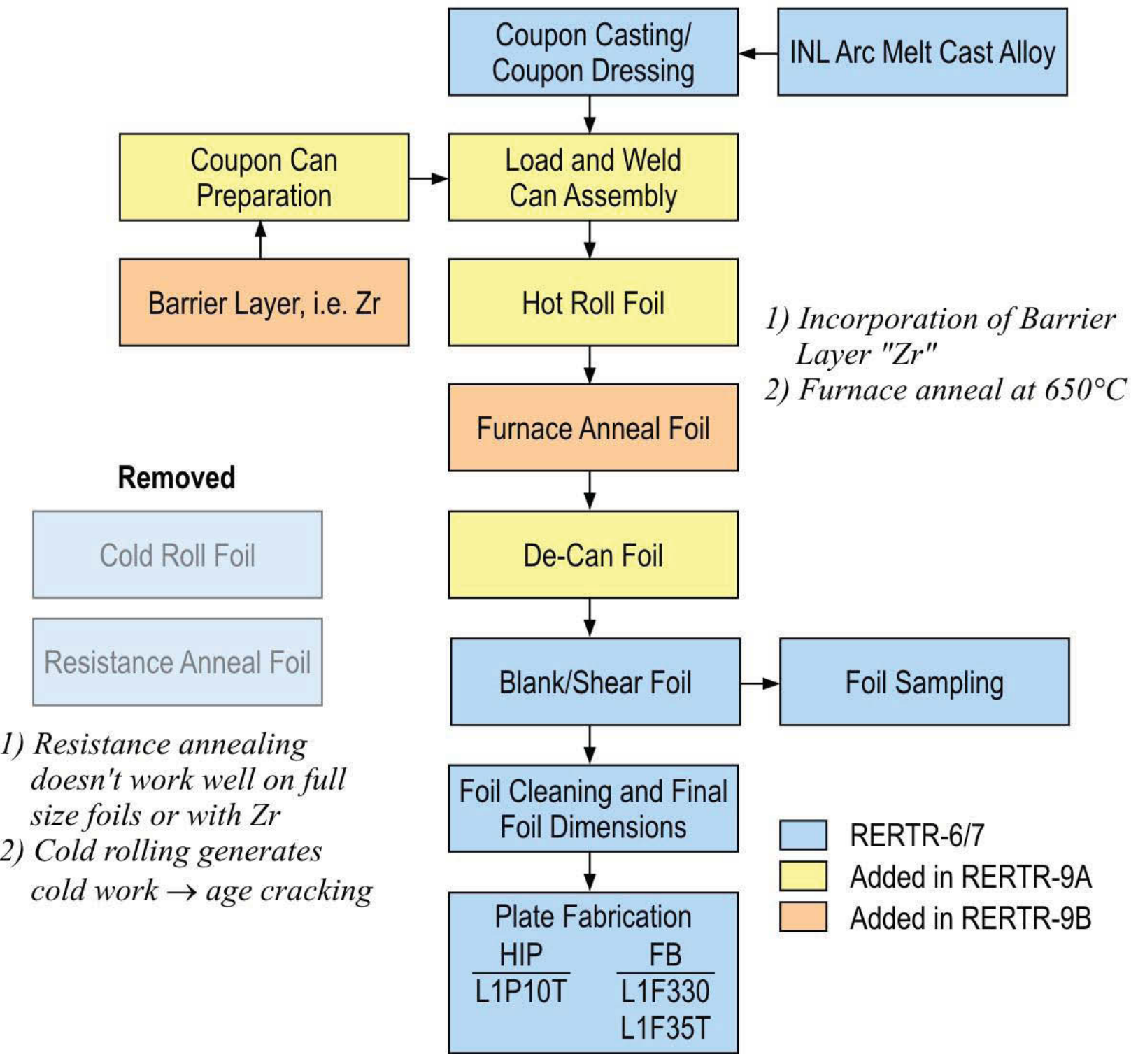




\section{RERTR-10A, 10B U-Mo Foil Fabrication "Bare and Zr co-rolled foils"}

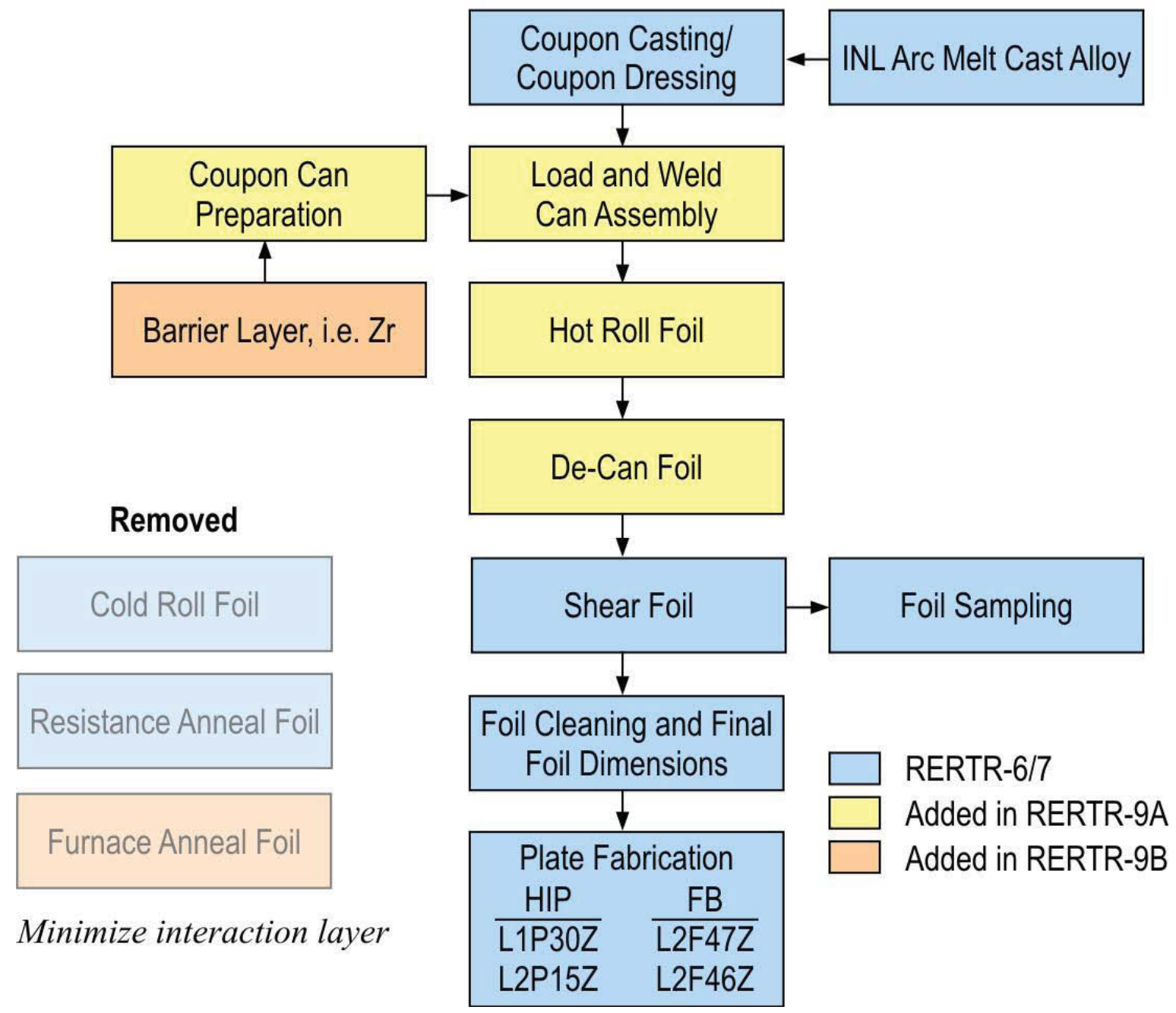




\section{AFIP-4 U-Mo Foil Fabrication \\ "Zr co-rolled foils"}

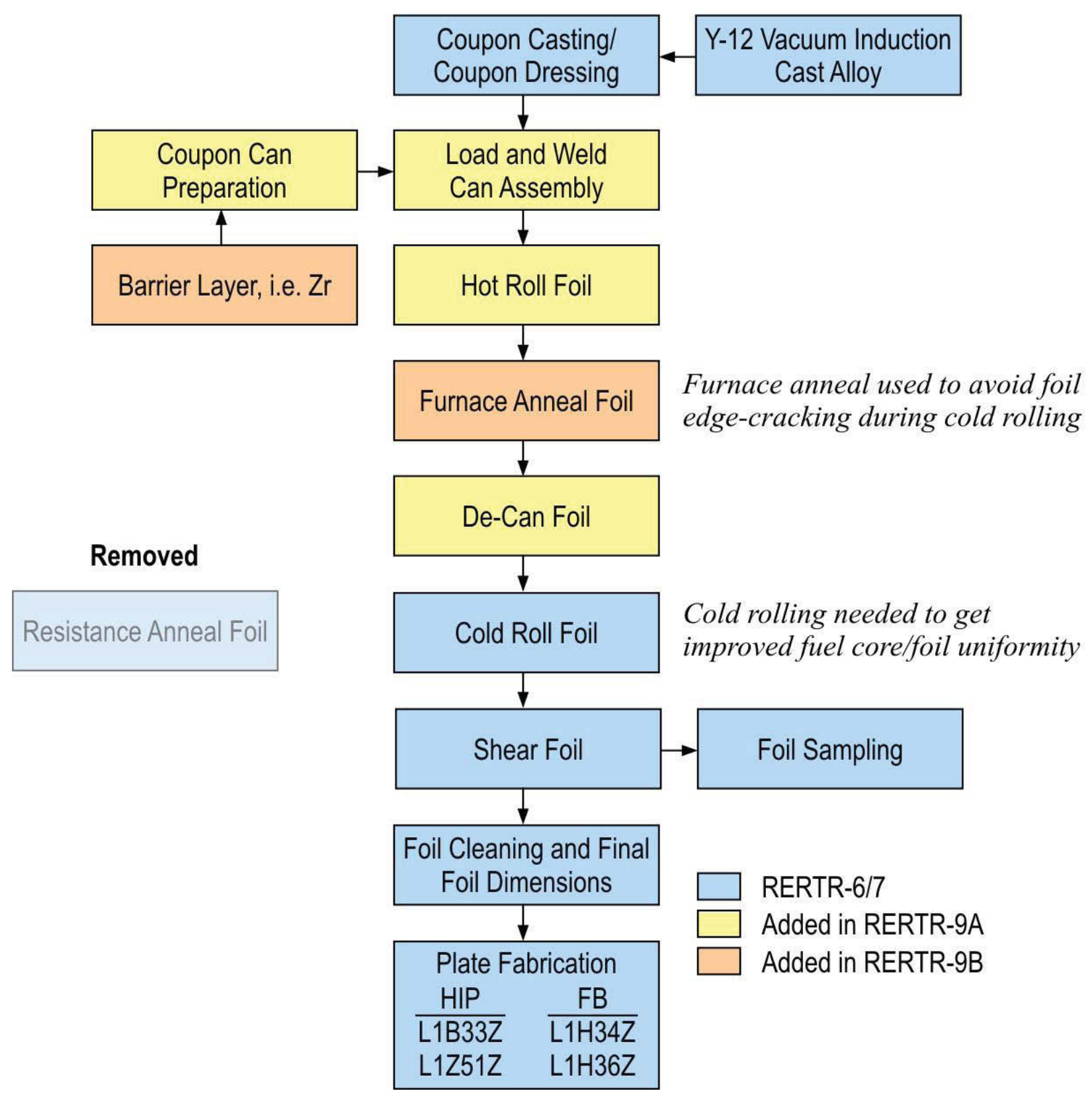




\section{RERTR-12 U-Mo Foil Fabrication \\ "Zr co-rolled foils"}

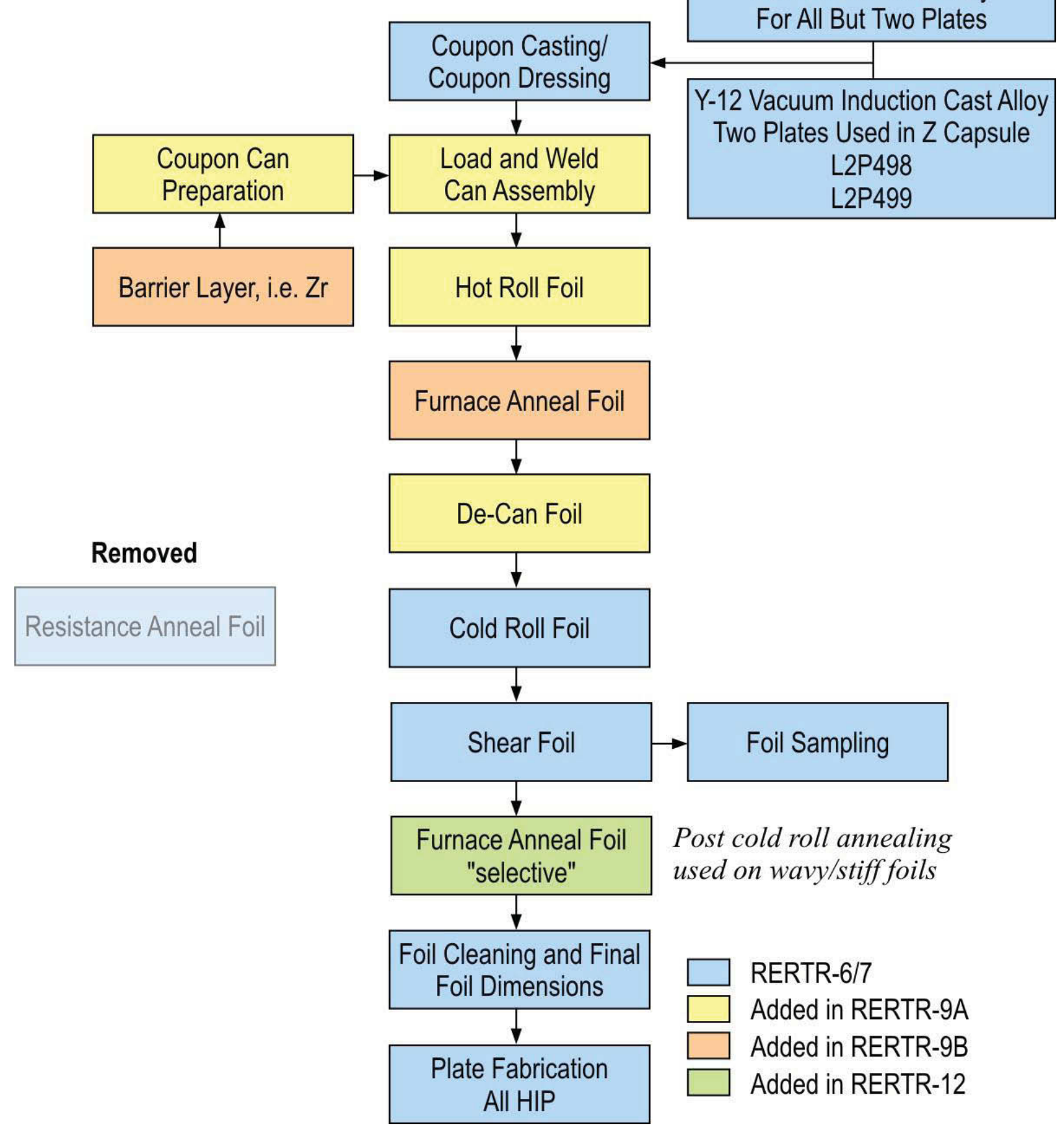


Appendix C 


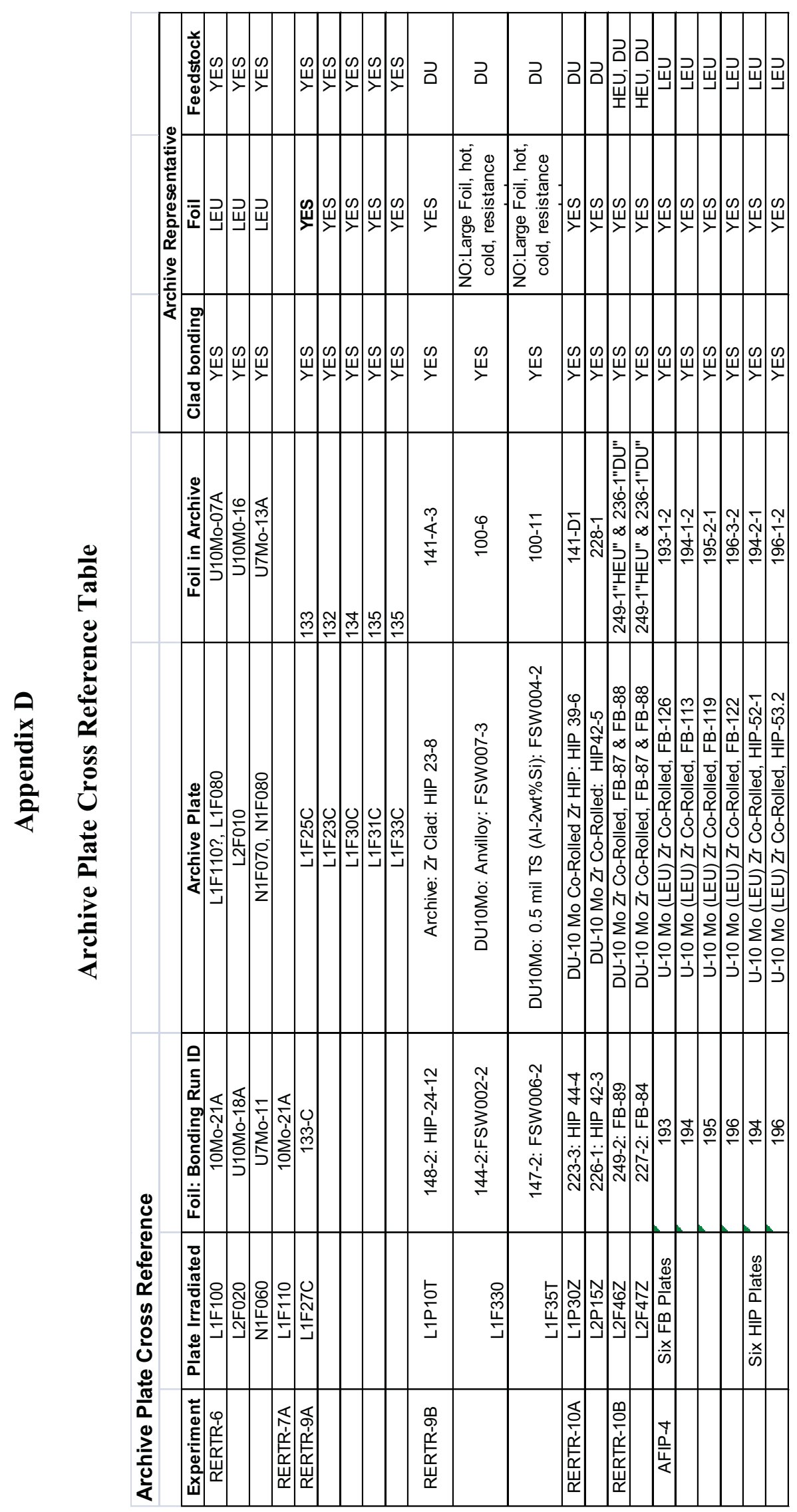

尿 
흘 


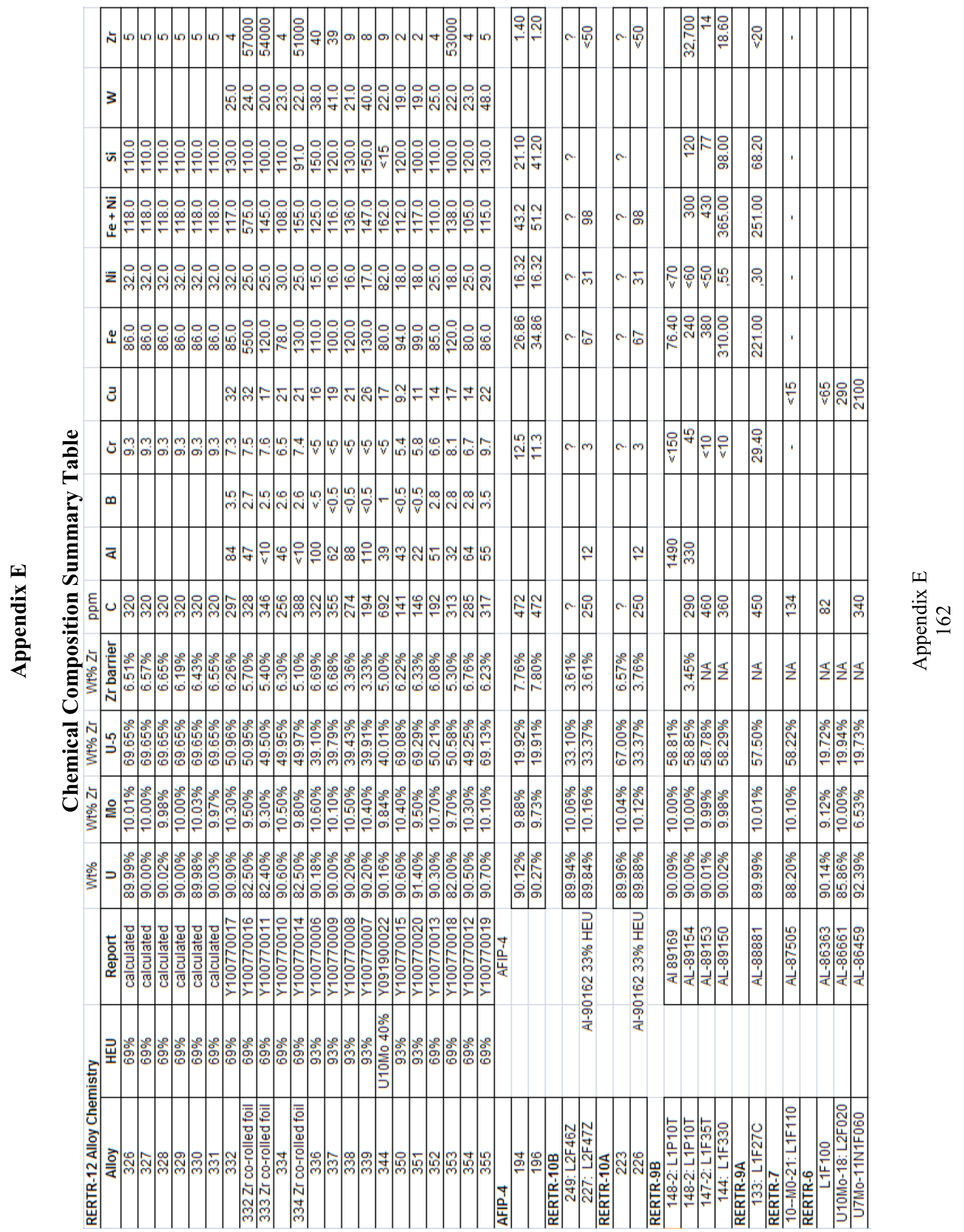



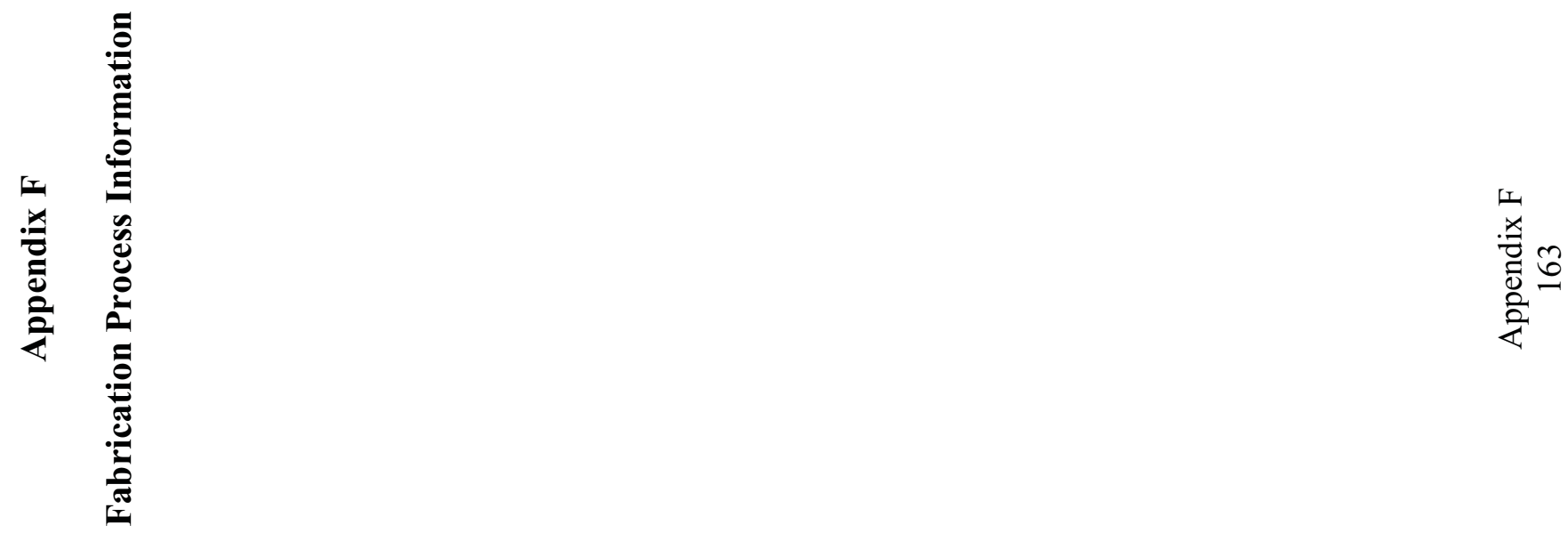


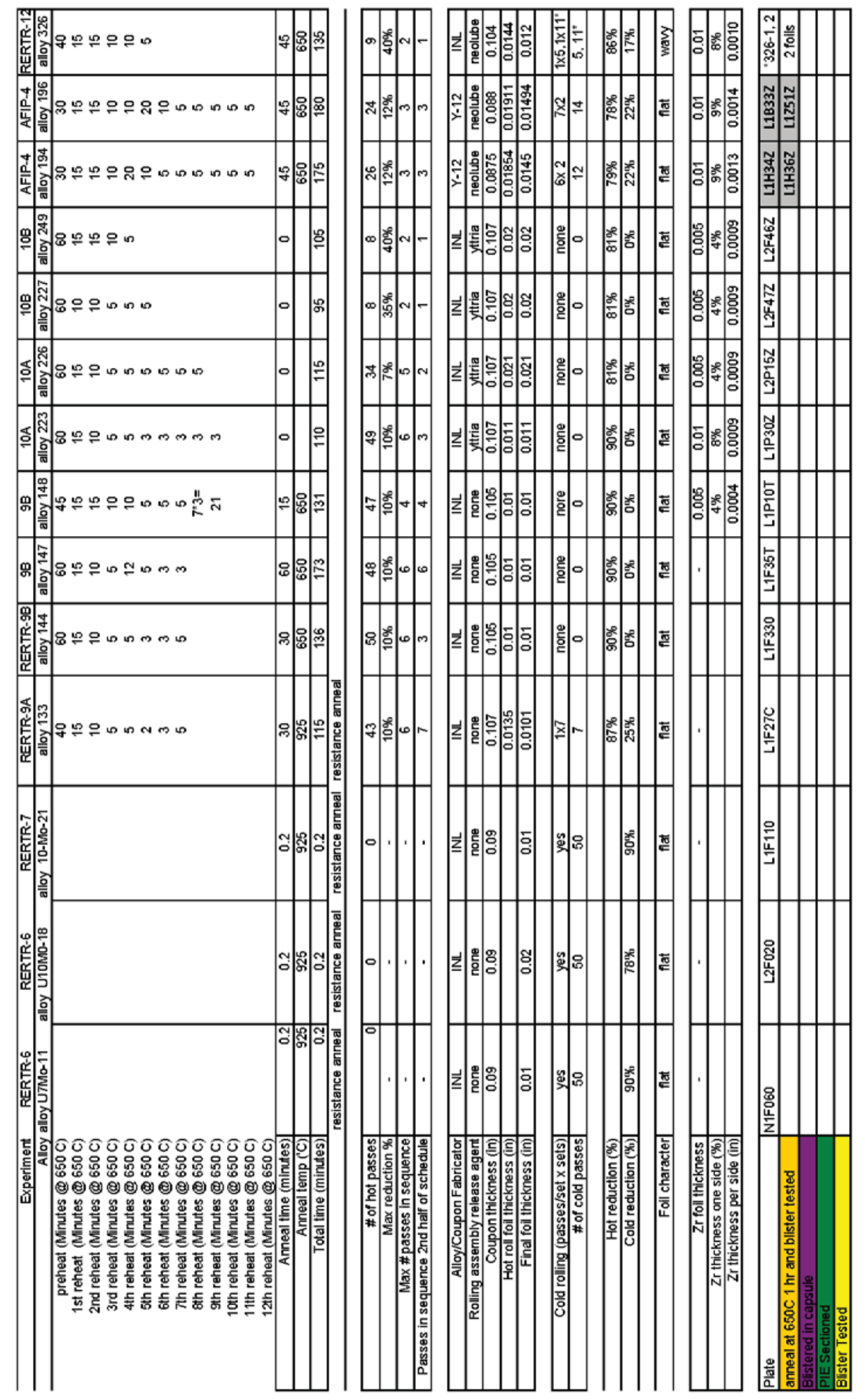

崖 


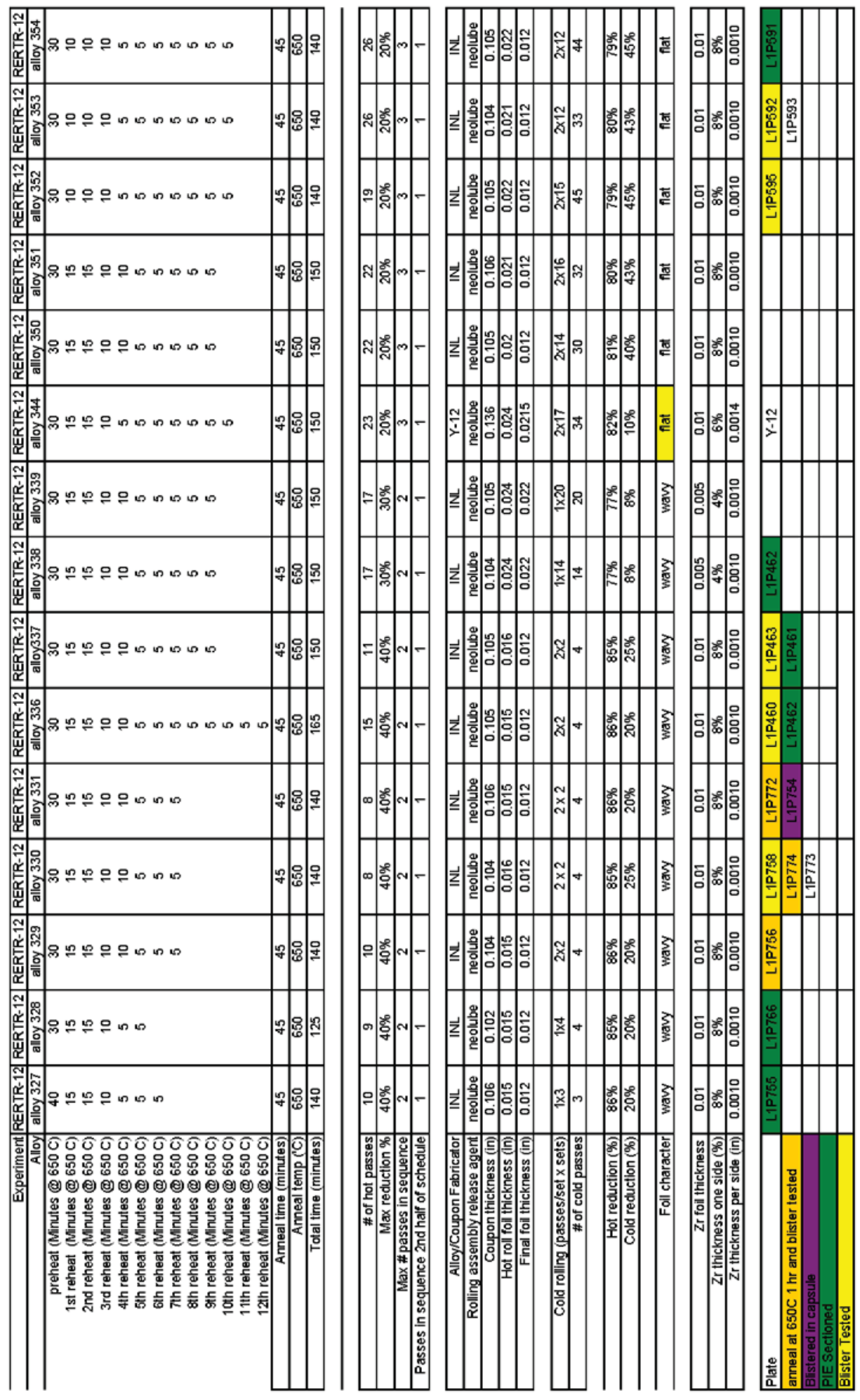

宸 


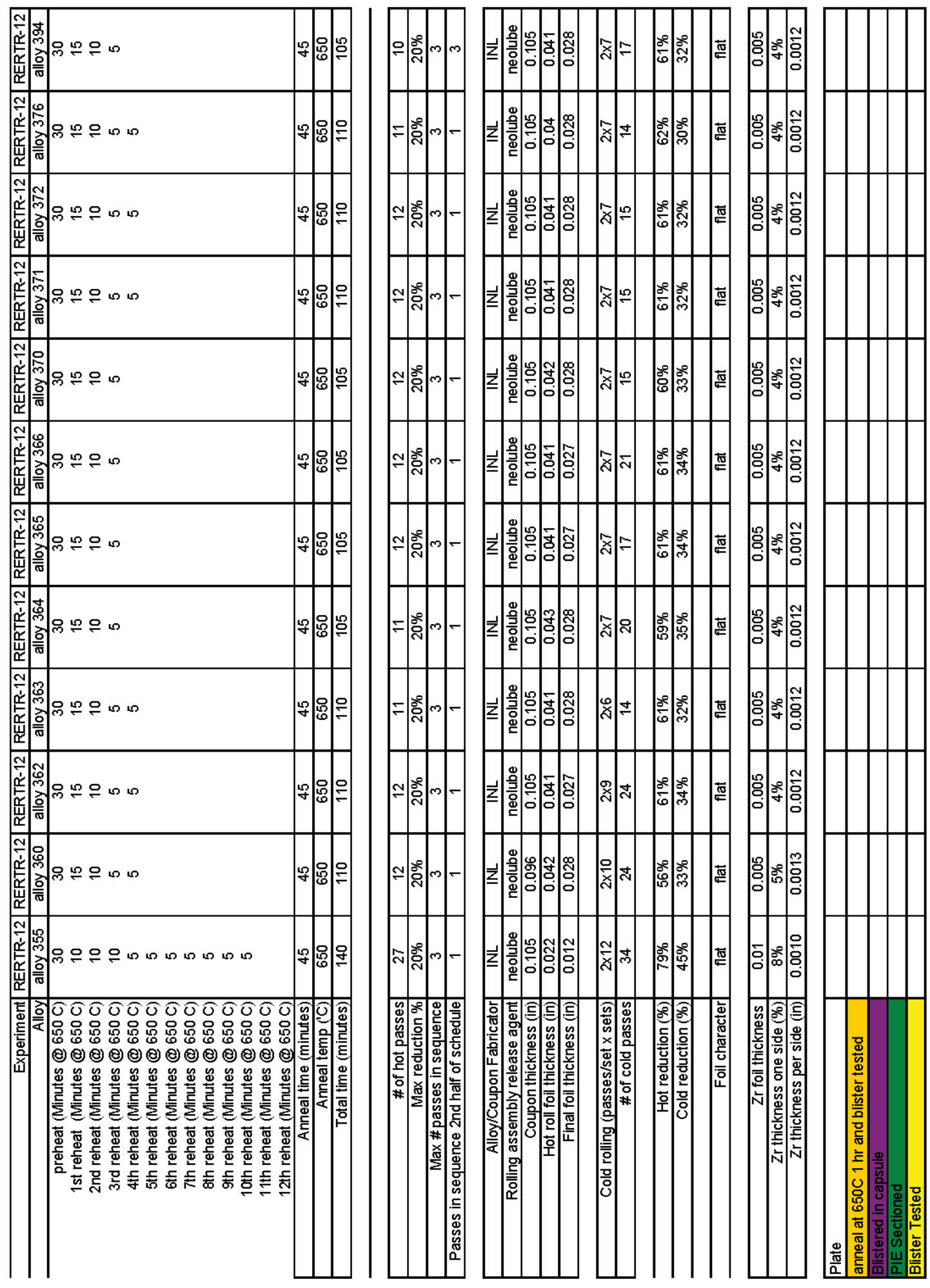

ڤ 


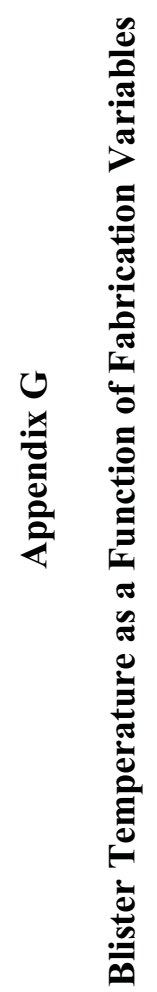

을 


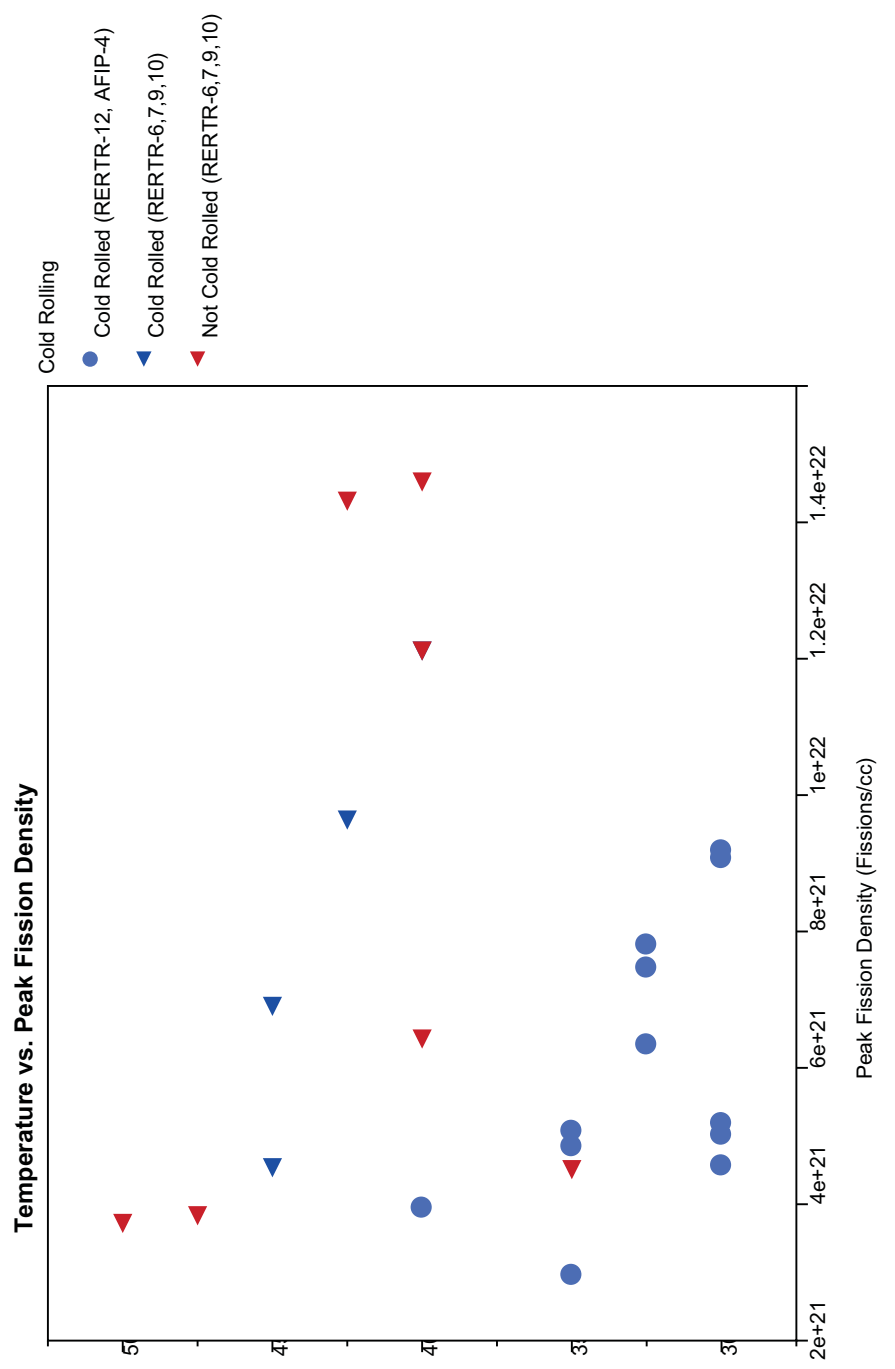

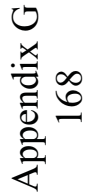

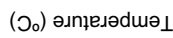




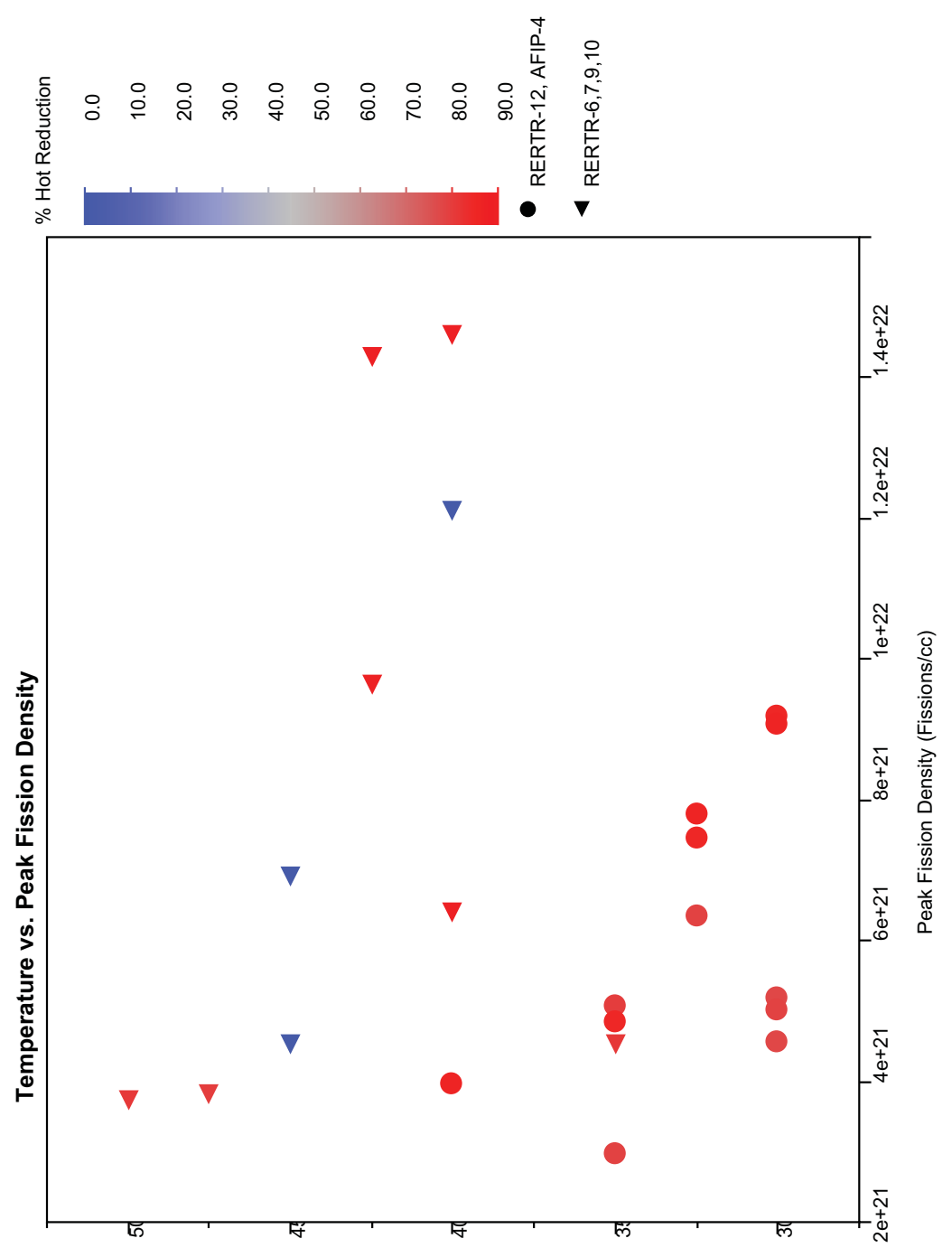

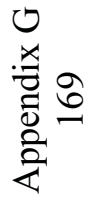

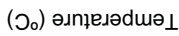




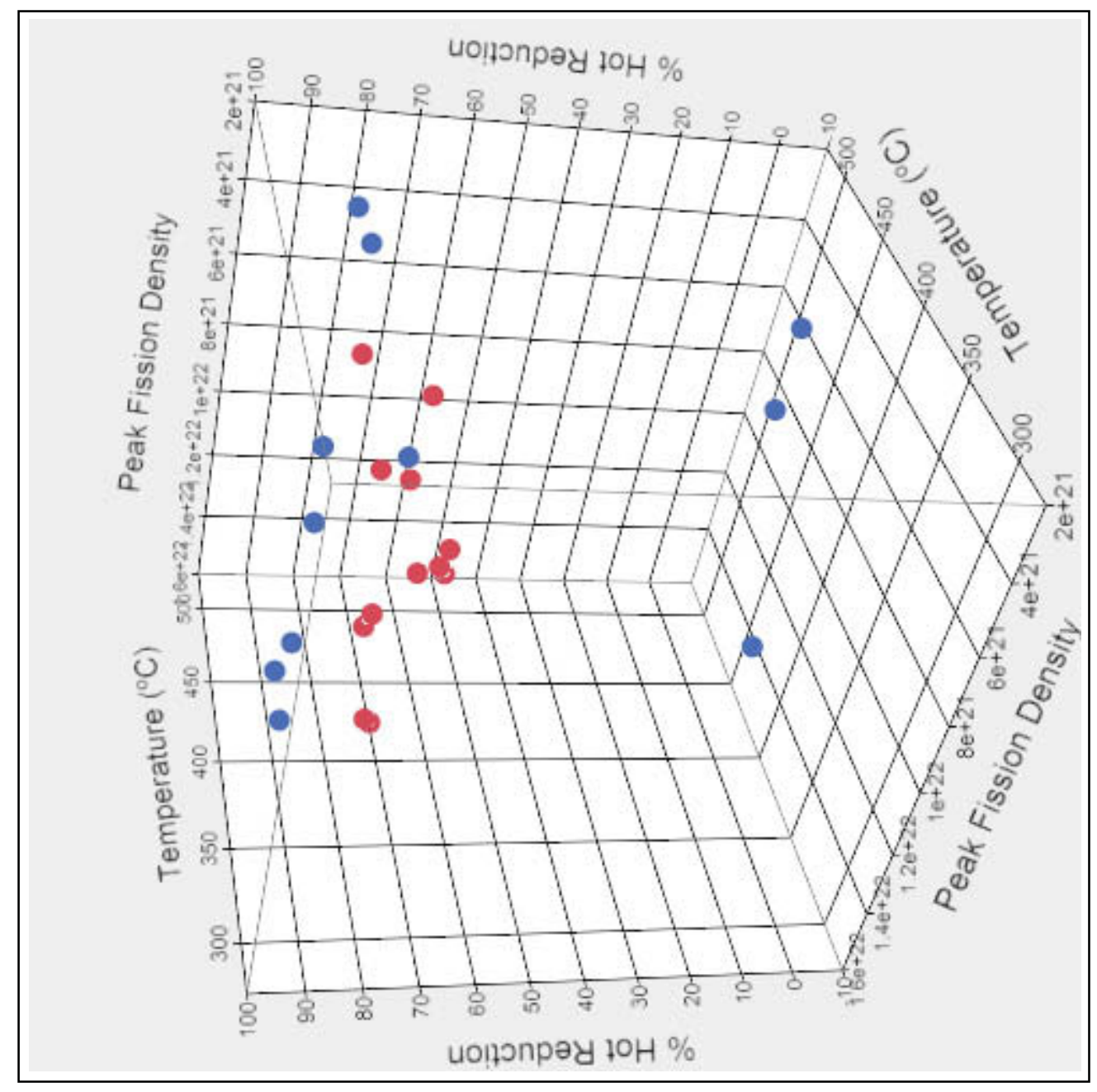

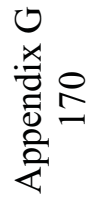




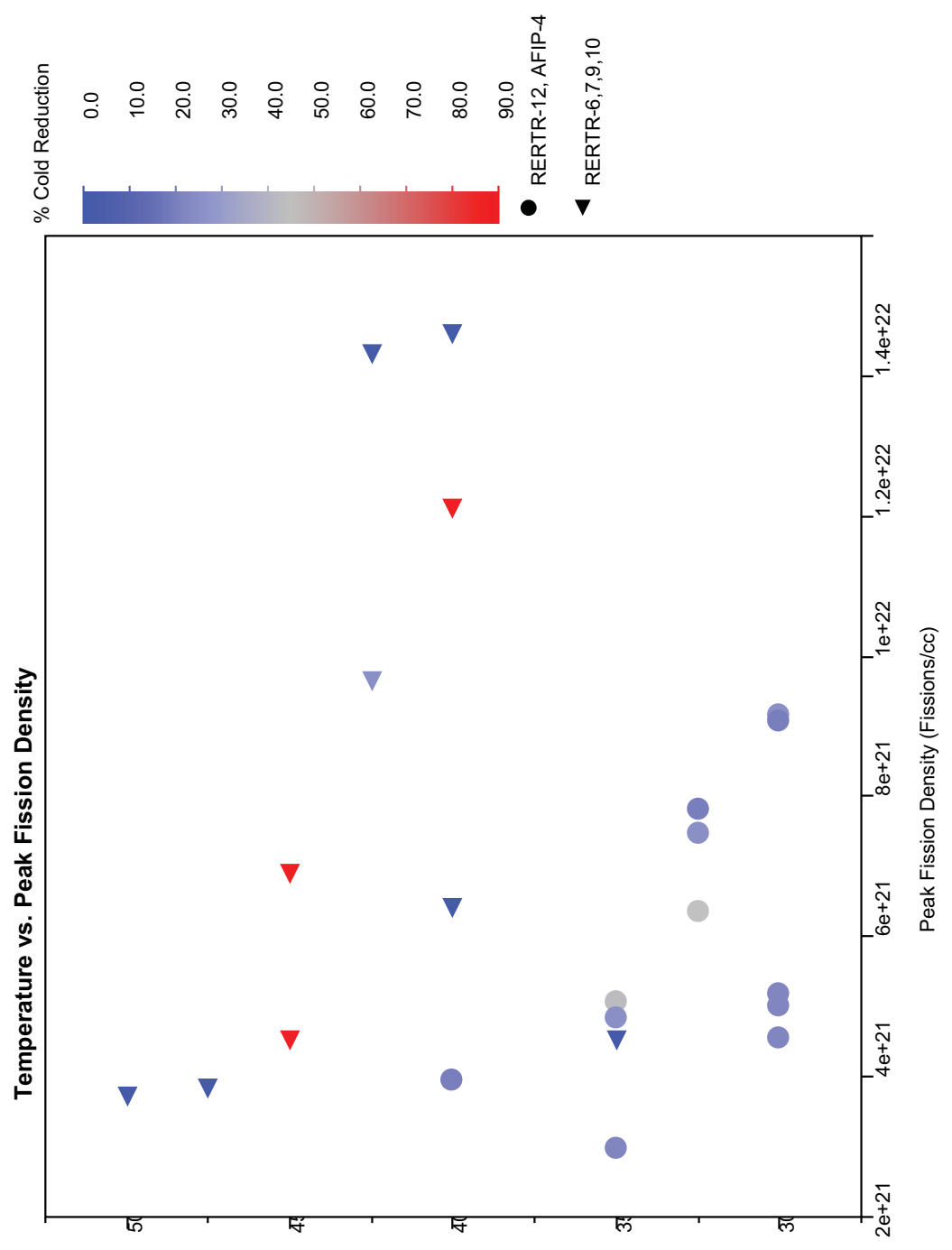

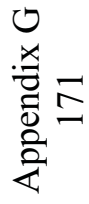

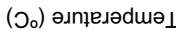




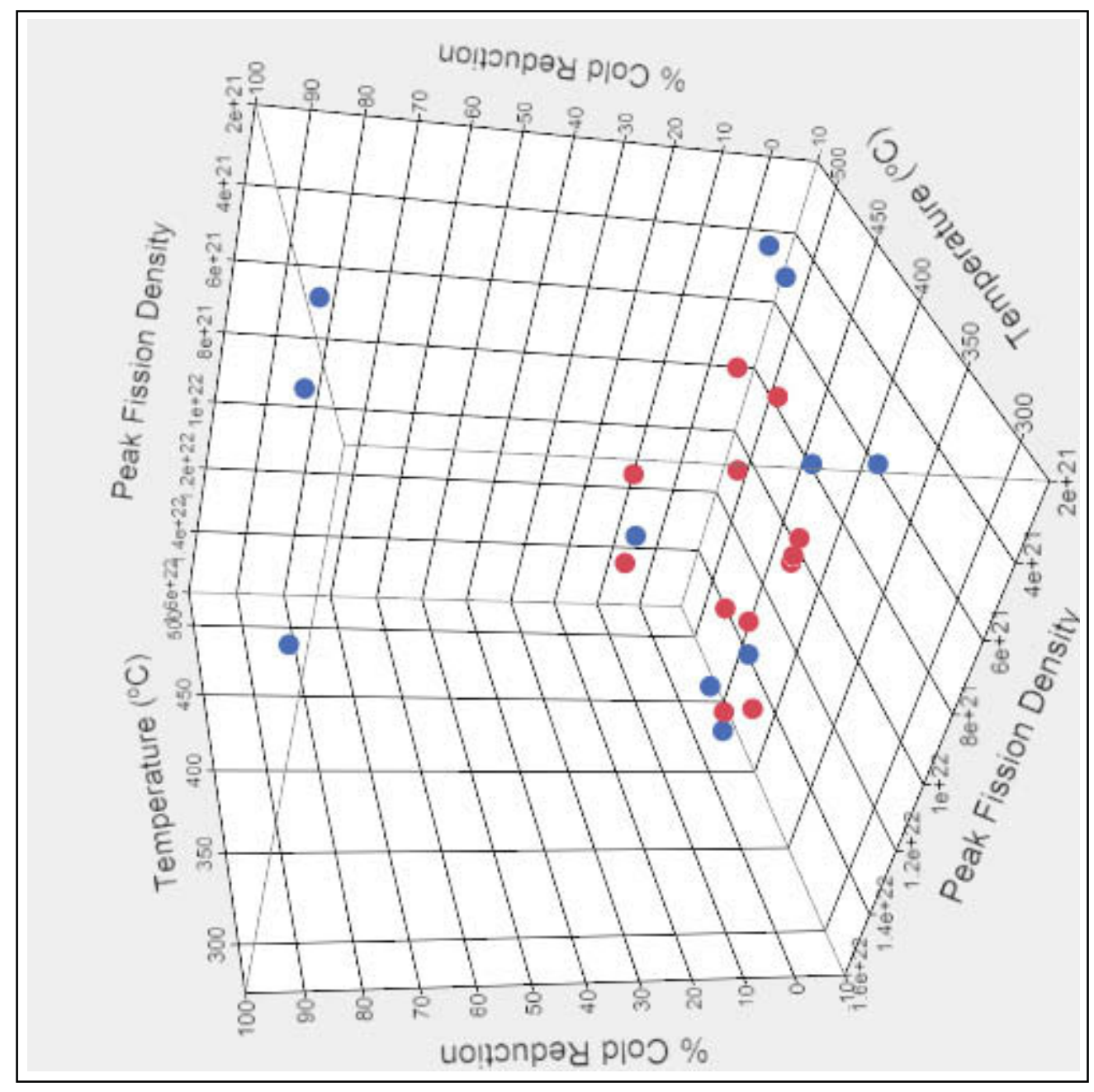

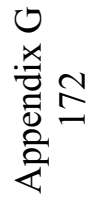




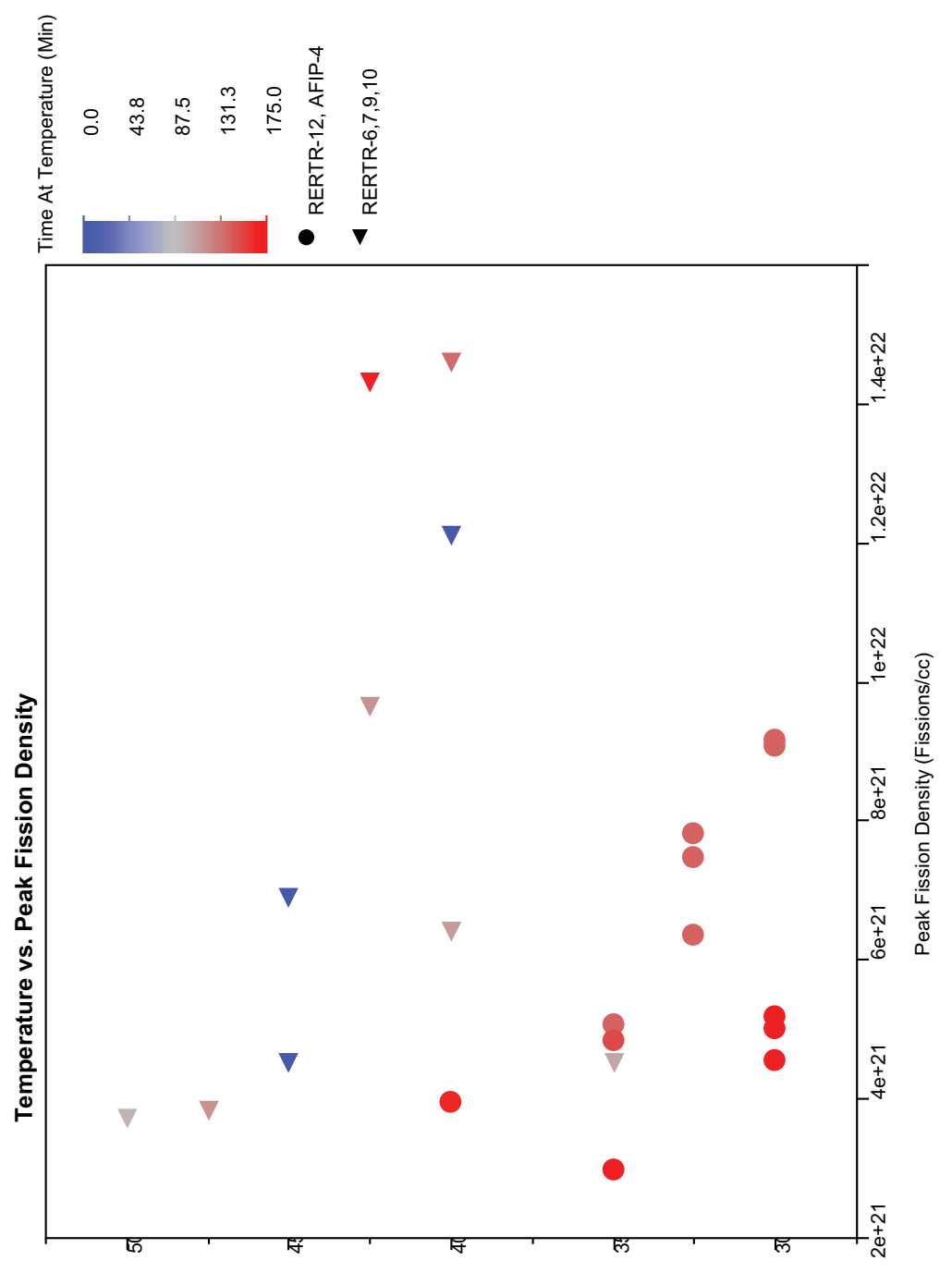

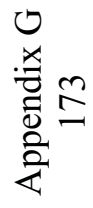

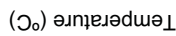




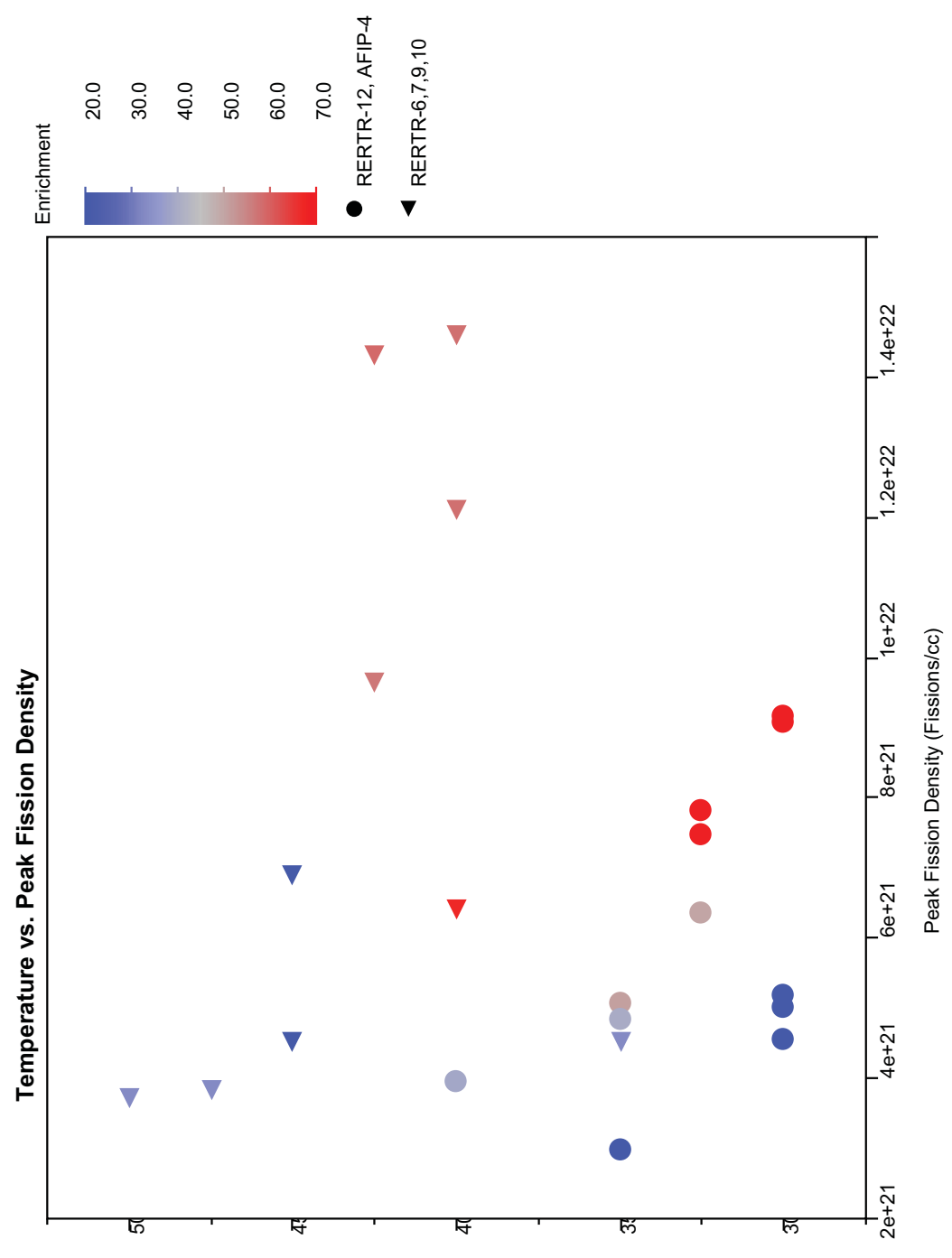

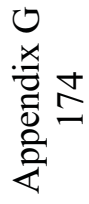

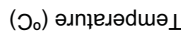




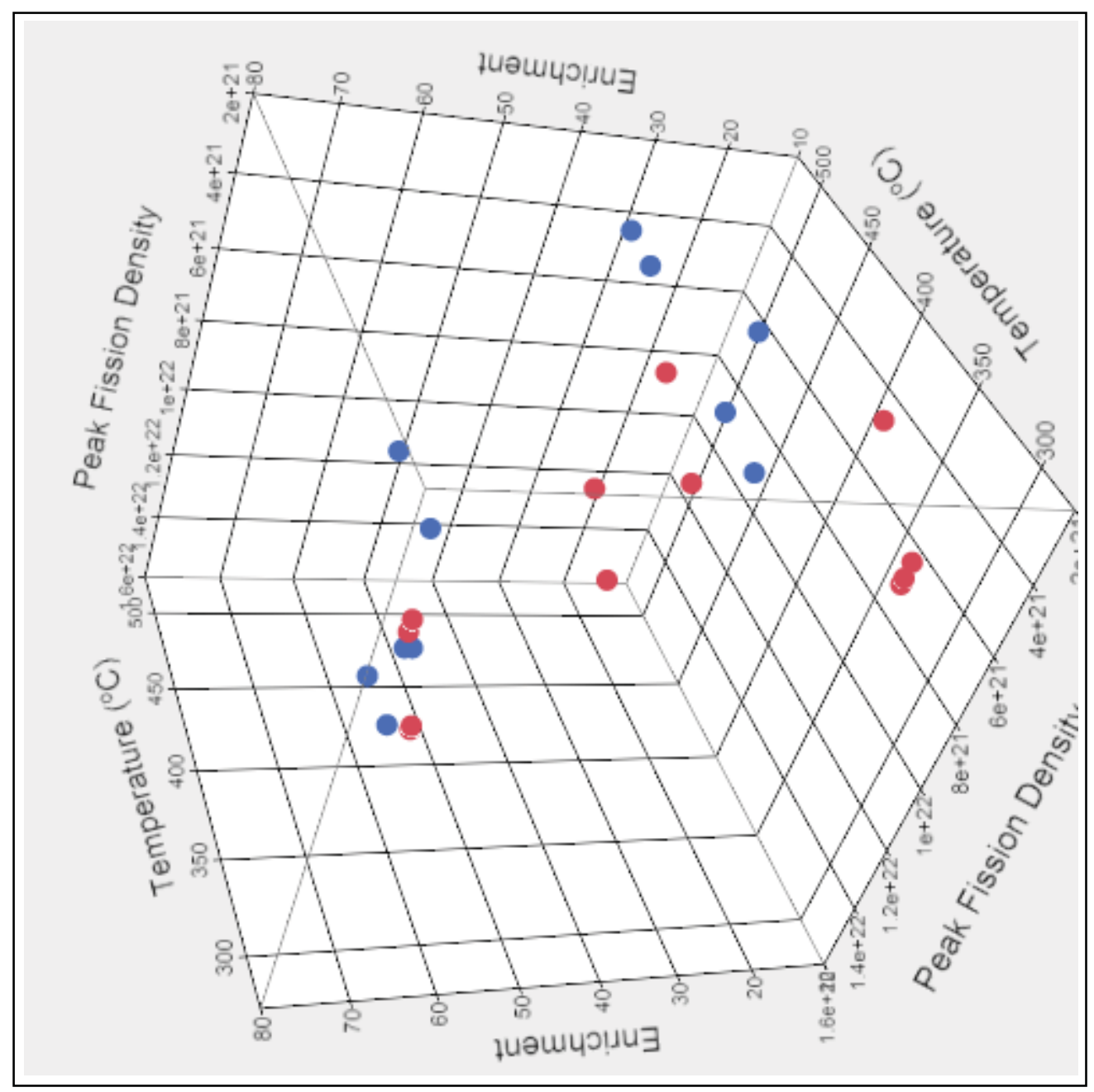

0
ñ
$\frac{2}{2}$
$\frac{2}{2}$ 


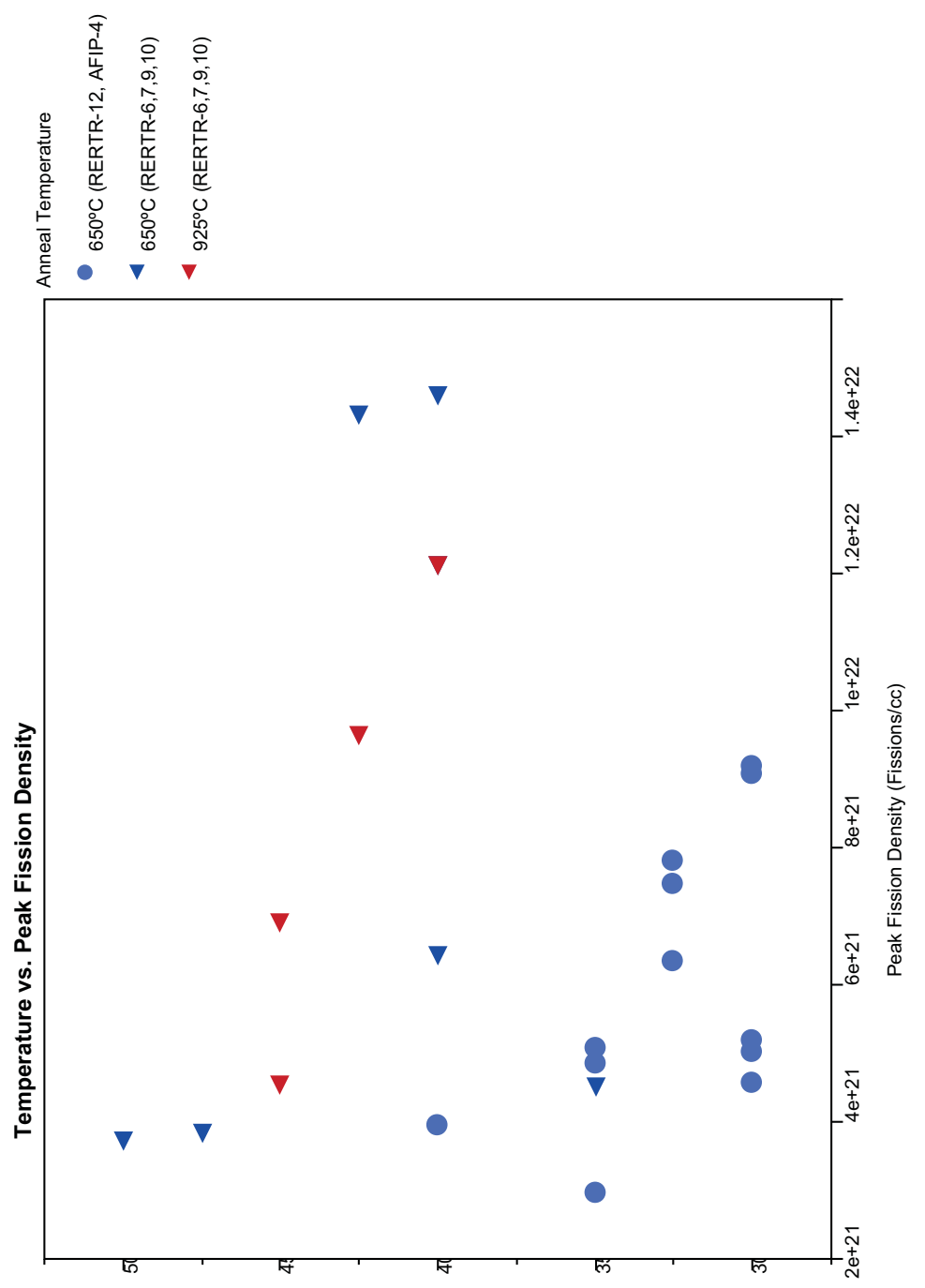

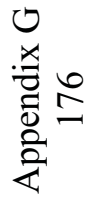

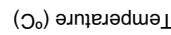




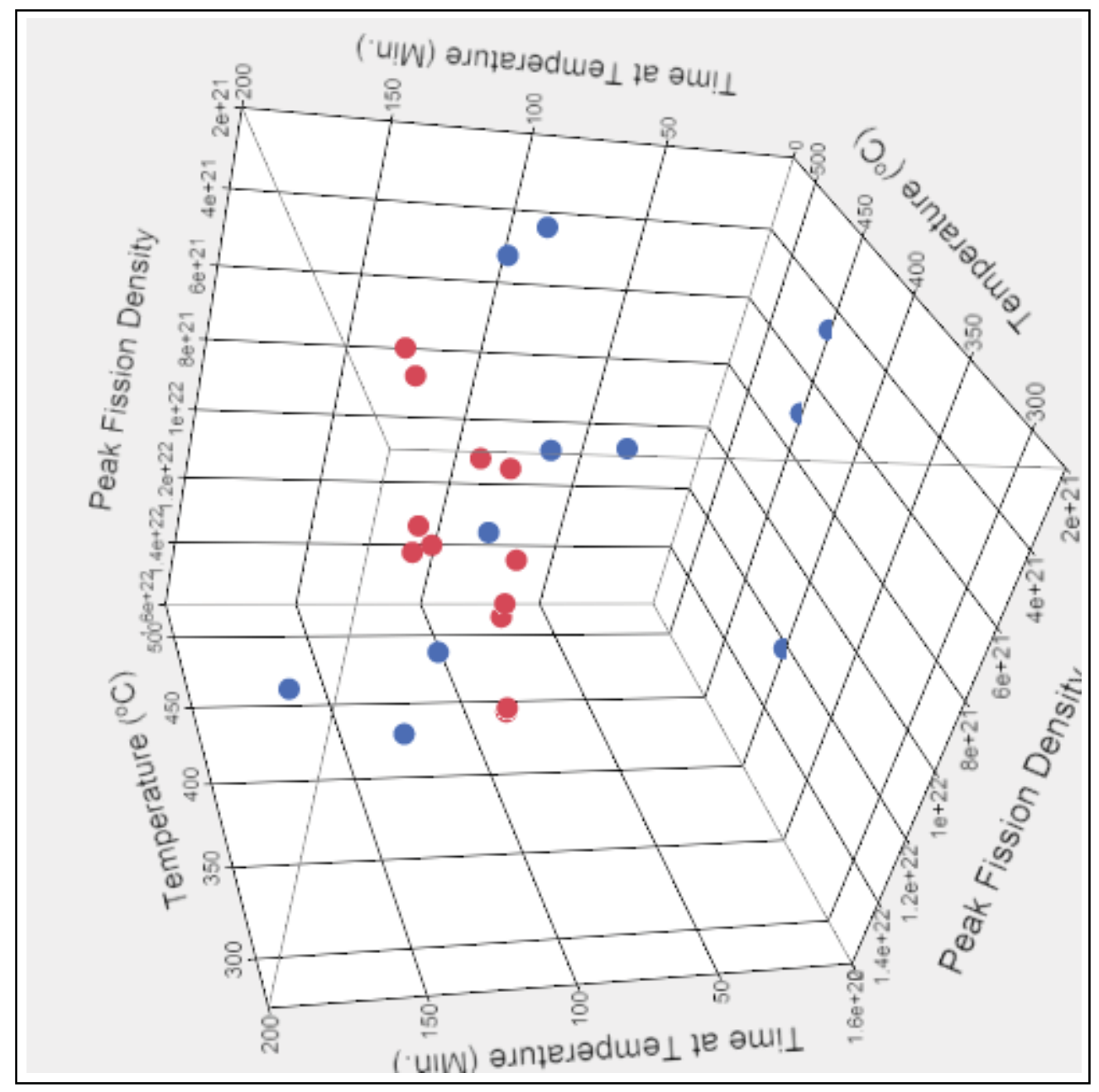

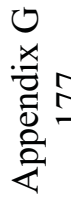




\section{Appendix H}

\section{Outlier Analysis of Plate L2F46Z (RERTR-10B)}

Figure 1 is a leverage plot resulting from the analysis of the older data not including L2F46Z. The confidence curves cross the horizontal line, indicating the effect (model) is signficant at the 5\% level. Figure 2 is a leverage plot resulting from the analysis of the older data including L2F46Z. The confidence curves do not cross the horizontal line, indicating the effect (model) is not significant at the 5\% level.

The model excluding the point has a $p$-value of $p=.0050$, indicating the regression model is significant. The model including the point has a $\mathrm{p}$-value of $\mathrm{p}=.0944$, indicating the regression model is not significant at the .05 level. This is one indication that the point is an outlier.

Using the significant model (which excluded L2F46Z from the fit), the studentized residual can be calculated for all of the points. The point L2F46Z has the largest absolute studentized residual, with a value of -4.8 . Typically a point whose studentized residual has magnitude 3 or larger is considered a possible outlier.

These are statistical arguments that the point corresponding to plate L2F46Z is an outlier. The justification to exclude the point from further analysis needs to be made from the experimental point of view, i.e., is there a plausible explanation such as differences in sample handling or measurement. 


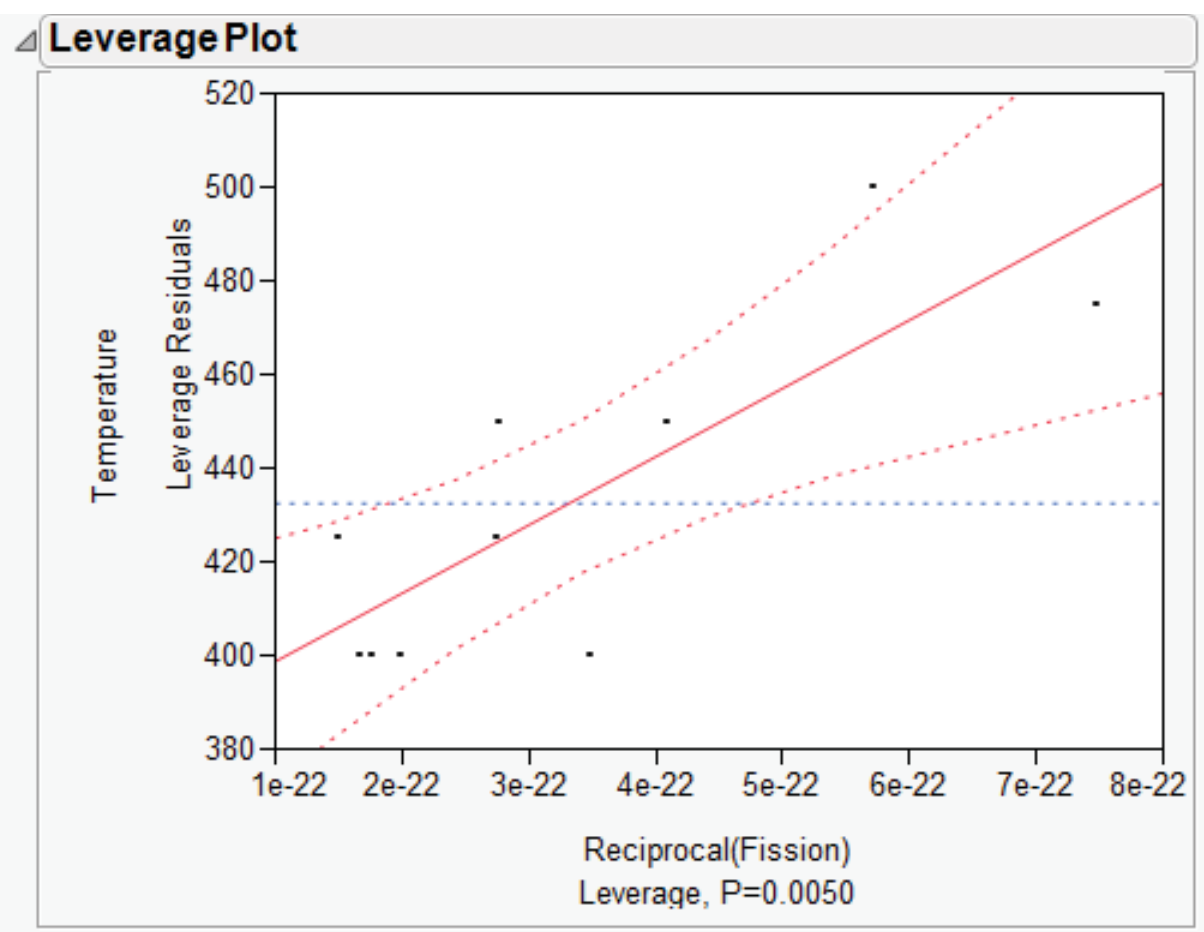

Figure 1. Leverage plot without data point L2F46Z.

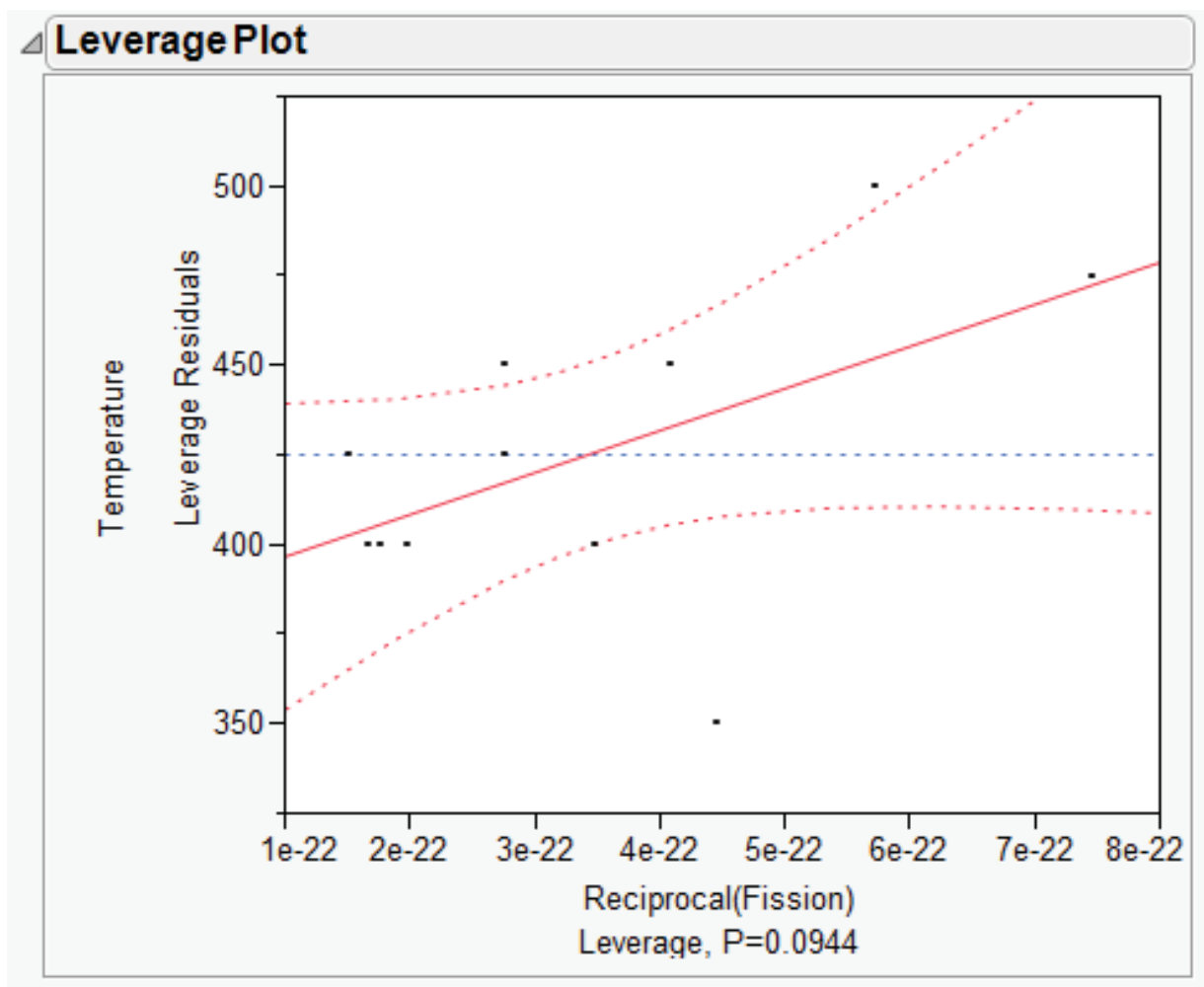

Figure 2. Leverage plot with data point L2F46Z. 